\title{
Dietrich Wörn
}

\section{Aleksandr Bloks Drama Pesnja sud'by \\ "Das Lied des Schicksals"}

Verlag Otto Sagner München · Berlin · Washington D.C.

Digitalisiert im Rahmen der Kooperation mit dem DFG-Projekt „Digi20“

der Bayerischen Staatsbibliothek, München. OCR-Bearbeitung und Erstellung des eBooks durch den Verlag Otto Sagner:

http://verlag.kubon-sagner.de

() bei Verlag Otto Sagner. Eine Verwertung oder Weitergabe der Texte und Abbildungen, insbesondere durch Vervielfältigung, ist ohne vorherige schriftliche Genehmigung des Verlages unzulässig. 


\section{SLAVISTISCHE BEITRÄGE}

BEGRÜNDET VON ALOIS SCHMAUS

HERAUSGEGEBEN VON JOHANNES HOLTHUSEN UND JOSEF SCHRENK

REDAKTION: PETER REHDER

Band 81 


\section{DIETRICH WÖRN}

\section{ALEKSANDR BLOKS DRAMA \\ PESNJA SUD'BY (DAS LIED DES SCHICKSALS) \\ ÜBERSETZT, KOMMENTIERT UND INTERPRETIERT}


Diese Arbeit wurde vom Facbbereich Neuphilologie der Universität Tübingen im SS 1973 als Dissertation angerommen.

Bayeriscire 8taatsbibliothek

Manchen

\section{ISBN $387690093 \mathrm{x}$}

Copyright by Verlag Otto Sagner, München 1974 Abteilung der Firma Kubon und Sagner, Nünchen Iruck: Alexander Großmann

8 München 19, Ysenburestraße $7^{I}$ 


\section{Inhaltsverzeichnis:}

Seite

Einleitung

VII

Teil I:

Entstehungsgeschichte

Ubersetzung

Abweichungen

Teil II: Kommentar

Titelseite

1. Bild: Einleitung

Kommentar 162

2. Bild: Einleitung 189

Kommentar

190

3. Bild: Einleitung

201

Kommentar

220

4. Bild: Einleitung

236

Kommentar

5. Bild: Einleitung 285

Kommentar

321

6. Bild: Einleitung

385

Kommentar $\quad 387$

7. Bild: Einleitung

399

Kommentar

410

Bahnhofsszene: Einleitung

Kommentar

Exkurs: Blok und der "raskol"

Bloks Zweifel an der Tragfähigkeit seiner

"Lyrik" und seine Hinwendung zum "Melodrama"

als Vorform des "Volkstheaters"

Bloks Drama "Das Lied des Schicksals" als besondere Version seines Mythos vom

"Ewig-Weiblichen"

1.) Mythos und Drama 
2.) Bloks Mythos vom "Ewig-Weiblichen" im "Lied des Schicksals"

3.) Der mythische Charakter der Handlung

4.) Der mythische Charakter der Raumund Zeitstruktur

5.) Sprache und Musik. Das IS als

523 Gesamtkunstwerk 


\section{EINLEITUNG}

Das Jahr 1904 und das Revolutionsjahr 1905 bedeuteten einen tiefen Einschnitt im Schaffen Aleksandr Bloks. Er wand te sich von der christlich gefärbten Mystik seiner "Gedichte von der Schönen Dame" ab und entdeckte neue Themen, so die GroBstadt und "RuBland", die seine Lyrik nach 1905 beherrschen. Gleichzeitig wandte sich Blok dem Theater zu und verfabte mehrere eigene Stiucke und Dramenubersetzungen. Daneben entfaltete Blok eine überaus rege publizistische Tätigkeit. Das publizistische Schaffen übertraf für mehrere Jahre das kinstlerische an Umfang, wenn auch nicht an Bedeutung. Die Zuwendung zu neuen Themen und Ausdrucksmitteln war eng verbunden mit einer weltanschaulichen Neuorietierung, die unter dem starken Einflub der irrationalen Philosophie Schopenhauers, R. Wagners und des jungen Nietzsche seit etwa 1906 zu der Verschmelzung einer eigenartigen Mystik des "Ewig-Weiblichen" mit einer irrationalen Kulturphilosophie des "Geistes der Musik" führte.

Blok versuchte in den Jahren 1907-08, die inn bedrängenden Fragen - Verfall der patriarchalischen Adelskultur und Heraufkunft der großstädtischen Massenzivilisation, Beziehung von Volk und Intelligenz, Schicksal und Sendung RuBlands, Verhältnis von persönlichem und kollektivem Schicksal angesichts der drohenden Umwälzungen -, die inm in seiner Publizistik zu unkünstlerisch behandelt und in seiner Lyrik sowie seinen lyrischen Dramen zu subjektiv gestaltet schienen, in einem Drama künstlerisch zu objektivieren ${ }^{1)}$ und einem breiten Publikum vorzustellen. Das Ergebnis dieses hochgreifenden Unternehmens, das Drama "Pesnja sud'by" (Das Lied des Schicksals), ${ }^{2)}$ gilt als küstlerisch zweitrangig. Es wurde nie aufgefüht, obwohl sich Blok sehr um eine Aufführung bemuhte. 3) Es nimmt aber im Schaffen Bloks einen uberaus wichtigen Platz ein. Trotzdem war das Stuick bisher noch nicht Gegenstand einer eingehenden Untersuchung. In den Blok-Monographien

1) Vgl. hierzu den SchluB der vorliegenden Arbeit (S. 496ff.).

2) Im folgenden wird der Titel des Stücks mit LS abgekürzt.

3) Vgl. Entstehungsgeschichte, v.a. S. $15 \mathrm{ff}$. 
wird es zumeist nur am Rande behandelt. 1) Die spezielleren Arbeiten uiber Bloks Theater gehen zwar ausfuhrlicher auf das IS ein, erschöpfen sich aber alle - genau wie die Monographien in einer mehr oder weniger genauen Inhaltsangabe, einigen summarischen Verweisen auf den Zusammenhang des LS mit Bloks ubrigem Werk und allgemeinen Aussagen uber den Ideengehalt. 2)

In der vorliegenden Arbeit wird versucht, eine möglichst erschöpfende Darstellung des Ideengehalts des LS zu geben und allen Verästelungen von Bloks esoterischer Mystik und anspielungsreicher Symbolik nachzugehen. Es zeigt sich, daß das IS zeitlich und thematisch einen besonders geeigneten Zugang zum Gesamtwerk Bloks ermöglicht.

Im Versuch, sein mythisches Weltbild in ein Kunstwerk mit objektivem Gültigkeitsanspruch zu gieBen, nahm Blok Zuflucht zu einer sehr weit gehenden Stützung seines eigenen Mythos durch vorgegebene literarische und religiöse Mythen. Das fürte dazu, daß das LS voll ist von Anspielungen auf Mythen verschiedener Herkunft und Bezugnahmen auf literarische Vorbilder. Bloks Auswahl und Deutung ist allerdings subjektiv; er baut das Vorgegebene in sein eigenes mythisches Weltbild ein.

Die Besonderheit gerade des LS - zahlreiche Anspielungen, Bezugnahmen und $\mathrm{Zitate,} \mathrm{sowie} \mathrm{die} \mathrm{aus} \mathrm{der} \mathrm{Publizistik} \mathrm{herübergenom-}$ mene kulturphilosophische Thematik - forderte für die Arbeit eine Verbindung von streng philologischer Detailforschung mit der übergreifenden Darstellung der geistesgeschichtlichen Zusammenhänge.

Die Arbeit enthält im 1. Hauptteil die Entstehungsgeschichte des LS. Hier werden die genetischen Zusammenhänge der langwierigen und für Blok sehr mühsamen Entstehung des Stúcks geklärt und

1) Ausfuhrlicher behandelt wird das IS nur in den Monographien K. Mocul'skijs und B. Solov'evs (hier bezeichnenderweise erst in der erganzten 2. Auflage) und in R.-D. Kluges grundlegender Arbeit über Bloks Weltbild.

2) Das gilt für Volkov und in dessen Gefolge auch für Medvedev, Bonneau (Laffitte), Mayr, Rubcov, Rodina, aber auch für Gromov . 
Einblicke in die Arbeitsweise des Dichters gegeben. Blok trug sein Stuck immer wieder im Freundes- und Bekanntenkreis vor und stellte es zur Diskussion. Es wird daher in der Entstehungsgeschichte etwas vom geistigen Klima Petersburgs in den Jahren nach 1905 sichtbar, das ins Stück selbst Eingang gefunden hat. Die Darstellung des Entstehungsprozesses soll den Zugang zum Stuck selbst erleichtern, denn hier werden im Vorgriff Probleme berührt, die an späterer Stelle der Arbeit systematisch abgehandelt werden.

Es folgt eine möglichst wortgetreue Ubbersetzung der endgultigen Fassung des LS von 1919 ins Deutsche. Bei dieser Übersetzung, die als Grundlage für den eigentlich wissenschaftlichen Teil der Arbeit dient, wurde die wortgetreue Wiedergabe des Originals dem Ideal einer dichterisch adäquaten Ubertragung aus methodischen Grïnden vorgezogen. Die hierbei kaum zu vermeidende Tendenz $z u$ einer "Intellektualisierung" des Originals ${ }^{1)}$ muBte im Hinblick auf das gesteckte $\mathrm{Ziel}$, der gründlichen Analyse des Symbolgehalts des Stücks, in Kauf genommen werden.

Der Übersetzung ist eine Aufzählung sämtlicher Abweichungen der von Blok als vorläufig betrachteten Druckfassung von 1909 vom endgiultigen Text angeschlossen. Diese Abweichungen enthalten manche interessanten Hinweise auf Bloks Bildersprache. Wichtig erscheinende Abweichungen werden im Kommentarteil an entsprechender stelle behandelt.

Der 2. Hauptteil enthält einen Kommentarteil, der sich auf die Ubersetzung bezieht. Er besteht aus Einleitungen zu den einzelnen Bildern des Stücks, in denen der ideelle Hintergrund und Gehalt erklärt wird, und aus einem fortlaufenden Kommentar. Dieser behandelt u.a. folgende Fragen:

Probleme der Übersetzung (spezieller Wortgebrauch, Wortspiele, stilistische Besonderheiten u.a.)

Unterschiede zwischen den beiden Druckfassungen

Wichtige Querverbindungen $z u$ anderen Werken Bloks (Iyrik, Kunstprosa, Theater, Publizistik, Tagebuchnotizen, Briefen)

1) Vgl. dazu Levf, J.: Die literarische Übersetzung, S. $117 f f$. 
Anspielungen auf und 2 itate aus Werken der altrussischen Literatur, der russischen Folklore, verschiedener russischer und nichtrussischer Autoren, Anspielungen auf verschiedene Mythen, christliches Glaubensgut u.a.

Es war nicht $z$ vermeiden, daB der Kommentar an vielen Stellen interpretatorische Ausführlichkeit annimmt. Nur so schien eine sachgerechte Kommentierung des Stuicks ohne Ausgliederung zahlreicher Exkurse möglich.

Als Ergänzung zum Kommentarteil folgt ein Exkurs über Bloks Verhältnis zum "raskol". In diesem Exkurs soll zunächst allgemein Bloks Beziehung zum künstlerischen lieopopulismus der Jahrhundertwende dargestellt werden. Auf diesem Hintergrund werden dann die für Bloks eigentümliches "narodnidestvo" besonders aufschluBreichen Beziehungen zum russischen Altgläubigentum und jektenwesen aufgezeigt, die gerade für das LS, darüber hinaus auch für die Interpretation der "Zwölf" und für Bloks RuBlandMythos insgesamt von grober Bedeutung sind.

Im schlubteil der Arbeit wird das is in Inhalt, Form und Intention als Ausdruck von Bloks mystisch-irrationalem weltbild interpretiert, das von den Begriffen "das Ewig-weibliche" und "der Geist der Musik" beherrscht wird.

An dieser Stelle möchte ich meiner Frau, die am Zustandekommen dieser Arbeit großen Anteil hatte, von ganzem Herzen danken. GroBen Dank schulde ich auch meinem verehrten Lehrer Herrn Prof. Dr. Dr. Ludolf Müller, der diese Arbeit angeregt und betreut hat. Mein besonderer Dank gilt auch Herrn Prof. Dr. Johannes Holthusen und dem Verlag Otto Sagner für die Veröffentlichung der Dissertation in der Reihe "Slavistische Beiträge". 


\section{ENTSTEHUNGSGESCHICHTE}

Ubersicht Uber die Texte:

Blok hat von 1907 - 1919 immer wieder am LS gearbeitet. Das Stuck liegt in zwel verschiedenen Druckfassungen vor:

-P1- Die erste Durckfassung erschien in Bd. 9 des Almanachs "Sipomik", SPb.1909, S.193-252.

-P2- Die zweite, endgültige Druckfassung erschien im Juni 1919 als Einzelausgabe im Verlag "Alkonost", Pb. Diese Fassung wurde in die späteren Ausgaben der Werke Bloks aufgenommen, so auch in den 4.Bd. von "Sobranife sotinenif $\checkmark 8$ tomach, M.-L., 1960-63". 1)

Die Abweichungen von P1 gegenüber $P 2$ werden in russischem Wortlaut im Teil "Abweichungen" vollständig aufgefuhrt, die wichtigsten im Kommentar bewertet.

Neben F1 und $F 2$ existiert ein Manuskript ${ }^{2)}$, das aus zwei Teilen besteht, die im folgenden $M 1$ und $M 2$ genannt werden.

- M.1- Der erste Teil des Manuskripts besteht aus 258 einseitig beschriebenen Blättern. ${ }^{3)}$ Auf dem Umschlag steht:

"Aprel' 1907 - 29 aprelja 1908 (Do Ctenija Stanislavskomu i Nemirovi(u-Dan (enko)". 4)

M1 ist eine in sich geschlossene Fassung des LS.

-M2- Der zweite Teil des Manuskripts besteht aus 46 Seiten mit eigener Seitenzählung. M2 trägt den Vermerk: "Éta scena napisana letom $v$ Sachmatove, posle vesennich razgovorov so Stanislavskim i NemiroviCem-DanCenko."5) Dieser Teil ist die handschriftliche Passung der "Szene auf dem öden Platz".

1) Diese Ausgabe wird zitiert: römische Zahl für den Band, arabische Zahl für die Seite. Das IS steht IV, 103-167. Die als Ergänzung zu dieser Ausgabe erschienenen Zapisnyje knizki werden als Zap.kn. zitiert.

2) Es befindet $81 \mathrm{ch}$ im Blok-Archiv im IRLI (rukopisnyj otdel, fond 654, op.1, ed.chr. 147).

3) Medvedev, Dramy i poemy, S.62.

4) IV, 578.

5) IV, 578 . 
Eine Darstellung der wichtigsten Abweichungen von M1 und 12 gegenüber $P 1$ gibt P. Medvedev in "Dramy i poèmy Al. Bloka", S.64ff." P. Gromov zitiert in seiner Arbeit "Pesnja Sud'by" $\checkmark$ trorłeskoj évoljucil Bloka"2) mehrfach M1. Doch finden sich fast alle dort zitierten Passagen aus $M 1$ in $F 1$ oder $F 2$ wieder, so daß sie fur die Beschreibung des Eigencharakters vom M1 nichts hergeben. Ehe nicht M1 und 42 vollständig veröffentlicht sind, mus man sich auf die Beschreibung Medvedevs verlassen. Für zwei Akte liegt der Wortlaut von $M 1$ in IV vor. Schon im Anhang zum Kapitel "Pesnja Sud'by" in "Dramy 1 poemy" veröffentlichte Medvedev 1928 erstmals die "Szene auf dem Bahnhof", die weder in $\mathrm{F} 1$ noch in $\mathrm{P} 2$ aufgenommen wurde. ${ }^{3)}$ Diese Szene ist nun in IV,436-444 erneut abgedruckt, dazu auch das letzte Bild nach $M 1$ in IV, 445-454.

Die wichtigsten Abweichungen von $M 1$ und $M 2$ gegenüber den beiden Druckfassungen werden im Kommentar am Schlus jedes Bildes kurz dargestellt.

Neben den aufgefuhrten Texten existierten weitere Skizzen und Vorarbeiten.

Blatt 1 von $M 1$ trägt den Vermerk Bloks, daB die beiden ersten Szenen des IS in jeweils zwei weiteren Entwirfen vorgelegen hatten. 4)

Auf Blatt 258 von $M 1$ steht der Vermerk Bloks: "AuBerdem existierten Entwirfe einer gelungenen Szene (nabroski talantlivol sceny) zwischen Helena, dem Freund, Faina und German in einer Spielhölle. Sie wurde vor mir vernichtet, ebenso wie alle sonstigen Entwuirfe. VI. 1921"5)

Als Entwurf zu einer wahrscheinlich nie ausgefuhrten Szene mu $B$ der Eintrag in den Zapisnyje knizki vom Mai 1908 gelten. 5)

1) Die Arbeit Medvedevs murde 1960 und 1971 neu herausgegeben. Ich beziehe mich auf die Erstausgabe von 1928.

2) in: Gromov, Geroj i vremja, S.482-521. M1 wird zitiert auf den Seiten 498, 499, 501, 508, 509.

3) Ubersetzung dieser Szene S.107-120.

4) P. Medvedev, aaO, S.61.

5 zitiert nach P. Medvedev, aao, S.61. Vgl. auch IV, 578. Blok ordnete in den Monaten vor seinem Tod seine Manuskripte.

6) Zap.kn., 107 
Blok hatte wohl die Absicht, elne Szene zu schreiben, in der Helena und German sich nach dem Verlassen des Hauses begegnen soliten. Diese Begegnung scheint im Mittelpunkt der von Blok vernichteten "Szene in der Spielhölle" und der Skizzen in den Zapisnyje knizki gestanden zu haben. Genaueres úber Bloks Absichten läbt sich jedoch nicht sagen. In allen sonst bekannten Fassungen findet eine solche Begegnung nicht statt. Wenn Blok eine Verbindung zwischen seinem mannlichen Helden und der Gestalt des Germann in Pứkins Erzăhlung "Pique Dame" hätte herstellen wollen, dann häte er wohl kaum auf die Ausarbe1tung der "Srene in der Splelhölle" verzichtet. 1)

Einige Manuskripte Bloks wurden 1918 bel der Zerstörung seines Landgutes Sachmatovo durch aufrührerische Bauern vernichtet. Darunter befand sich auch das Manuskript von F2.2)

1) $\mathrm{Vgl} \cdot \mathrm{S} .43 / 4$

2) $V_{g l}$. die Angaben in Literaturnoje lasledotvo 27-28, S.565f., Anm. 6 und 7 . 


\section{Die Entstehungsgeschichte des IS:}

2weckmäBigerweise tellt man die Entstehungsgeschichte des IS in die folgenden vier Etappen ein:

1.Etappe: Anfang 1907 - 29. April 1908. Das Brgebnis ist die Manuskriptfassung $M 1$.

2.Etappe: Mai 1908 - Frihjahr 1909. Das Ergebnis 1st die erste Druckfassung $F 1$ mit einer neuen Szene, deren handschriftliche Fassung M2 darstellt.

3.Etappe: Die Jahre nach dem Erscheinen von F1: 1909 - Ende 1918. In dieser zeit beschäftigte sich Blok nur wenig mit dem Stück. Aus diesen Jahren ist keine Umarbeitung bekannt oder erhalten.

4.Etappe: Anfang Januar 1919. In dieser Zeit entsteht die endgultige, zweite gedruckte Fassung F2.

Erste Etappe: (Anfang 1907 bis 29. April 1908)

Die ersten Pläne zum LS gehen au den Anfang des Jahres 1907 zurück. In einem Brief an V. Brjusov vom Januar 1908 klagt Blok darüber, daB er sich "nun schon ein Jahr abquäle", 1) ein Theaterstück zu schreiben.

Im Januar 1907 war der Gedichtzyklus "Sneznaja maska" (Die Schneemaske) beendet. Möglicherweise fallen die ersten Uberlegungen zum LS in diese zeit. Vielleicht darf man jedoch die Zeitangabe in dem Brief an Brjusov nicht zu genau nehmen. Die Angabe "April 1907 - 29. April 1908" auf dem Umschlag von M1 (8.0.) fuhrt nicht ganz soweit zurück wie der Brief.2) Am 24. Mai 1907 schreibt Blok an seine Prau:

"Ich schreibe Dir vom Bahnhof in Sestroreck. Ich sitze da und trinke. Das Stfick geht voran... Ein großer Teil des ersten Aktes ist iber Dich..."3)

1) IV, 578

2) Vgl. A. Turkov, A. Blok, S.310 und VIII, 529.

3) VIII, 185f. 
Schon in dieser ersten Aussage über das LS weist Blok auf den biographischen Gehalt in diesem Stuck hin.

Am 30. Mai 1907 schickte Blok seiner Prau sein soeben entstandenes Gedicht "Ty otoßla, - 1 ja v pustyne..." mit der Erklärung:

"Mir ist wehmitig ohne Dich; ich denke, das Dir dieses Gedicht angenehm sein wird, das eigentlich alles ausschöpft, was Ich Dir schreiben kann."1)

Uber das LS sagt Blok in diesem Brief:

"Das Drama schreibt sich schlecht" (Drama plocho piłetsja).2) Eine Tagebuchnotiz vom 9. Juni bezieht 8 ich ebenfalls auf das LS:

"Die "Hausierer" werden mit so einer geheimen Trauer gesungen. Besonders - "Ich habe selbst nicht wenig dafur bezahlt, feilsche nicht, geize nicht..." Die Stimme vergeht in Tränen in den verregneten Pernen. Alles ist in dieser Stimme: das weite RuBland (prostornaja Rus'), und die rote Eberesche, und der bunte Ärmel des Mädchens, und die zerstörte Jugend. Herbstrausch. Regen und zukünftige Sonne. Darin wird das Geheimnis ihres und meines Weges sein. So das Stuck schreiben, - in diesem Herbst." 3 )

Dieser Eintrag enthält einige Bilder, die in Bloks Gedicht "Osennjaja volja" (Herbstfreiheit; II,75f.) und in seinem Aufsatz "Bezvremen'e" (Zeitlosigkeit; $v, 66-82$ ) vorkommen und er verweist auf den Gedichtzyklus "Paina" vom Herbst 1907.4) Der vorletzte Satz des Eintrags bezieht sich au die Schauspielerin N.N. Volochova, die Blok im Winter 1906/07 zu dem Zyklus "Schneemaske" inspiriert hatte und die das reale Vorbild für die Gestalt der Faina in den Gedichten und im IS ist.

1) In dem Gedicht vergleicht Blok seine eigene Unbehaustheit mit der Einsamkeit Christi, der von sich sagte: "Des Menschen Sohn hat nicht, da er sein Haupt hin lege." Blok zitiert in der 3.Str. des Gedichts diese Stelle aus Matth.8,20 fast wörtilch. Das Gedicht, ohne die Initialen von Bloks Prau, eröffnet den Gedichtzyklus "Rodina". III, 246

2) VIII, 186

3) Zap.kn., 941.

4) Vgl. zum Zykius "Faina" die Einleitung zum 5. Bild, S.309ff. 
In selner Liebe zu N.N. Volochova sah Blok die glelchniahafte Widersplegelung seiner Llebe zu RuBland. Die Notiz zeigt, das Blok sein Verhaltnis ou der Schausplelerin und die Bedeutung, die er darin beschlossen sah, ab Juni 1907 in den Mittelpunkt seines neuen Stucks stellen wollte. Die lyrische Darstellung seines Ilebesverhältnisses gab Blok in den Gedichten von Herbst 1907, die dramat18che im IS in der Beziehung zwischen German und Paina.

Ein weiteres Mal erwaihnt Blok das LS in seinem Brief rom 9. August an seinen Freund Je. Ivanov. In diesem Brief legt Blok zunächst die Grunde dar, die linn bewogen, 1 . Belyj zum Duell zu fordern. 1) Er bittet seinen Freund um Rat und fragt Ihn, ob er bel dem Duell sein Sekundant sein wolle. Ganz am Schlus des Briefes heist es dann:

"Ich gehe viel spazieren, erhole mich, denke nach, verfasse ein Stuck."2)

Genauere Auskunft uber die Arbeit am IS gibt Blok jedoch erst am 8. Januar 1908 in einem Brief an seine Mutter. Man opurt, wie anstrengend und quälend die Arbelt an dem Stuck zu dieser Zeit war.

"Je kälter und schlimmer dieses ungluckliche und erfolglose "persönl1che" Leben 18t.... desto tiefer und weiter (glubere 1 (ire) sind meine ideellen Pläne und Absichten (idejnyje plany 1 nameren'ja). Ich habe deren so viele, das mir manchmal der wut sinkt, - so viel ist zu tun: das Nächste 1st das Stuck. Ich habe schon dre 1 Akte entworfen, $d . h$. 1 ch bin am Wendepunkt angelangt: das Schwerste ist getan, und nun blelbt nur die letzte Anspannung aller Kräfte und viel schwarze und angestrengte Arbeit. Ich bin hier nicht faul ( 1 ch werfe z.B. ganz den gut geschriebenen, aber ideell unbefriedigenden 5. Akt hinau 8 ). 3)

Mit dem Akt, den er nicht in das Stuck aufinimt, meint Blok offenbar die "Szene auf dem Bahnhof".

1) VIII, 191f., Brief an Belyj rom 8. Aug. 1907 mit der Porderung zum Duell. Das Duell kam nicht zustande.

2) VIII, 192-194. Das Zitat steht auf S.194.

3) VIII, 224 
Nach einer tberelcht Uber seine weiteren Pläe ${ }^{1)}$ berichtet Blok in diesem Brief dann von einer Unterredung mit der Schauspielerin V. Kommissarzevskaja:

"Etwa elneinhalb Stunden unterhielten wir uns uber alles sehr nett. Sie bittet, auBer um mein Stuck (uber das ich auswelchend geantwortet habe aus Dir bekannten Grinden), um die Ubersetzung eines deutschen Stucks fur die kommende Salson. Nebenbe1, Ich habe ihr das Drama von Grillparzer vorgeschlagen."2)

Die Schauspielerin V. Kommissarževskaja 18t eine der grösten Erscheinungen im Petersburger Theaterleben vor dem ersten Weltkrleg. Sie hatte $1904 \mathrm{mit}$ dem "Dramaticeskij teatr" 1hre eigene Buhne gegrilndet. Im Prihjahr 1906 hatte sie in ihrem Theater eine radikale Reform durchgefuhrt und $v$. Mejerchol'd zum Chefregisseur bestellt. Unter dessen Regle war am 30. Dezember 1906 Bloks Schauspiel "BalaganXik" (Das Schaubudchen) uraufgefürt worden. 3) Blok wollte jedoch das IS unter der Regie von K. Stan18lavsk1j im Moskauer Kunstlertheater unterbringen. Deshalb wich er dem Angebot der Kommissarzevskaja aus. 4)

Im winter $1907 / 08$ war Blok von einem tiefen Abscheu gegen den Fetersburger kulturbetrieb erfült, der direkt mit seiner Arbeit am LS zusammenhirg und im Stück seinen liederschlag fand. 5)

Am 17. Januar 1908 shrelbt Blok seiner Mutter:

"Das Drama geht voran (podvigajetsja), jetzt schreibe ich den vierten Akt.6) Das $18 t$ eln ganzer Bereich des Lebens (celaja oblast' zizni), in dem $1 \mathrm{ch}$ baue, abreibe und nach elgenem Ermessen schalte und walte (stroju, lomaju 1 rasporjazajus' posvojski). Ich begegne schon wohlbekannten Personen und bringe sie in verschiedene Situationen, ganz nach meinem Willen. Sie haben einen launischen Charakter (kapriznyj nrav), und sie enthullen mir vieles bei der Begegnung.

1) Es handelt sich um einige Aufsätze ("O teatre", "O sovremennoj kritike", "Genrich Ibsen").

2) VIII,224f. Blok Ubersetzte in dieser Ze1t "Die Ahnfrau" von Grillparzer. Blok arbeitete an der Ubersetzung von Jan. Mai 1908. Die Auffuhrung fand am 29.1.1909 $1 \mathrm{~m}$ Theater der Kommis8arzev8kaja statt. Vgl. dazu IV, 595 .

3) IV,567f.. Vgl. K. Rudnick1j, Rez18ser Mejerchol'd, S.87ff.

4) VgI. Anm. 5 zu dem Brief VII,224.

5) Vgl. Einleitung zum 4. Bild.

6) Viertes Bild von P2: "Szene in der Garderobe der Faina". 
Natal'ja Nikolajevna fuhr am 13. in der Nacht weg. In den Tagen ihrer Abvesenheit treffe ich verschiedene literaten, mit denen ich noch in Verbindung stehe. Woru 18t unbekannt. Bs 18t nehr ein politischer Akt der Preundlichke1t. Doch ich lebe in neiner Welt, und die Preunde stecken ihre blanken Nasen nlcht eehr herein."1)

Dieser Brief steht sicher in unmittelbarem Zusanmenhang ait der Bahnhofsszene.

Am 19. Januar $1908 \mathrm{glbt}$ Blok in einem Brief an A.N. Cebotarevskaja, die Prau F. Sologubs, als Grund fur sein Fernbleiben von Dichterlesungen die Arbeit am IS an:

"Ich mache eine sehr schwere Krise durch und schrelbe unter Qualen an einer groben Sache; deshalb kann 1 ch nicht mehr auf Abendveranstaltungen, ou denen $1 \mathrm{ch}$ sehr skeptisch stehe, melne Werke vortragen, sehe auch wenig Menschen und gehe nirgendwo $h$ in. Man mus erst mit dem fertig werden, was sich in einem festgesetzt hat und wie ein schwerer Stein im Innern liegt."2)

Erat an 25. Januar 1908 tellt Blok seiner Mutter Titel und Akteinteilung selnes Stucks mit:

"Nur wegen des Dramas schrelbe ich Dir so lange nicht, Mama, und komme $1 \mathrm{ch}$ nicht. Ehe ich nicht damit fertig bin, kann $1 \mathrm{ch}$ nicht. Es heiBt "Das Iled des Schicksals", Drama in 4 Aufzligen und 7 Bildern. Viele Bilder sind fertig und das allgemelne Gerist ebenfalls."3)

Ende Januar las Blok das Stuck seiner Tante M.A. Beketova vor.4) Daruber berichtet er seiner Mutter am 30. Januar:

"Hat D1r die Tante Uber mein Drama geschrieben? Ich habe ihr vorgelesen, we1l $1 \mathrm{ch}$ schwer einen Menschen finde, der mir die Wahrheit sagt: die Iiteraten sind einseitig, und die Nachstehenden sind selbst handelnde Personen. Die Tante machte mir einige reale Bemerkungen, die $1 \mathrm{ch}$ zu Herzen nahm. Die verfluchten $A b-$ straktheiten (prokljatyje otvlecennosti) verfolgen mich auch in diesem Stück, wenn vielleicht auch weniger als sonst."5)

Blok macht hierfur seinen Vater verantwortlich, den er als "Dekadenten b1s auf die Knochen"6) bezelchnet.

1) VIII, 225

2) VIII, 226

3) Pis'ma k rodnym I, S.191.

4 Vgl. VIII,228, Brief an Je.P. Ivanov vom 31. Januar 1908.

5) VIII, $226 f$.

6) VIII,227. Das Vater-Sohn-Problem als psycholog1sche und histod rische Schicksalhaftigkelt klingt in Bloks Poem "Vozmezdije" an. 
Man darf das, was er In diesem Zusammenhang seinem Vater anlastet, ohne Bedenken als aus sich selbst bezogen betrachten: es lst der Mangel an "Saftigkeit" (solnost'), "Prägnanz" (jarkost'), "Lebensnähe" (Ziznennost'), "Bildhaftigke1t" (obraznost'), "Typischem" (tipicnoje), "Charakteristischem" (charakternoje). "Aber im Leben gibt es noch sehr viel "Saftigkeit" (solnost'), die der künstler verkörpern muB". 1) Die "Saftigkeit", die sich im IS so schwer einstellen wollte, fordert Blok vom zukinftigen Theater. ${ }^{2}$ )

Wohl unter dem Eindruck der kritischen Einwände seiner Tante uberarbeitet Blok sein Stuck noch einmal. Am 25. März 1908 schreibt er an A. Belyj:

"Me in Drama habe ich schlieblich fast fertig; ich hatte grobe Muhe damit (ocen' perebolel jeju), und es ist, glaube ich, etwas Besseres herausgekommen als die früheren (vysio cto-to luçeje, rem predydustije). Ich winsche sehr, daB Du es kennen lernst." $\xi$ )

Am 15. April schreibt Blok seiner Mutter:

"Ich arbeite sehr viel, übersetze schon den vierten Akt der "Ahnfrau" und beende den zweiten Akt des "Ifeds des Schicksals" (wobei ich viel uberarbeite und schleife)."4)

Am 28. April schlieblich schreibt er seiner Mutter:

"Ich arbeite, streife umher, denke nach... Die "Ahnfrau" ist fertig (im Konzept), das "Lied des Schicksals" beende ich in diesen Tagen." 5 )

Einen Tag später, am 29. April 1908 1st dann die Manuskriptfassung $M 1$ beendet, wie aus der Datumsangabe auf dem Umschlag, hervorgeht $(8.0$.$) .$

1) VIII, 227

2) Vgl. Bloks Brief vom 23. Febr. 1908 an seine Prau und seinen Aufsatz "O teatre" (Uber das Theater; $v, 241-276$, vom

3) VIII,233.

4) VIII,236.

5) VIII,239. 
In die Wochen von Ende Januar bis zu diesem Datum fallen sicher auch die jeweils zweimal geschriebenen Passungen der beiden ersten Bilder, die Blok auf Blatt 1 von M1 erwähnt (s.o.).

2war sind Bloks Mitteilungen uber die Arbeit am LS recht knapp und allgemein gehalten. Doch lassen $81 \mathrm{ch}$ schon fur diese erste Phase einige Punkte zusammenfassen, die auch fur die weitere Arbeit an diesem Stick Geltung haben:

1) Die Arbeit ist sehr mühsam, besonders das Bemuhen um Lebensnähe und konkrete Bildhaftigkeit.

2) Das Stuck ist zu einem groBen Teil biographisch.

3) Wichtig für Blok ist die ideelle Seite seines Stucks, zu der er jedoch vorläufig keinerlel genauere Angaben macht.

4) In engem Zusammenhang mit dem ideellen Gehalt des Stlucks steht Bloks Wunsch, das LS im Moskauer Kunstlertheater unterzubringen. Er betrachtet die "realistische" Buhne Stanislavskijs als geeigneter fur sein Stück, als die "symbolistische" Bühne Mejerchol'ds.

\section{Zwe1te Etappe: (Ma1 1908 - Prühjahr 1909)}

In der Fassung $M 1$ las Blok sein Stück verschiedene Male vor. Am 1. Ma1 1908 hatte sich in Bloks Wohnung in der Galernaja ulica Nr. 41 in Petersburg ${ }^{1)}$ ein Kreis von Literaten zu einer ersten Lesung eingefunden. Das Stück fand geteilte Aufnahme. Das geht aus einem Tagebucheintrag Bloks vom folgenden Tag hervor. Es heibt dort:

"Am 1. Mai las ich das "Lied des Schicksals" bei mir vor... Je.F. Ivanov2) fährt fort zu tadeln - besonders wenn German auf die Knie fällt...3) Es versöhnen ihn bis zu einem gewissen Grad

1) heute: Krasnaja ulica, Nr. 41, Ecke plołčad' Truda in Leníngrad. Blok wohnte dort von Herbst 1907 bis ins Jahr 1910.

2) Je.P. Ivanov (1879-1942) war Bloks bester und wohl einziger Freund. Uber inn in: Blokovskij sbornik, S.344-361. Seine wertvollen Erinnerungen an Blok ibid., S.362-424.

3) VI. Orlov bezieht das auf das 1. Bild. (Vgl. Zap.kn., S.539, Anm. 13). Man sollte es eher auf den Schlus der Weltausstellung beziehen. Vgl. IV, 130 . 
die Worte des Monchs. 1) Sehr kunstroll. - A.P. Ivanov ${ }^{2}$ ) (er wurde mude und konnte nicht bis zum Schlus zuhören) gefällt es sehr, v.a. der Spiegel.3) Er sagte, das, sogar hier, ich nicht in Orthodoxie verfallen sei (ne provalilsja $\nabla$ pravosiavije) (u.s.ä.), sondern alles sel gemildert durch einen gleichsam "deutschen" Geist ("germanskim" duchom) (wie in den Gedichten uber RuBland). - Verchovsk1j4) - Uber den allegorischen Charakter. Besonders protestiert er gegen "RuBland" (und ebenfalls Remizov, 5) und alle mehr oder weniger). -

Remizov sagt, das Hausierer nicht völlig russisch reden, sondern international.6) - V.A. Zorgenfrej7) verneint die Vorwurfe wegen der Internationalität und behauptet, das dieses Stuck denen, die mich kennen, bekräftigt, das ich ein "nationaler Schriftsteller" werde.

Auf Helena hat offenbar niemand seine Aufmerksamkeit gerichtet, nun denn: meine liebste (milaja moja) wird vor menschilchen Blicken verborgen bleiben - meine Einzige.8) - Pantjuchov9) gefiel am meisten die 2. Hälfte im Sinne einer "Entzauberung des Weltalls" ( $v$ smysle "raskoldovyan'ja mirozdan'ja"). Ein wenig gegen das sechste Bild. - Ich meine, dab ich hier zum ersten Mal "den schwankenden rein lyrischen Boden verlasse" ("schožu 8 satkoj čjsto Iiriceskoj počvy") (wie ich heute druber I.N. Andrejev 10) geschrieben habe). Und ich liebe jetzt diese Sache (étu vesc') mehr als allf, die ich geschrieben habe: sie ist bedeutsamer als alle."11)"

1) VI. Orlov bezieht das auf das 2. Bild (aaO Anm. 14). Vermut$11 \mathrm{ch}$ sind jedoch die Worte des Mönchs "Am Ende des Wegs ist die Seele Germans", IV, 158, gemeint.

2) A.P.Ivanov, der Bruder des zuvor Genannten, war Kunstwissenschaftler, Autor eines Buches uber Vrubel' und Verfasser der Erzählung "Stereoskop". Vgl. Blokovskif sbornik, S.351.

3) Szene in der Garderobe der Paina, IV, 139.

4 ) Ju.N. Verchovskif (1878-1956), Dichter und Literaturwissen8 chaftler.

5) A.M. Remizov (1877-1957), einer der grobten Stilisten der modernen mssischen Literatur. Er war Emigrant und starb in Paris.

6) Im letzten Bild in $M 1$ und noch in $P 1$ versucht Blok, der Redeweise des Hausierers eine volkstumliche Pärbung zu geben. (Vgl. Abw. $492 \mathrm{ff}$. und Kommentar zum 7. Bild). Der Einwand Remizovs war wohl berechtigt.

7) V.A. Zorgenfrej (1882-1938), Dichter und Ubersetzer, Opfer Stalins.

8) Blok meint hier seine Prau.

9) M.I. Pantjuchov (1880-1910), Schriftsteller. Blok schrieb thm am 22. Mai 1908 einen bedeutsamen Brief, in dem er seine Abkehr von A.Belyj und S. Solov'ev begrundet; VIII,241.

10) Der erwähnte Brief an L.N. Andrejev (1871-1919), den damals sehr beruhmten Dramatiker, ist verschollen.

11) Zap.kn., 106. 
Vom gleichen Abend berichtet V.A. Zorgenfrej in seinen Erinnerungen an Blok:

"Mit dem Drama "Faina" (Das Iied des Schicksals) ging die Periode der Sturme zu Ende. In ihm, In seinen letzten zellen, im Iled des Wanderers, ist die Kunde von RuBland, die Ruckkehr zur Hoffnung. Dieses Drama las er, vor einer zahlreichen Gesellschaft, am 1. Mai 1908 bel sich zu Hause. ("Wenn Sie 81ch nicht vor einer langen Lesung furchten, kommen sie bitte..." - der Zug einer fur ihn gewöhnlichen Bescheidenheit im Binladungsbrief vom 28. April). Be1 der Lesung der "Faina", In den Worten dieses qualvolien, alizu persónlichen, literarisch nicht gegluckten Dramas fuhite und spürte man schmerzhaft eine furchtbare Mudigkeit; nach der Lesung folgte A.A. wie immer mit gespannter Aufmerksamkeit den Worten der Anwesenden, beteiligte sich jedoch nicht an der sich entspinnenden Unterhaltung, sondern horte schweigend zu..."1)

Die verschiedenen Elnwände, die bel dieser Lesung am 1 . Mal gegen das Stück vorgebracht wurden, scheinen Blok nicht sehr beeindruckt zu haben. Jedenfalls ist der Glaube an sein stuck ungebrochen. Am 3. Mal schreibt er seiner Mutter:

"Ich lebe mit dem "Iied des Schicksals", das ich kurzlich einem kleinen Kreis (etwa zehn Leuten) vorgelesen habe, und ich bin sehr zufrieden mit dem Eindruck und den einzelnen kritischen Einwänden (am hoffnungslosesten von allen steht dazu nach wie vor die Tante2); sie erkennt das Stuck irgendwie innerlich nicht an, und ich glaube ihr uberhaupt nicht, was dieses mein geliebtes Kind betrifft (ja sovsem ne verju jej otnositel'no etogo svojego 1 jubimogo detis(a))."3)

In einer Tagebuchnotiz vom gleichen Tag, dem 3. Mai, faßt Blok die Haltung seiner Zuhörer zusammen:

"Am bedeutsamsten ist das, was alle behaupten: 1) daß es sich lohnte, "den Garten zu heben". 2) dab das Drama auf eine neuartige Weise geschrieben 18t, daB es aber keinen Abgrund gibt, es vielmehr organisch mit dem Friheren verbunden 1st, mit den Gedichten und mit meinen fruheren Dramen."4)

Im oben zitierten Brief an seine wutter fährt Blok fort:

"Morgen lese ich das "Iled des Schicksals" bel den Culkovs. 5)

1) Zorgenfrej, A.A. Blok, in: Zapiski mextatelej, Nr. 6, 1922 , S.135. Die "Periode der Sturme" 1st die Zeit der Liebe Bloks zu N.N. Volochova.

2) M.A. Beketova.

3) VIII, 240

$4) \mathrm{Zap} \cdot \mathrm{kn} \cdot 106$

5) G.I. Cuíkov (1879-1939), Iiterat und Kritiker, zu dem Blok sehr wechselhafte Beziehungen hatte. 
Es werden guhören: L. Andrejer mit Prau, die Culkovs, Sologub, 1) Volynsk1j,2) zwe 1 Verleger (die "Pakely"3) und der "S (1povnik"4)), Nalepinskjj, 5) Vjac. Ivanoy,6) Sjunnerberg,7) Lapsere 8) mit Prau, Volosin, 9) Kuzmin, 10) die Sčegoleva,11) zilkin 12) mit Prau und viele andere. Dann werde ich vielleicht der Truppe Stanislavskijs vorlesen. Ich sammle alle Melnungen und höre sle sorgfältig an, sowohl die der Schriftsteller, wie die der Nichtschriftsteller; mir ist diesmal sehr wichtig, wie sie dazu stehen. Dies ist meine erste Sache, in der $1 \mathrm{ch}$ nicht $8 \mathrm{chwankenden} \mathrm{und} \mathrm{nicht} \mathrm{nur} \mathrm{lyri-}$ 8 chen Boden fuhle. So bestimme ich fur mich die Bedeutung des "Lieds des Schicksals", und deshalb liebe 1 ch es mehr als alles, was ich geschrieben habe. Sehr gern wirde ich es Dir in der neuen, umgearbeiteten Gestalt vorlesen."13)

Die Tagebuchnotizen und der Brief zeigen deutlich, welche Wichtigkeit Blok zu diesem Zeitpunkt seinem Stuck beimaB. Er glaubte fest, es sei thm mit dem LS gelungen, den Elfenbeinturm lyrischer Vereinsamung zu verlassen. Endlich schien er ein Drama geschaffen zu haben, dessen Gestalten jene Lebersfille besaßen, deren Mangel er im Brief vom 25. Januar so beklagt hatte. Er glaubte, ein Stuck geschrieben zu haben, das den Forderungen

1) F. Sologub (pseud. fur F.K. Teternikov, 1863-1927), bedeutender symbolistischer Dichter und Prosaist.

2) A.L. Volynskij (1863-1926), Literaturkritiker.

3) "Pakely" war ein Almanach, an dem Culkov mitarbeitete. In der ersten Polge dieses Almanachs erschien Bloks "Balagančik", in dem die "Pakely" verspottet werden. IV, 19. Die "Pakely" waren das Sprachrohr der "mystischen Anarchisten" (G. Culkov, S. Gorodeckij, Vją. Ivanov u.a.)

4) "Śipoonik" war ein Petersburger Verlag, in dem u.a. L. Andrejev, B. Zaicev, S.N. Sergejev-Censkij mitarbeiteten. Belyj bezeichnet den Verlag als "damaliges Stabsquartier L. AndreJevs"; in: Načalo veka, S.471, Anm. 2. - Von 1907-17 erschienen die Almanache "Sipornik". Im 9. A. "S." 1909 erschien P1.

5) T. Nalepinskij, polnischer Literat.

6) Vjačslav I. Ivanov (1866-1949), der bekannte symbolist.

7 K.A. Sjunnerberg (1871-1942), Dichter und Kunstkritiker.

8) Je.Je. Lansere (1875-1946), Maler.

9) M.A. Volosin (1877-1932), Dichter und Maler, bis 1910 Symbolist, dann Nähe zu den Akmeisten.

10) M.A. Kuzmin (1875-1936), Dichter und Komponist, komponierte die Musik zu Bloks "Balagančk", wichtige Gestalt des Petersburger Kulturlebens, 1910 vertritt er gegen den mystischen Symbolismus einen neoklassizistischen "Klarismus".

11) V.A. Stegoleva (1877-1931), Schauspielerin. Blok lerrite sie Ende 1906 im Theater der Kommissarzevskaja kennen. Ihr sind die Gedichte "Tri poslanija" gewidmet (III, 162f.)

12) I.V. Zilkin (1874-1958), Publizist und Politiker.

13) VIII, 240. 
entsprach, die er in seinem Aufsatz "O teatre" (Uber das Theater) ${ }^{1}$ von Februar - März 1908 an das zukunftige Theater gestellt hatte.

Am 4. Mai las Blok das IS wie angeklindigt bei Culkov vor. Einer der dort Anwesenden, Johannes von Guenther, berichtet in seinen Erinnerungen von diesem Abend, auf den Blok so groBe Hoffnungen gesetzt hatte:

"Das Theaterstück, von dem Block mir erzählt hatte, las er noch vor Ijubas Rückkehr ${ }^{2}$ ) in der Wohnung seines Preundes Georgij Tschulkow einem Kreis von etwa dreiBig leuten vor; auch mich hatte er gebeten. Alles, was in Petersburg Rang und Namen hatte, erschien...

Blocks Vorlesung dauerte, mit einer kurzen Pause, von acht Uhr bis Mitternacht, aber man merkte bald, daß sein Stuck allen miBfiel.

Block hatte sich damals aus nie ganz erhellten Grinden mit dem Dramatiker Leonid Andrejew aus der sozialistischen Gorkij-Gruppe befreundet, der auch unter den Gästen dieses Abends war. Aber er warde als Premdkörper empfunden, fuhlte es auch selber, und gab sich betont freundlich. Er war damals gewiB - oder vielleicht neben Gorkij - der am meisten gespielte Dramatiker RuBlands. ...Damals hatte sein grobschlächtiges "Leben des Menschen" gerade sensationelien Erfolg auf allen russischen Buhnen gehabt, und darum mag er Block als der rechte Mann erschienen sein, bei dem romantisch-symbolistischen "Lied des Schicksals" Patendienst zu leisten. Man sah es Block jedenfalls an, daB ihm Andrejews Ablehnung weh tat.

Block hatte in die etwas überspitzte Schlubhandlung seines Stuckes einige Strophen aus dem volksliedhaften, bezaubernden "Iied der Körbelträger"3) von Nekrassow eingebaut, die freilich in diesem künstlichen Gefüge fremd klangen. Alle verurteilten diese überraschende Einlage und am härtesten Andrejew, während Block darauf gerade sehr stolz war. Es gab ein erregtes Hin und Her; das Kuzmin und ich uns entschieden fur die Beibehaltung dieser Verse aussprachen, half in diesem erlauchten Gremium wahrscheinlich gar nichts. Es fehlte nicht viel, und man häte uns ausgelacht. Täusche ich mich nicht, äuBerte der arrogante Halbgott der Kritik, Akim Wolynskij, auf uns gemünzt, daB die Zustimmung der "jungen Dekadenten" aufs Klarste erhelle, wie grob der Pehler Blocks sei.

Block war niedergeschlagen. Trotzdem spotteten wir tags darauf weidlich mit ihm über die bärtige Jury."4)

1) $v, 241-276$

2) Ijubov' Din.Blok, Bloks Prau, war Schauspielerin in der Truppe Mejerchol'ds und damals auf Tournee.

3) Lied der "Hausierer" (Korobejniki) aus Nekrasovs gleichnamigen Poem.

4) J.v. Guenther, Ein Leben im Ostwind, S.220-222. 
Die Enttuuschung Bloks ze1gt elch darln, das er uber diesen Lbend des 4. Mal in sein Notizbuch nur den lapidaren Satz einträgt: "Schelte Andrejers" (Bran' Andrejeva). 1)

In Dezember 1919 bemerkte Blok in seinem Nachruf auf I. Andrejev:

"... Bs rerging noch ein Jahr, er fand einen gleichsam realen Anlas fur unsere Begegnung (das war meln Stuck "Das Lied des Schlcksals", das ihm Ubrigens ganz und gar nicht gefallen hat) ..."2)

Bs zeugt von Bloks Vertrauen in sein Stuck, dab er nach der allgemeinen Lblehnung selnen Plan nicht aufgab, das LS den Leitern des Moskauer Kunstlertheaters, K.S. Stanislavskif und V.I. Nemirovid-DanCenko, vorzulesen. Diese Lesung fand Mitte Mal statt. 3 ) Uber die Reaktion der belden Theaterleute liegen verschiedene Zeugnisse vor, die alle zelgen, das sie belde vom Wert und der Splelbarke1t des Stucks grundsätelich uberzeugt waren. Blok schrieb in sein Notizbuch:

"Begeistemung bel Stanislavskif und Nemirovič-Dančenkp. (Uvle Cenije Stan1slavskogo 1 Nemiroviða-Dančenko)."4)

Bloks Tante M.A. Beketova schrelbt in ihrer Blok-Blographie:

"Im Winter 1908 entstand das "Iled des Schicksals". Im Fruhjahr, wahrend der Gastopiele des Moskauer Kunstlertheaters, murde das Drama dem "Komitee" vorgelesen, das aus Staniglavsk1j, Nem1rovið-Dancenko und Burdžlov bestand. Das Stuck gefiel. Bel der Lesung rief V.1. Nemirovic-DanCenko aus: "Gott, Gott, was fur ein talentierter Junge." K.S. Stanislavskif wurde lebhaft, besonders nachdem der zweite Akt (Saal der Ausstellung) gelesen war. Hier entwarf er gleich Pläne wegen der Auffuhmung und machte einige Bemerkungen uber Einzelheiten. Die Sache galt fast als beschlosen: das Theater wird das Drama nehmen. Doch die endgultige Antwort versprechen sie aus Moskau zu schicken."5)

1) Zap.kn., 107

2) $\mathrm{VI}, 134$

3) Ein genaues Datum war nicht auszumachen. Falsch ist die Datlerung Medvedevs, Dramy 1 poèmy, S.63. Er verlegt diese Lesung auf den 1. Mai. Ihm folgt unverständicherweise

4) Zap.kn., 107

5) Boketova, A. Blok, S.112. DaB bel dieser Iesung neben Stan18lavokif und V.I. NemiroviČ-Dančenko (1858-1943), einem der Begrunder des Kunstlertheaters, auch G.S. BurdŹalov (1869-1924), der dort Schauspieler und Regiseeur war, tellgenomen hat, wiseen wir nur von Beketova. 
Am 24. Mal schreibt Blok an seinen Vater uber das IS und die Verhandlungen mit Stanislavskij:

"Bis 1. Juli bin ich auf dem Land, dann komme ich wieder hierher, um den Grillparzer zu inszenteren und mich an meinem "Iied des Schicksals" abzumuhen (chlopotat' nad svojej "Peonej sud'by") von dem Stanislavskif entzuckt war. vielleicht fuhrt er es auf. aber ich muB noch daran arbeiten."1)

Ende 1912, nach einer längeren Unterredung mit Mejerchol'd, der sich fur das IS interessiert, rief sich Blok die Bemithungen in Erinnerung, sein Stuck bei Stanislavskij unterzubringen. Er schrieb in sein Tagebuch:

"Stanislavskif lobte schrecklich, befahl zwei Bilder umzuarbeiten, und ich arbeitete sie im gleichen Sommer in eines um (hier wurde das "Kulikovo-Feld" geboren, - in Sachmatovo). NemiroviC-DanCenko lobte ebenfalis unmäBig, aber auf die ihm eigene recht abgeschmackte (poslovatyj) Art. Als 1 ch das Manuskript abgeschickt hatte, schwleg das Kunstlertheater lange. Schlieblich schickte Stanislavskij einen langen Brief dariber, daB man das Stuck nicht auffuhren solle und brauche ( $C_{t o} p^{\prime} e s u$ nel'zja i ne nado stavit'). Dem glaubte $1 \mathrm{ch}$, anders gesagt, das war fur mich ein SchluBpunkt, weil ich selbst vom Stuck Abstand gewonnen hatte und davon enttäuscht war."2)

Johannes $v$.Guenther, der in dieser Zeit mit Blok in engem Kontakt stand, schreibt daruber:

"Block versuchte nun gleich, 3) Fihlung mit Stanislawskij zu gewinnen, der, wie all jährlich um diese Zeit, fur einen Monat mit seinem Moskauer Kunstlertheater in Petersburg gastierte. Block las ihm sein Stück vor, und es begann Stanislawskijs beliebte Tour der halben und besonders enthusiastischen Zusagen, die sich nach Monaten, manchmal sogar erst nach Jahren in ein glattes Nein verwandelten. Stanislawskif setzte den armen Block dieser Folter gleich zweimal aus...4) Es spricht fur Blocks nennenswerte Härte im Nehmen, daß er sich diese alberne Ziererei so lange gefallen ließ, aber es zeigt auch, daß man Stanislawskijs Kinstlerisches Theater damals fur die oberste Instanz hielt."5)

1) Pis'ma k rodnym I, S.212f.

2) VII, $187 f$

3) d.h. nach der von v.Guenther beschriebene Lesung vom 4. Mai 1908.

4) Nach dem IS noch mit dem Drama "Roza i Krest" (Rose und Kreuz).

5) Guenther, aac, S.220. 
Aus dem von Bloks Tante Gesagtem geht hervor, daB Stanislavskif besonders von der Szene mit der Weltausstellung beeindruckt war. Die beiden Szenen, die Blok auf Stanislavgkijo GeheiB umarbeitete, und aus denen er schlieblich die "Szene auf dem öden Platz" machte, waren die "Szene in der Garderobe der Paina" und die "Szene auf dem Bahnhof". Sie beide fehlen in P1. Die "Szene in der Garderobe der Paina" wäre in inrem ersten Tell von Stanislavskij sicher akzeptiert worden. Die Mărchenepisode mit dem Erscheinen Germans gefiel inm wohl weniger.

Am 4. Juni 1908 fuhr Blok auf sein Landgut Sachmatovo, wo er "einen Teil des Sommers allein verbrachte, getrennt von seiner Prau, die zusammen mit einer Schauspielergruppe auf Tournee in den Kaukasus gefahren war." 1 )

In den folgenden Wochen arbeitete Blok am LS. Es entstand die "Szene auf dem öden Platz", die in das Stuck eine historische Perspektive bringt, die inm zuvor in diesem Umfang gefehlt hatte. Als neues Motiv erscheint die Kulikovo-Schlacht, die dann in Bloks Schaffen eine so groBe Bigenbedeutung erhält, daB der Dichter ihr einen ganzen Gedichtzyklus widmete.

Am 14. Juni 1908 schrieb Blok zwei Briefe, in denen er sich auch uber seine Arbeit am IS äuBert. An G. Culkov schrieb er:

"Es zieht mich schon nach Petersburg, doch vor dem 1. Jul1 fahre ich nicht, ich mu noch eine Weile hierbleiben. Die Natur hier ist uppig, es ist feucht und heib, die Perne ruft, und ich werde wohl trotzdem das "Lied des Schicksals" zu Ende schreiben. Ich habe viele widerwärtige Gedichte geschrieben und ein ordentliches, doch ich lese es Ihnen besser selbst vor."2)

Die ÄuBerungen im Brief an seine Prau sind deutlicher:

"Ich Überarbeite das "Lied des Schicksals". Vielleicht beende $1 \mathrm{ch}$ es zum 1. Jul1, wenn $1 \mathrm{ch}$ nach Petersburg zurlickfahre... Das "Lied des Schicksals" ist immer noch ebenso wichtig fir mich. Doch jetzt schon auf eine neue We1se, als ob ich noch mehr als es durchlebt hätte (točno ja ję̌xe bofl'̧e jeje perežil), und $1 \mathrm{ch}$ schaue es objektiver und freier an." 3 )

1) Turkov, A. Blok, S.152.

2) Pis'ma Al. Bloka, 1925, S.147.

3) VIII,243f. Dem Brief an seine Prau legte Blok das Gedicht "V nod., kogda Mamaj..." be1, vgl. VIII, 592, Anm. 1 zu Brief 178 . 
Zehn Tage später, am 24. Juni, schreibt Blok seiner Frau: "Das "Lied des Schicksals" ist fertig."1)

$\mathrm{Zu}$ diesem Zeitpunkt ist demnach die entscheidende Neuerung, die Hereinnahme der Schlacht auf dem Kulikovo pole in das stilck, vollzogen. Wie jedoch die Briefe zeigen, hat Blok gleichzeitig einen inneren Abstand zu seinem Stfick gewonnen.

Blok ertrug die Einsamkeit in Sachmatovo nicht lange. Am 1. Juli kehrte er nach Petersburg zurffck. Dort las er kurz darauf das LS S.M. Gorodeckij ${ }^{2}$ und Mejerchol'd in der neuen Fassung vor. He jerchol'd war nicht sehr begeistert:

"Mejerchol'd sagte sehr viel Wertvolles - kritisierte heftig. Ich bekam wieder Zweifel am Stlick. Mag es noch liegen bleiben. Žnja steht nach wie vor negativ dazu." 3 )

Am 20. Juni 1908 hatte Je.P. Ivanov sich in einem Brief an Blok sehr kritisch zum LS geäußert. Diesmal galt seine Kritik der iroika-Szene im neu entstehenden Bild. Er verglich die TroikaFahrt mit einer Zirkusparade. ${ }^{4)}$ offenbar hatte Ivanov, auch nachde $\eta$ er in Petersburg das neue Bild genauer kennengelernt hatte, seine Meinung nicht geändert. Anfang August widmet sich Blok wieder dem Stifk. Er schreibt seiner Frau an 2. August:

"Ich habe das "Lied des Schicksals" noch einnal durchgesehen. Ich lasse es jetzt abschreiben und schicke es wohl schlieBlich dem Kunstlertheater. Mag kommen, was will. Es tut mir nur leid, daß Du es in der neuen Fassung, bevor ich es abschicke, nicht ganz durchliest. Vielleicht warte ich auch damit, bis Du kommst."5)

Zwei Tage später schreibt Blok seiner Mutter fast in denselben worten und figt dann hinzu:

"Ich kann nicht länger daran arbeiten. Ich habe nur einige Sätze weggelassen."6)

1) VIII, 245 .

2) S.M. Gorodeckij (geb. 1884), stand bis 1912 dem Symbolismus nahe, war dann akmeist. Gorodeckijs Gedichtbände "Jar'" und "Ferun", die voll von Motiven aus der slavischen liythologie und Folklore sind, fanden Bloks begeisterte Zustimmung. Später kihlte sich das Verhältnis ab.

3) Brief an seine Mutter vom 18. Juli 1908, VIII,247. Ženja ist der Kcsename filr Je.P. Ivanov.

4) Vgl. Zap.kn., 539, Anm. 13 .

6) Pisima k rodnym I, S.222.

5) VIII, 250. 
Am 8. August 18t das IS auf der Maschine abgeschrieben. 1) Tage darauf kommt endlich seine Frau zuruck. ${ }^{2)}$ Blok verzögert hierauf offenbar die Absendung, denn erst am 16. August schreibt er seiner Mutter, er habe das IS an Stanislavskif und NemirovicDanðenko abgeschickt. ${ }^{3)}$ Es beginnen nun fir Blok Wochen, in denen er ungeduldig auf eine Antwort aus Moskau wartet. Noch im August war er mit seiner Frau nach Sachmatovo gefahren. Von dort schreibt er im September an den Verleger Grzebin:

"tber das Stfick schreibt mir Stanislavskij 1mmer noch nicht sie erwarten Maeterlinck."4)

Ähnlich heibt es in einem Brief rom 18. September an Culkov. 5) Anfang Oktober ist Blok wieder in Petersburg, doch die Antwort aus Moskau läBt auf sich warten. Blok nimmt in den Wochen nach seiner Ruckkehr aus Sachmatovo regen Antell am kulturellen Leben der Hauptstadt. Am 13. November häl er seinen Vortrag "Rossija 1 intelligencija" (RuBland und die Intelligenz).6) In diesen Wochen stand Blok in engem Kontakt mit den Merežkovsk1 j8, 7) die nach einem längeren Aufenthalt in Paris im FruhJahr 1908 wieder nach RuBland zurluckgekehrt waren. Sie nahmen an den zahlreichen Diskussionen teil, die im Herbst und Winter 1908 fiber das Problem Volk und Intelligenz in der russischen Geschichte und Gegenwart in Petersburg stattfanden, und bel denen sich die gesamte gelstige Elite Petersburgs traf. 8 )

1) Vgl. Bloks Brief an seine itutter vom 7. Aug. 1908 in: P1s'ma $k$ rodnym $I, S .224$. Nachdem er in diesem Brief eine hochpoetische Beschreibung Petersburgs gegeben hat, äuBert Blok die Absicht, noch ein lyrisches Drama zu schreiben. Offenbar gentigt inm das LS schon zu diesem Zeitpunkt nicht mehr.

2) Pis'ma k rodnym I, S.225.

3) aaC.

4) VIII, 251

5) VIII, 254

6) Vgl. VII,530; dazu Einleitung zum 4. B1ld.

7) Bloks Briefe zelgen, daB er damals bel den Merežkovskijs aus und ein ging. VGl. Briefe an seine Mutter vom 26. Okt. 1908, VIII,2551.; vom 2. Nov. 1908, VIII, 257 und vom 5./ 6. Nov. 1908, VIII, 2581 .

8) Vgl. V,742ff: Die zaristische Polizel versuchte ohne Erfolg, die Diskussionen zu unterbinden. 
Obwohl die Merezkovskijs über das Problem Volk und Intelligenz eine andere Ansicht hatten als Blok, ${ }^{1)}$ hatten sie fur dessen Ansichten Verständnis. Sicher las Blok in diesen Wochen das IS Z. Gippius vor, die daruber eine interessante Mittellung macht, ohne jedoch eine genaue Zeitangabe zu liefern:

"Blok liest mir sein Drama, sein bis jetzt unbekanntestes Werk. (Ich erinnere mich weder an eine Ausgabe noch an eine Auffuhrung). Nach meinem damaligen Eindruck ist es sehr schön, trotz seiner Unaugeglichenheit, Esoterik, zeitweisen Ungereimtheit. Sein späteres Stúck, "Rose und Kreuz", - wie $8 \mathrm{chwach}$ und eng ist es im Vergleich!

Dieses Drama ist in Prosa. An den Titel erinnere ich mich nicht; wir nanriten es im Gespräch "Faina", nach dem lamen der Heldin. Blok liest vor, genau wie er redet: dumpf, eintönig. Und das gibt seinem Vortrag eine eigenartige Kraft.

Eine sehr "Bloksche Sache". Je länger ich zuhöre, desto deutlicher erinnere ich mich an den fruheren, jungen, ewigen Blok. Paina? Ganz und gar nicht Paina, sondern noch immer dieselbe Schöne Dame, das Mädchen der Regenbogenpforte, nie - eine irdische Prau.

Du bist in die Felder entsghmunden ohne wiederkehr, Dein Name sei geheiligt... 2)

Nein, nicht ohne wiederkehr...

... die Jahre gehen voruber.

Ich ahne: Du wirst Dein Aussehen ändern. 3 )

Ich sage unwillkirlich:

- Aleksandr Aleksandrovid, aber das ist doch nicht Paina. Das ist doch wieder Sie.

- Ja.

Noch einige Seiten, der SchluB, und ich sage wieder, uberrascht und uberzeugt:

- Aber Sie, die Schöne Dame, Sie ist doch - RuBiland!

Und wieder antwortet er ebenso einfach

- Ja. RuBland... Vielleicht RuBland. Ja.4)

Mit ihrer positiven Beurteilung des IS steht $Z$. Gippius in der damaligen Zeit ziemlich allein. Es verdient Aufmerksamke1t, daB

1) Vgl. Einleitung zum 4. Bild.

2) Z. Gippius zitiert die beiden eraten zeilen von Bloks Gedicht "Ty v polja otobla...", II,7, das seinen zweiten Gedichtband einleitet.

3) Das ist ein ungenaues zitat von Bloks bekanntem Gedicht "Predčvstuju Tebja. Goda prochodjat mimo...", I,94.

4) Gippius, Živyje I1ca, Moj lunnyj drug, $\mathrm{S} .34 \mathrm{f}$. 
ele das IS Uber Bloks "Rose und Kreuz" stellt, das allgemein als sein bestes Theaterstuck betrachtet wird. Besonders interessant jedoch 1st, daB die feinfuhlige Zuhorerin Bloks spontan die Faina des IS mit der Schónen Dame in Verbindung bringt, deren neue Gestalt Bloks RuBland 1st. Blok hat dieser Gleichsetzung nicht widersprochen. 1)

Am Tag nach dem Entstehen seines Vortrags "Rossija 1 intelligencia"2) schrieb Blok einen längeren Brief an Stanislavskif, in dem er um Auskunft uber das Is bittet:

"Entschuldigen Sie, das ich Sie mit einer Antwort wegen meines Stuckes dränge: die Sache lit die, das man mir jetzt vorschlägt, es zu drucken, und es wäre nötig, es zu drucken, aus finanziellen Erwägungen; aber ich füle mich auch in dieser Beziehung abhängig von Ihrer Entscheidung. Wenn es Ihnen gelungen ist, meine Neubearbeitung zu lesen, schreiben Sie mir bitte, ob Sie sie fur das Theater als annehmbar finden, und ob sie das Stück auffuhren wollen. Wenn ja, kann $1 \mathrm{ch}$ es trotzdem jetzt drucken lassen, oder wollen Sie, daB es vor der Auffuhrung nicht godruckt wird?

Aus allen Gründen, sowohl innerlichen als äuBerlichen, ist für mich Ihre Antwort sehr wichtig. Ich weis augenblicklich nicht, ob ich noch am "Lied des Schicksals" arbeiten soll. Jetzt zumindest kann ich mich nicht daranmachen, denn es ist mir noch zu nah. Doch hat es wohl noch Mängel, und zwar große. Aber sind das nur Mängel, oder ist es ein ganzer Fehlschlag? (No tol'ko li èto nedostatki, 111 celyj porok?)."3)

Stanislavokif schickte daraufhin am 14. November aus Moskau ein Telegramm an Blok:

"In dieser Saison schaffen wir es nicht, das Stuck aufzufuhren. Einzelheiten in einem Brief in einer Woche. Ich rate, das Stuck zu drucken." 4 )

1) Das wird nan bei der richtigen Bewertung der Skizze eines Vorworts zu einer nicht zustande gekommenen Neuausgabe der "Stichi o Prekrasnof Dame" vom August 1918 berlicksichtigen musen. Dort wendet sich Blok gegen die Auffassung "von einer "Verwandlung" der Gestalt der Schonen Dame in die Gestalten seiner folgenden Blicher: der Unbekannten, der Schneemaske, RuBlands usw." Im Sommer 1918 stand filr Blok, in der Rflckschau auf sein Jugendwerk, der biographische Gehalt seiner Gedichte in Vordergrund. Vgl. I,560f.

2) Der Vortrag entstand am 6. Nov. 1908.

3) VIII,260. Blok schickte den Brief am 8. Nov.; Zap.kn., 120.

4) Stanislavakij, Sobr.sot., tom 7, S.414. 
Im Brief an seine Mutter vom 16. November meint Blok dasu:

"Für diese Saison habe ich auch nicht gerechnet, doch vielleicht kann man für die nächste Saison damit rechnen?"1)

Blok hat also noch immer die Hoffnung, Stanislavskij werde das LS nehmen.

Nachdem Stanislavskij empfohlen hatte, das IS zu drucken, gab Blok sein Stuck am 20. November D.I. Vajs, dem Chef des Verlagskontors des Verlags "Šipovnik", der es lesen und dem Chef des Verlages S.Ju. Kopel'man schicken sollte. ${ }^{2}$ ) Der von Stanislavskif angekündigte Brief blieb indessen aus. Am 24. November 8 chrieb Blok an seine Mutter:

"Stanislarskij schreibt immer noch nicht."3)

Blok entschloB sich daher, noch einmal an den Regisseur zu schreiben:

"Ich habe Ihr Telegramm erhalten und warte sehr auf den Brief. Sie wissen natürlich, wie wichtig es mir ist, von Ihnen eine bestimmte Antwort zu haben: werden Sie das Stück fur die nächste Saison nehmen? Davon hängen die Umstände für den Druck ab. Wenn Sie mir antworten wirden, daß das Stück bestimmt im kommenden Jahr gespielt wird, wirde ich es im Augenblick nicht zum Druck geben und die Auffuhrung abwarten.

Wenn irgendwie die Möglichkeit bestünde, wïrde ich nach Moskau fahren und mit Ihnen daruber reden. Doch ich stecke im Augenblick bis zum Hals in Arbeit.

Ertschuldigen Sie, dab ich sie mit dem stück so belästige, docin sein Schicksal besorgt mich sehr.

her.r irgend etwas im Stuick Sie nicht befriedigt, schreiben sie mir bitte! Hat Sie das Stick nach der Umarbeitung enttäuscht? Oder macht es fü das Theater zu grobe Schwierigkeiten? Hier bin ich selbst nicht der geeignete Richter. Doch indessen verlangt meine Seele die Buhne fur dieses Stück (A meždu tem dư̌a moja prosit scenu dlja étoj p'esy) - im Gegensatz zu allen anderen, die ich vor ihm geschrieben habe.

Sie verstehen, hochverehrter Konstantin Sergejevid, wie unangenehm es ist, iq einer fur mich so wichtigen Sache in Ungewibheit zu bleiben..."4)

Dieser drängenden Bitte um Antwort konnte sich Stanislavskij nicht versagen. Am 3. Dezember 1908 schrieb er Blok und legte

1) VIII, 261

2) Zap.kn., 120

3) Pis'ma k rodnym I, S.235.

4) Brief rom 29. Nov. 1908, VIII,263f. 
die Grunde dar, die ihn zu der Absage bewogen hatten. Zunächst entschuldigt er sich für sein langes Schweigen mit der Uberfulle an Arbeit, die die Inszenierungen der Stucke "L'oiseau bleu" von Maeterlinck, "Revizor" von Gogol' und "An des Reiches Pforten" von Hamsun verursachen. Mit diesen drei Stucken sei fur die laufende Saison gesorgt. Fur den Spielplan der nächsten Saison habe er noch keine Uberlegungen angestellt. Dann kommt Stanislavskif auf das IS zu sprechen:

"Ich habe Ihr Stuck etwa viermal gelesen. Nach wie vor liebe ich die ersten Bilder. Ich habe auch die neuen wegen ihrer Poesie und ihrem Temperament liebgewonnen, doch nicht liebgewonnen habe ich die handelnden Personen und das Stück selbst. Ich habe verstanden, dab meine Begeisterung sich auf das Talent des Autors bezieht und nicht auf sein Werk. Ich bin kein Kritiker, ich bin kein Literat, und deswegen verzichte ich darauf, zu kritisieren.

Ich bin zu keinerlel Schlubfolgerung gekommen, und deshalb kann ich nur schreiben, was ich über Sie und Ihr Stück gefühlt und gedacht habe.

Ich 8 chreibe fur alle Pälle, denn mich ermutigt Ihre rähigkeit, fremde Meinungen anzuhören...

Ich lese immer mit Begeisterung die einzelnen Akte Ihres Stucks, gerate in innere Unruhe und ertappe mich dabei, dab mich nicht die handelnden Personen und ihre Gefuhle interessieren, sondern der Autor des Stucks. Ich lese das ganze Stück, und wieder gerate $1 \mathrm{ch}$ in Unruhe und denke wieder daran, daB Sie bald etwas sehr Grobes schreiben werden. Es ist sehr wohl möglich, dab ich etwas nicht verstehe, was alle Akte zu einem harmonischen Ganzen verbindet, doch vielieicht fehlt dem Stlick die Geschlossenheit. Fast jedesmal beunruhigt mich, das die Handlung in RuBland spielt! Weshalb? 1)

An anderen Tagen scheint es mir, dab dieses Stilck eine wichtige Ubergangsstufe in Ihrem Schaffen darstellt, dab sie selbst mit ihm unzufrieden sind und sich in quälender Suche abmilhen.

Manchmal - und zwar oft - beschuldige ich mich selbst. Mir scheint, dab ich ein unverbesserlicher Kealist bin, das ich mit meinen Versuchen in der Kunst kokettiere; im Grunde genommen komme ich uber Cechov nicht hinaus ( $v$ sußznosti že, dal'̧e Cechova mne net puti). Dann nehme $1 \mathrm{ch}$ meine Arbeiten vom Sommer und lese sie durch. Manchmal ermutigt mich das. Ich beginne, den Eindruck zu gewinnen, dab $1 \mathrm{ch}$ recht habe. Ja!.. Der Impressionismus und jeder andere "Ismus" in der Kunst ist ein verfeinerter, veredelter und gereinigter Realismus.

Um mich nachzuprifen, stelle ich Versuche bel den Proben des "Revisors" an, und es dunkt mich, dab ich vom Realismus ausgehend zu einer breiten und tiefen Verallgemeinerung komme.

1) Im handgeschriebenen Entwurf des Briefes lautet diese Stelle: "...mich stort, daB die Handlung in RuBland spielt - ich fuhle es (erg. RuBland) nicht." Vgl. Stanislavskif, Sobr.soc. v 8 tomach, tom 7, S.727, Anm. 2 zu Brief 305. 
In dieser Sekunde scheint mir, das der Grund dafur, das $1 \mathrm{ch}$ Ihr Stück nicht verstehe, in mir selbst liegt (čto pričina neponimanija vał̌j p'esy - ležit vo mne samom). Die Sache ist die, daB während dieses Sommers sich mit mir etwas erelgmet hat. Ich arbeite viel an praktischen und theoretischen Untersuchungen der Psychologie des Schaffens des Schauspielers und kam zu Schlubfolgemungen, die sich in der Praxis glänzend bestätigt haben. Nur auf diesem neuen Wege wird man das finden, was wir alle in der Kunst suchen. Nur auf diesem Wege kann man sich und andere einfach und natürlich groBe und abstrakte Gedanken und Gefühle erleben lassen. Als ich mich Ihrem Stuck mit solchen Gedanken näherte, da zeigte sich, das die Stellen, die mich begeistern, mathematisch genau sind auch im Sinne der Physlologie und der Psychologie des Menschen, aber dort, wo das Interesse nachläBt, schienen mir Fehler zu stecken, die der Natur des Menschen widersprechen.

Was das 18t: eine Vermutung, meine Begeisterung für eine neue Theorie - Ich weiB es nicht und möchte filr nichts verantwortlich sein, sondern schreibe nur für alle Fälle. Wenn es dumm oder naiv aussieht, dann vergessen sie es, wenn es Sie interessiert, dann telle $i c h$ Ihnen bei einem Wiedersehen gerne die Ergebnisse meiner Versuche mit. In einem Brief kann man nicht alles wiedergeben.

Seien Sie nicht böse für den offenherzigen Brief. vielieicht ist er ungehörig, aber er ist aufrichtig..."1)

Die von Stanislavskij angefühten Gedanken sind der Kern, aus dem sich später das sog. "Stanislavskij-System" entwickeln sollte.2) Die Einsichten, die Stanislavskij bei der Arbeit an den von ihm erwähnten Stücken gewann, legte er dar in seinem Bericht über die Tätigkeit des Moskauer Kunstlertheaters zu dessen zehnjährigem Bestehen, ${ }^{3)}$ in den Notizen "Wie soll man sich für eine Aufführung vorbereiten", 4) und in den "Notizen über schauspielerische Ethik und Disziplin", 5) die zu einem großen Teil im Sommer 1908 entstanden sind.

Während der Probearbeiten zum "Revisor" beschäftigte sich Stanislavskij mit den Bemerkungen, die Gogol' etwa zehn Jahre

1) Stanislavskij, op.cit., S.415. tom 7 .

2) Vgl. die ÄuBerungen von B.M. Suzkevič in: Stanislavskij, aao, S.640. tom 5 .

3) "Otð̌et o desjatiletnej chudožestrennoj dejatel'nost1 Moskovskogo Chudožstrennogo teatre", aaO, S.405-415 tom 5.

4) "Kak gotovit'sja k spektaklju" in: Stanisiavskij, aao, tom 5, S. 416-417.

5) Stanislavskij, aao, tom 5, S.418-436, "Zametki ob artistið̌eskoj ètike $i$ discipline. 
nach der Urauffuhrung seiner Komödie unter dem T1tel "Vorherige Benachrichtigung fur diejenigen, welche den "Revisor" spielen wollen, wie er gespielt gehört", ") niedergeschrieben hatte. Gogol' warnte davor, die Gestalten durch Ubertreibung zur Karikatur zu verfälschen. Der Schauspieler solle vielmehr auf alle äuBerliche Komik und Effekthascherel verzichten und die "hauptsächliche und vornehmliche Sorge Jeder Person erkennen, auf die sich ihr ganzes Leben ausrichtet, die den ständigen Gegenstand ihrer Gedanken darstellt, den ewigen Nagel, der im Kopf oitzt."2) Wenn der Schauspieler sich mit der Leitidee der Gestalt identifiziere, uberzeuge er auch automatisch Im Detail. Stanislavskij machte sich diese Idee zu elgen. "Der schöpferische ProzeB des Erlebens erfährt seine Entfaltung dann, wenn der Schauspieler den Nerv der Rolle erfuhlt, derwe ein Leitmotiv die Gestalt in allen ihren Situationen begleitet. Gogol' nennt diese Grundnote den Nagel, den der Schauspieler sich in den Kopf schlagen muB, bevor es auf die Buhne geht." 3)

Eine solche Leitidee vermag Stanislavskif in den Gestalten des LS nicht zu sehen. Daruber hinaus gibt er in seinem Brief an Blok $z u, d a B$ er auch eine alles verbindende Grundidee in Bloks Stúck nicht zu entdecken vermag. ${ }^{4)}$ Ls ehrt ihn, daB er $81 \mathrm{ch}$

1) "Preduvedomlenije dlja tech, kotoryje pozelal1 by oygrat" kak sledujet igrat" "Revizora"", in: Gogol' Sobr.8oc.v 7 tomach, tom 4, S.389-397.

2) Gogol', aaO, tom 4, S.389.

3) Stanislavakij, aao, tom 5, S.416.

4) Diese Grundidee, die bel der Auffuhrung sichtbar werden mu, nannte Stanislavskif später "sverchzadaca" (Uberaufgabe). Diese Uberaufgabe stelit die Abhängigkeit des Theaters von der Literatur her. Sie ist das, was der Dramatiker mit seinem Stuck darstellen will. Voraussetzung fur eine suffuhrung ist, das Regisgour und Schauspieler die Uberaufgabe richtig erkannt haben und inr alles unterordnen. Damit ist ein prinzipieller Vorrang des geschriebenen Textes vor der Willkir des Regisseurs anerkannt. Die Grundthesen Stanislavskijs setzen voraus, das der Regisseur und die Schauspieler genügend Feingefuhl und Gespur haben, um die tberaufgabe des jeweiligen Stucks zu veratehen. Stanislavskij hat die theraufgabe des IS nicht verstanden.

Zum "Stanislavskij-System" siehe: Teatral'naja Éncyklopedija, tom IV, M. 1965, S. 1072-1079. Eine Darstellung gibt Abalkin, Das Stanislawski-System und das Sowjettheater, Kap. 3. Das Buch ist in seinen historischen Teilen ein typisches Produkt 
selbst die Schuld gibt und anerkennt, das ihm uber Cechov hinaus das Verständnis abgeht. 1 )

DaB Stanislarskij ein Organ fur alles fehlte, was nicht in seinem Sinne "realistisch" war, erfuhr Blok, als er am 27. April 1913 sein Drama "Roza $i$ krest" (Rose und Kreuz) dem Regisseur vorlas. Obwohl dieses Drama weit weniger esoterisch ist als das IS und Bloks frühere Dramen, und obwohl der Symbolgehalt dieses Stücks realistischer eingekleidet ist, konnte Stanislavskif mit dem Werk nichts anfangen. Blok vermerkte in sein Tagebuch:

"Das Stuck zu lesen fiel mir besonders schwer, und ich las besonders schlecht, als ich spurte, das Konstantin Sergejevic angespannt zuhört, aber nichts versteht. Aus der Unterhaltung wurde klar, dab es sich wirklich so verhielt. Er nahm die Ranze Handlung als eintönig, grau wahr, und er verlor den Paden. Als ich anfing, ihm alles ausfihrlich, mit sehr viel naiveren und gröberen Worten zu erzählen, fing er an zu begreifen."2)

Im weiteren Verlauf dachte sich Stanislavskij offenbar einige äuBerliche Theatereffekte aus, die er unbedingt im Stück haben wollte. Blok verhielt sich diesen Absichten gegenüber sehr reserviert. 3 )

Obwohl das Moskauer Künstlertheater auf Drängen I. Andrejevs hin

der Zdar.ov-Ara: chauvinistisch uno konservativ. Die russische Tradition des Moskauer Künstlertheaters wird über Gebuhr betont. Mejerchol'd wird als "prinzipienloser Sucher" und"ästhetisierender Regisseur-Kosmopolit" abgetan; S.129f. Der "vulgärsoziologische" Standpunkt des Buches ist in der UdSSR heute glücklicherwe ise uberwunden.

1) Hier muß nun der kinwand gegen den Regisseur erhoben werden, daß er auch vom Werk Čechovs überfordert war. Das Moskauer Künstlertheater hat mit seinen epochemachenden Aufführungen von Cechovs Dramen bei Cechov selbst keine Zustimmung gefunden. Cechov störte Stanislavskijs Stimmungstheater, das mit Hilfe von "realistischen" Details Stimmung machen wollte, die vom Autor gar nicht vorgesehen und völlig überflüsig waren. "Tschechows Urteil uber Stanislawskys Tschechow-Theater, durch! zahlreiche Briefstellen und bezeugte Aussprüche belegbar, läbt sich in dem Satz zusammenfassen, den er wenige Wochen vor seinem Tod über die Aufführung des Kirschgartens im Moskauer Künstlertheater geschrieben hat: Stanislawsky hat mein Stück ruiniert." ; Melchinger, Tschechow, S.59; im weiteren Verlauf wilrdigt Melchinger die Kommissarževskaja, Me Jerchol'd, Vachtangov, die Cechov besser verstanden hätten als Stanislavskij.

2) VII,240f., Eintrag vom 27 . April 1913.

3) VII,244f. Der Tagebucheintrag berichtet ausfuhrlich ilber die Unterredung zwischen dem Regisseur und dem Dichter. 
Bloks Stuck auffuhren wollte und es jahrelang probte, änderte sich an Stanislavskifs Unverständnis nichts.

Am 17. April 1917 schrieb Blok darlber an seine Mutter:

"... Ihm 1st "Rose und Kreuz" völlig unverständlich; meiner Meinung nach heuchelt er (er spielt mit sich selbst ein falsches Spiel), wenn er das Stuck lobt."1)

Auf den langen Brief Stanislavskijs rom 3. Dezember 1908 gab Blok am 9. Dezember eine sehr ausfuhrliche Antwort:

"Fur Ihren Brief - heiBen und von Herzen kommenden Dank. Wie können Sie denken, daß er fur mich ärgerlich, kränkend oder uninteressant sei? Er ist mir wichtig und teuer; alles was Sie schreiben, be rúcksichtige ich tief, nehme es zu Herzen. Und natürlich lot mir teuer vor allem Ihre innere Einstellung zu mir und zu diesem meinem Stück, Ihr inneres "Ja" und "Nein", - dann erst die Pragen der Annahme, Auffuhrung usw.

Mein Thema ist ja, ich weiB das jetzt bestimmt, ohne alle Zweifel, ein lebendiges, reales Thema; es ist nicht nur gröBer als $1 \mathrm{ch}$, es lst gröBer als wir alle; und es ist unser aller gemeinsames Thema. Wir alle, die wir leben, werden so oder $80 \mathrm{zu}$ ihm gelangen. Wir gehen nicht, -es selbst kommt auf uns zu, ist schon da. (Vse my, ¿̌ivyje, tak 111 inale $k$ nej ze pridem. My ne pojdem, ona sam pojdet na nas, uze posla.) Offnen wir das Herz, - es wird es mit Begeisterung, mit neuen Hoffnungen, mit neuen Kräften erfullen, es wird uns wieder lehren, das verfluchte "Tataren"joch der Zweifel, der widerspruche, der Verzweiflungen, der selbstmörderischen Schwermut, der "dekadenten Ironle" u.a.m. abzuwerfen, genau das Joch, das wir, die "Heutigen", in vollem Maße tragen. Offnen wir das Herz nicht, dann werden wir untergehen ( 1 ch weis das, wie zweimal zwei vier ist). Eine eineinhalbmillionenfache Kraft kommt auf uns zu, wieviele Bajonette wir auch aufstellen, was fur ein "GroBes RuBland" (nach Struve)2) wir auch errichten mögen. Sie wird uns heilig zertreten (Svjato nas rastoplet); mag es unsere Kultur noch so schlau anstellen, es wird von ihr kein Stein auf dem anderen bleiben.

In dieser Gestalt steht vor mir mein Thema, das Thema RuBland (tema o Rossii) (die Frage Intelligenz und Volk, insbesondere). Diesem Thema weihe $1 \mathrm{ch}$ bemut und unwiderruflich me in Leben. Immer deutlicher sehe ich ein, das dies die vordringlichste, lebenswichtigste, realste Frage ist. Eben $z u$ ihr komme ich längst, seit Beginn meines bewuBten Lebens, und $1 \mathrm{ch}$ weiB, daB mein Weg in seiner Grundrichtung wie ein Pfeil gerade, we ein Pfeil wirksam ist. Vielleicht ist mein Pfeil nur nicht gespitzt. Ungeachtet

1) VIII, 485

2) Blok bezieht sich hier auf den Artikel "Velikaja Rossija. Iz razmyslenif o probleme russkogo mogurtestva", den $P$. B. Struve (1870-1944) in der von inm geleiteten liberalen Monatsochrift "Russkaja mysl'" (Der russische Gedanke) 1908, Nr. 1 geschrieben hatte. Vgl. VIII,596, Anm. 2 zu Brief 201. Struve hielt Blokg Ansichten fur "naiv". Vgl. VIII,267. 
aller meiner Abweichungen, Stürze, Zweifel, Reueanfalle gehe ich. Und 8 chon jetzt (mit noch nicht dreibig Jahren) dämmerten mir, wenn auch undeutlich, die Konturen des Ganzen. Nicht ohne Grund, vielleicht nur äuBerlich naiv, ëuBerlich zusammenhangslos, spreche ich den Namen aus: RuBland (Rossija). Hier ist doch Leben oder Tod, Glück oder Untergang. Zu einer Wiedergeburt des nationalen Selbstbewubtseins, zu einem neuen, anderen "Slavophilentum" ohne die "drei Wale" (oder wenigstens ohne die WaIe Orthodoxie und Autokratie) und ohne "Slaventum" (das entscheide ich nicht im voraus, aber es ist doch selbst die Frage Bosnien und Herzegowina von geringer Bedeutung und wenig real) zieht es, ich weiB es, uns alle.1) Da das MaB unserer Verfeinerung voll ist, d.h. die Verfeinerung uns schon in Fleisch und Blut ubergegangen ist, immer mit uns ist, zittern wir schon nicht mehr um sie (natuirlich sage ich "wir" nur in der Vorahnung neuer Menschen, vorläufig sind es ihrer zweifellos wenige); und deshalb haben wir ein Recht darauf, Realisten in einem neuen Sinne zu werden. Alle diese meine Worte - zur Antwort auf 1) Ihre Beunruhigung dariber, dab ich in meinem Stilck immer wiederhole: RuBland; 2) zum Zeichen meiner völligen Ubereinstimmung mit Ihrer Behauptung, daB alle "Ismen" in der Kunst in einen "verfeinerten, veredelten, gereinigten Realismus" eingeschlossen sind.

Jetzt: was insbesondere das "Iled des Schicksals" angeht, so weib ich selbst darüber zu wenig, besser gesagt, es ist für mich bis jetzt so lebendig, daB mich selbst Inre Worte nicht restlos uberzeugen. Vielleicht, Sie haben recht, sind die Personen selbst leblos (mit Ausnahme von einigen). Doch ich liebe sie alle zärtlich, den gröBeren Teil sehe ich klar vor mir. Was Ihre Untersuchungen über die "mathematische Genauigkeit der menschlichen

1) Aus dem Orient gelangte, über griechische Vermittlung, die Vorstellung in den musischen Volksglauben, daB die Erde auf drei Walen wie auf Säulen ruhe. Vgl. die apokryphe "Beseda trech svfatitelef" (Unterredung der drei Metropoliten) und die "Golubinaja kniga" (geistliches Gedicht liber den Ursprung aller Dinge); siehe: Russian folk literature, S.175, Z. 95-101. Anfang der dreiBiger Jahre des 19. Jhdts. gab der damalige Minister für Volksaufklärung S.S. Uvarov (1786-1855) der unter Nikolaj I. geltenden offizielien Staatsideologie die Formel: pravoslavije (Orthodoxie), samoderzavije (Autokratie), narodnost' (Nationalität, volksverbundener Patriotismus). Diese drei Prinzipien galten als die Säulen des russischen Imperiums. Sie wurden schnell auch von den slavophilen akzeptiert. Bloks Skepsis gegenüber dem russischen Imperialismus, der die Vereinigung aller slaven anstrebte, zeigt, dab man auch bei ihm statt von "Slavophilentum" besser von "Russophilentum" spricht. Der panslavistische Chauvinismus schlug in RuBland hohe Wellen, als Österreich am 6. Okt. 1908 Bosnien und die Herzegowina annektierte und damit die Bosnische Annexionskrise heraufbeschwor. 
Natur" betrifft (das 18t im großen und ganzen eine Stelle Ihres Briefes), so ahne $1 \mathrm{ch}$ hier und aus Ihren indeutungen den auBerordentlichen Wert Ihrer Beobachtungen. Ich verstehe Sie, ich verstehe dieses Streben des Kunstlers eur "Mathematik" in höchstem Grade. Von diesem Gesichtspunkt aus wurden im "Lied des Schicksals" sicherlich viele Pehler gemacht.

Ich will, das Sle mich anhoren, das Sie wisien, das es in melner "Volkstümele1" ("narodničn'e") keinen Schatten von publizistischer Schlamperei gibt, daB ich in keinem Falle die "Form" ob des "Inhalts" vergessen will, die mathematische Genaulgkeit, das strengste Schleifen des Edelsteins vernachlässigen wili. Der Stein jedoch, den ich vielleicht im "Lied des Schicksalo" nicht zu schleifen verstand, - er ist edel. Ich selbst aber bin ein schlechter Meister, ein lästernder "Lyriker", - und es ist nicht mein Verdienst, daB der Stein mir in die Hände gerlet. Doch da ich ihn nun in Händen habe, bin ich betroffen von seinem Glanz, ich bereue mein Lästern, ich muB in mir Kraft, Geduld und Opferbereitschaft des Meisters finden. Sie selbst mit Ihror Arbeit waren immer und sind fur mich - das Beispiel eines strengsten Kunstlers. In Ihnen fuhle ich die Kraft, und die Geduld, und die Opferbereitschaft, und das Recht des strengsten Richters. Ich vertraue Ihnen tief; deshalb beunruhige $1 \mathrm{ch}$ mich, wenn Ich zu dem Stuck zurückkomme, im Grunde genommen nicht uber sein Schicksal; ich weiB, daß Sie es, wenn nötig, liebgewinnen, wenn nicht nötig, werden Sie es zurückweisen, wobei Sie sich leiten lassen von der Mathematik der Kunst, der Liebe zu ihren strengen Wahrheiten. Ich sehe in Ihnen einen Kunstler, dem nur Schönheit (krasota) und nur Nutzen zu wenig sind, der das braucht, was das eine und das andere elnschliest und ausschöpft - das Schöne (Prekrasnoje). 1) Und wegen alledem glaube $1 \mathrm{ch}$ an Ihren Realismus. Natúrlích wissen sie das. ...

AIles kann man naturlich nicht schreiben. Vielleicht mus man miteinander reden. Aber ich habe schreckliche Angst vor Worten, in ihrer Begeisterung ertrinkt man leicht. Eben deshalb will ich prinzipiell die Auffuhmung eines Stucks, wenn nicht des "Lied des Schicksals", dann irgend eines anderen (jetzt des neuen, das schon in mir sitzt, mich von neuem quäl); denn

1) 'Krasota' ist bei Blok die nur äuBerliche Schönheit, die "interesseloses Wohlgefallen" erregt. 'Prekrasnoje' (im Brief groß geschrieben genau wie im Titel "Stich1 o Prekrasnoj Dame") ist dagegen das moralische Schöne, das Zweck und Wohlgefalien verbindet. In der magischen Welt der Primitiven sind die Bereiche des Schönen und des Nutzlichen noch ungetrennt ( $\mathrm{vgl}$. $V, 51$ ). Der Verrat am Schönen (Prekrasnoje) ist fur Blok der Súndenfall der modernen Kunst ( $\mathrm{ggl}$. V,433ff.; die Ausfuhrungen Bloks beziehen sich ganz wesentlich auch auf sein eigenes Schaffen). Diese Anschauungen verraten eine starke Abhängigkeit von der Kunstphilosophie der Romantik. 
das Schauspiel auf der Buhne (teatral'noje dejotro ${ }^{1)}$ ) ist bereits mehr als ein Wort. Es ist nötig, daB mein Thema, von dessen Lebenswichtigkeit ich uberzeugt bin, nicht nur in die Ohren der Zuhörer dringt, sondern in die Augen, in das Herz, in den Willen des Zuschauers. Wenn das Wort eine unklare Vorahnung ist, 80 kann die Theatervorstellung ein echter, aus dem Winterschlaf erweckender und in den Glanz und die Trube des lebendigen Lebens2) werfender Peitschenschlag sein.

Auf Wiedersehen, lieber Konstantin Sergejevic. Wenn Sie in $\mathrm{Zu}-$ kunft zu irgend einem SchluB kommen, so schreiben Sie mir. Sie wissen jetzt, wie ich auf Sie höre und wie wichtig mir Ihr Wort ist.

Ihr ergebener Aleksandr Blok.

PS: Ich gedenke, das "Iied des Schicksals" im Almanàch "Šipovnik" zu drucken; wann, ist noch nicht vereinbart."3)

Blok legte seinem Brief ein Exemplar seines Referats "Rossija $i$ intelligencija"4) bei. Es ist zu bezweifeln, daß Stanislavskij Bloks ÄuBerungen über RuBland verstanden hat. Der Brief scheint Stanislavskijs ablehnende Haltung dem IS gegenuber nicht geändert zu haben. 5)

Als entscheidende Ergänzung von früheren ÄuBerungen Bloks uber das LS ist die Aussage über das "Thema" zu bewerten, das in dem Stück gestaltet wird. Blok erklärt, daB er im LS das Verhältnis von Volk und Intelligenz darstellen wolle, das er als Schicksals frage RuBlands ansah. 6)

Am 14. Dezember 1908 fabte Blok in einem Brief an seine Mutter die Einwände Stanislavskijs kurz zusammen. Dann fuhr er fort:

"Mein Eindruck und der von Ljuba ist, daß er das Stuck nicht auffihren wird, und ich gräme mich nicht darüber, denn ich glaube an Stanislavskij... Merezkovskij schlägt es filr das Alexandra-Theater vor, doch ich bitte zu warten, und ich will das Alexandra-'Sheater auch nicht sehr, es riecht immer schlechter. - Am

1) "dejstvo" ist ein altertümlicher Ausdruck für "Auffiihrung", der sowohl fiir das weltliche wie das geistliche Theater angewandt wurde. Blok ubersetzte das halbliturgische "Miracle de Theophile" von Rutebeuf mit "Dejstvo o Teofile" (Vgl. IV,267).

2) "lebendiges Leben" ist ein Lieblingsausdruck Dostojevskijs.

3) VIII, 265-267.

4 ) Endgultiger Titel: "Narod i intelligencija", V, 318-328.

5) Zu dem für das IS so wichtigen Verhältnis zwischen Blok und Stanislavskij siehe auch: V.Laksin, Blok i Stanislavskij; Gerasimov, Stanislavskij i Blok.

6) Vgl. Einleitung zum 4. Bild. 
18. werde 1 ch das "Lied des Schicksals" elnigen Leuten bei uns zuhause vorlesen."1)

Bel der Lesung vom 18. Dezember war auch eine junge Revolutionärin anwesend, mit der Blok mehrere Jahre hindurch in Verbindung stand. 2)

In diesen Tagen entschloB sich Blok endgiltig, das LS dem Verlag "Sipovnik" zu verkaufen. Am 23. Dezember schrieb er seiner Mutter:

"Das "Lied des Schicksals" habe ich ihm3) bereits filr 900 Rubel verkauft; es kommt in den 10. Almanach (Mal)."4)

Die Summe von $900 \mathrm{Rubeln}$ war nicht unerheblich. Am 18. Februar 1909 las Blok das IS vor dem Auditorium der "Höheren weiblichen Kurse" vor. Tags darauf berichtet er seiner Mutter:

"Mama, Du hast meiner Meinung nach viel versäumt, daB Du gestern nicht dabei warst. Sie haben 80 zugehört, wie man es sich nur wünschen kann - aufmerksam, auf alle meine winsche eingehend. Und $1 \mathrm{ch} 1$ as besser als gewöhnlich, ich beherrschte das Auditorium völlig. Am SchluB ein heiBer Ausbruch des Beifalls und der Dankbarkeit."5)

In den ersten März-Tagen erhielt Blok einen Brief von L. Andrejev, der ihn zu einer Unterredung zu sich einlud. Andrejev wollte Blok fur sein Neues Theater (Novyj teatr) gewinnen und bat um das LS.6)

Blok hatte jedoch am 15. November 1908 auf der Buhne des Neuen Theaters Andrejevs Stück "Dni nałej żini" (Tage unseres Lebens) gesehen und war so enttäuscht davon, das seine bisher hohe

1) VIII,268. Das 1828-32 von C. Rossi erbaute Aleksandrinskij teatr (von Blok geringschätzig mit "Aleksandrinka" bezeichnet) ist das heutige Akademische Puskin-Schauspielhaus (AkademiCeskij teatr dramy im. A.S. Pư̌kina).

2) Vgl. Turkov, A. Blok, S.193.

3) bezieht sich auf Kopel'man, von dem zuvor die Rede ist.

4) Pis'ma $k$ rodnym I, S.242. Das IS kam in den 9. Almanach.

5) Pis'ma k rodnym I, S.245, Brief vom 19.II.1909. Vgl. auch den Brief vom gleichen Tag an L.Ja. Gurevix, VIII.275.

6) Brief I. Andrejevs vom 2. März 1909. Vgi. Blokovikij sbornik, S.299f. 
Meinung von Andrejev sehr ins Wanken kam. 1) Er gab daher am 4. März eine ablehnende Antwort:

"Nach vielem wiederholtem Lesen, vielen Uberarbeitungen, Gesprächen und Briefen mit Stanislavskij, kam ich zu der Oberzeugung, das das Stück noch nicht zu der Deutlichkeit gefuhrt ist, bei der man es auf die Bühne bringen kann. Es hat vielleicht noch nicht einmal den halben Weg hinter sich gebracht. Ich spreche nicht einmal von den jetzt mir selbst klaren Mängeln in ganzen Dialogen (die zu verbessern mir jedoch noch die kräfte fehlen). sondern es ist im Ganzen noch irgend eine Zusammenhanglosigkeit. $\mathrm{DaB}$ ich all das selbst immer klarer sehe, tröstet mich sehr, doch es überzeugt mich gleichzeitig auch, daß auBer der Drucklegung mit dem Stück keine Manipulationen vorgenommen werden sollen. Es ist Zeit, daB es gedruckt wird; es werden wohl späterhin neue Varianten und Umarbeitungen entstehen, denn ich will, daB man das auf der Bühne höre, was der Leser schon lesen kann. Doch es in dieser Gestalt dem Zuschauer durch die Pfoten des Schauspielers darbringen, das wäre das gleiche, wie Salz in eine noch nicht geschlossenen Wunde streuen: es wird nur schlimmer weh tun."2)

Blok bedankt sich dann fiir die Einladung, entschuldigt seine Absage damit, daB er sehr nervös und übermüdet ist und äuBert dann den Wunsch, möglichst schnell aus Petersburg wegzukommen. Seiner Mutter berichtet $\mathrm{Bl}$ ok am 4 . März von der Einladung Andrejevs:

"Er lädt mich zu sich ein und bittet um das "Lied des Schicksals" für die kommende Saison. Ich lehne ab..., weil das Stück noch nicht reif für die bünne ist (potomu čto p'esa je došla do sceniðeskoj stadii). Ich werde wohl am "Lifd des Schicksals" noch kräftig arbeiten, auch nach dem Druck."3)

Blok möchte das Stück noch einige Male vorlesen, ehe er zusammen mit seiner Frau eine längere Italienreise antritt. ${ }^{4}$ Doch daraus wird nichts. 5)

Am 13. März teilt er seiner Mutter mit:

"Das "Lied des Schicksals" erscheint im 9. Almanach "క̌ipovnik" im April, und "Na pole Kulikovom" im 10. - im Mai. - Andrejev hat

1) Vgl. Bloks Brief an seine Mutter vom 16. Nov. 1908, VIII,262 und Blokovskij sbornik, S.300. Andrejev selbst war von der Inszenierung schockiert.

2) VIII,278.

3) Pis'ma $k$ rodnym I, S.248.

4) Vgl. Brief an seine Mutter vom 7. März 1909 in: Pis'ma $k$ rodnym I, S.249. Geplant war u.a. eine Lesung in der Petersburger Universität.

5) Brief an seine Mutter vom 13. März 1909, VIII,279. 
mir einen beleidigten und bösen Brief geschrieben - wegen meiner Absage. Doch habe $1 \mathrm{ch}$ auch Mejerchol'd abgesagt, der offenbar völlig überzeugt davon war, dab er das stuck in der kommenden Saison im Alexandra-Theater spielen wirde."1)

Am 17. März schreibt Blok seiner Mutter, daB alle Vorbereitungen fúr die Reise abgeschlossen sind. Dann sagt er zum IS:

"Das "Iied des Schicksals" gebe ich niemand fur nichts her (Pesnju sud'by ni za Xto nikomu ne otdam). Aber umarbeiten werde ich es, wenn 1ch kann, sehr stark, - filr das Theater und fur alch. Das ist unumgänglich."2)

Am 3. April teilt er seiner Mutter mit, das IS erscheine am 20. April. 3)

Am 14. April, also noch vor der Erscheinung des IS im Druck, verläBt Blok RuBland für mehr als zwei Monate. Am Tag vor seiner Abfahrt schreibt er seiner Mutter:

"Am Abend kam ich völlig erschüttert aus den "Drei Schwestern" nach Hause. Das ist ein Winkel der groBen russischen Kunst, einer der zufällig erhaltenen, nicht bespuckten Winkel meines gemeinen, schmutzigen, stumpfoinnigen und blutigen Heimatlandes, das ich morgen, Gott sel Dank!, verlasse...

wir alle sind unglücklich, das unser heimatliches Land uns e1nen solchen Boden bereitet hat - fur Gehässigkeit und Streit miteinander. Wir leben hinter chinesischen Mauern, uns halb verachtend, und unser gemeinsamer Feind, die russische staatlichkeit, Kirchlichkeit, die Kneipen, der Fiskus und die Beamten, zeigt sein Gesicht nicht, sondern hetzt den einen gegen den andern auf.

Aus aller Kraft bemilhe ich mich, jede russische "Politik" völlig zu vergessen... Entweder darf man uberhaupt nicht in RuBland leben, in seine besoffene Fresse spucken, oder aber mu man sich von der Erniedrigung isolieren, - von der Politik und von dem "geselischaftichen Engagement" (dem Parteigeist) (111 - izolirovat'sja ot uniženija - politiki, da $i$ "obšestvennosti" (partijnosti) ... Ich glaube, ich bin jetzt im Recht, mir die Hände zu waschen und mich mit Kunst zu beschäftigen. Sollen sie henken, die Schufte, und in ihrem spiliwasser verrecken."4)

Dieser HaBausbruch gegen RuBland weicht bald der Enttäuschung Bloks über Westeuropa. Die Briefe, die Blok aus Italien schreibt, zeigen, dab er in dieser Zeit eine 8 chwere innere Krise durch-

1) VIII, 280

2) Pis'ma $k$ rodnym I, S.251.

3) Pis'ma $k$ rodnym I, S.253.

4) Brief rom 12./13. April 1909 an seine Mutter. VIII, 281 f. 
macht, die inn nicht nur an RuBland, sondern auch an seinem Dichtertum fast verzweifeln läßt. Man muß annehmen, daß zu dieser Krise neben der allgemeinen politischen Entwicklung in RuBland, dem Sieg der Reaktion, unter der Blok selbst zu leiden hatte, ${ }^{1)}$ vornehmlich die Erkenntnis beigetragen hat, dab die eigene publizistische und gesellschaftliche Tätigkeit ohne Erfolg geblieben war. Auch die Enttäuschung dartiber, mit dem LS gescheitert zu sein, hat hierbei sicher eine grobe Rolle gesnielt. 2)

Ende llai schreibt Blok in einem Brief an seine Mutter:

"Ich weiB nichts aus RuBland, sehe keine Zeitungen; schreib, wenn irgend etwas geschehen ist! Schreibt man irgend etwas uber das "Lied des Schicksals", ist es erschienen! Hat nicht irgend jemand irgend etwas Gutes dariber geschrieben?"3)

Doch das LS löste bel seinem Erscheinen kaum eine Reaktion aus. Der Dichter und Kritiker B.A. Sadovskoj ging in einer Rezension der "Sipovnik"-Almanache auch auf das LS ein, in dem er die Verwandlung der "Neznakonka" in "Rus'", die Einbettung der bekannten Blokschen Symbole wie den Schwan, den Schneesturm etc. in ein eigentilmliches "narodničestvo" und bei German ein Pathos der selbstentsagenden Liebe zu RuBland entdeckte. ${ }^{4)}$ Auf Bloks mystisch gefärbtes "narodnilestvo" wiesen auch VjaX. Ivanov und S. Gorodeckij hin, Ivanov besonders in seinem kulturphilosophischen iufsatz "O russkoj ideje", der in vieler Hinsicht den Gedanken Bloks uber Wesen und Bestimmung RuBlands nahesteht. Hierbel bezogen sie sich auch auf das LS und die Gedichte "Na nole Kulikovom". 5 )

fim 13. Jul1 1909 schrieb Je.P. Ivanov, der das Stilck schon immer negativ beurteilt hatte, an Blok:

1) Die Polizei verbot die Diskussion ilber Bloks Vortrag "Rossija 1 intelligencija". Vgl. V,742.

2) Eine ähnliche Enttäuschung erlebte Gogol', der Rußland verlieB, nachdem die Auffuhrung des "Revizor" nicht die von inm erwartete Wirkung hatte. Vgl. v.a. seinen Brief an Pogod in vom 15. Mai 1836 in: Gogol', Sobr.sot. VII, S.146f.

3) VIII,287, Brief an seine Mutter vom 25./26. Mai 1909.

4 Vgl. "Vesy", 1909, Nr. 9, S.95.

5) Vgl. Russkaja literatura konca XIX - nađala XX v. 1908-1917, S. $429 \mathrm{f}$. 
"Das "Lied des Schicksals"1) ist in der Tat keine Tragödie und kein Drama, denn es gibt darin keine Persönlichkeiten, keine lebendigen Geschöpfe, sondern es gibt "handelnde Personen" und Worte... Es ist mit einem Wort ein "Lied des Schicksals", das das heimatliche RuBland (rodnaja Rus') in ein leeres Rohr heult und trompetet, vielleicht in ein Kaminrohr, vielleicht auch ein biBchen in die Posaune des endzeitlichen Erzengels...2) Ein tiefer Zug geht durch das ganze Stluck, das ist der quälende Drang nach Pleischwerdung: die Worte und die "handelnden Personen" drängen danach, Fleisch und Blut anzunehmen, sich zu verkörpern... Offenbar sucht das ganze Stilck dieses Sein des "Ich bin" auf dem Wege" (étogo bytija "az jes'm" v putjach", wie vjac. Ivanov sagen wirde, mit Hilfe der mystischen Ekstase, die an das Chlystentum erinnert, an die Tanz- und Gesangszeremonien der Sektierer (sektantskoje radenije), nur auf einer anderen Ebene... Hier ist ein Wendepunkt volier Scheitern mystischer Wege... alles läuft auf die Realität des Hausierers hinaus, auf sein "Sein" als eines "unverhofften Helfers aus einer anderen Welt!... "Der in den Kreis der Heiligen aufgenommene" (betrunkene) German verläBt den Weg des mystischen Anarchismus und klammert sich an das Dasein eines liederlichen realen Hausierers, der ohne Weg geht, denn in ihm ist der Weg des singenden Schicksals. Doch auch das ist nicht fur lange. Er wird in eine Kneipe am Wege gehen und vielleicht anfangen zu schimpfen. Doch dann ist der Faden völlig durcheinander. Reale Mystik, mystischer Realismus..."3)

Wichtig ist vor allem der Hinweis auf die Elemente im Stick, die an die ekstatischen Zeremonien der Geibler und anderer russischer Sekten erinnern. Der Vormurf des "Chlystentums" zielt auf die Verbindung von mystischer Religiosität mit vulgärer Erotik, wie sie in den Fraktiken der Geibler, aber nach Meinung Ivanovs auch im LS besteht. Daneben kann Ivanov den Schlub des LS nicht akzeptieren, denn er sieht hier keinen realen Ausweg aus Bloks Mystizismus.

Blok selbst gibt in seiner Antwort auf den Brief Ivanovs diesem recht:

"Zu allem was Du sagst, sage ich "ja", und dementsprechend sage ich zum "Lied des Schicksalg" nach vielen Vorbehalten "nein". Nun, Gott sei mit ihm!"4)

Dieser Brief schlieBt zunächst die langwierige Beschäftigung

1) Ivanov schreibt "Pesn' Sud'by".

2) Ivanov spielt mit der Doppelbedeutung "truba" - "Rohr",

3) VIII,599, Anm. 1 zu Brief 222.

4) Brief vom 9. Aug. 1909; VIII,290. 
Bloks mit dem IS $a b$, die trotz der anfänglichen Zusagen Stanislavskijs und der Umarbeitung im Sommer 1908 nicht zu dem erhofften Erfolg geführt hat. Das einzige Ergebnis der zweiten Etappe ist das Erscheinen des IS, das ohne Resonanz bei Lesern und Kritikern blieb.

Dritte Etappe: (1909 bis Ende 1918)

Nach der Veröffentlichung des IS wandte sich Blok von dem Stlick $a b$, obwohl er den Eindruck hatte, daB sein Stück noch im Stadium des Vorläufigen steckte und noch nicht ausgereift war. Doch hatten zunächst andere Pläne Vorrang. Die Italienreise fand ihren Niederschlag im Gedichtzyklus "Ital'janskije stichi" (Italienische Gedichte) und in dem unvollendeten Buch "Molnii iskusstra" (Blitze der kunst). Im Sommer 1910 entstanden die ersten Skizzen $z u$ dem großangelegten Poem "Vozmezdije" (Vergeltung), an dem Blok bis kurz vor seinem Tod arbeitete, ohne es zu vollenden. Ende 1910 bereitete Blok eine Ausgabe des ersten Bandes seiner Gedichte vor; im Mai und Juni 1911 arbeitete er am zweiten und dritten Band. Im Juli 1911 begab er sich wieder auf eine lange Reise nach Westeuropa, die inn diesmal bis in die Bretagne führte. Im Frühjahr 1912 entstanden, angeregt von dieser Reise, die ersten Skizzen zu dem Drama "Roza i krest" (Rose und Kreuz), an dem er das ganze Jahr uber angestrengt arbeitete. Daneben widmete sich Blok seiner publizistischen Tätigkeit, hielt Vorträge und Gedenkreden. Am 30. Mai 1912 notferte Blok in sein Tagebuch, welche Arbeiten er sich für die nächste zukunft vorgenommen hatte. Die Notiz zeigt, dab er als Ergänzung zur Neuausgabe seiner Gedichte eine Neuausgabe seiner Theaterstilcke plante, in die er auch das is aufnehmen wollte. 1)

Diese Ausgabe kam zwar nicht zustande, doch beschäftigte sich Blok nun wieder mit dem LS. Es kam hinzu, dab sich in den letzten Monaten des Jahres 1912 Mejerchol'd plötzlich wieder

1) VII, 147 . 
fur des IS interessiert. Blok schrieb am 29. Oktober 1912 in sein Tage bu ch:

"Me ine Liebste" ... war am Abend bei Mejerchol'd, der uber das "Lied des Schicksals" im Alexandra-Theater (?!) redet und mich sehen will."2)

Am 1. Dezember 1912 kam Mejerchol'd zu Blok und bat inn um die Erlaubnis, das IS aufafuhren. Die beiden hatten bei dieser Begegnung eine längere Aussprache, in der Mejerchol'd den Dichter von seiner Kunsttheorie und der Lebensnähe seiner Inszenierungen uberzeugen wollte. Der Regisseur versuchte v.a., Bloks Abneigung gegen das Alexandra-Theater zu uberwinden. Er wies darauf hin, daB er dort nur Gastregisseur se 1 und in der Auswahl der Stucke alle Freiheiten habe. Palls Blok inm erlaube, das Stuck aufzufuhren, musse er allerdings auch vom Dichter viel Freiheit zugestanden bekommen.

Blok konnte sich nicht zu einer positiven Antwort durchringen. Nachdem der Regisseur gegangen war, notierte Blok die wichtigsten Punkte ihrer Unterredung in sein Tagebuch. Zu den Darlegungen des Regisseurs schrieb er:

"So blelbt fur mich die Frage nach den beiden Wahrheiten ungelöst, - den Wahrheiten Stanislavskijs und Mejerchol'ds ("ich sei ein Schuler Stanislavskijs" hat ubrigens Mejerchold'd gesagt)." 3)

Am Ende dieser Eintragung steht eine kurze Rückbetrachtung Bloks uber die verschiedenen Stadien, die das Stuck seit 1908 durchlaufen hat. Uber seine Meinung vom IS nach dem Erscheinen im 9. Almanach "Šlpornik" schrieb Blok:

"Zu dieser Zeit (1910) hielt ich das "Lied des Schicksals" schon entschieden fur ein dummes stuck (durackoj p'esoj), und dafur hielt ich es bis zu den letzten Monaten, als ich anfing, es wieder durchzulesen im Hinblick auf eine Neuausgabe meines Theaters (zuerst bei "Al'ciona", jetzt be 1 "Sirin"). Und beim erneuten Durchlesen wirde ich von vielem darin wieder bewegt. Ich werde mir Muhe geben (sowohl fur den Druck als auch fur eine

1) d.h. Bloks Prau, die Schauspielerin in Mejerchol'ds Truppe war.

2) VII, 171. Blok benutzt auch hier wieder den abfälligen Ausdruck "Aleksandrinka".

3) VII, 187 
etwaige Auffuhrung), daraus alles Abgedroschene, alles Dumme, auch jenes Leonid-Andrejevsche, das daraus hervorragt, zu entfernen. Wollen wir sehen, was dann von diesem albernen (glupovatyj) German ubrig bleibt. Ubrigens - N.B.: die Merekkovokijs sympathisierten immer mehr oder weniger mit dem stuck."T)

Ende Dezember 1912 kam Blok für kurze Zeit in Berührung mit VI.A. Teljakovskij (1860-1924), dem damaligen Direktor der kaiserlichen Theater. D.S. Merezkovskij hatte dem Direktor vorgeschlagen, Blok in ein Komitee aufunehmen, das dem AlexandraTheater in Petersburg vorstehen sollte. ${ }^{2)}$

Am 30. Dezember überbrachte Mejerchol'd per Telefon die Einladung Teljakovskijs für den 1. Januar 1913. Als Gesprächsthemen waren vorgesehen: eine etwaige Auffuhrung des LS im Alexandra-Theater, ein neues Stück Bloks, die Frage von Bloks Mitgliedschaft im Komitee. 3)

Am 1. Januar fand die Unterredung statt. Sie dauerte etwa eineinhalb Stunden. Bloks Tagebuchaufzeichnung dariber zeigt, daß die Aussprache ziemlich trostlos verlief. Zum Is notierte er:

"Über das "Lied des Schicksals" - ich las Auszüge - gaben Merežkovskij und ich Erklärungen. Ich sagte, daB ich mit der Gestalt, in der das Stück existiere, nicht zufrieden sei... Die Gespräche über das Komitee und über das "Lied des Schicksals" wurden bis zum nächsten Mal verschoben."4)

Ganz offensichtlich zerschlugen sich die Pläne, denn Blok kommt weder in seinem Tagebuch, noch in seiner Korrespondenz auf sie zurück.

Das LS erschien weder in der Ausgabe von Bloks Theater von 1916, noch in der von 1918.

Vierte Etappe: (Anfang Januar 1919)

Erst sechs Jahre nach der Unterredung mit Teljakovskij wandte sich Blok dem IS wieder zu. Inzwischen war in RuBland die von Blok ersehnte Revolution ausgebrochen, die er in seinem Poem

1) VII, 188. "Al'ciona" hieB ein Verlag (1910-1919). "Sirin" hieß der Verlag, den M.I. Tereß̌enko (1888-?) und seine beiden Schwestern gegründet hatten. Terešenko war Finanz- und AuBenminister in der Provisorischen Regierung und verlieB dann RuBland. Blok stand ihm 1912 recht nahe.

2) Vgl. dazu VII, 195

3) Vgl. dazu VII, 198.

4) VII, 201 
"Drenadcat"" (Die Zwölf) als kosmisch-historische Zeitenwende begrubt hatte.

Anfang 1919 bereitete Blok eine Neuauflage seiner Dramen vor. Auch diesmal sollte das LS in die Neuauflage aufgenommen werden. ${ }^{1)}$

Blok will aus dem Stück "alles wirklich Dumme" (vse uz ołen" glupoje) entfernen. Er bezeichnet das LS als "Werk einer guten und dummen Zeit" (chorosego i glupogo vremeni proizvedenije). 2) Schon am 8. Januar ist die Uberarbeitung beendet. ${ }^{3)}$ Diese Schnelligkeit ist damit zu erklären, daB Blok den Text von P1 ziemlich zusammenstreicht. Dafür nimmt er die in $F 1$ fehlende "Szene in der Garderobe der Paina" aus $M 1$ in die endgiiltige Fassung $P 2$ auf.

Auch diesmal erscheint das LS nicht in einer Ausgabe von Bloks Theaterstücken, sondern in einer Einzelausgabe des Petersburger Verlags "Alkonost" am 10. Juni 1919, gleichzeitig mit der zweiten Ausgabe der Aufsatzsammlung "Rossija i intelligencija". 4) In diesen Sammelband nahm Blok sieben Aufsätze aus den Jahren 1907-1917 auf, die alle um das Problem Volk und Intelligenz kreisen. Sie gehören in ihrer Thematik ganz in die Nähe des LS, und das gleichzeitige Erscheinen ist kein Zufall. Der Dichter und Kritiker Vl.v. Gippius ${ }^{5)}$ schrieb kurz nach Erscheinen von P2 in einer Rezension liber das LS:

"Die zweite Passung entspricht besser dem grundlegenden lyrischen Motiv des Stucks, - dem Wind, der zum menschlichen Sturm aufruft. Der Wind pfeift heftiger, aufmunternder. Die Auffiihrung des "Lieds des Schicksals" muB man dreifach winschen: 1) weil es ein Drama eines genialen russischen Lyrikers ist, 2) es ist absolut literarisch, welche Mängel man in ihm auch finden mag,

1) Vgl. Zap.kn., $444 \mathrm{f} .$, Eintrag vom 6. und 8. Jan. 1919.

2) VII, 355, Eintrag vom 7 . Jan. 1919.

3) Vgl. Zap.kn., 445, Eintrag vom 8. Jan. 1919.

4) Vgl. Lit.Nasi,, 27-28, S.530; VII,539; Zap.kn., 463, Eintrag vom 10. Jun1 1919. Zum ProzeB der Drucklegung vgl. Zap.kn., 448 und 453, Einträge vom 5. Pebr. und vom 20. März 1919.

5) Vl.V.Gippius (1876-1941) schrieb unter den Pseudonymen VI. Bestuke $\nabla$ und vi. Neledinskij. 
3) es ist in ihm eine neue dramatische Bewegung, deren das mussische The ater allgemein so sehr bedarf. Die Mängel des Stủcks. Wie es scheint - einer. Abstraktheit (otvle cennost'). Doch das ist kein Mangel. - Der Geist Ibsens (vejan'e Ibsena). Doch liegt dieser Mangel, zum Glück fur die russische Literatur und das russische Theater, bei Blok weit zuruck. Die neu aufgenommene Szene ist eine Grenzlinie gerade in der Absage an einen uberlebten Ibsenismus. Wenn nur die russischen Bretter dieses Poem zu meistern verstehen! Entweder können sie eine Seele wiedergeben, die Sturm vorhersagt, oder es wird durch die ganze Vorsteliung ein künstlicher Zugwind leise vor sich hin pfeifen..."1)

Diese in etwas unausgegorener sprache verfabte Rezension fand be $i$ Blok keinen großen Anklang. Er fand das Lob über sein Stück "ein wenig hysterisch."2)

In einer kurzen Besprechung von fün Theaterstücken, die inm Mejerchol'd zur Begutachtung vorgelegt hatte, wirft Blok einem der Verfasser vor, er habe zu sehr unter dem Einflub von L. Andrejev und inm selbst gestanden. Vorbild sei dabei auch das IS gewesen, das Blok ausdricklich als "weniger reife Sache" bezeichnet, und dessen Sprache er als "konventionell und nicht nahrhaft, wie Sacharin" verurteilt. 3)

Die Skepsis gegenüber der zu schmeichelhaften Rezension von Gippius und die negative Bewertung der Sprache des IS zeigen, daB Blok sein Stủck nicht für ein Meisterwerk hielt.

\section{Zusammenfassung:}

Die Beschäftigung Bloks mit dem LS erstreckte sich ủber einen Zeitraum von mehreren Jahren. Besonders intensiv arbeitete Blok an seinem Stück von Frühjahr 1907 bis Frühjahr 1909. Er hatte bei der dichterischen Gestaltung des 'ihemas groBe Schwierigkeiten. Das Bestreben um Lebensnähe, konkrete Bildhaftigkeit, kilnstlerische Echtheit und das Suchen nach einer angemessenen Sprache fürten dazu, daB Blok immer wieder an seinem Stilck feilte 4 ) und auch die erste Druckfassung F1 als vorläufig betrachtete. Besonders im Mittelteil seines Stücks hatte Blok Schwierigkeiten,

1) Zap.kn., 593, Anm. 72.

2) Zap.kn., 465. Zusatz zum Eintrag vom 3. Juli 1919.

3) VI,330. Das bezieht sich auf das IS und das Stuck "Korol' na plošcadi" (Der König auf dem Platz).

4) Blok benutzt den Ausdmack "schleifen". 
was sich darin zeigt, das die Szenenfolge in den drei Fassungen jeweils verschieden 1st. In allen drei Passungen behält Blok die Szenenfolge am Anfang (die ersten drei Szenen) und am Schlub (die letzten beiden Szenen) be1. Er war sich jedoch nicht daruber im klaren, wie er das Verhältnis von German zu Paina nach der Weltausstellungs-Szene weiterfuhren sollte. Die mittleren Szenen haben in den drei Fassungen des IS folgende Anordnung:

\begin{tabular}{|c|c|c|c|}
\hline M1: & $\begin{array}{l}\text { Weltaus- } \\
\text { stellung }\end{array}$ & $\begin{array}{l}\text { Garderobe } \\
\text { d.Paina }\end{array}$ & $\begin{array}{l}\text { Szene auf } \\
\text { d.Bahnhof }\end{array}$ \\
\hline F1: & $\begin{array}{l}\text { Weltaus- } \\
\text { stellung }\end{array}$ & & $\begin{array}{l}\text { Szene aup d. } \\
\text { oden Platz }\end{array}$ \\
\hline F2: & $\begin{array}{l}\text { Weltaus- } \\
\text { stellung }\end{array}$ & $\begin{array}{l}\text { Garderobe } \\
\text { d.Faina }\end{array}$ & $\begin{array}{l}\text { Szene auf } d \\
\text { öden Platz }\end{array}$ \\
\hline
\end{tabular}

In M1 spielen alle drei Szenen des Mittelteils in der Großstadt. Im Charakter der Paina uberwiegt das Zigeunerhafte. Ihre Verwurzelung im russischen Volkstum wird nur in der Märchenepisode nochmals aufgezeigt; im weiteren Verlauf des Stücks wird diese Seite inres Wesens nicht weiter entwickelt.

Das zeitkritische Moment im Stuck kommt in M1 besonders stark zur Geltung, da in allen drei Mittelszenen die verderbliche Wirkung der Zivilisation auf Charakter und Beziehungen der Menschen gezeigt wird.

Im Gegensatz zu M1, wo eine gewisse Einheit in Schauplatz und Atmosphäre besteht, erzielt Blok in F1 eine starke Kontrastwirkung, wenn er auf die Weltausstellung sofort die Szene auf dem öden Platz folgen läbt. Die Wandlung der Paina von der vielbewunderten Estradensängerin in das russische Mädchen aus dem Volk geschieht unvermittelt. Auch das Auftreten Germans als erlösender Held in der neu eingefügten Szene auf dem öden Platz kommt unvorbereitet.

F2 steht, was die Szenenfolge des IS angeht, zwischen M1 und F1. Blok behält das stark zeitkritische Element von M1 und $F 2$ weitgehend be1, da er die Szene in der Garderobe der Paina in F2 wieder aufnimmt. AuBerdem leitet der SchluB dieser Szene (Märchenepisode, Befragung des Spiegels) uber in die folgende Szene 
auf dem öden Platz. Die Wandlung der Faina, inre Plucht aus dem Grobstadtmilieu, ihre Sehnsucht nach dem Erretter und das Hineinwachsen Germans in diese Rolle wird vorbereitet und veretandlicher. Dadurch erhält P2 eine gröBere innere Logik als P1.

Die Entstehungsgeschichte des IS zeigt, das dieses Stuck in engem Zusammenhang mit Bloks dichterischem Schaffen und seinen gesellschaftskritischen Aktivitäten steht. Selne Auffassung vom Wesen RuBlands und seinem Schicksal wollte Blok mit dem IS durch das Medium Theater dem breiten Publikum vermitteln. 1) Der Drang, andern sein Anliegen näher zu bringen, erklärt auch, daB Blok sein Stuck in zahlreichen Dichterlesungen Literaten, Kritikem, Regisseuren, Schauspielern und Zuhörern, die an Literatur interessiert waren, vorstellte.

1) Man vergleiche die Rolle, die Gogol' seinem "Revisor" zugedacht hatte. 


\section{UBERSETZUNG}

\section{DAS IIED DES SCHICKSALS ${ }^{1}$ )}

Dramatisches Poem ${ }^{2}$ )

Furcht ist nicht in der Liebe, sondern die völifge Liebe treibt die Furcht aus; denn die Furcht hat Pein.

Erster Brief des Johannes, IV, 18 RuBland! RuBland! - offen, wist und flach ist alles in dir - nichts verfuhrt, nichts bezaubert den Blick. Doch welche unbegreifliche, geheime Kraft zieht zu dir hin? Warum ertönt und klingt unaufhörlich im Ohr dein trauriges Lied, das uber deine ganze Länge und Weite, von Meer zu Meer erschallt? Was lst in ihm, in diesem Lied? Was ruft und schluchzt und greift ans Herz? - RuBland! Was willst du von mir? Welches unbegreifliche Band verbirgt sich zwischen uns? Was verheiBt dieser unermeBliche Raum? Soll nicht hier, soll nicht in dir der grenzenlose Gedanke geboren werden, wenn du selbst ohne Ende bist? Soll nicht hier der Recke leben, wenn es Platz gibt, wo er sich entfalten und umherziehen kann?

$$
\text { Gogol, 3) }
$$

Handelnde Personen

German 4 )

Helena, Germans Frau 5 )

Die Mutter Germans 6 )

Der Freund Germans 7 )

Ein Mönch ${ }^{8)}$

Faina 9)

Der Begleiter der Faina ${ }^{10}$ )

Ein Hausierer ${ }^{11}$ )

Die Menge ${ }^{12)}$ 
Nördlicher April - Palmsamstag. 1)

Auf einem Hugel steht das weiBe Haus Germans. Es ist von einem Garten umgeben, in dem sich das erste Grün zeigt, und es leuchtet unter einem fruhlingshaften Sonnenuntergang, der den ganzen Himmel umfaBt. Das grobe Fenster im Zimmer der Helena ist in den Garten geöffnet; draußen taut es. Ein Weg fuhrt von der Pforte hinab und windet sich unter dem Hugel hin, zwischen Strüuchern und jungen Birken hindurch. Andere Hügel, mit Wächten von schnell tauendem Schnee bedeckt, ziehen sich wie eine Kette in die Ferne und verlieren sich in den kahlen und rostfarbenen Weiten von Mooren. Dort flieBt die Erde mit dem kalten, hellen und klaren Himmel zusammen. - In der Ferne gehen kleine Lichter an, man hört Hundegebell und fruhes vereinzeltes Vogelgezwitscher.2)

Auf den Stufen der Treppe, vor einem groBen Blumenbeet, schlummert German ube $\xi_{j}$ einem aufgeschlagenen Buch mit Bildern. Helena, ganz in WeiB, 3) tritt aus der Tür, schaut einige Zeit German an und ergreift dann zärtlich seine Hand.4)

\section{Helena:}

Wach auf, German! Während du schliefst, brachte man zu uns einen Kranken. 5) 5)

German (im Halbschlaf):

Ich bin wieder eingeschlafen. Im Traum war alles weiB. Ich sah einen großen weiBen Schwan; ${ }^{6}$ er schwamm zum jenseitigen Ufer des Sees, mit der Brust gerade auf den Sonnenuntergang zu...7) Helena:

Die untergehende Sonne trifft dir in die Augen, du aber schläfst immer, siehst immer Träume. 8 )

German:

Alles ist weib, Helena. Auch du bist ganz in WeiB... Und wie strahlten die Federn auf der Brust und auf den Fligeln...

Helena:

Wach auf, Liebster, ich bin beunruhigt, mir ist bange. Man brach te zu uns einen Kranken...

Germann (erwacht):

Du sagst - einen Kranken? Eigenartig, weshalb zu uns? Hier geht doch niemand vorbei, denn der Weg fuhrt gerade auf unser Tor zu...9) 
Helena:

Er ist sehr krank, ganz durchsichtig und spricht nichts... Er schaute mich nur mit groBen, traurigen Augen an. ${ }^{1)}$ Mir murde unheimlich, und ich weckte dich...

\section{German:}

Warum nur brachte man inn hierher, wenn zu uns ke in Weg fuhrt?... Helena:

Mein Liebster, mir ist seltsam, mir ist mundersam zu Mute, gerade als ob etwas geschehen müBte... Schau 1 hn dir an, German! Er liegt in meinem 2 immer auf dem kleinen Diwan. Wie ein Engel mit gebrochenem Flügel.2)

\section{German:}

Da setzen sich die Träume fort. ${ }^{3)}$

Helena:

Das sind keine Träume German, das ist die Wirklichkeit. ${ }^{4}$ ) Das ist schrecklicher als Träume. Wenn er doch nicht anfangen wírde zu reden. Wie wenn er gekommen wäre, um mich aus dem Leben $z u$ rufen...5)

\section{German:}

So darfst du nicht denken, Helena. Furchte dich nicht!6) Sonst ängstige auch $i \mathrm{ch} \mathrm{mich}$. Wenn man einsam lebt, erscheinen einem die geringsten Ereignisse als groß...7) Es ist doch nichts geschehen, Iiebste. Und was sollte auch geschehen?

Helena:

Geh zu ihm, German! Schau ihn an - und komme zu mir zurick! Und wenn er anfängt zu sprechen, - höre nicht $z u$ !

\section{German:}

Du sagst doch, er sei krank. Und er schweigt? Und wenn er anfangen wirde zu sprechen... was kann er Neues erzählen? ${ }^{8}$ )

German geht ins Haus. Helena geht um das Blumenbeet herum. Es kommt der Freund.

\section{Der Freund:}

Guten Abend! Heute ist Ihr Haus irgendwie besonders hell. Schon von jenem Hugel sah ich Ihr weiBes kleid und gleichsam groBe weibe Flügel an Ihren Schultern.9) 
Helena:

Heute hat man zu uns einen Kranken ins Haus gebracht. Br sieht einem Engel sehr ähnlich. Mir selbst schlen, er habe grobe weibe Flügel. 1)

Der Freund:

Wie Sie Märchen lieben, eigenartige Fraul Aus dem kleinsten Ereignis machen Sie ein Fest. Und immer mit so einem ernsten Gesicht. Nun, wie dem auch sei, ich glaube Ihnen: das ist zum Lachen.2)

Helena:

Ihnen ist immer alles zum Lachen.

Der Freund:

Alles ist zum Lachen. Lebe 1 ch doch in Zeit und Raum, 3) und nicht auf den Inseln der Seligen, ${ }^{4}$ wie Sie. Die Menschen sind so dumm, das es besser 1st, man lacht; sonst muste man weinen. Nur eines ist nicht zum Lachen.

Helena:

Was?

Der Freund:

Sie wissen... Ich liebe Sie, Helena. 5)

Helena:

Schweigen Sie! Schweigen Sie! Sie sagen das nicht zum ersten Mal, doch das lst nicht wahr. Wie könnten Sie sonst der Freund Germans sein?6)

Der Freund:

Bel Ihnen ist doch alles möglich. Sie sind beide gar nicht von dieser welt. ${ }^{\text {) }}$ sie sind beide so ungewöhnlich...8)

Helena:

Zum Lachen?

Der Freund:

Ich sagte: ungewöhnlich. Ich liebe German. Doch ist in Ihnen, Helena, das ganze Geheimnis dieses Hauses. Ohne Sie geht German verloren. Er ist ein uberaus schwacher Mensch. German leuchtet durch Ihr Licht. Wenn er von hier weggeht, dann bleibt in ihm nur das Dunkle...9) 
Helena:

Schweigen Sie!

Der Freund:

Ich schweige... Wunderbare! Ungewbhnliche!.. So stimmt es also, dab German wegfährt? ${ }^{1)}$

Germans Mutter kommt auf die Treppeperaus. Sie ist eine groBe, ältere Frau in schwarzem Kleid.2)

\section{Die Mutter:}

Helena, man sollte das Ikonenlämpchen in Germans Zimmer anzünden.3) Ich sah heute im Traum...4)

Helena: (hört es nicht):

German? Wer hat Ihnen das gesagt?

Der Freund:

Ich habe selbst so gedacht...

Helena:

So ist es also... Wo ist German denn? Weshalb kommt er so lange nicht? Mutter, Mutter, wo ist German?

Die Mutter:

German ist im Haus. Bei dem Kranken.

Helena:

Spricht er?..5)

Die Mutter:

German schweigt und hört $2 u$. Der Kranke aber spricht mit schwacher und stockender Stimme; man kann nicht verstehen, was er sagt.6)

In diesem Augenblick führt German den kranken Mönch aus dem Haus und setzt inn vorsichtig auf eine Stufe der Vortreppe.7)

Der Mönch (spricht mit schwacher Stimme und lächelt still): Friede sei mit euch und eurem Hause. ${ }^{8}$ ) Nicht umsonst wurde mir leichter. Ich bat, mich zu euch zu bringen, weil ich aus der Ferne sah, dab euer haus hell ist, heller als alle, die auf den Hügeln stehen.9) Ist denn sonst niemand mehr im Hause?

Helena:

Wir sind nur zu dritt: German, ich una die Mutter. 


\section{Der Mönch:}

Schön 1st German, 1) der im stillen Hause mit Frau und Mutter lebt, denn sein Haus ist hell. Doch vom fernen Hugel sah $1 \mathrm{ch}$ daruber grobe weibe Flugel...

Der Freund (zu Helena):

$\mathrm{Da}$, auch er sah Ihre weiben Flugel.

Der Mönch:

...und ich dachte, hier sel - Paina. ${ }^{2)}$

\section{Die Mutter:}

Ich kenne nicht einmal einen solchen Namen.

Helena:

Das 1st sicher der Name einer Nonne? ${ }^{3)}$

\section{Der Mönch:}

Habt inr wirklich noch nie von der schönen Faina gehört? $\left.{ }^{4}\right)$

Helena (nachdenklich):

Noch nie.

Der Mönch (zu allen mit einem Lächeln):

Wenig wibt ihr doch. Ihr lebt sicher sehr einsam. Die ganze Welt kennt Paina. 5)

\section{German:}

Ein seltsamer Name: Faina. Ein Geheimnis ${ }^{6)}$ liegt in ihm. Ein dunkler Name. ${ }^{7)}$

Der Mönch (mit einem Lächeln):

Und du, Jiingling, ${ }^{8)}$ hast nicht von Faina gehört?

\section{German:}

Nein.

\section{Der Mönch:}

Friede sei mit dir, German! ${ }^{9)}$ Du wirst bald von ihr hören. Die Sonne geht unter, der Wind wird stärker. ${ }^{10)}$ LaBt mich in eurem Hause Ruhe schopfen. (2um Freund - mit List): Werden Sie mir helfen, Sie erstaunlicher Mensch? ${ }^{11)}$

Die Mutter und der Freund fuhren den Mönch ins Haus. - ${ }^{12}$ ) Es dämmert.

\section{German:}

Ein Tag voller Märchen... Die Portsetzung eines wunderbaren Traumes...13) 
Helena:

Woran denkst du, German?

German:

Du hast die Wahrheit gesagt: etwas mus geschehen. 1) Der Schnee taut. Es geht ein warmer wind. In der Nacht wird es Pfutzen geben, schwarzen Himmel und unglaubliche, riesige Sterne: weibt du, wie es im Fruhling ist? ${ }^{2}$ )

Helena (unruhig):

German, du hast mit ihm gesprochen?

German:

Er sprach. Ich hörte nur zu. Er erwachte und umarmte mich zärtlich. Und zeigte aus dem Fenster...3)

Helena:

Was gibt es dort?.. vor dem Fenster?..

German:

Ich sah, daß der Schnee von den Hügeln verschwindet. Ich hörte, wie die Mutter im Nachbarzimmer leise las: "Furcht ist nicht in der Liebe. Die völlige Liebe treibt die Furcht aus". 4)

Helena:

Liebster! Woran denkst du?

German:

Ich sah eine riesige Welt, Helena: blau, unbekannt, verlockend. Der Wind brach ins Fenster, es begann nach Erde und schmelzendem Schnee zu riechen; und dazu wie nach Blumen, obwohl es doch noch keine Blumen gibt. Die Sonne sank, und die Hügel färbten sich rot. Und hinter den Hügeln dehnte sich ein blauer, nebeliger Raum aus, wie ein grober see in der Ferne... Dort schwamm ein grober weiBer Schwan, mit glänzendem Gefieder... mit der Brust gerade auf den Sonnenuntergang zu...5)

Helena (froh):

Liebster! Du sahst das doch im Traum!

German:

Wachend, 6) Helena. Ich habe verstanden, dab wir allein sind, auf einer seligen Insel, getrennt von der ganzen Welt. Kann man denn so einsam und glücklich leben? ${ }^{7}$ ) 
Er erzählte mir von den Wundern der Welt. Und dort ist der Frlhling ankebrochen...

Helena (weint beinahe):

Ich höre dich, German... Doch es schmerzt...

German:

Du selbst hast gesagt: wach auf! Und jetzt bin ich aufgewacht. Ich muB zu den Menschen. Er befahl zu gehen. Doch ich komme bald zurück, Helena. 1)

Helena:

Ich glaube an dich. Ich höre auf dich. LaB mich allein weinen... (Sie geht ins Haus). 2)

Germar. (kniet nieder):

Oh Herr! So ertrage ich es nicht länger. Es geht mir zu gut in meinem stillen weiBen Haus. Gib mir die kraft, es zu verlassen und $z u$ sehen, wie das Leben in der Welt ist. ${ }^{3}$ Bewahre mir nur die Glut der jungen Seele und ein lebendiges Gewissen, Herr. Um mehr bitte ich Dich nicht an diesem klaren Friihlingsabend, an dem die Gedanken so ruhig und klar sind. Ich glaube, daB Du mich gehört hast. Jetzt bin ich ruhig.

Er erhebt sich.4) Aus dem Hause kommt der Preund.

Der Freund:

So fahren Sie also? ${ }^{5)}$

German:

Woher wissen Sie das?

Der Freund:

Das ist gut, German.

German:

Warum belehren Sie mich immer? Ich weis selbst. Der Freund:

Nein, Sie wissen wenig. Wenn wir uns begegnen, dort (er zeigt ins Theater), 6) da werden Sie sehen, dab ich mehr weis als sie.Mir mikfällt dieser Mönch sehr.

German:

Weshal b?

Der Freund:

Er ist hinterlistig ${ }^{7)}$ und sentimental, wie alle Mönche. Ich schämte mich, als ich hörte, wie er uber Sie spottete. 


\section{German:}

Spottete er?

\section{Der Preund:}

Sie wissen, wer diese Faina lst, mit der er Sie zum Narren machte? - Sle ist ganz einfach eine Kabarettsängerin mit oehr zwe1felhaftem Ruf. 1)

German (scharf):

Ich weis nicht warum, aber Sie sind mir manchmal zuwider, mein Freund. Wenn es etwas Wichtiges zu lösen gilt, wäre es besser, wenn die Freunde sich ihren Rat sparen wirden und sich etwas weiter entfernt hielten. 2)

Der Freund:

Wie böse Sle doch sind. Das wubte $1 \mathrm{ch}$ nicht. Das gefällt mir auch. 3)

German:

Was kann Ihnen denn hier gefallen? Das ist doch nicht besonders angenehm.

Der Freund:

Nun, ich sehe, daB ich hier überflüssig bin. Man mus Ihnen eben Zeit lassen, zum SchluB noch ein wenig sentimental zu werden. Auf Wiedersehen! (Er geht). ${ }^{4}$ )

German geht nachdenklich durch den Garten. Aus dem Haus kommt Helena, ganz weib, jung und leicht.

Helena:

Ist er weg?

German:

Ja. - Ist er nicht ein neugieriger Mensch?

Helena schweigt. 5)

Helena:

So ist es also entschieden, German?

German:

$\mathrm{Ja}$, es ist entschieden. 


\section{Helena:}

Ein letztes Wort, Liebster. Bleibe bei mir, wenn du kannst und willst! (Plötzlich mit einer Art prophetischer Verzweiflung in der Stimme). Ohne dich werde ich bald alt sein. Die Mutter wird sterben. ${ }^{1)}$ (Sie ringt die Hände). Die Lilie ${ }^{2}$ wird nie aufgehen! German:

Was ist mit dir, Liebste? Ich kehre doch bald zuruck. Helena:

Schau: bei mir im Penster steht ein Ikonenlämpchen. 3) Bei der Mutter ist noch Eis auf der Pensterscheibe, doch bei mir vor dem Fenster taut es schon.4) Du hast Bucher. ${ }^{5)}$ Im Ikonenschränkchen sind Pomeranzenblüten...6)

German:

Ich kann nicht, Helena. Du siehst: der Fruhling ist gekommen. 7) Helena:

Ich weib, German. Doch es schmerzt...

German:

Ich werde dir Neuigkeiten bringen.

Helena:

Erinnerst du dich, du hast selbst die Iilie im letzten Fruhjahr gepflanzt. Wir brachten Dung und Erde und machten uns ganz schmutzig. Dann hast du eine dicke knolle mitten in die schwarze Erde gesteckt und drum herum kasen gelegt. Wir waren fröhlich, stark, glucklich... Wenn du fort bist, wird die Lilie nicht aufgehen. 8)

\section{German:}

Die Lilie ist dir teurer als meine Seele.9) Schau in die Höhe! Verstehst du denn nicht, was dort vor sich geht? ${ }^{10}$ )

Helena:

Wenn du sprichst, verstehe ich alles. Ohne dich werde 1 ch es nicht verstehen.

\section{German:}

Hörst du, wie der Wind singt? Genau wie das Lied des Schicksals selbst... ein fröhliches Lied. Hörst du? - Oh Gott, wie unheimlich und frohlockend! Aber im Haus weht der wind nicht, und das Lied des Schicksals ist nicht zu hören.11) Du hast gehört, wie 
es heiBt: "die völlige liebe treibt die furcht aus"?")

Helena:

Ja, du sagst, die Mutter habe diese Worte gelesen...

\section{German:}

Die Mutter kennt das Herz des Sohnes...2)

Helena (wie wenn sie plötzlich zu sich kommen wirde):

Nein! Nein! Ich kenne das Herz meines Geliebten! ${ }^{3}$ Ich will mich nicht länger ängstigen! Wenn es sein muB, dann geh, mein Liebster, geh, mein Gebieter! ${ }^{4}$ ) Geh, wohin dich das Lied des Schicksals ruft ! 5)

Es ist ganz dunkel geworden. Die Mutter kommt heraus und bleibt auf der dunklen Schwelle stehen.

Die Mutter:

Mein Gott! Mein Gott! Weshalb gehst du fort, mein Kind? Sehe ich dich jemals wieder? Weshalb gehst du fort? (Sie setzt sich auf die Türschwelle. Man kann ihr Gesicht nicht sehen).6)

Helena:

Hier hast du ein Licht. Es ist hell wie dein Herz, German.7) Liebster, geh! Du wirst zurückkommen.

German:

Lebe wohl, Helena! Lebe wohl, Mutter! Es ist nicht schrecklich. Ich komme bald wieder. Am schwierigsten ist es, die Grenzlinie zu überschreiten. ${ }^{8}$ ) Lebt wohl! Bei euch im Haus ist der Mönch.

Er geht schnell zur Gartenpforte. Helena folgt inm. Die Mutter auf der Schwelle ist in furchtbarer Trauer.

Helena:

Ich werde warten.

Und plötzlich - wie ein Gewitterregen im Fruhling: die schluchzende Helena sturzt sich mit den Händen auf die Schultern Germans.

German (bewegt):

Bald, bald.

Sie lächelt unter Tränen.9) Er nimmt langsam ihre starken Hände auseinander. Er nimmt ein Licht, schuttelt den Kopf und beginnt 
dann, schnell den FuBweg hinabzustelgen. 1) - Das bleiche Gesicht des Mönchs ist an die große Fensterscheibe geschmiegt. Er schaut in die Nacht, gerade als ob es fur seine kranken, welken Augen keine Zuflucht gäbe.2) - Der Frihlingswind wird stärker; an einigen Stellen des schwarzen Himmels strahlen helle, groBe sterne.3) - Helena geht langsam zum Haus. Sie schwankt. Inr Kleid leuchtet weiB. 


\section{ZWEITES BILD}

Derselbe Schauplatz, beim Haus Germans. Es ist tiefe Nacht geworden, und es herrscht Stille. Hundegebell und Vogelgezwitscher sind nicht zu hören.1) Das spitzige Dach des Hauses versinkt Im schwarzen Himmel. Dort jagen vom Wind getriebene Wolken dahin, von denen stark leuchtende Sterne bald verdeckt, bald freigegeben werden. Alles ist in völliges Dunkel getaucht, nur das grobe Fenster der Helena steht offen.2) Helena sitzt bei der Lampe, das Haupt uber die Arbeit gebeugt. Vor ihr sitzt der Mönch und schaut sie mit groBen traurigen Augen an. Das ganze Bild ist uberzogen von einem zarten, hellblauen Mullvorhang, so, als ob das Haus, Helena und der Mönch in die Vergangenheit zuruckversetzt wären.3)

\section{Helena:}

Erzähle weiter, Bruder! Jetzt ist mein German schon auf dem Weg. Der Mönch:

Nicht leicht fällt es mir, weiter zu erzählen. ${ }^{4)}$ So sehr ermüdet mich der Fruhling. Nun, höre. - Es war eine schwarze Frühlingsnacht. Uber dem bewaldeten Abhang des weiten Flusses stand roter Feuerschein von den Scheiterhaufen, und es tönten die Lieder. 5) Hör zu, Helena!.. Hoch oben, uber dem Abhang stand ein Mädchen von schöner Gestalt und schaute weit uber den Flub. Wie eine Nonne6) war sie in schwarzes Tuch gehullt, und nur die Augen leuchteten unter dem Tuch hervor. ${ }^{7}$ ) So stand sie die ganze Nacht hindurch und schaute in das ferne Kubland, ${ }^{8)}$ als ob sie auf jemanden wartete. Doch dort war niemand, nur die Uferwiese und der verkümmerte Strauch und der Fruhlingswind. Wenn sie aber den $\mathrm{Blick}$ hob, waren ihre schwarzen Augenbrauen vor Zorn gekrummt, und ihre bleichen halbgeöffneten Iippen flehten...9) Decke mich $2 u$, Helena!

Helena (deckt ihn mit einem Tuch zu):

Du redest im Fieber, Bruder. ${ }^{10}$ )

Der Mönch:

Höre, höre weiter! - Ein Kloster stand am Fluß. Und jede Nacht wartete sie am jenseitigen Ufer. Und jede Nacht schlichen die Mönche zur weiben Klostermauer, um zu sehen, ob Faina nicht mit dem Ärmel winken, $\left.{ }^{11}\right)_{\text {nicht }}$ ein Lied anstimmen, nicht zum Flub herabsteigen wirde...

Helena (läBt die Arbeit liegen):

Faina? Du erzählst von Faina! Das sollst du nicht... 


\section{Der Mönch:}

Unterbrich mich nicht, höre zu! ${ }^{1)}$ Abends im Dorf uberschwemmte der Rausch die Seele Fainas, und alle Greise auf ihren Holzpritschen ${ }^{2)}$ mubten, dab sie sich dem Tanz ergab... Alle Barschen aus den Nachbardörfern kamen zusammen, um zu sehen, wie Faina die Arme in die Seiten stemmte und tanzte...3) Doch die Sehnsucht ergriff sie mitten im Tanz, und sie verlieb den Reigen und ging wieder und wieder zum Abhang des Flusses, stand dort lange und wartete auf jemanden. Und nur die Augen leuchteten unter dem Tuch hervor - immer heller und heller...4)

Helena:

Mir ist seltsam, mir ist mundersam zumute...

Der Mönch:

Und eine tiefe Traurigkeit erfabte mich, Helena. Und 1ch verging vor Schmerz, so sehr wollte ich ein Mensch sein...5) In der schwarzen Nacht sah ich purpurroten Feuerschein uber dem FluB. Da verbrannten sich die Sektierer: der alte Glaube erhob sich als Feuerschein (iber der Erde...6) Und uber dem Dorf der Faina wurde es taghell. Der Wind bog die Baume, und weit stoben die Funken, und die Flamme wirbelte in den Holzgeristen. 7) Aus dem Gebrüll der Psalmen, aus dem roten Feuer - da lief Paina hinab in den blauen Schatten des Ufers, und ich sah, wie eine Spur von blauem Silber hinter dem Boot dahineilte, ${ }^{8)}$ wie Paina beim Kloster aus dem Boot stieg, sich umblickte und vom Heimatdorf ins dunkle Feld davoneilte.9) Ich öffnete die kleine Tur in der weiben Mauer, und auch ich ging ins Feld hinaus. Ich verneigte mich zur Erde vor den goldenen Kuppeln des Klosters und machte mich auf in die dunkle Nacht. Doch fand ich Faina nicht, und nirgends nahmen mich Leute auf. Lange suchte $1 \mathrm{ch}$, und ich murde krank... 10)

Helena:

Erzähle nicht weiter. Es ist unheimlich...

Während der letzten Worte beginnt sich am FuB des Hugels ein mattes Licht zu bewegen, das die Umgebung nicht beleuchtet. Helena schaut unentwegt aus dem Penster. Hinter ihrer Schulter - der angespannte und traurige Blick des Mönchs. - Unten erscheint eine Laterne. 
German (sucht tastend den Weg):

Ich werde nirgends hingehen. Dort 1st es wunderbar und beunruhigend. Ich bin vom Weg abgekommen. Waren hier irgendwo drei Birken? Nun, Herz, bleiches Licht, ${ }^{1)}$ welse den Weg!

Er bleibt plötzlich stehen, als er zu dem matten Iicht herankommt. Inm scheint, als leuchte nur schwach, angelehnt an den stellen Abhang des Hügels, eine kaum sichtbare Gestalt: die Konturen einer Frau, uppig in schwere schwarze Tucher gekleidet. Diese sind ubersät mit silbernen sternen, auf den schultern une? der Brust bald dichter, bald düner. Unten sind die Sterne grösser. Auf der langen Schleppe liegt ein grober diamantener Stern. Das Gesicht ist nicht zu sehen. Nur große, traurige Augen blikken nach vorne.2) viellelcht war ein Windzug gekommen, oder es haben die Hände gezittert, - die Laterne Germans geht aus.3)

German:

Wer bist du? Eine Lebende? Eine Tote?

Die Erscheinung (undeutlich, wie eln Windzug):

Nein.

German:

Wartest du auf jemanden?

Die Erscheinung:

$\mathrm{Ja} .51$

German:

Ich gehe meines Wegs.

Die Erscheinung:

Geh!

German macht einen Schritt nach vorne, doch ein unsichtbares Hindernis zwingt ihn, zuriackzuweichen.

\section{German:}

Ich habe mich in meinem Garten verirrt. Die Laterne ist ausgegangen. (Er schaut in die Höhe). Mir scheint, $1 \mathrm{ch}$ kam von dort. (Er zeigt in die Ferne). Mein Haus ist dort. Ja. Ich gehe meines Wegs.

Die Erscheinung fïhrt thn langsam vom Hügel fort. Er geht tastend.

Die Erscheinung (kaum hörbar):

Folge mir! 
Das Licht verlöscht. D1e Erscheinung verschwindet. ${ }^{1)}$

Die Stimme Germans (in der Dunkelheit):

H1er lst der Weg. Gott se1 Dank! Es war nur ein Traum.2)

Man hơrt, wie seine Schritte sich entfernen.

Helena (im Fenster):

Es 1st, als sänge man gleich einen Trauergottesdienst. Oder träumte mir das nur? Oder lst es der Wind, Bruder? Oder ist es der Prihling? Ich habe Angst, gerade als ob dem Liebsten etwas zugestoßen wäre. Was schweigst du?

Der Mönch antwortet nichts. Wie zuvor sitzt er vor thr und schaut traurig aus dem Fenster. 3 ) 
DRITTES BILD

Die Stadt. Der siebenundsiebzigste Tag der Eröffnung der Weltindustrieausstellung. 1)

Das Hauptgebäude der Ausstellung ist ein gigant1scher Saal. In der Höhe sind runde Glasscheiben, - wie die Augen des Tages, doch Im Gebäude selbst 1st ewige Nacht.2) Elektrisches Licht aus Kugeln von mattem Glas ergleBt sich in blendenden Strömen auf hohe Gerliste, auf denen uberall Maschinen stehen. Die stählernen Leiber der Maschinen erinnern in ihren Formen an märchenhafte, ungeheure Tiere. Hier stehen Lokomotiven neuester Bauart mit riesigen Antriebsrädern, die genau in kurze Geleise passen; Automobile auf dicken Reifen, die auf den geringsten Peialdruck ansprechen; Motorboote, die ihre Raubtiernasen weit nach vorne strecken, gleichsam Ebenbilder ausgestreckt daliegender Seevögel; Landwirtschaftsgeräte mit nach oben ragenden gehärteten Spitzen. Und schlieblich glänzt ganz hinten im Saale, hinter einem Netz von ringförmigem und gerade gebogenem Stahl, hinter einem Wald von Querbalken und hochragenden Hebeln, eine riesige Flugmaschine in einem unbekannten und leichten Metall ihrer Flügel, die bis zu den Kuppeln des Saals ausgestreckt sind.3) Im Schatten dieser Flugel4) erhebt sich eine hohe Buhne. ther 1hr, in der Höhe unter der Kuppel, inmitten von Girlanden von lebenden Blumen und Griin, leuchtet eine bunte Aufschrift: Kulturpalast. 5) Noch höher oben bewegt sich gleichmäBig das pendel einer Uhr, die die halbe Kuppel einnimmt und aufmerksam halb iber den Saal geneigt ist.6)

Am gegenuberliegenden Ende geht ein geschlossenes Gittertor auf die Straße; zu beiden Seiten stehen rote, goldbestickte Lakalen. Schräg daneben ist die Eintrittskasse und eine Drehtiir. Direkt am Eingang hängt ein ReglerungserlaB: zwischen goldenen Wappen kann man die Worte entziffern: "Das Territorium der Weltausstellung lst unverletzlich".7) An allen Wänden, Säulen und Maschinen prangen bunte Plakate mit der riesigen Aufschrift: Faina. Das Lied des Schicksals.8)

Die Menge strömt in dichter Woge durch die Drehtür. Zwischen anderen Leuten kommen auch German und der Freund hindurch.

Zeitungeverkäufer (Tonleiter): 9)

Trlumpf des menschlichen Genies!

Die neuesten Entdeckungen der Wissenschaft!

Clowns, Akrobaten, verschiedenes Divertissment!

Die Unverletzbarke1t des Territoriums des Weltkulturpalastes wird von der Reglerung garantiert! 
Der siebenundsiebzigste Auftritt der berihmten Paina!

Die berihmte Faina trägt das "Lied des Schicksals" vor!

Die weltbekannte Faina!

Paina, die schönste Diva der Welt! ${ }^{1)}$

German (schaut sich um; seine Nasenlöcher weiten $81 \mathrm{ch})^{2}$ ):

wie haben sie denn erfahren, daB ich hier bin?

Der Freund:

Wie sollte ich den besten Freund nicht finden?...

German:

Welcher Lärm! Welche Musik! Welcher Wind in dieser Stadt! Seit dem Augenblick, als $1 \mathrm{ch}$ von zuhause fortging, vom Weg abkam und weiterging, verzaubert von dieser elgenartigen Erscheinung, hört der wind nicht auf. Ist das immer so?

Der Freund:

tiberall ist wind.

\section{German:}

Oh Gott, wie gut das 1st! Uberall Wind! Und Uberall solche Musik! Wenn $1 \mathrm{ch}$ blind wilde, dann wurde $1 \mathrm{ch}$ nur diesen anhaltenden Lärm hören. Wenn $1 \mathrm{ch}$ taub wirde, wïrde $1 \mathrm{ch}$ nur diese unaufhörliche, bunte Bewegung sehen. ${ }^{3)}$ (Er ballt dle Fäuste und reckt die Arme wie ein Mensch, der nicht we1B, was er mit seiner uberschussigen Kraft anfangen soll).

\section{Der Freund:}

Ich bene1de Sie. Es 1st amiusant, elnen erwachsenen Säugling zu sehen, fur den alles neu $18 t .{ }^{4}$ ) German: 5 )

...Auch lch kam auf den Platz der Stadt...

wie rauchig es am Morgen war!

Und am rauchigen Morgen sang eine schwache Frauenstimme

Von der Freihe1t. Ich konnte nicht verstehen,

Woher die Stime, woher das lied kam.

Ich schaute $\mathrm{m} 1 \mathrm{ch}$ um und blickte

Nach oben. Und $1 \mathrm{ch}$ sah ein Fenster,

Das mit elnem engen Gitter zugesperrt war, -

Das Fenster eines Gefängnisses. Ond still sahen

In meine Augen - ruhige Augen ... 
Wie hell sie waren! Mit welcher Traurigkeit!

Dort war ein Mädchen ...1)

Der Freund:

Ich nahm allerdings an,

DaB Sie spöttischer, kluger und scharfsinniger selen,

DaB Sie mit Ironie hierher gekommen seien,

Nur um zu betrachten, ohne s1ch der Seligkeit

Eines lyrischen Gefuhls zu ergeben.

Kommen Sie zu sich und verjagen Sie das Mitleid! ${ }^{2}$

\section{German:}

Ich wollte Ihnen nur geheimnisvolle

Erscheinungen des Lebens schildern:

Die Erzählung von Jenem blutbeschmierten Bettler,

Der, um eine milde Gabe zu erhalten, statt der Hände

Einen häblichen Stumel ausstreckte;

Von dem Jungen, der unter das Rad einer Kutsche geriet;

Von dem Weib ohne Nase ${ }^{3)}$, das mich ansah

mit einem bleiernen Blick aus roten Lidern.

Und so lst es uberall. Davon kommt man nicht 108.4)

Doch Mitleid kenne ich nicht ...

Doch viellelcht sollte ich das Mitleid kennenlernen?

Der Preund:

Nein! Betrachten Sie diese Welt mit einem Lachen!

Und Preuen Sie sich, daß sie hier nur ein zufälliger Gast sind ! 5)

Verjagen Sie das Mitleid mit der Peitsche des Lachens!

Wenn es Sie aber rihrt, dab Menschen umkommen,

Dann lache $1 \mathrm{ch}$ Sie aus.

\section{German:}

Oh, mir lst das Mitleid verhaßt,

aber verhaBt $18 t \mathrm{mir}$ auch dieses Lachen.

Das eine wie das andere wird dem Leben nicht gerecht:

Wer immer Mitleid hat, geht am Leben vorbe1.

Wer immer lacht, dem zerrinnt das Leben zwischen den Fingern.

Fern von Lachen und Tränen schleppt sich das Leben

Wie eine kraftlose Pringeburt, ein bleicher Traum.

Beides lst wie ein grauer Vorhang vor der Buhne. 
Be1des 1st wie ein Rausch, der dem Trunkenbold

Die Vielfalt der lebendigen Velt verbirgt.

Ich will nuchtern oein! ${ }^{1}$ Sie versprachen, mir das prichtige Pestmahl der Kultur ${ }^{2)}$ zu zeigen.

\section{Der Preund:}

Ja, wir sind im Innern des Kulturpalastes. Bie bunte

Inschrift, gleich der Inschrift am Tor

Der geheimnisvollen Dantiochen Holle,

xindet davon. ${ }^{3)}$ Wir wollen unter die Menge gehen

Und die Dummeit der Leute beobachten.

Sie mischen sich unter die Menge.

\section{Die Menge: ${ }^{4)}$}

Ruhe! Ruhe! Der Professor opricht!

Ein rosafarbener Grels mit einer Brille auf der langen Nase klettert mit zitternden Beinen auf die Buhne.5)

\section{Der Gre18:}

Sehr geehrte Damen ...6)

Die Menge:

Man hört fa nichts! Lauter!

Eine Kokotte ${ }^{7)}$ (knelft ihre Preundin):

Da nennt er mich eine Dame, hahaha!

Ein Mädchen (zu einem Ausländer):

Wenn sie nicht aufhören, rufe 1ch die Polize1; oder $1 \mathrm{ch}$ gebe Ihnen eine Ohrfelge ...

Der Ausländer (fährt sich selbotgefällig uber seine rasierte Wange ):

Das Territorium der Weltausetellung lot unverletzlich ...8)

Das Mädchen:

Flegel!

Der Gre18 (lauter):

Sehr geehrte Herren! In diesem Hauptgebäude der Weltausstellung finden Sie alle Produkte der modernaten Industrietechnik versammelt. Sie können $81 \mathrm{ch}$ mit elgenen Augen davon uberzeugen, wie unermidalich die Aktivität des menschlichen Gelstes 1st... 


\section{Die Mange:}

Geistes 1st! Geistes 1st!

Der Gre18:

Ond wie grob die Rraft des menschlichen Talents...

Die Kenge:

Talents! Talents! Oho! Oho! ${ }^{1)}$

Der Greis:

Heute halte ich zum siebenundsiebzigsten Mal die Rede ${ }^{2)}$ rom Triumph des menschlichen Fortschritts. Wir Wissenschaftler können klihn behaupten, daB die Wissenschaft der einzige Weg 1st, auf dem die Menschhelt alle Hindernisse uberwindet, die ihr die Natur in den Weg gestellt hat. In naher Zukunft, geehrte Herrschaften, werden die Menschen aufhören, sich vóm Raum beengt zu fuhlen, denn Sie sehen hier das Automobil der Bauart Louns ${ }^{3)}$, das mit einer Geschwindigkelt von 150 Kilometern in der Stunde fahren kann.

Ein Vertreter der Firma tritt vor und verneigt sich.

\section{Die Menge:}

Oh! Oh! In einer Stunde!

Der Greis:

Sie sehen, dab das Wissen den Glauben an das Wunderbare uberholt hat. Bs gibt keine wunder mehr, sehr geehrte Herrschaften. 4) Sie können sich nichts mehr winschen, wenn $1 \mathrm{ch}$ Ihnen die letzte grobe Erfindung ${ }^{5)}$ vorgestellt habe...

\section{Die Menge:}

Oho! Oho! Nichts mehr winschen!

\section{Der Greis:}

Vor Ihnen steht ein Flugapparat, der eine ungeheure Kraft besitzt. Es ist dies die letzte grobe Erfindung, die uns in der Zukunft die Möglichkelt des Verkehrs zu den Planeten ${ }^{6)}$ verspricht.

\section{Die Menge:}

Oh! Oh! Mit den Planeten! 


\section{Der Greis:}

Dieser Apparat hat ein Uberaus geringes Gewicht und 1st aus leichtestem Material hergestellt. Doch 1st, geehrte Herrschaften, die Kraft seiner Plugmuskeln so groB, daB er mit seinen gigant1schen Flügeln leicht einen Menschen erdrucken und aufressen kann... 1)

\section{Die Menge:}

Oh! Oh! Einen Menschen aufressen! Oh! Oh!

Der Greis:

Jetzt sofort, meine Herrschaften, wird die Bewegung der Flugel demonstriert. 2)

Ein Arbeiter drickt einen unsichtbaren Knopf, und die Fligel des Flugapparates beginnen langsam zu krelsen. Tosender Beifall. Der Greis ruckt seine Brille zurecht und steigt vom Podium her$a b$. Sofort treten auf der Buhne Akrobaten und Clowns an seine Stelle.

\section{Ein Clown:}

Gestatten Sie, daB $1 \mathrm{ch}$ Ihnen die letzte Entdeckung der Wissenschaft vorstelle! Es glbt keine Wunder mehr, geehrte Herrschaften! Die Kraft meiner siebenundsiebzigsten Flugohrfeige 1st so groB, daB dieser Mensch hoch hinausfliegen und aus Ihrem Gesichtsfeld verschwinden wird. 3 )

Er gibt einem traurigen Mann in schwarzem Frack eine schallende Ohrfeige. Ohne das Gesicht zu verzlehen, dreht sich der Manr einige Male in der Luft und fflegt kopfüber hinter die Bühne. Händeklatschen, Gelächter.

\section{German:}

Dumme, puppengleiche Menschen! 5$)$

Alles, was ich sah, ist nicht zum Lachen, sondern tief traurig.. Wo aber 1st die Pracht, das Gold, der Glanz? ${ }^{6)}$

Der Freund:

Sie sehen die leuchtenden Buchstaben:

Faina. - Deshalb 1st die Menge da.

\section{German:}

Faina? Wo ist die wunderbare Faina? ${ }^{7}$

Wie oft schon erzählt man mir von ihr,

Doch kann ich mir ihr Gesicht nicht vorstellen: 
Bo lst gleichsam durch einen Schatten ${ }^{1)}$

Vor mir verborgen... Doch wer 18t ole?

Der Freund:

Irgendeine Kabarettgängerin,

die es versteht, die Menge anzulocken... 2)

German macht eine ungeduldige Bewegung. Auf die Buhne tritt ein Redner.

\section{Der Redner:}

Burger! Das Territorium der Weltausstellung let unverletzlich. Hier, Im Reiche des Portschritts und des menschlichen Genies, wende ich mich an Sie, wie an Bruder, mit einer Rede über den zugrunde gehenden Bruder. Vor einer Stunde murde eine Verschwörung von größter staatlicher Wichtigkelt aufgedeckt. Dem Anfuhrer lst schon das Todesurtell verkundet worden. Doch gemäB den Gesetzen unseres frelen Landes, Blirger, hat feder von une dae Recht, den Wunsch zu äuBern, an Stelle dee Verbrechers hingerichtet $z u$ werden. Ich appelliere, Brider, an Ihre Grobherzigkeit. Wer von Ihnen wird sein Leben fur den verurteilten Bruder hingeben? (Schweigen). Brider! Bürger! Es geht hier nicht um Leben oder Tod. Mit aller Wahrscheinlichkeit wird die Reglerung dieess freien Landes denjenigen begnadigen, der aus Edelmut sein Leben opfern will. Sie wird auch den Verbrecher begnadigen, dem die Opferbereitschaft des Bruders Strafe genug sein wird. (Dumpfes Getöse. Einzelne Aufschrele). Ich verhehle nicht, Bürger, dab eine gewlsse Gefahr besteht. Denn unser Bruder hat sich gegen dae Wohl dee Staates eelbst vergangen... 3 )

Schweigen. Der Redner wartet ein wenig und verläßt dann die Bühne. Alle wenden $1 \mathrm{hm}$ den Rucken $z u$, während er $81 \mathrm{ch}$ einen Weg durch die Menge bahnt.4)

Stimme der Kokotte:

Warum gehst du nicht eelber? ${ }^{5)}$

German (bleich):

Sie richten inn hin... Was hat mich zurlickgehalten?

Der Freund (lacht inm ine Gesicht):

Die Neugier. 
German:

Nein! Ich schwöre Ihnen, nein!

Der Freund:

Was ist mit Ihnen? Finden Sie das nicht zum Lachen?

German (angespannt):

Oh Herr! Was ist? Beging ich Verrat? Gewissen, Gewissen... (Hebt den Kopf). Nein! Das Gewissen ist rein... (Beherrscht sich wieder). Sie müssen mir Faina zeigen. Wo ist sie? Sonst brauche ich hier nichts mehr... 1)

Der Freund:

Bleiben Sie ruhig! Sie erscheint gleich auf der Buhne. Ihr

Interesse an ihr ist geradezu verdächtig.

Ein Mensch (sturzt wie von Sinnen herein):

Faina! Faina! Faina ist da! Sie ist angekommen!

\section{Die Menge:}

Faina! Hier? Faina? Ich habe sie nicht gesehen! Hier?

Vom anderen Ende des Saales, wo sich die Flugel der Maschine bewegen, ertönt ein kurzes Wimmern.

Was ist? Was ist passiert? Ein Mensch wurde zerquescht? Die Maschine hat einen Menschen zerquescht.

Durch die Menge kommt medizinisches Personal.

Eine Dame (schïttelt sich):

Das ist doch sicher sehr schmerzhaft...

Eingalanter Doktor:

Oh nein, Gnädigste, keineswegs! Es hinterläßt keine Spur...2)

German sturzt zum Ausgang, wird aber vom Freund zuriuckgehalten. Und schon ertönt von der Straße her anfangs dumpfes, dann zunehmend stärkeres Getöse und Gebrül. Schrele: "Faina! Faina!" German wird von der Menge eingeklemmt, die zurickweicht und in der Mitte eine breite Bahn freiläbt.

Jetzt sieht man in der Menge einen schwerfälligen Mann mit breitem Hut. Es 1st der traurige Begleiter der Sängerin. Er ist um einen ganzen Kopf größer als die gipdern, geht mit schwerem Schritt und schaut nur auf Faina. 3 )

Die roten Lakaien machen das Tor des Kulturpalastes weit auf. Dort erscheint ein riesiges schwarzes, mit Rosen geschmicktes Automobil. Es gleitet langsam und geräuschlos zur Buhne. Unter dem unaufhörlichen Gebriil der Menge im Innern und auBerhalb des Kulturpalastes, in den Wogen der begeisterten Blicke der 
Manner und des neldischen Murrens der Frauen, kommt Faina aus dem tuto und steigt langsam auf die Buhne. Sie ist in ein einfaches schwarzes Gewand gekleidet, das wie eine Schlangenhaut ihre schlanke Gestalt umhullt. In ihren dunklen Haaren glänzt ein Edelstein, der das Flammen ihrer groBen Augen noch stärker hervorhebt. In der Hand hält sie eine lange Peitsche. Ohne GruB, ohne Lächeln, läBt sie den Blick über die Menge schwelfen und gibt ein leichtes Zeichen mit der Peitsche. Die Menge ist stumm.1)

Paina singt das Iled des Schicksals, allgemein verständliche Couplets, mit hochmiliger, hoher und klangvoller Stimme. Nach jeder Strophe zuckt sie kaum merklich mit den Schultern, und durch diese Bewegung zuckt drohend inre Peitsche.

\section{DAS LIED DES SCHICKSALS}

Wenn $1 \mathrm{ch}$ in deine Augen schaue

Mit den schmalen Augen einer Schlange,

Und dir liebevoll die Hand dricke,

He, nimm dich in acht! Ich bin ganz Schlange.

Schau: 1ch war einen Augenblick die Deine,

Und Ich habe dich verlassen.

Du bist mir uberdrilssig geworden. Geh doch fort!

Ich werde diese Nacht mit einem Andern zusammensein.

Such deine Frau!

Geh! Sie wird den Kummer verjagen;

Soll sie dich kosen, soll sie dich kissen!

Geh! Sonst schlage ich dich mit der Peitsche.

Versuche es doch und komme in meinen Garten,

Schau in meinen schwarzen, schmalen Blick! -

Du wirst in meinem Garten verbrennen.

Ich bin ganz Fruhling, ich bin ganz im Feuer!

Komm auch du mir nicht zu nahe,

Den ich liebe und erwarte!

Wer alt und grau und wer in der Blute der Jahre 1st, Wer am melsten klingende Münze gibt,

Der komme auf meinen schallenden, lockenden Ruf!

Uber euren dummen Kopf, -

21sche, meine dinne Peitsche! ${ }^{2)}$ 
Wenn Palna das lied beendet, 1st es elnen Augenblick leng st1ll. Dann eln Beffallstosen.1) German zwängt sich bis zur Bihne durch und, in Begeisterung geratend, redet er immer lauter.

\section{German:}

Ich kann und will das nicht ertragen!

So also sieht das große Festmahl der Kultur aus!

Dort gehen Menschen zugrunde, hier spielt man mit dem Untergang!

Hier kauft man mit einem goldenen Lied Wirde und Vermunft, Ehre und Pfllcht ... Dahin also haben uns die Jahrhunderte Der höchsten, höchsten Schwärmerelen gebracht?

Die Maschine hat den forschenden Gelot ersetzt!

Der hohe Traum wurde zu einer Zigeunerin!

Es brannten Leidenschaften! Der könlgliche Gedanke Ragte, der Spitze eines Turmes gleich, bis zum Himmel;

In unzähligen Essen schmolz die Seele...

Und der Chor der Jahrhunderte klang so edel

Nur dafür, das eine Zigeunerin,

In den Chor einbrechend, m1t wildem Lied

In euch die strenge stimme der pflicht erstickte!

(Er springt auf die untere Stufe).

Du hast mit süBem Gift das Herz vergiftet,

Du hast die zarteste Blume zertreten,

Du hast die höchste Lästerung begangen:

Du hast die Seele - mit schwarzer Schleppe weggefegt!

Verfluchte! Du hast genug gespottet!

Die Maske weg! Ein Mensch steht vor dir! ${ }^{2}$

Faina richtet sich starr auf und wird ganz schmal und hoch, wie die Peitsche, die sie in ihren Fingern zusamenpreßt.

\section{Faina:}

Komm nicht 'näher!

German springt auf die Bühne. Die aufwirbelnde Peltsche schlägt inm mit trockenem Klatschen ins Gesicht und läBt auf seiner Wange einen roten Streifen zurick.3)

In einer gleichsam unwillkirlichen Bewegung fällt German auf die Knie und schaut Faina an.4) 
Im Saal ist es still geworden. Das herausfordernde Iächein auf dem Gesicht der Faina verschwindet. Die Hand mit der Peitsche ist herabgesunken. Inr Blick geht in die Perne und ist grenzen108 traurig.

Faina:

Armer. 1)

Und, ohne zu vergessen, ihre schwarze Schleppe aufzuheben, geht Faina hinter die Kulissen, mit dem Gang eines Publikumileblings. Im gleichen Augenblick verschwindet im Publikum inr trauriger Begleiter, der das Geschehen aufmerksam verfolgt hat.2)

Der Freund (in der Menge, mit der inm eigenen Ernsthaftigkeit): Sehet, welch ein Mensch! 3)

Die Menge ist schon abgelenkt vom Gericht uber die Hinrichtung.4) 


\section{VIERTES BILD 1 )}

Die riesige Garderobe der Paina ist grell beleuchtet und luxuriös und geschmacklos ausgeschmuckt: sie ist voligepfropft mit Möbeln, ubergroßen Kränzen und bunten Sträußen.2) Im ganzen Raum verteilt sitzen Schriftsteller, Maler, Musiker und Dichter, die alle auf Faina warten. Spiegel verdoppeln sie und unterstreichen ihre Änlichkeit miteinander. 3 )

\section{Ein Schriftsteller:}

Meine Herrschaften! In Erwartung der schönen ${ }^{4}$ ) Hausherrin schlage $1 \mathrm{ch}$ Ihnen vor, einen müdlichen Wortstreit uber ihre Qual1täten zu veranstalten, - über die offenen und die verborgenen. Alle (kichern, einer ekelhafter als der andere):

Gern! Bitte sehr! Das ist ausgezeichnet! 5)

Der Schriftsteller (stellt sich mitten in der Garderobe in Positur) :

Aufgepaßt! Ich beginne! - In der Art eines alten Sängers, der dem Brauch gemäB die Schönheit und den Ruhm dieser Welt ${ }^{6}$ pries... Doch, meine Herrschaften, der alte Sänger mußte zuallererst seinem Herrn und Gebieter Ruhm darbringen, vor dem allein er die Ehre hatte, die schönheit zu preisen. 7) In unserem aufgeklärten Zeitalter, meine Herrschaften, glbt es keine Gebieter mehr...8) (Er lächelt vieldeutig; allgemeine Zustimmung; ein weibblonder Jungling applaudiert, schreit und geifert). Nichtsdestoweniger sehe $1 \mathrm{ch}$ unter uns unseren hochehrbaren Ivan Ivanovid...9) Ich schlage Ihnen vor, meine Herrschaften, den hochverehrten Ivan Ivanovid durch ein stummes Sicherheben zu ehren, denn Beifallsklatschen ist hier unangebracht.

Alle erheben sich und verneigen sfch. Der weibblonde Jüngling verbeugt sich gleich zweimal. 10)

Der berihmte Schriftsteller:

Ich bin bewegt. Das ist doch fehl am Platze, meine Herrschaften. Hier, im Témpel der Schönheit und des Portschritts sind wir alle gleich. Sie haben mich ja völlig überrascht, und ich entschuldige mich fü die miblungene Improvisation. Dort, Jenseits der Wände dieser Garderobe, ist das laute Pestmahl der Kultur. Wenn es dort, wo die fröhliche Menge lärmt und die Errungen- 
schaften des menschlichen Gelstes pre1st, keine Rangunterschlede mehr gibt, wie mein jungerer ${ }^{1)}$ Kollege so zutreffend bemerkt hat, so sind wir hier, in der Garderobe der Schonheit selbst, um so mehr alle glelch... Meine Herrschaften, so lebe denn die Schonhe1t!

Alle (brullen):

Bs lebe die Schonhe1t! Bs lebe Ivan Ivanovit! ${ }^{2)}$

Ein angetrunkener Journallst stimmt "LaB ruhen mit den He1ligen"3) an, doch er wird ermahnt. Der weibblonde Jungling schreibt schnell in elnem Notizbuch.

\section{Der Jungling:}

Morgen in den "Strahl der Wahrhe1t"! 4 ) tbermorgen werden bie es alle abdrucken.

Der Schriftsteller:

Nachdem ich den Genius unseres hochehrbaren Ivan Ivanovic in gebuhrender Welse gewlirdigt habe, beginne $1 \mathrm{ch}$ nun, die Schönheit zu lobpreisen... Da ich kelne Lyra habe, nehme $1 \mathrm{ch}$ diesen Stuhl. Und da mir Kothurne fehlen, stelle $1 \mathrm{ch}$ mich auf einen Schemel...5)

\section{Ein Reporter:}

Er zeichnete sich schon immer durch Witz aus...

Ein anderer Schriftsteller:

Du schwafelst aber schón was zusammen, mein Lleber. Kothurne hat man damals nämlich nicht getragen.6)

Der Schriftsteller:

Schon recht, das 18t doch ganz egal... Er hat m1ch drausgebracht, das Schwein...7) Er hat mir die Stimmung verdorben... (Steigt brummend vom Schemel).

Alle:

We1termachen! Weitermachen! Es wurde ja gerade erst lustig. Der berühmte Schriftsteller:

Ich wiederhole es, melne Herrschaften: wir sind alle glelch. Lassen wir doch persönllche Rechnungen belselte! Hier braucht nlemand historische Ausklinfte zu ertellen. Das könnte Gegenstand eines besonderen Vortrags sein. ${ }^{8}$ ) Wer unseren Frohsinn stören will, der soll von hler verschwinden... 
Ein Mann mit Brille: ${ }^{1)}$

Meine Herrschaften, wir sprachen hier von Falna. Aber weib von uns auch nur einer im Ernst, wer denn diese Faina ist? ${ }^{2}$ )

Der Schriftsteller:

Nur ${ }^{3)}$ um Gottes willen nicht im Ernst... Sie bringen noch alle um... Er hat die Angewohnhelt, nicht weniger als zwel volle Stunden hintereinander zu reden...

Ein anderer Schriftsteller:

Wenn's dir nicht paßt, dann hör nicht hin...

Der berihmte Schriftsteller:

Aber erlauben Sie! Hier sprechen alle, ohne Unterschied der Richtung. Sollen doch auch die Symbolisten ${ }^{4}$ sich zu der Frage äußern, die uns alle interessiert.

Der Mann mit Brille:

Henn ich Faina anschaue, dann kommt mir oft in den Sinn: warum läßt man hier eigentlich nur Schriftsteller, Maler, Schauspieler zu, nicht aber einfache sterbliche?..5)

Der Schriftsteller:

Darauf also will er hinaus! Das wird also eine Anklagerede! ${ }^{6}$ ) Ein anderer Schriftsteller:

Iassen Sie ihn nur machen! Der schneidet sich am Ende doch nur ins elgene Fleisch...

Der Mann mit Brille:

Viellelcht sind meine Worte nicht allen angenehm. Wir sind doch alle schrecklich einseltig, meine Herrschaften, und wir sehen das Gesicht des eigentlichen Lebens nicht. ${ }^{7)}$ Wir schreiben, reden, streiten zu viel...

Der Schriftsteller:

So haben Sie etwa nicht gestritten...

Ein anderer Schriftsteller:

... und nicht geschrieben...

Ein dritter Schriftsteller:

Ich habe ja gesagt, er schneidet sich ins elgene Fleisch. ${ }^{8}$ ) Der Mann m1t Brille:

Ich wiirde dennoch gern zu Ende sprechen. - Sie können Faina $n:$ cht verstehen... 
Der Schriftsteller:

Wo ${ }^{1)}$ sollen wir denn...

\section{Der Mann mit Brilie:}

Sie hat uns einen Tell der Volksseele gebracht. Dafur mussen wir une thr zu FuBen werfen, 2) nicht aber lachen. Wir, die Schriftsteller, leben das Leben der Intelligenz, aber RuBland, unwandelbar in seinem innersten Wesen, lacht uns ins Gesicht. Diese Millionen sind in Nacht gehullt. Noch schweigen ihre schlummernden Kräfte, doch sie verachten und hassen uns schon. Sie werden kommen, und, das weib $1 \mathrm{ch}$, sie werden uns unbekannte schöpferische Prinzipien bringen. Wird dann von uns irgendeine Spur zurilckbleiben? Ich we1B es nicht. In meiner Seele öffnet sich ein Abgrund, wenn ich die Lieder der Faina höre. Diese Ileder gleichen Scheiterhaufen: Sie verbrennen völlig die öde, schlaffe Intelligenzlerseele. ${ }^{3)}$ Wenn ich inre stimme höre, fuhle ich, wie schwach und nichtig meine stimme ist. Vielleicht sind Menschen mit einer neuen Seele schon da und verbergen sich unbemerkt irgendwo unter uns. Sie warten nur auf ein Zeichen. Sie schauen der Faina gerade ins Gesicht, wenn sie das Lied des Schicksals singt. Hören Sle doch nicht die Worte dieses Lieds, hören sie nur die Stimme: ${ }^{4)}$ sie singt von unserer Mijdigkeit und von den neuen Menschen, die uns ablösen werden. Das ist das frele mssische Lied, meine Herrschaften. Die Weite selbst, rufend, uns unbekannt. Das sind blaue Nebel, rote Sonnenaufgänge, endlose Steppen. Und was sind die Worte lhres Liedes? vielleicht singt sie andere Worte, doch nur das hören wir...5) Der Schriftsteller: Sieh mal einer an, was fur ein symbol er da angebracht ${ }^{6}$ ) hat. Ein anderer Schriftsteller:

Das 1st gar kein Symbol, sondern eine schlechte Allegorie. Unser verehrter Kollege gehört nicht zu den bedeutenden Vertretern des Symbolismus...7)

Der berihmte Schriftsteller:

Nicht ubel. Interessant. Wenn auch ein wenig abstrakt und nebelhaft. Ubrigens, ich möchte diesen Vorwurf elgentlich der ganzen neuen Schule machen. Etwas mehr Farben, Frische, Leben...8) 
Der Mann mit Brille:

Ich habe doch aber vom Mangel an Leben gesprochen...

Der Schriftsteller:

Genug, genug!

Der Mann mit Brille (setzt sich bescheiden in seine Ecke):

Ich bin fertig. Ich bitte um Entschuldigung, da $\beta$ ich Ihre Aufmerksamkeit so lange in Anspruch nahm. ${ }^{1)}$

Ein anderer Schriftsteller:

Widerlicher Zieraffe! Und so macht der Karriere.

Ein Maler:

Meine Herrschaften, ich nehme die Stelle des aus den Reihen geschiedenen Redners ein. Wozu brauche ich Lyra und Kothurne, Symbole und Stimmung? Ich bin ja nur ein Maler. ${ }^{2)}$ So werde $1 \mathrm{ch}$ denn das Vergnïgen haben, Ihnen zu erzählen, wie und unter welchen Umständen sich mir die Gelegenheit bot...

Ein Laka1 an der Tür:

Eräulein Faina fühlt sich nicht ganz wohl und bittet, sie heute in Ruhe $z u$ lassen.

illgemeines Geschre1:

Áber so etwas! - Das ist nicht das erste Mal! - Ich gehe nicht weg! - Sie kann uns doch nicht hinausjagen!

Der beriihmte Schriftsteller:

Unangenehm, meine Herrschaften, ach wie unangenehm! sie alle streiten iber Lappalien... Ich gehe. (Er zieht sich seine Gummischuhe an, setzt seinen Hut auf und geht. Alle schweigen eine Weile).

Der Schriftsteller:

Der weib, wann er gehen muß. 3)

Ein anderer Schriftsteller:

Der verkalkuliert sich nicht. Sollen wir nicht auch gehen? Es heibt doch, die großen Schriftsteller wiibten alles, was kommt, lange im voraus. 4 )

Der Schriftsteller:

Nun bleib' schon sitzen! Das sind die Großen, aber wir sind die kleinen. Wenn sle uns hinausjagt, dann ist's ja gut; wenn aber nicht, dann ist er der Narr. 
Bs geraten Jedoch alle in Aufregung. Ein schweigsamer Verehrer, der die ganze Zeit uber eine Puderdose vom Toilettentisch der Faina in den Händen hin und her drehte, läBt sie fallen. Der Puder steigt wie elne Wolke in die Höhe. Alle lachen schallend, um thren Schrecken zu verbergen.1)

\section{Ein Dichter:}

Sie lst sowieso schlechter Laune. Was sollen wir denn tun? Viellelcht aufheben, meine Herrschaften?

Der Schriftsteller:

Heben Sie's doch selber auf!

Der Dichter sucht eine Burste und beginnt zu fegen.

Ein anderer Schriftsteller:

Er fegt den Kehricht aus dem Tempel...2)

Ein Maler skizziert den fleiBig kehrenden Dichter in ein Album. Die Musiker umarmen sich und summen lelse etwas vor sich hin. Alle bemuhen sich, elne ungezwungene Haltung anzunehmen. Die Tur geht auf, und Faina tritt ungestum ein. Zwischen den Augenbrauen hat sie eine Zornfaite. Sie bleibt in der Mitte des Raumes stehen. Die Peitsche hat sie in eine Ecke geworfen. Alle springen auf.

\section{Faina:}

Was sind das fiir Leute? Ich habe befohlen, niemand zu empfangen. Der Schriftsteller (kriecherisch):

Schriftsteller, Maler und Dichter wagen es, Sie zu belästigen... Faina (zornig):

Schriftsteller? Maler? Dichter? - Hinaus!

Der Schriftsteller:

Aber, Strahlende...

Faina (stampft mit dem FuB):

Hinaus ! 3)

Die ganze Gesellschaft schlelcht verlegen und mit eingezogenem Genick aus der Tur. 4

\section{Paina:}

Alte! Iösch die Ilchter! 
Sie setzt sich in einen Sessel vor einem großen Spiegel. 1) Von der Seite, aus einer kleinen Til, tritt ein altes Mutterchen ein und löscht die Iichter. Sie läßt nur eines brennen, das uber dem Spiegel.2)

Die Alte: ${ }^{3)}$

Schimpfen werden sie uber dich, liebes Kind, schimpfen werden sie...4)

\section{Faina:}

Ach die! Iaß sie nur schimpfen! Ich frage nicht danach. 5) - Ach, müde bin ich, Alte... So müde... Meine Augen wollen nicht mehr sehen...6) Kämme mir die Haare! Erzähle Märchen!

Die Alte (kämmt die dunklen Haare der Faina und erzählt ein gewöhnlich klingendes Märchen): 7)

"Es schwamm vom fernen blauen Meer ein weiBer Schwan mit Mädchenantlitz daher. Er schwamm aus dem Terem im Abendrot; in die Locken sind schwarze Perlen gesteckt, die weiBen Fligel brennen wie Feuer"...

\section{Faina:}

Weiter! Vom Schwan weib 1ch.9)

Die Alte:

"Es fuhren vom fernen Hafen Schiffe daher, dreiundareibig scharfbristige Schiffe. 10) Auf dem ersten Schiff ist ein wackerer Jiingling, 11) und er steht unter einem segel mit schachbrettmuster" ${ }^{12}$ ) Faina:

Unter einem Segel mit Schachbrettmuster? Das gefällt mir. 13)

Die Alte:

"Auf den schwarzen Locken hat er ein Seemannskäppchen und über den wohlgeformten Schultern einen bunten Kaftan. Die Wangen sind purpurrot, und die Lippen sind wie Himbeeren"... 14)

Paina:

Nun, mach schneller Schluß!

Die Alte:

"Als der wackere Jüngling den weiBen Schwan erblickte, entflammte er ganz. 15) Er spricht zum weiben Schwan: Wirst du wohl, we1Ber Schwan, die junge Frau des wackeren Junglings? ${ }^{16)}$ wle gesagt, so getan"... 17)

Faina (enttäuscht):

So getan? 


\section{Die Alte:}

"... So getan. Es verwandelte sich der weibe Schwan in ein mundervolles schönes Mädchen. ${ }^{1)}$ Es glelcht aufs Haar der schönen Paina. Und er nahm sie an den weißen Händen"...2)

Faina:

Ach...

Die hlte:

"... Und er fuhrte sie ubers Meer und erbaute ihr einen Terem mitten in einem weiben Kirschgarten, und er bereitete ihr das Daunenlager"...3)

Faina:

Schweig, Alte! Weibt du keine neuen Märchen, dann schweig!

Faina lehnt sich im Sessel zurilck und wird blab. Sie hat jetzt ein einfaches, fast kindliches Gesicht. Es list das Gesicht elner gehr schönen Frau, die mlide 1st und niemanden gefallen w111.4)

Le1se, von niemand bemerkt, tritt German ein. Er hat einen blutroten Streifen auf der Wange. Er bleibt in der dunkelsten Ecke stehen, blickt von hinten auf Faina und erscheint schwach im Splegel. Doch der Splegel wird von der Alten verdeckt, und Faina sieht German nicht.

\section{Faina:}

Ich vïde gern selber erzählen, doch kann $1 \mathrm{ch}$ es schwer in Worte fassen. Aber es ist ein schönes Märchen: Es war Frühling, der Wind weinte, und eine junge Bauerin ${ }^{5)}$ wartete am Ufer...6) Und es treibt $z u$ inr auf einer Eisscholle ein so heller Jingling..• er brennt und strahlt... als sel er Jesus Christus selbst... Nur - 1ch kann die rechten Worte nicht finden... (Sie wird nachdenklich). Sicher langwellen sich die jungen Burschen ohne mich... Aber ich brauche sie nicht. Ich brauche niemanden. ${ }^{8)}$ Ich stand uber dem $P l u B$ und wartete... Ich liebe meinen FluB, Alte...

\section{Die hite:}

Es 1st ein schöner, wasserrelcher Flub...9)

Faina (schaut in den Spiegel):

Auf, lab uns den Spiegel befragen, wie lch es fruher zur Weihnachtszeit getan habe, - ob $1 \mathrm{ch}$ wohl im Spiegel den Bráutigam erblicke? ${ }^{10}$ Nur hatte $1 \mathrm{ch}$ damals keinen solchen Spiegel... 11) 
Nein, ich sehe inn nicht... Geh weg, Alte! Dich nur sehe ich hinter mir. Wie alt, wie runzelig du doch bist...

Die Alte (geht zur Seite):

Alt bin ich, liebes Kind, alt...

Faina (inr Blick ist angespannt):

Täusche mich nicht, Spiegel! Wen ich erblicke, der wird mein Bräutigam sein. (Sie schre1t auf). Oh Gott!

Die Alte:

Was hast du, liebes Kind?

Faina:

Schau nur! Es ist furchtbar, Liebe, es ist furchtbar...

Die Alte:

Was hast du, was hast du? Gott steh dir be1!...

Faina:

Schau, Alte! Siehst du, was fitr einer da steht? Auf der Wange hat er einen schwarzen Streifen. Die Kraft des Kreuzes sei mit uns! So einen will ich nicht!.. Nein!.. (German macht einen Schritt nach vorne). Schau, er kommt, er kommt... 1) Ach, sieh mal an! ${ }^{2)}$ (Ihre Augen blitzen vor Zorn; ${ }^{3)}$ sie dreht sich um). Wer hat dich hereingelassen?

German:

Ich bin von alleine gekommen.

Faina:

Wie konntest du es wagen?

German:

Ich will dich ansehen.

\section{Faina:}

Willst du, daß ich dich noch einmal schlage?

German:

So $8 \mathrm{chlag}$ !

Faina:

Has fur einer bist du? Kier bist du eigentlich?

German:

Ein Mensch.4)

Faina:

Ein Mensch? Zum ersten Mal höre ich das. 5) - Dir blutet das Gesicht. 


\section{German:}

Mir blutet das Herz. ${ }^{1)}$

\section{Faina:}

Du bist also ein Mensch? Nun gut, wir wollen sehen. (Sie nimmt inn an der Hand und schaut ihm fast eine Minute lang aufmerksam in die Augen; er hält dem Blick dieser riesigen, wahnsinnigen und im geheimen traurigen Augen stand). ${ }^{2}$ ) Hast dich verliebt? Und wenn es mir mit dir langweilig wird?

\section{German:}

Wenn es dir langweilig wird, jagst du mich davon. 3) - Ich habe viel verstanden. Hier beginnt erst alles. Selt dem Augenblick, als du mich mit der Peitsche geschlagen hast. ${ }^{4)}$

Faina (mit einem Lëcheln):

Was beginnt denn da? Wie verliebt er ist ... und weshalb? Ich liebe mein Gesicht nicht: du siehst, wie miide und blab ich bin. In mich verliebt man sich nur aus der Ferne. - Wenn man näherkommt, geht man gleich wieder fort. Kann man sich in mich iberhaupt verlieben? ${ }^{5)}$ Ich bin ein Wesen des Zufalls.6)

\section{German:}

Du bist ewig. 7) Wie ein Stern.

Faina (lacht):

Wie ein Stern. Wie eine Sternschnuppe...8) Nun, verzeih, daß ich dich geschlagen habe... geh...

German:

Wohin soll ich gehen?

Faina ist in Gedanken versunken. German geht zur Tur.

\section{Faina:}

Wohin willst du?

\section{German:}

Du befahlst mir, zu gehen.9)

Faina (steht auf):

Aber viellelcht habe ich d le ganze Zelt die Unwahrheit gesagt. Du glaubst wohl, ich liebe mein Gesicht nicht, glaubst, man habe mir nur selten die Hände gekiBt? Millionen Mal. ${ }^{10)}$ Nur - ich will das nicht. Ich brauche eine Liebe, die einfach ist und zart. We ein Gebet. Keiner lst wirdig. ${ }^{11)}$ 
German (leise):

Leb wohl!

Faina:

Warte! Du hast Angst vor mir? Komm her!.. hierher!.. hierher!.. In deinen Augen ist so etwas - Einfaches, wie bei keinem sonst.) (Sie dreht German an den Schultern zu sich her und schaut ihm in die Augen mit lachenden, zusammengekniffenen Augen. ${ }^{2)}$ Fr schließt die Augen. Da umfaBt sie seinen Hals mit ihren Händen und kiBt inn mit gieriger Neugierde auf die Iippen). 3) Nun, ich hab' dich gekiibt. Und was welter? Nichts! Und du dachtest, noch etwas? Ách, du! ${ }^{4}$ 


\section{FUNFTES BILD}

Ein weiter, oder Platz wird vom Herbstmond erleuchtet. Im Hintergrund steht ein mit Brettern verschlagenes Gebäude. Ringsum sind Flecken von Mondlicht.

Vom Gebäude zum Vordergmund her neigt slch ein schräger Platz, auf dem große Haufen von Schotter, Zlegelsteinen und Balken herumliegen. Da und dort wächst lipplges herbstliches Steppengras. Hinter der Ecke des Gebäudes öffnet sich die weite Perne.1)

Eine endlose Ebene. An einlgen stellen glänzen entlang eines FluBlaufes stille Buchten: Spuren häufiger herbstlicher tberschwemmungen. tber den Wipfeln der Bäume glänzen silbern vereinzelte Kreuze von Kirchen.2) Irgendwo in der Ferne sieht man Signalmasten, abwechselnd grine und rote Lichter; sie zeigen den Verlauf einer Eisenbahnlinie. Von dort ertónt ab und zu das dumpfe Getöse und das Pfelfen elnes dahinkriechenden Zuges.3) Hinter den weiten Feldern sieht man helle Herbstwälder und den ruhigen Feuerschein eines sehr weit entfernten Brandes.4) Am Horizont sind die undeutlichen Unrisse von Fabrikschioten und Stadttilmen zu sehen.5) Rechts befindet sich der Teil elnes Parkgitters mit einem Pförtchen. Dahinter glänzen silbrig durch das fahle Gold von Ahornbäumen herbstliche Teiche. und in der Tiefe, halb verborgen im Schilf, schaukelt ein schlummernder weiber Schwan.6)

Wenn sich der Vorhang hebt, herrscht einige Zeit Stille. Aus der Ferne hört man das Krähen eines frthen Hahns. Der Zug kriecht langsam vorbei. Und wieder herrscht Stlile. Dann fegt ein lindstob daher, biegt das stachlige steppengras nieder. raschelt in den Brennesseln und trägt den Klang eines Glöckchens, das eilige Lärmen von Schellen und das Getrappel von Pferden daher. Irgendwo in der Nähe hält elne Iroika an.7)

Nach einer Minute, vor dem Hintergrund der unermeBlichen weite und des Feuerscheins, tritt Faina auf. Sie bleibt eine Zeitlang stehen und schaut in die Ferne. Ihr Haar ist mit einem schwarzen Kopftuch bedeckt, und der Feuerschein ist wie ein Leuchten llber ihrem Haupt. Sie trägt ein festtägliches russisches Gewand, das einem Sarafan gleicht.8)

Faina ist erregt und bleich. Ihre Augen brennen. Im daherjagenden Wind zerrt und reiBt sie an den scharlachroten Bändern, die sie um die Taille geschlungen trägt.9)

Hinter Faina kommt ihr riesiger trauriger Begleiter in einem grauen Mantel, mit einem großen, weichen Hut; er hält einen dicken Spazierstock in der weiBen Hand. In seinen Bewegungen, seiner Kleidung, seinem ganzen ÄuBeren erinnert er an einen Kaiser oder einen aristokratischen Ausländer, der inkognito ein fremdes, befreundetes Land besuchen wili.10) Als er sich schwer atmend auf einen großen stein mitten auf dem öden Platz setzt,11) fällt sein Bart herab, und an der Hand, die den Spazierstock hält, schillert im Mondschein ein kostbarer edelsteinbesetzter Ring.12) 
Faina (geht in Erregung im Steppengras hin und her): Schlafe ich auf Schwanenfedern, ${ }^{1)}$ dann vergesse ich alles auf der Welt. Galoppiert die Troika, ${ }^{2}$ dann kann man noch atmen, wenn der Wind einem ins Gesicht pleift. Doch wenn man erwacht oder irgendwo ankommt, dann kann man nichts mit sich anfangen. Kein Schlaf, kein Wind - nichts! ${ }^{3}$ ) Wind, Wind! Wissen sie denn, was das ist, Wind? Oh Gott, Sie können keinen Schritt machen, ohne sich hinzusetzen.

Der Begleiter (einfach):

Ich bin mude.

Faina (reibt nervös Blätter ab):

Was geht mich das an? Sie erfullen meine Launen, sie fahren mich auf der Troika. Aber was können Sie sonst fur mich tun? Sind Sie vielleicht ein Mann? Sehen Sie doch, wie schön ich aussehe! Mit mir wilide jeder bis ans Ende der Welt fliehen. Ich werde Sie ohne Zögern verlassen...4)

Der Begleiter (hebt schwerfällig den Kopf):

Ich weib, dab Sie längst daran denken, Faina. Doch was soll ich tun? Wir sind verschieden. Vielleicht liebe ich sie deshalb mit so hoffnungsloser Liebe. (Läßt den Kopf wieder sinken). 5) Faina:

Sie lieben mich? Für eine solche Liebe verdient man Schläge! ${ }^{6}$ ) Schauen Sie doch, was fiir eine Nacht! Die Ferne ruft. ${ }^{7)}$ Schauen Sie, dort ist ein Brand! Es riecht nach Verbranntem. Uberall, wohin die Weite sich dehnt, riecht es nach Verbranntem. ${ }^{8}$ )

Sie setzt sich am Rand des Abhangs nieder, die Arme um die Knie geschlungen, und schaut in die Ferne mit beschwörenden Augen.9)

\section{Der Begleiter:}

Faina, es hat viel Tau. Sie werden Ihre Stimme verlieren. ${ }^{10)}$ Faina (dreht sich nicht um):

Lassen Sie mich! (Spricht in die Ferne). Mein Bräutigam! Stattlicher, mit hellbraunem Haar, 11) wunderbaren grauen Augen! ${ }^{12)}$ Komm, schau mich an! Lange habe ich auf dich gewartet, die Augen habe ich mir ausgesehen; ${ }^{13)}$ ich bin ganz im Morgenrot entbrannt, 14) habe mich ganz in Liedern verströmt, mich ganz mit blauen Nebeln geschmickt, wie eine Braut mit dem Schleier. ${ }^{15)}$ 


\section{Der Begle1ter:}

Mit wem sprechen Sie, Paina?

Faina (beachtet ihn nicht):

Mein Bräutigam, komm zu mir, Bräutigam, schau mich an! Schau doch in meine klaren Augen; ${ }^{1)}$ sie warten auf deinen sturm! ${ }^{2)}$ Höre doch meine stimme! Meine stimme windet sich dahin wie ein silberner Bach. Offne doch meine weißen Händchen, 3) nimm das schwere Kreuz von meiner jungfräulichen Brust! ${ }^{\text {) }}$ (Sie streckt die Hände aus über den Abhang). Sie wecken mich so früh, wie ein Schwarm schwarzer Raben, kreisen uber mir und lassen mich nicht schlafen. 5) Du aber bewahrst mich vor allem MiBgeschick, läßt keinen mich berühren, erzählst mir Märchen, bereitest mir das Schwanenlager und behütest meine jungfräulichen Träume.6) Dich, du Heller, erwarte ich, den Sturm erwarte $1 \mathrm{ch}$, die schöne Sonne erwarte $\left.1 \mathrm{ch} !{ }^{7}\right)$ Erheb dich, Sonne! Zerteile die Nebel, zerstreue sie mit hellem Wind! $\left.{ }^{8}\right)$

Der Begleiter erhebt sich vom Stein und ninmt den Hut von der Stirn. Man kann sein Gesicht sehen: es ist aufgeschwollen, mit Spuren von vergangener Schönheit; auf ihm kann selbst der stärkste Sturm nichts wecken, auBer dumpfer, leidender Erregung.9)

\section{Der Begleiter:}

Faina... Sie sind genial... 10)

Faina (hat die Hände über dem Abhang ausgestreckt und murmelt in prophetischem Traum):

In jener Nacht, als die Greise brannten, da erschienst du mir hinter den roten Flammen am jenseitigen Ufer. Ich ellte ins Feld, auBer mir; ${ }^{11)}$ ich gab dir meine ganze seele hin, alle meine Iieder entlieb ich in die Freiheit; wie ein Vogel flog lch die ganze Nacht, die ganze Nacht... 12) Ist dir das zu wenig? Du hast mich getäuscht. 13) Wenn ich ein schamloses Lied singe, singe ich dann etwa dieses Iled? Von dir, von dir singe 1ch. ${ }^{14}$ ) Ist es dir zu wenig, daß die Menschen - wie Sklaven vor mir sind? Daß, wenn ich mit der Hand winke, sie mich mit Gold überschutten? Wenn ich sie in den Tod schicke, sie in den Tod gehen? ${ }^{15)}$ Ist es dir zu wenig, daß ich mich hüte wie einen Augapfel, 16) dą ich meine Schönheit zügle, daß ich an allen vorbelschaue? ${ }^{17}$ oder hörst du nicht? Herbstwind, trage meine stimme zu ihm! tiberschäumender Flu?, bring dem Iiebsten Kunde von mir! ${ }^{18)}$ 
Der Begleiter (mit Erregung):

Faina, Liebste, beruhigen Sie sich!.. Sie sind verwirrt... Sie müssen ausruhen...

Faina (ringt die Hände):

Oh mein Gott! Du hörst - er füht mich fort. Der Alte, Ruhige, Mächtige fïhrt mich wieder fort! ${ }^{1}$ ) Höre mich, höre! Befreie mich! ${ }^{2)}$

Sie hält inne und wartet. Ihre stimme erschallt irgendwo in silbernem Echo und erstirbt.3)

Der Begleiter (behutsam):

Faina...

Faina (in schrecklichem 2 orn): ${ }^{4}$ )

Niemals!.. Ich sage Ihnen: niemals! Ich habe mein Leben im Schlaf versäumt. Ich werde nicht die ganze Nacht schlafen. Ich brauche sie nicht! ${ }^{5}$ ) (Wirft sich auf die Erde). Vertraute! Liebste! ${ }^{6)}$ Bring Sturm! Sturm! Oder - Ruhe! Gib mir deine schwarze, deine unstörbare Ruhe!..7) (Sie erhebt sich,mit Tränen wie blitzende Dizmanten in den Augen). ${ }^{8)}$ Dort, jenseits des Gitters... ist es ruhig... dort schläft ein weiBer Schwan...9) :Iöre! (Si€ stampft zornig mit dem FuB). Du wirst kommen. Du wirst mich finden. ${ }^{10}$ ) Ich werfe dir mein rotes 3 and $z u$.

Voller Ungestiim reißt sie ein rotes Band vom Gürtel und wirft es den Abhang hinab.11) Dann geht sie schnell zum Gitter, öf net das pförtchen und verschwindet Im Park.12) Ihr nach geht schwerfällig der traurige Begleiter.13)

Stille. Das ferne Schnauben eines Zuges. Der Mond wird fahl. l’orgenröte. Die Hähne krähen sich zu - immer ferner, immer ferner. Ein Morgenwind kommt auf und rauscht immer kihner, immer begeisterter.14) - Und langsam wachsend lind sich ausdehnend erhebt sich die erste triumphale Woge des Weltorchesters.15) Es ist, als sei hinter dem Dirigentenpult schon jemand aufgestanden, 16) der vorläufig die leidenschaftliche Erregung der Weltgeigen zilgelt.17)

German steigt auf die Böschung und springt mit einem leichter. Satz auf die Stelle, wo Faina gerufen und mit den Blicken beschworen hat. 18) Die Schramme vom Peitschenschlag ist noch. zu sehen auf seinem erleuchteten Gesicht; ${ }^{19}$ in seinen weitgeoffneten Augen - die Vorahnung des Sturms. Wie Faina steht er iiber der 3öschung und s chaut in die Ferne.20) In seinen Händen hält er das rote Band.21)

iner. hugenblick später steigt der Freund Germans auf die Böschung. Er krimmt sich vor Kälte.22) 


\section{German:}

Der Morgen! Der Morgen! ${ }^{1)}$

Der Freund:

Wann beruhigen Sie sich endlich? Sie schleppen mich die ganze Nacht hinter sich her uber irgendwelche öden Plätze und fallen mir mit den Schönheiten der Natur auf die Nerven, während ich todmulde bin und schlafen will...2)

\section{German:}

Ich whiste gerne, wer das rote Band verloren hat. Was fuir ein rotes Band - wie die Morgenröte! Und es riecht nach frischem Parfum. 3)

Der Freund (lacht vor sich hin): ${ }^{4}$ )

Sicherlich hat irgendeine schöne Unbekannte ${ }^{5)}$ Ihnen das Band zurïckgelassen. Sie sind viel männlicher und schöner geworden, German; ${ }^{6)}$ die Sängerin würde Sie jetzt wohl nicht mehr mit der Peitsche schlagen...7)

\section{German:}

Sie lachen auch daruber, ${ }^{8)}$ als ob sie nicht wißten, wie wichtig das für mich ist. Nicht das Gesicht, sondern das ganze Herz blutete. 9) Das Herz erwachte, und es schien, als habe es stärker zu klopfen begonnen... 10) Ich vermahm damals erregende Musik sie verfolgt mich bis jetzt, mit jedem Sonnenaufgang immer lauter, immer triumphaler. ${ }^{11)}$ Nachts wache ich plötzlich auf, und eine Stimme sagt mir: "Du bist auserwählt, du bist auserwählt."12) Und ich kann nicht mehr einschlafen. Ich irre verzaubert durch die Straßen, ich stürze ins Feld, ${ }^{13)}$ in diesen trunkenen herbstlichen Brandgeruch. ${ }^{14)}$ So vergehen Tage und Wochen, - und die Seele ist wie ein lärmender Wasserfall. ${ }^{15}$ ) wibte ich doch, wohin ich ihre kraft richten soll! Ich weib es nicht, wieviel zu tun wäre, aber ich kann nicht anfangen, kann nicht unterscheiden. Und wieder flustert diese glelche Stimme, warnt, daB der Morgen noch nicht gekommen sei, dab der Nebel sich noch nicht gehoben habe, dab es unmöglich sei, im Nebel Gut und Böse zu unterscheiden... Doch ich will es! ${ }^{16)}$ Oh mein Gott! Welche schreckliche Freude, welche schwere Last ist dieser rauschhafte, hungrige, ewig verliebte Geist! ${ }^{17}$ ) 
Ein Windsto $B$ fegt daher und biegt das Steppengras, - und der filr einen Augenblick hinter dem geneigten Steppengras verborgene Freund spricht mit lachender, herausfordernder stimme.

Der Freund:

Ewig verliebter Geist! Nehmen Sie sich in acht, German! ${ }^{1)}$ Sie gingen von zu Hause fort. Auf Sie wartet Ihre Frau. He, German! Ist Ihr Gewissen rein, mit dem sie sich so beschäfigen? ${ }^{2}$ ) German (zuckt zusammen):

Ich verga, , daß Sie hier sind. ${ }^{3)}$ - Wie schrecklich Ihre Stimme ranchnal ist! Ich sehe sie nicht. Wo sind Sie? - Ach, es hat der wind sie im Steppengras verborgen...4) Ja, ich ging von $z u$ Hause weg, ich verstand den Befehl des Windes, ich sah im Fenster den Frihling, ich hörte das Lied des Schicksals. Ist es etwa ein Verbrechen, aus dem Fenster, zu schauen? ${ }^{5)}$

Der Freund:

Nehmen Sie sich in acht, German! 6)

German:

Sie schrecken mich nicht mehr, - ich sehe Sie, ich kenne sie schon längst. 7) Ich ploh von ihr. Ich floh von ihrem Kuß. ${ }^{8)}$ Ich floh, fiel hin und floh wieder, - und da habe ich sie vergessen. Ich erinnere mich nicht an ihr Gesicht. Ich erinnere mich nicht einmal an diese schrecklichen Augen. 9 )

Der Freund lacht froh. Und der Wind lacht zusammen mit inm.

Der Freund:

Doch an die Augen haben Sie sich erinnert. Nicht wahr - es sind schöne Augen? ${ }^{10)}$

German:

Sie verstehen mich nicht. Sie glauben, ich sei ein Sklave. Nein! Ich bin frei! Ich weib nur nicht, wohin ich gehen soll; doch sind alle Wege frel.

Der Freund:

Und Sie werden auf allen gleichzeitig gehen...

German (schreit):

Ich bin treu! Ich bin treu!11) Niemand darf es wagen, von Verrat zu sprechen! ${ }^{12)}$ sie verstehen nichts! Der Weg ist frei. 
Doch hier beginnt erst das Leben, hier beginnt erst die pelicht. Wenn der Weg frel ist, muB man unvermeidlich gehen. ${ }^{1)}$ vielleicht mus man das Zärtlichste, das Trauteste ${ }^{2}$ - zerstören. Doch auch der Frihling ist zerstörerisch: ${ }^{3)}$ im Fruhling dröhnt die Erde, es gibt rote Sonnenaufgänge, es stehen blaue Nebel in den Schluchten. ${ }^{4}$ Hören Sie, - ich mubte aus diesem stillen Haus fortgehen, aus diesem ausweglosen Gluck! ${ }^{5)}$ Well der Wind das Fenster offnete, der Mönch kam, mir Träume erschienen, das Unbekannte hereinbrach, - ich weib nicht, weib nicht...6)

Der Freund:

Sie streiten so heftig, gerade als ob sie sich selbst nicht sicher wären oder sich rechtfertigen wollten. Ich beschuldige sie doch nicht. Ich begrube Inre Prinzipienlosigkeit... 7)

\section{German:}

Sie wissen nichts, nichts! Ich bin nicht allein! ${ }^{8)}$ Ich ging nicht fort in meinem eigenen Namen. 9) Mich rief der wind, er sang mir ein Lied. ${ }^{10)}$ Ich bin in schrecklicher Unruhe, wie vor dem Kampfe!.. 11) Mein Herz brennt und wartet auf etwas, weint uber etwas, doch es felert schon, feiert im voraus den sieg. ${ }^{12}$ ) Und diese ganze unermebliche Weite hier ist gleichsam eins mit meinem Herzen. Auch sie brennt und sehnt sich und strebt irgendwohin, zusammen mit mir. ${ }^{13}$ )

\section{Der Freund:}

Worlber sie sich beunruhigen, verstehe ich nicht. Sie sind schrecklich mit sich selbst beschäftigt, Sie finden keinen Platz fur sich, sie rackern $81 \mathrm{ch} a b$, - wozu das alles? ${ }^{14)}$

German (mit wachsender Leidenschaft):

Sie fragen - wozu? Halten Sie mich fur verruckt, wenn sie wollen. Ja, vielleicht stehe ich an der Schwelle des Wahnsinns... oder der Erleuchtung! ${ }^{15)}$ Alles was war, alles was sein wird - hat mich umringt: als ob $1 \mathrm{ch}$ in diesen Tagen das Leben aller zeiten lebe, die Qualen meines Vaterlandes ${ }^{16}$ ) lebe. ${ }^{17)}$ Ich erinnere mich des schrecklichen Tages der Schlacht auf dem Schnepfenfeld. ${ }^{18)}$ - Der Furst hatte sich mit seinem Gefolge auf dem Hugel aufgestellt, ${ }^{19)}$ die Erde bebte vom Knarren der Tatarenwagen, ${ }^{20)}$ der Schrei der Adler drohte mit Ungluck. ${ }^{21)}$ Dann kroch 
die unhellverkiindende Nacht heran, und die Neprjadva schmickte sich mit Nebel, wie eine Braut mit dem Schleier. ${ }^{1)}$ Der Pürst und der Heerfuhrer hielten beim Higel an und lauschten auf die Erde: die Schwäne und Gänse schlugen unruhig mit den Flügeln ins Wasser, die Witwe schluchzte, die Mutter warf sich an den Steigbügel des Sohnes. ${ }^{2)}$ Nur über dem russischen Lager herrschte Stille, und es zuckte fernes Wetterleuchten. 3) Doch der Wind vertrieb den Nebel, es brach ein Morgen an, ${ }^{4)}$ so herbstlich wie dieser, und wie jetzt, ich erinnere mich, roch es nach Verbranntem. 5) Und vom Hügel herab bewegte sich das leuchtende fürstliche Banner. ${ }^{6}$ ) Als der Mönch und der Tatar als erste gefallen waren, 7 ) da stießen die Heere aufeinander, und den ganzen Tag schlugen sie sich, schlachteten sich, verbissen sich ineinander...8) Doch ein frisches Heer muBte den ganzen Tag über im Hinterhalt bleiben, konnte nur zusehen und weinen und nach Kampf diirsten... Und der Anfiihrer wiederholte und warnte immer wieder: noch ist es zu frih, noch ist unsere Stunde nicht gekommen. 9) - Oh Gott! Ich we1B, wie jeder Krieger in jenem Heer im Hinterhalt, wie das Herz nach Arbeit verlangt, 10) und wie es noch zu früh ist, zu fri?h!.. Doch da - der Morgen! Wieder die triumphale Musik der Sonne, wie Kriegstrompeten, ${ }^{11)}$ wie ferne Schlacht... Aber ich stehe hier, wie ein Krieger im Hinterhalt, wage nicht zu kämpfen, weib nicht was tun, ich darf noch nicht, meine Stunde ist noch nicht gekommen! ${ }^{12)}$ - Deshalb schlafe ich nachts nicht: ich warte mit ganzem Herzen auf den, der sagt: "Leine Stunde ist gekommen! Es ist Zeit!"13) 14)

In der Tiefe des Farks erscheint das schwarze Kopf tuch der Faina.15) Es dampfen die morgenfrischen Teiche. Im Schilf erhebt sein Haupt der aus dem Schlaf erwachte Schwan16) und schreit mit Trompetenstimme17) der aufgehenden Sonne entgegen.18)

Faina kommt. Ihre Bewegungen sind unsicher, als ob sie von tödlicher Sehnsucht erstickt wiirde und ihr, wie einer Gewitterwolke, kein Ausweg bliebe; sie wird getragen vom tönenden, sich biegenden Steppengras und vom Morgenwind. 19)

Der Schwan schreit und schlägt mit den Fliigeln.20) Faina erfiillt die Iuft mit dem leidenschaftlichen Klang ihrer Stimme und nimmt den Schrei des Schwans auf.21) 


\section{Faina:}

Komm zu mir! ${ }^{1)}$ Ich bin es mude zu leben! ${ }^{2)}$ Befreie mich! ${ }^{3)}$ Ich will nicht einschlafen! ${ }^{4)}$ Püst! Freund! Bräutigam! 5)

Das gesamte Weltorchester greift die leidenschaftlichen Rufe der Faina auf.6) Von allen Richtungen der Erde branden die Wogen der morgendlichen Klänge heran. Das ganze Meer der Weltgeigen zerschlägt alle Fesseln, zerbricht alle Dämme und felert den Sieg der Leidenschaft. In diesem Augenblick spriht am Horizont tiber dem lilafarbenen Streifen ferner Wolken der schmale Rand der roten Sonnenschelbe hervor,7) und es lodern auf alles Gold der Wălder, alles Silber der Flußwindungen, alle Fenster der fermen Dörfer und alle Kreuze auf den Kirchen. Das Antlitz der Sonne wächst uber dem Abhang und überflutet mit seinem Leuchten Erde und Himmel.8) Auf ihm erscheint die entzuckte Gestalt Germans mit brennendem Gesicht.9)

Faina kommt nëher, schwankend wie im Rausch, und wie in Raserel erhebt sie die Hände.10)

\section{Faina:}

Se1 gegrubt! ${ }^{11)}$

\section{German:}

Du schlugst mich mit der Peitsche. Du vergiftetest mich mit deinem KuR. Von dir träumte $1 \mathrm{ch}$ in all den Nächten. Du warfst mir vom Abhang herab das rote Band zu. ${ }^{12)}$

\section{Faina:}

Nein! Du bist nicht wie jener Andere. Er war schwarz, böse und erbärml1ch. 13) Du bist hell, du hast - hellbraunes ${ }^{14}$ Haar, dein Gesicht brennt im Feuer des Herrn. 15)

German:

Schau! Auf meinem Gesicht trage ich die rote Narbe von deiner Peitsche. 16)

Faina (faßt ihn an der Hand):

Das ist die Sonne, die auf deinem Gesicht brennt. Du bist der, auf den 1ch gewartet habe. ${ }^{17)}$ Der schwan schreit, die Trompete ruft! Die Stunde 1st gekommen! 18) Komm! ${ }^{19)}$

German (in Furcht und Entzucken): 20 ) Auf deinem Gesicht - das ganze Schicksal! 21) Du bist der Tag ohne Untergang! 22) Die Stunde 1st gekommen! ${ }^{23)}$ 
Faina linst feierlich inren roten Gurtel ${ }^{1)}$ und verbeugt sich vor Gernan bis zur Brde.2) Der Schwan ist verstummt.3) Nur das Meer der Weltgeigen felert die Leidenschaft. Und nach Atem ringend, zitternd, wie die Erde vor der Sonne,4) ruft Faina mit schwanengleicher Trompetenstimme.5)

\section{Faina:}

Alter, Alter, lebe wohl! Alter, ich bin frei! ${ }^{6)}$ Alter, ich bin Braut! ${ }^{7)}$ - Eine Troika! eine Troika!

Sie zieht German dorthin, wo, von ihrer Stimme aufgeschreckt, die Schellen einer irolka ertönen. - Nach einem Augenblick erschallt der Ruf des Kutschers, ein Pfiff und Pferdegetrappel; die Stinme eines Glöckchens besiegt die Schellen und stimmt ins i. eltorchester ein, liberninmt darin die Fihrung, doch verliert sich dann, vergeht und erstirbt irgendwo in der Ferne auf der leuchtenden Ebene.8)

Der traurige, einsame Begleiter setzt sich auf den großen Stein nitten auf den öden Platz. Sein Bart ist ganz liber seine Brust herabgefallen, seine wei Ben Hände haben den Spazierstock fallen lassen. Der kostbare edelsteinbesetzte Ring glänzt auf dem kraftlosen Finger wie eine brillantene Träne.9) Und gleichsam in eins mit inn geht die unbeständige und unsichere Stimme des lindes in Stöhnen und Schluchzen liber, und in der luft beginnen Abschied verkfindende Holken von goldenen Blättern zu kreiseln.10) 


\section{SECHSTES BIID}

Das Haus Germans. 1) Ein klarer Wintertag. Die Hügel, Sträucher und Wege sind mit Schnee bedeckt.2)

Helena steht in der Tür auf der Treppe, der Freund Germans steigt die Stufen hinab.3)

\section{Der Freund :}

Leben Sie wohl!

Helena:

Zwischen uns ist alles zu Ende.

Der Freund:

Danke. Sie jagen mich aus Ihrem Haus, weil ich Sie Iiebe. $\left.{ }^{4}\right)$

Helena:

Nein, nicht deshalb.

Der Freund:

Nicht etwa deshalb, well ich Ihnen die Wahrhe1t dariber erzählt habe, wie Ihr Mann Sie betrogen hat? ${ }^{5)}$

Helena:

Zun letzten Mal bitte ich Sie, lästern Sie nicht.

Der Freund:

Oh, ich werde nicht einmal diesen Namen merr ausscrechen.

- Leben Sie wohl!. .

Helena:

Warten Sie... Sind sie noch im Stande, venigstens etwas zu verstehen, trotz allem? Vergersen Sie für einen Augenblick, da? Sie ir mich verliebt sind; es fällt Ihnen sicher nicht schwer. Sagen Sie mir ohne Umschweife, in Freundschaft, wie ein Mersch dem andern: ist Faina schön? ${ }^{6}$ )

Der Freund:

Ich bin in Verlegenheit, mit Ihnen uber diese Frau zu sprechen. vielleicht ist sie schön, ${ }^{7}$ doch ist in inr nichts Geheimnisvolles, nichts Weibliches. ${ }^{8)}$ Ich kann mich nur vundern...

Helena:

Doch können Sie sich auch nicht wundern - das ist die Hauptsache. Ich winsche Ihnen alles Gute. Wir trennen uns in Frieden. Der Freund:

So sind sie mir nicht böse? 


\section{Helena:}

Ich - Ihnen? Nie im Leben. Wollen Sie, daB ich Ihnen die Wahrheit sage?

\section{Der Freund:}

Sorechen Sie! Ihnen ist es doch ganz einerle1, wenn ich wegen Ihrer Kälte und Verachtung ${ }^{1)}$ den Verstand verliere.

\section{Helena:}

Oh nein!.. Sie werden nie den Verstand verlieren. ${ }^{2)}$ Und es wird Ihnen nie zuwider sein, sich zu zieren, denn sie sind der allergewöhr:lichste, allerfriedlichste Mensch. Ob Sie drohen, ob Sie Schrecken einjagen wollen oder Bosheiten sagen, - Sie können तamit niemand kränken. Sie sind, was mar die goldene Mitte ${ }^{3)}$ nennt... Das ist alles.

\section{Ler Freund:}

Ja, lєben Sie wohl! Sie haben mich nie verstanden, das weiß $i c h$. i/as tun? - Ich wïnsche Ihnen Glück... mit Ihrem Mönch... 4) Ielena:

Sie Armer... Wie leid Sie mir tun... Oh Gott, und so sind die Henschen alle... Wie unglücklich.

Der Freund geht. 5) - Helena setzt sich auf die Treppe und weint leise. - Nach eiriger zeit tritt der Mönch aus der Tir.

\section{Der ainch:}

Viel hast du ertragen. Nicht f:r ein lefchtes Leben wurdest du geboren. 6) Schau dich an: wie gesund, jung, stark du bist. ${ }^{7)}$ yelena:

Wie er ${ }^{8}$ ) vich liebte... wie er mich liebte...

Der Mönch:

Wirst du denn noch lange weinen?

Helena:

Das ganze Leben.. das ganze Leben... Weshalb fragst du?

Der Mönch:

Weinen solche wie du etwa ein ganzes Leben?

Helena:

Das ganze Leben werde ich weinen... Meinen Kummer kann 1 ch nicht ausweinen... 


\section{Der Monch:}

Du wirst eine Weile weinen und dann aufhören. Ich habe viele Tränen gesehen: doch nur die mutter zerfließen in Tränen; die Mutter, der auBer dem Sohn nichts geblieben war auf der Welt. 1) Aber dir steht das ganze Leben noch bevor. Da schau: der weibe Weg; diesen ganzen Weg wirst du noch gehen... 2) Hör zu, Helena! Du weibt selbst, $1 \mathrm{ch}$ kann von hier aus nirgendwo hin, und auch zu leben habe $1 \mathrm{ch}$ nicht mehr lange...

Helena:

Was kümmerst mich du? Leb oder stirb, mir ist es einerlei! Ich habe genug mit meinem elgenen Schmerz.

\section{Der Mönch:}

Nicht um mich, Helena, sorge ich mich. Denk doch an eines: dein Mann ist fortgegangen...

Helena:

Wir hätten in Frieden gelebt...

Der Mönch:

Aber kann denn jetzt ein lebender Mensch in Frieden leben, Helena? Einen lebenden Menschen zerbricht es doch völlig: er schaut sich um, - nur Menschentränen... er schaut in die Ferne, - und da zieht es inn in diese Ferne...3)

Helena:

Ich verstehe, was du sagst. Auch German sprach javon. 4) Aber ich bin doch auch schön. ${ }^{5)}$ Und meine Seele ist wie die Ferne. ${ }^{6}$ ) Der Mönch:

Deine Seele 1st ruhig, Helena. Du hörst mir zu. Aber jene wijrde die vielleicht zuhören? Sle kennt keine Ruhe, weder bel Nacht, noch bei Tag...7)

Helena:

Du redest, als ob du sie sähest...

Der Mönch (schaut in die Ferne):

Ich sehe sie, Liebste. Ich sehe sie. Helena (erschreckt):

Wen siehst du?

Der Mönch:

Meine Heimat. ${ }^{8)}$ 


\section{Helena:}

Die Menschen wissen nicht, verstehen nicht... selbst du verstehst nicht. In der Schrift steht geschrieben: der Prophet sah den Herrn nicht im Feuer und nicht im Stura, sondern in der Stimme der sanften Kühle. ${ }^{1)}$

Der uönch:

Auch $1 \mathrm{ch}$ dachte, $1 \mathrm{ch}$ wiirde verstehen. Doch nein: das Geheimnis ist groB. 2) Wo soll ich verstehen, wer wird je verstehen? ${ }^{3)}$ Du siehst, wie es um mich steht. An Leben ist mir nur soviel geblieben wie Wachs an der Kerze nach der Messe. ${ }^{4}$ ) Ich habe alle Klöster besucht, mir die Augen ausgesehen. ${ }^{5)}$ Aber da - ich schaue, und wieder zieht es mich fort, ich kann nicht davon loskommen...6)

\section{Helena:}

So meinst du also, German wird nicht zurickkommen? - Du bist

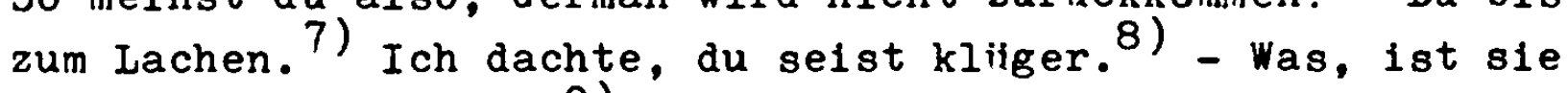
etwa schöner als ich? 9 )

Der Mönch (lächelt):

Inh wiirde es dir sofort sagen, wer besser ist und wer schlechter. Aber kann man denn sagen, was besser ist, Sturm oder Stille? ${ }^{10)}$

\section{Helena:}

Schäme dich, Mönch! Schau dich an: du mußt bald sterben und hast dich - verliebt... 11) on Gott! Und niemand kann mich trösten! Mir gehört German, mir! Wir beide brauchen nichts, außer dem stillen, weiben Haus...

Der Mönch:

Die Mutter ist tot. Es wird kein weibes Haus mehr geben, Helena."2)

\section{Helena:}

Wie, nicht mehr geben? Was redest du da? Versteh, German wird zurickkommen! Er hat hier alles zuriickgelassen. Geh nur ins Haus: alle Bilcher, all seine Sachen; sogar die zerrissenen Hemden, in denen er in diesem Blumenbeet herumwihlte, liegen noch auf dem Tisch. Seine ganze Seele ist hier... 13) 


\section{Der Mönch:}

Die Seele Germans ist weggegeben...1)

\section{Helena:}

Und wie kannst du es wagen, mir das zu sagen? Mir, die er liebte und liebt. Mir gehört German! - Schweig, dummer, dummer Mönch!.. (Sie weint bitterlich). 2)

\section{Der Mönch:}

Weine, Helena! Deine ganze Seele wirst du ausweinen, vor Schreien vergehen, - dann wirst du selbst erfahren... ${ }^{3)}$

Helena (steht auf):

Schweig, Mönch! Er hat zu mir gesagt: ich werde bald zurickkommen. ${ }^{4}$ (Sie richtet sich ganz auf; angespannt schaut sie in die Ferne, auf den schneeiken Weg). Da - er kommt gleich.5)

In diesem Augenblick ertönt, von der Ebene her ein zarter, weicher, wohlklingender Laut: wie wenn ein Rahe gekrächzt hätte, oder wie wenn jemand eine gespannte Salte berihrt hätte.6)

\section{Helena:}

Hast du gehört?

Der Monch:

Ja.

\section{Helena:}

Was soll ich tun?

Der Monch:

Zieh dich gut warm an! ${ }^{7)}$ Zünde eine Hochzeitskerze an! $\left.{ }^{8}\right)$

Helena gehorcht und geht ins Haus. - Der Mönch sitzt still auf der kleinen Treppe und stimmt an: "Wo kein irauern und Seufzen ist"...9) Heleno tritt mit einer brennender Kerze heraus.10)

\section{Helena:}

Bin ich so recht angezogen?

Der Miönch:

Ja, Liebste.

\section{Helena:}

Was soll ich jetzt tun?

Der Mönch:

Stecke die Kerze auf der Treppe fest... 11) 
Er kniet nieder, Helena ebenfalls. Dann stehen sie auf. 1)

\section{Helena:}

Was soll jetzt geschehen, Bruder?

Der Mönch stimmt leise an: "Ewiges Leben"...2) - Helena, im warmen Pelz, steht vor ihm.

\section{Helena:}

Singe nicht ein Trauerlied! ${ }^{3)}$ Es zerreibt das Herz.

Der Mönch:

Vor Freude singe ich, Helena. Vor Freude dariiber, daB dein Liebster - lebt. ${ }^{4}$ )

\section{Helena:}

Ir lebt. Ich weiB es, ich weiß es.

Eer Hinch:

Es ist fiir inn $z u$ frith, um $z u$ sterben. Er hat sich nur verirrt!) Hier sollt inr beide leben, Helena. Neige dich ein bißchen! Das ist fiir dich, Liebste, auf den Weg! (Ir hängt ihr ein kleines Kreuz um den Hals). 6)

Helena:

Yo soll icin denn hingehen, Bruder?

Der liönch:

La ist er, dein weiBer schneeiger Weg. 7) Er ist lang, er dauert viele Jahre. aber am Ende des Hegs ist die Seele Germans.

ㅂelena:

am Ende des Hegs ist die Seele Germans. ${ }^{8}$ )

Der Mönch:

Geh - und du wirst sie finden. 9) Du bist stark. Geh, meine Liebe, der Herr sei mit dir! ${ }^{10}$ )

Helena:

Danke, Bruder!

Der ijunch:

such dir, Liebste, Dank fiir alles!

Helena:

Lebe wohl, Bruder! (Sie weint). Behüte das stille Haus!

Der Mönch:

Ich werde es behiiten, meine Liebe. Dich wird der Herr behüten!1) 
Helena stelgt hinab, dreht sich um und schaut auf inr stilles, schneebedecktes Haus. Dann geht sie fort. Der Monch schliebt behutsam dle Tur und die Lkden. Dann setzt er sich auf elne Treppenstufe und schaut Helena nach. Auf der Treppe brennt die kerze.1)

\section{Bayerische} Staatsbibllothok München 


\section{SIEBTES BILD}

Ein truber Frosttag. 1) Eine öde Ebene, vom Schnee verweht. In der Mitte - ein Schneehigel. Der Wind pfeift und droht mit Schneesturm;2) durch den Wind erklingt, wie aus weiter Ferne, verwegenes Schellengeläut.3) German steht auf dem Hugel.

\section{German:}

Alles ist vorbe1. Das Vergangene ist wie ein Traum. Ein kalter, bleicher Tag. Die Seele, wie die Steppe, Ist von keiner Kette gefesselt; sie ist frei

Von einem Ende bis zum andern.

Es hätte die beklagenswerte Seele,

Die an häusliches Behagen gewöhnt 1st,

An Licht und Wärme des Familienherdes,

Solche Freiheit und solches Glück nicht ertragen.

In meiner Seele ist eine neue Kälte,

Aufmunternd und gesund, wie der winter, Durchdringend, wie die Nadeln der Schneestilirme, Verbrennend, wie der dunkle Blick der Paina. Ich bin gleichsam in einer zweiten Taufe In einem andern, kalten, schneeigen Becken getauft. Ich brauche nicht ein sieches Leben; selbst dreimal leben wäre mir zu wenig! 4 )

Ich brauche keinen Herd und keine Ruhe -

Ich brauche die Welt, wo der Wind mir Lieder singt!

Ich brauche nicht einen Sklaventod. Es sei mir

Leben und Tod - ein einziger Schneewirbel! ${ }^{5)}$

Ein Schneesturm fängt an zu singen. Es wird dunkler. Die Stimme der Faina: ${ }^{6}$

He, German! Wo bist du?

German:

Hierher! zu mir! Auf den Schneehügel! 
Faina erscheint aus der Dunkelheif, 1) faBt German an der Hand und ergötzt sich an seinem Anblick. 2) Der Schneesturm jagt vorbel, es wird heller. 3 )

\section{Faina:}

Ich konnte die Pferde nicht zurickhalten. Irgend etwas erschreckte sie, sie scheuten, kamen in eine schneewehe und jagten davon... (sie lacht). ${ }^{4}$ ) Da sind wir nun allein. Was stehst du dort oben?

\section{German:}

Hier sieht man besser.

\section{Faina:}

Hier sieht man besser! Hier - bin ich! 5) Setz dich neben mich! Erzähle von dir: du hast mir noch nichts erzählt. German (setzt sich unten am Hugel neben sie): Zu erzählen gibt es nichts. Es war nichts. Was ich tun soll. weiB ich nicht: du bist gröBer als 1ch.6) Nur zu deinen PüBen sich nach Ruhm sehnen. 7) Du schaust mich an mit unbekanntem, brennenden Blick: ${ }^{8)}$ aber $1 \mathrm{ch}$ bin ein Nichts, ich bin fremd, $1 \mathrm{ch}$ bin schwach, -1 ch vermag nichts... ich erinnere mich an nichts.. an nichts...9)

\section{Faina:}

Immer nur Worte! Schöne Worte. ${ }^{10)}$ Und deine Kindheit? Verwandte, Familie, Haus, Frau? Und die Stadt? Und meine Peitsche - erinnerst du dich? ${ }^{11)}$

\section{German:}

Nur an die Peitsche. Und sonst an nichts. Der Schlag deiner Peitsche hat mich betäubt, hat alles Vergangene erschlagen. 12) Jetzt ist es in meiner Seele weib und voller Schnee. Und ich habe nichts zu verlieren - es gibt nichts Trautes... 13) Und es gibt nichts mehr, woruber ich reden könnte, denn die seele ist, wie die Erde, - in Schnee gehililt. 14)

Paina:

Ach, alle seid inr so... Wie Tote... Ich aber lebe! ${ }^{15)}$ Nie hatte ich ein Haus, oder Verwandte, oder Freunde! Wohin $1 \mathrm{ch}$ w111, dahin gehe $1 \mathrm{ch!}$ !6) 


\section{German:}

Zertritt nicht die Blumen der Seele. Sie sind blau, fruh. Was kummern sie dich? ${ }^{1)}$ Dich, Faina, trage 1ch im Herzen. 2) Das übrige ist vorbe1. Vielleicht werde ich im Schnee sterben. Das ist einerle1: ich kann auch sterben. ( $\mathrm{cr}$ legt 8 ich in den Schnee, mit dem Gesicht zum Himmel). 3)

Faina:

Wieder - Worte? ${ }^{4)} \mathrm{Zu}$ wenig hast du gelebt, um zu sterben! Nur in den Märchen stirbt man!..5) (sie springt plötzlich auf und ruft schallend). He, nimm dich in acht! ${ }^{6}$ Ein Schneesturm kommt! 7)

Es fegt Schnee heran, und mit ihm bricht Dunkelheit herein. ${ }^{8}$ ) Aus der Ferne hört man, wie eine rauhe stimme singt:

Ach, so voll, so voll mein Kästelchen:

Goldbrokat und Stoffe fein.

Hab doch Mitleid, liebstes Schätzelchen

Mit dem armen Liebsten dein! 9)

Das Lied bricht ab.

\section{Faina:}

Hörst du?

\section{German:}

Jemand geht in der Ferne.

Faina (hat sich niedergebeugt und schaut in der Dunkelheit German an):

Er geht ohne Weg, 10) singt ein Lied... Keiner wird uns stören, alle werden vorbeigehen. (Sie umschlingt seinen Hals mit den Händen)! Mein Liebster. ${ }^{11)}$ Mein Bester...

\section{German:}

Hir ist bange, Faina.

\section{Paina:}

Hab keine Angst, mein Liebster! Niemand wird es erfahren...

Einen solchen wie dich sah $1 \mathrm{ch}$ im Traum... auf einen solchen wartete $1 \mathrm{ch}$ nachts am FluB...13) 


\section{German:}

Du schauet gerade in die Seele... mit schwarzen Augen... Paina:

Falsch! Schau besser hin! Nur nachts sind die Augen schwarz. Aber am Tage sind sie rotbraun; siehst du - rotbraun? ${ }^{1)} \mathrm{Hab}$ keine Angst, German, armer Junge, mit hellbraunen 2) Locken... 3)

Sie neigt ihr Gesicht noch näher zu ihm. - Und wieder hört man, näher da:

Komm Ins Kornfeld, liebstes Mägdelein!

W111 dort warten b18 zur Nacht.

Seh' 1 ch delne schwarzen Äugelein,

Zeig' ich gern die ganze Pracht...4)

Das Iied bricht ab.

\section{Paina:}

Hörst du?

\section{German:}

Ich höre es nicht mehr... Es lst still... N1e hörte 1ch eine solche stille... Dort war eine andere stille...5)

Der Schneesturm geht voriber, es wird wieder heller.

Faina (setzt sich hin wie zuvor):

He, German! Deine Frau - weint wohl um dich? ${ }^{6)}$

\section{German:}

War das im Traum, Faina?

Faina (scharf):

Im Traum! Hörst du, wie der Wind weint? Das lst deine Prau, die weint! 7)

Sie fängt an, unruhig aufzuhorchen: im Stöhnen des Windes erwacht ein und derselbe alte Fon: wie wenn jemand schluchat, rufend, klagend, untröstlich.8f)

\section{German:}

Denke nicht zurick, Faina!

\section{Faina:}

Es steht mir fre1, zurickzudenken! Ich bin immer frei! Prei, 
wegzugehen, frei, zu erwirgen, 1mmer frei. 1) Hör den Wind! Höre! 2)

\section{German:}

Weshalb bist du so streng? ${ }^{3)}$

\section{Fa1na:}

We1l $1 \mathrm{ch}$ wartete und mein Warten umsonst war! Weil du ein Mensch warst, solange dein Gesicht blutig war! - Oh Herr! Oh Herr! Werde Mensch! ${ }^{4}$ )

Der Schneesturm schluchzt in der Ferne mit den alten Tränen.5)

\section{German:}

Du schlägst mich mit Worten und Blicken, wie mit einer Peitsche, wie der Schneesturm. 6)

\section{Faina:}

Ich schlage dich für deine Worte! Viele schöne Worte hast du gesagt. Aber weiBt du vielleicht etwas anderes auBer worten? ${ }^{7)}$ German:

Ich weiB alles. Jetzt weiB ich alles. ${ }^{8)}$ Sel beruhigt: du wirst mich weder mit der Peitsche, noch mit einem KuB mehr wecken. 9) Faina (in Unruhe):

He, German, nimm dich in acht! German, ein Schneesturm kommt! 10) German:

Das macht nichts. Wecke mich nicht! Soll doch ein anderer den Weg finden. 11)

Faina (in größter Unruhe):

Du schläfst ein, German? Es ist Zeit, aufzuwachen! 12)

Ein Schneesturm jagt heran. Dunkel und Getöse. Noch klarer klingen die alten Tränen.13)

\section{German:}

Ich sehe nichts. Ich erinnere mich an nichts. ${ }^{14)}$ Wessen Augen sind das - diese dunklen? ${ }^{15)}$ Wessen Hände sind das - diese zärtlichen? Wessen Hände sind das - diese sanften? ${ }^{16)}$ So bist du - meine Braut? Enthille dein Gesicht! 17) 
Faina (schmiegt sich an ihn):

Komm zu dir! Alles wird neu beginnen: $1 \mathrm{ch}$ werde meinen gestickten Ärmel schwenken, ${ }^{1)}$ ich werde ein kihnes Lied singen, ${ }^{2)}$ wir werden auf der Troika dahinjagen...3) Weiter weg von ihm... weiter weg...4)

German (im Fieberwahn): ${ }^{5}$ )

Wohin? Alle Wege sind verweht...6)

Faina:

Fest ans Herz drilcke 1ch dich, Ersehnter. Höre, höre, das Herz schlägt, das Herz erwacht, das rote heibe Blut beginnt zu singen, höre, höre!..7)

German (im Fieberwahn):

Ich höre, es tönt. Die Pferde sind davongejagt. ${ }^{8)}$ Enthillle dein Gesicht: ich erinnere mich nicht an dich.9)

Faina (traurig):

Nicht Tod sondern Leben bringt dir mein Atem! ${ }^{10}$ ) (Sie legt eine Handroll Schnee auf seine Stirn). ${ }^{11)}$ Mein Liebster, Ersehnter, kilsse mich! Er ruft. Der Alte ruft. Der Mächtige ruft nach mir. Kisse $\mathrm{mich} !^{12)}$

German:

Was 1st das? Rreischen Maschinen, sterben Menschen? Ja, ja: breite Plätze, lange Reihen von Lichtern... Das 1st - eine Stadt, eine riesige Stadt... Ein grauer Turm... Aus dem Turm blickt mich jemand an... 13) Wer 1st das? Ach, meine Mutter, meine Mutter. Sie neigt den Kopf. Was sagst du? Mutter! Ich kann es nicht hören...

Paina:

Erwache, Liebster! Die Mutter ruft nach dir! ${ }^{14)}$

German:

Wer ist das? Ein Engel in weißem Gewand! Goldene Locken! Flugel an den Schultern! ${ }^{15)}$ Wie er leuchtet! In den Händen - eine Lilie... 16) eine Lilie oder eine Kerze? Eine Hochzeitskerze! ${ }^{17}$ ) Helena! On Herr! Helena! ${ }^{18)}$

Faina (in wahnsinniger Trauer):

Wach auf, German! Genug mit Schlafen! Hier bin nur ich! Wach doch auf! 
German:

Sie sagt: wach auf, German! ${ }^{1}$ - Nein, nein: ihr 1st es ganz einerle1, ganz einerle1... Sle zelgt mir dorthin... Wie weis es dort 18t. 2) sie nickt mir zu... geht fort... geht fort... 18t verschwunden... Sie ist nicht mehr da. ${ }^{3)}$ - Es ist kalt. Welch ein Glanz! Welche Laute! Was 1st das? Ein Horn? Das trockene Dröhnen von Trommeln! Da kommt er... es kommt der Held - mit geflugeltem Helm, das schwert auf der schulter... is) und ihm entgegen...

Faina (ganz eng an ihn geschmiegt):

Was siehst du jetzt? An was erinnerst du dich jetzt?

German:

Kommst du ihm entgegen, - Unauswe1chl1che? Sch1cksal? ${ }^{5)}$ Welch dunkle Augen! 6) Welch kalte I1ppen! 7) Nur frage nach nicht8...8) Es 1st dunkel... Es 18t kalt. Ich kann mich nicht erinnern...9)

Faina hält Germans Kopf. Er schaut sie an mit weit geöfeneten Augen.10)

\section{German:}

Das war alles ein Traum? ${ }^{11)}$ - Faina! Du weibt den Weg? ${ }^{12)}$

Faina (mit ungewöhnl1cher Traurigkeit und Zärtlichke1t): 13)

Du liebst mich?

German:

Ja.

Faina:

Du kennst $\mathrm{mlch}$ ?

German:

Nein.

Paina:

Du wirst mich finden?

German:

Ja.

Und plötzl1ch, ganz nahe, ertönt sieghaft-traurig die Melodie, vom Schneesturm hergetragen: 
We sie elnig wurden $81 \mathrm{ch}$ darauf,

Weib die tiefe Nacht allein.

Hohes Kornfeld, bitte richt dich auf,

Hulle inr Geheimnis ein!..1)

\section{Paina:}

Dreimal 2) kusse $1 \mathrm{ch}$ dich. Die Zeit fur unsere Begegnung 1st noch nicht gekommen. ${ }^{3)}$ Er ruft. Lebe! ${ }^{4)}$ Llebe mich! Suche mich! ${ }^{5)}$ Mein Alter, mein Mächtiger, mein Trauriger ist gekommen, mich zu holen. 6) Ich werde nahe sein. 7) Mein Teurer, Llebster, Eroehnter! Lebe wohl! Lebe wohl ${ }^{8}$ )

Der weinende Wind verweht die letzten Worte der Paina. Sie läuft in den Schneesturm und ins Dunkel davon.9) German bleibt allein am PuBe des Hügels zurück.

\section{German:}

Alles ist weib. ${ }^{10)}$ Nur elnes ist geblleben: das, worum ich dich gebeten habe, oh Herr - ein reines Gewissen. ${ }^{11)}$ Und es gibt keinen Weg. Was soll 1ch Bettler tun? ${ }^{12)}$ Wohin soll ich gehen? ${ }^{13)}$

Die Dunkelheit ist fast vollständig. Nur Schnee und das Tosen des Windes.14) Und plötzlich taucht neben German ein vorbe1ziehender Hausierer auf.15)

\section{Der Hauslerer:}

He, wer lst da? Was stehst du da? Willst wohl erfrieren? ${ }^{16)}$

\section{German:}

Ich komme selbst ans Ziel. ${ }^{17)}$

Der Hauslerer:

Nun, bewege dich, Bruder, bewege dich: eln Helliger kann vielleicht so stehenbleiben, aber für unsereinen ${ }^{18)}$ ist das nichts!9) uns weht der Schneesturm ${ }^{20}$ ) $z$. Gar viele Leute hat er eingewiegt und in den Schlaf gesungen...21)

\section{German:}

Und du weibt den Weg?

Der Hausierer:

Ich weiB inn. Wie soll ich inn nicht wissen. 22) - Du bist wohl nicht von hier, was? ${ }^{23)}$

German:

Nein, ich bin nicht von hier. ${ }^{24)}$ 


\section{Der Hausierer:}

Dort das Licht, ${ }^{1)}$ siehst du?

German:

Nein, ich sehe es nicht.

Der Hausierer:

Nun, wirst dich an die Dunkelheit gewöhnen ${ }^{2)}$ und es sehen. 3) Wohin willst du denn?

\section{German:}

Ich weib es selbst nicht.

Der Hausierer:

We1Bt es nicht? Komischer Mensch. Ein Umherziehender ${ }^{4)}$ also. Nun, komm schon, komm! Blelb nicht an einer Stelle stehen! Ich bringe dich zum nächsten Ort, und dann kannst du selbst gehen, wohin du weist. 5)

German:

Finre mich von hier heraus, Wandersmann! ${ }^{6)}$ Dann werde $1 \mathrm{ch}$ selbst gehen, wohin ich weis.7) 


\section{Anhang:}

Szene Im Bahnhof ${ }^{1}$ )

Bin Bahnhof. Bin groBer gewslbter Saal. Durch die halbkreisförmigen Penster in der hinteren Wand sieht man einen ablahrbereiten Zug am Bahnsteig, grine und rote Signallampen und Schneesturm. Im Saal herrscht unruhiges Treiben. In der Ferne hört man Läuten und Pfeifen von Lokomotiven.2)

\section{German:}

Sie wissen immer, wo Sie mich finden konnen.

Der Freund:

Die Erde 1st voller Gerucht. Und schlieblich treffen Sie sich Immer mit dieser 21 geunerin ${ }^{3)}$ in aller offentlichkeit, im Theater, in den Klubs, auf den Bahnhöfen. Das 1st doch schlieblich schon allen klar. Und $1 \mathrm{ch}$ kenne viele, die uber sie Geruchte verbreiten, schwatzen und sich uber sie unterhalten...4)

\section{German:}

Ich verstecke mich vor niemand. 5)

Der Preund:

German, Sie urteilen wie ein Kind, ${ }^{6}$ ) Innen schadet das nichts, Sie sind ein Mann. Doch in welche Lage bringen Sie Ihre Frau?

\section{German:}

Ich verstehe nicht ganz, was Sie sagen. Begehe ich etwa ein Verbrechen? ${ }^{7)}$

\section{Der Preund:}

Ja, so nannte man das in friheren Zeiten. Doch heutzutage kann es keinerlel Romantik geben. Und deswegen handeln Sie einfach wie ein gewöhnlicher Ehemann, der seine Frau betrilgt. ${ }^{8}$ )

German:

Da sieh mal einer an! Ja, ich weiß, Sie lieben Helena seit langem. 9)

Der Preund:

Ich bin aber auf offene Geständnisse nicht vorbereitet... 10) German:

Ich kann nicht anders. Ich habe nichts zu verbergen. Sie sagen, ich wirde meine Frau betrigen. Das ist nicht richtig. Ich habe das Lied des Schicksals vernommen. ${ }^{11)}$ 


\section{Der Fround:}

Sie sind entweder ein Kind oder ein unverbesserlicher Romantiker. Also reden wir doch ernsthaft miteinander. (Sie setren sich an einen Tisch). Pangen wir von vorne an. Warum sind sie von zuhause weggegangen?

\section{German:}

W1rkl1ch, 1ch weis es nicht. Ich bin weggegangen, we1l $1 \mathrm{ch}$ in Penster den Pruhling sah. ${ }^{1)}$ Mehr kann ich nicht sagen.

Der Preund:

Und wiseen Sie, wozu unbedachte Handlungen fuhren?

German (nachdenklich):

Ich weis nur, $\mathrm{da} B$ 1 ch mir meine Handlungen nicht uberlegen kann. 2)

Der Freund:

Wenn Sie es nicht wissen, dann will ich es Ihnen sagen. Das lst alles ganz schön - ein elnziges Mal. Sie sind verliebt, Sie sind jung. Aber sie treffen sich mit dieser zigeunerin...

German:

Wer hat Ihnen gesagt, sie sel eine Zigeunerin?

Der Freund:

Das lot einerle1. Sie treffen sich mit der Sängerin ${ }^{3)}$ Faina schon viele Tage. Zum ersten wird das langweilig. Zum zweiten ist das fur Ihre Frau sehr beleidigend.

\section{German:}

Ach, sieh mal an! Ihnen ist es vor allem langweilig. Aber das 1st doch nicht Ihre Sache, lieber Freund.

Der Preund:

Ich hätte nicht angelangen, mich so um sie zu kimmern, ${ }^{4)}$ wenn lch nicht Ihr Freund wäre. Besonders, wenn Sie im Zustand der Unzurechnungsfähigkeit sind.

German:

Halten sie mich fur verrickt, oder fur was sie wollen. 5) Doch sehen sie sich um! Schauen Sie aus dem Fenster! Sehen Sie, die signallampe 1st grün. Das bedeutet: der Weg 1st frei. 6 )

Der Freund:

Wie soll ich Ihre nebelhaften Ausdricke verstehen? 


\section{German:}

Was soll ich Ihnen antworten? Ich we1B selbst nicht viel. 1) Doch sehr viel mehr, als $1 \mathrm{ch}$ vor einigen Tagen wuBte. Und das sage ich Ihnen mit Bestimmtheit: Das Zärtlichste, das Trauteste, das suBeste muB man zerstören. ${ }^{2)}$ Genau so unvermeidlich, wie dieser Zug unvermeidlich abfahren wird - weil der Weg frel ist. 3 )

Der Freund:

Ich verstehe sie nicht.

German:

Gut. Ich will es anders sagen. Ich lebte mit Helena in dem we1Ben Haus, in völliger Stille. Unser ganzes Leben war wie das Leben der Blumen ${ }^{4}$ und der Morgenröte. ${ }^{5)}$ Kein Mensch weiB, auf welch geheimnisvolle Weise ich ihr begegnete. 6 )

Der Freund:

Machen Sie keine Geständnisse! Dazu bin $1 \mathrm{ch}$ ganz und gar nicht gekommen. Das ist mir etwas zuwider.

German:

Das ist Ihnen zuwider? Das ist mir einerle1. Ich hielt sie frilher für einen Freund. Und jetzt möchte ich Ihnen das nur zu Ende erzählen, und Sie werden bis zum Schluß zuhören. - Wir lebten nicht so, wie andere Leute leben. ${ }^{7)}$ Und deshalb können wir uns trennen. Ist es vielleicht ein Verbrechen, daß ich aus dem Fenster schaute und begriff, was das ist: Frihling? ${ }^{8}$ ) Im Frihling dröhnt die Erde, es gibt rote Sonnenaufgänge, in der Ferne ist blauer Nebel.9) Ich konnte nicht anders, ich muBte gehen...10)

Der Freund:

Aber damit, daß Sie weggehen, brechen Sie das Herz einer Frau. Sie zerstören das Helligste.

\section{German:}

Tu 1ch das? Nun denn. Ich firchte dieses Wort nicht. Aber muB ich denn nicht auch zerstören, wenn selbst der Frihling zerstörerisch ist? ${ }^{11)}$ Wenn der Friihlirg nur dafiir blitht und singt, damit 1 ch begreife, daB der Weg frei ist? Begreifen Sie, was das bedeutet? Der Weg ist frei? ${ }^{12)}$ 


\section{Der Freund :}

Jetzt begreife ich. Das ist die äußerste Prinzipienlosigkeit. ${ }^{1)}$

Friher einmal warfen Sie mir vor, daß ich uber alles lache. Aber jetzt, ich versichere Ihnen, sind Sie wesentlich prinzipienloser als ich.

\section{German:}

Oh nein, Sie verstehen also nicht. Wie soll ich das erklären? Der Weg ist frei! Doch hier beginnt erst das Leben. Hier beginnt erst die Pflicht. Wenn der Weg frei ist, muß man diesen Weg gehen, 2) koste es was, es wolle!

Der Freund:

Und deshalb verbringen sie angenehm Ihre Zeit in der stadt mit einer Zigeunerin?

\section{German:}

Sie wollen mich beleidigen? Das wird Ihnen nicht gelingen. Ich stehe fest auf meinem Weg. Aber wissen Sie denn, wer diese Frau ist, die sie eine Zigeunerin nennen? ${ }^{3)}$

Der Freund:

Ich we13 es sehr wohl: eine Kabarettsängerin.4)

German:

Ich könnte Ihnen antworten. 5) Aber - leben Sie wohl! Da ist sie.

Faina kommt durch den ganzen Saal. Sie ist ganz in Schwarz, nit schwarzen StrauBenfedern am Hut.6) Sie ist durch irgend etwas erregt und ist bleich.7)

\section{Der Freund :}

Auf Wiedersehen, mein verrickter Freund! Ich werde sie so nicht zuriicklassen...

Der Freund geht ab, German geht Faina entgegen. ${ }^{8}$ )

German:

Endlich bist du da. Ich habe lange auf dich gewartet.9)

\section{Faina:}

Du hättest noch länger warten können. Einen Tag. Eine Woche. Einen Monat. Ha! Ein ganzes Jahr.10) 


\section{German:}

Sei nicht otreng zu mir. ${ }^{1)}$ Ich kann auf dich eine ganze Ewigkeit warten. 2 )

\section{Paina:}

Gib mir die Hand! Ich will mit dir noch dorthin gehen, wo es Lichter und Schnee und Wind und Finsternis gibt. ${ }^{3}$ ) Wie ich diese Stadt liebe! Ohne sie kann lch nicht leben... 4) Der Kopf schwindelt einem vor wind. Komm mit, komm mit dorthin, zu den grilnen und roten Iichtern!

Sie gehen auf den Bahnsteig hinaus.5) An einem der Tische im Saal kommen drel Freunde Germans zusammen.6)

\section{Der Freund:}

Sie haben natirlich die traurige Neulgkelt gehört? Von dem Unglick, das unseren gemeinsamen Freund German befallen hat?

Der zweite Freund:

Ja, es kursieren Geriichte. Wenn Sie sein Verhältnis mit dieser Zigeunerin ein Unglilck nennen.

Der dritte Freund:

Mit einer Zigeunerin? Ja, Ja, ich habe davon gehört. Ich habe German Immer filr einen bemerkenswerten Menschen gehalten. Im Hinblick darauf wäre es mir interessant, thn in diesem Augenblick zu beobachten. Ein Mensch, der elne familiäre Krise durchmacht, lst ein äußerst Interessantes Phänomen.

Der Freund:

Das wird Ihnen gelingen, denn German befindet sich hier. Doch es geht nicht um ihn, sondern um seine Frau, auf die dieses Ereignis einen deprimierenden Eindruck macht. Um so mehr, als sie, wie ich weiß, iberzeugt ist, daß German bald zurilckkehren wird. 7)

\section{Der 2. Freund:}

Und was ich davon halte? Natiirlich wird er zurlickkehren. Denn er 1st doch an den häuslichen Herd gewöhnt. Nun, im äußersten Fall nimmt er die Zigeunerin mit, und es wird ein allerliebstes ménage à tro1s ${ }^{8)}$ geben, das ist alles. Es lst ze1tgemäß und pikant. 
Der 3. Freund:

Mich interessiert das alles uberhaupt nicht. Besser gesagt, in diesen Alltagskombinationen 1 st jeder Mensch frei, sich zu verhalten wie es ihm behagt. Ich sehe darin nur elne ungewöhnlich interessante ästhet1sche und psychologische Erscheinung.

Der Freund:

Ach, meine Freunde, Sie haben beide unrecht! Wenn es nur um German ginge, na, dann wohl bekomm's! Soll er doch zehn Frauen auf einmal nachsteigen. Doch hier geht es um die Familie... Der 2. Freund:

Ich erkenne Sie aber gar nicht wieder! So ein ironischer Mensch und redet da plotzlich von Familie...

Der Freund:

Wenn es meine Freunde betrifft, muB ich ihnen schlieblich sogar meine Weltanschauung opfern. Das ist eine ganz gewöhnliche Geschichte, und man kann sie nicht so von oben herab betrachten: da betrigt ganz einfach ein mir nahestehender Mensch seine Frau, die zu achten $1 \mathrm{ch}$ verpflichtet bin. Und deshalb bin ich der Meinung, daß es unsere hellige Pflicht ist, das zu verhindern, koste es was es wolle. ${ }^{1)}$

Der 3. Freund:

Aber meine Pflicht vor der Wissenschaft 1st: beobachten, beobachten und beobachten!

Der Freund:

Ausgezeichnet! Wenn sie beobachten, wird das German schon in ausreichendem Maße ernuchtern.

Der 2. Freund:

Ich schließe mich an. Im Namen der Birgerpflichten ${ }^{2)}$ jedes Menschen im Verhältnis zu seinen Nächsten...

Der Freund:

Sehr gut! Ich muß Sie davon in Kenntnis setzen, daß German mit der Zigeunerin sich hier befindet. Und wir können uns wunderschön in ihre intime Unterhaltung einmischen...

Der 2. Freund:

Oh, das ist sogar interessant... 


\section{Der 3. Preund:}

Erlauben Sie! Sie haben doch gesagt, dab die the elne burgerliche Einrichtung 1st?

Der 2. Preund:

Ja, und ich habe es aus Uberzeugung gesagt...

Der 3. Preund:

Sie lassen vergebens außer acht, daß es eher eine kirchliche Einrichtung ist...

Der Preund:

Verschieben Sie doch Ihre ewigen Streitereien bis zu einem geeigneteren Anlaß. Da kommen sie schon. Nach einiger zeit milssen wir uns innen anschließen...1)

Faina und German kommen zurijck und setzen sich an einen entfernten Tisch. Man bringt innen Wein.2)

\section{German:}

All dlese Tage quälst du mich: du läBt mich nicht einmal den Saum deines Kleides berihren. ${ }^{3)}$ Ich war mit dir keine einzige Stunde allein zusammen. Nur in Gegenwart von anderen schaust du mich mit deinem unbekannten und brennenden Blick an, ${ }^{4}$ ) Faina, relzt mich mit einer zufälligen Berihrung und einem zärtlichen Wort.

\section{Faina:}

All das ist Einbildung. Schöne Worte. ${ }^{5)}$

German:

Das 1st keine Einbildung. Ich will neben dir leben und atmen. Ich habe noch nie gelebt, Faina. ${ }^{6}$ )

\section{Faina:}

Das meinst du ernst? Genau das hast du zu deiner Frau auch gesagt! Oder etwa nicht? Oder etwa nicht? Und du wirst es noch einmal und noch einmal, zu einer dritten, zu einer vierten sagen...7) Nun, spiele nur, wohl bekomm's, in Gottes Namen!.. (plötzlich streng:) Nur - kann man denn mit der Liebe spielen? ${ }^{8)}$ Die Liebe ist streng. Die Liebe bringt strafe. ${ }^{9}$ Kehr zu deiner Frau zuruck! ${ }^{10}$ ) 


\section{German:}

Kann ich denn zurikckkehren? Ich habe keine Vergangenheit. 1) Das Haus ist zerstört...

\section{Faina:}

Wie hast du gesagt? Das Haus ist zerstört. Du dummer, dummer Mensch. Du hast es wohl traurig gesagt: das Haus ist zerstört. Nun, dann sei traurig. 2) Ich hatte nie ein Haus... 3) Ha! Das Haus ist zerstört, - dann bau ein neues... Ihr alle liebt zu bauen, zu bauen... Das Bauen ist fir euch ein spiel...4)

\section{German:}

Wenn du fortgehst, Faina, werde ich nicht weiterleben. Ich werde dich iberall suchen. Finde ich dich nicht, sterbe ich.5) Du bist die Freiheit selbst, die Ferne selbst. Du gehorchst keinem Gesetz, wie der Wind. Wie der Wind fliegst du davon, wie die Ferne lockst du, fihrst einen fort, richtest einen zugrunde...6)

Faina:

Weshalb bist du hier? Ich bin gern allein. Ich höre gern ferne Musik... Und ich warte gern. Nein. Ich schaue gern auf die menschliche Niedertracht. Und dann... kauft mich vielleicht einer... 7)

\section{German:}

Was sagst du? Mit dieser Stimme! Mit diesen Augen!

Faina:

$\mathrm{Ja}$, es ist wahr. Meine Stimme windet sich wie ein silberner Bach. 8) Und von meinen Augen hat ein Dichter gesagt, sie seien tragisch...9) Na und? Gerade deshalb wird er mich kaufen... und wird seine Schulden bezahlen...

German (leise):

Faina, wirst du mich betrigen?

\section{Faina:}

Wie hast du gesagt? Ha! Was soll das heißen? Was soll das heiBen? Und wie kannst du es wagen? Bin ich vielleicht deine Frau? cder die eines andern? Ha! Geh zu deiner Frau! ${ }^{10)}$

\section{German:}

Du hast gesagt: die Liebe ist streng. Ich weiß, Ich will alles von dir ertragen. Laß mich dich nur ansehen... 11) 


\section{Paina:}

Dahin fuhrt also das Spiel! Alles ist Spiel! Oh Gott, alles ist Spiel! 1) Gib mir noch Wein! Kann man denn von Liebe so viel reden? Etwas ist in dir, ach! etwas so Totes!.. Und in allen 1st das... Alle seid ihr so. Ich aber lebe, lebe, lebe! ${ }^{2)}$ und werde dir nie gehören... und nie einem andern... nie! ${ }^{3}$ )

\section{German:}

Dich, Faina, muB man zähmen wie ein wildes Tier. ${ }^{4)}$ Du wirst trunken von der Iuft und vom wind und kannst lange nicht zu dir kommen. 5) Begreifst du, dab ich nichts zu verlieren habe? Ich habe nichts mehr, was mir vertraut war. Alles hat der feurige Schlag deiner Peitsche ausgebrannt. 6) Weshalb zertrittst du die zarten Blumen meiner seele? ${ }^{7)}$ Du denkst wohl, ich brauche von dir dasselbe wie die andern? ${ }^{8)}$ Ich schwöre, ich weiß nicht, was 1 ch brauche. Aber ich bin auf ewig mit dir verbunden. ${ }^{9)}$ Und der Kopf schwindelt mir wahnsinnig. Mein Gott! Wie die Gedanken dahinjagen! 10)

Faina (schaut inn an):

Vielleicht stimmt das. Sonst wäre ich nicht mit dir zusammen. Und im ibrigen - (sie macht eine weit ausholende Bewegung uber den Kopf) bin ich betrunken! Von der Luft, vom Wind, von der Nacht. Wie ich diese Stadt Iiebe! 11)

\section{German:}

Die Gedanken jagen dahin wie Vögel. 12) Halt! Ich brauche einen Augenblick lang Ruhe; Der Freund hat doch die Wahrheit gesagt: nirgends ist Ruhe. ${ }^{13)}$ Du aber kannst mit einem einzigen Wort die Gedanken anhalten. Nicht umsonst hat man von dir gesagt, daß du Schiffe zur Umkehr zwingst... 14)

\section{Faina:}

Wer hat das gesagt?

German:

Ein Mönch.

\section{Faina:}

Ein Mönch? Ich erinnere mich: auf dem andern Ufer stand ein Kloster. Wie schön es war. Ich wartete. Alle Nächte hindurch. Was, er kennt mich? ${ }^{15)}$ 
German:

Ja. Er hat mich zu dir geschickt. 1)

Paina:

Ich sah die Mönche. Alle sind sie so streng, bleich, ernst... wie du. 2)

German:

Nun, es ist ruhig geworden. Es ist wunderbar, Faina. Dein Sturm hat sich gelegt. Und schau: im Glas perlt der funkelnde Wein. 3) Oh, wie lange habe ich auf dich gewartet! Das ganze Leben. ${ }^{4}$ Da kommt jemand zu uns her. ${ }^{5)}$

Die Freunde treten heran.

Der Freund:

Ich hoffe, German, Sie machen uns mit Ihrer Dame ${ }^{6)}$ bekannt. Sie setzen sich an den Tisch.

\section{German:}

Was winschen sie?

Peinliches Schweigen.

Der 2. Freund:

Was für ein angenehmer Abend. Widmen Sie sich schon lange Ihrer Kunst? 7 )

Faina antwortet $1 \mathrm{hm}$ nicht, sondern schaut aus dem Fenster, in die Finsternis, zu den Lichtern und dem Schneesturm.8)

Der dritte Freund:

German, sie haben jetzt ein uberaus interessantes Gesicht: es ist angespannt und voller Inspiration. Wahrscheinlich arbeitet in diesem Augenblick stark Ihre Phantasie...9)

Der Freund:

Ich sehe, sie sind nicht in Stimmung. Scherz beiseite! Ihre Frau...

\section{German:}

Wer hat Ihnen das Recht gegeben, von meiner Frau zu sprechen? 
Der Preund (spottisch):

Entschuldigung! Vielleicht weis Ihre Begleiterin nicht, das Sie eine Prau haben?

Paina:

Doch.

Der Freund:

Ach, Sie wissen es? Und trotzdem bringen Sie thn von seinen ehelichen Pflichten $a b ?^{1)}$ Ich will ganz offen reden. German, diese Prau...2)

\section{German:}

Alles, was Sle mir sagen wollen, we1b 1ch. Und deshalb - schwelgen S1e!

Der Preund:

Mir 1st es gar nicht angenehm, Sie an das zu erinnern, was Sie vergessen haben. Doch, - es lst meine hellige Pflicht, 3) $1 \mathrm{ch}$ bin Ihr Preund. Und deshalb bitte $1 \mathrm{ch}$ S1e, mich wenigstens anzuhören.

German:

Ich we1B alles, was Sle sagen wollen. Ich kann und will keine Ze1t mit Ihnen verlieren. Sle wollen, das $1 \mathrm{ch}$ diese Frau verlasse und zu melner Frau zurlickkehre?

Der zwe1te Preund:

Aber gestatten Sie...

German:

Nein! Ich gab nlemand das Recht, sich in mein Leben einzumischen. Ich verberge nichts. ${ }^{4}$ Sie beunruhigt anscheinend, daB Palna bei mir lst? Nun, so wissen Sie und hören Sie zu: (er steht auf, erhebt das Glas, und, Indem er den Blick auf Faina heftet, deklamiert er):

Mögen auch Gluck und Ruhm vergangen sein,

Und mein Stern versunken,

Du allein hast dir das Recht nicht genommen,

Mich zu schmähen und zu beunruhigen... 
Mögen die schamlosen Menschen auch lästern

Und dem grausamen Schicksal helfen, -

Sie können die geharnischte Brust nicht durchbohren:

Sie hat als Schutz - den Traum von dir.

Von den îenschen hast allein du mir nicht geschmeichelt,

Von den Frauen bist nur du mir treu geblieben;

Iu hast mich auch in der Trennung nicht vergesser.,

Hast den Lästerungen als einzige kein Gehör geschenkt...

Inmitten von Felstrijmmern und in der wilden Wiiste

Stehe ich oline Furcht und stolz:

Sie können mir das letzte Heiligtum nicht entreißen, -

teine I.iehe werde ich nicht verlieren!

Und der Anblick jener wiiste ist nicht traurig,

Und jene Felstrimmer sind mir lieb,

Und es glänzt aus dem Trümmerhaufen hervor

Ein Brillant, der im Feuer unversehrt bleibt. ${ }^{1)}$

$$
\text { Germen wirft sein Glas fort }{ }^{2} \text { ) }
$$

Paina:

iie schön! 3)

Der zweite Freund:

Gar nicht ibel. Von wem ist denn das Gedichtchen? $\left.{ }^{4}\right)$

German:

Es sind Verse von Byron.

Der dritte Freund:

Ganz recht, es ist ein Jugendwerk von Byron. Erlauben Sie, daß ich Sie iiber seine Entstehung informiere: der groBe Dichter hat diese Zeilen im Jahre 1816 in Italien verfaßt. Das Gedicht heiBt "Stanzen an Augusta" und ist an die Stiefschwester Byrons gerichtet...5)

German:

Ich habe diese Verse nicht deswegen vorgetrager. ${ }^{6}$ )

Taina:

German, sind alle deine Freunde so? 
German steht auf. Die Freunde ebenfalls.

Der zweite Freund:

Sehr bedauerlich, wir haben ein angenehmes tête-à-tête ${ }^{1)}$ gestört...

Der Freund:

Was für eine Ungerechtigkeit! Ich habe Ihnen Immer Gutes gewinscht. Sie zahlen mir das mit einer Satire zuruck! ${ }^{2}$ )

Faina:

German, sie öden mich an. 3)

German:

S1e haben gehört, was sie gesagt hat? Ihr Wort ist Gesetz. Es muB Gesetz sein - für alle. ${ }^{4}$ )

Der Freund:

Sie hätten sich wenigstens an die Regeln der Höflichkeit erinnern können...

German:

Ich weib nicht, ob es höflich ist, sich in ein fremdes Leben einzudrängen? Eine Frau zu verachten, die sie nicht kennen? In einer fremden Seele schalten und walten zu wollen, ordnung in sie bringen zu wollen?

Der dritte Freund:

Wir sind aber doch - deine Freunde...

German:

Verstehen Sie, Sie sind zum Lachen, Sie sind längst - tot. ${ }^{5)}$ Solche wie sie hat man in den alten Romanen ausgepeitscht. ${ }^{6}$ ) Doch brauche ich sie und braucht Sie die Welt nur deshalb, um auf Sie einen neuen, schöpferischen Groll zu richten. ${ }^{7}$

Der zweite Freund:

Wir sind nicht deinetwegen gekommen, sondern wegen deiner unglicklichen, beleidigten Frau, gegen die ru diese Zigeunerin eingetauscht hast...

German:

Gehen Sie mir alle aus den Augen! Alle gleichermaßen! Alle, die liigen und die die Wahrheit sagen, alle alle! Ich bleibe allein, - mit dieser Frau! Und wissen Sie, dab es mir gut geht, dab es mir süb ist, dab ich mich frei fühle - mit meinem stürmischen 
Groll! (Er schreit uber den Tisch, dem weggehenden Freund nach). Wenn du noch mein Freund bist, dann richte meiner helligen, reinen, schönen Frau Helena aus, dab ich nicht mehr zu ihr zurilckkehre, nie mehr! ${ }^{1)}$ - Mein Gott! Mein Gott! Wie soll man erkennen, was Gut und was Böse ist! ${ }^{2}$ )

Er neigt sich uber den Tisch und läBt das Gesicht auf die vor Qual zusammengepreBten Hände sinken.3) Faina schaut ihn mit aufmerksamen Augen an.4)

Faina:
Se1 st1ll! Sel still! Dein Gut und Böse sind nur Worte. 5) 


\section{ABWE ICHUNGEN}

Dieser Teil enthält die Abweichungen von F1 gegenüber F2. ( Vgl. Entstehungsgeschichte S.1).

Die Angaben der Seiten und Zeilen beziehen sich auf den Text des LS in IV,103-167, so ist z.B. 109,8 zu lesen als IV, Seite 109, Zeile 108 .

Die Orthographie von F1 wurde der heutigen angepasst.

1) 103,2 Драматнческая поэма / Драматичесний пролог

2) 103,31 Фанна / Фанна, певица

3) 103,35 Auf die Aufzählung der Personen folgt:

Действие длится оноло года: наше время - от весны до ПредчУвствня новой весны на Снованной снегами земле.

4) 104,0 Vor Первая нартина: Первое действне

5) 104,17f. Statt der Replik Проснись... больного. in F1: Проснись, Герман! Что я расснану тебе, милый: пона ты спал, два человена принесли н нам на носилнах больного монашна.

6) 104,20 Я опять... белое / Я опять уснул сегодня. И во сне все белое.

7) 104,24f. Die Replik Cолние... сны. lautet in F1: Солние на занате и бьет тебе прямо в глаэа: а ты все спишь, все видишь сни. Проснись, Герман, я расснажу тебе He COH, a ABb.

8) 105,1 Герман / Герман (в полусне)

9) 105,5 Просннсь... тоснливо/ Проснись, милый Герман, мне тревонно. Проснись, Герман, мне тоснливо.

10) 105,6 Tн... больного? / Tн говоришь - больного монашна?

11) 105,12f. Der Anfang der Replik lautet: He знаю, зачем принесли н нам... Он совсем больной наной-то, прозрачнй̆, Н ничего не Говорнт...

12) 105,16 Der Anfang der Replik lautet: Hy, что же тут странhого? Больные всегда смотрат грустно... Почему тольно...

13) 105,20 должно случнться... Взгляни... / долнно случнться... Он таной прозрачный, похон на белого ангела н необнчайно смотрнт. ВэглянН...

14) 105,22 с поломанным нрылом / с поломанным нрылом н светлым

15) 105,24 Это Сни продолжаются. / Это белые снн продолжаются.

16) 105,26 Не сны... снов/ Не снн, Герман, не сны, а явь.

17) 105,32 जтост большимн... folgt die Replik

Елена: Ах, наной ты недоверчивнй, Герман. Ти больше веришь своим снам...

Герман: Но ведь ничего...

16) 106,3 но мне. А если / но мне. Тольно поснорвй воэвращайся но мне. А если

19) 106,6 момет он рассназать? / может рассназать мне больной монашен? 
20) 106,14 прннесли больного. Он очень / принеслн больного. Я уложила его в своей номнате - теперь он спит. OH очень

21) $106,26 \mathrm{ff}$. а не на блаженных островах... не смешно. / а не на бланенных островах. Вину людей. Они тан слепн и тупы, что лучше смеяться, нначе прншлось бы планать. ТОЛЬНО ОДНО Мне не смешно.

22) 106,30

23) 106,32 Что? / Что не?

Вн знаете... Я люблю вас, Елена. / Вы знаете... Елена (резно): Нет. - Что?

Aруг: Я люблю вас, Елена.

24) 107,2

25) 107,4

26) 107,11

27) 107 ,

28) 107,17

29) 107,19

30) 107,27

31) 107,31

32) 107,34

33) $108,4 f$.

34) 108,6

35) 108,7

Молчите, молчите. / Ну, молчите, молчите. другом Герману? / другом Герману? Нначе - разве я могла бы прннимать вас у себя тан... спонойно? необынновенные. Я люблю... / необынновенные. Точно дети. Я люблю... / необынновенные. Точно дети. Я люблю...

в вас, Елена, вся тайна / в вас, Елена, в вас вся тайна

Замолчите / Замолчите. Замолчите же. необычайная... Тан это / необычайная... Молчу. Тан это

Герман... сназал? / Герман? Нто вам сназал?

Нто зто вам сназал?

Тан вот оно... / Мой Герман? Тан вот оно...

Statt C больным. / Говорнт С монахом.

Statt A больной... голосом, / A монах говорит много, слабым н прерывистом голосом,

Statt Герман выводит... беренно / Герман выводит монашна из дому и беренно

Nach ступеньну нрыльца. ist F1 umfangreicher.

Es heist dort: ступеньну нрыльца. Монах в грубой холщевой рясне, худой и прозрачный.

Герман: Ему стало лучше, Елена. Пусть посидит на нрнльце и погреется на весеннем солнце. Он рассназал мне тан много...

Занрывает лицо рунами н эадумывается.

36) $108,12 f$. Naeh стоящих на холмах. vor der Replik der Helena Hac тольно тpoe folgen in F1 einige Repliken:... стоящих на холмах.

Eлена: Другие дома эаросли старыми деревьями. А у нас все деревья молодые И тонние. Н холм наш Самый өнсоний. Потому здесь целнй день солнце. Монах: Да, молодые деревья н молодые души. Должно быть эдесь глубоно пустило норни счастье. У вас очень молодо в доме.

Елена: Нет, вот мать Германа, - она ун не молода. Moнax: Зато у неe светлое и строгое личо. - A нет תи еще кого-нибудь в этом доме?

Eлена: Нет, ниного. (Поназнвает на Друга).

Hac только трое, он не нивет с нами.

Mонах: (пытливо смотрит и улыбается):Внну, вину.

उтот больше вашего знает. А что знает, про то ниному не снанет.

Друг: Почему вн же думаете, что я много энаю? Монах (лунаво): Да уж вижу, вижу. Много вы знаете, 
37) 108,15

38) 108,19

39) 108,23

40) 108,26

41) 108,27

42) 108,31

43) 108,32

44) $109,2 f$.

45) 109,6

46) 109,8

47) 109,12

48) 109,12

49) 109,16

50) 109,16

51) 109,24

52) 109,29

\section{3) $109,29 f$.}

54) $110,2 \mathrm{ff}$.

оттого от смеху у вас все лицо дрожит. А ито же вы сами-то будете?

Герман: Это мой друг, братец.

Монах: Друг твой? Ну, ну, дело ваше. Тан больше

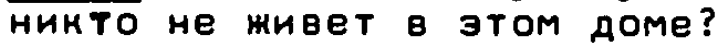

Герман... мать. / Герман, я - жена его, и мать!

над ним большне / над ним нан бы большне

... Н подумал, что эдесь - Фанна / ... Н подумал, не здесь ли жнвет Фанна.

Елена / Елена (задумчиво)

Это... иMа? / Я внделд это имп - в святLах.

Это верно - Монашесное ИMа?

Ниногда. I Ниногда не слыхала.

Vor der nächsten Replik folgt in F1:

Монах: (Аругу, лунаво): Может быть и вы ничего не слыхали о прекрасной Фанне?

Aруг: Нет. Я слышал только о пренрасной Елене. Die Replik Мало же... Фанну. lautet in F1:

Мало же вы энаете. Должно быть, одиноно живете. Должно бЫть, дом вас подобен нелье. Весь мир энает Фанну. Вся эемля поклоняется пренрасной Фанне. има. / има. - Я энаю тольно светлое има: Елена. Die Replik $\mathrm{H}$ TH... O Фанне? lautet in F1:

Ведь и ты, юноша Герман, претде не слыхал о Фанне, сонровнще мира, о Фанне, которая по воле своей ннзвергает царей и героев Н Обращает вспать норабли? Statt Cноро услышишь. in F1: Сноро уэнаешь Фанну. Vor Солнце садится... lautet F1: Друг: Должно быть, вы нарочно путаете имена. Вы рассназываете сназну о Аревней царице. Троянсной Елене, нэ-эа ноторой, действительно, боролись цари и герои н обращались вспять норабли. Рассназывайте, здесь любят слушать сназки. Но зачем тан лунаво путать имена?

Монах (грозит ему тонним пальцем): По вашему сназна, а по моему - быль. Была Елена, а теперь Фанна. - Ну, солнце садится...

Matb и друг уводат / Мать и друг бережно Уводат Nach Zeile 16 folgt in F1:

Елена: Солнце село.

Ночью будут... нан весной? / Ночью будут лужи н черное небо. Н совсем невероятные, огромные эвезды, энаешь, нан весной?

Nach cлушал. folgt in F1:

Eлена: Что mе он сназал тебе?

Герман: Ногда я вошел в твою номнату, он спал. Я натнулся над ним. Мне стало любопнтно - y hero Совсем восновов Лнцо И таная СТрашная Тонкая носточна на средине носа. Нан у мертвого.

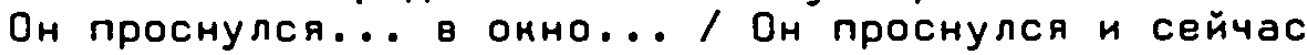
Же нежно ОбняЛ Мена. И ГрУстно ПОГлядеЛ Мне

глаза. Н поназал в онно...

cбeraet c холмов... B любвn нет страха. I

сбегаet с холмов и ито ветер - весенний.

Елена: Герман! Герман!

Герман: Я услихал, что мать в соседней номнате тихо читает. Прнслушайса; она говорила: "В любви 


$\begin{array}{ll}\text { 55) } & 110,6 \\ \text { 56) } & 110,10 \\ \text { 57) } & 110,13 \\ \text { 58) } & 110,17 \\ \text { 59) } & 110,21 \\ \text { 60) } & 110,22 \\ & \\ 61) & 110,24\end{array}$

62) 110,26

63) $110,27 f$.

64) 110,30

65) 110,32

66) 110,34

67) 110,35

68) 111,2

69) 111,3

70) 111,10

71) 111,18

72) 111,20

73) 111,23

74) 111,27

75) 111,29

76) 111,32 нет страха.

Милый! / Герман! Милый!

Н еще - будто цветами, / Н еще будто наними-то цветами,

вдали... Там / вдали... Н там -

Милый... во сне! / Милый! Мильй! Ведь ты не видел это во сне!

Oн рассказывал / Брат рассказывал

А там... началась... / A там - снега растопились, весна началась...

Die Replik A слышу... больно... lautet in F1:

Сердие мое слышит тебя, Герман... Но больно... НО бОЛЬнО...

проснись./ проснись, Герман.

Мне надо... Елена. / Мне надо н людям, Елена.

Ты сльшишь мою душу. Брат велел идтн. Но я вернусь сноро. Очень скоро, Елена.

Слышу тебя. / Слышу тебя, Герман...

Герман (становится / Герман (один, становится

Тан не могу больше. / Тан я не могу большв.

Проститься С ним / Проститься с родиной

rocnоди / Господи (so auch weiterhin)

нe npowy тебя / he npowy a Teбa

Statt Отнуда вы знаете? / Да еду.

этот монаX. / этот ваш монаX.

Почему? / Почему не?

над вами. / над всеми вами...

Вы знаете... / Ну, да, конечно. Вы знаете...

репутацией. / репутацией. Детище холодного городского разврата и фабричной гнили.

... мой друг. Ногда предстонт... / мой друг. Н вообще - друэья, ноторне всегда высказывают самые противоположные мнения и желают, чтобы им верили. Сегодня говорите вы, а завтра придет другой и снажет ман раз наоборот. Ногда предстонт...

77) $112,8 \mathrm{ff.} \mathrm{Особенно} \mathrm{приятно...} \mathrm{НУ,} \mathrm{я} \mathrm{внжу.../} \mathrm{Особенно} \mathrm{Приятно}$ на Меня иноТда НаХодИТ необъяснимая элость именно на друзей. Сам не знаю, почему. Нзвините. Дeуг: Накой вы задира. Нзвинаю охотно. Bсе это пренрасно. Монет быть, от злости вы станете менее ребячливым...

Герман: Перестаньте, мильй друг! Я давно уже не péенон.

Деуг: Посмотрим. Ребенном, положим, быть хорошо, а вот взрослым младенцем - гораздо хуне. - Ну, ค вину...

78) 112,11

дать время / оставить время

79) $112,11 \mathrm{ff}$. До свиданья. (Уходнт.) Герман задумчиво бродит по саду. / До свиданья. Да, не советую вам, все-тани, слишном вернть этому монаху. - Мы еще встретимся С вами - там?

Герман: (рассеянно): Да, да, до свиданья. Друг уходит. Герман задумчнво бродит по саду.

80) 112,14

81) 112,18 и легная. I и легная. Она останавливается на крыльия Правда... человен?/Наной Он, все-тани, любопытный человен. Правда, Елена? 
Nach Eлёня-молчит. folgen in F1 vor der nächsten Replik drei Repliken:

Герман (смотрит вдаль): Что это там. Елена? Неужели - еще друэья? Прослышали, что я уезжаю, Н полэут сюда Своей төрананьей тропой?

Елена: Нет, милый. Это детн - несут огни - тихоньно, чтобы не погасли. Н - освященные вербы. Ведь сегодня - Вербная Суббота.

Герман: Ах, энаю. Энаю. Оттого тан светло на душе. Таная вланная весна.

83) $112,25 f$. если можешь / всли тольно можешь

84) 112,27f. Мать умрет. (Ломает рунн.) / Мать умрет. Цветы завянут. (Ломавт руни.)

85) 112,33 . У тебя... цветн.../ у тебя - нрасивне нниги. И тоже

86) 113,2 - зеленая лампада. $Н$ в ниоте - померанцевые цветн... весна настала. / весна настала. С тобою останется mö сердце.

87) 113,4

88) 113,6

Но больно... / НО больно... но тревожно...

новые вести. / новые вести. Н весну - на острие Hопья.

89) 113,8

90) 113,9

91) 113,11

Помнишь, ты сам... / А лилия, Герман? (Опуснается оноло цветннна.) Помнишь, ты сам...

лилию / ее

вонруг дерн. Веселье... / вонруг дерн. А помнишь тн, что било Потом?

Герман: Ну... помні.

Елена: Веселье...

$92)$ 113,14f. Лилня тебе... что пронсходнт там? / Лилия тебе дороже моей душн. Точно эемля дороже неба. Посмотрн наверх. Разве не понимавшь тн, что там - таная же страсть?

93) 113,17ff. Nach Без тебя - не пойму. vor Слышишь, нан поет ветер? stehen in Fq sechs Repliken:

Герман: Помни: я вернусь. Тн вндншь, скольно туч на занате? Цельй Город. Вот стольно же у меня дум. Если я спрячусь от ветра, тучн наполэут друг на Aруга, Понроют всю мою душу и весь наш дом. Тогда нечем будет дышать. Чтобн разогнать тучн дум, нужен ветер событий.

Eлена: Разве наша любовь - не собнтие?

ерман: Молчн, Елена! Ты не поннмаешь мужсной души! Это женственной душе не надо ветра. Ты, Елена, не знавшь Страстной Мужской воли, царственной Мысли. Bо все вена пуснались в путь цари н герон, потому

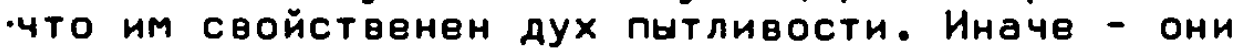
погнбли бЫ.

Eлена: Ти герой, Герман.

Герман: Я верю этому, милая. Мой царственннй дух требует трех жизней, Елена. Вечно влюбленний дух. Eлена: A я - разве не царнца? Влюбленная царнца твоя. Н TH, оставаясь Со мною, будешь царем.

Герман: Нет, Еленв. Смотри: полэут лиловые, багрянне тучн. Еще горят золотые нрая, а уж в середнне трепещут зарнице. Всіо ночь будут ндтн тУчн. Надо, чтобы нХ прогнал ветер. Н будет - яснов небо. Слышншь. нан... 
94) 113,20f. песня самой судьбы... / Песня самой Суаьбы... (so auch weiterhin).

95) 113,23 Zwischen судьбы. und Tu cлыwana... steht in F1: Horда будет ясное небо, ногда отэвучит Песня, тогда тольно человен Станет героем!

Елена: За тучами идут новые тучн. Не дождаться ясного неба...

Герман: Будет ясное небо!

Eлена: Hогда?.. ногда?.. Ты Говорншь Тан вдохновенHO... R GONCb...

96) 113,31

97) 114,1

98) 114,2

99) $114,4 \mathrm{ff}$.

100) 114,9

101) 114,11

102) 114.13

103) 114,21

104) 114,23

105) 114,26

106) 114,27

107) $115,2 f$.

108) $115,8 f$.

109) $115,10 f$.
Герман: Ти слышала...

Нет... возлюбленного! / Нет! Нет! Нет! Я энаю сердие воэлюбленного!

Zwischen मेдй, мой Царственный! und Идн туда... steht in F1: R долнна энать, нуда тө пойдешь?

Герман: Вон той дорогой. В мир. Н самому сердиу Россин.

Eлена: Тан. - Ндн туда...

судьбы! / Судьбы. Я энаю: ты вернешься героем. Ты часто снился мне в одендах вонна. Тан буду вспомннать о тебе. мой неланный. Нан сладно. Я останусь и буду Прясть мою вечную прану. Я СотнУ ала тебя белую тнань. Брачные н торнественные оденды.

Nach nopore. vor Боже мой! steht in F1:

Герман: Хорошо. Тан - хорошо. Я буду в длинной белой оденде. Таной прямой И строгий. $И$ в венне. Мать (тревожно): Зангите свет. Я ничего не внну. Тольно слышу, что Сын мой говорит страшныв слова. Боне мой, зачем вы говорите о страшном, ногда мой Мальчнн УХоднт?

Eлена: я не боюсь. Dн вернется.

Герман: Это не страшно, мама. Я мечтаю о пренрасном н царственном будущем.

Мать: Мальчик мой, ты начнтался глупых сказон?

Боне мой!...

Eлена / Eлена (выносит из дому фонарь)!

Tw вернешься / Ты вернешься в венке.

Прощай, Елена. Прощай, мама. / Прощай, Елена.

в венке. Прощай, мама.

на плечн Германа. / на плечи Германа, вся содрогаясь, нан верная, нарная и беснонечно долго танвшаคСя СТИХия.

Сноро. Сноро. / Сноро. Сноро. В өвнне. С твонм огнем в сердце.

Eледное лицо монаха. / Страшно бледное и печальное лицо монаха

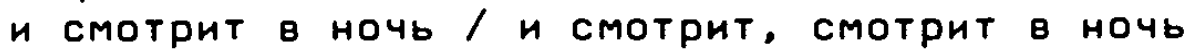
Тб нв место... и тишина. / То не место - оноло белого дома Германа. Прошло неснолько часов. Настала глубокая ночь и глубоная тишина. оольшими грустными глазамн. Вся нартина... / большими грустными глазами и поначивается. Но вся нартина...

Nach отошли в npownoe vor der folgenden Replik stehen in F1 eine kurze Ergänzung der Regieanweisung und drei Repliken: C внду Eлена спонойна. 
Монах говорнт С ней голосом слабым н усталым.

Монах: Слушай меня, Елена, печальная Елена. Тя приПТтИла меня. Ун недолго осталось мне нить, Н весна томнт меня. Я расскану тебе грустную сказну. Елена: Я слушаю тебя,брат.

Монах: Жил ногдо-то на свете честннй вонн, таной не пренрасный, нан твой Герман, Елена. Когда пал Он, Сранаясь, на пустынной равнине, белая дева, подобная тебе, Елена, обвила его рунамн нежными н Подняла Над землею. Тан н Стал вонн ангелом: ему дано было видеть все, что совершается на эемле, во всех странах и во всех временах. С теX пор прошли вена, Елена, но для него они были, - нан однн МИГ: ИбО ВНДЕЛ ОН ВСЕ ОДНО: ПОКОЛЕНИЯ СМЕНЯЛН ПОКОления, Н народы побеждали народы, шались Н внов вознинали Нэ пепла. Н долго хотел

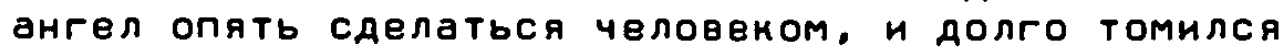
он в небе и жадно смотрел на землю, пона не прнмельналась ему нружащаяся земля. Привычно смотрел Он, Кан рондаются н умирают люди, сгорая $и$ тлея. Больше не хотел ангел стать человеном. - Слышишь ты меня, Eлена?

110) 115,13f. Nach в пути vor der nächsten Replik folgen in F1 noch zwei Repliken:

Mонах: Слушай дальше. - Наждую ночь очерчивал он предназначенный ему круг над миром, Н звездочеты мерили пути его, а влюбленные смотрели на его восХод и занат. Они томились его зеленым мерцанием АУМалН, ЧТО ЗеМнОю, СТРАСТнОю ЛюбОВью ГОРНТ ОН ИМ, но, разлюбив, проклинали его. Он не по преннему озарял ХолодныМ Н зеленЫМ Мерцанием новЫе нлятвЫ и новне измены. Тан летели вена, Елена, И Снился

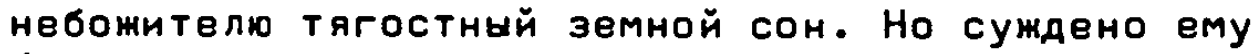
было проснуться н лицом н лицу, а не в зерцале гадания, увндеть землю. И мерцала в летящих венах, Кан зарнича в тучах, последняя ангельская ночь, таная не, Кан сегодня, черная ночь. Верно, много небонителей слушает с черного неба буйный ветер земли. - Ты слышишь, Елена?

111) 115,23 Елена: Рассказывай, брат. Мой Герман теперь уже в мире

112) 116,2 бУАто ждала ного-то. / бУдто мдала мого-то с верХОвьев РенН.

губы... Унрой меня, Елена. / губы... не просили, а прнказывали, н будто смотрели черные глаза прямо мне в личо...

Елена: Что ты говорншь, брат? Тебе - в лицо? Ты вздрогнул...

Монах: Унрой меня, Елена. Сназна стала былью. Ты бредишь, братец. / Ты бредншь, братец. Кто же ты, ангел или монах? Чего не спросишь в таную ночь...

114) 116,7 Слушай, слушай дальше. / Что ангел, что монах, Елена, - все равно не человен... Слушай, слушай дальше .

115) 116,9 ползали монахн н белой ограде, / ползали монахн на нарачнах н белой ограде, 
116) 116,13

117) $116,13 f$.

118) 116,16

119) 116,33

120) 117,2

121) 117,6

122) $1.17,8$

123) 117,12

124) $117,13 f$.

125),117,15

126) 117,16

127) 117,16

128) 117,19

129) 117,20

130) 117,24

131) 117,25

132) $177,26 \mathrm{ff}$.

Ты расскаэнваешь / Ты говорил

Говорнть, не надо... / Говорить, братец, не надо... слушай. Вечером... / слушай. Ведь я пою, нан соловей по весне. - Вечером...

в срубах. Нз рева псалмов... / в срубах, точно седая борода старина. И буря ночная раздувала полымя, раздувала дикие, точно пьяные голоса. Из рева псалмов...

поле. Отнрыв / поле. Н отнрыв

и стал я хнреть... / и стал я болеть и хнреть... Не рассназывай больше. Нутно... / Не рассназывай больше. Не рассназнвай. Жутно. Светает. Нанется... душа Германа Говорит со мной.

Внизу появляется фонарнн. / Внизу появляется фонарнн: это Герман ощупью ищет дорогу.

Герман (ощупью... дорогу) / Герман

Там днвно и тревожно. / Там дивно, тревожно и mУтно.

с дороги. Здесь... / с дороги. Сердие бьетсғ. точно перед подвигом. Здесь...

Ну, сердце, / Ну же, Тн, сердие,

Мерещится ли ему, тольно слабо мерцает / H несбыточное Ли СӦлось, или тольно мерещнтся ему, но слабо мерцает

еле зримый образ: очертания / еле зримый образ: обрисовнваются очертания

огромные печальные глаза. / огромные и беснонечно печальные глаза.

дрогнули руни, - фонарь / дрогнули руни, - но фонарь Nach Германа гаснет. vor der folgenden Replik stehen in F1 zwei Repliken: Германа гаснет.

Герман (отступает): Здесь ходят цыганкн. Ты - цыганна?

Bидение (невнатно, нан ветер): Нет.

Герман: Нто не ти? Нан тебя зовут? Нивая? Мертвая?

133) $117,29 f$ Видение (невнятно, Нан ветер) / Видение

134) 117,33

135) 118,6

Ндешь ного-нибудь? / Тн ндешь кого-ннбудь?

Погас фонарь. / Погас фонарь Елены.

136) $118,9 f$.

Nach OH идет omymbl. vor der folgenden Replik steht in F1 die Replik:

Герман: Фонарь погас. Тольно сердце осталось?

Этот бледннй свет - От сердца? Нли чуной сөет.

Ну же, сердие, указывай путь! До сих пор я өерил Teбe.

137) 118,14 Это бал тольно сон. / Это бал тольно сон. Теперь снорее, снорее, в путь!

138) 118,17

139) $118,20 f$.

Точно сейчас... / Задумалась я. Точно сейчас...

Die Regieanweisung Монах ничего... смотрит в онно.

lautet in F1: Тан тревожно спрашнвает Елена. Но ничего не отвечает монах. По прежнему, он сидит перед нею, поначивается и печально смотрит в онно. Третья нартина / Второе действне

140) 119,1

141) 119,3

142) 119,4 внставни. / выставни в Россин.

- гигантсний эал. Нруглье стенла... / - гигантсний эал возведенный нз тончайших металлических прутьев. उдесь все Громадно. 
143) 119,6

144) 119,7

145) $119,8 f$.

146) 119,18

147) 119,20

148) 119,21

149) $119,22 f$.

150) 120,2

151) $120,3 f$.

Елентричесний свет из шаров... / Елентрнчесний свет, нсходящнй нз шаров...

ослепнтельными / слепительными ist vermutlich ein Druckfehler.

стальные тела... чудовищных зверей. / стальные тела машин, напоминающие формами наких-то чудовнщных эверей, жадно вбирают в себя н вновь отбрасывают яркий Свет.

свонх простертых н сводам... / Свонх гигантсних, простертих н сводам...

Der Satz Под сенью... эстрада. lautet in F1:

Там же, в глубине, под сенью этих нрыльев, возносится высоная эстрада, на ноторую ведет ряд ступеней. високо под куполом, / высоно, под самым нуполом Еще выше / $\mathrm{H}$ еще выше Фанна. Песня Судьбы. / Фанна. И немного мельче: Песна СуAьб̈.

Der Schlub der Regieanweisung Tonna... c Apyrom. lautet in F1: Минута поднятня занавеса - минута отнрытия выставни. Толпа начинает ГУстою волною проливаться в турникет. Среди других проходят и Герман с Другом. Газетчнни нрнчат с помостов, образуя музннальные гамму:

152) 120,5f. Газетчини (музынальная гамма) / Газетчнни

153) $120,14 f$. Nach Zeile 14 var Zeile 15 stehen in F1 die beiden Zeilen:

Фанна, назнваемая иначе - Эолото!

Фанна, называемая нначе - Пышность!

154) 120,17 его ноэдрн раздуваются) / его ноздри раздуваются ман у молодого скануна, выпущенного на свободу.)

155) 120,20

156) 120,22

157) 120,27 найти лучшего друга... / найти своего пучшего друга...

Наной ветер... / И наной ветер...

Всюду ветер. / Всюду ветер. Тишнны нет нигде.

158) $120,29 f$.

Всюду - ветер! И всюду - таная музына! / Нигде нет тишины! $И$ всюду - таная слонная, таная дрязнящая музына!.

159) 120,32

Nach nестрое двнжение! sagt German in F1 zusätzlich: Я чувствую в себе что-то звернное: ноздри раздуваютСя от любопытства. Наной я здоровнй, Сильный и молодой!

160) 120,33

нан человен, не знающй, нан применить избытон... / нан человен, Увндавший новое, восхищенный им и не знающнй, Нан Применить н немУ избытон...

161) 120,36

162) 121,13

Я вам эавидую. / Да, я вам завндую.

Там девушна была... /

Там девушна была заточена,

А мы нивем...

163) 121,19

In F1 folgt danach noch eine Zeile:... лиризмy,

В котором тает мысль, нан мягний восн...

164) 122,14f. Statt der beiden Zeilen Я трезвым... помазать! heibt es in F1:

Я трезвим, трезвим быть хочу!

Apyr: Нан мудро!

Герман - озираясь:

Вы обвщали поназать мне пир

Нультуры! Небывалый, пышный мир! 
ногами на эстраду. / ногами на эстраду. Ногда речь вго прерывают возгласами, Он строго хмурится И Сдвигает Очни на Кончин носа.

166) 122,30

167) 123,10

168) 124,7

169) 124,24

170) 124,27

171) 124,33

172) 125,7

173) $125,15 f$.

174) 125,17

175) 125,28

176) 126,3

177) 126,6

178) 126,8

179) 126,21

180) 126,24

181) 127,3

182) 127,4

183) 127,7

184) 127,14

185) 127,26

186) 129,14

187) 129,32

188) 129,40

189) $130,3 f f$.
Не слышно! / Что? Не слышно.

Милостивые государи. / Прошу не прерывать.

Милостивне государи.

силой. Это последнее... / силой. Науне принадленит честь отнрытия сенрета управления им.

Это последнее...

медленно вращаться. Оглушительные... / медленно вращаться. Толпа почтительно дефилирует.

Оглушительные...

Нлоун / Нлоун (ломанным языном. Перед ним стоит печальный человен в черном Фраке)

Дает печальному человену в черном Фране звонную оплеуху. / Дает печальному человену звонкую onлeyxy.

Фаина - Вот зачем... / Фанна? Вот зачем...

Die Replik Наная-то... толnу... lautet in F1:

По моему - наскадная певица,

Сумевшая привлечь н себе толпу.

По вашему, - выходит блеск и слава...

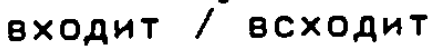

Я взываю... / В атмосфере свободной науни, я

взываю...

Молчание. / Шелестящее молчание.

Nach der Replik... He noenewb! folgt in F1 eine zusätzliche Replik. Es heisst in F1:

.... He noenewb?

Оратор (гордо, уходя): Мое дело сделано. Я -

народный трибун.

Что меня удернало? / Что меня удернало?..

Фанна... Что меня удержало?

появится на эстраде. / появится там, на эстраде. Здесь прошла! / Здесь прошла! Тольно... платье... тольно... след! .. (Падает).

Галантный донтор / Галантный донтор (Утешая)

ниснольно: без следа... / ниснольно: Нран - и без следа...

Нрини: / Отдаленные нрики:

н эстраде. / н эстраде И останавливается.

вздрагивает бич. / вздрагивает бич. Нончив песню,

Фанна насмешливо взмахивавт бичем и умолнавт, улыбаясь чему-то - мимо толпы.

говорит все громче. / говорит все громче. Ero начинают слушать.

(Вснанивает на ниннюю ступень.) / (Подходит н эстраде).

в eе пальцах. / в eе пальцах. Tело еe трепещет Под узним платьем, Глубоний Голос звучит угірозой

Die Regieanweisung Герман вснанивает на зстраду... В зале стало тихо. ist in F1 ausführlicher, und es steht dort dazwischen noch eine Replik: Гибним и стремительным прынном Герман вснанивает на эстраду.

Фанна: $X-x a$ !

Ивзвившийся бич сухим плесном бьет его по личу: 
раз, - оставляя на щеке нрасную полосу. Каним-то случайным двинением, согнувшись, Герман падает на нолени: Словно впервые увндал Он Фанну: Н Смотрнт на нее С изумлением Н обонающей ненавистью. В зале очень тиХО. Счет мгновениям ведет тольно ничем не победимый городской шум.

190) 130,8 печален. / печален, нан в ту черную ночь, под отноcом холма. A в голосе, все еще воннствующем, звучит презрительная ласна.

191) 130,14 пронсходящим. / пронсходящим. Нз толпи поднимается никем не замеченный Друг Германа. Он говорит со свойственной ему необычайной серьезностью, за ноторой скрыта насмешна.

$192)$ 130,15f. Друг (в толпе, со свойственной ему серезностью) / Дpyr

193) 130,18 Tолпа уже отвлечена слухом о назни. / Но толпа уже отвлечена. Разносится слух о назни. Тольно машина все еще поднимает и опускает нрылья над эстрадой: бУАтО ГОтОвИтСя лететь.

194) 131-141 Dieses Bild fehlt in F1.

195) 142,1 Пятая мартина / Третье действие

196) 142,2 озарен осенней луной. / озарен спонойной осенней луной.

197) 142,1f. На втором плане - каное-то... / На втором плане,

198) 142,2 здание. Вонруг...; здание, онруненное лесами. Вонруг...

199) 142,7f. За углом здания отнрывается просторная даль. / Это место нстоптано людьми; но эа левым углом здания и Под относ - взору отнрывается просторная даль.

200) 142,22 доносится пение / доносится призрачное пение

201) 142,27 Через минуту, на фоне... / Через минуту, за углом эдания, на Фоне...

202) 142,28 в даль. / вдаль.

203) 142,32 Фанна возбундена чем-то, / Фанна сходит ниже. Она возбундена чем-то,

204) 143,2

205) 143,11

в белой руне. / в ленивой белой руне.

Сплю на лебяньем пуху - забываю все на свете! /

Ногда я сплю на лебяньем пуху, я забываю все на cвete!

206) 143,12

207) 143,12

Сначет тройна / Horда сначет тройна пона / Потому чTO

208) 143,13

209) 143,16

A проснешься / A ногда пооснешься

Bu не можете сделать шагу, чтобы не сесть! /

Вы не монете сделать ни одного шагу, чтобы не сесть! Ну, зачем вы сидите тут, на каном-то пустыре, ногда я хочу бенать, бежать, бенать...

210) 143,21 Вы нсполняете мон прихоти / Вы исполняете все мон прнхоти

211) 143,22 что еще / этого не

212) 143,22 Разве/ Наной же

213) 143,23f. Посмотрите, нанова я из себя? Со мной... । Посмотрите, нанова я нз себя? Разве я ненрасива? Да со мной...

214) 143,33 За таную любовь - бьют! Смотрите... / За таную любовь - бьют! (Ударяет его сломанным стеблем по 
215) 143,34

216) 143,34

217) 143,35

218) $144,4 f$.

219) 144,5

220) 144,6

221) 144,6

222) 144,7

223) $144,7 f$.

224) $144,11 f$.

225) 144,13

226) 144,13

227) $144,14 f$.

228) 144,16

плечу). 8ы мена любите? Я не виновата! Смотрите...

Гарью пахнет! / $\mathrm{H}$ гарью пахнет.

пахнет Гарью! / пахнет Гарью. - Если бы тольно

пришел сейчас милый мой, милый мой, ного я всю

низнь ндала...

нолдуя / точно нолдует

(Говорит, обращаясь в пространство.) / (Говорит в Пространство, бУдто обращаясь н ному-то).

Статный, русый, днвные серые очи! / Ты - статный, ты - светлый, ты - русый, днвные твон серые очи. взглани. / взглани на Меня.

Долго mдала теба, все очн... / Долго ждала тебя, все очн...

зарей / зарею алой

вся Синими... / вся я синими...

(не обращая на него внимания) / (не обращая внимания Жених мой / Нених мой назяаный

суженый / суженшй мой

они твоей бури ндут! / они, нан моря, твоей бурн mдут! Dabei ist mopa als nom.plur. zu werten.

Разомнни ТЫ мон белые рученьни, $/$ Разомнни ты мон бедные, белые рученьни,

229) 144,17ff.(Простирает руни над обрывом.) / (Простирает руни над обрывом, ному-то налуясь, нан тревонная птица).

230) $144,20 \mathrm{ff.A} \mathrm{Tы} \mathrm{хоронишь...} \mathrm{не} \mathrm{даешь...} \mathrm{говоришь...} \mathrm{стелешь...}$ сторонишь. / А он, т甘 знаешь, хоронит... не дает... говорнт... стелет... сторонит. Тольно - не хочУ я, He xочу a cחatb!

231) 144,23 светлый, / светлий мой,

232) 144,23

233) 144,24

234) 144,25

235) 144,26

236) 144,27

солнца нрасного / солнца моего нрасного

развей туманы, / развей туманы мон,

Видно... / Теперь видно...

нрасоты; / нрасоты, личо, углубившееся в себя;

волнения. / волнения. $Н$, нося ГУбами, Он ГОворит АРОнащим ОТ волнения ГОЛОсом.

237) 144,29f. Nach Bu гениальный... folgt in F1 als Regieanweisung: Файна простерла руни над обрывом, эамерла $и$ бормочет в наном-то вещем сне. Es fehlt dann (npoстерла.... сне) тебе отдала, / отдала тебе,

239) 145,1

Ты обманул меня. Hогда пою / Ты обманул меня. - Я видела днвные сны: нан весна была, да ветер планал, да , молодица, на берегу ждала. И плывет но мне на Льдине таной Статный и Светлый... Тан и горит весь, тан н сияет... будто Сам Христос... Плывет и улыбается мне, и уплывает, пропадает за далями, за берез ками, за серым небом... Мало тебе этого? - Horда חою

240) 145,4 мною? Руной махну - золотом осыплют... / мною, что руной махну - һ золотом осыплют...

241) 145,5f. 4то берегу себя, / что берегу я себя,

242) 145,7

смотрю? Нли не... / смотрю, не прндешь ли ты, Статный мой нених? Или не...

243) 145,8

244) 145,9

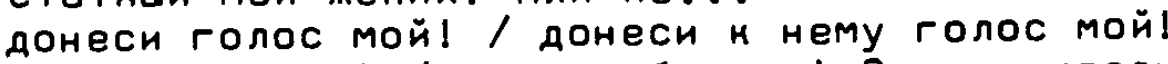
весть обо мне! / весть обо мне! Солнце нрасное, взойди! 
245) 145,10

246) 145,12

247) 145,14

248) 145,16

249) 145,18

(С волнением) / (С волнением подходит н Файне) надо / пора

Старый, / Тот старый,

Усльшь। / Услышь меня!

замирает. / замирает. Проходит миг щестоной

тишнны.

250) $145,22 f$. Я жизнь мою проспалаl / Я жизнь мою, жизнь мою проспала!

251) 145,23

252) 145,27

не HaдO! / не нунно!

253) 145,28ff.Ты придешь... алую лентуl / Слушай. Ты придешь.

254) 145,33 в парн. За ней - тяжно идет.../ в парн. - За ней

255) 145,34f. Zwischen Спутнин. und Tишина. steht in F1 die Replik:

Голос Файны: Дай тишины! Дай тишины!

256) 145,37 шелестя все смелей / шелестя смелей

257) 145,40 встал нто-то, Сдержнвая... / встал Нто-то Властный И СПОНОЙНО ПОДНАЛ СМЫЧОН, СДЕРжНвая...

258) 146,1f. Подымаясь на относе... на то место, где... / ПроходКт минУта $K$, - ПодЫМаясь СнКэу, легкКМ Прынном вснаннвает на то место относа, Где...

259) 146,2

260) 146,2

261) 146,9

262) 146,11

263) 146,17

Факна, Герман. / Фанна, - Герман.

Срам / Занивакощий срам

Утро! Утро! / Утро! Утро! Утро!

264) $146,17 f$.

Таснаете / Вы таснаете

Наная алая лента / Наная широная алая лента

265) 146,20

свежими духами! / свежими духами. Вот таними лентами женщины вершат судьбы людей и народов.

266) 146,21

267) 146,25

268) 146,26 Должно бнть, маная-ннбудь... / Ви правы, должно быть наная-ннбУдь...

оставила вам ленту. / оставила вам ленту, чтобы вы могли ее разыснать. -

Вы И над зтим... / СТранно, что вн и над этим... Не личо, а все сердце... / Не лицо, а сердче,

269) 146,27 вce cepaue...

270) $146,27 f$. Сердие / H cердие

271) 146,28

272) 146,30 нрови.

тогда волнующую / тогда наную-то волнующую

все торнественней. По ночам... / все торжественней. Будто я отмечен не бичем ненщины, а жезлом Судьбы.

По ночам...

273) 146,34

осеннюю Гарь! / осеннюю Гарь, К рябины Подают мне

274) 146,36

275) $146,36 f$.

276) 146,37 нрасными рунавами таннСтвенный УСловный энан!

277) $147,1 \mathrm{f}$. нуда направить ее силу! / нуда направить силу водопिад!

снольно дела, / снольно там дела, H опять/ Töá опять

278) 147,4

279) 147,13

Наная страшная радость, наное тянелое бремя / Если бы вы энали, наная страшная радость и наное тянелое бремя

280) 147,14

налетает ветер / Впять налетает ветер AX, это... / AX, Вот: это...

8 бурьяне... / 8 бурьяне; но 8ы - все тот не, предатель и насмешнин. - 
281) 147,16

282) 147,16

283) 147,20

песню судьбы! / Песню Судьбы Vgl. 94)

284) 147,21

смотреть / сMотрел

He ncnyraete / Teneps he hспугаeте

Я бенал от неe! Я беmал от неe поцелуаl / Разве вы hе энаете, что я бемал от нее, ногда она ударила Мена бИчеM?

285) 147,26 нраснвне глаза? / нраснвые глаза? Нраснвые глаза?

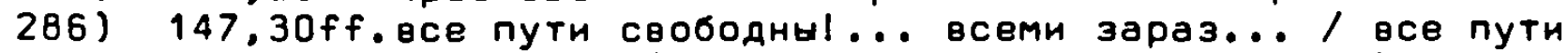
СвободнН! (ТВердО ГОворНТ, СМОТРА вдаль). ПОСМотрнте, там семафор әеленый. Это значнт: путь свободен; Поеэд неминуемо Пойдет этим путем... Тан и MHE ОтнDUTH BCE ПVTH!

Aруг: $И$ вн поедете, наперекор всему. Хота бы вам прншлось...

287) 148,6 ндти. Может быть... / ндти этим путем. Да, тот, нто усльшал Песні СУдьбы, долмен ндтн через все. Монет быть...

288) 148,7 Ведь н весна / Ведь сама весна

289) 148,9

290) 148,10 THXoro/ Genoro

291) 148,12

Счастья! / Счастья, От этой Прекрасной тншнны!

не энаю... / не энаю... Но твердо стою на маном-то Пути... нуда? нуда?...

292) 148,14

тан / слишном

293) 148,19

Мена поэвалветер, он спел... / Меня поэвал Нто-то, ветер спел...

294) 148,27 места, вы нз ноти / места, геннальннчавте, из ноти

295) $148,29 \mathrm{f}$. (с воэрастающей страстью) / (выпрямляясь, говорит

с возрастающей страстью)

296) 148,33 илн прозрення! / Нлн беззанатного Аня!

297) 148,35f. жн8у мунами моей роднны. Помню страшный день Нулиновсной бнтвы. - Ннязь встал... / живу огнем и мунами моей родины. Н вся ее вещая, страдальчесная Старнна Со Мной, Точно Сам а перемнл высоние народные Муни. ЭТи воспоминания посещали Меня 8 Детстве, Н ОТРОНОМ ТРевОЖИлИ МенА: И ТеПерЬ -

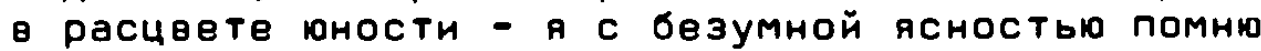

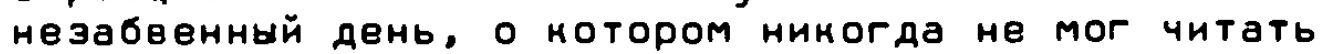
без өолнения: Страшннй день НУлиновской битвы. Вы помннте: еще нанануне ннязь встал...

298) 149,2f. Потом поползла зловещая ночь, / А потом поползла THХая, эловещая ночь,

299) 149,8 настало/ н настало

300) 149,9

301) 149,11

тан не, / танме,

302) 149,18f.

Horá/ $\mathrm{H}$ morá

149,18f. раноl... Но вот оно - утро! Опять - торжественная музнна / рано, раноІ... Но я не однн, я - заодно С НеОбъатнОЙ равнНнОЙ: НСТОСКовалаСь ОНа, захлебнулась Она осеннимн разлнвамн, ждет н нличет богат甘ря лебяньим Голосом, Кан невеста мениха! Вот Оно - Утро! Н опять - торнественная муэына

303) 149,22 क mду всем сердцем того/ क щау всем окровавленным сердцем того

304) 149,22f. нто прндет н сканет / нто прндет, нанонец, и скамет мне твердо

305) 149,24 В глубине парна мелькает / 8 глубнне парна уже мельнает

306) 149,27f. In F1 steht zusätzlich eine Replik. 
солнцу. Фанна идет. / солнцу.

Герман: Лебедь нричит!

Фанна идет вдали.

$307)$ 149,26f. точно ее захлестнуло смертной тосной /

308) 149,29

точно эахлестнуло ее смертной тосной

309) 149,31

310) 149,31

311) 149,32

ее несет певучий / Н несет ее этот певучий

Лебедь кричит и бьет / Лебедь нричит победно и бьет Наполняя воздух / Нзнемогая, наполняя воздух

звоном Голоса, вторнт / Звоном голоса, будто песно о воле поет, вторит

312) 149,33

313) 149,35

Фанна / Фанна (издали)

314) 149,36

Ннязь! Аруг! Жених! / Мой князь! Мой друг! мой жених! Весь мировой орнестр / $\mathrm{H}$ вьотся у пояса эмеи алых лент. Весь мировой орнестр

315) 149,37

Утренних эвонов. Разбивая / Утренних звонов, ни весть нание песни заводит ветер над равниной.

H, разбивая

316) 150,1

H все крести на храмах. Затопляя сиянием / и все кресты на храмах. Разбуненные ветром, в неслыханной мольбе простирают нрасные рунава пышные рябины все в однУ сторону. Стремительно затопляя сиянием

317) 150,7 Здравствуй!/ Oн встал надо мной! (Герман идет).

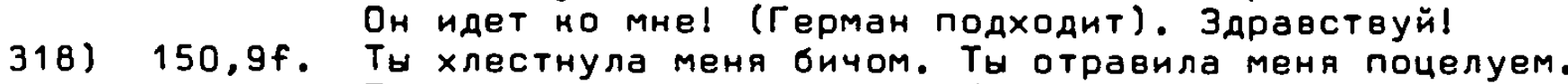

Ты снилась мне все ночи. / Ты хлестнула меня бичом.

Ты снилась мне все ночн, все ночн.

319) 150,12

Фанна / Фанна (в восторженном сне)

320) 150,20

Смотрнт ему в лицо) / СМотрит ему в лицо Истосновавшимися очами)

321) 150,22 труба вэывает! Час пробил! / труба взывает, невеста поет! Час твой пробил!

322) $150,26 \mathrm{f}$. Ты - день беззанатнай! Час пробил! / Ты - день беззанатный, в очах твонх - дали моей родины!

Час пробил! Bequ!

323) $150,28 f$. Фанна торжественно распускает алый пояс и кланяется Герману в ноти. Лебедь умолн. / Отнрывает руни. Фанна торжественно распуснает алый пояс, Ман бы творя високий обряд, и безмолвно обнигает его губы первым девичьим поцелуем. Лебедь умолн.

324) 150,29 Тольно море / Тольно неведомое море

325) 150,30 H. задыхаясь $\mathrm{h}$ трепеща / $\mathrm{H}$ уронив на мгновение руни, задыхаясь и трепеща

326) 150,33

Старый, старый, прощай! / Старый, старый, старый, прощай!

327) 150,34

328) 150,36

Тройку! Тройку! / Тройну! Тройну! Тройку!

329) $151,3 f$.

Через мгновение / $\mathrm{H}$ через мгновение

вдали на Сияющей равнине. / вдали, под откосом, на сияющей равнине.

330) 151,4

In F1 folgt nach dem Abgang von Faina und German noch eine knappe Szene zwischen dem Freund und dem Begleiter der Faina.

Печальный, одиноний СПутнин садится на большой намень / Спутнин Фаины, ноторей давно молчал, ндет, шатаясь, н Другу Германа, протягивает руни и

Говорит Аромащим Голосом.

Спутник: Н вы тоже - тольно спутнин?.. 
Друг, досадливо махнув руной, уходит прочь. И Садится печальный, одиноннй Спутнин на большой намень

331) 151,5f. его белые руни / его большие белые рунн

332) 151,6 Драгоценный перстень / И драгоценний перстень

333) $151,7 f$ Н, СЛОвно Заодно С нИМ / НО сЛОвно эаодно наД нИМ

334) 152,1

335) 152,2 Шестая картина / Четвертое действие. Первая нартина Дом Германа. / Денорация первого действия: дом Германа.

336) 152,6 Apyr / Apyr (оборачнваясь)

337) 152,9ff. Zwischen der Replik der Helena Bce нончено межау нами. und der folgenden Replik des Freundes stehen in F1 zwei Repliken: Apyr (улнбаясь): Это эависит от вас.

Елена:

338) 152,16 4то я рассназал вам правду / 4то я рассназал вам всю правду

339) 153,2 D, я ниногда больше не пронзнесу / 0 , романтизм! Я больше ниногда не пронзнесу

340) 153,21f. Хотите, я снану правду? / Хотите, я снану правду; тольно вы өсе равно не поверите.

341) 153,31 Вы, что называется / Потому что вн, что называется

342) 154,3

Что делать? - Желаю вам счастья... / Что делать? Таной ун я непризнанний человен. - Жеяаю вам Счастья...

343) 154,7 и тание все люди... / и танне, долнно быть,

344) 154,9 выходит монах. / внходит монах, бледный, нан половсе людн... тно, И останавливается над Еленой.

345) 154,11 Много перенесла ти. / Много перенесла ты, печальная Eлена.

346) 154,16 Monax / Монax (строго)

347) 154,21 Разве танне плачут всю жизнь? / Всю жизнь будешь планать - слезами изойдешь. Разве тание плачут всю низнь?

348) 154,23 Всю жизнь проплачу... Моего горя не выплакать... / Всю низнь проплачу... Hогда $и$ ты не веришь мне, братен, Ступай н людам... Моего горя не өыпланать..

349) 154,25 Много a вндел слез: это тольно матери / Mного а ходил по миру и много видел слез: это одни тольно матери

350) 154,26 мать, ноторой / матери, ноторым

$351) \quad 154,28$ белая дорога: / белая дорога, белая:

352) 154.29f. Слушай-на, Елена: сама знаешь, уйти мне отсюда некуда / Слушай-на, Елена: а С тобою ман брат говорю: сама знаешь, уйти мне отсюда больше ненуда

353) 155,2f. Ты об Одном подумай: вот Мун төой ушел... / Ты тольно подумай: ведь твой Герман, Мун твой в Россин пошел...

$354) 155,5$ Жили бы мирно... / Что мне до Россин твоей? Жили бу мирно...

355) 155,9

356) 155,10 одни человечесние слезы... / тольно человечесние слезы н видит...

Тан И тянвт его в этУ даль... / Тан И Потянет его в эту даль. Разве монно, Елена, ей противитьса? Но ведь и а пренрасна. / Но ведь и я богата. Н я пренрасна. 
358) 155,15 Твоя душа тиха, Елена. Ты вот слушаешь меня. / Твоя душа - тишнна, Елена. А в той душе - бурн ХОДят. ПОЙмн тЫ: ВОт Сидим Мы С тобой на нрылечне. День белий. Ты слушаешь меня.

359) 155,16f. А та - разве стала бы слушать? Нет ей поноя ни ночью, ни анем... / А та - разве стала бы слушать? Все ее мчат нуда-то безпонойные нрылья, нет ей

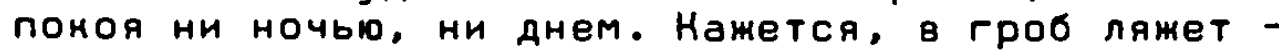
мятенная, С раскрытымн черными глазами...

360) 155,23

361) 155,25

362) 155,28 Ного видншь? / Кого ты вндншь, брат? Родину мою. / Родину мою вижу.

В Писании сназано: пророн увидал господа / B писаниИ сназано, Ты долтен Помнить: Пророн увидал Господа

363) 155,32 Где мне понять, кто поймет? / Где мне понять Н НтО ПоЙМет?

364) 155,32f. Каной я: Н низни-то во мне осталось, кан воску / наной я Нз себя: Н жизнИ-то всей во Мне осталось всего, Кан воску

365) 156,1f. глаза свон проглядел: / глаза свон на дали проглядел;

366) 156,2ff. Der Schluss der Replik des Mönchs a вот - rлamy, H опять тянет, не оторваться... ist in F1 ausführlicher. Ausserdem folgen zusätzlich vier Repliken vor der Replik

Eлена: Тан, значнт, не вернется... Es lautet in F1: а вот сижу, Гляжу, Н опять тянет туда: взору не оторваться. Кажется, сам бы полетел, набы нрылья были. Может, помирать стану, тан н тншнну пойму.

Eлена: Тан и я, по твоему, не понимаю?

Монах: Ты-то? Тн-то, может, н понимаешь. Oттого я Много ти энаешь. За тебя не страшно.

Eлена: Герман энает больше моего. Монах: Герман? Ничего Герман не энает, ничего. у него н душа совсем другая. То, что ты с нолыбели узнала, ему надо всей жизнью пройти. И нинто ему в этом не уназ. И нинакая сила его с этого пути не свернет.

Eлена: Тан, значнт, не вернется...

367) 156,5

368) 156,5 Смешной ты. / Смешной ты, брат.

Да что, она / Да, что она Diв Versetzung des Kommas ist sicher ein Druckfehler.

369) 156,8 Сейчас тебе.../ Эх, ненщина ты, Елена. Сейчас тебе...

370) 156,9ff. Zwischen буря или тишнна? und Стыднсь, монах. stehen in F1 vier Repliken. Es heisst dort: буря нли тишина? Eлена: Лнешь ты все: ты ее видел, эначнт монешь сназать! А я, Почем знаю: может она - нрнвобоная! Монах: Вон туда взгляни, Елена. Чай, хорошо там? Елена: Хорошо. Просторно. Тольно - Страшно. Монах: Вот н она - таная: просторная, днная... И с ней - тоне страшно. Елена: Стыдись, монах.

371) 156,12f. Н нинто не утешит! / И нинто не утешит, никто не снажет! 
372) 156,13 Мой Герман, мой! Нам с ним ничего... / Мой Герман - свят! Ниного Герману не надо, он сам полон, кан мир! Нам С ним ничего...

373) 156,18f. Что тн говоришь? Пойми, Герман өернется оставил здесь... / Что ти Говоришь мне? Поймн, монах: Герман вернется! Мой Герман вернется но мне! У тебя - все тольно мирсное на умеl Пойми, Герман все оставил здесь...

374) 156,21 Он копался / нопался Герман

375) 156,21f. Вся душа его здесь.../ Вся душа Германа нивет здесь...

376) 156,24 Душа Германа отдана... / Душа Германа отдана Россин.

377) 156,26f. Mне, которую он любил и любит! / Мне - Eлене, ноторую однУ тольно любил н любнт Герман?

378) 156,30 Плачь, Елена. Всю... / Плачь, Елена. Громче кричи, Елена. Даже, бей меня, если хочешь. Всю душу...

379) 156,30f. мрином изойдешь, - тогда... / нрином изойдешь, Елена, тогда...

380) 157,2 Молчи, монах. Он сназал мне: вернусь скоро. / Молчи, монах. Небо ясно. Год миновал. Он сказал мне: вернусь, ноГда будет ясное небо. Вот оно.

381) 157.4 Сейчас он прндет./ сейчас он придет. Ндет.

3е2) 157,6 точно ворон нарннул, / точно сердие человечесное надорвалось, или ворон карннул,

383) 157,7 натянутую струну. / натянутую струну. -

$384)$ 157,9 Tu cлыwan? / Tu cлыwan, брат?

385) 157,10f. Zwischen den Repliken des Mönchs und der Helena stehen in F1 zwei weitere Repliken.

Монах: C льшал.

Елена: Что же мне делать? /

MонаX: Cлишал.

Eлена: Ты слышал? Тан бывает, ногда смерть блиэно. Монах: Слышал. Нан там бело.

Eлена. (wопотом): Бело. - Что mе мне делать?

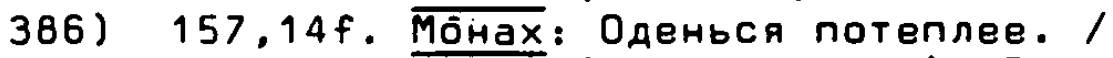

Монах (торжественно): Войди в горницу. Оденься nотеплеe.

387) 157,16f. на нрнлечне и напевает... / на нрылечне, покашливает н напевает...

388) 157,18 С занженной свечой. / С эажненной свечой в руке.

389) 157,24 ...делать? / ..дяелать, брат?

390) 157,26 на нрылечне... / на нрылечке. - Помолчим.

$391)$ 157,27 Елена - за ним. Потом встают. / Елена за ним.

392) 157,30 Монах тихо... / Молчание. Монах тихо...

393) 157,32f. Елена: Не пой панихндного. /

Елена (тихо): Братец. Не пой панихидного.

394) 158,2f. Моя радость оттого, что твой милый - жив. / Сввтла моя радость, потому что твой милый - жнв и здоров.

395) 158,5 Жив. Я знаю, знаю./ Жив и здоров. Я знаю, знаю. Спасибо, что сказал тан.

396) 158,7 Рано ему умирать. / Рано ему умирать. Много, много дела впереди.

397) 158,7 Только заблудился он. / Только заблудился Он 
398) 158,8

нищнм стал. ТУт-то только все Н начннавтся:

бляненни нищие духом.

обонм н нить, Елена. Нанлонись-на. Вот тебе, / обоим и мнть, Елена. Вот об этой-то радости н пою. Наклонись-ка, Елена. Вот тебе,

399) 158,14 Путь многолетний. / Путь многолетннй, путь тернистый.

$400) 158,19 f$. Т甘 сильная. Ндн, родная, господь с тобой. / Ты

сильная - тебе там дела много. Много дела в Россин.

Свато ты начннала, - Свято и нончншь. - Идн, родная,

Господы $\mathrm{C}$ тобой.

401) 158.26 In F1 fehit: (Плачет.)

402) 158,28f. Сохраню, родная. Господь сохранит тебя. Елена

Сходнт... / Буду, буду, родная. Господь сохрани тебя. Елена: Ну, прощай... Ангел Боннй.

Монах: Прощай. Елена прекрасная.

Елена сходит...

403 ) 158,29 обернувшнсь, на сөой тихнй, / обернувшнсь, на белый, Свой, тихий, (Komma vor oder nach свой ist sicher ein Druckfehler.)

404) 158,30f. Монах осторомно замынает... / Монах обходнт дом.

Осторожно замынает...

405) 158,31 Потом садитса... / Потом опять садитса...

$406) 159,1$ Седьмая нартина / Вторая нартина

407) 159,2 Хмурый морозный день.// Действне одновременно с

408) действием предыдущей нартины. Хмурый морозн甘й день.

408) 159,2 Пустая / Густая (Sicher ein Schreibfehler wegen der

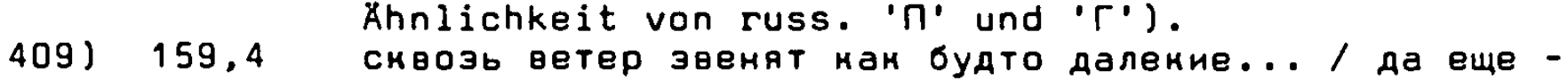

10) Словно эвенат СКвоэь ветер даление...

410) 159,4f. Герман стонт на холме. fehit in F1.

411) 159,6 Герман / Герман (однн на холме)

412) 159,7f. Zwischen Zeile 7 und Zeile 8 stehen in F1 zwei

zusätzliche Zeilen. Ausserdem lautet Zeile 8 in F1

etwas anders. In $F 1$ heisst es:

Bсе мнновало. Прошлое - нак Сон.

Завладевай душой освобомденной

Ты, белосненная, родная Русь.

Холодный, белый день. Душа, нан степь,

413) 160,3 Метель эапевает.../ / Герман стонт, выпрямившнсь смотрит вдаль. Метель эапевает...

414 ) 160,4 Голос Фанны/ Голос Фанны (нличет нздали)

415) 160,5f. Zwischen Zeile 5 und Zeile 6 stehen in F1 zusätzlich zwei Repliken:

Герман: 3десь!

Фанна: Ей, Герман!

416) 160,8

и любуетса / Н Точно любуется

417 ) 160,13 Zwischen Tenepb мы одни. und Что ты стоншь там, Haвepxy? stehen in F1 fünf Repliken. Es heisst dort: Tenepb мы одни.

Герман: Чего mе ты смевшься?

Фанна (садится под холмом): Ты будешь целовать меня? Да? Ты, ведь, мущнна, и сильней меня. Можешь делать Со Мной все, что хочешь...

Герман: Почему ты Говоришь тан?

Фанна: Нан я говорю?

Герман: Tи забыла? 
418) 160,22

419) 160,24

420) 160,28

421) 160,31

422) 161,2

423) $161,2 f$.

424) 161,4

425) 161,6

426) 161,7

427) 161,7

428) 161,8

429) 161,9

430) 161,12

431) 161,13

432) 161,24

433) 161,28

434) 161,31

435) 162,4

436) 162,5

437) $162,7 f$.

438) 162,16

439) 162,22

440) 162,25

441) 162,28

442) 162,33

443) 163,2

444) 163,4

445) 163,6

446) 163,9

447) 163,15

448) 163,16

449) 163,18

450) 163,22

451) 163,26
Фанна: Да, я часто забываю. Bce эабнваюl Bce равно. - Что mе ты стопшь там, наверху?

ты больше меня. / ты выше меня.

ГОрящнМ вэором, а я ничтожный, / ГОрящнм вэором:

ТОчнО ТУЧИ ИДУТ, НЛН СТЕПЬ ГОРИТ, - а А ННЧТОЖН甘Й, жена? А город? / жена? Ты ведь всю жизнь провел С женщинамн. A город?

все прошлое. / все прошлое мое.

Вот, все вы танне... / Признаться, страшно тебе

без дорогИ остаться? Вот, все вы тание...

а ค живая! У меня - ни дома, / а я - живая, живая, нивая. $И$ У Меня - ни дома,

туда пойду! / тУда пойду. $H$ не страшно!

Они - голубые, ранние. / Они - голубые, холодные, Ранние - ПОАСнежнинИ.

Что тебе до ниХ? / Что тебе?

в сердце. / под сердцем.

я умрУ в снегУ. / я умрУ здесь, В снегу.

Лонится на снег, / OH ложнтся на снег,

тольно в снаэнах / тольно в старых сназмах

Ей, берегись! / Ей, Герман! Берегись!

Нто-то ндет вдали. / Слышу. Нто-то ндет вдали.

все пройдут мимо. (Обвнвает его... / все прондут

мимо. Тольно песна осталась... (Обвивает его...

Мне страшно, Фаина. / Мне страшно, Фаина.

Ниногда... ниногда...

Неправда. Смотри блине... / Неправда. Молчи, совсем молчи. Смотри блише...

А днем рыжие: / А днем они рыжие:

И ОПАТЬ С ЛЫШНО блИне:

Выди, выди в ронь высокуо, /

H Oпять слышно блище.

Голос.

Выди, выди в рожь высоную,

Тихо... Ниногда не слихал / Тан тихо... Не виму

больше. Тан темно... Ниногда не слыхал

Герман / Герман (тихо)

ветер плачет? / ветер плачет налобно?

та mе старая нота / та не старая, осенняя нота

Уйти вольна, эадушнть / Уйти вольна, Убить,

эадушить

тан сурова? / тан сурова со мной?

не дотдалась! / не дондалась милого!

Стань человеном! / Будь человеном!

нан метель. / нан метель, - прямо в лицо.

Таная звонная метель - перед новой весной. $И$ зта весна не похона на ту: ненуда унрыться от ее Ударов.

8се энаю теперь. Hе тревонь... / Bce энаю теперь. Тишина наступает. Не тревожь...

ни поцелуем. / нн словами.

Ей, Герман, берегись! Герман, метель идет! /

Ей, Герман, Герман, берегись: метель!

nopa! / nopa! Тн крепко спишь!

руни / речн 
$452)$ 163,27f. Такие нежные? Тан ты - невеста моя? Открой лицо. / тание нежные?

Фанна (прннинает н лицу Германа), Тебя ждала а. Теба нснала. 0 тебе н сназни слушала. Ты магадался мне, нених мой светлый... Пробудишь, умчи, освободи. Старый нличет.

Герман (в бреду), Мне страшно и холодно. Тан ту невеста моя? Отнрой лицо: не знаю тебя.

453) 163,29 Фанна (прининает н нему)// Фанна

454) 163,31 полетим на тройне... / полетим на тройне с бубенцами...

455) 164,2 Нуда? / Нуда? Hуда?

456) 164,8 Отнрой личо... / Смерть моя, отнрой лицо...

457 ) 164,11 дышу на тебяl (Она... / дышу на теба! Остнвайте старые, темные, жарние мысли! (Она...

458). 164,12 Милый мой. Неланный, / Милый мой, нони умчались। Неланный,

459) 164,16 Что это? Внзнат машнны, / Что это? 3aпахло цветамн... Словно пчель жужнат в голове.

Или - визнат машнны,

460) 164,17 вереницы огней... Это - город, / вереннцы огней, вечн甘Й ГрОХОТ. ЭТО - ГОРОА -

461) 164,18 огромный Город... / огромный, старый Город.

462) 164,18f. НтО-то ГлядИт/ НтО-то ПрНСтально Гладнт

463) 164,20 Не слышу... / Слышу тебя!

464) 164,22 Мать нличет! / Голосом матерн нличу!

465) 164,24f. Нто это? Ангел в белой оденде! Золотые пради волос! / Нто это? Наной белый! Aнгел в белой оденде! Серебраные латы, золотне Пради волос!

466) 164,25

467) 164,25

468) 164,26 Нрылья за плечами! / Наное нротное лицо! в рунах / H в рунах

469) 164,27 Eленаl / Это - Eленаl

470) $164,29 f$.

Eлена! / Eлена! Здравствуй!

Будет спать! Здесь я одна! Только проснишь! / Будет спать! Й Она услышала ветер! она пройдет мимо! Здесь - я одна! Все вн Придете но мне! Тольно проснись! Тольно стань человеном!..

471) 164,33 ТУда / ВОН ТУАа

$472)$ 164,34 Она нивает мне... / Здравствуй! Oна строго ннвает мне...

473) 165,1 ушла... / ушла... миновалась...

474 ) 165,1 Холодно. / Только днвно, ХОлодно, Тихо.

475) 165,2 Что это? Рог? Сухой тресн...// Что это? Словно далекий рог эаблудившегося героя... Ту погибнешь? Ты погибнешь? Нет, нет, нетІ.. Сухой тресн... 476) 165,3 идет герой / идет сам герой

$477)$ 165,9f. Судьба? Накие темные очн. / Судьба? Bсегда ты эдесь, ногда ө поле умирает герой... Нание темнНе Очн.

4783 165,10 Нание холодные губы. Тольно не... / Нанне Кание холодные Губы. Тольно не... / Нанне

479) 165,12 Он смотрит на нее/ Oн встает и смотрит на нее 480 ) $165,16 \mathrm{f}$. (С небнвалой тосной и нежностью) / ( С небнвалой тосной Н нежностьо. Н Словно ГОворит Уже не она сама, а Нто-то Повелевающнй всемн судьбами, стоящий у кормила Трагедни) 


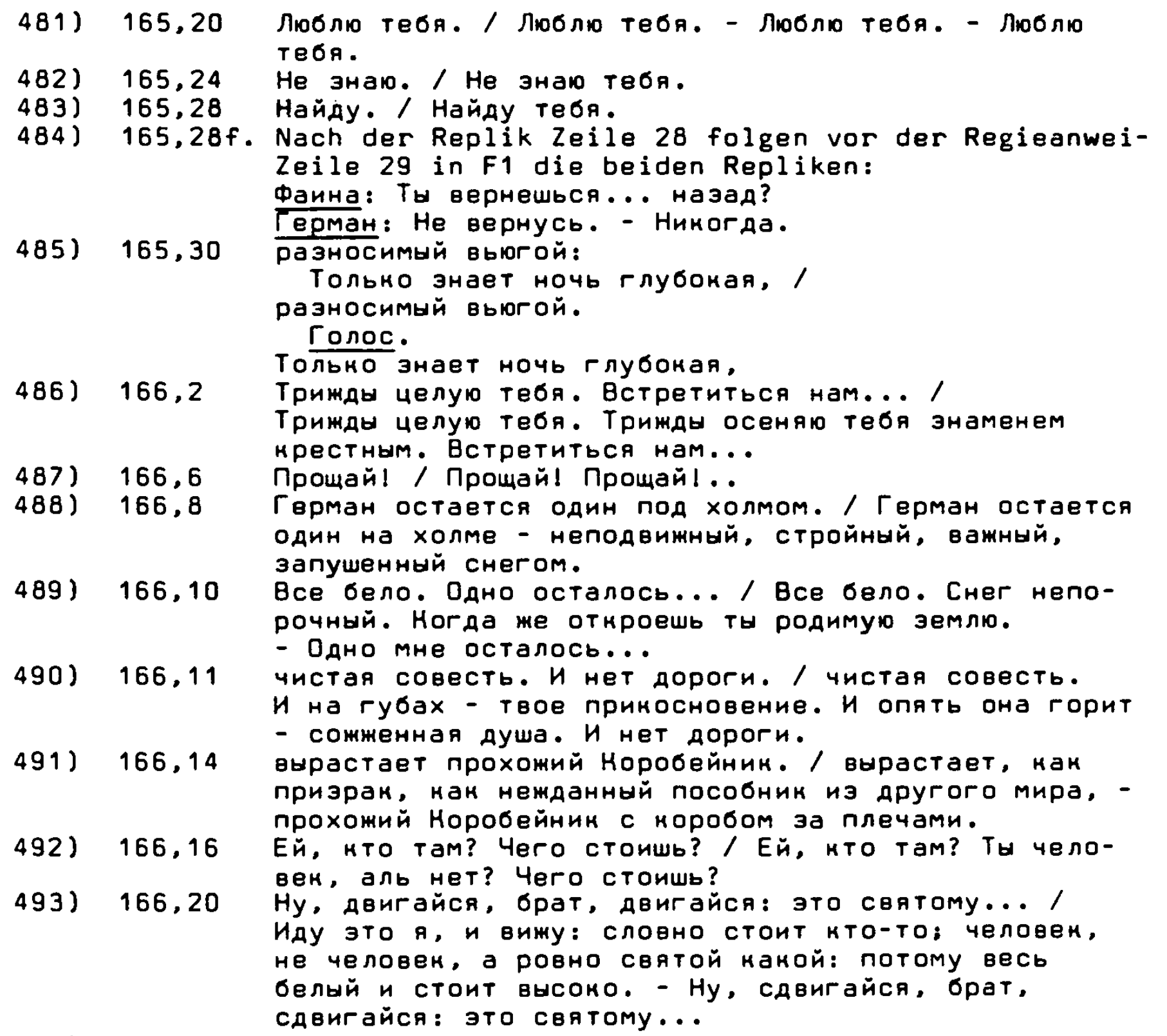

494) 166,21f. занесет вьюга! / потому - замерзнешь!

495) 166,22 Мало ли народу / Мало что ль народу

496) 166,22 убаюнала... / да убаюкала

$497)$ 166,22ff. Nach убаюнала... vor der Replik A tu sopory

энаешь? stehen in F1 zwei Repliken:

Герман: Ты про ного говоришь?

Норобейннк: Про кого? Нзвестно, Про кого: про

рассею-матушну: не одну живую душу она в снегах

Свонх да в ствпях свонх успоноила...

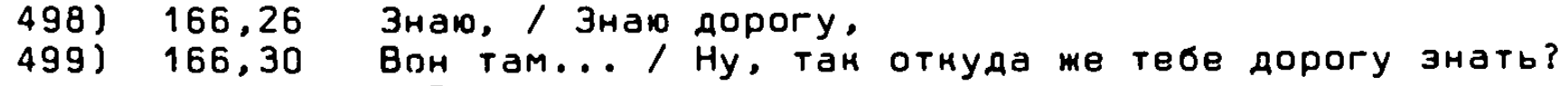

500) 167,6 Чудной человен. / Чудной Тн, я вину, человен.

501) 167,11

502) 167,11

Потом, / A пOTOM,

503) 167,12 Die Jahreszahl 1908 fehlt in F1.

( $V$ gl. dazu die Entstehungsgeschichte.) 


\section{ROMUENTAR}

Die Anmerkungen des Kommentars beziehen sich auf die tbersetzung des I.S.

Querverwelse innerhalb des Kommentars beziehen sich normalerweise auf die bezelchnete stelle des tbersetzungstextes und die zugehörige Kommentarstelle.

S.43/1 M1t "Pesnja sud'by" betitelte Blok neben dem vorliegenden Theaterstïck auch anfängl1ch den Gedlchtzyklus in seinen Gedlchtbänden "Zemlja $\nabla$ snegu" (fertiggestellt Im März 1908, also gleichze1tig mit M1, vgl. II,371374; erschienen Im JuI1 1908) und "Snežnaja noč" (erschlenen Im März 1912 als 3.Buch elner Ausgabe von Bloks Gedichten), der in den letzten von Blok besorgten Ausgaben seines Werks den endgültigen Titel "Falna" erhielt (vgl. Ilteraturnoje nasledstvo, 27-28, S.519ff.). Der Titel "Pesnja sud'by" wird Im Verlauf des Sticks mehrmals genannt; ihn trägt auch das Lled, das Falna Im 3.Bild singt. Der anspruchsvolle Titel spiegelt Bloks "musikal1sches" Weltbild wieder, In dem Nietzsches "amor fat1" grobe Bedeutung hat. Das Schicksal, das die Personen erleiden, ist Ausdruck des elementaren Weltwillens. Es tritt in Falna verkörpert an den Mönch, an German und an Helena heran. Nach dem Zeugnis Zorgenfrejs (vgl. Entstehungsgeschichte, S. 12; von Volkov, Blok 1 teatr, S.87 ungenau ubernommen; vgl. auch die Erinnerung von Z. Gipp1us, Entstehungsgeschichte, S.20) hieb das Stuck urspringlich "Faina". Dem widerspricht allerdings Bloks Brief vom 25. Januar 1908 an seine Mutter (vgl. Entstehungsgeschichte, S.8).

S.43/2 In F1 nannte Blok das IS elnen "dramatischen Prolog" (vgl. Abw.1). "Prolog" 1st dabel nicht zu verstehen als kurzer Hinwe1s auf eln folgendes Stuck mit Erklärung von Titel, handelnden Personen, Inhalt o.ä.. Vielmehr sollte das IS die symbolische Darstellung elnes vorläufigen Geschehens seln, der Versöhnung von Volk und 
Intelligenz in der Revolution von 1905 und inr Scheltern, dessen elgentliche Vollendung in der historischen $\mathrm{Zu}-$ kunft stattfinden sollte. Die spätere Bezelchnung "poèma" lst dt. als "Poem" wiederzugeben. "In der deutschen Poetik kaum gebraucht, englisch glelchbedeutend mit dem Wort "Gedicht", beze1chnet "poema" Im Russischen ein gröBeres eplsches oder eplsch-lyrisches Werk, 2.B. die Homerischen Epen und die Äneis, die klassizist1schen Epen und später die Epen von Byron und die sie nachahmenden russischen "byronistischen Poeme". (Tschlžewskif, Rus8. L1teraturgesch1chte, Bd.1, S.9). Als Poeme bezelchnet man Bloks Dichtungen "Jeje pribytije", "Nocnaja flalka", "Solov'inyj sad", "Vozmezdife" und "Dvenadcat'", die alle in Versen geschrieben und relativ umfangreich sind. Das sind die beiden kriterien, die man normalerwelse als nötig erachtet. Das is lot zum größten Tell in Prosa gehalten und erinnert hierin an Gogol's "Poem" "Mertryje dül". Der Grund fur die Bezelchnung "Poem" 18 t in beiden Pällen im Stofflichen zu suchen. Im LS geht es Blok um die Darstellung einer Schicksalsfrage der russischen Geschlchte. Als ein dem "klassischen" Poem entsprechendes Element kann man die Ruckgriffe auf Mythen und Sagen (allerdings verschiedener Provenienz) ansehen. Entscheidend fur Blok war zweifellos die GröBe des darzustellenden Problems.

$5.43 / 3$ Das erste Motto aus dem 1. Johannes-Brief wird in der Ubersetzung Luthers wiedergegeben. Es wird im 1.Bild wiederholt. Die "völlige Liebe" soll Germans Verhältnis zu Faina bestimmen (vgl. Volkov, Blok 1 teatr, S.86f.). Das zweite Motto stammt aus der beruhmten "lyrischen Stelle" Im 11. Kapitel von Gogol's Poem "Mertvyje duši" ( $\nabla g l$. Gogol', Sobranije sočinenif $\nabla$ semi tomach, Bd.5. S.2581.; die Gedankenstriche geben die Auslassungen an). Der Auszug, den Blok aus Gogol' wählte, unterstrelcht einerseits den mystischen Zauber, den Rusland ausubt, fuhrt andrerseits zu dem Thema des LS hin: dem Erstehen elnes Helden, der das gefangene RuBland erlösen soll. 
Bloks RuBland-Mythos war stark von Gogol' gepragt (vgl. bes. V.,321, 325ff., 343f., 349, 376ff.; VI,9, 27f., 1401.: VII,359, 363 u.ö.; eine sehr ausführliche, aber etwas zu oberflachliche Darstellung gibt Minc, Blok 1 Gogol'). Die beiden Mottos nehmen zwei wesentliche Elemente des Stucks, das "christliche" und das "russische", vorweg.

S.43/4 Der Name Germans ist im Russischen griechischen Ursprungs. Gromov, Geroj i vremja, S.509, behauptet zu Unrecht, die männliche Hauptgestalt des IS trage einen "Puß̌kinschen Namen". Er spielt damit auf Germann, den Helden von Puðkins "Pique Dame" an, dessen Name jedoch als Wiedergabe des Personennamens Hermann gelten muB. (Gromov stüt sich möglicherweise auf Ivanov, Zapisi ob A. Bloke, in: Blokovskij sbornik, S.406, Eintrag vom 4. Mai 1906; Gromov, A. Blok, S. 303, hält trotz richtiger Orthographie an der Gleichsetzung von German und Germann fest, wird damit dem LS jedoch nicht gerecht; ihm folgt Rodina, A. Blok i russkij teatr nałala XX veka, S.177ff.). Mayr, Die lyr. Dramen Bloks, schreibt "Hermann". In der Ubbersetzung wird die Schreibung "German" beibehalten. Der Name bezieht sich trotz seines griechischen Ursprungs zweifellos auf Deutschland als der geistigen Heimat des Helden, wobei sich biographische und kulturgeschichtliche Elemente verquicken. Blok, der sich in dieser Gestalt verbirgt, war väterlicherseits deutscher Abstammung (vgl.z.B. Mocul'skij, Blok, S.13, 57). Deutschland war zeitlebens Bloks geistige Heimat; er entwickelte sein Weltbild an deutschen Anregern und gehörte zusammen mit Ivanov und Belyj zu den deutsch geprägten russischen Symbolisten (vgl. dazu grundlegend Kluge, Westeuropa und RuBland im Weltbild Aleksandr Bloks). Völlig zurecht weist Moðul'skij, aao, S.247 auf den deutschen Ursprung von Bloks "narodnicestvo" hin. Bunin sagte von Blok: "Das ist ausgeklügelte deutsche Fapierpoesie." (Vgl. Katajew, Kraut des Vergessens, S.60). German ist im LS die Verkörperung des "westlerisch-deutschen", "romantischen" Intelligenzlers, der sich vom "abendländischen", in Helena verkörperten, dem "russischen", in Faina verkörperten Ideal 
zuwendet. (Zum "deutschen" Geist des LS vgl. die Entstehungsgeschichte, S. 11).

S.43/5 Der Name Jelena ist griechischen Ursprung8. Da im IS ausdrucklich auf die "schöne Helena" angespielt wird, steht in der Ubersetzung Helena. In der griechischen Sagenuberlieferung ist Helena der Inbegriff weiblicher Schönheit, wobei deutlich ein aphrodisisch-dionysisches Element mitschwingt ( $\nabla g l$. Nietzsche, Die Geburt der Tragödie, S.57; Bachofen, Mutterrecht, S.332). Blok gibt der Gestalt der Helena eine andere, nur aus seiner Geschichtsphilosophie erklärbare Deutung. Hierbel hat er ganz sicher den 2. Teil von Goethes "Faust" im Sinn. Diese Deutung wird von Blok in seinem Aufsatz "Devuška rozovoj kalitki i murav'inyf car'n (Das Mädchen vom Rosenpförtchen und der Ameisenzar; $V, 83-94$ ) entwickelt. In ihm kommt die Abwendung Bloks von einer Geisteshaltung zum Ausdruck, die er in dieser Zeit als typisch deutsch und romantisch ansah, und aus der ein großer Teil seiner Jugendgedichte entstanden ist. Die wichtigsten Kennzeichen dieser Geisteshaltung sind das Streben nach dem Ideal, die Vergeistigung der Liebe zu ritterlich-religiösem Minnedienst und die Sehnsucht nach einem "goldenen Zeitalter", das Tjutcev ebenso wie Goethe in der klassischen Antike (VII,31; VI,95f.), die deutschen Romantiker und Blok selbst im westeuropäischen Mittelalter verwirklicht sahen. Ausdruck dieser Geisteshaltung ist die unerfullbare Sehnsucht nach Helena.

"Seit jeher suchte man im Westen Helena, - die unerreichbare, vollendete Schönheit. Daher all diese Kriege und blutigen $Z$ wiste mit einem halbphantastischen Feind; diese Gestalten der treuen Ritter mit heruntergeschlagenem Visier und der listigen Mönche... Deshalb die funkelnden Haufen abstrakter Ideen, philosophischer Konzeptionen, nationalistischer Hoffnungen... Alles ist abgesondert, weit entfernt, "unerkennbar", angefangen mit der gesuchten idealen Helena, die sich immer weiter entfernt hat und schlieblich zum katholischen Heiligenbild geworden ist und die endet als "Ding an sich", als Noumenon, auf dem geschrieben steht: "Unerkennbar, ungreifbar. Weitergehen!"... Alles ist weit,unerreichbar, reizvoll durch seine Ferne... Der unbewegliche Ritter - der Westen - hat alles vergessen, da er hinter seinem Visier ganz und gar in Betrachtung der himmlischen Rosen ver- 
sank. Sein Gesicht ist verstelnert; or murde zur Skulptur und trat selbst ein in diese allumfassende Harmonie des Ihn Ungebenden, die so vollkommen 1st. Mit totem Blick sucht er auf der vielgestaltigen Ebene das, was nicht in thr ist und nicht sein wird... Und seine Träumerelen kommen zu keinem Ende. Sie gehen nicht in Erfullung." $(v, 881$.

Dem im Schlaf erstarrten Westen stellt Blok ein myth1sches RuBland gegenuber, das in selner öden Trostlosigke1t die maglsche Ursprunglichkeit bewahrt hat. Die Menschen dieses Landes haben keine historischen Erinnerungen, und sie ziehen seit Jahrhunderten in Gegenden, "die fur die Sucher der Helena immer wilde, barbarische, hyperbore1sche Gegenden waren" $(V, 92)$. Hier lebt eine auf die Zukunft gerlchtete Lebenskraft, und in den russischen Weiten wohnen echte, den Kräften der Natur noch verbundene Menschen, denen die Zukunft gehören wird. Helena lst im LS die Verkörperung abendländisch-aristokratischer, klas818ch-apollinischer, ruhig-heller Schönheit und Ge1steshaltung. Inr Gegenpol 1st Faina. In der Gestalt der Helena verbirgt sich Bloks Frau Ljuba Dm1trijevna. (Vgl. Entstehungsgeschichte, S.4 u.ö.).

"Ljubov' Dmitrijevna nahm in Bloks Leben einen wahrhaft uberragenden, mit nichts zu vergleichenden Platz ein. Ljuba - das ist sein ewiges Thema. Sie ist in seinem Bewubtsein immer anwesend. Die Gedanken, die Erinnerungen an sie, die lrăumerelen und Hoffnungen, die an sie geknüpt waren, all das begleltet Blok ständig, wo er auch war. was er auch tat." (Orlov. Istorlja odnoj ljubvi, In: Put1 1 oud'by, S.647).

Bloks Tagebuch von 1901-02 (VII,19-68) und die Tagebuchaufzelchnungen vom August und September 1918 uber die Ze1t vom Fruhjahr 1897 bis Ende 1901, die als Kommentar zu den Gedichten jener Ze1t gedacht waren (VII,338-350), zeigen, daB er seine Frau als irdische Verkörperung der "Ewigen Welblichke1t" ansah. Kurze Ze1t nach der Helrat geriet Bloks the in eine schwere Krise, die besonders zur Zeit der Entstehung des IS zu einer tiefen Entfremdung $z$ wischen den belden Eheleuten fuhrte. (Eine ausfuhrliche Darstellung gibt Orlov, aao.). 
S.43/6 Die Mutter Germane tritt nur im 1.B1ld auf. In ihr verbirgt 81ch Bloks Mutter ( 8 gl. S.53/2).

S.43/7 Im Preund Germans gibt Blok die Karikatur eines nuchternen Verstandesmenschen, der weniger Preund als Peind Germans 18t. Wahrscheinlich wollte Blok im Kontrast von German als dem "Romantiker" und dem Preund als dem "Real1sten" das Doppelgänger-Problem gestalten, ähnlich wie in den Stucken "BalaganCik" (Plerrot und Harlekin) und "Neznakomka" (zwel Reihen von mannlichen Helden) und in vieIen Gedichten. Streckenwelse funglert der freund als mephistophelischor Begleiter Germans. Sein Werben um Helena enthält ein stark blographisches Element. Als Vorbilder fur den Freund Germans gelten G.I. Culkov ( 80 bel Orlov, Istorija odnoj Ijubvi, in: Put1 1 sud'by, S.717; Gromov, "Pesnja sud'by", in: Gerof 1 vremja, S.515) und A. Belyj (so Kluge, Westeuropa und RuBland, S.351, Anm.45). Bloks Verhältnis zu Culkov und Belyj wurde nicht nur durch 11terar18ch-ph1losoph1sche Gegensätze bestimmt. In einer bitteren Tagebuchnotiz schrieb Blok am 27. Oktober 1912:

"Die Antwort auf meine nicht aufhörenden Vergehen waren: zuerst A. Belyj, den $1 \mathrm{ch}$ wahrschelnlich hasse. Dann die Herren Culkov..." (VII, T10; vgI. auch Culkov, A. Blok 1 jego vremja, in: Pis'ma A. Bloka, S.111f.). Auch mit dem etwas rätselhaften "drug jedinstrenny j" in Bloks Gedicht "Neznakomka" (II,185f.. Str.5) lat nach Meinung von F.W. Neumann Čulkov gemeint (Neumann, A. Bloks "Neznakomka", in: WSI, 1963, Jg.VIII, S.7). v1. Orlov bringt Culkov in Zusammenhang mit dem Redner In Bloks Poem "Dvenadcat'" (III,347f1., Tell 1, Str.6; Orlov, Poema A. Bloka "Dvenadcat'", S.55). In Belyjs "Kubok metelej" wird neben Vjač. Ivanov, Remizov, Blok und Vološin auch Culkov verspottet. Belyj gibt inm den Namen Nulkov (vgI. Močul'sk1j, Belyj, S.115). In den Jahren 1902-03 verbanden 81 ch A. Belyj und S. Solov'er mit Blok in einem schwärmerischen Kult um Ljuba. Doch die Freundschaft $z w i s c h e n ~ B l o k$ und Belyj wandelte $81 \mathrm{ch}$ schon 1904 in eine persobnliche Rivalität, die elch in den Jahren 1907-08 zu einer heftigen l1terarischen Polemik ausweitete. Einzelne Passagen des LS nehmen 
direkt auf Bloks Auseinandersetzung wit Belyj Bezug. In der Ilebesintrige zwischen Helena und dem Freund GermanB, d1e als Gegensplel zum Ilebesverhätn18 zwischen German und Paina von zweifelhaftem dramatischem Wert 1st, Indet mit Sicherhelt Bloks gespanntes Verhältnis zu Belyj seinen Niederschlag.

S.43/8 Die Gestalt des Mönchs, der in M1 und $\mathrm{P} 1$ deutlich die Zuge elnes gefallenen Engels trägt, lst von einer Reproduktion elnes Bildes des finnischen Malers Simberg Inspiriert (vgl. Medvedev, Dramy 1 poèmy A. Bloka, S.65). Besonders in P1, aber auch in P2 zeigt die Gestalt des Mönchs starke Áhnllchkelt mit dem B1ld, das Blok von V1. Solov'ev hatte. Der Mönch, der m1t seiner Suche nach Paina schelterte, beauftragt German, seinen Weg fortzusetzen und enthüllt Helena das wahre Wesen ihrer Rivalin. Anfang 1908, also glelchze1tig mit der Fertigstellung von M1, fuhlte sich Blok erneut zur Poesie Solov'evs hingezogen (vgl. den Brief an seine Prau vom 27. Pebruar 1908, VIII,230f.., der von kosmischer Mystik erfulit $18 t$ ).

S.43/9 Auch der Name Paina 18t griech18chen Ursprungs. Er geht zurúck auf eine der "sieben Märtyrerinnen von Ancyra". Eine Phaina erlitt im Jahre 303 in Ancyra (heute Ankara) in der Ze1t der Diokletianischen Christenverfolgungen den Märtyrertod. Sie wurde ertränkt, we1l sie sich we1gerte, den römischen Ka1serkult anzuerkennen. Als 1hr Gedenktag gilt in der katholischen und in der orthodoxen K1rche der 18. Mal (vgl. den Artikel "Seven Martyrs of Ancyra" in: Dictionary of Christian Blography, vol. IV, p.624 und Boll.Acta SS. 18. Ma1). Der Name dieser He1ligen kam aus der griechischen Haglographie nach RuBland, wurde allerdings dort nicht populär. In $P 1$ bezelchnet Helena diesen Namen als "monašskoje Imja", den sie im Heiligenkalender gesehen habe (vgl. Abw.41). Es 1st zu bezweifeln, daB Blok die haglographische tberlieferung kannte. Doch 1 st die christliche Wurzel des Namens Faina im IS von groBer Bedeutung. Paina ist ein rus818ches Bauernmädchen aus dem M1l1eu des Altgläub1- 
gentums, das die erlosende wiederkunft Chrlsti erwartet. Blok war davon uberzeugt, daB in russischen Altgläub1gentum die christliche Brwartung des Weltgerichts und des Anbruchs des Relchs des Gelstes noch lebendig sel, und er sah darin eine Bestätigung selner elgenen apokalyptischen Ahnungen und selnes Mythos vom elementaren russischen Volk ( $\nabla g l$. den Bxkurs "Blok und der"raskol"n). Faina ist in IS die Verkbrperung rus81sch-volkhafter, romant $18 \mathrm{ch}$-diony $818 \mathrm{cher}$, dynam18ch-dunkler Schbinhe1t und Lebensdranges. Im Gegensatz zwischen der hellen, "ganz in WeiB" auftretenden Helena und der dunklen. "ganz in Schwarz" auftretenden Paina splegeln olch naturphilosophische tberzeugungen Bloks wieder. Das Dunkle lot fur Blok das Symbol fur den Urgrund des Seins, fur das uranfängl1che Chaos, das Elementare (st1ch1ja) aus dem das Helle entsteht ( sinnlichen Wahrmehmung im lyrischen Werk A.A. Bloks, S.67f., 84ff. mit Hinweisen auf die literarische und philosophische Tradition).

Im LS, aber auch in vielen Gedichten Bloks und besonders in Gedichtzyklus "Faina", der in groBer Nähe zu einigen Passagen des IS steht (vgl. Einleitung zum 5.Bild, S.309ff.), 18t die "dunkle" Schönhelt Bloks eine russische Schwester der exotischen "dunklen" Frauengestalten Baudelaires und des fin-de-siecle (vgl. dazu Praz, Liebe, Tod und Teufel, Bd.1,S.63f., mit Hinwels auf das Hohe Lied, 1,4f. u.ö., das auch in Bloks Werk seine Spuren hinterlassen hat.). In der Gestalt der Paina verbirgt sich die Schauspielerin N.N. Volochova, In deren Bann Blok Ende Dezember 1906 geriet. In Ihr sah Blok das reale Abbild elner rätselhaften wystischen Erscheinung ( $\nabla$ gl. Zap.kn., S.90), die Ird1sche Verkbrperung der visionären "Neznakomka". N.N. Volochova sind die Gedichtzyklen "Sneznaja maska" und "Paina" gewldmet. tber die Heldin der belden zyklen und des IS schrelbt M.A. Beketova in ihrer Blok-Blographie: 
"In diesem schneeigen, sturmischen winter entstand die "Schneemaske". Wie dieses Werk, so lot alles, was der Zyklus "Paina" enthält, ein Bericht (povest'). Die Gedichte sprechen fur sich... Ich sage eines: der Dichter verschönte seine "Schnee jungerau" nicht. Wer sie damals gesehen hat, in der leit seiner Leidenschaft fur sle, der weib, welch wandervoller Zauber das war. Eine hohe, schmale Gestalt, ein bleiches Gesicht, feine Gesichtsalge, schwarze Haare, und Augen, eben "geflugelt", schwarz, weit geöffnete "Mohnbluten böser Augen". Und erstaunilch war ihr Lächeln, das im Weis ihrer Zähne aufleuchtete, ein triumphierendes, ein siegreiches Iächeln. Jemand sagte damals, daB das Aufflammen ihrer Augen und thres Iächelns die Finsternis durchdringe. Andere sagten: "eine Altgläubigen-Gottesmutter"." (Beketova, Blok, S.105f.)

Blok sah in N.N. Volochova die Verkörperung russischen Wesens:

"Nur Natal' ja Nikola jevna ist musich, mit ihrer russichen "Zufälligkeit", nicht wissend, woher sie kommt, stolz, schön und fre1. Mit kleinen sklavischen Gewohnheiten und ungeheurer Freihe1t." (Zap.kn., 94, Eintrag vom 20. April 1907)

In ihrem gemeinsamen Weg oah Blok das Geheimnis RuBlands beschlossen, was zum Thema des LS werden solite (Zap.kn., 94f.. Eintrag vom 9. Jun1 1907; vgl. Entstehungsgeschichte, S.5). In der Rỉckerinnerung 1 st die Volochova mit der Paina des LS geradezu identisch (VII. 187. Eintrag vom 1. Dezember 1912). (tber sein Verhältnis zu der Volochova schrieb Blok an seine Frau:

"Du bist mir wichtig und besonders urentbehrlich; genauso auch N.N. - Prellich auf völlig andere Weise. In euch beiden 1st etwas Schicksahaltes fur mich. Wenn dir das weh tut, - es ist nichts zu machen, es muB 80 sein." (Unveröffentlichter Brief von 1907; zit. nach Solov'ev, Poèt 1 jego podvig, S.188).

Im IS schlugen $81 \mathrm{ch}$ demnach Bloks drel "groBe Sorgen" nieder, "Ijuba, Natal'ja Nikolajevna und Borja" (d.h. Belyj; vgl. VIII.210, Brief an selne Mutter vom 28. September 1907).

S.43/10 Der Begle1ter der Paina verkörpert das Alte, die böse Macht des Zarismus, in deren Bann Falna wieder gerät. In dieser Gestalt verbirgt sich Graf Witte (vgl. S.81/ 10). 
S.43/11 Der Hauslerer 18t eine Gestalt aus N.A. Nekrasova Verserzählung "Zorobejnik1" (Die Hausierer), die Verkörperung des russischen Volkes (vgl. S.100/9 und S.105/1).

$\mathrm{S.43/12}$ Zur Menge $\nabla \mathrm{gl}$. S.62/4.

Es fällt auf, daB Blok bel der Aufzahlung der handelnden Personen nur diejenigen einzeln aufuhrt, die in den beiden ersten und den dre1 letzten Bildern aufreten. Sämtliche Personen, die nur in elnem der belden stadtbilder auftreten, fehlen in der Personenliate, obwohl sie z.T. recht ausfuhrlich zu Wort kommen (z.B. der Greis, der Redner, der Schriftsteller, der beruhmte Schriftsteller, der Mann mit Brille u.a.). Blok fuhrt also nur die NichtStadtmenschen besonders auf. Die Stadtmenschen gehoren insgesamt zur Menge, auch wenn sie mehr oder weniger stark aus ihr hervortreten. Von den einzeln aufgezählten Personen tragen nur drei einen Bigennamen (Helena, German, Faina). Diese sind danit deutlich als die Hauptpersonen gekennzelchnet. Drei weitere Personen werden benannt nach dem Verhältnis, in dem sle zu einer der Hauptpersonen stehen (die Mutter Germans, der Freund Germans, der Begleiter der Faina). Der Monch und der Hausierer, benannt nach inrem Stand, stehen am Anfang und am Ende von Germans Weg und sind Gestalten aus eigener Machtrollkommenneit. 
Das erste Bild des IS spielt in einem herrschaftlichen Landsitz. Der Niedergang der Adelswelt ist ein in der russischen Literatur der Jahrhundertwende haufig wlederkehrendes Thema. Der "Adelssitz" kontrastlert dabel als besonderer Raum normalerweise mit der "GroBstadt" und dem russischen "Dorf". Das Thema bezog seine Aktualitat aus der rapiden Industrialisierung RuBlands, dem Voraringen des Kapitalismus aufs russische Land und der damit verbundenen Auflosung der landlichen Wirtschaftsstruktur. ${ }^{1)}$ Der Vormarsch des Kapitalismus fuhrt nicht nur zum Untergang der alten patriarchalischen Adelswelt, ${ }^{2}$ ) sondern auch zum Untergang der bäuerlichen Dorfgemeinde und zum Absterben der "slawischosteuropäischen Altkultur". 3) Politisch hellsichtige Schriftsteiler zeigten deshalb häufig den gemeinsamen Niedergang von Adel und Bauerntum, "Herrenhof" und "Dorf". 4)

Be1 den "jungeren" russischen Symbolisten fuhrte die Ablehnung des "Positivismus", des "Kapitalismus" und der "burgerlichen Lebensformen" 5) in vielen Fällen zu einer Idealisierung der

1) Thalheim, Die wirtschaftliche Entwicklung RuBlands, und willerts, Die Agrarfrage, in: RuBlands Aufbruch ins 20. Jhat., S.86-136.

2) Ein verkikrtes Bild der Adelswelt gibt z.B. Arsen'ev, Iz russkoj kul'turnoj 1 tror ${ }^{2}$ eskoj tradicil, S.15ff. ("Duchovnaja tradicl ja maskoj semejnoj kul' tury").

3) Der Ausdruck stammt von Trautmann, Die Volksdichtung der Grobrussen, 1.Bd.. S.4. Ein erschutterndes Dokument des Untergangs der bäuerlichen Dorfkultur ist Gleb Uspenskifs "Vlast zeml1" (Die Macht der Erde, 1882). Vgl.a. Tschizewskif, Russische Geistesgeschichte II, S.112ff. und Utechin, Geschichte der politischen Ideen in RuBland, S.124-142.

4) Das bedeutendste Belspiel aus der Ilteratur der Jahrhundertwende lst Bunins Novelle "Suchodol" (1912). Die Gemeinsamke1t von Landadel und Bauerntum im Gegensatz zur Stadt 1st ein wesentliches Element bel Tolstoj (vgl. etwa "Anna Rarenina").

5) Die Kritik wandte sich häufig gegen Phänomene, die den Kritikern in ihrem elgentlichen Wesen verschlossen blieben. 
Vergangenhe1t, besonders des Mittelalters. 1) Die Plucht in die Ideal gesehene Welt des Mittelalters 18t eine Frscheinung, die in der Kunst ${ }^{2}$ ) und Iiteratur ${ }^{3)}$ der Jahrhundertwende weit verbreitet ist, und in der sich romantisches Erbe ${ }^{4}$ mit der ungeheuren Wirkung verbindet, die die Opernwelt Richard Wagners ausetrahlte. 5)

Die Idealisierung des Mittelalters lst die deutlichste Ausprägung des rückwärts gewandten Utopismus in der Kunst und Literatur der Jahrhundertwende. Blok träumte eine Ze1t lang, ebenso wie Belyj und S. Solov'ev, von der Wlederherstellung des Mittelalters. 6

Eine Sonderform der Verherrlichung der Vergangenheit in RuBland lot die Idealisierung der alten patriarchalischen Adelswelt. In Belyjs Gedichtband "Zoloto v lazuri" (Gold in Azur; 1904) verbindet sich die Poetisierung des Mittelalters mit der St1lisierung der versinkenden Welt des russischen Landadels in der Art der Rokoko-Idyllik. 7) Bel Bal'mont, Sologub und Ell1s bleibt die Welt der altväterlichen Landsitze, die in den Bildern Borisov-Nusatovs fortlebt, Immer das "verlorene Paradies". 8) 1) Belyj, "Zoloto v lazuri" (1904) und "Pervaja ("Severnaja",

Blok. "Stich1 o Prekrasnof Dame" (1904), "Roza 1 krset" 1912/13) und viele Gedichte, so insbesondere der Zyklus "Na pole Kulikovom".

S. Solov'ev, Ell18, Remizov u.a.

2) Vgl. Hof stätter, Symbollsmus, S.71ff, u.ö.

3) Vgl. Michaud, Message poét1que, S.404f.

$4)$ In Deutschland $z . B$. Noval18, Wackenroder, Uhland, Tieck. In Prankreich 2.B. V. Hugo.

In England $2 . B$. Scott, Coleridge, Keats.

In RuBland z.B. Puskin, Lermontov, Jazykov, BestužvMarlinskij.

Vgl. van Tieghem, Le romant18me, S.76ff, S.2631 .

5) Vgl. Mlchaud, aaO; Hof etätter aao, S.144; ders., Jugendst1lmalere1, S.35.

6) Vgl. VIII,79, Brief an S.M. Solov'ev vom 20. Dez. 1903.

7) Man denkt an Verlaines "Pêtes galantes" (1869). In der rus8. Malerel der Jahrhundertwende wird die hofische Welt des 18. Jhdts. v.a. von A. Benua (Benols) und $K$. Somov geschildert.

8) Vgl. Russkaja literatura konca XIX - naČala XX v.. Bd. 2 , S.253. 
Belyj und Blok dagegen brechen aus der 1dealen Welt ihrer ersten Gedichtzyklen aus, entdecken die GroBstadt, ${ }^{1)}$ die sie ganz im Sinne der Romantik und der "Neo-Romantik" der Jahrhundertwende als Symbol des Maschinenzeltalters ablehnen, und sie ersetzen den retrospektiven Eskapismus durch einen elgenartigen RuBlandMythos, der bel Belyj zeltwelse die Einflusse der Anthroposophie, ${ }^{2}$ bel Blok dagegen seit etwa 1906 die Verwandtschaft mit der neueren Lebensph1losophie ${ }^{3)}$ erkennen läBt.

In Belyjs Gedichtband "Pepel" (Asche; 1909) entsteht das trostlose Bild des russischen Landes, in dem das Adelsnest und das Dorf von der Kneipen-Zivilisation des Kapitallsmus verseucht sind. Im Vorwort zu "Pepel" schreibt Belyj:

"Der Kapitalismus hat bel uns noch keine solchen Zentren geschaffen wie im Westen, doch schon zerfällt die dörfliche Gemeinschaft, und deshalb lst das Bild der wachsenden Schluchten mit Steppengras und der Weller das lebendige Symbol der Zerstörung und des Todes der patriarchal 1 schen Lebensformen. Dieser Tod und diese Zerstörung schwemmt mit mächtiger Welle die Dörfer und Landsitze hinweg. Doch in den Städten wächst der Fieberwahn der kapitalistischen 21vilisation heran."4)

In den 2yklen "Derevnja" (Das Dorf) und "Pautina" (Das Spinngewebe) dieses Gedichtbandes wird der Verfall von Dorf und Adelsnest als gemeinsames Schicksal geschildert. Im Gegensatz zu Blok sleht Belyj nach 1905 im rus81schen "Dorf", in der Welt der russischen Bauern, P1lger, Hauslerer, Sektierer, Vagabunden, Verbrecher, in der Armut und Trostlosigkelt des russischen Landes keine Kraft, die der Stadt mit ihrer alles zersetzenden Maschinenkultur gewachsen wäre. Das wird besonders deutlich in Belyjs Roman "Serebrjanyj golub'" (Die silberne Taube, 1909).

1) Vgl. Einleitung zum 3.Bild.

2) Besonders stark in Belyjs Roman "Peterburg". Vgl. Mocul'skij, Belyj, S.169ff. und Hol thusen, Studien, S.109ff. Man muB Močul'skif, aaO, S.173. gegen Hol thusen, aao, S.144 und S.125, Recht geben, wenn er die These Ivanov-Razumniks von einer Anderung der Idee des Romans in den Fassungen von 1913 und 1922 libernimmt.

3) Diese Verwandtschaft zeigt zusammenfassend Kluge, Westeuropa und RuBland.

4) Belyf, Stichotrorenifa 1 poèmy, S.544. 
Die untergehende Welt des "kultivierten", nach Westen orientierten Adels findet eine letzte edle Verkörperung in der reinen und schönen Katja. Doch der Intelligenzler Dar'jal'skif verläBt ihre Sphäre und verfällt der sinnlichen, häßlich-verfuhrerischen Matrena, der Verkörperung des wilden, unkultivierten Volkes. Im Augenblick seines Untergangs erkennt Dar'jal'skij, daß sein "ins-Volk-gehen" kein Weg zum Wesen RuBlands, sondern in die Abgrinde östlichen Barbarentums gewesen war. ${ }^{1)}$

Das elgenartige Verhältnis Bloks zur Welt des russischen Landadels hat schon imner die Blographen Bloks bewegt. Die Verwurzelung Bloks im Adel legt A.V. LunaCarskif seiner klassischen Darstellung von Bloks gelstigem Standort zugrunde. Lunacarskif kannte das geistige Leben des vorrevolutionären RuBland wie kaum ein anderer marxistischer Ifteraturkritiker. Sein Aufsatz iiber Blok, 2) obwohl streng ldeologisch im Grundsätzlichen, zeichnet sich durch ein wohltuendes Gespfir fllr den mystischen und irrationalen Charakter von Bloks Weltbild aus. Lunacarskif ist luberdies zu frei und ehrlich, als dab er sich zu einer Assimilierung Bloks an die kommunistische Ideologie aus Grinden der kunstpolitischen Opportunität ${ }^{3)}$ oder zu einer "vulgärsozio-

1) Vgl. Moðul'skij, Belyj, S.157-168.

2) A.V. LunaCarskij, A. Blok. Vstupitel'naja stat'ja k sobranije sotinenif A. Bloka v 12 tomach, 1932-36, t.1, L. 1932. Der Aufsatz, der als Einleitung in die groBe BlokAusgabe besondere Bedeutung hatte, wurde wieder abgedruckt in: A.V. Lunatarskij, Sobr.sot. v 8 tomach, 1.Bd., S.464496. Nach dieser Ausgabe wird zitiert.

3) Dieser Vorwurf muB mit mehr oder weniger Nachdruck gegen fast alle sovetischen Darstellungen seit Trockif erhoben werden, insbesondere gegen die zahlreichen Arbeiten von V1. Orlov. Dieser Blok-Spezialist kann zwar den "idealistischen" Charakter von Bloks Weltbild nicht leugnen, versucht aber, Bloks Entwicklung als Annäherung, wenn auch mit unbewältigten Resten, an die revolutionäre Ideologie des Kommunismus darzustellen. Besonders kraB ist der propagandistische Eifer bei M. Baade, "Zur Aufnahme von Aleksandr Bloks Poem "Die 2 wölf" in Deutschland" (in: ZfSl, Bd.IX, Heft 2 und 4, 1964). Fllr Baade "besteht zunächst und vordringlich die Verpflichtung, sich mit den verfälschenden Interpretationen deutscher Herkunft unversöhnlich auseinanderzusetzen.. Daruber hinaus gilt es, sichtbar $2 u$ machen, von welch aktueller Bedeutung, von welch propagandistischer Wirksamkeit das Wissen um den Entwicklungsweg Aleksandr Bloks als Mensch und Klinstler gerade fllr unsere Zeit ist..." (aao, Heft 2, 
logischen" pauschalen verdammung Bloks hergeben wirde. 1) Da das LS Bloks eigenen Werdegang gleichsam in st1lisierter und abgeklirzter Splegelung enthalt, sind Lunacarskijs Aussagen uber Bloks Verhältnis zur Welt des russischen Adels, zum kapitalistischen Burgertum und zum Bauerntum von besonderem Wert. Als entscheldende Tatsache wertet Lunałarskif Bloks Herkunft aus dem Milieu des russischen Landadels:

"Blok ist ein Vertreter des Adels... In gewissem Grad kann er als der letzte hervorragende Kilnstler des russischen Adels bezeichnet werden."2)

Der Haß auf den Kapitalismus und das Burgertum sowie die Ideal1sierung des Bauerntums im Geist der revolutionăren Romantik, des primitiven Sozialismus Herzens, des gelebten Christentums Tolstojs, - das 1st nach LunaCarskij typisch flir den Adel, der sich tlber sein eigenes Ende klar wird. 3 )

Blok list abgestoßen von der im ganzen als ekelhaft empfundenen Gegenwart.

"Und vielleicht kann man nicht nur im Flug zum heiligen Sehnsuchtstraum auf weißen Flügeln... die anderen Welten berlihren, sondern auch auf dem Grund des Lasters, ... Im "Abgrund" die Verbindung mit einer ewigen Kraft finden, die jenseits von Gut und Böse steht, die aber den Menschen aus allen beengenden Regeln, Problemen, Unsicherheiten, Sorgen befreit und inn in den flammenden Uzean einer außerhalb von Zeit und Raum wirkenden inusik des echten seins tauchen labt."4)

Lunatarskif bezelchnet Blok als "Revolutionär in Beziehung auf das Dasein, wie es sich täglich darbietet". 5) Der Kern von Bloks Weltbild ist die "Musikalität".

"Die musikalische Auffassung der Welt, die feste Uberzeugung, das das innere hesen des Seins musikalisch lst (das heibt nicht tonal, sondern vor allem emotioral-dynamisch...) haben Blok sein

S.557). Dieser Standpunkt ist glifcklicherweise in der UdSSR liberwunden. ( $V_{B}$ l. die Darstellungen $A$. Turkovs und $B$. Solov'evs, der in seinem sehr umfangreichen Buch "Poèt 1 jego podvig" auf die in seinem Aufsatz "Vol ja $k$ podvigu", in: Zvezda 11, 1955, S.157-172, zu splirende Tendenz der Interpretation Bloks als eines "Realisten" verzichtet hat).

1) Gegen "vulgärsoziologische" Verfälschungen polemisiert $P$. Gromov, $\dot{A}$. Blok, S.132ff... Er hat dabei besonders die Darstellungen des streng marxistischen Literaturwissenschaftlers $V$. Desnickijs im Auge, der m.E. Jedoch trotz seiner Ablehnung Blok eher gerecht wird als Gromov.

2) Lunacarskij, aao, S.465.

3) ders., aao, s.465f.

4) ders., aao, S.467.

5) ders., aao, S.467. 
ganzes Leben begleitet."1)

Es ist auch abwegig, in Blok einen Widerstreit von mystischromantischen und realistischen Prinzipien hineinprojizieren zu wollen.

"Elemente eines Realismus, im vollen Sinne dieses Wortes, 2 ) gibt es bei Blok fast kelne... Als er sich von der himmelblauen und rosaroten Mystik abkehrte, versank er in eine andere, in eine trunkene, sinnliche, zilgellose Mystik."3)

Blok stammte aus der Adelsklasse, war aber zum "Schreiberling" deklassiert, der vom Dichten leben muBte. Er wuBte, daB die alte Adelskultur tot war. ${ }^{4)}$ Doch weder die Bourgeoisie, noch die professionelle, entwurzelte Intelligenz konnten nach seiner Meinung die missische Kultur weitertragen. ${ }^{5)}$

"Wenn die Adelswelt zusammenbrach, wenn alles zusammenbrach, dann konnte man nur noch auf das rätselhafte "Volk" hoffen. "6) Die Unbehaustheit in Bloks Aufsatz "Bezvremen'e", der thematisch das IS vorwegnimmt, wird von Lunacarskif soziologisch gedeutet.

"Der Gutsherr, aus seinem sorglosen Leben geworfen, hat längst seine Naturalwirtschaft vergessen, er ist deklassiert; man hat $1 \mathrm{hm}$ das Letzte genommen, Jenen trauten Herd, den Hof, die "liebe Erde"..."7)

In Rausch, im Orglasmus, in der "Musik" sah er etwas, "was dem "Wesen der Dinge" năher war, als ein maßvolles Leben in einem weißen Herrenhaus." 8 )

Iuna Carskijs sozlologische Betrachtungsweise mag einseitig sein. Insbesondere wirkt die von inm stillschweigend vollzogene Verbindung von adliger Herkunft und "musikalischer" Weltanschauung etwas kilnstlich. Selne Aussagen ilber Bloks nur musikalisches, orgiastisches Verhältnis zur Revolution, in der er nur eine "elementare kosmische Erscheinung"9) sah, Uber Bloks Enttäu-

1) ders., aao, S.473, Vgl, dazu S.84/15.

2) D.h. einer "einbödigen", nur auf das greifbar Reale sich beschränkenden Sehweise.

3) Lunałarski $j$, aaO, S.475f.

4) ders., aao, s.480.

5 Vgl. dazu Einleitung zum 3. und 4.Bild.

6) ders.., aao, S.481.

7 ders., aao, S.482.

8) ders., eao, S.478.

9) ders., aao, S.493. Der Formuliemung LunaXarskijs, die Bloks Einstellung zur Revolution von 1917 zusammenfaBt, lautet: "Wir sind Zeuge eines völligen politischen Idiotismus." Len ist nichts hinzuzufilgen. 
schung am Gang der Dinge, als der "Gelst der Musik" aus der Revolution entwich, ${ }^{1)}$ durfen als endgultig angesehen werden. Doch findet auch Lunačarskijs Einordnung Bloks in die Reihe der "deklassierten Adligen" in Bloks Blographie, Weltbild und dichterischem Werk genugend Unterstutzung.

Die "adige" Atmosphäre von Bloks Jugend und seiner fruhen Gedichte einschlieblich der "Stich1 o Preskrasnoj Damen" hebt besonders $\mathrm{K}$. Cukovikif hervor.

"Wenn er sich an seine Kindheit erinnerte, wiederholte er ständig, daß das eine adlige Kindheit war... - Fur seine Pamilie hat er nur ein Epitheton - adlig... Sein ÄuBeres war herrschaftlich (barskoje)... Seine Hochzeit war herrschaftlich, sie fand nicht in der Gereindekirche, sondern in der alten, zum Gutshof gehorenden Kirche statt...3) Die "Gedichte von der Schonen Damen konnten nur in einer herrschaftlichen Panilie entstehen: man kann sich nicht vorstellen, dab bel einem Nicht-Adligen... die voreheliche Verliebtheit so andauernd, so losgelöst vom täglichen Leben upd ein so unmenschlich erhabenes Gefühl hätte sein können." 4 )

Cukovskijs Hinweise auf die Schilderung des 1dyllischen "Adelsnestes" in Bloks Poem "Vozmezdije" (Die Vergeltung), 5) auf die "Avtoblografija" (Autoblographie) von 1915, 6) besonders aber auf die "Stich1 o Prekrasnoj Dame" muß durch den auf das IS ergänzt werden.

Ein wesentliches Thema des IS, das wie immer bei Blok einen stark selbstblographischen Anstrich hat, 1st der Zerfall der Adelswelt, 7 ) der Niedergang der "goldenen Ze1t", 8 ) deren Symbol

1) ders., aao, S.490.

2) Vgl. v.a. die Blographien seiner Tante; M.A. Beketova, A. Blok; dles., Blok 1 jego mat'; dies., Sachmatovo. Semejnaja chronika; und die Erinnerungen Belyjs.

3) Bloks Hochzelt war ein letzter Nachhail der russischen "Altkultur".

4) Cukovskij, $A$. Blok, in: Sobranije socinenif $v 6$ tomach, Bd. 2, S.275ff. Zu Bloks "Aristokratismus" vgl. V,482; VII, 283, Eintrag vom 14. Jul1 1917.

5) Vgl. III,466, 471. Dieser Tell entstand im Jahre 1921; dazu: III, 463 .

6) VII,5-16.

7) Die Adelswelt 1st in $P 1$ noch stark mittelalterlich stilisiert.

8) Vgl. "Rossifa", III,254f., 1. Zeile. Die Stadtzivilisation lat die "elserne Zeit"; vgl. Einleitung zum 3.Bild. Das gleiche Thema hat Bloks Gedichtzyklus "Solov'iny s sad" (Der Nachtigallengarten; 1915). 
das "weiBe Haus" Germans 1st. Die Atmosphäre hochgespannter Erwartung, die den 2yklus der "Gedichte von der Schönen Dame" bestimmt, 1st im 1. Bild des LS elner Stimmung wehmlitiger Onbestimmtheit gewichen, die weniger an den ekstatischen Grundton der "Gedichte von der Schönen Dame", als an die Melancholie von Maeterlinks "Pelléas et Mélisande" erinnert. Die "aurora" der "Schönen Dame" wich dem milden Abendrot, die das Ende dieser "Insel der Seligen" beleuchtet. Die Figuren glelchen in ihrer traumwandlerischen, zwischen Schlaf und wachen schwankenden Kraftlosigke1t, den Märchenbildern des Jugendstils. Der "schöne Jilngling" German, die "weibe" Helena, der rätselhafte Mönch und die ahnungsvolle Mutter Germans erinnern an die halb mythischen Gestalten der "Gedichte von der Schönen Dame", noch mehr aber an den Mythos von Bloks 1dyllischer Jugend, vom "dobryj molodec" Saba, den die Erinnerungen Belyjs und die Blographien der Beketova der Nachwelt weitergeben, und in dessen Licht Blok seine Jugend offenbar auch selbst gesehen hat. Germans Streben in die Perne, im LS weniger der von Blok gewlinschte faustische Drang als die ewig romantische Sehnsucht nach dem Unbekannten, erinnert an die Aufbruchsstimmung, die Blok aus dem Elfenbeinturm der "Schönen Dame" trieb."

Die filr Cukovskif unerklärliche Spannung zwischen Bloks 1dyll1scher Jugend und seinem ubersteigerten KatastrophenbewuBtsein, 2) die LunaCarskif soziologisch deutete, schlägt sich im 1.B1ld des LS nieder als kinbruch des Windes, des "Lieds des Schicksals" in die frledliche, entrickte Atmosphäre von Germans Haus. Im LS interpretiert Blok seine Abkehr vom hochgespannten Idealismus der "Schönen Dame" als Gehorsam gegenuber dem "Gelst der Musik", dem Walten Uberirdischer, kosmischer Kräfte. Mit seinem Aufbruch setzt German-Blok die Suche des rätselhaften Mönchs, $d . h$. der Verkörperung der besten Traditionen des "heiligen RuBlands", nach dem Wesen RuBlands fort. Das wahre RuBland, ver-

1) Vgl. VIII,79, Brief an S. Solov'ev rom 20. Dez. 1903; VIII, 94, vom 8. März 1904; Zap.kn., 63, Eintrag von Ende April 1904; VIII, 104-108, Briefe an Je.P. Ivanov vom 15. Jun1 und 18. Jun1 1904 .

2) Cukovskij, aaO, S.275, $278 f f$. 
kn̈rpert in Paina, 1st nicht im adligen Herrenhof zuhause, wie der Monch offenbar annahm, auch nicht in der Grobstadt, wo German nur einem entstellten Zerrbild RuBlands begegnet, sondern in der Weite des russischen Landes. 1)

Im Aufbruch Germans schlagen sich Bloks personliches Schicksal und die zeitstimmung nach der Revolution von 1905 nieder.

"Ja und uberhaupt, es begann eine beunruhigende zeit. In der Luft lagen die zerstorerischen 2eichen der Revolution. Davon war die gesamte neue Literatur durchdrungen. Bal'mont, Brjusov, die Merezkovskijs, Vjac. Ivanov, Hamsun, Przybyszewski - alle sagten dasselbe, indem sie zum Protest gegen ein ruhiges, ausgeglichenes Leben, gegen den Pamilienherd aufriefen, zum Verzicht auf Glllck, zur Absage an den gewohnten Lebensstil, zur zerstbrung der Familie und der Häuslichkeit. All das ergriff Al.Al. Die Ideologie jener Ze1t erklang später besonders deut$11 \mathrm{ch}$ in seinem "Lied des Schicksals". Der Weggang Germans vom persönlichen Gluck, aus dem stillen Hafen, - das ist das Fcho jener Stimmungen... In dieser stimmung war der Dichter, als er von zuhause und von den Pittichen der Mutter wegging und zusammen mit seiner Frau in eine eigene Wohnung ubersiedelte."2)

1) Vgl. Einleitung zum 5.B1ld, S.285f.

2) Beketova, Blok, S.1011. 
S.44/1 "Verbnaja Subbota" (wbrtl. "We1densamstag") ist der Samstag vor Palmsonntag. An diesem Tag werden im ostkirchlichen Brauchtum Weidenzweige, Symbol des neu beginnenden Lebens nach dem Winter, in der Kirche geweiht und dann umhergetragen; vgl. Cechovs Erzählung "Archijeref" (Der Bischof). Seit der Spätantike wird in der 0atkirche dieser Tag als "Lazarus-Sonnabend" gefelert (Auferstehung des Lazarus; Joh.11). "Im Hymengut dieses Tages wird auf die eigene Auferstehung Christ1 von den Toten hingewiesen." (Onasch, Einfuhrung, S.144). Germans Erwachen wird von Blok als Auferstehung von den Toten dargestellt. Sein Weggang erscheint als der Beginn seiner Paseion. Die christliche Symbolik ist jedoch säkularisiert. Der Hinweis auf den Palmsamstag hat besonderes Gewicht, da er die einzige absolute Zeltangabe 18t. In F1 wird dieser Tag im Gespräch genannt ( $\mathrm{ggl}$. Abw.82 u. S.53/5). In F2 steht die Zeitangabe nur in der Regieanwelsung und lot nur fur den Leser in inrem Symbolwert zu erkennen.

S.44/2 "Hundegebell" erwähnt Blok auch in der Beschrelbung der Idylle von Sachmatoro in seinem Poem "Vozmezdije" (vgl. III, 468).

Vogelgezwitscher, Bestandtell des locus amoenus, hat hier neben der Punktion, die Idylle von Germans Haus zu unterstreichen, einen Symbolbezug zum Dionysos-Kult. Vgl. Nietzsche, Die Geburt der Tragödie, S.181:"...erster dionysischer Lockruf..... Im Nahen des Frihlings..."; S.184: "...wonnig lockender Ruf des dionysischen Vogels." S.44/3 In der Darstellung des Hauses Germans und der Helena hat die Farbe weiB die Bedeutung des Ruhigen, Reinen. Vgl. VIII, 88: "Chočteja 8vjatogo, t1chogo 1 belogo" (Ich will He1liges, St1lles, WeiBes).

"Ganz in We1B" tritt auch Nina Zarexnaja im 1. Akt von Cechovs "Cajka". (Die Möwe) auf, wo aie in ihrem Monolog die damals beginnende strömung des Symbolismus darstellt. Im IS atehen der ganz in We1B auftretenden Helena die Mutter Germans "In schwarzem Kleid" (S.5) und Faina "In einem einfachen schwarzen Kleid" (S.26) gegenuber. 
Im Gedicht "V belom", dae Bal'mont im Jan. 1904 beim Beouch Bloke und selner Prau uber Ijubor' Dmitrijevna gedichtet hatte, lautet 2.2: "Du warst ganz in We1B" (Bal-mont, Stichotvorenija, S.3081. vgl. Anm. S.634). Man vgl. etwa Blok, I, 194. Pur Bloks Zeltgenossen war der blographische Zusammenhang klar. Auch Kolombine, in der sich wie in Helena Bloks Prau verbirgt, tritt im "BalaganCik" ganz in weiB auf (IV,11 u. ..), wobel "weib" die Apokalypse und den Tod symbolisiert.

S.44/4 Die Regleanweloungen im LS sind integrierender Bestandtell des Werks. Pur sie gilt in hohem Mabe die Peststellung Bicillis uber die Regleanweisungen Cechovs: "Zum Tell sind diese Angaben eindeutig nicht fur den Regisseur, sondern fur den Leser bestimmt. Es 1st, als hätte Cechov (hier: Blok) manchmal vergessen, daB das, was er schrieb, fur die Buhne bestimmt war." (Bicilli, Cechov, S.126)! Die Regleanwelsungendes IS ähneln in ihrem dichterischen Charakter stark den Regleanwelsungen von L. Andrejevs Stuck "ŽLizn' Čeloveka" (Das Leben des Menschen), das Blok sehr geschätzt hat. (Vgl. Andrejer, $P^{\prime}$ e8y, 89-151, v.a. S.93, 100, 121, 126, 131, 143 u.a.). Die szenerie des 1.Bildes hat stark autoblographischen Charakter. Die Lage von Germans Haus erinnert deutlich an Sachmatovo, dem etwa $70 \mathrm{~km}$ nordwestlich von Moskau gelegenen Landsitz Bloks. Die Landschaft Mittelmublands gibt in vielen Gedichten Bloks den Hintergrund ab. Die Bedeutung Sachmatovos in der geistigen Blographie Bloks kann nicht hoch genug eingeschätzt werden. Bloks Leben und Werk 1 st bestimmt von den belden Polen Sachmatovo und Petersburg. Zur Bedeutung Sachmatovos fur Blok vgl. Lesnevik1f, "Sachmatovo. Semejnaja chronika", (S.116 zum LS; der Autor referiert die unveroffentlichten Erinnerungen von Bloks Tante M. Beketova); Beketova, A. Blok, S.37f.; Belyj, Vospominanija o Bloke, Epopeja I, S.150, 23611.. 24211.; Mocul'sk1f, A. Blok, S.20; Bonneau, L'Univers poétique, S.37f1.; (Lesnevsk1j, aa0., S.104, sagt: "skroz' Šachmatovo, દerez Sachmatovo videl Ros81ju".). 
Zu den schönsten Gedichten, die die Landschaft ron Sachmatovo als Hintergrund haben, gehören II,751., 77, 106; III,1721., 254 und viele Gedichte ron Band I. Bine Sch1lderung der Idylle von Sachmatovo, die in vielen Deta1ls mit dem 1.B1ld des IS ubereinstimmt, gibt Blok in seinem Poem "Vozmezdife" (Vergeltung), III,46619. und in den Skizzen zu einem nicht ausgefuhrten, stark blographisch gefärbten Drama "Nelepyj Celovek"; vgl. VII,251ff..

S.44/5 Diese Passage 1st in $\mathrm{F} 1$ wesentlich konkreter (vgl. Abw.5)). S.44/6 Rus8. "lebed'" lst hier feminin (normalerwelse: lebed' m. - lebedka 1.); dieser Gebrauch 1st hăufig in der russischen Folklore. Der Schwan 18t in der russischen "Folklore" ebenso zuhause (Igorlied; Zadonł̌lina; Bylinen; Märchen) wie in der Poesle und Malerel um die Jahrhundertwende (Bal'mont, "Belyj lebed'"; Vrubel's beruhmtes Bild "Carevna-Lebed'"). Der Schwan war eines der bellebtesten Tiersymbole des Jugendst1ls: Hof stätter. Symbolismus, S.207. Er 1st Gegenstand vieler Gedichte französischer und deutscher Dichtungen, v.a. selt Baudelaire (Mallarmé, Prz. Symbolisten; vgl. Mlchaud, Le Message poétique, S.40411.; R.A. Schröder, St. George, Dehmel, R1lke u.v. a.).

5.44/7 Germans Traum von der Schwanenjungfrau steht in Beziehung zu dem Märchen, das die Alte der Faina erzählt (S.761.). German träumt von Faina, die im Märchen der Alten als Schwanenjungfrau erscheint und von einem jungen Märchenprinzen erlöst wird.

S.44/8 Im 1.B1ld des LS 1st mehrmals von Träumen die Rede. Blok maB Träumen groBe Bedeutung be1. Vgl. Zap.kn., 21, 41; VII, 19; VIII,142. Das Poem "Nocnaja flalka" (Dle Nachtviole), II,26-34, lst die Uberarbeltung eines Traumes (II,386-88). Der Traum eröffnete Blok den Zugang zu der hinter der Tageswelt verborgenen Real1tät, die Korrespondenz mit der Weltseele. Bel Blok finden sich Anklänge an die romantische Deutung des Traumes, verbunden mit dem EinfluB der mystischen Dichtung VI. Solov'evs (vgl. St1chotvorenija, S.117, 2.31.: "V et1 sny na javu..." S.139 "Son najavu", S.227, 231f. u.a.) und Dostojevskijs 
("Idiot"; vgl. IV,72). Weit mehr als siebzig Gedichte handeln allein im ersten Band von Traum und Traumgeslchten. Blok bezleht sich bel der Erklärung dieser Gedichte ausdrlicklich auf VI. Solov'ev (vgl. VII,347). Zur Bedeutung des Traums bel Blok vgl. v.a. II,106f. ("Rus'n); II, 185f. ("Neznakomka". Vgl. Strophe 7, Z.2 mit I,380, Z.20); III,29f., 330, Z.92ff.; V.168 (über Gribojedov "Gore ot uma"); VI,169 (Titel); Zap.kn., 21, 41, 53, 71, 149, 221, 232, 237. Blok kannte mit sicherheit die Darlegung, die $R$. Wagner von Schopenhauers Traumtheorie gab. (Vgl. Wagner, Hauptschriften, S.267f.). Wagner stiitzt sich auf Schopenhauers Ph1losophie bel der Erklärung seines elgenen Künstlertums.

Im LS geht, ganz in Entsprechung zu Wagner-Schopenhauer, der Traum Germans in Erfullung in der Begegnung mit Faina Im 5.Bild. Die prophetische Bedeutung des Traumbilds wird dann erst offenkundig.

S.44/9 Die etwas rätselhaften Worte Germans unterstreichen die Abgeschiedenheit seines Hauses.

S.45/1 Die großen, traurigen Augen des Mönchs sind gleichsam sein leitmerkmal. Sie sind Symbol seines gelstigen Wesens, selnes Wissens um die "dahinterliegende" Wirklichke1t. In ihrer Trauer druckt sich sein Scheitern aus.

S.45/2 Der Mönch erscheint im IS als gefallener Engel. In F1 1st dieser Aspekt stark ausgearbeitet (vgl. S.55/4)). In F2 verzichtete Blok auf die Darstellung der myst1schen Natur des Mönchs zugunsten elner größeren Wahrscheinlichkeit und Lebensnähe.

S.45/3 Demnach stehen Germans Traumgesicht und das Erscheinen des Mönchs in einem Inneren Zusammenhang. Beide Ereignisse bestimmen Germans Schicksal.

S.45/4 Vgl. S.44/8. Der Gegensatz "son - Jav'" (Traum - Wirklichke1t) findet sich in F1 schon fruher (vgl. Abw.7)). Er lot in Bloks Werk eine feste Formel.

S.45/5 Helenas mehrfach geäuBerte Unruhe verdichtet sich zur Angst vor den Worten, die der Mönch sagen wird. 
S.45/6 "Ne boj8ja!" sind worte der Bibel. Vgl. Im AT 1.M08.15, 1; 26, 24 u.b.; 1m NT Mark.5, 36 u.8.

S.45/7 Der Freund nimmt S.46 dieses Motiv in anderer Form wieder auf.

S.45/8 Die erste Szene 1st hier zu Ende. Sie zeigt Merkmale, die fur andere Szenen des LS ebenfalls typisch sind. In dialogischer Rede werden in einer Art zyklischer Weiterbewegung wenige Motive eingefuhrt, wiederholt und neu verbunden. Die Rede list nicht diskursiv, sondern sie besteht aus einem Geflecht von wenigen, alogisch verknupften Elementen, deren Wiederholung und Häufung den PluB der Bewegung bremsen. Blok wiederholt Bilder und Motive nicht nur im engen und uberschaubaren Rahmen einer Szene (hier: Traum, weiber Schwan, weibe Helena, kranker Monch, Einsamke1t, Unruhe der Helena, Schweigen des Mönchs), sondern auch luber grobere Abstände hinweg. Im weiteren Verlauf werden nur diese Pälle der "Fernwirkung" aufgefuhrt.

S.45/9 Helena wird hier mit einem Engel verglichen. Die Prau als Bngel lat ein häufiges Bild der Romantik. Es geht zurick auf Beatrice in Dantes Divina Commedia und aup Laura in Petrarcas Canzoniere. Die geliebte Frau ist ein Engel, der vom Himmel herabgestiegen 1st, um das Herz des Geliebten zu reinigen, inm belzustehen, sein Leben zu behilten. "La femme-ange est un type romantique." (Tleghem, Le Romantisme, S.240). Bloks Abhängigke1t von der deutschen Romantik hebt zuletzt Kluge, Westeuropa und RuBland, S.27ff. hervor.

In Bloks Gedichten, v.a. Im 1. Band, kehrt dieses Bild häufig wieder. Auch hier lot der EinfluB VI. Solov'evs deutlich zu spúren. Vgl. I,79 (dazu VII,347), 128, 129, 390, 393,405, 436, 4391, u.v.a.; II, 102 .

Das Erscheinen von Engeln bel Blok entbehrt jedoch der echt religiösen Bindung ( $\nabla$ gl. Kluge, aa , S.44f.). Es handelt sich um "ruinöses Christentum".

S.46/1 Die Szenerle im LS 1st präraffaelitisch angehaucht. P1 verbindet noch stärker als $P 2$ eine anscheinend alltägliche, "reale" Episode mit mystischem Beiwerk. Vgl. 


\section{Abw.20).}

S.46/2 Diese unmotivierte Wendung fuhrt zur Enthullung des Charakters des Freundes: seine Devise 1st "das 18t zum Lachen". Er 1st Vertreter des Zynismus, einer Gelsteshaltung, die Blok in seinem Aufsatz "Ironijan (Ironie; v,345-349) scharf verurtellt hat. Der Aufsatz zeigt, daB Blok selbst von dieser Frage stark betroffen war.

S.46/3 Anspielung auf die Kritik der reinen Vernunft von Kant, wo Raum und Zeit als die apriorischen Anschauungsformen bel jeder Erkenntnis erklärt werden. Der Freund stellt sich selbst als vernunftigen Realisten dar. Blok spielt hier vermutlich auf die Kantstudien Belyjs an, der sich in gewisser Weise hinter der Gestalt des Preundes verbirgt. Ab Sommer 1904 (erster Beguch in Sachmatovo) widmete sich Belyj dem Studium Kants und der Neukantianer Riehl und Rickert. Vgl. Belyj, Vospominanija o Bloke, Épopeja II, S.105f.; Mocul'sk1j, A. Belyj8, S.70; Stepun, Mystische Weltschau, S.11 u. 2921. u. 358. Blok selbst hatte ein recht elgenartiges Verhältnis zu Kant. Nach elner vorwiegend ablehnenden Haltung, die inren Grund in Bloks Abscheu vor jeder systematischen Philosophle hatte, interpretierte der Dichter den Philosophen im Sinne einer mystisch gefärbten Lebensphilosophie. Vgl. Kluge, Westeuropa und RuBland, S.55f1. und I,294 mit Anm. auf $\mathrm{S.623}$.

S.46/4 Dem Leben "in Zeit und Raum" stellt der Freund das weitabgeschiedene Leben "auf den Inseln der Seligen" gegenuber. Die Inseln der Seligen werden erwähnt bel Homer, Odyssee IV,561ff. und Hesiod, Werke und Tage, $159 f 1$. Sie lagen nach griechischer Vorstellung am Westrande der Erde im Meer. (Möglicherweise steht der Sonnenuntergang im 1.B1ld des IS und die Lage von Germans haus am Meer in einer frihen Phase der Entstehung des IS damit in Zusammenhang. Die Sonnensymbolik ist im LS jedenfalls deutlich zu sehen.). Dort lebten die Lieblinge der Götter dem Tod entruckt in ewiger Jugend. Nach seinem Tod wurde, nachhomerischer Uberlieferung zufolge, auch Achilleus auf die Inseln der Seligen entruckt, wo er 
sich mit Helena verband. Ihr Sohn war Euphorion. (Daran knupft Goethes Paust II an).

S.46/5 In dem Verhaltnis des Freunds zu Helena, das sich erst im 6.B1ld löst, splegelt sich die Llebesaffäre zwischen Belyf und Bloks Prau wider.

S.46/6 Mit dieser Ansplelung auf den Namen ihres Gesprächspartners fuhrt Helena das Motiv des falschen Preundes ein, das im weiteren Verlauf des Stucks weiter entwickelt wird. Vgl. Andrejer, P'esy, S.126 in "Žizn' celoveka".

S.46/7 Blok behält die altertúmliche Wendung "ot mira sego" be1. Vgl. Joh.8, 23; 18,36 .

$5.46 / 8$ Blok bezelchnet seine Prau und sich als "ljudi neobyknovennyje" in der Ruckschau auf seine fruhere mystische Liebe. (VII, 353; in dieser wichtigen Notiz vom 6. Jan. 1919 versucht Blok, den Untergang Sachmatovos, das Symbol dieser Llebe, vom Standpunkt des "reuigen Adligen" her zu verstehen). Die ÄuBerung des Freundes ähnelt auch auffallend einer Passage bel Belyj, Načlo veka, S.338, 341: "...1 Ljuba 1 Sała - osobennyje." Der blographische Bezug lat offenkundig.

S.46/9 Diese Passage ähnelt in manchem der Darstellung, die Bely $f$ von seinem ersten Besuch in Sachmatoro gegeben hat. Vgl. v.a. BelyJ, Nacalo veka, S.331-347. (Die bedeutsame, rätselhaft-mystische Rolle von Bloks Prau in den Augen Belyj8; der "dunkle", labile Charakter Bloks).

S.47/1 Diese Prage fuhrt v8lig unmotiviert zum wichtigsten Erelgnis des 1.Bildes, dem Weggang Germans. Der Freund we1B berelts, daB German sein Haus verläbt; er setzt das als allgemein bekannt voraus, obwohl weder German und Helena, noch die Zuschauer etwas davon wissen. Hier endet die 2.Szene, die in ihrer dialogischen Form und der mehrfachen wederholung von Bildern und Motiven ebenfalls einen statischen Charakter hat.

S.47/2 Zum Gegensatz zu Helenas Kleldung vgl. S.44/3.

S.47/3 Man beachte das christlich-orthodoxe "Lokalkolorit". Die Mutter verkobpert gegenuber Helena eine christlich geprägte Lebenshaltung. 
S.47/4 Die Mutter hatte, wle ihr Sohn German, ein Traumgesicht. S.47/5 Helena meint den Mönch.

S.47/6 Hier endet die 3.Szene. Sie hat die Aufgabe, die Mutter Germans als Antipoden der Helena elnzufuhren. Die Hutter stellt die Verbindung zu dem hinter der Buhne spielenden Geschehen her. Damit wird die folgende Szene vorbereitet.

Die Abweichungen 4)-33) der drel szenen in $\mathrm{F} 1$ gegenuber F2 sind weitgehend stilistischer Art. Blok strich v.a. wederholungen und errelchte eine gewisse straffung.

S.47/7 Die Abwelchung 35) bringt v.a. mehr Detalls uber das Aussehen des Mönchs.

S.47/8 Blok zieht hier zwe1 Bibelpassagen zusammen, nämlich Luk.24, 36 (bzw. Joh.20,19.21.20.) und Luk.10,5 (bzw. Matth.10,12). Dabel vermeldet er die arch. ksl. Form "mir domu semu".

S.47/9 Hier folgt in F1 elne längere Passage, an deren Ende der Freund vom Mönch als welterfahrener Zyniker "entlarvt" wird. Vgl. Abw.36).

S.48/1 Blok verwendet das Wort "prekrasny f" ("Prekrasen German..."). Es ist bei Blok ein "mot-clén, das er in seinem dichterischen und publizistischen Werk häufig und mit einer ganz besonderen Bedeutung benutzt. Ein Vergleich der verschledenen Stellen, wo Blok dieses Wort gebraucht ( $V, 51$ im Zusammenhang mit einer mag1schen Welterfahrung; $V, 2381 ., 290,384,433,435 \mathrm{im}$ Zusammenhang mit Fragen der Kunst- und Lebensphilosophie; V,473 am ausfuhrlichsten; VI,13; VIII,267 im Brief an Stanislavskif vom 9.12.1908; VIII,265ff.; Im Titel "Stich1 o Prekrasnof Dame"; bezliglich RuBland "Tro1 prekrasnyje Certy", III,254; bezügl1ch des Lebens uberhaupt "mir prekrasen kak vsegda", III,344, Z.460), zeigt, daB er danit nicht nur die ästhetische Schönheit ("krasivyj") meint, sondern eine ethische Größe, ähnlich dem platonischen "Gut-Schönen" (Kalokagathie). In den "Stich1 o Prekrasnof Dame" lat die pseudo-relig1öse Sinngebung vorherrschend. Später, mit der Hinwendung zu einer tragischen Lebensphilosophle, wird die ästheti- 
sche Wurzel deutlicher; "prekrasnyf" bzw. "Prekrasnoje" 1st die asthet1sch-eth1sche Qualität, die im "Geist der Musik" spurbar wird.

S.48/2 Der Mönch nimmt das B1ld vom Engel auf. Doch im Gegensatz zum Freund bezleht er es auf Falna. Im Irrtum des Mönchs, der Faina in der Idylle von Germans "weiBem Haus" zu finden hofft, wollte Blok das Scheitern VI. Solov'evs darstellen, der das "Ewig-Weibliche" im hellen Ideal verkörpert sah.

S.48/3 Faina 1st eine "Chr1stusbraut"; vgl. S.43/9, S.55/6, Einleitung zum 5. Bild, S.312 und S.83/4.

S.48/4 "o prekrasnof Faine" lat mit "Prekrasen German..." zusammenzubringen. Der Mönch verbindet German und Falna m1t der Klammer "prekrasnyj": In Ihnen wirkt eine Qualität, die sie vor den anderen Personen auszeichnet. Möglicherwelse wollte Blok an das hohe Died 1, 14f. u.ö. erinnern.

S.48/5 Vorverwelse auf das 3. und 4.B1ld. (Vgl. noch $u . S .48 / 12$ ) S.48/6 Möglicherwelse liegt in "...Falna. Tajna..." ein von Blok beabsichtigtes Wortsplel. Zum "Geheimnis" vgl. S.94/2.

S.48/7 German nimmt die Hell-Dunkel-Symbolik, die in den ersten Szenen schon mehrfach auftrat (Haus Germans, HelenaMutter, Helena-German), wieder auf und dehnt sie auf Faina aus. Uber die Dunkel-Symbolik besteht eine weitere Verbindung von German zu Faina. Vgl. a. S.46/9.

S.48/8 Die Bezelchnung Germans als Jingling lot befremdlich, denn German 1st 1mmerhin verheiratet. Blok hat wohl eine Passage aus R. Wagner, Hauptschriften, S.240 im Sinn. Dort 1st die Rede von Schiller und dem "deutschen Jungling", dem Symbol deutschen Heldentums im Kampl gegen Napoleon. German soll der Retter der Faina, die die Verkörperung RuBlands 1st, sein. Kurz zuvor erwähnt Wagner Fausts Verb1ndung mit Helena in Goethes Faust II. S.48/9 Vgl. S.47/8. Die Wlederholung des Frledenswunsches $18 \mathrm{t}$ hier nicht mehr nur eine Begrubungsfloskel, sondern erhält im Hinblick auf die kommende Begegnung Germans mit Faina größeres Gewlcht. 
S.48/10 Der Wind hat bel Blok immer Symbolwert. Im Wehen des Windes spiegelt sich der dynamische Urgrund des Seins wider. Das Motiv wird im Verlauf des Stucks mehrfach wiederholt.

S.48/11 In dieser Passage wird das Verhältnis des Mönchs zum Freund als zwlespältig dargestellt. Offenbar sieht der Mönch im Freund einen Verbündeten, dem auch daran liegt, das German sein Haus verläbt. Obwohl diese Passage in F1 ausfihrlicher 18t, bleibt der Sinn der Worte unklar. $V_{g l}$. folgende Anmerkung! Das russische Wort "lukavo" bedeutet "böse, arglistig, hinterlistig, diabolisch". "Lukaryj" lot im Ksl. ein Synonym für "Teufel" (vgl. Matth.13, 19; 1.Joh.2, 14; 3, 12; 5, 18). Irgendwie 18t es bel Blok mit dem B1ld des Mönchs verbunden. Vgl. "èt1 figury vernych rycarej s opuscennymi zabralami 1 lukarych monachov..." V,88f. Es wird in F1 wiederholt. Vgl. Abw. 38) und 40). Vermutlich versucht Blok damit das Zwiespältige in der Natur Vl. Solov'evs darzustellen, der sich wahrscheinlich in der Gestalt des Mönchs verbirgt. $V_{g l}$. V.449, wo Blok das rätselhafte lachen Solov'evs erwähnt. Dazu V,760, Anm.5 und Stepun, Myst1sche Weltschau, S.92. Viellelcht ist es auch nur der Reflex der "dämonlschen" Natur des Mönchs. (Vgl. S.56/4).

S.48/12 Hier endet die 4.Szene. In F1 18t diese Szene fast doppelt 80 lang wie in F2 (Abweichungen 35)-49)). Dabe1 werden folgende Punkte ausfuhrlicher behandelt: Das Aussehen des Mönchs und die Tatsache, dab er German viel erzählt hat (Abw.35)); die besondere Lage von Germans Haus auf der Höhe, das Lokalkolorit und die Idylle; der zynische, falsche Charakter des Freundes (Abw.36)); die Vermutung des Mönchs, im Hause Germans Faina anzutreffen (Abw.39)); das Rätselhafte des Namens Faina und die Tatsache, daB keiner im Haus Germans die weltbekannte Faina kennt (Abw.41)-48)).

Besondere Aufmerksamkeit verdienen die Aussagen des Mönchs uber Faina. "Die ganze Erde verneigt sich vor der schönen Faina" (Abw.44)). Sie 1st "der Schatz der Welt", sie "sturzt nach ihrem Willen Könige und Helden 
und zwingt Schiffe zur Omkehr" (Abw.46)). Ond als der Freund dem Monch vorwirft, er erzable dae Märchen von der schonen Helena, wegen der sich wirklich Könige und Helden gestritten hätten, und die Schiffe zur Umkehr gebracht habe, da verwahrt sich der Mönch dagegen, die Namen verwechselt zu haben. "Für Sie lst es ein Märchen, doch fur mich ist es Wahrheit. Es war Helena, doch jetzt 18t Faina". (Abw.48)). Der Mönch schreibt hier der Faina göttliche Allmacht zu (vgl. etwa 5.Mos.10, 17 und off.17, 14). Dem klassischen weiblichen Ideal typus Helena stellt der Mönch einen neuen, russischen Frauentypus gegenuber, der in vielen Einzelheiten an Aphrodite (bzw. an die römische Venus) erinnert:

Als Mondgöttin (mit deutlichem Bezug zur semitischen Astarte) war sie die Herrin der Gestirne. (Vgl. I,503f. Dort 1st "Sie" "Astarte". In I,91 18t "Sie" die "Russ1sche Venus". Vgl. dazu S.57/2). Sie entfachte die Liebe in allen Geschöpfen. Weder die Menschen noch die Götter konnten sich inrer Gewalt entziehen. (Vgl. den Homerischen Hymnus auf Aphrodite; Hesiod; Alschylos; Lukrez u.a.). Symbol inrer Macht ist inr Gürtel (II1as, 14, 197ff.). (Vgl. S.85/3). Als allgewaltige, schicksalsmächtige Göttin der himmlischen Liebe (Aphrodite Urania) galt sie in Athen als die "alteste der Moiren". (Faina lst das verkörperte Schicksal. Vgl. Titel und Lied Im 3.Bild). Als Göttin der sinnlichen Liebe und als Ideal weiblicher Schonheit war sie Schutzgattin und Vorsteherin der Hetären (Aphrodite Pandemos). (Faina als Dirne im 3.Bild). Als urspringliche Mondgöttin stand sie in enger Beziehung zu Wasser und Meer ("Schaumgeborene"), und sie verlieh den Schiffern gunstige Pahrt (Aphrodite Euploia). (Vgl. Abw.46) und viele Gedichte Bloks mit Schiffen als Symbol der Hoffnung; "Korol' na plošcad1"). Die der Meeresgörtin Aphrodite geheiligten Tiere waren Schwan und Delphin. (Der Schwan 1st das Tier der Faina im 1. und 5.Bild.). AuBerdem stand Aphrodite in Beziehung zum Totenrelch und der Unterwelt. Daneben war sie eine kriegerische, 
bewaffnete Gobtin. (Diese beiden Aspekte werden im 7.B1ld angedeutet.)

Der römischen Venus war der April besonders heilig (Prihlingsgöttin). (Vgl. Zelt und Natursymbolik des 1.B1ldes). (Roscher, Mytholog. Lexikon; Pauly-Wissowa, Realencyklopädle; Lexikon der Alten Welt).

Obwohl die Bezugnahme auf Aphrodite-Venus im LS deutlich 1st, kann man nicht von einer Ident1tät von Faina mit Aphrodite sprechen. Blok schöpft nicht nur aus elner, sondern aus mehreren Mythologien (neben der griechischrömlschen v.a. aus der germanischen und $2 . T$. aus der slavischen). So können die mythologischen Ansplelungen $81 \mathrm{ch}$ uberschneiden und unterstutzen. Hinter dem Synkretismus verbirgt sich ein privater Mythos, der oft in vorgeprägter Form erschelnt. Die Bezugnahme auf den bipolaren, ambivalenten, Himmel und Erde, Leben und Tod, Liebesfreude und Liebesleid in sich vereinigenden Charakter der Aphrodite-Venus war in hervorragender Welse dazu geelgnet, den in Faina verkörperten Mythos vom elementaren RuBland darzustellen. Bloks RuBlandmythos, der im Grund die besondere Ausprägung eines Weltseelen-Mythos ist (Paina als "sokrovizce mira" in Abw.46), steht wohl hiermit in Beziehung), nimmt $2 u-$ flucht zu verschiedenen vorgeprägten Mythen, die bel analoger Grundstruktur leicht die Materialien fur die Darstellung des privaten Mythos stellen können. "Als Personifizlerung psychischer Eigenschaften scheint Venus besonders die Aufgabe einer Ergänzung des Mannes zu erfullen und das Wunschblld der männlichen Seele, d.h. des unbewaten und infantilen Teils seiner Psyche, zu verkörpern. Venus lst die dem Manne verlorengegangene Hälfte seiner urspringlichen Einheit, von der er nach dem platonischen Mythos durch die Götter getrennt worden war und nach der er seither sucht." (Das moderne Lexikon der Erotik, Band 10, S.149). Die romantische Philosophie der Liebe stutzt sich deshalb häufig auf den VenusMythos (so etwa v. Baader). Auch Vl. Solov'ev nimmt den Venus-Mythos auf. In seinem Gedicht "Das Ewig-Weibliche" 
(Stichotvoren1ja, S.163f.; der Titel 1st deutsch!) wird der Sieg der himmlischen Schönheit uber die 1rdische Aphrodite prophezeit:

Vse Cem krasna Afrodita mirskaja,

Radost' domov, 1 lesov, 1 morej, -

Voe sovmestit krasota nezemnaja

Cizce, sil'nej, 1 živej, 1 polnej.

(Strophe 9)

Blok geht es nicht um die Ablösung und Erhöhung der Antike durch das Christentum, sondern um den Sieg der russischen Schönheit uber die abendländische. Er hat F2 von dem allzu vordergriindig gebrauchten mythologischen Beiwerk befreit.

S.48/13 Wiederaufnahme des Traumotivs.

S.49/1 Hier nimmt German die Worte der Helena (S.45) wieder auf und widerspricht damit der beruhigenden Antwort, die er seiner Frau gegeben hatte. Nun ist in German der Wandel von Ruhe in Aufbruchstimmung vollzogen.

S.49/2 Hier beginnt German, eine Art Motivierung fur seine Absicht zu geben, sein Haus zu verlassen. Diese Motivierung lst nicht psychologisch, sondern "mystisch-kosmologisch". Die Diskrepanz zwischen intimem Gesprächsstil und irrationalem Inhalt füht hier und anderswo $z u$ dichterisch miblungenen Passagen.

S.49/3 Das "Fenster" als Trennung und Verbindung von außen und innen, ist ein Leitmotiv der romantischen Malerei (vgl. Hof stätter, Symbolismus, S.102). In Bloks Werk 18t das Motiv uberaus häufig. (Vgl. I, 13; 127; 191 u.ö., IV,9 u.ö., III,279f. u.ö.)

S.49/4 Hier nimmt German das erste Motto zum LS auf. Auch diese Passage trägt zum christilchen Lokalkolorit bel und rundet den christlich geprägten Charakter der Mutter ab. Allerdings wird die Punktion des Mottos weder an dieser Stelle, noch bel der wederholung 5.53 ganz klar. In beiden Fällen steht es ziemlich unverbunden im Kontext. Keinesfalls dient es nur dazu. Helena zu beruhigen. Das Motto muB vielmehr auf das gesamte Stück bezogen werden. In einer langen Erwiderung auf mehrere Fragen A. Belyjs zum Wesen und Charakter der Schönen Dame (Bely f war irritiert vom dämonischen Charakter der Schönen Dame in 
einigen Gedichten der "Stich1 o Prekrasnof Dame"; vgl. etwa I,94. 101, 186, 190 u.a.), beruhrt Blok das Problem des Skeptizismus in der Mystik. Er bejaht ausdricklich den Skeptizismus, denn "er liegt dem Mystizismus zugrunde, der nicht auf Sand gebaut ist, und bildet jene "Furcht", die "die völlige Llebe austrelbt" . (Blok-Belyj, Perepiska, S.36; Brief vom 18. Jun1/1. Jul1 1903; der Brlef 1st unverständlicherweise nicht in VIII aufgenommen!).

Die skeptischen Zweifel des Mystikers werden von der völligen Hingabe in der Liebe uberwunden. Ebenso besiegt im LS die Liebe alle Zweifel und Unsicherheiten, die German und Helena zunächst haben. Sie rechtfertigt Germans Abschied (im Verhältnis zu Helena), seine Llebe zu Faina (in der Schicksalhaftigkeit ihrer Bezlehung), und sie begrilndet den schlleßlichen Aufbruch der Helena (6.Bild).

Die Llebe als alle Zwelfel lösende Urkraft ist eln zentrales Thema in Bloks Dichtung. Häufig betont Blok jedoch den dämonischen Charakter der Liebesleidenschaft, die Im Gegensatz steht zu der im Motto beschworenen auf ruhige Sicherheit begrundeten Liebe. (Blok als "Dichter der Liebe" bei Žirmunskij, Poezi ja Al. Bloka, S.193; Reeve, A. Blok, S.65ff., 136ff.; Bonneau, I'univers poétique d'A. Blok, S.114ff.; iber die Verankerung der Liebe in inrem ambivalenten Charakter in Bloks irrationalem Weltbild vgl. Kluge, Westeuropa und RuBland, S.124).

S.49/5 Dieses Traumbild Germans enthält einige fiir Blok typische Bilder (die blaue, unbekannte Ferne, vgl. den Symbolwert der Farbe "Blau" ("sinif") bel Peters, Symbole, S.122ff.; der Geruch von Blumen, vgl. aao, S.249ff.; der Sonnenuntergang, der die Landschaft rot färbt, vgl. aa0, S.24, 31). Daneben nimmt es das 2.Motto auf (die grenzenlose Weite, zu der es German hinzleht; die grenzenlose Weite RuBlands). In seiner Rede zum 100.Geburtstag Gogol's ("Ditja Gogolja", Das Kind Gogols, V.376379) zitiert Blok weitere Stellen aus Gogol', die die- 
selbe Sehnsucht nach der Ferne beschwören. Blok indentiflzlert die "blaue, unbekannte Ferre" mit Gogol'g Vision eines "zukilnftigen RuBland", elner "neuen Heimat", die "auf uns herblickt aus dem blauen Abgrund der Zukunft und uns dorthin ruft." (v,378f.). Das Motto aus Gogol' und die Gogol'-Rede deuten die Lösung des Traums, die fir German selbst noch unbekannt 1st, an. Die blaue unbekannte Ferne 1st RuBland; der Schwan ist die Seele der Paina, die im LS RuBland verkörpert.

Zum Motiv des Fernwehs, das in Bloks RuBland-Mythos eine grobe Rolle spielt, vgl. Kluge, Westeuropa und RuBland, S.188, 193; dazu v.a. das Ged1cht "Osennjaja volja" (Herbstfreiheit; II, 75f.), das erste "RuBland-Gedicht" Bloks.

Zum Motiv des ins Fenster brechenden Windes vgl. die Ged1chte I, 38, 127; III,2791 . und IV,9.

Der hier wiederholte Ausdruck "grud'ju prjamo na zakat" kommt in ähnlicher Form in I,251 in elnem Gedicht vor, dessen urspriinglicher Titel "Deva-Obida" an das Igorlied 19, 5ff. erinnert: "Es erhob sich das Unhell (obida) im Heer des Daz'-Bog-Enkels. Es kam als Jungfrau (deva) in Trojans Land, schlug mit Schwanenfligeln auf dem blauen Meer am Don." Dasselbe B1ld kommt in "Skazka o toj, kotoraja ne pojmet jeje" vor; vgl. Blok, Sobranije sodinenif, Bd.4, S.139.

S.49/6 Das russ. "najavu" bedeutet glelchermaBen "wachend" wie "In Wirklichkeit". Germans Traum 1st also kein bloßes Hirngespinst, sondern die Vision einer transzendenten Wirklichke1t.

S.49/7 German nimmt bekannte Motive wieder auf. Er stellt sein b1sheriges Leben im Elfenbeinturm in Frage.

S.50/1 German "motiviert" sein Weggehen in doppelter Weise: mit seinem Traum und mit dem Befehl des Mönchs.

In den "Bridern Karamazov" von Dostojevskif schickte der Starec Sozima den Jungling Alesa ebenfalls in die Welt (7.Buch, Die Hochze1t von Kana). 
S.50/2 Hier endet die 5.Szene. Sie wiederholt und modifiziert schon bekannte Motive. Die Unterschiede zu $\mathrm{F} 1$ aind in dieser Szene unbedeutend und rein stilistischer Natur. Die Dialogform lat auch hier gewahrt.

S.50/3 German fast in kurzer Form den eigentlichen Inhalt des 1.B1ldes zusammen. Vgl. S.87/5, wo das Motiv des "ausweglosen Glicks" ausfihrlicher behandelt wird.

S.50/4 Das Gebet Germans verstärkt die christliche Komponente Im IS. Dabel 18t jedoch der völl1g unkirchliche Gehalt des Gebets zu beachten, sowie die gänzlich "unorthodoxe" Gebetsiltuation. Es handelt sich hier um eine völlig private Religiosität. Motive des Gebets werden im IS Im weiteren Verlauf wiederholt, so das Motiv ntberdrub am häuslichen Glikck" in der Replik Germans S.87 und im Monolog Germans S.98, und das Mot1v "Gew1ssen" S.66/1 und $S .86 / 2$. Auch hier kann man von einer "Fernwirkung" der Motive sprechen.

Der Monolog Germans bildet die 6.Szene. Die Abweichungen in F1 sind rein st1l1st1scher Natur. Abweichung 67) 1st verständlich, da Faina als "rodina" (Heimat, Vaterland) bezelchnet wird (vgl. S.93/8).

$\mathrm{S.50/5} \mathrm{Vgl}$. S.47/1. Der Freund we1B im voraus, daB German sein Haus verläBt.

S.50/6 German und der Freund treten zusammen wieder im 3.B11d, in der Weltausstellung auf, und zwar im Publikum, das auf Faina wartet. Das Theaterpublikum wird also mit der Menge im 3.B1ld glelchgesetzt. Dahinter verbergen $81 \mathrm{ch}$ Gedanken Bloks iber das Theater und das zeitgenössische Publikum (vgl. "O teatre", V,241-276). Blok beruft sich v.a. auf den Prolog von $L$. Andrejevs "Žln' Celoveka", wo das Publikum als "dem Tode geweiht" bezelchnet wird. (Andrejev, P'esy, S.94). Im IS 18t dieser Zusammenhang erst nach dem 3.B1ld klar.

S.50/7 Vgl. S.48/10.

S.51/1 In $F 1$ fllgt der Freund als weitere Charakteristik der Faina hinzu: "sin Kind des kalten städtischen Lasters und der Fäulnis der Fabriken". Das hätte zu sehr die städtische Selte im Charakter der Faina betont und die Herkunft aus dem bäuerl1chen, der Erde verbundenen Volk 
verschleiert. Deshalb fehlt diese Passage in $\mathrm{F} 2$. S.51/2 Das Thema der falschen Freundschaft (vgl. Jer.9, 3ff.) hatte filr Blok existentielle Bedeutung. Private und sehr Intime Erlebnisse verbanden $81 \mathrm{ch}$ bei ihm mit Enttäuschungen im Bereich literarischer Auseinandersetzungen. (Vgl. Orlov, Istorija odnoj "družby-vraždy"; Solov'ev, Poèt 1 jego podvig, S.239ff.). Die auf persönliche Erlebnisse und Enttäuschungen sich grilndende Loslösung von "Freunden" (vgl. etwa Zap.kn., S.108f., Eintrag vom 26. Juni 1908; VIII,241, Brief an Pantjuchov; VII,216, Eintrag vom 10.2.1913) wuchs sich bel Blok zu der Grundfiberzeugung aus, daß der echte Dichter nur in der Abkehr von allen "Schulen" oder "Systemen" und in der Entfaltung seiner persönlichen Veranlagung und Fähigkeit seiner Bestimmung treu blelben könne. "...Dichter sind darin interessant, worin $81 \mathrm{e}$ sich voneinander unterscheiden, und nicht darin, worin sie sich gleichen. Und da der Schwerpunkt jedes Dichters seine schöpferische Persönlichkeit 1st, ist die Stärke der Nachahmung immer umgekehrt proportional zur Stärke des Kerks. Deshalb ist die Frage der Schulen in der Dichtkunst eine zweitrangige Frage." (V,135; vgl. ähnliche Äußerungen V.311 in der Beurte1lung Ibsens; V,34off., Abschnitt "Differencacija" in "Voprosy, voprosy, voprosy" (Fragen, Fragen, Pragen)). Der Ln̈sung von seinen "Preunden" wollte Blok mit der Versenkung in die Volksseele antworten, die thn aus der Vereinsamung heraus in die Verbindung mit dem Volk fiihren sollte (vgl. "Duła pisatel fa" (Die Seele des Schriftstellers), v,367-371). Insofern berihrt das Motiv der "falschen Freunde" elne Problematik, die den Kern von Bloks Kunstphilosophle bildet. Auch hier gehen Blographie und Werk nahtlos ineinander iiber. "Man kann seine "persönlichen Lieder" und seine "objektiven Lieder" herausgeben. Das gerade ist lustig zu trennen - sogar der Teufel wird sich dabel das Bein brechen!" (Zap.kn., S.109, Eintrag von Ende Jul1 1908). 
S.51/3 Mit dieser etwas unglilcklichen Formullerung wird der Zynismus des Freunds noch elnmal unterstrichen.

S.51/4 Hier endet die 7.Szene, die ebenfalls Dialogform hat. Die Szene ist in F1 ausfilhrlicher. Dort bezelchnet der Freund German als "erwachsenen Säugling"(Abwe1chung 77)). Das Motiv der Relfwerdung taucht wieder auf im 5.B1ld (S.85/6) und im 7.Bild (S.101/3; dort mit deutlich sexual patholog $18 \mathrm{cher}$ Komponente).

S.51/5 Das Schweigen der Helena 1st in inrem ungeklärten Verhältnis zum Freund begriindet.

S.52/1 In 6.B1ld ( 5.94 ) erfahren wir vom Mönch, daß Germans Mutter tot 1st. Hier wird deutlich, daß die autoblographischen Elemente im IS frei verarbeltet sind, denn Bloks Mutter hat den Dichter iberlebt. Der Tod der Mutter 1st hier Symbol filr das Ende der in Germans Haus herrschenden Lebensform.

S.52/2 Die L1lie 1st das Symbol der Keuschhe1t und in dieser Szene filr die Ehe von German und Helena. Vgl, welter unten S.52/8.

S.52/3 Man beachte wiederum den christlichen Dekor!

S.52/4 Offenbar soll die Gegensätzlichkelt zwischen Helena und der Mutter Germans (weiß, jung - alt, schwarz) erneut betont werden.

S.52/5 Diese Bemerkung rundet das Bild von Germans bisheriger Lebensweise ab. Sie nimmt eine Passage der Regieanweisung S.44 wieder auf. Vielleicht spielt Blok auf Goethes Faust I an (Nacht; Monolog des Faust).

S.52/6 Pomeranzenbliiten wurden wegen inres sehr aromatischen und angenehmen Geruchs in die Ikonenschränkchen gelegt.

S.52/7 Wieder nimmt German Zuflucht zu einer kosmisch-mystischen Begrilndung.

S.52/8 Diese Passage 18t stark autobiographisch gefärbt. Blok liebte die Gartenarbeit und widmete inr viel zeit und Aufmerksamke1t während selner Aufenthalte in Sachmatovo. $\mathrm{Vgl}$. "Der Grund ( $d . h$. filr mein langes Schweigen) liegt im Nichtstun in geistiger Hinsicht, im Pflanzen von Blumen, Herrichten von Zäunen..." 
(VIII,104; Brief an Je.P. Ivanor vom 15. Jun1 1904; vgl. Belyj, Vospominanija o Bloke, Epopeja I, S.248; Stepun, Myst1sche Weltschau, 363f.).

Die nicht aufgehende Lilie ist das Bild filr das Scheitern, die Nichterfullung der the von German und Helena, die offenbar unter dem Zelchen der Keuschheit hatte stehen sollen. Auch in diesem Motiv der "keuschen the" brechen autoblographische Elemente durch. Das AuBergewöhnliche in seiner Bezlehung zu seiner späteren Frau betonte Blok schon im Sommer 1902. In der Skizze eines nicht abgeschickten Briefes an L.L. Mendelejevna drickt er seinen Glauben aus, in ihr die "Irdische Verkörperung der viel berufenen Allerreinsten Jungfrau oder der Ewigen Weiblichkelt" gefunden zu haben. Einer Verbindung steht die Tatsache im Wege, "dab es unmöglich 1st, eine Porm zu finden, die diesem iberaus verwickelten Fall der Beziehungen angemessen ist" (VII,62f.).

Anfang Jul1 1903 notierte Blok in sein Notizbuch: "Verbotenes" ("zaprełcennost'") muß 1mmer auch in der Ehe bleiben" (Zap.kn., 48). In einem kurzen Gedicht rom 11. August 1903 nimmt Blok Bezug auf seine zukinftige Ehe. Die belden letzten Strophen lauten ( $I, 289)$ :

Filhre mich! Um alles zu durchschreiten, Brauchen wir ilberirdische Kräfte.

(Eine Notiz Bloks vom 20. Jun1 1909 zeigt, dab filr inn weibliche Schönheit und Sexus in seiner schwärmerischen Jugendzeit unvereinbare Größen waren. Zap.kn., 149). Die Krise, In die Bloks the sehr schnell geriet, ist bel dieser Elnstellung Bloks verständlich. Vgl. dazu v.a. Solov'ev, Poét 1 jego podvig, S.41f., 102ff., der endgillig das von orlov in haglographischer Einseitigkeit gezelchnete Bild Bloks korriglert (wie zuvor schon v. Guenther). Germans Aufbruch und seine Abkehr von Helena ist auch zu verstehen als Abwendung von dem Ideal einer vergelstigten Liebe, an dessen Stelle das Ideal der dionysischen Liebesleidenschaft tritt. 
Die Illie als Symbol der Keuschheit findet sich in mehreren Gedichten Bloks vom Jahr 1902 (I, 170, 195, 235. 299). Ohne Zweifel macht sich hier ein starker EinfluB der Präraffaeliten auf Blok bemerkbar.

In G.D. Rossettis "The Blessed Damozel", einer Dichtung, deren Titel deutlich in Bloks "Stichi o Prekrasnoj Dame" durchscheint, hält die "Hellige Jungfrau" drei Iilien in der Hand. (Zum Verhältnis Bloks zu den Präraffaeliten vgl. Pis'ma A. Bloka, Vosp. S. Solov'eva, S.9ff., 20, 51; Belyf. Vosp. o Bloke, Épopeja I, S.127; ausfuhrlich Solov'ev, Poèt 1 jego podvig, S.27ff.). Den Einfluß der Präraffaeliten auf den frz. Symbolismus hebt Michaud. Le message poétique, $\mathrm{S} .204$ hervor (vgl. etwa das bekannte Bild "Ophelia" von J.E. Millais und die Dichtung "Ophélie" von Rimbaud). Die Bedeutung der Präraffaeliten fir die Malerel des Jugendstils unterstreicht Hof stätter, Geschichte, S.120ff. Nicht nur fir die Spiritualisierung der Liebe, sondern auch fü die Darstellung der Frau als rätselhaftes, Gut und Böse in sich vereinigendes Wesen konnte Blok Vorbilder bel den Präraffaeliten finden (am deutlichsten im Bild der Sphinx, das seit Rossetti zum Bildervorrat der Kunst des ausgehenden 19. Jhdts. gehört).

Daneben $18 t$ wieder der EinfluB VI. Solov'evs zu nennen (Stichotvorenija, S.230 u.a.), bel dem das symbol der Iilien aus dem christlich-mystischen Charakter der Gedichte zu erklären sind.

S.52/9 Germans "anima" ist Faina. Vgl. S.48/12.

S.52/10 Wieder benutzt German das "mystisch-kosmische" Argument. In $\mathrm{P} 1$ wird in der Abwelchung 92) der Antithese Lilie (d.h. keusche, ruhige Liebe) und Leidenschaft ("strast" ") der Gegensatz von Erde (hier im Sinne von Erdgebundenheit) und Himmel zugeordnet. Die Seele Germans gehorcht dem Walten der kosmischen Kräfte. Hier zeigt sich wiederum deutlich, wie sehr Blok von der romantischen Vorstellung der Abhängigkeit der Einzelseele von der Weltseele beeinflubt 1st. ( $\mathrm{Vgl}_{\mathrm{g}}$. "Es ist von Nutzen, wenn der Wind der Ereignisse und die Weltmusik die Musik der 18o- 
lierten Seelen und ihre wertvollen Zugluftchen ubertönen"; $v, 114$ ).

S.52/11 Hier nennt Gerwan den Titel des Stúcks. Uber den Zusammenhang von Leidenschaft (strast'), Lied (pesnja) und Wind (veter) schrelbt Blok: "Wie selten 1st doch groBe Leidenschaft. Doch wenn sie kommt, dann läBt sie nichts zurick auBer einem allgemeinen Lied. Wenn die Leidenschaft lange ausbleibt (Monate), tritt an inre Stelle die ekelhafte Lust, der schwere Gedanke; dann kundet ein "nachtlanger Sehnsuchtsschmerz" von ihrem Kommen. Und völlig unerwartet kommt der Wind der Leldenschaft. "Sturm"... Aber es gibt eine Leidenschaft wie ein befreiender Sturm, wo man die ganze Welt von elnem hohen Berg aus sieht ..."; Zap.kn., 130, Eintrag rom 25. Januar 1908. (In diesem Eintrag wird die mystische Verankerung von Bloks "Leldenschaften" deutlich. Vgl.: "Mein System, die Verwandlung von faden Professionellen fur drei Stunden in leldenschaftiche und zarte Frauen, triumphiert wieder." Zap.kn., 129).

Genauso unberuhrt vom Wind wie das Haus Germans bleibt im 5.B1ld ( $5.83 / 9)$ der alte Begleiter der Faina: beide haben am Walten des Kosmos keinen Antell.

S.53/1 Wiederaufnahme des ersten Mottos. $\mathrm{V}_{\mathrm{Gl}}$. S.49/2.

S.53/2 Das Mutter-Sohn-Verhältnis spielt in Leben und Werk Bloks eine entscheidende Rolle, der eine ähnlich groBe Bedeutung zukommt wie seinem Verhältnis zu seiner Frau. Es verbanden Mutter und Sohn die tiefe verachtung der modernen Zivilisation und ein von mystischen Ahnungen erfill tes Katastrophenbemubtsein. Sein ganzes Leben hindurch stand Blok mit seiner Mutter in regem Briefwechsel. Diese enge Bindung war jedoch uberschattet von der dauernden Spannung zwischen der Mutter Bloks und seiner Frau. "Die Verschiedenhelt inrer Naturen und Bestrebungen, der Kampf der gegensätzlichen Einflisse, die beide auf inn auslibten, schufen einen ewigen Konflikt zwischen ihnen... Und diese Differenzen zwischen den $1 \mathrm{hm}$ nächsten Wesen quälten Al.Al. schrecklich." 
(Beketova, Blok, S.29of. und ähnlich in: dies., Blok 1 jego mat', S.104f.)

wie sehr Blok unter den Spannungen zwischen den beiden Prauen gelitten hat, zeigt eine Tagebuchnotiz vom 18. Februar 1910: "Ljuba hat Mama krank gemacht (Bloks Mutter war nervenkrank.) Ljuba hat die Menschen von mir weggejagt... I juba stöBt von sich und von mir alle besten Menschen ab, darunter - meine Mutter, das heibt mein Gewissen... Ljuba auf der Erde, - das ist das Schreckliche, das geschickt wurde, um die irdischen Werte zu quälen und zu vernichten. Doch die Jahre 1898-1902 machten, daB ich mich nicht von ihr trennen kann und sie liebe." (Zap.kn., 166).

Blok hat funf Gedichte mit dem Titel "Mojej materi" (Meiner Mutter) geschrieben. (Dazu kommt die Ubersetzung dreier Gedichte des Armeniers Isaskjan; III,390-392). Ist das erste Gedicht I, 7 noch sehr traditionell, so klingt in den weiteren Gedichten I,31,83 das Thema der seelischen Unruhe als unerklärbarem Schicksal an. Im Gedicht II, 57 wird das KatastrophenbewuBtsein zur erlösenden Gewibhelt von der baldigen Ankunft Christi:

Doch, eroh uber das schöne Vergangene, Soll das Herz uber das Zukinftige nicht weinen. Voll Ruhe we1B ich: der Lohn wird kommen:

Der blendende Reiter sprengt bald daher. (Blok spielt hier auf das Bild der Apokalypse an, in dem Christus auf einem weiBen Pferd reitet. "Seine Augen sind wie eine Feuerflamme", Apok.19, 11f.). Auch im Gedicht II,72, das gegeniiber den anderen etwas abfällt, klingt das Motiv der Zukunftserwartung an.

Das Thema des Helden, der die Mutter verläBt und in den Kampf zieht, hat Blok in dem Gedicht "Syn 1 mat'" (Sohn und Mutter, II,108f.) gestaltet. Er nimmt hier ein Thema auf, das in der Folklore (vgl. V,59) und in Gogol's "Taras Bul'ba (vgl. Gogol', Sobr.sod., Band 2, S.45f. und $v, 77$ ) vorkommt, kleidet es jedoch in die inm eigentúmliche, an die Gedichte "Na pole Kulikovom" erinnernde Form. Die mittelalterliche Stilisierung verhullt nur unvollkommen die aktuelle Bedeutsamkeit. In der Identifi- 
kation von Mutter und Mutter-Erde scheint Bloks RuBlandMythos durch. Dies erklärt auch den sonst unverständI1chen Schlub:

Gegrabt selst du, Ferne, befreit

Von nächtlicher nebliger Finsternis!

In Herz der zuruckgelassenen Mutter

Ist goldene Freude:

Da ist er, mein Sohn, blutiberströmt!

Wie nur ist die Preude zu ertragen!

Nur Mutter-RuBland, die groBe Leiderdulderin, kann sich iber den Heldentod inres Sohnes freuen.

Das Gedicht "Son" (Traum; III,134) 1st Bloks Mutter gewidmet. In der Behandlung der Auferstehung Christ1 verweist das Gedicht deutlich auf das Gedicht II,57. Fur das IS bedeutsam lot die Konstellation der Personen in diesem Gedicht. Mutter, Sohn und Frau erleben gemeinsam den Morgen der Auferstehung und vernehmen den klang der Posaune (off.1, 10; 4, 1). Mutter und Sohn ersehnen die Befrelung aus dem Grab, doch kann der Sohn den Stein nicht aus elgener Kraft wegwälzen (wie Christus es tat). Die Frau jedoch liegt ruhig im Grabgewölbe:

Doch inr 1st die Freiheit nicht teuer:

Sie will nicht auferstehen... (2. 15f.).

Mutter und Sohn verbindet eine seelische Unruhe und ein Ahnungsvermögen, an denen die Frau nicht teilhat. ( $\mathrm{Vgl}$. noch I, 359).

$5.53 / 3$ Helena versucht, sich selbst zu beruhigen und den Unterschied im Mutter-Sohn- und Frau-Mann-Verhältnis zu uberspielen. Im Gebrauch der Ausdricke "duša" (Seele) und "serdce" (Herz) scheint bel Blok die traditionelle Vorstellung durch, nach der das Herz der Sitz der Gefuhle, der religiösen Empfindungen, des Mutes, der Llebe, der willensbewegungen usw. 1st. Die Seele dagegen 1st Trägerin der unbematen Lebensvorgänge. Sie stellt die Verbindung zum Kosmischen, zur "Astralwelt" her. S.53/4 "moj carstrenny j" von "car" " (Zar; bibl. König). S.53/5 Mit der Wiederholung des Titels dieses Stucks endet die 8.Szene des 1.B1ldes. Der Zuschauer 1st gespannt, was es mit dem Lied des Schicksals auf sich hat. 
Diese Dialogszene 1st in F1 wesentlich ausfuhrlicher (Abweichungen 80)-98)). Zunächst nimmt German das Motiv der "falschen Freundschaft" noch einmal auf. Die Lichter, die man in der Ferne sieht, sind Jedoch nicht "Freunde", sondern ein Zug von Kindern, die das Fest des Palmsarstag feiern. ( $V_{g l}$. dazu die Gedichte "Verbnaja Subbota", I,290, mit dem Lokalkolorit in Str.1 und 2 und dem Motiv "Frihlingsahnungen" in mittelalterlicher stilisierung sowie das Gedicht "Verbotki" II,95.). In F1 wird die Regleanweisung (vgl. S.44/1) in der Handlung realisiert. Die "Auferstehung von den Toten" klingt an in Germans Worten "Deshalb 1 st es in der Seele so hell" (Abw.82)). In Abw.93) wiederholt German in sehr uberspannter Weise die "kosmisch-mystische" Motivation. Sein Abschied gleicht dem Aufbruch eines Helden. Er verspricht zurückzukommen, wenn die Sturm- und Gewitterwolken sich verzogen haben und der Himmel wieder klar 1st. Dann ist auch das Lied des Schicksals verklungen. (Zu der Symbolik des Windes und dem Ausdruck "nužen veter sobytij", (es 1st der Wind der Ereignisse nötig) vgl. V,114). German fühlt $81 \mathrm{ch} z \mathrm{z}$ einem aktiven, heldischen Leben berufen. Deutlich spielt hier Blok auf Arkadif Dolgorukij in Dostojevskijs Roman "Podrostok" (Der Jiingling) an. Germans "herrscherlicher Gelst fordert drel Leben". Von Arkadif wird gesagt, daB er, wenn man ihm drei Leben geben wirde, damit nicht zufrieden wäre (Podrostok, 1.Te11, Kap.4, II). Blok hatte den Roman im Sommer 1902 gelesen. Die genannte stelle hat inn sehr beeindruckt (vgl. VIII,34, 36 und Zap.kn., 414, Eintrag vom 25. Juni 1918). Sie drilckte seine eigenen Wunsche aus. Germans Wunsch nach "drei Leben" wird am Anfang des 7.B1Ides (S.98) wiederholt. Auch der Ausdruck "ewig verliebter Gelst" wird wiederholt (5.Bild, S.86).

In Abwelchung 97) nennt German als Ziel seines Strebens RuBland. Blok hat diese Stelle weggelassen, weil er dieses Ziel durch das Stuck selbst klarmachen wollte. In Abweichung 98) greift Helena das Bild der Göttin auf, die den Lebensfaden webt. Dieses Bild ist aus der 
griechischen, römischen (Homer, Illas 20, 1271.; Hesiod, Theogonie, S.904; Parzen) und germanischen Mythologie bekannt (die dre1 Nornen). Bloks Anreger war wohl Wagner (Vorspiel der Götterdämmerung). Das Bild der webenden Schicksals-Jungfrauen erwähnt Blok in seiner Ontersuchung "Poezija zagovorov 1 zaklinanij" (Die Poesie der Zauberlieder und Besprechungen; $v, 38$ ). Es kehrt wieder in seinem Poem "Nocnaja fialka" (Nachtviole, II,26-34) und in mehreren Gedichten; vgl. II,46, 220, 269ff. und in "Roza 1 krest" IV,203, 232; vgl, auch Holthusen, Studien, S.92).

Die Heldensymbolik in den Abwe1chungen 93)-99) 18t nur auf Grund von Bloks Begeisterung fir die Musikdramen von Richard Wagner, insbesondere filr den "Ring des Nibelungen" zu erklären. Blok kannte die Musik Wagners selt seiner Jugend. Einige Gedichte beziehen sich direkt auf Wagner-Opern ( 1,373 "V Zarkof pl jaske vakchanal1 J..." auf den "Tannhäuser"; I,349f. "Valkirija" auf den 1.Akt der "Walkiire". Die endgiltige Fassung entstand 1908; I,465 "Ja nikogda ne ponimal..." auf die Wirkung des "Parsifal"; III,29 "Idut Casy, 1 dn1 1 gody..." auf "Tristan und Isolde"). Die letzte Szene von Bloks Drama "Roza 1 krest" (Rose und Kreuz) erinnert an den Tod Tristans (wie III,291.). Unter dem Eindruck von Wagners Musik schrieb Blok die letzte Szene von "Roza 1 krest" in Verse um (vgl. VII, Eintrag vom 16. Januar 1913,208; IV,240ff.). Wagners Musik wirkte auf Blok wie ein Elementarereignis. "Wagner in Bad Nauheim, - das 1st etwas völlig Onaussprechliches: es erinnert an Anamnesis." (Zap.kn., 150, Eintrag rom 29. Jun1 1909). "Abende war $1 \mathrm{ch}$ in den "Heistersingern von Nurnberg". Ich murde sehr mude. Alles war "ziviln, auch das Singen. Trotzdem - man schwimmt im musikalischen Ozean Wagners." (VII,208; Eintrag vom 15. Januar 1913). Blok zitiert in seinem Aufsatz "O drame" einige Stellen aus Andrejevs "Žizn' Celoveka" ( $\mathrm{V}, 187$. Die stellen sind aus dem 2.B1ld. Andrejev, P'esy, S.115f.), die in inrer Heldensymbolik an Wagner erinnern. (Blok vergleicht den "Menschen" aus 
Andrejevs Stuck mit Sigmund in Wagners "Walkure". $\nabla .191)$. Das "Leonid-Andrejevsche" in dem Stuck, das sich v.a. auf die Gestalt Germans bezieht (VII,188; VI,330; Vgl. "Bntstehungsgeschichte", S.38), ist hauptsächlich in der unechten Heldensymbolik von F1 zu sehen.

S.53/6 In der bangen Frage der Mutter und in der Regleanweisung ist der baldige Tod der Mutter angedeutet. In F1 wird in Abweichung 99) die Heldensymbolik weltergeführt (Germans Repliken). Daneben wird das Mutter-Kind-Verhältnis betont (Repliken der Mutter). Sehr aus dem Rahmen fällt die letzte Replik der Mutter: "Mein Junge, hast du zu viele dumme Märchen gelesen?"

$\mathrm{Zu}$ dem Motiv "German als Kind" vgl. S.51/4 und das 7.B11d.

S.53/7 Der Realbezug (hereinbrechende Nacht) und der symbolische Bezug (Germans Herz als ein Ilcht) werden am Ende des 2.Bildes wiederholt (vgl. S.57).

S.53/8 Der Ausdruck "perejti Certu" erhält besonderes Gewicht, wenn man Bloks Vortrag "Narod 1 intelligencija" zur Deutung heranzieht. Dort fuhrt Blok aus: "Es gibt zwischen den zwei Lagern - zwischen dem Volk und der Intelligenz - eine gewisse Grenzlinie (nekaja certa). wo die beiden zusammenkommen und Abmachungen treffen" $(v, 323)$. "Auf der schmalen Grenzlinie zwischen Volk und Intelligenz erwachsen bisweilen grobe Menschen und grobe Taten" $(V, 324)$. Als letzte grobe Erscheinung auf dieser Grenzlinie betrachtet Blok M. Gor'kij (V,325). Im IS ist ganz offensichtilch eben diese Grenzinie gemeint. Die Stelle ist ein Selbstzitat. German will die Grenzlinie zum Volk uberschreiten; $\nabla$ gl. S.256.

S.53/9 Beim Abschied von ihrem Gatten Hektor lächelte Andromache unter Tränen (II1as, VI,484). Germans Abschied von seiner Frau ähnelt dem Abschied des trojanischen Helden. Die stolzen Worte Germans in Abweichung 97) haben eine gewisse Ähnlichkeit mit Hektors Abschiedsworten (IIlas, VI,490f.).

S.54/1 Das Hinabsteigen ist auch symbolisch zu verstehen als Verlassen des "Elfenbeinturms". Der Abschied Germans, 
v.a. in der St1lisierung nach F1, hat elne Parallele in dem Gedicht "Tak okrylenno, tak naperno..." (II,115). Dort nimmt ein Held Abschied von der Prinzessin. Sie legt ihm die Hainde auf die Schultern und entlabt ihn in den Kampl mit dem Versprechen, seiner zu harren:

$\mathrm{Ja}, 1 \mathrm{ch}$ bin berelt zur späten Begegnung, Ich werde dir die Hände entgegenstrecken, Wenn du aus der Schlacht

Den Frihling auf der Spltze des Speers bringen wirst. (Str.5)

(Vgl. die letzte Zeile mit Abw. 88)). Dieses Gedicht verarbeltet Bilder und Motive von V. Hugo ( $v g l$. II,409, Anm. zu dem Gedicht; dazu: V,92; VI,455; Zap.kn.,440). S.54/2 Die Augen des Mönchs dricken hier sein Fernweh aus. Das Motiv kehrt wieder im 6.Bild (S.93f.).

S.54/3 Die Szenerie bereitet das folgende Bild vor. Die Sternennacht ist ein typisch romantisches Bild. Viele Gedichte Bloks schildern inr Geheimnis.

In $M 1$ befand sich das haus Germans am Meer. Es war ein "Landhaus mit einem Taubenschlag, auf einem Hügel gelegen; in der Ferne sieht man den schmalen blauen Streifen des Meeres."

(Medvedev, Dramy 1 poèmy Bloka, S.64). Die Lage am Meer erinnert an den Schauplatz des lyrischen Dramas "Korol' na plostad1". In der Regieanweisung zum Prolog dieses Stücks heibt es: "Eine Bank am Ufer des Meeres, das sich als schmaler Streifen aus der Ferne heranzieht" (IV,23). Die für RuBland etwas fremdartige Lage am Meer 1st in F1 und F2 durch eine Lage inmitten einer "echt russischen" Landschaft ersetzt. Der Schauplatz des 1.B1ldes erhielt dadurch einen stark blographischen Charakter. German ist in 11 noch stärker mit heldenhaften Zügen versehen als in F1. Seln Ausspruch "Ich will Herrscher uber das Leben sein" (Ja chocu byt' carem nad Zizn'ju; Medvedev, aa0, S.64f.) fehlt in F1. Dennoch gilt Medvedevs Charakteristik des German von 1 auch noch fur F1, wenn er German mit Brand und dem Baumelster Solness in Ibsens Dramen vergleicht. "Im weiteren Verlauf verschwinden diese Züge Germans immer mehr, sein heldischer Wille löst sich auf, aus einem Lehrmelster verwandelt er sich in einen Schüler. Sein Weg nähert sich dem Vieg Fausts und Peer Gynts." (Medvedev, aa0, S.65; vgl. Elnleitung zum 7. Bild, S.405ff.). 


\section{ZWEITES BIID}

Der Schauplatz des 2.Bildes ist nur kuBerlich mit dem Haus Germans 1dentisch. Entscheldend 1st, das das Bild aus Raum und Ze1t herausgehoben $18 t$ und einen Blick in die elgentliche, hinter der Welt der Erscheinungen liegende Wirklichkeit erbfenet. Die Erzählung des Monchs, formal die Vorgeschichte ${ }^{1}$ ) seiner Bezlehung zu Faina, schildert deren eigentliches Desen und ihre Herkunft aus dem Milieu des Raskol. Diese "russische" Hypostase der Faina wird im 4.Bild in einer Art Anamnesis der Heldin wieder lebendig.

Am Schluß des Bildes werden Helena und der Monch Zeuge, wie die kosmische Hypostase des "Ewig-Weiblichen" German von einer Ruckkehr in sein Haus abhält. Zur "kosmischen" Lotivation seines Weggangs im 1.Bild tritt nun das schicksalhafte ingreifen des "Ewig-Weiblichen" selbst. Der Zusammenhang, v.a. die Reaktion des Mönche am Schluß des Blldes, macht klar, daß die kosmische Erscheinung mit Faina in Grunde identisch 18t. Der ausgesprochen myst1sche Charakter war in F1 noch stărker ausgeprägt. Das 2.B1ld, besonders in F1, ist ein deutliches Zeugnis filr das astralnythologische Moment in Bloks Weltbild.

1) Volkov, Blok 1 teatr, S.90 bezelchnet die beiden ersten Bilder mit gewissem Recht als Exposition. Doch 1st die Anwendung dieses Begriffs auf das LS unangemessen. 
S.55/1 Vgl. S.44/2. Der ausdrllckliche Hinweis, daß Hundegebell und Vogelgezitscher nicht zu horen sind, unterstreicht den Charakter des Irrealen dieser Szene.

S.55/2 Vgl. Regieanweisung zum $1 . B 11 d$ ( .44 ) und S.49/3.

$5.55 / 3 \mathrm{Zu}$ diesem Regiehinweis schreibt J. Peters, Symbole der sinnlichen Wahrnehmung im lyrischen Werk A.A. Bloks, S.135: "Die Gegenfigur der wilden und geheimnisvollen Faina ist die sanfte Elena, die Zuge der "Schönen Dame" trägt, und ihr ist die Farbe "goluboj" zugeordnet." Diese Zuordnung ist falsch. Die Farbe der Helena ist weiB. Die Farbe "hellblau" bezieht sich nicht auf Helena, sondern auf das traumhafte Geschehen des 2.Bildes. Die Geschichte des Mönchs und die Begegnung Germans mit der Erscheinung werden aus der realen $\mathrm{Zeit}$ in eine mystische Vergangenheit und Traumzeit herausgehoben. Das erinnert an die Gestalt des "Goluboj" im Drama "Neznakomka" (IV, $84 \mathrm{ff.}$ ). ( $2 u$ der falschen Beziehung von "sinif" (blau) auf Faina bei Peters, vgl. S.56/8).

S.55/4 Die Handlung setzt mitten in der Erzählung des Mönchs ein.

In F1 erzählt der könch zuvor das Märchen von einen wackeren Krieger, der im Kampfe fiel, und den eine wei3e Jungfrau von der Walstatt emportrug. Der Ritter wurde zum Engel, der als Stern am Himmel die bielt umkreiste (vgl. damit VI. Solov'ev, Stichtvorenija, S.110 $(X I))$ und das Weltgeschehen der Jahrtausende betrachtete. Die Menschen beteten ihn an oder verfluchten ihn. So vergingen die Zeitalter. - Doch in einer dunklen Frihlingsnacht mußte der Himmelsbewohner zur Erde zurickkehren. (Abweichungen 109) und 110)). Damit ist der inschluß an die Erzählung des Mönchs in F2 erreicht. Die in F2 fehlende Vorgeschichte erklärt, daß der liönch im 1.Bild als "gefallener Engel" erscheint. Das Motiv des "gefallenen Engel" taucht bei Blok mehrmals auf. Blok kennt den Ursprung des ilythos. (Vgl. "Vozmezdije", 1.Kap., III,305, Z.56f. und "Vozmezdije", Prolog, III, 57 und VII,390, Eintrag vom 5. Januar 1921). Ganz im Sinne der Romantik ist für Blok der Künstler ein "ge- 
Pallener Engel". (Vgl. die Gedichte: "Ty byl osypan zvezdnym cretom...", II, 100 und dazu v. Guenther, Ein Leben, S.113; "Demon", III,26 und 60; "Devurke", II,133; $V, 130 f$. und Bloks Bemerkungen uber Lermontov und Vrubel' in "Bezvremen'e", V,76f.; "Pamjat1 Vrubel ja", V,421-424. Entstehung und Entwicklung des romantischen Dämonen schildert Praz, Bd.I, S.66ff. in "Llebe, Tod und Teufel". Se1t Byron 1st der gefallene Engel ein stehender Typus.). In $\mathrm{F} 1$ erinnert die Schilderung des Sternenlebens an den Anfang von Lernontovs "Demon" (1. Teil, I-IV). Ähnlich wie bei Lermontov der Dämon, entbrennt in LS der gefallene Engel in irdischer Liebe zu einem schonen Mädchen (dort: Tamara, hier: Paina; vgl. unten). Wesentlich ist jedoch, daß bei Lermontov der Dämon eindeutig der Satan, der Böse ist. (Vgl. "Demon", II, Z.6ff.) Bloks "gefallener Engel" lst nicht die Verkörperung des Bösen; er ist nur zu einem tragischen Schicksal verdammt. (Bloks Behandlung des Themas "gefallener Engel" beschränkt sich fast nur auf diesen Aspekt). Da der Monch in seiner Erzählung den wackeren Krieger mit German und die engelgleiche Jungfrau mit Helena vergleicht, entsteht der Eindruck, als sei er in $\mathrm{P} 1$ eigentlich der Doppelgänger Germans. "In der Manuskriptfassung (die hier identisch lot wit F1; D.W.) lst das Erscheinen des Monchs im Hause Germans die Ankunft von Germans Doppelgänger, der unruhigen, rastlosen, suchenden Hälfte von Germans seele..." (P. Gromov, Geroj 1 vremja, S.507. Gromov hätte $81 \mathrm{ch}$ eher auf Abw. 109) stitzen sollen). Besser wäre wohl von einer fruheren Hypostase Germans zu sprechen. wie filr Gott tausend Jahre wie ein Tag sind (Psalm 90 (89), 4; 2.Petr.3, 8), so sind filr den Engel die Jahrhunderte wie ein Augenblick (vgl. Lermontov, "Demon", II, 2.2ff.). Der Himmelsbewohner erblickt die Erde "von Angesicht zu Angesicht, und nicht im Spiegel der Wahrsagung". Hier zitiert Blok ungenau 1.Kor. 13, 12 (Luther ubersetzt schlecht!). Das Motiv des "wahrsagenden Spiegels" kehrt wieder im 4.Bild. (Vgl. S.77/10). Blok kannte es aus VjaX. Ivanov; vgl. V,12. Das Motiv "Sehn- 
sucht nach Menschwerdung" aus Abw. 109) ist von Blok v.a. im Drama "Neznakomka" ausfihrlich gestaltet (IV,85ff. in den Repliken der "Neznakomka": "Kannst du mir Irdische Horte sagen?" "Die fallende Sternenjungfrau/Will irdische Reden." "ilie sil ist es auf eurer Erde!"). Es ist ein Aspekt des Mythos vom "weiblichen gefallenen Stern", der in Bloks Dichtung eine zentrale Bedeutung hat. Die Parallele, der Mythos rom "männlichen gefallenen Stern", tritt demgegeniiber stark zurlick und ist nur im IS in F1 in gro?er husfiuhrlichkelt behandelt (vgl. noch das oben erviähnte Gedicht II,100). Im Mythos vom gefallenen Stern kommt Bloks mystische Natur besonders deutlich zum Ausdruck. ( $\mathrm{Vgl}$. dazu weiter unten).

:it der Streichung der kommentierten Passage in $F 2$ hat 3lok das IS von allerhand esoterischen und mystischem Beiwerk befreit. Die Gestalt des Hönchs verliert fast ganz ihren ursprianglichen kosmischen Aspekt (dieser bleibt nur der Faina, s.u.).

Auch fehlt in F2 das Bild des Ritter-Mönchs, das von der Erzählung in F1 suggeriert wird. Von der komplexen, sunthetischen Gestalt "Ritter-Stern-Engel-iönch" bleibt nur der letzte Aspekt mit wenigen indeutungen des isjekts "gefallener Eneel" ibrig.

Blok hat das Bild des Ritter-gonchs zur Schilderung, seines "Lehrers" ( $V, 433)$ Vl. Solov'ev verwendet (vgl. "Rycar'-monach", V,446-454). Dieser war in "iahrheit ein "wackerer Krieger Christi" $(V, 450)$. Der Sinn seines Lebens var "der Ka upf un die Befreiung der gefangenen Prinzessin, der Veltseele", aus der Umarmung des Chaos $(v, 451)$. Das Vorbild Solov'evs gibt den inut, diesen Kampf weiterzufihren. Die Behandlung des Aonchs in $F 1$ lä?t vernuten, da3 sich hinter inm die Gestalt VI. Solov'evs verbirgt, allerdings in der ahnlich persönlichen Interpretation, wie sie Blok in seinem Vortrag "Rycar'-7onach" gab. Áuch Gernan versucht, die gefangene ineltseele zu befreien (zur Deutung der Faina als Verkörperung der weltseele s.u.). Luf diesen Veg hat inn der könch gewiesen. 
Der berihnteste Ritter-Mönch RuBlands war Peresvet, der beim Zweikampf in der schlacht auf dem Kulikovo-Feld fiel (vgl. Germans Monolog $5.88 / 7$ ).

S.55/5 Die Erklärung glbt der Mönch im weiteren Verlauf seiner Brzăhlung. Es 18t das Peuer, In dem sich die Altgläublgen unter Psalmengesang verbrennen; vgl. S.56. Der Plus, an dessen Ufern das Altglaubigendorf und das Kloster (s.u.) lagen, lst wohl die Volga. Das wilrde der "h1storlschen Wirklichke1t" am nachsten kommen.

S.55/6 Vgl. S.48/3.

S.55/7 Dieses B1ld lst bel Blok hăufiger anzutreffen. Es 1st Bloks B1ld vom "rus81schen Mädchen". (Vgl. Anm. zu "Sneznaja Deva", II,431; Anm. zu "Zadebrennyje le som kručl...", III,586; "Ros81 jan, III, 2541.) Wichtig lst die schwarze Parbe des Kleids.

S.55/8 RuBlaind helBt auch hier "Rus'"; vgl. das 2. Motto. "RuBland" ist hier keine geographische, sondern eine mythische Größe.

S.55/9 Faina wartet auf Erlösung. H1er klingt erstmals deut$11 \mathrm{ch}$ der Mythos der auf Erlösung wartenden Weltseele an.

S.55/10 In F1 fragt Helena, ob inr Gesprächspartner Engel oder Monch se1. Die Antwort 18t: "Ob Engel oder Monch, auf jeden Fall kein Mensch..." (Abwelchungen 113) und 114)).

S.55/11 Dieses B1ld gehört ebenfalls zu Bloks "russischem Mädchen". Es geht zurfick auf seine studien zur russischen Folklore. (Vgl. Pomeranceva, A. Blok 1 fol'klor, S.208f.). Auf Potebnja bezugnehmend erklärt Blok das Bild folgendermaßen: "Der Wind bringt Krankheiten und Nachrichten. In WestruBland, Iltauen und Polen gibt es den Volksglauben, die Pest sel ein Wind: das Pestweib streckt die hand ins Penster oder in die Tur der Hutte und fachelt den Tod mit rotem Tuch. Doch liebe und Tod sind gleichermaßen geheimnisvoll dort, wo das Leben einfach 18t; deshalb schickt das Mädchen Ilebe, wenn sie mit den Armeln winkt, nach dem kleinrus81schen Lied: "Es geht ein Hadchen den Weg entlang und 
winkt mit den Xrmeln." n $(v, 38)$

Faina nimmt im 7.Bild das Motiv wieder auf (S.103/1). Es erscheint auch im Gedicht "Osennjaja volja", II,751., Str.3.

S.56/1 In P1 sagt der Monch dann noch: "Singe ich doch wie eine Nachtigall im Pruhling." Die Nachtigall war schon in der Antike symbol fur den Prthling und ein Attribut der Aphrodite. Als Nachtigall dachte man sich die Seele des thrakischen Săngers Thanyris. Vermutlich dachte Blok an den Sänger Bojan, der im Igorlied "Nachtigall" genannt wird $(6,1019)$.

S.56/2 "palati" oder "polati" ist eine pritschenartige Schlafstelle in den russischen Bauernhutten.

S.56/3 Vgl. dazu "Garmonika, garmonika!..." (II,280f.) und "O $\chi_{\text {to }}$ me zakatny $j$ rumjanec..." (II,278ff.). In diesen Gedichten versinnbildlicht der Tanz die dionysische Natur der lyrischen Heldin. Die Gedichte stehen im Zyklus "Faina". (Vgl. noch "Osennjaja volja", II,751. 8.0.)

S.56/4 Der Tanz befriedigt Paina nicht. Ihre Sehnsucht nach Erlosung ist mächtiger als der Rausch des Tanzes.

S.56/5 Vgl. S.55/4.

S.56/6 Das Bild des Feuerbrandes hat bel Blok eschatologische Bedeutung ( $\mathrm{Zu}$ dem reinigenden Feuer im Poem "Drenadcat'" vgl. Orlov, Dvenadcat', S.591., wo dleser darauf hinweist, daB Carlyle dieses Bild fur die Französische Revolution gebraucht. Vgl. V.a. Peters, Symbole der sinnlichen Wahmehmung, S.34ff., 247ff.). Es geht auf die biblische Symbolik zurlick. (Vgl. Porstner, Welt der Symbole, S.80ff.) Die ambivalente Symbolik des zerstörenden und reinigenden Feuers bel Blok hat seine Entsprechung in der Bibel. Im IS spiegelt sich Bloks Weltenbrand-Mystik in den Selbstverbrennungen der Altglaubigen. ( $\mathrm{Vgl}$. a. S.82/8).

S.56/7 "srub" ist das Balkengerust der russischen Holzhutte. S.56/8 Die Passage "...aus dem roten Peuer... hinter dem Boot dahineilte..." zitiert Peters, aao, S.135 und will aus inr begrunden, daB im IS die Farbe "blau" (sinif) 
"als Attribut der Zigeunerin Faina vorkommt". Diese Deutung 1st falsch. Die Verwendung von "blau" in "blauen Schatten des Ufers" und "Spur blauen Silbers" hat mit der Gestalt der Faina nichts zu tun. Es lst die Farbe der nächtlichen Schatten und des liassers. Das "rote Feuer" lst an dieser Stelle kein Symbol des Dämonlschen (Peters), sondern das Feuer im hltgläubigendorf.

S.56/9 Die Häufung der Epitheta soll offenbar die Nähe zur russischen Folklore unterstrelchen.

S.56/10 Zu der Erzählung des Mönchs vgl. das Gedicht "Inok", II,283 (v.a. die 5. Strophe:

"...Daß keine Gebete nötig sind,

Wenn du den FluB entlang gehst

Jenseits der Klostermauer

In deinem Nonnenkleid..." ).

In seiner Erzählung berichtet der Mönch sowohl iber sein Schicksal wie iber die Herkunft der Faina. Er selbst ist ein gefaliener Engel bzw. Stern, der sein Kloster verlassen hat, um der Faina nachzufolgen. Im Mönch verbinden sich zwel in der Romantik häufige iypen, der gefallene Engel mit dem geheimnisvollen Mönch. Der letztere Typ geht auf Ann Radcliffes Gestalt Schedoni zuriick und kehrt wieder in Byrons Giaur. Typische Leitmerkmale dieser Figuren sind die großen, melancholischen Augen, die krankhafte, schwermutige Erscheinung und das dämonische Iächeln ( $v g l$. dazu Praz, Iiebe, Tod und Teufel, Bd.1,S.72ff.). Dieser romantische Typus ist eine Spielart des gefallenen Engels. Blok kannte die romantische Iiteratur, v.a. die ierke Byrons sehr genau. Er ubersetzte flir die russische Gesamtausgabe der Werke Byrons bei Brockhaus und Efron elne Rethe von Byrons Gedichten (II,346-358, inm. S.449ff., vgl. 118/1) und berief sich ausfihrlich auf ihn in seinem Referat "O teatre" (vgl. v,243f.). Der Mönch, der äußerlich in der romantischen Tradition des Byronschen Dämonen steht, verkörpert im IS die russische Kirche im weitesten, völlig undoktrinären Sinne und das christlich gefärbte Slavophilentum. Als bedeutendste Erscheinung der russischen Religiosität galt unter den Synbolisten VI. 
Solov'ev. In der unerfuliten Liebe des Mönchs versuchte Blok den angestrengten Versuch und das Scheitern Solov'evs darzustellen, das Hesen RuBlands zu enträtseln. Im russischen Altglăubigentum sah Blok das "echte RuBland". Vgl. Exkurs "Blok und der raskol" und Einleitung $\operatorname{zum}$ 5.Bild, S.311ff.

S.57/1 Vgl. S.53/7.

S.57/2 Die Erschelnung gleicht völlig der kosmischen Hypostase der "Unbekannten" in Bloks zweitem Gedichtband. Im Gedicht "Not'" erscheint sie noch als personifizierte Hacht, "Im langen schwarzen Gewand, in den Myriaden schwarzer wagen..." (II,48, Str.3). Das Bild der Sternenjungfrau entsteht schon klar im Gedicht "Tam, v notnoj zavyvajułcej stuze..." (II,81):

"Es entsteht aus den Spitzen ein Gesicht. Da schwammen ihre Schneesturmtriller,

Helle Sterne als schleppe hinter sich herzlehend..."

(str.1 und 2)

VGl. das Gedicht "Šleif, zabryzganny z zezdami..." (II, 105):

"kine Schleppe, von Sternen ubersät, Ein blauer, blauer, blauer Blick. 2wischen der Erde und den Himmeln Ein vom Wirbelwind hochgepeitschter scheiterhaufen.

Ieben und Tod in ewigem Krelsen, Ganz in enger seide Bist du den Milchstraßen geöfinet. In Gewitterwolken verborgen.

(Str.1 und 2)

Im Gedicht "Troje blednej, Cem bylo..." ist ihr Fall dargestellt (II,183f.):

"Glaube, wir kannten beide den Himmel:

Als blutiger stern schwammest du dahin.

Ich ma $\beta$ deinen Heg voller Trauer.

Als du anfingst zu fallen."

(str.3)

Unter der schwarzen Seide ist ihre Herkunft noch $2 u$ sehen. 
"Du ziehst eine Schleppe, wie jener Stern."

(str.7)

Das Gedicht "Tam damy కčegoljajut modami..." (II,187f.) verbindet das vorausgehende Gedicht "Neznakonka" (II, 185f.) mit den oben zitierten Gedichten. is ist eine Variation des beriihmten Gedichts "Neznakomka", verleint jedoch der "Unbekannten" die kosmische Dimension (Str.5). Die deutlichste Gestaltung des in den Gedichten anklingenden inythos vom gefallenen Stern, der sich als illädchen nach irdischer Liebe sehnt, gibt 3lok in seinem lyrischen Drama "Neznakomka", IV,72-102, einem "Meisterwerk romantischen Theaters" (Mocul'skij, s. Blok, S.155).

Das 3ild der Sternenjungfrau durchzieht die Gedichte, die N.is. Volochova gewidmet sind oder von ihr inspiriert uurden ("Snezna ja maska"; vgl. II,212f., 215, 217f., 225f., 23of., 232ff., 235; "Faina", II,256, 257, 264f., 267f., 269ff.).

Im Gegensatz $z u$ den Gedichten, in denen sich die einzelnen Hypostasen der "Unbekannten" gegenseitig iiberlagern, durcharingen und ergänzen, tritt in ls die weibliche Heldin nacheinander in deutlich unterschiedenen Verkörperungen auf.

Das Bild der Frau als Stern ibernahm Blok aus seinen Jugendgedichten. i's liegt schon dem Gedicht "Nebesnoje umom ne izmerimo..." (I,91) zugrunde, wo der Mythos des zur Erde herabsteigenden Sterns an das Bild der russischen Venus gekniloft wird. Die anspielung auf die antike inythologie ist deutlich. Da im gleichen Gedicht das Bild der Seraphime erscheint, die den krwählten der Erde ein heiliges Traumbild bringen, ist die Beziehung zur christlichen iythologie hergestellt. Der Mythos vom gefallenen Stern ist bei Blok z.T. ronantisches Erbe. Das zeigt sein stark mystisch gefärbtes Verhältnis zur Natur und zum Kosmos (vgl. v.a. Terapiano, Tajna poeta), das ihn in besondere Jähe zu ijuttev bringt (vgl. v.a. Dolgopolov, Tjuttev i $310 \mathrm{k})$. Dieser war in seiner Naturphilosophie völlig 
von der deutschen Romantik abhängig ( Tjutčev und die deutsche Romantik). Die beiden Epigramme zum Drama "Neznakonka" stammen aus Dostojevskijs Roman "Idiot" (IV,72). Das erste zeigt, daß Bloks "Unbekannte" der Nastas'ja Filippovna nachgebildet ist. Das zweite unterstreicht die Nähe Bloks zur romantischen Liebesnystik Dostojevskijs. Im "Idiot" verbindet Nastas'ja Filippovna in sich auf rätselhafte Weise himmlische und irdische Schönheit. Sie ist die Verkörperung der gefallenen lieltseele.

Die Behauptung von P. Gromov, das Bild des "MlannesKometen" und das der Frau als gefallener Stern sei "genetisch mit der Lyrik Ap. Grigor'evs verbunden", trifft in dieser Forn nicht zu (P. Gromov, Geroj $i$ vrenja, S.507). Blok kannte zwar die Lyrik Grigor'evs seit seiner Jugend. Die jotizen zu verschiedenen "Sternen"-Gedichten Grigor'evs vom Juni 1 7o2 (Zap.kn., 283o) zeigen jedoch, da? Blok in Grigor'ev einen romantischen Dichter in der srt eines Žukovskif, Tjutłev, Iet oder Polonskif sah. Die iusfihrungen Gromovs an anderer stelle (A. Blok, S.103ff.) zu der Abhängigkeit Bloks von Grigor'ev sind sehr vage und in sich widersnrifchlich.

Sie frihen Gedichte $310 k s$, die das Bild der Sternenjungfrau aufnehmen, entstanden vor dem Sommer 1902. Das gilt v.a. auch fil die Gedichte I,100, 101, 103, wo dieses Bild besonders deutlich ist. Mit Grigor'ev verbindet 3lok jedoch die gemeinsame romantische Grundhal tung.

lleben dem romantischen ïrbe ist der influß der SophienMystik vl. Solov'evs nicht zu unterschatzen, die neben Belyj auch Vjač. Ivanov und dessen Kreis stark ereriffen hatte. "ährend bei Ivanov die christliche Verankerung nie verlorenging, wurden bei Blok die christlichen ২uellen der Sophien-iystik fast vollig verschilttet. Las "..eib der Anokalypse, auf dem Mond stehend, mit Sternen bekränzt, mit der Sonne bekleidet" (vgl. z.B. Ivanov, Das alte iahre, S.76) wurde bei Blok zur 


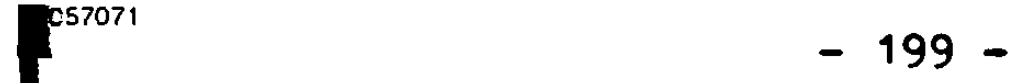

rätselhaften, aphrodisischen Sternenjungfrau. Die Parallele zwischen dem Erscheinen der sternubersäten Frauengestalt und dem Erscheinen der gottlichen lieisheit in VI. Solov'evs "Iri svidanija" ist augenfällig. Bedeutsam ist jedoch der Unterschied, der auch das Aussehen der Blokschen Unbekannten erklärt. ilit dem Verlust der christlich-religiösen Verankerung gehen auch die traditionellen Attribute der Hl. Sophia verloren. Es bleibt der siderische sspekt. Die kosmische Hypostase hat jedoch die eindeutig ethische Qualität verloren. Ler ambivalente Charakter der gottlichen Frauengestalt zeigt, daß es sich bei Blok nicht um eine Sophiensondern um eine Mystik des "Ewig-keiblichen" handelt (vgl. Einleitung zum 5.Bild, S.2861f.).

S.57/3 Damit ist seine Verbindung zu Helena abgebrochen (vgl. Volkov, Blok 1 teatr, S.90; Hayr, Die lyrischen Dramen Bloks, S.53).

S.57/4 Die Erscheinung 1st kein sterbliches Vesen, sondern eine metaphysische iesenheit, deren intwort vom iind getragen wird (vgl. S.89/6 und S.98/6). In F1 fragt German die Ërscheinung zuvor, ob sie eine Zigeunerin sei. Die irscheinung verneint. Im $3.3 i l d$ tritt Faina als Zigeurerin auf $(S .68 / 3)$. Durch die Streichung wollte Blok offenbar in $F 2$ jeden verfruhten Hinweis auf diese Hypostase vermeiden.

S.57/5 ian vergleiche damit das sehnsilchtige liarten der Faina am Ufer des Flusses. Der hieltseelenmythos scheint hier wieder durch.

S.58/1 Ahnlich wie German im LS wird der lyrische Held in dem Gedicht "Zacatyj $v$ nox', ja $v$ nox' rozden..." (II,130f.) von einer rätselhaften Erscheinung auf einen unbekannten Heg gelockt. Zwar ist die Szenerie anders als im IS (sie gleicht dem 2.Bild des Dramas "Neznakomka"), doch ist der Inhalt derselbe: 


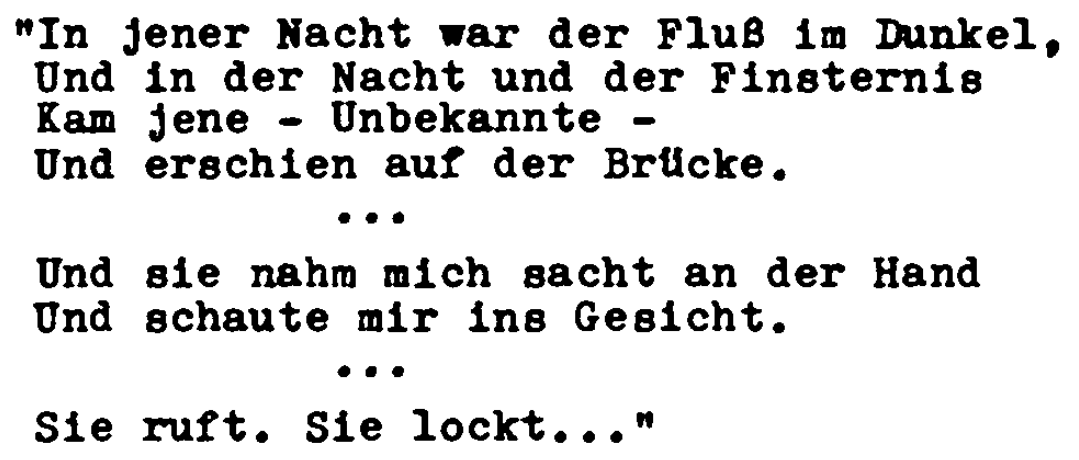

Das Gedicht hieb ursprunglich "Sud'ba" und hatte ein Motto aus L. Andrejers "Žizn' Celoreka" (vgl. II, 411f1.).

S.58/2 Hier glaubt German seinem Traumbild nicht.

S.58/3 Helena 1st von der Erscheinung beunruhigt. Der Mönch verrat durch sein Schweigen, daB die Erscheinung tiefere Bedeutung hat.

Die Finbettung der Begegnung Germans mit der rätselhaften Frau in eine ohnehin sehr irreale szene verstärkt den Charakter des Unwirklichen und Traurhaften.

In 11 sind die Motive, die den Mönch als gefallenen Engel kennzelchnen, noch etwas ausfihrlicher als in F1. Allerdings ist auch in 51 die Gestalt des Mönchs noch so deutlich als gefallener Engel zu erkennen, daß die von Medvedev, Dramy 1 poemy Bloka, S.65 zitierte Passage aus M1 kein neues Moment enthilt. Der stärkere Unterschied besteht zwischen F1 und F2. Das Erscheinen Germans am Ende des Bildes war in M1 damit motiviert, daß German seiner Frau noch etwas sagen wollte. Die Antworten der Erscheinung auf die Fragen Germans waren urspringlich jedesmal "nein". (Medredev, aao, S.66). 


\section{DRITTES BILD}

Die erste Station Germans lat die Stadt.

Seit dem Beginn der Neuzelt mit industrieller Revolution, zunehmender Automatisierung. Technisierung immer weiterer Lebensberelche, unaufhaltsamem Vordringen der Maschine und zunehmender Verstädterung, ist das Ergebnis und die Wirkungsstätte des technischen Geistes, die GroBstadt, zu elnem zentralen Thema besonders der westeuropäischen Literatur geworden. Zwar hatte schon die Antike das GroBstadthema gekannt und der verdorbenen Stadt das gesunde und einfache Land gegenubergestellt. ${ }^{1)}$ Doch mit dem Sieg der industriellen Revolution, des Kapitalismus und der Bourgeoisie hatte das GroBstadtthema eine neue, verschärfte Aktualität erhalten, der sich die Iiteratur und die Kulturkritik des 19. Jhdts. nicht entziehen konnte. ${ }^{2)}$

Mit Baudelaire, der auch hier frihere Anregungen weiterentwickelte, 3) fand das Grobstadthema Eingang in die Poesie, wo es seither ein Leitthema der modernen Lyrik ist. ${ }^{4)}$

Das Verhältnis Baudelaires und Rimbauds, der Begriunder der modernen Poesie, zur Stadt war zwiespältig. Elnerselts war ev1dent, daB die moderne Grobstadt das Ergebnis des in der Technik triumphierenden Geistes des Positivismus war, gegen dessen Anspruch sie mit der Plucht in die Welt des Traums, der Phantasie,

1) Vgl. etwa Theokrit, dazu Hauser, Sozialgeschichte II, S.18; Verg11, ecl.4, 6; georg.2, 458ff.; Horaz, sat.2, 6; ep.10 und 13; Dion Chrysostomos, Juvenal, Tacitus u.a.

2) z.B. Balzac mit dem "Mythos von Paris als dem neuen Babylon", Hauser, aao, S.290; Zola; Dickens, Carlyle, Ruskin, Morris in England; Goethe, die Romantiker A. Miller, v. Baader, Görres, Schopenhauer, Jak. v. Burckhardt, Nietzsche, vgl, dazu Schnabel, Deutsche Geschichte im 19. Jndt., Bd.6, S.239f., $263 \mathrm{ff}$.

3) Schon A. Vigny, den Baudelaire sehr schätzte, hatte in "Paris" (1831) die französische Hauptstadt als neues Babel gezelchnet, das vom Feuer der Apokalypse hinweggefegt wurde. Ähnliches findet sich bei Gautier.

4) Friedrich, Struktur, S.35, 42f., 55, 66 u.ö.; Sartre, Baudelaire, S.52f., 132 u.ö. Eine ubergrelfende Darstellung des Großstadthemas in der modernen Lyrik gibt Hamburger, Die Dialektik der modernen Lyrik, S.347ff.. 
der Rauschzustände und der Dichtung antworteten. Andererseits war die Großstadt als kunstliches Gebilde, als "Un-Natur", fur Baudelaire ${ }^{1)}$ und Rimbaud ein Analogon zu ihren eigenen konstrulerten Kunstgebilden. Die Faszination an der Grobstadt entsprach der Aversion gegen die Natur. Die Flucht aus der Banalität und Enge einer vom Rationalismus beherrschten Welt sollte mit einer "kreativen Phantasie" vollzogen werden, deren Operieren ebenfalls rational und voluntativ gesteuert murde, und die weitgehend den Charakter eines mathematischen Kalkils annahm. ${ }^{2)}$ Die Auseinandersetzung mit dem Positivismus wurde von Baudelaire und Rimbaud mit Mitteln gefuhrt, die dem Geist des Bekämpften verhaftet waren.

Die "erste Generation" der russischen Symbolisten war in dichtungstheoretischer wie thematischer Hinsicht weitgehend abhängig vom Vorbild der französischen Symbolisten. ${ }^{3)}$ Das gilt besonders fiir Brjusov, der das GroBstadthema in die russische Lyrik eigentlich erst eingefuhrt hat, ${ }^{4}$ ) und dessen rationaler Geist und Interesse an der Grobstadt ${ }^{5)}$ deutlich an die französischen Symbolisten erinnern. Durch die Vermittlung Brjusovs wurde v.a. die Großstadtichtung Verhaerens in RuBland wirksam, ${ }^{6)}$ die auch fiir die "zweite Generation" der russischen Symbolisten von Bedeutung war. 7 )

Die Grobstadtgedichte Brjusovs ubten auf Blok schon im "mystischen Sommer" von 1901 eine groBe Faszination aus. ${ }^{8}$ ) Die Lyrik Brjusovs riickte fur Blok in jener zeit in die Nähe der Gedichte V1. Solov'evs, was auch den Versuch Bloks erklärt, Brjusovs

1) Sartre, Baudelaire, S.126; Priedrich, Struktur, S.54.

2) Priedrich, aao, S.53f. u.ö.

3) Vgl. dazu ausfuhrilch: Donchin, The Influence of French Simbolism on Russian Poetry.

4) Mocul'skif, Br jusov, S.88; Maksimov, Brjusov, S.138, 143 u.ö.

5) Maksimov, aao, S.145, sieht hierin mit Recht einen Hauptunterschied zu Bal-mont, Sologub und vjac. Ivanov.

6) Brjusov ubersetzte Verhaeren ins Russische. Vgl. Bloks Rezension V,626-629; 633-635. Holthusen, Studien, S.76.

7) Vgl. S. Solov'ev, Vorwort zu "Crurifragium" (1908).

8) Vgl. Zap.kn., 22, Eintrag vom sept. 1901; VII,19-20, Eintrag vom 29. Dez. 1901; VII,344, Eintrag vom 30. (17.) Aug. 1918. 
Zyklus "Orbl et orb1" und die Poesle Solov'ev aus derselben apokalypt1schen Inspiration zu deuten. ${ }^{1)}$ Blok befurchtete eine Zeitlang sogar, nur noch "Duplikate" der Brjusovichen Gedichte, 2) aber keine "vollifig elgenen Gedichten 3) mehr schrelben zu können. Bloks Begelsterung ${ }^{4}$ wich allerdings schon im Ortober 1904, also vor den "Neznakomka"-Gedichten ${ }^{5)}$ einer deutlichen Ernuchterung. 6) Blok erkannte den parnassischen, voluntativen Charakter von Brjusovs Grobstadtpoesie.

"A.A. (Blok) verstand Brjusov als erster: er ist nur ein Mathematiker, ein Rechner, ein Nomenklaturist und keinesfalls eln ernstzunehmender Mag1er." 7)

Blok ubernahm von Brjusov die aus dem französischen Symbolismus bekannten Themen: Schönhelt des HäBllchen und Banalen, das Laster, die Prostitution, die Welt der Spielhöllen und Kneipen, die Welt der Jahrmarktsbuden und des Z1rkus, das Elend, die Armut und Einsamkeit der Alten etc. ${ }^{8}$ ) Nicht mehr in der geistigen Höhe einer mystischen Liebe auf dem Hintergrund einer kosmischirrealen Landschaft, sondern in der Banalität und Trivialität des Alltäglichen entdeckte Blok eine neue, faszinierende Wirklichkeit.

Im Gegensatz zu Brjusov, der "keine Atmosphäre der GroBstadt an und für sich" kennt, ${ }^{9}$ ) und dessen Stadt in Anlehnung an Verhaeren melst die moderne, kosmopolitische "urbs" 18t, 10) handelt es sich bei der Stadt in Bloks Gedichten fast immer um Petersburg und die Vororte, mit den Nebeln, Sonnenuntergängen, dem

1) $V_{g l}$. etwa $V, 540-544,2$.Rezension Bloks zu "Urbi et orb1".

2) VIII.93ff.., Brief an S. Solov'ev vom 8. März 1904.

3) VIII,89, Brief an Brjusov vom 23. Febr. 1904.

4) VIII, 43,69,72f.,76f.. 101; V.532f.

$5)$ "Noti", das die Rélhe einleitet, entstand am 19. Nov. 1904.

6) VIII,109f., Brief an S. Solov'ev vom 21. Okt. 1904.

7) Belyj, Vospominanija, Ep.I, S.262; vgl, dazu: VIII,117, Brief an S. Solov'ev vom Jan. 1905; VIII,134, Brief an Bely J vom 8. Aug. 1905.

8) Vgl. z.B. Močul'skij, Blok, S.84f, 91, 98f.. Dieselben Themen finden sich naturlich bel vielen Dichtern der Jahrhundertwende. Pur Blok war, "genet1sch" gesehen, das Vorbild Brjusovs besonders wichtig.

9) Holthusen, Studien, S.81.

10) Die Stadt bel Verhaeren ist melst London; be1 Brjusov Paris, London, Reval u.a. ohne elgene, "lokale" Atmosphäre. 
Brandgeruch, den weiBen Nächten, oder dem Schneetreiben. 1) Die Frauengestalten in Bloks GroBstadtgedichten des zweiten Bandes, die "Unbekannte", die "Schneejungfrau", "Paina", erscheinen in der geheimnisvolien Atmosphäre der Petersburger Vororte, ${ }^{2)}$ des Stadtrandes auf den Inseln, ${ }^{3)}$ der Petersburger Winternacht, 4) der weiBen Nächte, 5 ) oder der Herbstwinde. 6 )

Die Petersburger "Landschaft" mit der Neva, den Brucken, den StraBenzugen, den Kolonnen und Turmen, dem elektrischen Licht und dem Mondschein, den Nebeln und den Sternennächten bleibt in Bloks Gedichten nach 1903 trotz aller Greifbarkelt in ähnlicher Weise mystisch und irreal, wie der landschaftliche Hintergrund der "Stichi o Prekrasnoj Dame". Die "Realien" der Landschaft verschmelzen mit den typisch Blokschen Symbolen Troika, Sche1terhaufen, Schneesturm, Wind, Feuer, Komet, Stern, M1lchstrabe, Finsternis, Nacht etc. zu einem Geflecht, dessen einzelne Bestandteile bald mehr "real" bald mehr "symbolisch" nuanciert sind, 7) und die sich in immer neuen Verbindungen varileren und gegenseltig beeinflussen. 8 )

Die Atmosphäre, die Brechung der Wirklichkelt im Tagtraum des Dichters, die Auflösung der Realität in Traum oder Rausch und das Zusammenspiel von Natur 9 ) und Stadt zu einer unwirklichen,

1) Vgl. zuletzt Maksimov, Brjusov, S.139.

2) II,187f. "Neznakomka"; vgl. Neumann, A. Bloks "Neznakomka".

3) IV,82, 2.Erscheinung des Dramas "Neznakomka". Die Szene splelt auf der Brilcke, die von der "Bol'baja Zelenina"Straße auf die Krestovskij-Insel fuhrt; Orlov, Blok in: Literaturnyje pamjatnyje mesta Leningrade, S.503. Der Aufsatz Orlovs ist eine gute Darstellung von Bloks Petersburg.

4) II,81, 130f :; Zyklus "Schneemaske",257; IV,82.

5) I,90, 449; II , 129, 132; III, 36f ., 161, 174 u.ö. Vgl. Peters, Symbole der sinnilchen Wahrnehmung, S.52f..

6) II, 267

7) Bloks beliebtes Symbol "Schelterhaufen" hat neben dem symbolischen Gehalt (Liebesleidenschaft und Liebertod etc.,vgl. Wagners Brilnhilde) noch einen stark vom Lokalkolorit geprägten Wert. In den Straßen Petersburgs brannten im Winter Schelterhaufen, an denen man $81 \mathrm{ch}$ bel Kälte aufwärmen konnte. Vgl. z.B. Belyj, Vospominanija o Bloke, Zap.me tt.. S.156.

3) Vgl. Hol thusen, Studien, S.85 und besonders Pasternak, Anm. zu "Veter" (Wind; vier Gedichte uber Blok) in:

St1chotvorenija, S.694, wo eine Passage uber Blok aus Pasternaks Autoblographie "Vstupitel'nyj oxerk" zitiert wird.

9) Vgl. auch VIII, $130 f$., Brief an Je. Ivanov vom 25. Juni 1905; zitiert $S .81 / 6$. 
phantasmagorischen Bigenwelt in Bloks GroBstadtgedichten verweist auf den EinfluB Dostojevskijs. 1)

Das phantastische vilieu der Knelpe in der "ersten Erscheinung" von Bloks Drama "Neznakomka" scheint direkt von Dostojevskijs Roman "Podrostok" beeinfluBt zu sein. 2) Der "Dichter" in diesem Drama, aber auch das "lyrische Ich" des berihmten gleichnamigen Gedichts 18t einer jener "mextateli" (Träumer), 3) in deren Phantasie die Grenzen von Traum und Wirklichkeit zerfließen. 4 ) Fur die Optik der GroBstadtgedichte Bloks ist besonders Dostojevskijs Vision vom phantasmagorischen Petersburg mabgebend; Dostojevokif hat den irrealen, phantastischen Charakter Petersburgs mehrmals beschworen. ${ }^{5)}$ Blok beruft sich direkt auf den Roman "Podrostok", wo die Traumvision Petersburg sich zusammen mit dem Nebel in Nichts auflost. 6) Die fur Blok typlsche Poetislemung des Banalen. HäBlichen und Alltäglichen lst weniger

1) Pozniak, Blok 1 Dostojewskif, in: Slavia orientalis, XIV,4, 165, S.419-434; B. Solov'ev, Blok 1 Dostojevsk1f, in: Dostojevskij 1 russkije pisatel1, S.246-322.

2) IV.73-81; Kellerwirtschaft in "Podrostok", 2.Te11, 5.Kap.. III und 6. Kap.. II u.ö. Vgl. B. Solov'ev, aao. S.261ff.. Die platonische Iiebesmystik des Stucks ist von Dostojevskijs "Idlot" beeinfluBt (vgl. die belden Mottos).

3) Blok schreibt ironisch "mlČtatel'n: IV,75 u.ö.; normal "mextatel'", IV, 971 ..

4) Vgl. etwa aus "Podrostok": Fiebertraum - 1.Te11, 8.Kap.. I; 2. Te11, 9.Kap.. I; "In vino veritas" - 3.Te1l, 6.Kap.. II. Die Schilderung, die Je.P. Ivanov vom Besuch Ozerkis, dem "Schauplatz" des Gedichts "Neznakomka" gibt (vgl. auch das 21 tat von S.107/2), konnte aus Dostojevskij entlehnt sein; vgl. Ivanov, Zapisi ob A. Bloke, in Blokovakif sbornik, S. $405 \mathrm{ff}$.

5) z.B. In "Zimnije zametk1 o letnich vpetatlenijach" "Zapisk1 12 podpol'ja" und "Slaboje serdce". Vgl. aus der Iiteratur zum Thema "Dostojevskif und Petersburg": Cholgevn1kov, Dostojevskif, in Iiteraturnyje pamjatnyje mesta Leningrada; S.460499.

6) VIII.34, Brief an Z. GIpplus vom Jul1 1902. Vgl "Podrostok" 1.Teil, 8.Kap.. I. Belyjs Roman "Petersburg" steht in direkter Abhängigkeit von Dostojevskij: vgl. Holthusen, Studien, S.151f. Schon K.M. Fofanov hatte Gedichte geschrieben, In denen das BIld der gespensterhaften, phantastischen Stadt Petersburg mit deutlicher Anlehnung an Dostojevskij entstand (Na Neve; Cudovilce; vgl. V,438). 
Brjusovsches Erbe, 1) als das Erbe Dostojevskijs, dessen Auflösung des Realen ins Phantastische Blok geradezu als eigenes Programm ansah:

"Man kann uberhaupt sagen, dab mein Realismus ans Phantastische grenzt und offenbar grenzen wird ("Der Jungling" von Dostojevskij)".2)

Bloks Verständnis des Dostojevskijschen Petersburg ist stark von den apokalyptischen Ahnungen bestimmt, die gerade im Sommer 1902 einen Höhepunkt erreichten ${ }^{3)}$, und die auch für seine Haltung Brjusov gegentiber eine Zeitlang maBgebend waren. ${ }^{4}$ ) Blok stand in dieser Ze1t dem Merezkovskij-Kreis nahe, was die stark apokalyptısch eingefärbte Deutung von Dostojevskijs Werk verständlich macht. 5)

Die Behandlung des GroBstadthemas im IS unterscheidet sich stark vom "magischen Realismus" der Blokschen Gedichte. Im IS macht sich ein "zweiter Brjusovscher EinfluB" geltend. Im Dezember 1906 erschien ein Prosaband Brjusovs unter dem Titel "Zemnaja 08'" (Erdachse), der eine Reihe von Erzählungen und das Lesedrama "Zemlja" (Die Erde) enthielt. Die Erzählungen entstanden in den Jahren 1901-1906, das Drama 1904. Die Werke waren zuvor schon einzeln veröfentlicht worden, und Blok kannte sie schon z.T., als Brjusov ihm den Sammelband schickte.

1) so scheint Kluge, Westeuropa und RuBland, S.71 anzunehmen.

2) VIII, 40, Brief an seinen vater vom 5. Aug. 1902. BIok bezieht sich direkt auf "Podrostok", 2.Teil, 5.Kap..III. VI. Orlov kommt von hierher zur Formel "Mystik im Alitäglichen" (Orlov, Blok, in: Lit.pamjatn. mesta Leningrada, S.514; vgl. Zap.kn..73) oder "phantastischer Realismus" (ders.. aao, S.63). Die beste Formel scheint mir (in Berufung auf Kluge, aao, S.73) "magischer Realismus" zu sein, die Joh. v. Guenther, A. Blok, S.494, prägte.

3) Vgl. die Briefe aus jener Zeit, VIII,34-41;

4) Orlov, A. Blok, S.64.

5) Merežkovskij hatte im Werk Dostojevskijs die neue Poesie der stadt entdeckt und ein tieferes Verständnis fil Dostojevskij bel der "modernen" Leserschaft geweckt; vgl. Hol thusen. Studien. S.11ff. Die starken apokalyptischen Elemente im Werk Dostojevskijs sind ebenfalls erst von Merezkovskif entsprechend gevirdigt worden; vgl. Doerne, Tolstof und Dostojemskif. S.123f. 
Blok war von Brjusovs Prosawerken so begelstert, daB er sofort eine Rezension zu verfassen begann. 1) Diese Rezension ${ }^{2)}$ ist streckenweise eher eln lyrischer Monolog, als eine Darstellung oder kritische wurdigung von Brjusovs Werken. Neben der Erzahlung NV zerkalen (Im Splegel) schätzte Blok besonders die utop1schen Erzăhlungen "Respublika Južnogo Kresta" (Die Republik des Sildkreuzes) und "Poslednije mučeniki" (Die letzten Märtyrer) sowie das utopische Drama "Zemlja".

Die Hauptstadt der Republik des Sudkreuzes, die "Sternenstadt"

"... lag genau am Pol... Die Straßen der Stadt verliefen vom Rathaus entlang den Meridianen und diese wurden von anderen Straßen gekreuzt, die in parallelen Kreisen zueinander lagen... Fenster gab es in den wänden nicht, da die Gebäude von innen elektrisch beleuchtet wurden. Ebenfalls elektrisch waren auch die Straßen beleuchtet. Wegen der Strenge des Klimas war liber die Stadt ein lichtundurchlässiges Dach gebaut... Die Straßen der Sternenstadt waren dauernd von hellem und glelchmäßigem Iicht ibergossen..."3)

Die Sternenstadt mit ihren Trabantenstädten wird von einer pestartigen "mania contradicens" heimgesucht und geht in einen Rausch von Mord und Verbrechen unter.

Diese utopische stadt ist filr Blok

"die ungeheuerliche Sternenstadt der Zukunft (der nahen, fast schon gegenwärtigen Zukunft)."4)

In der Erzählung "Poslednije mucenik1" wird ein Geschehen dargestellt, das von den Siegern als "Weltrevolution" gefeiert wird. Es ist die Katastrophe einer hochzivilisierten, elitären Gesellschaft, die von einer barbarischen Generation abgelöst wird, von der alle kulturellen und sittlichen Ideale der Elite uber Bord geworfen werden. Die Vorwirfe der Elite -

"Ja! Ihr seid Barbaren ohne Ahnen. Ihr verachtet die kultur der Jahrhunderte, well ihr sie nicht versteht. Ihr brilstet euch mit der Zukunft, we1l ihr Arme im Geiste seid..."5)

- werden vom Boten, der den Todgeweinten den Beschluß des neuen Regimes verklindet, stolz zurflckgewiesen:

1) VIII,172, Brief vom 26. Dez. 1906 an Brjusov; VIII, 174, Brief vom 13. Jan. 1907 an Brjusov; dazu V,784. Der Briefwechsel mit Brjusov fand in der Zeit der Entstehung der "Snežnaja maska" statt.

2) $v, 637-642$.

3) "Zemna ja os'", S.26.

4) $v, 639$.

5) "Zemnaja os'", S.75. 
"Was bristet ihr euch, das ihr Dichter und Denker seid! In uns schlummern genug Kräfte, um eine neue Generation von Weisen und Künstlern heranzuziehen, wie sie die Erde noch nicht gesehen hat... Wir sind eine schöpferische Kraft. Wir brauchen nichts Altes. Wir sagen uns von jedem Erbe 108, weil wir uns unseren Schatz selbst schmieden. Ihr seid die Vergangenheit, wir sind die Zukunft, aber die Gegenwart, - das ist dieses Schwert in unseren Händen."1)

Die Iiturgie der todgeweihten Elite, eine sich steigernde Gruppenekstase, endet in dem Blutbad, das die Revolutionäre beim Sturm auf den Tempel anrichten.

Auch das Lesedrama "Zemlja" hat zum Schauplatz eine imaginäre Stadt der Zukunft.

"Die Luft, das Licht, das Wasser werden kiinstlich beschafft von einem System von Maschinen, die vom Zentralfeuer in Gang gehalten werden. Doch die Erde erkaltet, das Wasser in den Becken versiegt, die letzten Menschen sehen in ihrer Verzweiflung keinen Ausweg. Nur einer von ihnen, der in die schwindelerregende Höhe der Etagen der Stadt hinaufgestiegen war, sah durch die Scheiben der Dächer "die blutrote sieghafte Kugel", die Sonne."2)

Dem Jungen Mann gelingt es, die Kuppel zu heben, die die stadt von der natirlichen Umwelt isolierte. Doch der Anblick der Sonne bringt nicht die erhoffte Rettung, sondern den Tod. Längst hat die Welt außerhalb der Kuppel keinen Sauerstoff mehr. Sowie die Iuft aus der Stadt entweicht, kommen die Menscheli in ihr um. Im Bericht von seinem Erkundungsgang drickt der junge Mann Ideen aus, die Blok teuer sein musten:

"Ich begriff die tödliche krankheit und verstand, worin unsere Genesung liegt. Wir sind ein Geschöpf der Erde, wir sind ihre Kinder, und wir können leben und gedeihen nur in Berührung mit jer Erde. Losgerissen von ihr müssen wir sterben, wie abgerissene Blumen. Wir haben die Erde mit Platten zugedeckt, - sie existiert nicht mehr für uns; wir haben die Sonne durch unsere Lampen ersetzt, die freie Luft durch künstliche. Und unser ganzes Leben wurde $z u$ einer ungeheuerlich Schimäre, alles verdrehte und entstellte sich. Was für unsere Vorfahren, die in der Weite der Felder lebten, so einfach und klar war, wurde in unserem Halbdunkel kompliziert, unklar, unsinnig. In uns ist das Lebensgefühl erschlagen, und wir sind in den Tod verliebt. Wir haben uns vom alten Leben losgesagt, doch hatten wir nicht die Kraft, ein neues zu schaffen. Es gab eine Zeit, wo im Fruhling die Erde von einem Teppich frischen Grases, Blumen und Blättern bedeckt war... Unser Sinnen vergeht in der Suche danach, wie man die Menschheit

1) $\mathrm{aa0}, \mathrm{S} .96 \mathrm{f}$

2) $\mathrm{V}, 641 \mathrm{f}$. 
retten kann, doch es gibt nur elnen Heg: zurilck zur Natur. Entfliehen wir aus unserem freiwilligen Gefängnis, werfen wir unsere Brust dem Wind entgegen, tauchen wir ins Sonnenlicht und in die nachtlichen Schatten, und die Große Mutter wird uns neu gebaren, uns zu einem neuen Fruhling rufen, wie sie einst das Grtin der Gräser und Baume hervorgerufen hat!"1)

Das "zurflck zur Natur!" gelingt in "Zemlja" nicht, sondern beschleunigt nur den Untergang.

Die Verbindung von Rousseaulsmus und Mutter-Erde-iystik ist bel Brjusov nur aufgesetzte Attitude. ${ }^{2)}$

Blok stellte das Drama "Zemlja" Hber die andern Prosawerke Brjusovs. 3) Es galt inn als das bedeutendste lierk des russischen symbolistischen Theaters neben "Tantal" von Vjac. Ivanov. 4) Dem uberflussigen "Frihlings Erwachen" Wedekinds" etellte er "Žizn' Celoveka" von I. Andrejev und "Zemlja" von Brjusov entgegen. 6) Brjusovs Prosawerke sind Antiutopien, 7) die von E.A. Poe, Jules Verne, H.G. Hells und anderen utopischen Schriftstellern des 19. Jhdts. beeinfluBt sind. 8) irotz ihrer bluttriefenden Dekadenz behaupten sie einen wichtigen Platz in der russischen I1teratur. Sie haben zum Thema die Dämonie der Technik 9 ) und die Ankunft des neuen, barbarischen und kulturfeindlichen Massenmenschen. Die Ablösung der erschlafften Geisteseliten, die Zerstörung der Kultur und die Vermassung hatte Le Bon in seinem 1895 erschienenen Werk "Psychologie des foules" geweissagt und damit dem Endzeitbewn Btsein des fin-de-siècle einen elementaren Ausdruck gegeben. Die Ankunft des neuen, jungen ilenschen, die

1) "Zemnaja $08^{\prime \prime}$ ". S.14 of .

2) Das gilt auch fur das Gedicht "U zemli" (1902), das Blok sehr schätzte; vgl. V,542.

3) $\mathrm{v}, 642$

4) $v, 169$

$5)$ Vgl. auch Einleitung zum 4.Bild.

6) $v, 196$

7) oder "negative Utoplen"; vgl. Tschižewskij, Elnleitung zu "Zemna ja os'", S.10.

8) Vgl. Mocul'skif, Brjusov, S.132; Maksimov, Brjusov, S.203; S.150, Anm. 2 wird auf den Einflub eines utopischen Romans des französischen Astronomen C. Flammarion verwiesen.

9) Dieses Thema liegt schon den Antiutopien Jean Pauls, E.T.A. Hoffmanns und $M$ Shelleys zugrunde; vgl. Fischer-Lexikon der Iiteratur, Bd. 2/2, S.599. 
Zerbröckelung der alten Kulturwerte unter dem unerbittlichen Tritt des unschöpferischen Herdenmenschen war um die Jahrhundertwende ein 'Thema, das die Geister beherrschte. 1)

Der Untergang der alten, humanistischen Kultur und die Ankunft des neuen Massenmenschen ist auch in Brjusovs Gedichten ein häufig wiederkehrendes Thema. 2) Anarchistische Stimmungen waren Brjusov nicht fremd. 3) Die Darstellung der modernen Großstadt in seinen Gedichten ist daher meist pessimistisch. ${ }^{4}$ )

Blok selbst wies darauf hin, daß Brjusovs Drama "Zemlja" aus dem Poem "Zamknutyje" (die Abgeschlossenen), einem wirklichen Me1sterwerk, erwachsen ist. ${ }^{5)}$ Die kiinstliche Atmosphäre der Stadt in "Zemlja" erinnert außerdem stark an Brjusovs Gedicht "Kon' bled" (Das fahle Pferd, 1903), das Blok wegen seines apokalyptischen Charakters wohl am meisten von allen Brjusovschen Gedichten schätzte. 6 )

Brjusovs satirisches Poem "Zamknutyje" schildert das Aussehen und das Leben "einer alten und strengen, unbekannten stadt", 7) die in sich geschlossen ein völlig isoliertes Dasein fihrt. Der Dichter besucht die "iippigen oder öden Kirchen", die "Säle der gelehrten Versammlungen". wo "gehorsame Ochsen, unter dem Knall der Peitschen, den riesigen Götzen des wissens ziehen". Er gent in die Werkstätten der Kiinstler, wo "bittere srmut verwisteter iedanken" herrscht.

1) Vgl. Kanda, Handbuch der Weltgeschichte, Bd.3, Sp.2297ff.; vgl. auch $A$. Weber, Kulturgeschichte als Kultursoziologie, S. $418 f f$.

2) z.B. in: "v dni zapustenenij", 1399; Brat' ja bezdomnyje", 1901; "V neokon Cenno:n zdani1". 1900; "Noxt", "Posledneje zelanije". 1902; "Kinzal", 1903; "Slava tolpe", 1904; "K scastlivum", "Grjadułxije gunny", 1904-05; "Lik Meduzy", "Dovol'nym", 1905; "Gorodu". 1907 u.a.

3) Literaturnoje nasledstvo $27-28, S .642$; Brief an Gor'kij vom Sebruar 1901.

4) Das entspricht Verhaerens Gedichten Mitte der 90-er Jahre.

5) V,641; vgl. auch VII,19f . Eintragung vom 29. Dez. 1901, dazu Anm.2; V,534, 545 und VIII, 220. Brief an Brjusov vom 8. Dez. 1907 .

6) Vgl. VIII, 101, Brief an Percov vom 10. Mai 1904; VIII,110, Brief an S. Solov'ev vom 21. Okt. 1904.

7) Reales Vorbild war Reval. 
"Von dieser vorbedachten, gewohnten Trivialität,

Wie durstete es mich, nur fur eine stunde, davon auszuruhen! Doch wo konnte $1 \mathrm{ch}$ Lebender in lebende Augen schauen?

Dort wo die Spielhölle lst und das Bordell!...

Und ein schrecklïcher Gedanke quälte mich in jenen Tagen:

Was 1st, wenn meine stadt der Vorbote der Jahrhunderte ist?

Und wie ein Alptraum, als gnadenlose Erscheinung,

Als proportioniertes riesiges Untier.

uit einem gläsernen Schädel, der die Weltkugel bedeckt,

Erschien die zukinftige Stadt, ein einziges Haus, vor mir.

Gegen die Maschinenstadt der Zukunft erhebt sich die ungebändigte Kraft eines neuen Geschlechts.

"Doch nein! Es kann nicht dem qualvolien sturz, Allen Segnungen des Untergangs entgehen, worilber wir jetzt stolz sind.

Es wird von neuem der Flebertraum von plut und Kampf beginnen,

Wieder wird die Welt in zwei feindliche Horden zerfallen, Der Kampf wird wie ein wilder Wirbel durch das All jagen Und wird in selner Raserei die Städte wie Gras hinwegfegen, Und es werden an der verödeten seine die wölfe heulen. Und die wände des Tower werden spurlos verschwinden...

Die völker lachen wie die kinder,

wie wildtiere sich beiBen und ihre wut nicht verbergen.

Und auf Erden wird ein neuer stamm aufgehen,

Und die Welt wird von neuem geheimnisvoll und neu sein.

In den Ruinen, die einst Parlament hieBen,

Wie froh wird da der Schrel der Kinder sein,

Wie lustig wird es sein, die Reste der alten statuen

zu zerschlagen

Und Scheiterhaufen aus zahllosen Buchern zu entfachen.

Freiheit, Entzücken einer großen Freiheit,

Ich gruBe dich und preise dich aus Ketten!

Ich bin gefangen, ein Sklave im Gefängnis, doch ich sehe

on Sonne, oh lielte, oh Höhe der Steppen!" das Feld, das freie Feld...

("Zamknuty je") 1)

Die Stadt bel Brjusov ist Symbol der Endphase des stagnierenden Rationalismus, Festung des schon vom Untergang gezeichneten Kap1tal1smus, Gigant18ches Wohnhaus der Bourgeolsie.2)

Brjusov steht völlig im Gegensatz zu Cernysevskij, dessen beruhmter sozialutopischer Roman "Cto delat? (Was tun 1863) die vision einer voll technisierten superstadt enthält, in der

1) Brjusov, Stichotvorenija, S. 164-172.

2) Vgl. Dolgopolov, Poémy Bioka 1 russkaja poèma konca XIXnacala XX vekov, S.42ff. 
sich eine glickliche Menschheit den Segnungen der modernen Wissenschaft ergibt. 1)

Gegen die Sozialutopie Cernysevskijs richtete Dostojevskij seine "Zimnije zametki o letnich vpecatlenijach" (Winterliche Aufzeichnungen iber sommerliche Eindrilcke; 1863) ${ }^{2}$ ) und seine "Zapiski iz podpol'ja" (Aufzelchnungen aus dem Kellerloch; 1864). 3) Dostojevskij beschwört den Mythos vom russischen Gotträgervolk ${ }^{4}$ ) gegen den Ungeist der westeuropäischen Bourgeoisie, gegen die totale Entmenschlichung der Maschinenzivilisation, gegen den "Ame1 senhaufen".

An die Antiutopien Brjusovs trägt Blok seine, bei der Beschäftigung mit R. Wagner und Fr. Nietzsche seit etwa 1906 gewonnene, "musikalische" Kulturkritik heran. 5) Die GroBstadt ist fir Blok das Symbol der unmusikalischen Zivilisation. Die GroBstadtszene des LS wirkt stellenwelse fast wie eine Dramatisierung einiger Passagen aus Wagner ${ }^{6}$ ) oder Nietzsche. ${ }^{7)}$ Damit steht sie näher

1) Cerny ševsk1j, Poln.sobr.soð. v 17 tomach, M. 1939ff., tom. XI, S.578ff. Der Glaspalast Cernysevskijs ähnelt dem Kristallpalast, der 1851-54 bel Sydenham, sidöstlich von London, unter tellweiser Benitzung des Materials der ersten Weltausstellung von 1851 im Hydepark, errichtet wurde. Das Gebäude enthielt Konzerthallen, einen Theaterraum und unzählige Ausstellungsräume. Es war von riesigen Gartenanlagen umgeben, und drei Bahnlinien sorgten firr die schnelle Verbindung mit London. Der Kristallpalast, eine Art permanenter Weltausstellung. war das Symbol fiir den Sieg der Technik, des Fortschritts und des Rationalismus.

2) Besonders wichtig ist hier das Kapital "Vaal" (Baal). Dostojevskij bezeichnet die Weltausstellung von 1862 in Kensington, wo Hunderttausende zusammenkommen, als "Babylon", als "apokalyptische Prophetie". Der Weltausstellung stellt er das Elend und das Laster des Hay-Market gegeniber.

3) Vgl. Grossmann, Dostojevskij, S.299.

4) "Besy", II, 1.7. Abschnitt; "Idiot", 2.Tell, 4.Kap., VII u.ö. Dazu kritisch zuletzt Doerne, Tolstoj und Dostojewskij. S.118ff.

5) Vgl. hierzu Kluge, Westeuropa und RuBland, S.84ff.

6) Wagner, "Die Revolution", "Das Kunstwerk der Zukunft", "Deutsche kunst und deutsche Politik" u.a.

7) Nietzsche, "Die Geburt der Tragödie" (z.B. Teil 20); Die 2. unzeitgemäße Betrachtung "Vom Nutzen und Nachteil der Historie fiir das Leben" (z.B. Teil 7 mit dem Angriff auf das "Popularisieren", "Feminisieren" und "Infantisieren" der Wissenschaft) u.a. 
bel Bloke kulturkritischen Schriften als bel den Grobstadtgedichten des 2. Bandes. 1 )

Das 19. Jahrhundert ist fur Blok

"Ein glänzendes und friedhöliches Jahrhundert, das auf das lebendige Antlitz des Menschen das Glanzbrokatlelchentuch der Mechanik, des Posivitismus und des ökonomischen Materialismus warf, das die menschliche Stimme im Iärm der Maschinen begrub; ein metallenes Jahrhundert, in dem die "Eisenschachtel" - E1senbahn - die "unilberholbare Troika" iiberholte, in der "Gogol' ganz RuBland verkörperte", wle Gleb Uspenskij sagte."2)

In deutlicher Anlehnung an den uralten Mythos der vier weltalter ${ }^{3)}$ schildert Blok das 19. Jahrhundert als das "elserne":

"Die Zeit fliegt dahin, die Zivilisation wächst, die Menschheit progressiert.

1) Bloks Kritik an der Großstadt als dem Symbol der Zivilisation erinnert an Spenglers Schilderung der "Weltstadt" in "Der Untergang des Abendlandes" (2.Bd., 2.Kap.).

Brjusovs Großstadt ist in der Tat die spenglersche "Weltstadt", was schon im Titel "Urbi et orbi" anklingt. Spenglers Bild von der Metropole, die das umgebende Land aussaugt, war um die Jahrhundertwende weit verbreitet. Die häufig festgestellte Ahnlichkeit zwischen Bloks Kulturkritik und der Kulturmorphologie Spenglers beruft sich normalerweise auf Bloks "Krułenije gumanizma" (Der Untergang des Humanismus), vgl. dazu Kluge, Westeuropa und RuBland, S.107, Anm. 147 auf S.319. Bloks Ansichten zum Gang der europäischen Geschichte sind jedoch so dilettantisch, daß sich ein Vergleich mit Spengler, aber auch mit Danilevskij von vornherein verbietet. Die Analogie zwischen römischer Antike und zeitgenössischer Ziviliation, auf die Blok mehrfach eingeht, war um die Jahrhundertwende ein Gemeinplatz, und das "musikalische Kriterium" von Bloks analogiebildendem Geschichtsverständnis kann sich mit der Methode Spenglers nicht messen. Blok stand zwar wie Spengler im Bann der Lebensphilosophie, worauf auch sovetische Forscher hinweisen; von Spengler unterscheidet inn fedoch die Begrenztheit des W1ssens und des Horizonts, auBerdem aber der ausgesprochen apokalyptische, chiliastische Zug seines Weltbilds.

2) V.347 in "Ironifa". Bloks Ausspielen der Eisenbahn gegen die Troika erinnert an das beliebte Wildwestfilm-Thema: Wettlauf owlschen Elsenbahn und Postkutsche. Vgl. auch S. $81 / 7$.

3) Zaratustrische Religion; Daniel 2, 31ff.; Heso1d, Werke und Tage, $109 \mathrm{ff}$; Aratos von Solol, Himmelserscheinungen, V.96136; Vergil, 4.Ekloge; Horaz, Epode 16; Ovid, Metamorphosen, 1. Buch, 89ff. 
Das 19. Jahrhundert ist ein eisernes Jahrhundert... Die Zeit fliegt dahin: von Jahr zu Jahr, von Tag zu Tag, von Stunde zu Stunde wird immer klarer, daB die Zivilisation auf die Köpfe ihrer Urheber einstilizen wird, sie mit sich einschlagen wird; doch sie schlägt noch nicht ein; und der Wahnsinn dauert an: alles ist ausgedacht, alles vorherbestimmt, der Untergang 1 st unausweichlich; doch der Untergang zögert... Revolutionen schlagen zu, entladen sich, verfliegen. Die Menschen zittern vor Schrecken..., sie sind längst keine Menschen mehr, sie tun nur 80; es sind Sklaven, Tiere, Reptilien... Die Zivilisation wächst. An Anfang des Jahrhunderts sprach Balzac von der "menschlichen Komödie",1) in der Mitte des Jahrhunderts Scherr2) von der "Tragikomödie". Jetzt ist es eine Straßenposse. Die Stunde der Posse hatte geschlagen, als sich das erste Flugzeug von der Erde abhob. Die Atmosphäre ist erobert - welch groBartiges Schauspiel. Ein jämmerlicher Geck hat sich bis zu den Wolken erhoben: ein Huhn hat jit den Fligeln geschlagen und sich zu fliegen angeschickt, und es ist iber den Misthaufen geflogen."3)

Die stärkste Vemurtellung des Gelstes des 19. Jahrhunderts enthält das erste Kapitel von Bloks Poem "Vozmezdije" (Die Vergeltung ):

"Neunzehntes, eisernes Jahrhundert, Wahrlich grausames Jahrhundert!

Du hast in nächtliche, sternenlose Finsternis

Den leichtsinnigen Menschen geworfen!

In die Nacht spekulativer Begriffe,

Materialistischer Bagatellen,

Kraftloser Klagen und Verwilnschungen

Blutloser seelen und schwacher Körper!

Mit dir kamen an Stelle der Pest

Neurasthenie, Langeweile, Spleen;

Jahrhundert, in dem sich die scheidel an die Wand

Von ökonomischen Doktrinen,

Kongressen, Banken, Föderationen,

Tischreden, schönen Worten schlagen;

Jahrhundert der Aktien, Renten und obligationen,

Und der schwachen Geister.

Und der mittelmäßigen Talente

(So ist es gerechter: halbe-halbe!);

Jahrhundert nicht der Salons, sondern der Wirtshäuser, Nicht der Récamiers, sondern nur eben der Damen...

1) Balzac nannte sein monumentales Romanwerk "Comédie humaine".

2) Blok bezieht sich auf den Kultur- und Iiteraturhistoriker Johannes Scherr (1817-1886), dessen geschichtliche und I1terarische Essavs unter dem Titel "Menschliche Tragikomödie" ("Celoveceskaja tragikomedijan, M. 1877) erschienen.

3) V, 385f.. in: "Molni1 iskusstva". In diese Betrachtung verarbeitete Blok Eindrilcke seiner Italienreise von 1909. Bloks "berzeugung, Italien sei von der Zivilisation vergiftet, spiegelt sich auch in seinen "Ital'janskije stich1". III,98122 ; vgl. besonders III,106f. Ähnlich: V, $355 f$. 
Jahrhundert des Relchtums der Bourgeoisie

(Des unslchtbar wachsenden Bösen!).

Unter dem Zeichen von Gleichheit und Bruderlichkelt

Reiften hier dunkle Dinge heran...

$$
\text { -. }
$$

Doch der, der alies in Bewegung hielt,

Die Marionetten aller Länder lenkend,

Der wuBte, was er tat,

Als er den humanistischen Nebel sandte:

In jenem grauen und modrigen Nebel

Welkte das Fleisch, und der Geist verdorrte,

Und selbst der Engel des helligen Streites

Flog, so scheint es, davon..."1)

Doch das 19. Jahrhundert war erst ein Vorspiel.

"Zwanzigstes Jahrhundert... Noch unbehauster,

Noch schrecklicher ist die Finsternis des Lebens.

(Noch schwärzer und riesiger

Ist der Schatten von Luzifers Fligel).

Und das unaufhöriliche Brililen der Maschine,

Die Tag und Nacht den Untergang schmiedet,

Das schreckliche Bewußtsein des Irrtums

Aller frihheren kleinen Gedanken und tfberzeugungen,

Und der erste Flug des Aeroplans

In die Wiiste unbekannter Sphären...

Und die Abkehr vom Leben.

Und die wahnsinnige Liebe zum Leben,

Und die Leidenschaft und der Haß zum Vaterland...

Und das schwarze Blut der Erde2)

Verspricht uns, die Adern sprengend,

Alle Grenzen zerstörend.

Unerhörte Umwälzungen,

Nie gesehene Erhebungen...."3)

Ein Hauptmerkmal der Zivilisation des 19. Jahrhunderts ist der "Verlust der Ganzheit" (celost'nost'), 4) ein Vorwurf, der eine lange kulturphilosophische Tradition hat, ${ }^{5)}$ bei Blok aber den

1) III, $304 \mathrm{f}$

2) Anspielung auf das Erdbeben von Messina (vgl. III,305, Z.61), in dem Blok die Rache des Elements gegen die menschliche Hybris erblickte.

3) III, 305f.

4) $\mathrm{V}, 351$; VI, 103

5) Der "Verlust der Ganzheit" ist ein Vorwurf, den schon Schiller gegen den modernen Zivilisationsmenschen erhebt (vgl. seinen 6. Brief iber die ästhetische Erziehung). Hölderlin warf in Hyperions Strafrede an die Deutschen diesen den Verlust der "Ganzheit" vor. Die "Ganzheit". "Totalität" ist auch das Ideal der Romantiker (vgl. Kluckhohn, S.53; dazu VI, 145). Wagner wollte in Rilckgriff auf die griechische Tragödie die "Ganzheit" im "Gesamtkunstwerk" vieder herstellen. Die russischen Slavophilen stellten der "abstrakt-rationalen wissen- 
Verlust des "Geistes der Musik", die Lösung vom dynamischen Urgrund des Seins bedeutet. 1 )

Der Verlust der Ganzheit äuBert sich im Sieg des nur rationalen, diskursiven Weltverständnisses, des Spezialistentums, in der Herausbildung zweier mit gegensätzlichen Methoden arbeitenden Wissenschaften, der Natur- und der Gelsteswissenschaften, die ihrerseits wieder in eine unilbersehbare Zahl von Einzeldisziplinen zerfallen. 2) Mit dem Sieg des Rationalismus sagt sich der Mensch von seiner eigentlichen Heimat, der Mutter Erde 108. Symbol fiir die Lösung von der Erde ist das Flugzeug. 3) Die typische Geisteshaltung des "entururzelten" Rationalisten ist ein flacher Optimismus. ${ }^{4)}$ Der Verlust der Ganzheit fürt zur Degradierung der Kunst, die zur billigen Zerstreuung ausartet. 5)

Bloks Kulturkritik entzilndet sich besonders an Hesteuropa, vor allem an Frankreich ${ }^{6)}$ und Italien, 7) wo die Zivilisation das echte Leben aus dem "Geist der Musik" vernichtet habe. Auch in

schaft" des Westens die vermeintliche "ganzheitliche Weltanschauung" RuRlands gegenilber (vgl. Cizevskij, Russ. Geistesgeschichte II, S.70; Stepun, Der Bolschewismus u. die christliche Existenz, S.55ff.; die grundlegende Bedeutung des "Integralismus", der "Ganzheitlichkeit" fiir das russische kulturhistorische u. politische Denken, hebt Sarkisyanz, RuBland und der Messianismus des Crients, S.14ff. hervor.

1) Vgl. Kluge, Vesteurona und RuBland, S.84ff.

2) $V I, 103 f f$

3) V.355f.; vgl auch III, $296 f$.

4) Ví,105; In seinem 1919 verfasten Vorwort zum Poem "Vozmezdije" schreibt Blok: die Konzeption zu diesem Werk ist entstanden "unter dem Druck des in mir wachsenden Hasses auf die verschiedenen Theorien des Fortschritts". III,298. Die Antithesen "rational"-"intuitiv", "analytisch"-"synthetisch", "Spezialistentum"-"Ganzheitlichkeit" etc. kehren im Antirationalismus der dt. Romantik und der "Lebensphilosophie" immer wieder.

5) V,262ff. in "O teatre".

6) Vgl. 2.B. VIII, 358-371, Briefe an seine Mutter vom Sommer 1911 aus der Bretagne una Pár1s; VI, 14, 176f.., 281 u.ö. In der kritischen Einsteliung zur französischen Zivilisation trifft sich Blok nicht nur mit Nietzsche, Wagner und Heine (vgl. Kluge, aac. S.160), sondern auch mit Gogol' ("Rim") und Dostojevskij.

7) "Ital'lanskije stichi", III,98-121; "Molni1 1skusstva" (Blitze der Kunst), V, 385-405.'Dazu Kluge, aao, S.144-160. 
Rußland hat sich die Zivilisation eine Bastion erobert: Petersburg, das "gigantische Freudenhaus", aus dessen tödlicher Atmosphäre es Blok in die Randgebiete $20 g .1$ ) Schon Gogol' hatte dieser stadt jede Echtheit und Verwurzelung im Volksboden abgesprochen ${ }^{2}$ ) und dem echt russischen Moskau das leichtlebige, flatterhafte, den Verlockungen der Zivilisation nur allzu zugängliche Petersburg in einer Reihe von glänzenden Antithesen gegenibuergestellt. ${ }^{3)}$ Die schöne Unbekannte in seiner Novelle "Nevskif prospekt" ist die direkte Vorgängerin der Blokschen "Neznakomka". 4) Von noch gröBerer Bedeutung ist fir Blok wiederun Dostojevskij.

"Unter dem hauptsächlichen EinfluB Dostojevskijs bildet sich bel Blok eine bestimmte Vorstellung von Petersburg als der "unfaßbaren Stadt"5) heraus... In der Vorstellung des jungen Blok war Petersburg, als bilrokratisches und kapitalistisches Zentrum, icht organisch mit RuBland verbunden, welches von ihm im Lichte ronantischer Theorien als drohendes und irrationales "Element des Volkes" ("narodnaja stichija") gedacht wurde, das dem Geist und den Formen der zaristischen und kapitalistischen Zivilisation fremd und feindlich war...

In der Zeit der Entstehung des größten Teils der "städtischen" Gedichte war Petersburg in der Vorstellung Bloks der Ort, "wo Rußland gleichsam zu Nichts wird, wo es noch Rußland und doch nicht mehr RuBland ist", ...die Grenze zwischen RuBland und Europa."6)

1) VIII,1301., Brief an Je.P. Ivanov vom 25. Juni 1905, zitiert S.42, Anm. 6 .

2) Gogol', Sobr.sot. v 7 tomach, Bd.7, S.61f., Brief an seine Mutter vom 30. April 1829.

2) Gogol', aaO, 3d.6, S.188-201, "Peterburgskije zapiski 1836 goda". Auch Blok stellt dem "unechten" Petersburg das "echte" Moskau gegenilber; vgl. II,141ff. und Anm. S.414f.

4) Vgl. S.85/5.

5) Vgl. Bloks Ged1cht "Snežnaja Deva", II,267f., Str. 6.

6) Orlov, A. Blok, in: Literaturnyje panjatnyje mesta Leningrada, S.511. Orlov meint, Blok habe später seine "romantisch "slavophilen" Vorstellungen von RuBland" iberwunden. Das ist unrichtig. Bloks Mythos vom "elementaren" RuBland blieb bis zu seinem Tod unverändert und liegt auch den "Dvenadcat" " zugrunde (vgl. auch Exkurs). Zu Bloks Bild von Petersburg vgl. v, 599 . 
"Al. Blok ging in die stadt wie in ein "Schauspiel" (na "pozorisce"). Die stadt, wie auch das Theater, ist nach altem Glauben ein Schauspiel, ein Jahrmarktsrummel."1)

Petersburg war fitr Blok die Bilhne, auf der er glaubte, den Kampf der Zivilisation ums therleben und schlieblich ihren Untergang Jurch die Rache des "Elements" beobachten zu können.

Die Großstadtgedichte Bloks zeigen die vielfältigen Gesichter der Zivilisation gleichsan von innen. Die kulturkritischen Schriften Bloks geben die ideelle Grundlage. Das Bindeglied ist ein von apokalyptischen Ahnungen erfilltes, mit einer irratiosalen, "musikalischen" Lebensphilosophie begründetes KatastrophenbewuBtsein. 2) Petersburg und die Superstadt von Brjusovs Drama "Zemlja" rücken im BewuBtsein Bloks zusammen. 3 ) Das nahende Feuer, ein apokalyptischer Weltenbrand, wird es vernichten. ${ }^{4)}$

Die Großstadtszene des IS, zu der auch der erste Teil der Szene in der Garderobe der Faina gehört, enthält in satirisch-grotesker Verzerrung eine Reihe der Motive, die aus den Werken Brjusovs und den kulturkritischen ÄuBerungen Bloks bekannt sind. Die Stadt des IS ist die kiinstliche, der Natur entfremdete Superstadt Brjusovs, wobel Blok den aspekt der Stadt zeigt, in dem die Zivilisation sich am deutlichsten offenbart: die weltausstellung. Hier verschmelzen die beiden Errungenschaften der Zivilisation, die Wissenschaft und das amllsement zu einer perversen Einheit. Die Weltausstellung ist der Ort, an dem sich die Hybris des vissenschaftlichen Geistes, die Dämonie der Technik und die Sensationslust des Pöbels begegnen. Die Welt-

1) Je. Ivanov, Vospominani ja ob A. Bloke, in: Blokovskij sbornik, S.377; vgl, auch S.368f. Ivanov hatte uber Petersburg ähnliche Ansichten wie Blok; vgl, aaO, S.347, 352f., $376 \mathrm{f}$. . Diese Vorstellung geht auf den uralten pythagoreischen Vergleich des Lebens mit einem Jahrmarkt zuriick (vgl. Kranz, Die griechische Philosophie, S.38).

2) Vgl. besonders II,17of.. Die apokalyptische Dimension in Bloks Gro3stadtgedichten wird in neuerer "Jeit auch von den sovetischen Forschern gesehen und einer zu einfachen sozialkritischen Interpretation als Korrektiv beigegeben; vgl. etwa Solov'ev, Poet i jego podvig. S.107ff.

3) VIII, $131^{\circ}$ in dem mehrfach erwähnten Brief an Je. Ivanov.

4) VIII,131; vgl, das Gedicht "PoZar", II,201f. 
ausstellung ist die große Bildungsstätte, der Jahrmarkt und das "große Freudenhaus", das Revier der Professoren, Clowns, Kokotten und Lustlinge. Das Idol dieser freien und briderlichen kosmopolitischen Gemeinschaft 1 st die vamphafte Diva, der Star. Hinter Bloks lberzogenen "Anspielungen auf moderne Zeiterscheinungen (die Probleme der Zerstreuungs- und Unterhaltungskunst, der modernen technischen Gesellschaft, Sensationslust, Schaugeschäft, Boulevarderotik, käuflicher Liebe usw.)"1) Ist deutlich der mythologische Bezug auf "Babel" zu spiiren, "Qle Mutter der Hurerei und aller Greuel", 2) die Stadt der menschlichen Hybris und der Sprachverwirrung, ${ }^{3}$ ) die gottfeindliche weltstadt, die dem Untergang geweint ist. ${ }^{4)}$ Das Symbol Babylons ist Astarte (I tar), die ausschweifende, männermordende Göttin und mitleidsvolle Kurtisane, vor deren aggressiver Sexualität und iberlegenen Allmacht sich die Männer beugen. Die Zigeunerin ist Bloks moderne Astarte, die "große Hure" des modernen Babel, das von der neuzeitlichen Großstadtzivilisation pervertierte "EwigWeibliche", das sein eigentliches Wesen hinter einer Maske verbirgt. In der "Welt", in der Hölle der Großstadt zerbrechen die hohen, der Vergangenheit verhafteten Ideale Germans unter dem Peitschenschlag der Zigeunerin. Doch ist diese Erniedrigung nur der Durchgang zu einem neuen Ideal, das die eigentliche Faina verkörpert und das German im 5.Bild unverfälscht entgegentritt: RuBland.

1) Kluge, Westeuropa und Rußland, Anm. 37 auf S.350.

2) Offenb. 17,5 .

3) $1 . \mathrm{Mos}, 11,9$

4) Jes. 13, 19-22; 21,9 u.ö. 
S.59/1 Wahrscheinlich wollte Blok mit der Zahl siebenundsiebzig an die Apokalypse erinnern, die ja ganz von der Zahl sieben beherrscht ist. Falls Blok die spokalypse im Sinn hatte, dann vermutlich die Prophezeihung vom Pall der großen Hure Babylon. In Dostojevskijs Roman "Podrostok" geht die kapitalistische ielt nach "siebenundsiebzig Niederlagen" zugrunde, mit ausdrucklichem Hinweis auf die spokalypse (2.ieil, 1.Kap., IV). In $F 1$ sollte die $H e l$ tausstellung in RuBland stattfinden (vgl. abw. 141)). Blok hat in F2 einen Einwand Stanislavskijs berlicksichtigt (vgl. "Entstehungsgeschichte", S.23).

S.59/2 Die Stadt ist die Hölle, "das Land der Finsternis und des Dunkels" (Hiob, 10, 21). Blok libernahm das Bild wahrscheinlich aus $R$. Wagners enthusiastischem sufsatz "Die Revolution" (1849), wo es von der Staatsmaschinerie des von Hetternich beherrschten Europa he13t: "Dort dringt kein Strahl des Lichtes hinein, dort herrscht ewige lacht und Finsternis, und in sacht und Finsternis r.1rd das Ganze spurlos versinken." ( $R$. Kagner, Hauptschriften, 3.76)

$5.59 / 3$. Jer Jergleich dieser jaschinen mit märchenhaften Raubtieren bereitet das Bild der :aschine als menschenverschlingendem foloch vor, flihrt jedoch auch zu unfreikilliger konik (vgl. S.64/1).

S.59/4 Diese Passage erweckt das Bild eines riesigen Vampirs.

S.59/5 Der Ausdruck "dvorec kul'tury" (kulturpalast) hat in der Zeit der Stalinschen Finf jahrespläne große Verbreitung gefunien. Er bezeichnet seither die iempel der neuen Religion. Leider gaben die mir zugänglichen Lexika keinen ilnveis auf eine Verwendung dieses susdrucks vor der cktoberrevolution.

S.59/6 Die Uhr, Symbol des technischen Zeitalters, ist hier Sinnbild des unverneidlichen Untergangs. Jie Zeit fur die Stadt läuft ab. (Jer Gott der Zeit ist der menschenfressende lironos, der in der sntike als "chronos" gedeutet wurde). 
S.59/7 In 3. und 4.Bild verspottet Blok die Leltideen der Französischen Revolution und der burgerlichen Demokratien: Freiheit, Gleichheit, Briderlichkeit. Die hier garantierte Freiheit erhebt den Kulturpalast $z u$ einer Freistatt (Asyl) in der Art der griechisch-römischen Tempel und der mittelalterlichen Rirchen.

S.59/8 Die Nennung von Heldin und Titel auf den Plakaten bereitet den Auftritt der Faina vor.

S.59/9 Das ganze 3.Bild ist von husik erfiillt. Die Zeitungsverkäufer sind auch bei Brjusov ein ittribut der "urbs" (vgl. "Pariz"). Ihre Parolen enthalten in knapper Form eine Darstellung der modernen Großstadtivilisation.

S.60/1 Die "Diva" 1st einerseits die vergötterte Frau, v.a. die vergötterte antike Kaiserin, andrerseits die von Publikun gefeierte Sängerin. Die Doppeldeutigkeit ist sicher beabsichtigt. Im Rufen der Zeitungsverkäufer verden in veränderter Form die sussagen des liönchs und des Freundes iber Faina wiederholt (vgl. S.48/4; S. $48 / 12$ und $S .51 / 1)$. In $F 1$ folgen noch zvel ausrufe der Zeitungsverkäufer: Faina, anders Gold genannt!

Faina, anders Pracht genannt!

Zedeutsan ist v.a. die Identifikation der Heldin nit der Farbe Gold. Diese Farbe symbolisiert bel 3lok das Gottliche, ganz wie in der geistesgeschichtilichen 'iradition. (Dazu: Forstner, kelt der Symbole, S.154ff.) "Gold ist ... in Bloks Lyrik immer das Attribut eines göttlichen iirkens, das in irgendeiner Form Gestalt angenomnen hat." (Peters, Symbole der sinnlichen iahrnehmung, S.137). Es sel daran erinnert, das Homer von der "goldenen iphrodite" spricht (Ilias 19, 282; Cdyssee 4,14 . Hymnus an Áphrodite, 1.Zeile).

S.60/2 Das leiten der Nasenlöcher ist wohl als Ausdruck der Verachtung beim inblick des Freundes zu verstehen.

$5.60 / 3$ Wind und ifusik sind in 1.Bild Synbole des sufbruchs, der Dynamik, die German aus seinem Haus treiben. Sie sind Attribute der Faina. In 3.Bild ist jedoch ein anderer symbolgehalt gleichwertig. German und dem Freund schlägt chaotischer Lärm entgegen, genau wie 
Dante und Vergil beit Betreten des Infernos.

"Ein Heulen, Seufzen, ein Geschrel entstand In dieser Luft, die Sterne nie erhellten, Da.3 1ch zuerst mich weinend abgewandt.

Zahllose Sprachen, die das Ohr durchgellten Mit Stirmen rauh und tief, ein Schmerzgestohne Und Zorngekreisch, dazwischen unter Schelten irteilter Faustschlag: machten ein Getine Durch endlos-8chwarze Luft, wie lockrer Sand, Der raschelnd stiebt im Wirbel vor dem Föhne."

(Inferno, III,22-30; ubersetzt von R. Zoozmann) Bloks Stadt hat große Ähnlichkeit mit der Hölle Dantes (vgl. S.62/3). Das erinnert an Brjusovs "Poslednije muXenik1". (Vgl, auch III, 15ff. "Pesn' Ada"). Hier wie dort herrscht Lärm (tumul to - šum; turbo - veter; voci, suon etc. - nuzyka). Im Gegensatz zu Dante 1st Gernan von der Stadt-Hölle zunächst fasziniert.

$5.60 \% \mathrm{Vgl}$. S.51/4.

3.60/5 Die folgende Dialogszene zwischen German und dem Freund steht in reimlosen finfhebigen Jamben (Blankversen), die unregelmäBig männlich oder weiblich enden. Blok ninnt also das Metrum des klassischen Lramas auf. Der :iechsel von Prosa zu gebundener Rede ist in Bloks lyriscnen Irazen hüufig (vgl. Balagancik, IV,14ff.; Korol' na plosčadi, IV,23f., 32ff., 4 off., 53ff.; Neznakomka, IV,82ff.; Kosa i krest, IV,169ff.). Die gro?te dichterische irikung zieht Blok aus dem kiechsel von Prosa und gebundener Rede in lyrischen Irama "Neznakomka". Dort steht die Traumszene (2. Erscheinung) ganz in gebundener kede, die "realen" Bilder (1. und 3.Bild) in Prosa.

Im IS kommen Verse nur im 3. und 7.Bild vor. Im 3.B1ld steht der größte Teil des Dialogs $z$ wischen German und dem Freund in Versen und damit in scharfem Kontrast zu dem Geschehen um sie herum.

S.61/1 Dieses Bild des gefangenen : Kädchens enthält in gedrängter Form ein zentrales hotiv des IS. Das gefangene Aädchen, das sich nach Freiheit sehnt, ist eine "Schwester" der Faina. 
S.61/2 Der Freund tritt hier und in den folgenden Repliken wieder als Vertreter einer zynischen Lebenshaltung auf.

S.61/3 M1t "beznosaja" (wörtl. "Nasenlose") ist wohl eine Frau gemeint, die an Hauttuberkulose (Lupus) erkrankt 1st. Diese Krankhelt befallt an häufigsten das Gesicht und fihrt $z u$ einer Verstummelung oder einem Einsinken der Nase und greift auch die hugenbindehaut an. Die Krankheit befallt vorwiegend das weibliche Geschlecht.

S.61/4 D1ese Replik Germans steht thematisch in der Whihe zu einigen Großstadtgedichten Bloks mit sozialem Inhalt. (Vgl. I,302; II,162, 176, 189f., 191f., 193f., 197, 198, 199f., 203, 205f.). Das Elend 1st der erste hspekt der Großstadt, mit dem German konfrontiert wird. Es will schlecht zum Glanz der heltausstellung passen.

S.61/5 Der Freund gebraucht das biblische Bild (vgl. Hebr.11, 13; Psalm 39(38), 13; 119(118), 19 u. ̈̈.) in der fiur inn typischen, individualistischen Sinngebung. Das hier anklingende Motiv des "homo viator" wird Im LS in anderem Zusammenhang wieder aufgenommen (vgl. S.106).

S.62/1 Die Replik Germans drilckt in mehreren Bildern und Vergleichen eine Haltung aus, die man als tragisch-heroische snnahne der welt bezelchnen kann. In der ablehnung des individuellen :itleids nimmt German eine Position ein, die den paradoxen Gedanken iagners zum Problem des Nitleids ähnlich 1st (vgl. Wagner, Hauptschriften, S.198ff.). German will sich nicht durch litleiden mit dem Schicksal Iinzelner vor dem Urleiden der lielt retten lassen (vgl. Nietzsche, Geburt der Tragödie, 70, S.169). Die absage an den Zynismus bedeutet die ibkehr vom elitären Egoismus des späteren Nietzsche. Die Haltung Germans widerspricht Bloks eigener Haltung, wie sie im Gedicht "Neznakomka", II,185f. zum husdruck kommt ("Ja znaju: istina $v$ vine." Vgl. dazu Bloks Brief an Pjast vom 7. hai 1906; VII,154f., wo er das Trinken "philosophisch" vertieft vgl. S.113/2). In der "Nilchternheit" allein liegt die Gewähr, ein sowohl von alihrseligkeit als auch von Zynismus unverfälschtes Bild der hilt zu gewinnen. 
S.62/2 Blok benutzt das traditionelle Bild des Festmahls in ganz ähnlicher heise im Gedicht "Skify" (Die Skythen, III, 36off.; vgl. die letzte Strophe). Im russischen Text steht "Kul'tury" mit Großbuchstaben. Bloks Gebrauch der Begriffe "Kultur" und "Zivilisation" mit der seit spengler iblichen ijebenbedeutung von Lebensfille und Zerfall ist erst seit 1912 folgerichtig. (Vgl. Jaksimov, Kriticeskaja proza, Blokovskij sbornik, 3.51, zum IS: snm. 30). In IS ist nur von "Kultur" die Rede (Kulturpalast, Festmahl der Kultur). Blok hat daran auch 1919 nichts geändert, obwohl er selbst als "Zivilisation" bezeichnet hätte, was die Personen des IS als "Kultur" bezeichnen.

S.62/3 ther dem Höllentor steht:

"Durch mich geht's ein zur Stadt der Schmerzerkorenen; Durch mich geht's ein zu Qualen ew'ger Dauer, Durch nich geht's ein zum Volke der Verlorenen. -.....

Laßt, die thr eingeht, alle Hof fnung schwinden!" (Dante, Inferno, 3.Gesang, 2.1ff.)

5.62/4 Russ. "tol pa" bedeutet "Menge". "kopfloser Haufe", "Pöbel" (vgl. Pußkin "Poet $i$ tolpa"; Vją. Ivanov, "Poet i Cern'", in: Vesy, 1904, isr.3, S.1-8; Bloks Rezension, v,7-11). Es entspricht Baudelaires "multitude vile" ("Recueillement"), kagners "Pöbel", der "keinesv'egs ein normales Produkt der wirklichen menschlichen iatur ist, sondern vielmehr das kilnstliche Erzeugnis eurer unnatilrlichen Kultur" (Wagner, Das Kunstwerk der Zukunft, in: Hauptschriften, S.125), Nietzsches "P ïbel-dischnasch", "Herde" etc. Dem "P̈̈bel" stellte Blok das "Volk" (narod) entgegen (wie hagner, aac, S.126; Nietzsche, Von wutzen und Nachteil der Historie filr das Leben, 71, S.159f.), scheiterte jedoch genau wie hagner, Nietzsche und Ivanov bei den Versuch, flir das idealisierte "Volk" ein reales Substrat zu finden.

5.62/5 Bloks Professor entspricht dem Bild, das Nietzsche vom Gelehrten zeichnet: 
"Die Gelehrten sind Höflinge einer greisenhaften Kultur..." (Menschliches, Allzumenschliches, 72, I, S.204); "Der Gelehrte hat Immer etwas von der aiten Jungfer..." (Jense1ts von Gut und Bbse, 76, S.122); "Der Gelehrte ist das Herdentier im Reiche der Erkenntnis..." (Der Wille zur Macht, 78, S.286); "Die Zeiten, in denen der Gelehrte in den Vordergrund tritt, sind Zeichen des Niedergangs." (Jenseits von Gut und Böse, Zur Genealogle der Moral, 76, S.402) u.v.a.

In F1 ist der Professor noch schärfer karikiert:

"Wenn seine Rede von Rufen unterbrochen wird, schaut er finster und streng drein und ruckt seine Brilie auf die Nasenspitze." (Abw.165)).

S.62/6 Die Anrede "M1lostivyje gosudaryni" und weiter unten "milostivyje gosudari" ist recht altmodisch und paßt zu dem Greis.

S.62/7 Die Kokotte gehort, wie der Auslënder, zum Bild der Großstadt, zum "gemischten Publikum", vor dem die popularisierenden Gelehrten auftreten (vgl. Nietzsche, Vom Nutzen und Nachteil, 71, S.160).

S.62/8 Die Freiheit ermöglicht und beginstigt das Laster. Im "Ausländer", der das Mädchen belästigt, gibt Blok auf niederer Stufe ein Analogon zum "ausländischen" Begleiter der Faina (vgl. S.81/10).

S.63/1 Die Menge besteht aus Marionetten. (Vgl. S.64/5). S.63/2 Das russische "slovo" bedeutet "offentliche Rede", "Ansprache", aber auch "Predigt".

S.63/3 Blok wählte hier bewußt eḷen englischen bzw. amerikanischen Namen. England war zu Beginn des 20. Jhdts. das industriell fortgeschrittenste Land Euronas. Es wurde jedoch von den USi fiberfligelt, das zur fihrenden Industriemacht wurde. Blok hat 8 päter fur das von ihm erhoffte zukilnftige RuBland das Bild eines "neuen Amerika" gewählt (III,268ff.). Das alte RuBland sollte von einem industrialisierten Rußland abgelost verden, ohne jedoch dem Gelst des Rationalismus und Positivismus zu verfallen. Im IS ist die Haltung Bloks jedoch entschieden feindlich gegeniber dem englisch-amerikanischen Geist der Technik.

S.63/4 Der Geist des Rationalismus hat gesiegt. 
S.63/5 Im russ. Text steht "otkrytije", "Entdeckung". Blok war mit der naturwissenschaftichen Terminologie offenbar nur schlecht vertraut.

S.63/6 Blok kannte die Zukunftsromane von Jules Verne (vgl. VII,11). Von der damals beginnenden Fliegerei war Blok fasziniert (vgl. III,33f. und Anm. S.506f.).

S.64/1 Blok ninmt hier das Bild der Maschine als Raubtier wieder auf. (Vgl. S.59/3). Fifr den modernen Leser wirkt der Ausdruck "Flugmuskeln" komisch. Die Technik wird von Blok als menschenfressendes Ungeheuer dargestellt. Dieses Bild geht zurlfck auf die Gestalt Frankensteins in H.W. Shellevs glelchnamigem Roman. Das 3.Bild des IS steht mit diesem Bild deutlich in der Tradition der "negativen Utopie".

S.64/2 In der Stilisierung der Ansprache des Professors zeigt sich Blok als großer Könner. Er legt dem Vertreter das geforderte hohle, deklamatorische Pathos in den Mund.

S.64/3 Der Clown ist das "alter ego" des Professors. Er zieht dessen Ausfithrungen ins Lächerliche.

S.6́/4 Einen "slap-stick gag" wie im IS gibt es auch im "Balagantik". Dort springt harlekin durch ein Fenster, das nur auf die papete gemalt ist (IV,20). Las Treiben der skrobaten ist eine abgektirzte wiederholung der Ansprache und Vorfihrung des Professors. Lessen dusfihrungen werden danit auf das Niveau der Jahrmarktsbude oder des Zirkus herabgedrilckt.

S.64/5 Die ilenge ist ein Haufen von Harlonetten. Das zeigt auch das mechanische Nachplappern der Worte des Professors. Blok nimnt hier ein auf Platon zurlickgehendes Motiv auf, das in 19. Jhdt. in neuer Sinngebung verwendet wird (z.B. als Symbol des Determinismus bel Büchner; vgl. Frenzel, Stoff-, Motiv- und Symbolforschung, S.78f., 94 ).

S.64/6 Vgl. S.60/1.

S.64/7 Die Zeitungsverkäufer nannten Faina "die schönste Diva der Welt". German sagt: "Gde Ke divnaja Faina." Das bortspiel ist nur in russischen Text zu erkennen. (Vgl. "Javis" moje divnoje divo!" in den Gedichten "Na pole 
Kulikovom" 4, 2.25; die Stelle beruft sich auf die Zadongtina, die "Divo" aus dem Igorlied zu "divo" macht.)

S.65/1 Der "Schatten", der Faina vor German verbirgt, hat einen ähnlichen Symbolgehalt wie die "Maske" (vgl. S.68/2) und der "Schleier" (vgl. S.82/15). Er unterscheidet die gedoppelte Weltseele von der klaren Sophia (vgl. BlokBelyj, Perepiska, S.35; zitiert S.289).

S.65/2 Ahnlich äußerte sich der Freund im 1.Bild (S.51). Hier ist die Aphrodite Pandemos-Hypostase der Faina am deutlichsten ausgesprochen.

5.65/3 Bloks Verspottung der freiheitlichen Demokratie und der Idee der Brilderlichkeit ist kaum zu tlberbieten. Die Wiederholung der Ausdrilcke "Bürger" und "Brilder" und die satanische Selbstentlarvung des Staates stehen in wirkungsvollem Kontrast zueinander.

S.65/4 Die Masse kennt keine Soldarität und kein Mitgefihl. S.65/5 In F1 antwortet der Redner auf die Frage der Kokotte: "Meine Aufgabe 1st getan. Ich bin ein Volkstribun." (Abw.177)). Er ist es schon seinen inhägern schuldig, sein Leben nicht zu riskieren!

S.66/1 Die Reaktion Germans auf das Geschehen ist recht eigenartig. In dieser einzigen schwachen Stelle des 3.Bildes wollte Blok offenbar das Motiv der Gewissensbedrängnis wiederholen ( $v g l$. 1.Bild, Gebet Gernans S.50 und 5. Bild, S.86). German ist zwar betroffen. Sein Gewissen bleibt jedoch rein, weil seine eigentliche Bestimmung, die Begegnung mit Faina, noch nicht erfillt ist. Davon darf inn witleid nicht abhalten. Der Ruf des Schicksals gilt inm mehr als eine moralische Tat.

S.66/2 Die Technik ist ein Holoch. Has in Vergleich der Maschinen mit Raubtieren angedeutet wurde, wird jetzt Wirklichkeit. Selbst die Tötung ist technisch perfekt.

s.66/3 Faina ist die Maitresse des alten Mannes (vgl. a. das 5.Bild).

S.67/1 Faina ist der Vamp, das Schlangenweib. Diese Hypostase des "Ewig-Weiblichen" durchzieht viele Gedichte Bloks, besonders die "Neznakomka"-Gedichte und die Zyklen 
"Schneemaske" und "Paina" ( $\nabla$ gl. II,127, 136, 165, 211, 221f., 239, 2581., 260, 26919., 2841. u.ö.). Dabei entspricht dem Sternenkleid der kosmischen Hypostase ( $\nabla g 1$. S.57/2) die Schlangenhaut ( $\nabla g l$. "Skazka o tof, kotoraja ne pojmet jeje" in: Blok, Sobr.sod., Bd.4, S.140; II, 269f.). Der diamantene Stern der kosmischen Erscheinung wurde zum Edelstein, einer Art säkularisierter Spica (in der Ikonenmalerei ein stilisierter Stern auf dem Schultertuch der Gottesmutter als Zelchen inres kosmischen Wesens). Die Plammenden großen Augen der Paina sind Zeichen ihrer geistigen Unmuhe. Sie verraten, daß inre Vamp-Hypostase nicht ihrem eigentlichen Charakter entspricht, denn der traditionelle Vamp-Typ, die Schlange, hat kalte Augen. Die Peltsche ist ein stark sadomasochistisch aufgeladenes Symbol der Macht, dessen Gegenstick bei der Sophienikone der caduceus, der Schlangenstab 1st. Die Peltsche 1st bel Dressurvorstellungen im Zirkus das natirliche Requisit der Dompteuse bzw. der Zirkusreiterin. Wenn hier Faina mit einer Peitsche auftritt, so ist das etwas ungewöhnlich. Blok hat das Bild der Zirkusreiterin als dem verkörperten Schicksal u.a. Im Vorwort zu dem Gedichtband "Zemlja $\nabla$ snegu" gebraucht (vgl. II,373). Es verschmilzt bei inm mit dem Bild der Zigeunerin. Paina als "femme fatale" entspricht weitgehend dem dämonischen Frauenideal des fin-de-siècle. $M$. Praz hat die Entwicklung dieses Typs in der Literatur des 19. Jhdts. ausfuhrlich dargestellt (M. Praz, Liebe, Tod und Teufel, Bd. 1, S. 167ff.). Blok war mit der "einschlägigen" Iiteratur (Flaubert, Gautier, Merimee, Wilde und d'Annunzio) gut bekannt. Daneben darf der russische EinfluB nicht vergessen werden. Im Werk Gogol's (vgl. "Nevskif Prospekt", "Taras Bul'ba"), besonders aber in den dämonischen Frauengestalten Dostojevskijs (v.a. Nastas'ja Filipporna, aber auch in der "Chozjajka", in Grušen'ka, Jekaterina Nikolajevna etc.) fand Blok die Vorbilder fur seinen dämonischen Frauentyp. Dasselbe Prauenideal beherrscht auch die Malerei des fin-de- 
siècle (Hof statter, Symbolismus, s.187ff.). Blok kannte und schatzte $\nabla . a$. Rossetti und Beardsley. Die zeitgenossischen Zeitschriften enthielten eine Unmenge von Darstellungen der dämonischen Frau (vgl. z.B. "Vesy", die starkes Interesse an der frz. Literatur und Kunst hatte.). Die "Unbekannte", die Bakst fllr das Titelbild von Bloks Zyklus "Snezna ja maska" gemalt hat, ist typischer Jugendstil. (Das Titelbild ist zuletzt abgebildet in Turkov, A. Blok, S.121).

S.67/2 Das Titellied der Faina besteht aus vier Strophen mit Je sechs Versen. Der erste und zweite, sovile der vierte und funfte Vers sind vierhebige Jamben in Paarreim. Die Verse drei und sechs reimen ebenfalls, ele bestehen jedoch nur aus dreihebigen Janben. ille Reime sind männ$11 \mathrm{ch}$.

Blok hat das lied als "Pesnja Fainy" in den Gedichtzyklus "Faina" aufgenommen (II,284f.).

In inrem lied enthillt sich Faina als hochmiltige Dirne mit aggressiver Sinnlichkeit. Sie ist die Schlange, die inre Liebhaber nach Lust und Laune wählt und wieder verstößt. Die 3.Strophe hebt sich aus der irivialität des ganzen liedes heraus. Hier wird klar, daR die pervertierte Sinnlichkeit nur vordergrindig ist. Ganz kurz gibt Faina ihrer "metaphysischen" Sehnsucht Ausdruck. Das Bild des Gartens (v. 13 u. 15) erinnert an das Hohe Lied $4,11-16 ; 5,1 ; 6,2 ; 8,11 \mathrm{ff} .$. Die Frihlings- und Feuer-Symbolik erinnert an die Erzählung des Hönchs in 2.Bild. Faina ist die Verkorperung dionysischer Lebenskraft. (Vgl. dazu V,416, wo Blok von V.F. Konmissarževskaja sagt: "Sie war ganz Auf muhr und ganz Frithling...") Diese Strophe rechtfertigt auch allein, das das Lied der Faina in den zyklus "Faina" aufgenommen wurde (vgl. Einleitung zum 5.Bild, S. 3091.). Insgesamt erinnert das Lied der Faina stark an die Habanera der Carmen ("Ja, die Liebe hat bunte Flidgel"; 1.Akt der Cper "Carmen" von Bizet). Die inhaltliche Nähe des LS zur Oper Carmen kann nicht gut geleugnet werden (so Kluge, Westeuropa und RuBland, S.201, Anm. 53). 
Der von Lotman und Minc festgestellten vagen Ahnlichkeit in dem Verhältnis der aktiven, fuhrenden Carmen zu dem passiven Don José mit der Beziehung zwischen Faina und German ("Celovek prirody" v russkoj literature ..., Blokovskij sbornik, S.154f.) können die folgenden Motive hinzugefugt werden: der männliche Held zwischen zwei konträren Frauentypen (wobei in der Carmen und in IS das sutter-Sohn-Verhiltnis hinzukommt) und die weibliche Yeldin zwischen zwei Männern. Blok hat die oper Carnen erst richtig kennengelernt, als er sich in die Darstellerin der Carmen I.A. Andrejeva-Del'mas verliebte (vgl. Zan.kn., 200, Eintrag vom 12. Januar 1914; 210ff.). Der Gedichtzyklus "Karmen", der manche Ansnielungen auf die oper enthält, entstand in einer Jeriode dionysischen Schaffensrausches, die Blok selbst mit den Wochen verglich, als er die Gedichte des Zyklus "Snežnaja naska" schrieb (vgl. III,474). Als großer Verehrer Nietzsches und Wagners kannte Blok nit Sicherheit Nietzsches "Fall i.agner", wo dem Frauenideal Wagners die Varnen der Cper Bizets entgegengehalten wird. "Keine Senta-Sentinentalit:t! Sondern die Liebe als Fatuฑ, als jatalität, zvnisch, unschuldig, Erausan - und eben darin vatur!" ("Der Sall vagner", 77, s.7). Die Faina des LS reiht sich allerdings in तie Reine der von Hetzsche so böse Eeschnähten Erlösung, suchenden Heroinen wagners ein. Zun Lied der Faina sagt Kluge ("esteurona und RuRland, S.197, Ann. 40): "Das Lied erinnert stark an Couplets aus Frank Wedekinds "Erdgeist" 1895 (vor allem das Symbol der Peitsche: das erotisch-freie Triebleben, die Schönheit des Fleisches, gei relt und entlarvt die bilrgerliche Scheinnoral)." Ein Vergleich nit dem Prolog von Vedexinds "sidgeist", wo die schöne "Schlange" Iulu, die "Urgestalt des Veibes" dem Publikum präsentiert wird, zeigt jedoch, daß die Ähnlichkeit zwischen Wedekinds und Bloks Heldin recht äu3erlich ist. Beide Heldinnen sind zwar Ausfor ungen des Vamp-Tyns. Bei Paina ist jedoch selbst in "Lied des Schicksals" die Sehnsucht 
nach ihrer eigentlichen Bestimmung zu spüren. Die VampHypostase ist nur eine zeitweilige Verirmung.

S.68/1 Das Beifallstosen des Publikums zeigt, daß an eine Entlarvung einer wie auch immer gearteten Moral im Lied der Faina nicht gedacht ist.

Die Rolle des "Entlarvers" fällt German mit dem folgenden Monolog zu.

S.68/2 Gernans Antwort steht wiederum in Blankversen. Er tritt in diesem Monolog als Verteidiger einer idealistischen, humanistischen Geisteshaltung auf. Wirde, Vernunft, Ehre und Pflicht sind die höchsten hierte dieses Idealismus, der in Schiller seine hochste Verkbrperung gefunden hat. Blok sah in Schiller den "Gipfel des Humanismus" (VII, 357), einer Kulturepoche, die nach Bloks Ansicht von der Renaissance bis zur Französischen Revolution reichte (vgl. "Krusenije gumanisma", VI,93-115). Ihren stärksten Ausdruck fand die Geisteshaltung des Humanismus in der Gestalt des Marouis Posa (VI,95), an dessen 1dealistisches Pathos German in dieser Szene erinnert. (Blok flbernahm in seinem oben erwähnten Vortrag das Schillerbild Wagners und $z . T$. auch das von ivietzsche).

Der erste Teil des Monologs wendet sich an die Gesamtheit der Anwesenden, vornehnlich an die Menge (vgl. v.16). Zun̈̈chst richtet sich die Empörung Germans gegen das Schauspiel, das sich ihm bietet, gegen die Sensationslust der Menge, die bel ihrem "Tanz uns goldene Kalb" jedes Geflihl der ilenschlichkeit verloren hat und blind ins Verderben stlirzen wird. In V.3 stellt Blok mit der Antithese "dort" und "hier" und der Wiederholung des Ausdrucks "Untergang" die Wirklichkeit und die Scheinwelt der Großstadtzivilisation gegeneinander. Die hohen Ideale der Vergangenheit sind käufliche Ware geworden. (Im Ausdruck "goldenes Lied" 1st "golden" als Symbol fur Geld, als Symbol fur die "klingende Munze" der Faina zu verstehen; vgl. den Symbolwert des Goldes in Wagners "Ring des Nibelungen"). 
In prägnanter Weise stellt er Vergangenheit und Gegenwart in Form eines Chiasmus gegeneinander: dort forschender Geist und hoher Traum (mit dem letzteren meint Blok vielleicht das ideale "Ewig-Weibliche" Dantes, Petrarcas, Goethes, seiner eigenen Jugendgedichte), hier Maschine und Zigeunerin (V.8 und 9). Noch einmal evoziert German in etwas unklaren Bildern die verlorene Zeit (V.10-13), die zur Gegenwart degenerierte. Besonders virkungsvoll 1st das zweimalige "cyganka" ( $V .9$ und 14 ), das beide Male lautlich (Häufung von a) sowie durch die Stellung hervorgehoben wird. Die Welt des idealistischen Humanismus wird gekennzeichnet durch abstrakte Begriffe (Wilde, Vernunft, Ehre, Pflicht, höchste Schwärnerei, forschender Geist, hoher Traum, Leidenschaften, königlicher Gedanke), die verstärkt werden durch das Bild des hochstrebenden Purnes (V.11). Rätselhaft ist das Bild der Esse, in der die Seelen schmelzen (V.12; ein ähnliches Bild verwendet Blok schon VII,27 in seinem Jugend tagebuch und bei der Charakterisierung Strindbergs, V,465). Die welt der Gegenviart wird beherrscht von der Maschine und von der Zigeunerin, deren wildes inbrechen in den harmonischen Chor des Idealismus an das Bild des Kometen erinnert, der das harmonische Kreisen der Gestirne stört (vgl. die beiden Enigrame, die 3Iok dem Gedichtband "Zemlja v snegu" voranstellte; II,371 und 'iurkov, A. Blok, S.129).

Nach der kulturphilosophischen Vorbereitung wendet sich Gernan mit seiner anklage direkt gegen raina (V.17ff.). Sie ist die große Verfthrerin.

(.lit V.17 vgl. II,48; zu V.18 siehe $\mathrm{S.100/1.V.20} \mathrm{er-}$ innert an eine Passage in Dostojevskijs Ronan "Podrostok". Der junge sirkadij Doleorukij enpört sich jber die unanständige Kleidung gewisser "Damen": "Da geht sie den Boulevard entlang und wirbelt mit ihrer meterlangen Schleppe den Staub auf!", den Staub, den der arme Mann noch schlucken nu? (1. Teil, 2. Kap., III). Arkadif verliebt sich kurz darauf in die rätselhaftschöne "Dame" Jekaterina iikolajevna. - Die Schleppe 
1st ein Attribut der "Unbekannten" und der Faina der Gedichte; Vgl. II,105, 137, 1831., 187f., 2541., 256, 257, 2691..; Skazka o toj, kotoraja ne pojmet jeje.) Das Symbol der Maske in $\mathrm{v} .22$ erinnert an den Zyklus "Schneemaske" und an das Symbol des Schleiers (vgl. S.82/15). Die Maske verdeckt das wahre Wesen; sie lst ein Leitsymbol in der Kunst der Jahrhundertwende. Mit dem letzten Ausruf bereitet German das "ecce homo" des Preundes vor (vgl. S.69/3). Bei der erneuten Begegnung mit Faina im 4.Bild wird das Motiv unter direkter Bezugnahme auf Dostojevskif wiederholt (vgl. S.78/4 und 5).

S.68/3 Faina gleicht in inrem Verhalten und in inrem Xußeren einer schlange.

Der Schlag, den Faina German erteilt, 18t ein Anklang an eine Szene in Dostojevskijs "Idiot". Dort schlägt Nastas'ja Filippovna einen offizier, der sie beleidigt hat, mit einer Rute ins Gesicht (2.Bd., 3.Teil, II; vgl. Orlov, Blok, S.156). Xhnlich wie im LS greift im Idlot der ältere Begleiter der Heldin nicht ins Geschehen ein. Im Unterschied zum IS bedauert Nastas'ja Filippovna ihr opfer nicht. AuBerdem gilt ihr Schlag nicht dem Filrsten Myłkin, dessen Rolle German im LS in gewisser Hinsicht einniunt (vgl. S.78/5), sondern einer Nebenperson.

Mit dem Peltschenschlag ist die stolze, hochmutige und anklagende Haltung Germans gebrochen und es beginnt das Liebegverhältnis zwischen German und Faina ( 5 und 4). Solange German das Stigma vom Schlag der Paina trägt (vgl.S.84/19,S.89/16), an Faina leidet, vom Schicksal gezelchnet ist, hält die erlösende liebe zu ihr an. Im 7.Bild ist die Narbe verschwunden (vgl. S. 102/4).

S.68/4 Germans Geste lst pseudoreligiös.

S.69/1 Die Reaktion der Paina, inre Traurigkeit und ihr Bedauern, zeigt, daß sie in diesem Bild in einer Hypostase auftritt, die ihr eigentliches Wesen verdeckt. Der "grenzenlose traurige, in die Perne gehende" Blick erinnert an den Mönch und list wiederum der deutliche 
Hinweise auf die andere, geistige Natur der Gestalt. In F1 wird an den sehnsiuchtigen Blick der Faina am FluBufer erinnert (ibw.190).

S.69/2 Hier ist Faina wieder die "femme fatale".

S.69/3 Das russisch-kirchenslavische "Se Kelovek!" entspricht dem lateinischen "Ecce homo!"; deshalb wurde die Obersetzung Iuthers (Joh.19, 5) gewählt. (Vgl. a. III,29f.). Wie im 1.Bild der Heggang Germans von christlichen Bildern und Symbolen begleitet war, so wird im 3.Bild die Begegnung mit Faina als Parallele zur Passion Christi dargestellt. German ist als echter Mensch (vgl. die letzte Zeile seines Monologs) das Ebenbild Christi. (Vgl. auch die Einleitung zun 5.Bild, S.302ff.).

S.69/4 Die kenge ist von Germans fuftritt nur fllr kurze leit betroffen. Sie hat schon eine neue Sensation.

Iie Regieanweisung zu Beginn des Bildes mit der Beschreibung des Schauplatzes ist in $\pi 1$ noch ausfihrlicher als später. Urspringlich hatte sich in Saal noch ein Restaurant befunden, typischer Bestandteil der nodernen Großstadt. Das Publikum wird in $M 1$ genauer geschrieben:

"ienn der Vorhang hochgeht, befinden sich einige Leute im Saal: es gehen vorbei ordner mit arnbändern, didchen aus dem iestaurant, akrobaten mit ihren Sachen. ilusikanten stimmen inre Instrumente. in der Kasse beginnt sich das Publikum zu versamineln: Journalisten, Studenten, Stutzer, Kokotten, Ausländer." ('ledvedev, Lramy i poèny, S.67)

Blok hat diesen Pell der Regleanweisung in F1 weggelassen. Er wollte die ohnehin recht lange Regieanweisung wohl kilrzen. Die Akrobaten, Kokotten und ein Ausländer kamen ja später zu Wort, und es war unnötig, sie besonders aufzuführen. Mit der Kürzung erreichte Blok, daß die Menge einheitlicher, "uniformer" wurde. Der Begleiter der Faina fehlt in $M 1$ in diesem Bild. Diese filr den ideellen Gehalt des Stlicks recht wichtige Figur erschien erst später (Medvedev, aac, S.67). Die sp̣atere Einbeziehung ist sicher der Grund dafir, daB der Begleiter in F1 und F2 in diesem Bild nur stumm agiert. In $: 11$ besteht ein geringerer Unterschied in der Haltung Germans und des Freundes gegeniber dem Schauspiel, das ihnen auf der 
Ausstellung geboten wird. Belde, nicht nur der Freund, treten als distanzierte Betrachter auf. Die letzte Zeile von Germans Monolog (vgl. Abw.162)) lautet in M1: "A ja dyž, Živu 1 sozercaJu." (Ich aber atme, lebe und betrachte.; Medvedev, aao, S.68).

In den späteren Passungen setzt sich German immer deutlicher vom Freund ab.

Das Lied der Paina enthält in M1 nach der 1. Strophe (Zeile 1-6 in F1 bzw. F2) weitere 14 Zeilen, von denen 2 nicht ganz vollständig sind und die nicht alle dem Vers- und Reimschema der vorhergehenden Strophe entsprechen. Blok ersetzte diese 14 Zeilen am 30. Mal 1907 durch die Zeilen 7-9 der belden gedruckten Fassungen und erreichte damit ein Straffung des Lieds. Nach Zeile 12 des gedruckten Textes folgen in M1 weitere 18 Zeilen, d.h. drei Strophen. Diese Skizzen wurden von Blok an 27. März 1908 in die endgillige Gestalt von F1 und F2 ungearbeitet (vgl. II,434f. und Medvedev, Dramy i poemy, s.69f.). Der Monolog Germans nach dem Lied der Faina hat in $M 1$ einen zusätzlichen Akzent. Die Kultur, als deren Verteidiger German sich auf schwingt und die von Faina mit FilBen getreten wird, ist vom Christentum geprägt (vgl. Hedvedev, aac, S.68). Der Schluß des Bildes ist in M1 etwas ausfihrlicher als in den späteren Fassungen.

"Wenn German nach seinem Anklagemonolog auf die Bllhne springt, mu sich hinter ihm her die "halbtrunkene Bruderschaft der Elenden" (polup'janoje bratstvo obezdolennych) stürzen. Und ganz am Schlu? steht der "skeptische Freund" ("Mephistopheles"), bisher von niemand bemerkt, vom Tisch auf, stellt sich zwischen German und die Bruderschaft der Elenden und sagt $z u$ ihm mit der ihm eigenen ungewöhnlichen Ernsthaftigkeit, hinter der sich immer Spott verbirgt:

Sehet welch ein Mensch!" (Aedvedev, aac, S.71)

German wird hier als eine Art zweiter Christus der klenden und Entrechteten dargestellt. Das erinnert an den Schluß von Bloks Revolutionspoem "Dvenadcat" und an seinen Aufsatz "Katilina". In beiden Werken wird Christus als Vorkämpfer fir die Belange der niederen Volksschichten dargestellt. Dieses Element fehlt in F1 und ebenso in F2, obwohl $\mathrm{F} 2$ nur etwa acht Monate nach dem Aufsatz "Katilina" entstanden ist. In den beiden Druckfassungen des LS ist die Christussymbolik des sozialen Aspekts entkleidet. 


\section{VIERTES BILD}

Mit der satirischen Darstellung des Kunstlermilieus greift Blok im LS ein Thema auf, das ihn seit 1906 immer wieder beschäftigte: Sinn und $\mathrm{Zweck}$ des "Kulturbetriebs". Die kritische Auseinandersetzung mit dem literarischen Leben gehort bei Blok in den Rahmen seiner Kulturkritik und ist ein besonderer, für ihn als Dichter entscheidender Aspekt in der Behandlung des Grobstadtthemas. Die Auseinandersetzung mit dem Kulturbetrieb mindete schlieblich in die Stellungnahme zu dem Thema "Volk und Intelligenz", mit der Bloks publizistisches Wirken Ende 1908 einen vorläufigen Höhepunkt erreichte.

Während Blok im 3.Bild des LS eine Darstellung der Sensationslust des Pobbels und des Ungeists von Technik, Wissenschaft und Staat gibt, fuhrt er im 4.Bild das Milleu vor, in dem er selbst verkehrte und das er in zahlreichen publizistischen ÄuBerungen mit einem fast krankhaften HaB geiBelte: "Ich hasse mein Dekadententum und geible es in meiner Umgebung..." 1 )

Blok hatte schon Anfang 1904 seine Abneigung gegen das literarische Leben Fetersburgs geäußert, und er glaubte, im russischen, patriarchalischen ifoskau eine bessere und reinere Welt zu finden. 2) Auch die Verspottung der "Mystiker" in seinem lyrischen Drama "Balagancik" spiegelt die Abneigung gegen Petersburg wider. ${ }^{3)}$ Seit 1906 wandte sich Blok mit wachsender Aufmerksamkeit "aktuellen" Pragen zu, worin sich die starke, v.a. von vjac. Ivanov angeregte Beschäfigung mit kulturkritischen Schriften $R$. Wagners und $F$. lijetzsches und das diskussionsfreudige Klima der "Mittwoche" in Ivanovs "Turm" niederschlug (s.u.).

1) VIII,156, Brief an Je.P. Ivanov vom 25. Jun1 1906. Zu Bloks Publizistik vgl. v.a. Kaksimov, KritiCeskaja proza A. Bloka in: Blokovskij sbornik, S.28-97;

ders., 0 proze A. Bloka in: V,695-708; Dikman, Blok-Kritik, in: Istorija russkoj kritiki, Bd.2, S.646-664.

2) Vgl. VIII,81-93, Briefe an seine Mutter vom 14, 15. und 19. Jan. 1904; Brief an A.V. Gippius vom 28. Pebr. 1904;

3) VgI. IV,9-13 mit VII,88 und 92. 
Schon Bloks emphatischer Aufsatz uber Bakunin, 1) mit dem seine eigentliche publizistische Tüigke1t begann, murde von den "Freunden" aus dem symbolistischen Lager mit unwilligem Erstaunen zur Kenntnis genommen. 2)

Im Fruhsommer 1907 murde Blok Leiter des literarischen Teils der Moskauer Zeitschrift "Zolotoje runo" (Das goldene Vlies), was zu heftigen Angriffen von seiten der Mitarbeiter der zeitschrift "Vesy" (Die Wage) fuhrte. ${ }^{3}$ ) Fur Blok war die Zeitschrift "Zolotoje runo" ein erwlinschtes Medium, das ihm erlaubte, seine Ansichten uber die zeitgenössische Literatur an eine größere Leserschaft heranzutragen und darlber hinaus zu anderen aktuellen Fragen Stellung zu beziehen. ${ }^{4}$ ) In kurzen Abständen erschienen nun Aufsätze Bloks, deren Grundtenor elne immer schärfer werdende Kritik am zeitgenössischen Rulturbetrieb war. Blok nahm nacheinander zu fast samtlichen Themenkreisen des damaligen literarischen Lebens Stellung, so etwa zur viel diskutierten Frage nach der Bedeutung der "realistischen" Iiteratur

1) $\mathrm{Vgl} \cdot \mathrm{V}, 31-35$.

2) Vgl. Tovarił̌ German (Pseudonym fur 2. Gippius), "Trichina", in Vesy, $1907 \mathrm{Nr} .5, \mathrm{~S} .68 \mathrm{ff}$.

3) Zu den außeren Umständen dieser Affäre vgl. Orlov, Istorija odnoj "družby - vraždy" in: Put1 1 sud'by, S.554ff. Brjusov und Belyj hatten sich mit dem Besitzer der Zeitschrift "Zolotoje runo" uberworfen. Bloks Einwilligung in der Mitarbeit wurde als "Streikbruch" (Beljy, Mezdu dvuch revoljucij, S.247) angesehen, der als umso unverschämter galt, weil sich damit die Petersburger Symbolisten-Gruppe in Moskau einen Brlickenkopf erobert hatte. Der Streit um das "Zolotoje runo" ist auf dem Hintergrund des erbitterten Kampfes Belyjs, der Merežkovskijs u.a. gegen Culkovs "mystischen Anarchismus" zu sehen, mit dem mehr oder weniger zurecht auch Ivanov und Blok in Verbindung gebracht wurden. Vgl. Orlor, aaO, S.562ff. und S.75/1.

4) Vgl. dazu Bloks kurze Mitteilung uber seine Tatigkeit in "Zolotoje runo" vom April 1907, v,675. 
des Gor'kij-Kreises und inres Verhältnisses zum Symbolismus, 1) zur stellung der lyrischen Dichtung ${ }^{2}$ und des Theaters ${ }^{3)}$ in der zeitgenos8ischen Iiteratur und zum Sinn und der Aufgabe der literarischen Kritik. ${ }^{4}$ )

Bloks Publizistik ist allerdings nur äuBerlich und vordergrundig als Stellungnahme zu Problemen der schonen Iiteratur zu verstehen. Im Gegensatz zu anderen Symbolisten, etwa zu Brjusov und Belyj, behandelte Blok nirgends Fragen der kinstlerischen Technik, der sprachlichen Struktur von Gedichten u.ä.. Seine Publizistik ist in erster Iinie Kulturkritik, und es ist bezeichnend, daB die scharfen Angriffe von seiten seiner Gegner sich immer auf den kulturph1losophischen, programmatischen Teil seiner ÄuBerungen bezog.

Besonders starken widerspruch rief Bloks Eintreten fur Gor'kij hervor, der fur Blok die Verkorperung des echten RuBland war.

"Ich behaupte ferner, daB, wenn es den realen Begriff "Rossija", oder besser: Rus' gibt, abgesehen von Territorium, staatsmacht, Staatskirche, klassen usw., wenn es also jenes Große, Inilbersehbare, Weite, Traurige und VerheiBene gibt, das wir gewbhnlich unter der Bezelchnung Rus' zusammenfassen, dann lst dessen Repräsentant in hohem MaBe Gor'kij."5)

Gor'kijs Qualitäten sind seine "Intuition", der "Adel seiner ibsichten", die "Endlosigkeit seines Ideals", das "groBe MaB seelischer Qual".6) und "die grobe Aufrichtigkeit", die den "von Furcht, Zweifel und Qual" belasteten, der "Magle des Europäertums" verfallenen "Kritikern mit Geschnack" abgeht.7)

1) In: "O real1stach" V,99-129; "O sovremennof kritike", V,203208; "Narod 1 intelligenc1ja", V,318-328.

2) in: "O lirike", V,130-159; "Pis'ma o poèzil", V,277-300.

3) In: "O drame", V, 164-193; "Probuzdeni je vesny", V, 194-196; "Pelleas 1 Melizanda". V,197-202; "0 teatre", V,241-276; "Genrich Ibsen", V, 309-317.

4) in: "O sovremennoj kritike", v,203-208.

5) $\mathrm{v}, 103$.

6) $v, 103$

7) $v, 102 f f$ 
Wertvoll an Gor'kij ist seine kinstlerische, nicht seine publizistische Ader, sein "instinktiver HaB auf das trockene und strenge Rasonieren; ${ }^{1)}$ sein "Herz, dem wir mehr glaubten als seiner Vernunft", ${ }^{2}$.a. aber seine tiefe "volkhafte", "konkrete" Liebe zu RuBland. ${ }^{3)}$ Blok argumentiert nicht als Literatur- sondern als Kulturkritiker, wenn er den "dionysischen" Kunstler Gor'k1j, der eine Stimme der Volksseele ist, gegen seine "apollinischen" Widersacher in Schutz nahm. ${ }^{4}$ )

Auch Bloks Angriffe gegen jede Schulenblldung und seine Proklamation der volligen Freiheit und Unabhängigkeit des lyrischen Dichters ${ }^{3)}$ wurden scharf kritisiert. ${ }^{6)}$ Bloks Forderung absoluter Freiheit fur den Lyriker wurde als Prinzipienlosigkeit verstanden. In Wirklichkeit verstand Blok unter Freiheit das Horen auf die mystischen Eingebungen, die "hohe Harmonle, den alten Rhythmus, unter dem langsam die wiege der Zeiten und volker schaukelt", 7) auf die Bewegungen des Chaos, 8 ) auf das Wirken des "Geistes der Musik".9) Kulturkritische und nicht literaturkritische Kategorien liegen auch Bloks AuBerungen uber das westeuropäische und russische Theater zugrunde. In RuBland sind groBe Werke ohne Vorbelastung durch die zersetzende Kultur entstanden, aus den Tiefen des dichterischen Genies und nicht als Bildungsprodukte. ${ }^{10)}$

Der deutlich antieuropälsche fffekt von Bloks Aufsätzen setzt sich auch in der Ablehnung von Wedekinds "Fruhlings Frwachen"

\footnotetext{
1) $v, 320$.

2) $v, 321$

3) V,321. Diese Aussagen charakterisieren weniger Gor'kif als Biok selbst.

4) Zur Reaktion bei den "kultivierten Kritikern" vgl. V,720.

5) $V, 133-136,207$

6) Vgl. Belyjs Brief an Blok vom 27. Sept. 1907 in: BlokBelyj, Perepiska, S.217-219 und v,724.

7) $\mathrm{v}, 132$

8) $v, 161$

9) So ist auch Bloks Rechtfertigung im Brief vom 15. - 17. Aug. 1907 an Bely $j$ zu verstehen; VIII,199. Vgl. dazu den Anfang von Bloks Aufsatz "O drame", V,164.

10) $V_{g} 1 . V, 168-171$.
} 
und Maeterlincks "Pélleas et Mél1sanden" ${ }^{1}$ ) durch. Der dekadente Charakter dieser stilcke mache sie fur das russische Repertoire unbrauchbar. Insgesamt entsprangen Bloks Urtelle der Sorge, die russische Bilhne werde von den vergifteten Frlichten der europäischen Dekadenz heingesucht. Seine Ausfihrungen zum Thema "Theater" sind in erster Linie Zeitkritik.

Besonders augenfällig ist der zeitkritische Gehalt von Bloks Aufsatz "Literaturnyje 1tog1 1907 goda" (Der literarische Ertrag des Jahres 1907), mit dem Blok in "Zolotoje runo" die Bilanz des Jahres $1907200^{2}$ ) wie gewohnt schickte Blok seinen Bemerkungen zu einzelnen Buchern und Autoren ÄuBerungen allgemeiner und programmatischer Art voraus, die in polemischer Schärfe auf die Versammlungen der "Religiös-philosophischen Gesellschaft" eingingen?

1) Bloks negative, von seiner kulturkritischen Position her zu verstehende Haltung gegenilber dem dramatischen Werk Maeterlincks wich später einem tieferen Verständnis. Die Besprechung von Maeterlincks "L'o1seau bleu", V,410-419, vom 15. Nov. 1920 weist auf die Verbindung des Belgiers mit der deutschen Ro- mantik hin. Im Märchenspiel Maeterlincks komme, wie in jedem Märchen, der Rhythmus des echten Lebens, die Volksseele zum Vorschein; V,418f. Bloks Besprechung gehört in die Reihe der Reden, die er als Einfihrung vor den Schauspielern des "GroBen dramatischen Theaters" hielt, und die von einer "Cassiodor"Stinmung durchzogen sind. Angesichts der zunehmenden Unkultur versuchte Blok die Werte der vorrevolutionären Kultur zu bewahren. In diesem Sinn trat er z.B. fur Merezkovik1j, VI,393395, ein. BIoks ÄuBerungen sind unverhohlene Angriffe gegen die "Unmusikalität" des sich gerade etablierenden Sovet-Regimes; vgl. z.B. VI, 390, 393, 395, 396, 401 u.ö. Höhepunkt dieser "Cassiodor"-Stimmung ist Bloks berihmter Vortrag "O naznacenil poeta" (Ifber die Bestimmung des Dichters), VI,160-168 vom 10. Febr. 1921, der eine scharfe antisovetische Polemik in das Gewand einer Rede Hber Purkins Dichtertum kleidet; vgl. dazu Kish, A. Blok, S.189-194.

2) V. 209-232.

3) Die belden ersten Kapitel, die die grundsätzlichen Uberlegungen Bloks enthalten, nahm Blok unter dem Titel "Religioznyje Iskanlja" 1 narod" (Das "religiöse Suchertum" und das Volk) in seinen Sammelband "Rossija 1 intelligencija" (RuBland und die Intelligenz) von 1918 auf. Der Sammelband enthielt daneber "Narod 1 intelligencija" (1908), "Stichija 1 kul'tura" (1908), "Ironija" (1908), "Ditja Gogol ja" (1909), "Plamen'" (1913) un. "Intelligencija $i$ revoljucija" (1918). Vgl. auch "Obnovlenije religlozno-filosofskich sobranij v Peterburge", V,329-334 vom Jahr darauf. 
Die Versanmlungen der "Relig16s-philosophischen Gesellschaft" murden im Herbst 1907 von Berdjajev und Rozanov als Neuauflage der "Petersburger religios-philosophischen Versammlungen" der Jahre 1901-1903 organisiert. ${ }^{1)}$

Damals hatten Vertreter der Intelligenz, an inrer Spitze Merezkovikif, seine Prau Z. Gippius, Rozanov, Ternjavcev, N. Losskif, Bulgakov, Berdjajev u.a. den Versuch unternommen, mit Vertretern der orthodoxen $\mathrm{zirche}$ zu einem Gespräch luber das beiderseltige Verhältnis zu kommen. Dabel war es ein Hauptanliegen der Intelligenz, die Vertreter der $\mathrm{xirche}$ auf die brennenden sozialen Fragen hinzuweisen und die Kirche aus inrer völligen Apathle gegenuber den sozialen Problemen aufzuwecken. Es ging den Vertretern der Intelligenz darum, zu einem Christentum der Tat zu finden. Andere Diskussionsthemen waren die Einstellung der Kirche zu russischen Gelstesgrößen wie Dostojevskij, Gogol' und v.a. Tolstoj oder zu Fragen wie Gewissensfreiheit und the. Es kann nicht verwundern, daß die Diskussionen häufig einen theologisch-scholastischen Charakter annahmen, denn die belden Selten waren sich fremd. Hinter äuBerlich akademisch anmutenden Fragen verbargen sich jedoch auch Probleme von großer aktueller Bedeutung (z.B. In der Diskussion um die Kirchenordnung). Die Diskussionsbelträge wurden in der von Merežkovskij, Z. Gipplus und Percov gefiuhrten Zeitschrift "Novyj put'" z.T. In zensierter Fassung veröffent$11 \mathrm{cht}$ und einem größeren Publikum zugängig gemacht. In der konservativen Zeltung "Novoje vremja" wurde uber die Versammlungen ausfihrlich berichtet. ${ }^{2)}$

Nach dem Scheltern der Revolution von 1905, die Merežkovskij begeistert begrubt hatte, verlieb er zusammen mit seiner Frau 1906 RuBland, da er Schikanen seitens der Reglerung und der Staatskirche befilrchtete. BeI ihren Besuchen in RuBland nahmen die

1) Vgl. Z, Gippius, Merežkovskif, S.186f.

2) VGl. Schelbert, Die Petersburger religiös-philosophischen Zusammenklinf te von 1902 und $1903 ; Z$. Gipplus, Merezkovski, S.95ff.; Zernov, The Russian religious renaissance, S.9off.; Onasch, Russische Kirchengeschichte, S.124. 
Merezkovskijs an den Versammlungen der "Religiös-ph1losophischen Gesellochaft" regen Anteil.

Blok lernte die Merezkovskijo im März 1902 kennen und fuhrte in den folgenden Monaten eine ausfuhrliche Korrespondenz mit $\mathrm{Z}$. Gippius. Doch schon der Brief vom 14. Juni 1902 zeigt, das Blok den abstrakten Theorien Merezkovskijs uber die Synthese von Geist und Fleisch, Himmel und Erde, Heidentum und Christentum in einem kinftigen Reich des Dritten Bundes mit groBer Skepsis gegenuberstand. 1 ) Deutliche Spuren hinterließ in Bloks Briefen die Beschäftigung mit Dostojevskij und der Apokalypse, die von Merežkovskijs Arbeit "L. Tolstoj 1 Dostojevskij" 2 ) angeregt wurde. 3) Trotz der negativen Einstellung zu Merežkovskijs Theorien ${ }^{4}$ ) besuchte Blok im Jahr 1904 den Merezkovskij-Kreis sehr regelmäßig und lernte dort u.a. Rozanov, Minskij, Sologub und Filosofov kennen. Die Themen dieses Kreises waren "KIrche und Kultur", "Heidentum und Christentum", "Religion und Politik".5) Neben Bloks Abscheu vor allem Theoretisieren war es v.a. die zwielichtige Rolle von Z. Gippius während der persönlichen Konflikte mit Belyj, die wesentlich zu der Abkihlung zwischen den Merežkovskijs und Blok beitrug.

Der Atmosphäre des Merezkovskij-Kreises suchte Blok zu entgehen, als er Anfang 1904 zusammen mit seiner Frau nach Moskau fuhr und dort Belyj, Bal'mont, Brjusov und weltere Größen der modernen Kunst kennenlernte. Anders als in Petersburg glaubte Blok in Moskau "echten Menschen" begegnet zu sein:

"Ich habe keine Lust, die Merežkovskijs zu sehen. Ehensowenig all diese Petersburger "Mystiker" und Studenten... Von den Menschen in Petersburg erwarte ich nichts auBer "literarischen" Gesprächen im besten Falle und im schlechtesten abgeschmackte Spötteleien oder "verstecktes Zublinzeln"."6)

1) VIII, $29 f f$

2) in: "Mir iskusstva" Januar - November 1900.

3) Vgl. Briefe Bloks an: A.V. Gippius vom 23. Juni 1902, VIII, 32; VIII, $34 \mathrm{ff.,} \mathrm{an} \mathrm{Z.} \mathrm{Gippius} \mathrm{vom} \mathrm{Juli} \mathrm{1902;} \mathrm{VIII,40f} \mathrm{,} \mathrm{an}$ seinen Vater vom 5. Aug. 1902; VIII,45f.., an Z. Gippius vom 14. Sept. 1902 .

4) Vgl. VII,67f., Notiz vom 13. Dez, 1902

$5)$ VEl. Culkov, A. Blok 1 jego vremja, S.102ff.

6) VIII,88, Brief an seine Mutter vom 19. Jan. 1904. 
"Ich lebte unter den "Petersburger Mystikern" hörte aber in der Theorie nichts iber das Gluck; alle schrien (und schreien) sie uber die dunkle, feurige "Synthese"..."1)

In seinem Aufsatz "Merezkovskif"2) zeigt Blok mit groBem Scharfsinn den Widerspruch zwischen dem gebildeten, in die Kultur verliebten Kinstler Merezkovskij und dem Apokalyptiker auf, dessen einfacher und schrecklicher Glaube an den russischen Raskol erinnere. Da Merežkovskij ein geborener Kinstler sei, werde sein Glaube immer wieder von den schönen Wahngebilden der Kultur verdeckt. (Die Spannung zwischen schöngeistigem Ästhetentum und apokalyptischer Erlösungssehnsucht, zwischen Kunst und Religion ist nicht nur filr Merezkovskij, sondern filr die gesamte russische "Neuromantik" schicksalhaft). Auch in Bloks Aufsatz "O Merežkovskom" 3 ) steht das Kinstlertum Merežkovskijs im Zentrum. Allerdings hat sich Bloks Einstellung inzwischen stark gewandelt. Merezkovskijs Kiinstlertum ist fir Blok nun ein tragisches Verhängnis, fih das in RuBland niemand mehr Verständnis hat. Als Kinstler ist Merezkovskif ein Träger der Kultur.

"Kultur ist Kultur, - man kann sie als "etwas Veraltetes" oder "heute völlig Unnötiges" nicht iber Bord werfen. Kultur kann man nicht totschlagen; sie ist nur eine gedachte Iinie, nur eine tönende, nicht greifbare. Sie ist Rhythmus. Wer Ohren und Augen haben will, der kann hriren und sehen."4)

Bloks Hochschätzung der "großen... Kultur des Krelses um die Zeitschrift "Mir iskusstvan"5) entspricht der wehmiltigen Rijckerinnerung an den "Turm" V. Ivanovs"). Die sarkastische Abrechnung mit dem Petersburger "Kulturbetrieb" wich in Bloks letzten Lebensjahren der zunehmenden Sorge um die Erhaltung des vorrevolutionären kulturellen Erbes, was zu einer geänderten Einstellung Bloks v.a. zu Merezkovskif fijhrte. Die völlige Entfremdung zwischen Blok und den Merežkovskijo bahnte sich an, als Merezkovskij den Vorwurf erhob, Bloks Vortrag "O sovremenom sostojanil russkogo simvolizma" ${ }^{7}$ enthalte

1) VIII,92, Brief an A.V. Gippius vom 23. Febr. 1904; vgl. auch VIII,94f.

2) $V, 360-366 ; 1909$

3) VI, 393-395; 1920.

4) $V I, 395$.

5) VI, 395.

6 VI,439. In: "Jubilejnoje privetstvije M. Kuzminu".

7) $V, 425-446$. 
eine verräterische Verleugnung der Revolution von 1905.1) Bloks Aufsatz "Intelligencija 1 revoljucija"2) und sein Poem "Dvenadcat'n fihrten zum Bruch. Bloks Befahung der Revolution als einer kosmischen Zeitenwende, als Sieg des "Geistes der Musik" war für die Merežkovskijs unannehmbar. Sie emigrierten 1919 nach Polen und dann nach Frankreich. Ihre Hoffnung auf eine Erneuerung RuBlands in christlichem Gelste, die ihnen 1905 berechtigt schien, hatte sich nicht erfiillt. 3 )

Fiir Bloks gelstigen werdegang ist sein Verhältnis zum Merezkovskif-Kreis mit seinem pseudochristlichen Klima, besonders auch das Interesse der Merezkovskijs am Phänomen des Raskol bedeutsam. (Vgl. Exkurs "Blok und der "raskol"").

Blok wandte sich in seiner Betrachtung der literarischen Ereignisse des Jahres 1907 zunächst gegen die Versammlungen der "Religiös-ph1losoph1schen Gesellschaft", aber auch gegen die Versammlungen von 1901-1903. Seine Kritik wuchs zu einer schroffen Abrechnung mit dem gesamten Kulturbetrieb seiner Zeit aus, als dessen Symbol er Merezkovskif ansah. Der Sieg der Reaktion in Ru3land nach dem revolutionären Aufschwung von 1905 hat nach $3 l o k s$ Heinung der Intelligenz das Gespiir fir ihre eigentliche Aufgabe geraubt. ${ }^{4}$ ) Vor allem die Schriftsteller, Lyriker, Belletristen, Theaterleute usw. sollten Qual dariber empfinden, da3 sie geistig isoliert sind, unfählg, dem einfachen volk auf seine Eragen zu antworten und in ihm einen reinigenden Brand $z u$ entfachen.

"Wenn es aber "Vertreter des religiös-philosophischen Bewußtseins" sind, dann missen sie mehr als alle andern leiden: dariber nämlich, daß sie schon seit elnigen Jahren stolze Wahrhelten vom Katheder der religiös-philosophischen Versammlungen

1) Vgl. V,757f.; VIII,321, Bloks Brief an seine Mutter vom 22. Nov. 1910; Bloks Entgegnung "Otvet Merežkovskomu", V,442445, wurde erst 1924 veröffentlicht.

2) $\mathrm{VI}, 9-20$

3) Vgi. Bonneau, I'univers poétique, S.53f.; MoCul'skij, Blok, S.410; Orlov, Poema "Dvenadcat" ", S.154ff; VII.335f ; nicht abgesandter Brief Bloks an Z. Gippius; III,372, "Z. GIppius" und Anm. S.634.; Zap.kn., 430, Elntrag vom 3. Ckt. 1918 und Anm. 179, S. 587 .

4) Die Ansicht, die Intelligenz sei nach dem Sieg der Reaktion in eine Krise ihres Selbstbewußtseins geraten, war ab 1907 in RuBland weit verbreitet. 
herunter verkilndigten, selbstsicher belehrten, anmaßend und boshaft schimpften, wollistig mit stumpfinnigen Popen polemisierten, daB sie in diesem Jahr ihr Geschwafel wieder erneuerten (und nur das Geschwafel). wohl wissend, daB vor der Tir Arme in Geiste stehen, die der Tat bedirfen. Gebildete und anmaßende Intelitgenzler, ergraut im Streit um Christus und den Antichrist, Damen, Gattinnen, Töchter, Schwägerinnen in schicken Jäckchen, gedankenreiche Philosophen, Popen, die vor selbstzufriedenem Speck glänzen - dieser ganze unvorstellbare und abscheuliche Bre1, dieses idiotische Geschwirr von Worten! Da - ein dilnner, kleiner Geistlicher in einer armen Kutte ruft Jesus herbel, und allen wird es unangenehm; ein ehrenwerter Sozialdemokrat mit' beuliger stirn stelit Dutzende von Fragen, aber ein Glatzkopf, vor Salböl glanzend, antwortet nur, daß man nicht auf einmal so viele Fragen beantworten kann. Und all das wird modisch, ist schon Mode, zugänglich filr die Frauen von Privatdozenten und wohltätige Damen. Aber draußen auf der Straße bläst der Wind, erfrieren Prostitulerte, hungern Menschen, werden Menschen aufgehängt, und im Land herrscht die Reaktion, und in RuBland ist das Leben hart, kalt und ekelhaft. Und wenn all diese Schwätzer des "Novoje Vremja", des "Novyj Put'" bis zu den Knochen abmagern vom eigenen Suchen, das fïr niemand auf der Welt außer den "felnen" Naturen nötig ist, geht in RuBland nichts verloren und kommt nichts dazu. Man muB zugeben - der hilbsche Anarchist hat schön bewlesen, daß die permanente Revolution nötig 18t: schön hat der junge Pope mit "iligem Äuglein den "interessierten" Damen zugeblinzelt (er hat "rechtgläubig" geblinzelt); schön hat der scharfsinnige Philosoph die Wortgefechte resilmiert. Doch sie sprechen iber Gott, dariber, woruber man nur allein weinen, zu zweit flistern kann; sie aber befassen sich damit bel hellstem elektrischem Licht...1) Von den religiösen Versammlungen geht man nicht nur mit dem Gefihl der Unzufriedenhelt weg, sondern mit dem Gefihl nagenden Uberdrusses, voller Wut auf die ganze Nutzlosigkeit, mit dem Gefihl, das die Schönhelt beleidigt wurde, denn all das ist so unnötig und abscheulich. Zwi schen den Romanen Merežkovskijs, dem Buch Rozanovs und ihren Vorträgen auf den religlösen Versammlungen liegt ein Abgrund... All das ist verbaler café chantant, dem nicht nur $1 \mathrm{ch}$ den gewöhnlichen café chantant vorziehe... Filhrt nur ein Intelligenzlerleben.... aber glaubt nicht, dab der einfache Mann mit euch iber Gott reden wird."2)

Das Treiben der Intelligenz, allen voran das Gottsuchertum des Merezkovskij-Kreises, ist ein "widerliches Faktum". 3) Dem Kulturbetrieb der russischen Hauptstädte mit den Diskussionen, religiösen Versammlungen, Vorlesungen im Kilnstlerkreise, Abenden der freien Ästhetik stellt Blok das Leben des russischen Volkes gegeniber, von dem "D.S. Merežkovskij und die "Gebildeten" 4 ) keine Ahnung haben. Das Volk ist noch gesund. Zum Beweis fihrt
1) Vgl. damit die Regleanwelsung zum 4. Bild S.7o.
2) $\mathrm{Vgl} \cdot \mathrm{V}, 21$ off.
3) $\mathrm{v}, 212$
4) $v, 215$. 
Blok das "drohende und grobe Phanomen des Sekt1erertums" an. 1) Ein besonders deutliches Symptom fur den Niedergang der Intelligenz 1st das tberhandnehmen der Iiteraturkritik und das Versiegen der Quelien echten Schbpfertums. 2)

Un die Jahreswende von $1907 / 08$ hatte 81 ch Bloks HaB gegen das kulturelle Leben in Petersburg so verstärkt, daB er sich we1tgehend aus den Veranstaltungen zurllckzog und auf Vorträge und Dichterlesungen verzichten wollte. Am 9. Dezember 1907 schrieb er an seine intter:

"Dein Brief uber die Unnotigkeit von Legungen in Konzerten fiel mit elnem groBen Abend der "Neuen Kunst" zusammen, nach dem wir dre13) beschlossen, daB ich kinftig nicht mehr lesen werde."4)

An Belyj schrieb er:

"Ich habe uberhaupt volilg aufgehort, auf Abenden zu lesen und sehe fast keine Leute." 5 )

In einem Brief an die Frau Sologubs bringt er selne Ablehnung, auf Dichterlesungen aufutreten, direkt mit seiner Arbeit am LS in Zusammenhang. 6) In Januar 1908 lieB Blok elne BekanntTachung verbffentlichen, aus der hervorging, das er nicht mehr auf "literarischen ibenden" auftreten werde. 7)

Als dann die Saison 1908/09 in Petersburg nach der Sommerpause $e^{q}$ begann, ohne daß sich etwas gebessert hatte, trat Blok wiederum mit einer scharfen Verurteilung des Kulturbetriebs an die öffentlichkelt. Schon die Anfihrungszeichen im iitel "Večra "iskusstv" (Die hbende der "Kunste")" waren eine Kampfansage.

1) V.215; vgl. a. Exkurs "Blok und der "raskol"".

2) V.215, 217. Blok spricht von elner "kommentativen Periode"; vgl. auch VIII.219, Brief an seine Mutter vo.n 27. Nov. 1907. Bloks erneute Kampfansage an den Merezkovskij-Krels lobte wiederum eine heftige Polemik aus; vgl. V,732 und VIII,228, Brief an Je.P. Ivanov vom 31. Jan. 1908.

3) Blok, seine Frau und N.N. Volochova.

4) VIII,221.

$5)$ Brief vom 28. Dez. 1907; VIII, 222

6) VIII,226, Brief an A.N. 'Cebotarevskaja vom 19. Jan. 1908. Vgl. Entstehung geschichte, S.8.

7) $v, 676$, Brief an die Redaktion der Zeitung "Svobodnyje mysli" (Freie Gedanken).

8) In Sommer 1908 war in Sachmatovo die "Szene auf dem bden Platz" entstanden; vgl. Entstehungsgeschichte, S. 17 .

9) $v, 304-308$ 
"Die Petersburger literarische Saison mit allen ihren ziemlich eintönigen Einzelheiten hat begonnen. Und es haben auch die literarischen Abende begonnen, - eine der ubelsten Einzelheiten... Im vergangenen winter ${ }^{1}$ witete die 11 terarisch-musikalischvokalische Epidemie; $\operatorname{man} r i B$ sich um die Salle, und wohin man kam, wurde deklamiert, gesungen und gespielt. 2 ) Nach den Gerüchten zu urteilen droht uns jetzt etwas anderes: von gewöhnlichen oder sogar stilisierten Abenden hort man selten, dafiir werden uberall Auffuhrungen von Einaktern organisiert, und nach den Namen der Leiter, die man so hört, kann man erwarten, daB das theatralisch-literarisch-vokalisch-musikalisch-ballettösküntlerische Treiben Erfolg haben und einen ebenso epidemischen Charakter annehmen wird."3)

Der "Abend der nördlichen Hirtenflöte", den Blok besuchte, glich den andern Abenden aufs Haar.

"... dieselbe Durftigkeit, dieselbe Nutzlosigkeit; Schriftsteller, die fast ausnahmslos nicht lesen können, lesen träge, langweliig, durch die Nase, monoton, fade... Das Publikum besteht aus Leuten, denen alies egal ist und aus Jugendlichen. Die nicht sehr zahlreiche Jugend, die solche Abende besucht, spaltet sich wie bekannt jetzt in zwei Lager. Die einen wolien politische Themen. Wenn ein Dichter uble Gedichte mit politischer Note vorträgt, wird applaudiert, wenn er gute Gedichte ohne politische Note vorträt, wird gepfiffen (diese Gruppe ist nach meiner festen tberzeugung der beste Teil des Publikums, das die Abende der neuen Kunst besucht). Die andere Gruppe kommt mit stilfrisur..."4)

Selbst wenn ein solcher Abend als Wohltätigkeitsveranstaltung ausgegeben werde, sei es Bïrgerpflicht, nicht hinzugehen. 5) Blok beschwört dann die "gute alte Zeit", als ein Dostojevskij, ein Majkov, ein Polonskij, ein Plešejev auf Dichterabenden auftraten. 6) Das Auftreten der Dichter heute ist schädlich,

"schädlich, weil die neuen Dichter fast noch nichts getan haben; weil man das Publikum daran gewohnen soll, Schriftsteller anzuhimmeln, die nicht von der Aureole des Dienstes an der Gemeinschaft geschmulckt sind, die noch nicht das Recht

1) Winter $1907 / 08$.

2) In Petersburg war es eine Zeitlang Mode, zur Musik zu deklamieren. Auch Bloks Frau, die ja Schauspielerin war, hatte dieser Mode Tribut gezollt.

3) $v, 304$

4) $\nabla, 305$

5) $V, 307$

6) $v, 307$. 
haben, Bich als Nachfahren der heiligen russischen Literatur zu betrachten; schädlich, well man das Publikum nicht an Neugier auf den Schriftsteller auf Kosten des Interesses an der Literatur gewöhnen soll; schädlich, weil die Mehrqahl der neuen Werke ... dem großen Publikum unzugänglich $18 \mathrm{t}$, das völlig recht hat, wenn es aufrichtig nichts versteht; schädlich, well all das zusammen nicht nur eine Atmosphare der Abgeschmacktheit und der Vulgarität erzeugt, - nein, schlimmer: die Abende der neuen Kunst im besonderen, aber auch alle andern... werden zu Zellen der Reaktion." 1 )

Es folgt ein Aufruf an alle Schriftsteller, Kunstler und Veranstalter, an der Gestaltung solcher Abende nicht mehr mitzuwirken. 2)

Bloks publizistische Angriffe gegen den Kulturbetrieb richteten sich nicht gegen Vjac. Ivanov, dessen "Mittwoche" ein Mittelpunkt des Petersburger gelstigen Lebens waren. Doch fallit Bloks Entfremdung mit dem Ivanov-Kreis in die Entstehungszeit des IS und begleitet seine Zeitkritik.

Ivanov war Anfang 1905 endgiltig aus Westeuropa nach RuBland zurückgekehrt und hatte sich in Petersburg niedergelassen. In seiner Wohnung, der berühten "bał́nja" (Turm) in der Tavričeskaja ulica Nr. 25, versammelten sich seit Ende 1905 Gelehrte, Philosophen, Dichter, Maler, Musiker und Schauspieler. ${ }^{3)}$ Die Bedeutung der "Mittwoche" im geistigen Leben der russischen Hauptstadt kann kaum überschätzt werden. ${ }^{4)}$ Blok kannte Ivanov seit 1904 ${ }^{5)}$ und nahm häufig an den "Mittwochen" teil, wo er u.a. das Gedicht "Neznakomka"6) und in Anwesenhe1t von N.N. Volochova die

1) $v, 308$

2) V,308; Blok selbst hielt sich nicht an sein Versprechen, nicht mehr bei Dichterlesungen aufzutreten. Er war zu sehr in den Kulturbetrieb integriert.

3) Die "Mittwoche" wurden bis Ende 1907 veranstaltet. Zum Datum des Beginns vgl. Belyj, Vospominanija o Bloke, Epopeja II, S.288f.; die Angabe 1903-1906 in West, Russian Symbolism, S. 199, Anm.1 zu S.49 ist falsch.

4) Vgl. Stepun, Das Antlitz RuBlands, S.199ff.; ders., Mystische Weltschau, S.209ff.; Volołin, Die grïe Schlange, S.173ff.; Maslenikov, The Frenzied Poets, S.205ff.; Belyj, aa0, S.288f.; Zorgenfrej, Blok, in: Zapiski mettatelej, 1922, Nr. 6, S. $133 \mathrm{f} . ;$ Eine ausführliche Schilderung der Atmosphäre und der Bedeutung der "Mittwochen gibt Tschöpl, vjaX. Ivanov, S.27-52.

5) $\mathrm{Vgl} \cdot \mathrm{VIII}, 96$

6) Vgl. Cukovikij, Sobr.soX., Bd.2, S.266f. 
(iedichte des Zyklus "Schneemaske" vorlas. 1) Die philosophischen Diskussionen verfolgte Blok meist schweigend. ${ }^{2)}$ Filr die Wintersaison 1905/06 der "Mittwoche" Ivanovs waren folgende Themen wichtig: "Kunst und Sozialismus", "Die Romantik und die zeitgenössische Seele", "Das Glück", "Individualismus und neue Kunst", "Der Schauspieler der Zukunft", "Religion und Mystik", "Der mystische Anarchismus". 3)

Ivanov selbst beschäftigte sich besonders mit dem Problem des Dionysischen und seinem Verhältnis zum Christentum, dem Sinn kinstlerischen Schaffens, der Erneuerung der Kunst und v.a. des Theaters. 4)

wichtig filr Blok war, daB er v.a. durch Ivanov mit der Ideenwelt Nietzsches und Wagners genau bekannt murde. Se1t etwa 1906 wandelte sich Bloks Weltbild unter dem EinfluB der deutschen Denker zu einer tragischen Weltanschauung in der Art der neueren Lebensphilosophie. 5 )

Das besondere Interesse galt der Bestimmung des Dionysischen im Frihwerk Nietzsches. Glelchzeitig versuchte Ivanov den rigorosen Individualismus Nietzsches, der in einer pseudoherolschen Selbstijberhebung erstarrte, durch eine an Wagner orientierte Kunstphilosophie zu ersetzen. Die kurze studie "Poèt 1 cern" "6) in der die Uberwindung des Individualismus durch die wiederbelebung einer mythenbildenden Kunst vorgeschlagen wird, hatte filr Blok große Bedeutung. Im Teil VII dieser Studie erklärt Ivanov das Symbol als Rudiment alter religiöser Vorstellungen. Deshalb ist das Schaffen des symbolistischen Dichters ein unbewuRtes Versinken in das Element der Folklore. "Symbole sind Erlebnisse

1) Vgl. Gorodeckij, Vospominanija o Bloke, in: Mocul'skij, Blok, S.178.

2) Belyj, aac, S.293.

3) Vgl. "Zolotoje runo", 1906, Nr. 4, S.80.

4) Vgl. Ivanovs Aufsätze "Niç̌ 1 Dionis" in: Vesy, 1904, Nr. 5 S.17-28; "Ellinskaja religija stradajušego boga" in: Novyj Put', 1904, Nr. 1-3, Nr. 5, Nr. 8-9; "Vagner 1 Dionisovo dejstvo" in: Vesy, 1905, Nr. 2, S.13-16; "Poet 1 čern" In Vesy, 1904, Nr. 3, S.1-8; "Kop'e Afiny" in Vesy, 1904, Nr. 10, S.615 u.a. Eln Darstellung von Ivanovs Kunstphilosophle glbt West, Russian Symbolism, S.50ff. Wichtig ist auBerdem Stepun, Mystische Weltschau S.221ff. und Tschöpl, Vją. Ivanov.

5) Vgl. die grundlegende Darstellung Kluges, Kesteuropa und RuBland im Vieltbild A. Bloks, S.84ff.

6) Vesy, $1904, \mathrm{Nr} .3, \mathrm{~S} .1-8$. 
(perezivanifa) eines vergessenen und verlorenen Zustandes der Volksseele". Der Dichter ist das "Organ des sich Rilckerinnerns des Volkes (organ narodnogo vospominanifa)". Das echte syabol wuB de.. Dichter und den Föbel (Cern') in einer groBen, das Volk umfassenden Kunst versöhnen. Der Dichter schöpft aus den Quellen der Volksseele. ${ }^{1)}$

Der romantische Charakter dieser Darlegung ist offenkundig. Ivanovs Kunsttheorie hat der Realität nicht standgehalten; sie wurde durch die Tatsache ad absurdum gefihrt, daß Ivanov selbst ein Dichter von größter Esoterik war. Bloks Rezension des Aufsatzes von Ivanov zeigt, daß er diese Ideen vorbehaltlos akzeptierte. ${ }^{2)}$ Die gesamte spätere Kunstphilosophie Bloks beruht auf der Ivanovschen Idee von der Versöhnung zwischen Kitnstler und "Pöbel" im "Lichte des allumfassenden Mythos".3) Da seit etwa $1906 \mathrm{Bloks}$ Lebensphilosophie ausgeprägt ist und um den zentralen Begriff der "Musik", des "Elementaren" kreist, wird von nun an auch das Verhältnis von Dichter und Volk unter diesen Begriff gestellt. ${ }^{4}$ ) Genau wie Ivanov ist Blok gezwungen, einen idealisierten Volksbegriff in der Art Nietzsches ${ }^{5)}$ und besonders Wagners ${ }^{6)}$ seiner Kunstphilosophie zugrunde zu legen. Der idealisierte Volkstumsbegriff deckte sich nicht mit der Erfahrung, die Blok von der zeitgenössischen wirklichkeit machte. Die Bevölkerung der Hauptstädte Rußlands var wenig geeignet, als Träger des "Geistes der Musik" in Betracht zu kommen. Bei dem Versuch, ein reales Substrat fir sein idealisiertes "Volk" zu finden, wich Blok zu der Hilfskonstruktion aus, im russische Bauerntum sei, im Gegensatz zu der Stadtbevölkerung, der "Geist der Musik" noch lebendig. 7) In zunehmendem Maße wandte sich Blok seit 1906 der russischen Folklore $z u$ und beschäfigte sich mit der filr die russische Geistesgeschichte iberaus bedeutenden Erscheinung des Altgläubigentums und des Sektenwesens.

1) Vgl. dazu Viest, Russian Symbolism, S.71ff.

2) "Tvor ̌estvo Vjač. Ivanov", V,7-19.

3) $\mathrm{VgI}, \mathrm{V}, 10$.

4) VgI. z:B. "Duša pisatel ja", V,367-371.

5) Vgl. "Homer und die klassische Philologie"; "Die Geburt der Tragödie".

6) Vgl. "Deutsche Kunst und deutsche Politik"; "Publikum und Popularität".

7) VgI. V,94 
Als wichtiges Problem erhob sich fiir Blok die Frage nach dem Kunstwerk, das die Einheit von Kunstler und Volk verwirklichen sollte. Im Sinne Ivanovs, der selbst auf Nietzsches und Wagners Deutung der griechischen Tragödle zurückgriff, und angeregt von der Beschäftigung mit der Schauspielkunst des Mittelalters, forderte Blok eine Erneuerung des Theaters und als neue, dem Volk angemessene Gattung das Melodrama. ${ }^{1)}$

Die Anregungen, die Blok aus dem Krels um Ivanov erhielt und deren Bedeutung Bonneau zu Unrecht bestreitet, ${ }^{2)}$ spiegelt Bloks Tagebuch dieser Zelt nit großer Deutlichkeit wider. Der ausfihrliche Eintrag Bloks vom 18. Januar 1906 unter der tberschrift "Religion und Mystik"3) greift ein Thema der "Mittwoche" auf. Bloks Ideen $z u$ diesem Thema sind von einer bei ihm seltenen Klarheit. ${ }^{4)}$ Ein weiterer Eintrag enthält mehrere Gedichte, die Blok zur Lesung bel Ivanovs "Mittwochen und den "Sonntagen" des bekannten Symbolisten F. Sologub ausgewählt hatte. ${ }^{5}$ Im Dezember 1906 machte sich Blok ausfihrliche Notizen aus Nietzsches "Geburt der Tragödie" und bedauerte, nicht alles notieren zu können. ${ }^{6}$ ) In den Einträgen, die hierauf folgen, häufen sich die Spuren des von Ivanov inspirierten "Dionysiasmus".7) der seinen Höhepunkt in den Skizzen zu einem später nicht ausgefithrten Stijck mit dem Titel "Der hyperboreische Lionys" erreichte. ${ }^{8)}$ Besondere Bedeutung fiir Blok hatte die Urauffinrung des "Balagantik" im Dezember 1906. Unter dem Einfluß der Diskussionen des Ivanov-Kreises iber das Problem des Theaters reifte in Blok die Absicht, einen großen Aufsatz iber das Theater zu schreiben. 9) Bei den Probearbeiten kam er mit dem Theatermilieu in Berihrung. $\left.{ }^{10}\right)$ Dabel verliebte Blok sich leiden-

1) VgI. "O teatre", V,241-276; dazu den SchluB, S.50off.

2) Bonneau, I'univers poétique, S.62.

3) Zap.kn. 72-74.

4) Vgl. Močul'skij, Blok, S.127.

5) Zap.kn., 74 .

6) Zap.kn., 78-84.

7) Zap.kn., 84-86, Einträge vom 21, Dez. 1906.

8) Zap.kn., 87-91.

9) Zap.kn. 86, Notiz vom 29. Dez. 1906. Der Auf satz "O teatre", $\mathrm{V}, 241-276$, entstand erst ein Jahr später.

10) Vgl. VIII,169ff., Brief an Mejerchol'd von 22. Dez. 1906. 
schaftlich in die Schauspielerin N.N. Volochova, die ihn zu einer großen Zahl von Gedichten inspirierte. Der Zyklus "Sneznaja maska", 1) den Blok in einem wahren Schaffensrausch in der ersten Januarhälfte $1907 \mathrm{schrieb,} \mathrm{ist} \mathrm{ohne} \mathrm{den} \mathrm{Einfluß} \mathrm{von}$ Ivanovs Dionysiasmus nicht $z u$ verstehen. ${ }^{2)}$ Eine Notiz vom Januar 1907 zeigt, daB Ivanov sogar Anregungen zur Wahl einzelner Ausdrifke gegeben hat. ${ }^{3)}$ Es ist nach alledem erstaunlich, daB Bloks Verhältnis zu Vją. Ivanov und dessen Kreis, v.a. zu S. Gorodeckif und G. Čulkov, bereits im August 1907 stark abgekihlt war. Gorodeckij und sein Gedichtband "Jar" "waren die Sensation der "Mittwoche" in der Wintersaison 1905/064) und Blok hatte die mit russischer Mythologie verbrämten ekstatischen Gedichte enthusiastisch aufgenommen und war des Lobes voll fiir den jungen Dichter. ${ }^{5)}$ Gorodeckij stand in dieser Zeit wie Blok ganz in Banne von Ivanovs "Dionysiasmus". 6)

Die Auseinandersetzung mit Bely $j$ un den "mystischen Anarchismus" Čulkovs hatte dazu gefihrt, daß Blok sich vom Ivanov-Kreis und dessen exaltiertem Erotizismus löste. ${ }^{7)}$ Noch in der Absage an Ivanov ist Bloks Anerkennung von dessen persönlicher Bedeutung zu spiren:

"Völlig abseits steht fiir mich in dieser Beziehung Vjačeslav Ivanov, der hochgebildet und ein hervorragender Schriftsteller ist (seine uufsitze in den "Vesy" und seine Gedichte)... Unangenehn ist mir sein schwiiler Erotismus und seine widerliche Leichtiekeit."8)

Nach einer lïngeren Zeit der Entfremdung kam es im Frihjahr 1910 noch einmal zu einer Annäherung zwischen Ivanov und Blok; sie fand ihren Niederschlag in Bloks Vortrag "O sovremennom sostojanil masskogo simvolizma". 9) Diese Annëherung war nur von kurzer Dauer. Schon 1912 scheint Bloks Kontakt mit Ivanov end-

1) II, 211-253.

2) Vgi. Orlov, Blok, S.89ff.

3) Vgl. Zap.kn., 92 .

4) Vgl. Pjast, Vistrexi, in: Russkaja literatura konca XIX - nacala XX v., 3d.2, S.464.

5) Vgl. Zap.kn.. 85, Eintrag vom 21. Dez. 1906.

6) Vgl. M. Gofmann, Gorodeckij, in: Poety Simvolizma, S.333-342.

7) Vgl. Zap.kn., $96 \mathrm{ff}$., Einträge vom 1. und 20. Aug. 1907.

8) Zap.kn.. 97; vgl. dazu Briefe an Bely j vom 6. Aug. 1907, viII, 190 und vom 17./18. Aug. 1907, VIII,200.

9) V.425-436; vgl. dazu v,756ff; zur Bedeutung dieses Vortrags vgl. Bonneau, L'univers poétinue, S.66f.; Stepun, Mystische deltschau, S. 385-391; Kluge, Westeuropa und RuBland, S.74-80. 
gultig abgerissen zu sein. 1) Die Verspottung Ivanovs im ${ }^{2}{ }^{2}$ ) spiegelt die seit dem Sommer 1907 uberwiegend kritische Einstellung Bloks zu diesem bedeutenden Vertreter des Symbolismus wider.

Im Gedicht "Vjaceslavu Ivanovun"3) druckte Blok im Ruckblick den mächtigen Zauber aus, der von Ivanov ausging und dem Blok in den Jahren der Revolution von 1905 und der "Schneemaske"-Gedichte erlegen war.

Schon in seinen Ausfällen gegen das kulturelle Leben seiner Ze1t hatte Blok imer wieder Kritik an der "Intelligenz" gelibt und damit zu einer prage stellung genomen, die damals die Gelster beherrschte, nämlich zu der Frage nach dem Verhältnis von "Volk" und "Intelligenz".

Die Diskussion um das Verhaltnis von "Volk" und "Intelligenz" in RuBland ist alt und kann mit thematisch gleichen Diskussionen im Westen schwer verglichen werden, da die gesellschaftliche und politische Entwicklung in Hesteuropa weitaus vielschichtiger verlief als in RuBland. Die Termini "Volk" und "Intelligenz" sind außerdem zu unprăzise, als daß eindeutige Aussagen zu diesem Thema möglich wären. ${ }^{4)}$ Blok unternimut keinen Versuch, die Begriffe zu klären. Das "Volk", das ist bei inm "der Arbeiter, der Sektierer, der Bosjak, der Bauer", 5) die Unterschicht, besonders aber die bäuerliche Landbevölkerung. 6) Es ist dis "sanior pars", der Tell des Volksganzen, auf dessen Selte die Wahrheit steht. Die "Intelligenz" ist weder berufsetändisch noch klassenmäBig definiert. Blok zăhlt zu ihr die Techniker, die

1) Vgl. Bonneau, aao, S.57-62.

2) Vgl. $5.70 / 9$

3) III, $141 \mathrm{f} ., 1912$.

4) Eine sehr ausfuhrliche Darstellung der Diskussion um die russische Intelligenz gibt $0 . W$. Muller, Intelligencija.

5) $v, 324$.

6) $v, 356 \mathrm{ff}$. 
Wissenschaftler, 1) in erster Iinie jedoch die "Literaten", d.h. Dichter, Schriftsteller, Theaterleute, Journalisten, Kritiker, dann die Kinstler, Philosophen etc.2)

Seine Kritik an der Intelligenz ist in erster Inie Kritik an den "Literaten". Die Klammer, die die Intelligenz zusammenhált, ist das subjektive Selbstbewußtsein dieser Gruppe, das sich im Gefihl einer Art geistiger Blutsbriderschaft äußert, v.a. aber in der ?'berzeugung, die geistige Fihrerschicht des Landes zu sein und als solche verpflichtet zu sein, dem Volk zu dienen. 3 )

1) Die naturwissenschaftliche Intelligenz hat Blok besonders in "Stichija i kul'tura", V,350-359, im Auge. Als ihren besten Vertreter betrachtet Blok seinen Schwiegervater, den berihmten Cheniker D.I. Mendelejev (1834-1907). Dieser war der bedeutendste apolitische Technokrat des vorrevolutionären RuBland; vgl. Utechin, Geschichte der politischen Ideen in RuBland, S.174f. Der Gegenpol zu Mendelejev ist nach Bloks Auf fassung Tolstoj (vgl. V,324f.; Zap.kn., 114). Beide sind Gegner einer toten humanistischen Bildung $(v, 579)$, beide sind naturverbunden $(v, 258 f$.$) . Tolstoj jedoch fordert zur Rilckkehr$ in das vorindustrielle bäuerliche Leben auf, Mendelejer ist Verfechter einer möglichst rasanten Industrialisierung.

2) Vgl. etwa "Iiteraturnyje itogi 1907 goda". Zur Intelligenz gehrirten fiir Blok auch die Revolutionäre; vgl. V,21 of. ("Marxist", "Sozialdemokrat") und V,324 ("Revolutionär").

3) Ein entscheidender Mangel des sehr materialreichen Buches von 0.W. Miller (s.0.) ist m.E., daB dem spezifischen Gehalt dieses Selbstgefihls nicht genilgend Aufmerksamkeit geschenkt wurde. Eine ganze Reihe von Sachkennern spricht von einem "Crdenscharakter" der russischen Intelligenz, so z.B. der Iiteraturkritiker $P, V$. Annenkov (1812-1887), der revolutionäre Narodnik N.V. Cajkovskif (1850-1926), der Sozialrevolutionär, Terrorist und spätere orthodoxe Emigrant I.I. Bunakov-Fundaminskij (1880-1942), der Religionsphilosoph N.A. Berjajev (1874-1948), der Kuiturhistoriker F.A. Stepun (18841958), der Theologe N.A. Zernov (1898- ); vgl. dazu: Berdjajev, Les sources et le sens du communisme russe, S. 3off.; Stepun, Bolschewi smus und christliche Existenz, S.181ff., $314 \mathrm{f}$.; Zernov, The Russian Religious Renaissance of the 2oth Century, S.1ff. Mit dem "Crdenscharakter" soll das Bemustsein einer geistigen Zusanmengehörigkeit und ein dogmatischer, (pseudo)religiöser Anspruch auf Eesitz der Vahrheit, verbunden mit einer Ideologie des Dienstes am Volk, umschrieben werden. Die Kritik Tschizewskijs am Ausdruck "Orden" (Russ. Geistesgeschichte II, S.50) ändert am Kern des Problems nichts. 
Mit seinem Vortrag "Rossija i intelligencija" (RuBland und die Intelligenz) ${ }^{1)}$ griff Blok direkt in die Diskussion fiber die Bestimmung und das Selbstverständnis der russischen Intelligenz ein.

Nach Bloks Auffassung stehen sich in RuBland zwei Gruppen gegeniber:

"das Volk und die Intelligenz; 150 Millionen auf der einen Seite und ein paar Hunderttausend auf der andern; Menschen, die einander im Wesentlichen nicht verstehen."2)

Diese beiden Gruppen gleichen den Heerlagern der Russen und Tataren am Vorabend der Schlacht auf dem Kulikovo-Feld. 3) Das Volk zeichnet sich durch große Selbstsicherheit und physische Kraft aus.

"Auf der anderen Seite - dieses leichte Lächeln, dieses selbstsichere Schweigen (moltanije "sebe na ume"), diese Dankbarkeit fiir "Belehrung" und die Entschuldigung fiir die Unbildung,4) worin man das "wir werden es euch schon zeigen" spiurt. Eine schreckliche Trägheit und ein schrecklicher Schlaf, wie uns immer schien; oder aber das langsame Erwachen eines Riesen, wie uns immer häufiger scheint. Das Erwachen mit so einem spöttischen Lächeln auf den Lippen. Die Intelligenzler lachen nicht so, obwohl sie doch alle Arten des Lachens kennen; doch vor dem Lächeln des Bauern (mužik), das so völlig anders ist als jene Ironie, die uns Heine und das Judentum beigebracht haben, als jenes Gogol'sche Lachen unter Tränen oder das Gelächter Solov'evs, - davor erstirbt sogleich all unser Lachen: es ergreift uns Furcht und Unbehagen."5)

1) Späterer endgiiltiger Titel ist "Narod 1 intelligencija" (Das Volk und die Intelligenz), V,318-328. Bloks Vortrag vom 13 . November 1908 vor der "Religiös-philosophischen Gesellschaft" in Petersburg wurde lebhaft diskutiert, und die Polizei verbot die vorgesehene Aussprache iber die Thesen Bloks (vgl. V,742f.). Unter Umgehung des Verbots fand am 25. November eine geschiossene Sitzung der "Religiös-philosophischen Gesellschaft" statt, wo iber Bloks Vortrag diskutiert wurde. Am 12. Dezember 1908 hielt Blok seinen Vortrag ein weiteres Mal, diesmal vor der "Literarischen Gesellschaft". Er wählte den Titel "Obozestvlenije naroda v literature" (Die Vergötterung des Volkes in der Literatur) und wies damit auf den äußeren AnlaB seines Diskussionsbeitrags hin: die Verteidigung Gor'kijs. Dieser hatte sich mit seiner Erzählung "Ispoved'" (Die Beichte) offen zum "bogostroitel'stvo" (Gotterbauertum) bekannt, was inm als biligerliche Verirrung angekreidet worden war.

2) $\mathrm{v}, 323$.

3) $v, 323 f \cdot i$ vgl dazu S.87/16ff

4 wörtl. "temnota" (Dunkelheit); "temnyj narod" ist ein stehender Ausdruck.

5) V, 323; vgl, zum Lachen Heines: "Ironija", V, 345-349; zu dem Gogol's: VIII, 153; zu dem V. Solov'evs: $\dot{v}, 346,449,685$ und VIII, 127, 129 . 
Gor'kif, der nach Bloks Meinung das Wesen des russischen Volkes am besten verkorpert, liebt besonders diese Menschen mit dem selbstsicheren Lachen. 1)

Die russische Intelligenz hat seit der Zeit Katharinas der Großen versucht, das Wesen des russischen Volkes zu ergrtinden.

"Man sammelte und sammelt Materialien zum Studium der "Folklore"; die Bucherschränke quellen uber von Bänden russischer Lieder, Bylinen, Legenden, Zaubersprlichen, Klageliedern; man. erforscht die russische kythologie, die Riten, Hochze1ts- und Begräbnisbräuche; man bemitleidet das Volk; man geht ins Volk, hegt Hoffnungen und erlebt Enttäuschungen; RchlieBlich kommt man um, geht aufs Schafott oder verhungert für die Sache des Volkes." 2 )

Und doch bleibt die Frage: "Sind diese Menschen die "Unsrigen" oder sind es "Fremde"?n3)

Die Tragödie RuBlands ist die Munzugängliche Grenzlinie ${ }^{4}$ ), die einst Slavophile und Westler trennte und die heute zwischen Polstof und Nendelefer besteht. 5) Eine solche Grenzlinie besteht nach Bloks Meinung auch zwischen Volk und Intelligenz.6) Zwar gibt es in einzelnen Fállen uber diese Linfe hinweg eine Annäherung $z$ wischen beiden Lagern. ${ }^{7)}$ Doch Blok weib selbst nicht, was zur therwindung des Konflikts getan werden soll. 8) Er beruft sich auf einige Passagen aus Gogol's "Vybrannyje mesta iz pereplski s druz'jaml" (Ausgewăhlte Stellen aus dem Briefwechsel mit Freunden), 9) in denen eine allumfassende, religiobse liebe voller Selbstentsagung zu RuBland gepredigt wird. In der "helligen Fornel"10) Gogol's, dem Gebot der Selbstentsagung, in einer mönchischen Liebe zu RuBland, die der Opferbereitschaft Pere-

1) $v, 322$

2) $v, 322$

3) $\nabla, 322$

4 Der Ausdruck "nedostupnaja Xerta" stammt aus Puß̌kins Gedicht "Pod nebom golubym..." (1826) und bezeichnet die Schranke, die der Tod zwischen "Sie" und "Ihn" gelegt hat.

5) $\mathrm{v}, 324 \mathrm{f}$

6) $v, 324 f$.

7) v,324; Blok nennt Lomonosov, die Volksdichter, die Slavoph1len, Dostojevskij und v.a. Gor'kij.

8) $v, 324$

9) Biok zitiert V,325f. auszugsweise den 19. und 20. Brief (Gogol', Sobr.sod. $\nabla 7$ tomach, Bd. 6, s.292ff.).

10) So nennt Blok Gogol's Gebot zur Selbstentsagung in "Ironija", $v, 349$, und stellt inm ähnliche Gebote Ibsens und Vl. Solovievs an die Seite. 
svets gleicht, 1) scheint Blok die einzige Moglichkelt zu sehen, die Kluft zwischen Volk und Intelligenz zu iberwinden. Doch einer solchen aufopferungsvolien Liebe ist die Intelligenz nicht fähig. 2) Denn die Intelligenz ist in Ästhetentum und Individualismus gefangen, sie ergibt sich dem Laster, dem Alkohol und der geistigen selbstzerriittung.

Die Intelligenz sucht sich von ihrem "Willen zum Tode" zu befreien, indem sie sich ins Volk wirft, das den "Willen zum Leben" verkörpert. 4) Doch trifft sie dort auf "Spott, Schweigen, auf Verachtung und herablassendes Mitleid, auf die "unzugängliche Grenzlinie", Ja vielleicht auf noch Schrecklicheres und Unerwartetes."5) Blok warnt vor jeder leichtfertigen Hoffnung auf eine friedliche Beilegung des Konflikte zwischen Volk und Intelligenz.

"Gogol' und viele russische Schriftsteller stellten sich Rußland gerne als die Verkörperung von Ruhe und Schlaf vor; doch dieser Schlaf geht zu Ende; die Ruhe verwandelt sich in ein entferntes und stärker werdendes Grollen, das dem wirren Lärm der Großstadt nicht gleicht.

Derselbe Gogol' stellte sich RuBland vor als dahinfliegende Troika. "RuBland, wo jagst du hin? Gib Antwort!" Doch die Antwort bleibt aus; nur das "GIn̈ckchen tönt mit wundersamen Klang." Jenes Grollen, das 80 schnell wächst, dab wir es mit jedem Jahr

1) 20. Brief der "Ausgewählten Stellen".

2) $\mathrm{V}, 326$

3) V:327. Blok spricht hier in eigenem Namen. In einem Entwurf zu einem Theaterstilck mit deutlich biographischen Elementen (Niederkunft seiner Frau mit einem außerehelichen Kind; seine Liebe zu N.N. Volochova), heiBt es vom männlichen Helden: "Er kennt die Krankheit der Melancholie (toska; das entspricht dem Baudelaireschen "ennui"), die inn zerfriBt, und er liebt sie insgeheim und leidet an ihr. Er denkt manchmal an Selbstmord... Er hofft auf irgendein RuBland, auf alles erfassende Rhythmen der Leidenschaft; und er verrät jeden Tag RuBland und die Leidenschaften. Und er versteht nicht die inn verfolgende und quälende Formel Ibsens und Gogol's. Oder besser, er versteht sie (wie alles), aber ibernimmt sie nicht. Er ist verdorben (ein Intelligenzler)."; Zap.kn., 12of... Eintrag rom 19.-20. Nov. 1908.

4) $v, 327$

5) $v, 327$. 
deutlicher vernehmen, ist dieser "wundersame Klang" des TroikaGlöckchens. Has ist, wenn die Troika, um die herum "die zerfetzte Luft tost und zum wind wird", geradewegs auf uns zufliegt? Wenn wir uns ins Volk werfen, werfen wir uns gerade vor die rube der tollen Troika ins sichere Verderben."1)

Kommt, so fragt Blok abschliebend, die Finsternis, die alles einhililt, etwa daher, "daß iber uns schon die zottige Brust des Leitpferds der Troika sich erhebt"? 2$)$

Bloks Vortrag zeichnet sich nicht durch logische Gedankenfihrung aus. Mit Recht sprach man vom "lyrischen Charakter der Ausfuhrungen".3) die in der Tat ein "Mittelding von Aufsatz und Prosagedicht über RuBland"4) sind. Die entscheidende Aussage Bloks war die Betonung des Abgrundes zwischen Volk und Intelligenz. Seine Tagebuchnotizen aus jenen Wochen zeigen, daß es ihm gerade hierauf besonders ankam.

"Mir 1st eines klar; ein ABGRUND, eine unzugängliche Grenzlinie zwischen Intelligenz und Volk EXISTIERT. Jener Teil der Intelligenz, fiir den die Wege zum Volk versperrt sind, ist ungeheuer groß, er wächst, und es sind nicht nur Lyriker..."5)

In der Diskussion, die bei Versammlungen und in der Presse gefihrt wurde, fihlte Blok sich allein gelassen. 6) Er war besonders von der Leichtfertigkeit betroffen, nit der die nach seiner

1) V.327.; zur Troika vgl. S.90/8.

2) $\mathrm{V}, 328$

3) So Culkov, vgl v, 743 .

4) So Z. Gippius, Merezkovskij, S.187.

5) Zap.kn.. 126, Eintrag vom 22. Dez. 1908. Dieser Punkt rief in der is iskussion die schärfsten viderspriche hervor. ilaupteinwände gefen Bloks Vortrag waren 1. die These, die Grïßen "Volk" und "Intelligenz" wirde:i gar nicht mehr bestehen (V,743 das vertraten Vjač. Ivanov und I.Je. Galic. Vgl. dazu V,331f. und Zap.kn., 125); 2. die These, Volk und Intelligenz wiirden sich aufeinander zubewegen ( $V, 743$; das vertrat Merežkovskij. Vgl. dazu Zap.kn., 124); 3. die These, eine Kluft besteht nur $2 w i s c h e n$ Volk und Dekadenz, mit welcher Blok fälschlicherweise die Intelligenz indentifiziert habe ( $V, 744$; das vertrat culkov. Vgl. dazu Zap.kn., 125). Verschiedentilch wurde bemängelt, dạ Bloks Vorstellungen allzu naiv seien. P.B. Struva der an den Diskussionen teilgenommen hatte (vgl. V,742 und Zap.kn., 128), lehnte es ab, Bloks Vortrag in seiner Zeitschrift "Russkaja mysl" abzudrucken (vgl. VIII,261f .. Brief an seine Mutter vom 16. Nov. 1908). Das filhrte zu einer Entfremdung zwischen Struve und Merezkovskif, der fiir Blok eingetreten war (vgl.Z. Gippius, Merezkovskij, S.187).

6) Vgl. Zap.kn., 128, Eintrag vom 30. Dez. 1908. 
Melnung verhängnisvolle Isolierung der Intelligenz vom Volk heruntergesplelt wurde. Insbesondere irritierte ihn die Meinung Culkovs, die dieser in seinen Erinnerungen folgendermaßen zusammenfaBte:

"Mir war in seinem Vortrag jener unerträgliche, erstickende Pessimimus unangenehm, der aus diesem ganzen mystischen Gestammel hervortrat. Ich widersprach Blok damals mündich und schriftlich."1)

Die Verliebtheit in Individualismus, Ästhetentum, Verzweiflung sei kein Kennzeichen der Intelligenz, sondern der Dekadenz. Seit Belinskij trete die russische Intelligenz für das Volk ein, selt Plsarev lehne sie das Ästhetentum ab, und seit dem Sieg des revolutionären Geistes in der Intelligenz habe sie Apathie und Verzweiflung überwunden.

"Das Bild eines Doppelgängers verdeckte fiir Blok das Bild der Intelligenz, und das Siegel des Todes auf dem Gesicht dieses Doppelgängers nahm Blok als trauriges Zeichen des Untergangs unserer ganzen Gesellschaft."2)

Blok versuchte, seine Thesen zum Problem "Volk und Intelligenz" zu untermauern, indem er es als Sonderfall eines viel allgemeineren Konflikts darstellte, des Konflikts zwischen dem "Elementaren" und der "Kultur". 3) Im Ausweichen auf eine irrationale Kulturphilosophie, die stark von vagner und Nietzsche geprägt war, ${ }^{4}$ ) hoffte Blok, seine Ansichten iberzeugend und unwiderlegbar darzutun.

"Als ich iber einen Bruch zwischen RuBland5) und der Intelligenz sprach, erschitterte mich vor allem der erstaunliche optimismus der meisten Elnwände... Sprach ich vom Tod, bekam ich zur Antwort, die Krankheit sei heilbar... Ich sprach von Spaltung, doch man sagte mir, eine spaltung gebe es nicht und könne es nicht geben. Ich sprach davon, daß wir das ferne RuBland lieben und hassen; man antwortete: "wir selbst sind RuBland".

1) Čulkov, A. Blok 1 jego vremja, in: Pis 'ma A. Bloka, S.113.

2) Culkov, A. Blok i jego vremja, in: Pis'ma A. Bloka, S.113.

3) "Stichija i kul'tura", v,350-359. Zur Bedeutung von "stichija" vgl. S.84/15; zur Bedeutung der Ausdricke "Kultur" und "Zivilisation" vgl. S.62/2. Zur Deutung der Probleme "Volk und Intelligenz" als Sonderfall des umfassenden Konflikts vgl. V, 353 .

4) Vgl. dazu Kluge, Westeuropa und RuBland, S.104ff.

5) "RuBland" und "Volk" ist bei Blok eigentlich dasselbe. Deshalb konnte er den urspringlichen Titel "Rossija 1 intelligencija" später in "Narod 1 intelligencija" umändern. 
Es 18t schrecklich zu horen: "Die Krankheit 1st hellbar, es gibt sie nicht, wir konnen alles selber." Wenn man in elnen Amelsenhaufen tritt, fangen die Ameisen sofort wieder an, das Zerstorte wiederherzustellen; nach einigen Stunden scheint es ihnen, als habe niemand thr Wohlergehen gestort. Sie sind in ihrer ewigen Arbelt... wie im Traum. Im glelchen Traum ist der Schmetterilng, der um die Kerzenflamme flattert. Im glelchen Traum vor dem Tod kann man um den Krater elnes Vulkans elnen frohlichen Reigen tanzen. Man arbeitet, singt, tanzt - Im Traum, in Selbstvergessen, Im Rausch.

Ein solcher großer Traum und zersetzender Rausch $18 t$ der Traum und Rausch der endlosen Kultur. Mit Nietzsche zu sprechen - eln "apolitnischer Traum"."1)

Das Wirken von Maschinen und Plugzeugen, der Kampf um die Unterjochung der Natur, - das wird glelch einem Ameisenhaufen von der Rache des "Elementaren" hinweggefegt werden. Das "Elementare" brach im Erdbeben von Messina durch, 2) und es wird sich In Gestalt der Volksmassen wie eln Iavastrom uber die Intelligenz ergieben. 3)

Blok sah es als seine Aufgabe an, vor einem lelchtfertigen Optimismus zu warnen. Insofern sind selne ÄuBerungen zu diesem Thema aus den Jahren 1907/08 als Hohepunkt selnes KatastrophenbemBtseins zu werten. Hierbel darf aber nicht ubersehen werden, daB Blok einen, wenn auch kleinen 'ie1l der Intelligenz ${ }^{4}$ fur fahig hielt, sich aus den Pängen der Ironie und des individualistischen Asthetentums, also dem Erbe der westeuropaischen Z1vilisation, zu befreien.

1) $v, 353$

2) $\mathrm{v}, 354 \mathrm{f}$; vgl. "Gor'k1j o Messine" (Gor'kijuber Messina), $v$. 380-384: Biok sah im Erdbeben, das am 15. Dez. 1908 Sizlilen und suditalien helmsuchte, das Wirken der "stichija". Ähnlich beurtellte er den Untergang der Titanic am 15. April 1912, die die gesamte westliche Welt erschutterte. Das Ereignis "schien die Hybris des westlichen Menschen zu enthullen, der sich stolz damit brlistete, er habe... die Naturgewalten unter seine Herrschaft gebracht." (G. Masur, Propheten von gestern. S.11). Blok schrieb in sein Tagebuch: "Der Untergang der Titanic gestern freute mich unsäglich (es gibt noch einen ozean)." VII, 139, Eintrag vom 5. April (a.St.).

3) V, 359; Blok ubernimt Kl jujev, vgl. dazu Exkurs "Blok und dèr "raskol"", S. $482 f 1$.

4) Vgl. Zap.kn., S.126, Eintrag vom 22. Dez. 1908: "Wenn diese Grenzlinie zwischen dem Volk und einem (immer wachsenden)

Tell der Intelligenz besteht, heiBt das: viele sind dem Untergang geweiht." Dazu V,352: "Als ich zugab, daB vielleicht ein inell der Intelligenz nicht vom Volk getrennt 1st..." 
Am 12. September schrieb Blok in sein Notizbuch:

"Wunschtraum von einer Zeitschrift in der iradition des "Sovremennik" (Zeitgenossen) von Dobroljubov. Zwei Intelligenzen. Widerlichkeit der "westlerischen" Kampagnen ("Vesy", mystischer Anarchismus u.ä.). Ein einzigartiges Manifest und ein allerstrengstes Program. Es soll nicht nach Pornographie riechen, weder nach einer mit Duldermiene noch nach einer flegelhaften. Den "Vesy" Lebewohl sagen. Boykott der neuen westeuropäischen Iiteratur. Das revolutionäre Vermächtnis - die Verachtung."1)

Bloks Sympathien galten ganz offensichtlich dem Slavophilentum, "dessen Prinzipien einen großen Rickhalt im Volk hatten"2) und den "echt russischen" Dichtern wie Puskin, Gogol', 3) Lostojevskij, Tolstoj, Uspenskij, Gor'kij etc., die von einer tieferen Iiebe zu RuBland beseelt waren als die "restler". Die in der rat sehr "westlerische" Zeitschrift "Vesy" setzte nach Bloks Meinung die unheilvolle Tradition des Westlertums in Rusland fort. ${ }^{4}$ )

ift der Reise, die Blok in Friihjahr 1909 nach Italien antrat, tritt das Thema "Volk und Intelligenz" in seiner Publizistik zurilck. 5) Hahrscheinlich viar die fibwesenhelt von Rusland auch ein Gmind daf"ir, da? Blok an der Diskussion un die "Vechi"

1) Zap.kn., 113

2) $\mathrm{v}, 324$

3) In diesen Zusamnenhang muR auch Bloks Hochschätzung fiir Gogol's "Vybrannuje nesta" gesehen verden, die einen starken iviederschlag in "Jarod i intelligencija" fand. Blok tacelte Belinskij wegen dessen Kritik an Gogol' und sprach sich noch im Frihjahr 1318 und im Dez. 1919 ffir eine wiederentdeckunE dieses 3uches "ohne" "westlerische" Scheuklapper." aus (VI, 27f., 140), eine Limpfehlung, die bei den Urhebern der ievolution nur Kopfschitteln auslösen konnte.

4) Bloks Berufung auf den revolutionären Demokraten iJ.Á. Lobro1 jubov (183,6-1861), der seit 1856 im "Sovremennik" als Propagandist eines engagierten Realismus auftrat, bedeutet eine hbsage an die Eesamte modernistische Literatur. Blok war allerdings völilig unfähig, das in der Notiz erwähnte Projekt in die tat umzusetzen.

5) Eine gewisse Ausnahme ist der Aufsatz "Planen'" vom ckt. $1913 ; \mathrm{V}, 483-486$. 
(Wegmarken) 1) nicht tellnahm. Blok war zu sehr in seinem "musikal1schen" Weltbild gefangen, als daB er die elgentliche Bedeutung der Auselnandersetzung um die "Vech1"-Sammiung hrtte begreifen können. Das zelgt die skizze zu elnem nicht ausgefubrten Aufsatz vom Oktober 1911; Blok sieht nach den heftigen Diskussionen um die Frage "Volk und Intelligenz" seine eigene Auffassung in einem Artikel $K$. Cukovskijs bestatigt.

"So 18t "Intelligenz und Volk"... ein ewiges Leitmotiv, eines der wichtigsten Leitmotive jenes musikalischen Dramas, das phantast $18 \mathrm{cher}$ und genlaler als viele gedichtete Dramen $18 \mathrm{~s}$ und das russ18ches Leben heiBt. Das Leitmotiv erstirbt, uberläBt fur einige Zeit andern den platz oder verliert sich im musikalischen Chaos, doch im Verlauf der Zeit taucht es immer wieder auf..."2) Mit der cktoberrevolution gewann auch fïr Blok das Thema nVolk und Intelligenz" neue Aktual1tät. An der "musikalischen" Behandlung des Themas anderte sich jedoch nichts. ${ }^{3)}$ Der Aufruf,

1) "Vechi" war der Titel einer im Frihjahr 1909 erschienenen Sammlung von Essays llber die russische Intelligenz, die Be1träge von P.B. Struve, S.N. Bulgakov, N. Berd jajev, M. Gerzenson, A. Izgojev, S. Frank, B. Kist jakovikij enthielt. Die Sammlung richtete sich gegen den revolutionaren Utopismus der Intelligenz, in dem ein religioser Elan ohne religibse Bindung zu einer blinden Gegnerschaft gegen den staat und zur Flucht aus der Verantwortung filr das Gemeinwesen fuhre. Gegen atheistischen, revolutionären Sozialismus und agnostischen, radikalen Liberalismus vertrat die "Vechi"-Gruppe eine christliche, reformerische leilnahme am staatlichen Leben. Die "Vechi"-Gruppe wurde von fast allen Seiten heftig kritisiert. Der prophetische Charakter einiger Aussagen wurde von vielen erst 1918 und spater erkannt. Belyj, dessen poli$t 18 \mathrm{che}$ Anschaungen nicht ganz so unrealistisch wie die Bloks waren, nahm in seinem Beitrag "Pravda o russkoj intelligencii" in: Vesy, 1909, Nr. 5, S.65-68 das Erscheinen der "Vechin mit Zustimmung auf.

Vgl. Zernov, The Russian Religious Renalssance, S.111-130; Utechin. Geschichte der politischen Ideen in RuBland, S.179185; speziell Schapiro, The Vekh1 group and the mystique of revolution, in: The Slavonic and East European Review, 1955, $\mathrm{Nr} .34, \mathrm{~S} .56-76$; ders., Die vorrevolutionáre Intelligenz und die gesetzliche Ordnung, In: Pipes, Die russische Intelligentsia, S.33-48.

2) $\mathrm{V}, 686$

3) Díe Kontinuität zeigt sich darin, daß Blok in seinen Sammelband "Rossija 1 intelligencija" vom Okt. 1919 die wichtigsten fufsätze von 1908 aufnahm. 
m1t dem Bolschewismus zusamenzuarbeiten, den Blok im Januar 1918 an die Intelligenz richtete, ${ }^{1)}$ ist nur zu verstehen, wenn man Bloks Hoffnung berlicksichtigt, daB die Intelligenz inrer hohen Verpflichtung vor dem Volk noch gerecht werde und noch fähig sel, dem "Geist der Musik" zu gehorchen.

Das 4.Bild des LS ist eine Dranatisierung der polemischen Angriffe Bloks gegen die Iiteraten und kllnstler, gegen die "Intelligenz". Der "berihmte Schriftsteller" ist mit sicherheit eine Karikatur VjaX. Ivanovs ${ }^{2)}$ und D.S. Merežkovskijs. 3) Die Gruppe der Intelligenzler im LS besteht nur aus Männern, womit Blok den artifiziellen Charakter, die dem Leben entfremdete Geisteshaltung der Intelligenz unterstreichen wollte. Auch die Intelligenzler sind Marionetten, denn durch die Splegelung verlieren sie inre personhafte Individualitat. Die Diskussion der Intelligenzler, deren hellenisierender Bildungseifer an die Versammlungen in Ivanovs "Iurm" erinnert, entzlindet sich an Faina-RuBland. Diese wird gleichzeitig als Schonheit und Herrin gepriesen und umworben und als Frau mit zweifelhaftem Ruf verachtet. Danit versuchte Blok offenbar, eine allegorische Darstellung der damaligen Diskussionen um das liesen RuBlands und des russischen Volkes zu geben, in denen das hohle Pathos einer abstrakten Verehrung Rußlands nur schlecht den Abscheu vor seinem wirklichen wesen verdeckte und einer echten, organischen Liebe zu Rußland im 'iege stand. Nur der "hann mit Brille", in dem Blok eine Karikatur seiner eigenen, in den Kulturbetrieb integrierten Person gab, hat einen Blick fil das wahre riesen von Faina-RuBland, das schon aus der Erzählung des Mönchs im 2. Bild des LS bekannt ist. Im 2.Teil des 4.Bildes legt Faina Pur kurze zelt inre großstadtische Hulle ab und offenbart sich als russisches Volksmädchen. Um Fainas wahres Wesen aufzuzeigen, wählte Blok das Medium des Märchens.

1) VI,8 und "Intelligencija i revol juc1ja", VI,9-2o.

2) $\mathrm{VgI} . \mathrm{S} .70 / 9$

3) Vgl. $5.74 / 3$. 
Im Rahmen seiner Studien der russischen Folklore ${ }^{1)}$ beschäftigte sich Blok auch mit dem Volksmärchen und den verschiedenen Theorien ther seinen Ursprung. Einer Besprechung von A.N. Veselovskijs Buch "V.A. Zukovskij. Poèzija Cuvstva 1 "serdęnogo voobraženija"", 2) stellte er eine t'bersicht iber die wissenschaftlichen Arbeiten des großen Literaturhistorikers voran. 3) Dabei skizzierte er die historische Entwicklung der russischen Märchenforschung in ihrem Zusammenhang mit westeuropa. Die "nythologische Theorfe"4) wurde auch in Rußland von der "Wandertheorie"5) abgel ïst, die in gemäßigter Form auch von Veselovskij akzeptiert wurde. Die wissenschaftliche Beschäftigung mit den Märchen-Theorien beeinfluBte jedoch Bloks "musikalische" ${ }^{6)}$ Auffassung des Märchens nicht. Ganz im Sinne der Romantik sah Blok im Mărchen die ÄuBerung des urspriinglichen Volksgeistes. In

1) Jgl. Exkurs "Blok und der "raskol"", S.476ff.

2) Das Buch erschien 1904 und in 2. Auflage 1918. Bloks Besprechung, V,568-576, war für die Zeitschrift "Voprosy zizni" (Fragen des Lebens) der "Gottsucher" verfaßt.

3) Aleksandr N. Veselovskij (1838-1906) war "RuBlands erste Autorität auf dem Gebiet der vergleichenden Iiteraturgeschichte"; Erlich, Russ.Formalismus, S.28. In literaturtheoretischer Hinsicht war er Vorläufer des Formalismus; vgl. aao, S.28ff. suf seinem Spezialgebiet, der Folklore, widmete er sich besonders den "duchovnuje stichi" (geistiichen Versen), den Bvlinen und der rituellen Folklore; vgl. Azadovskij, Istorija russkoj fol'kloristiki, Bd.II, S.180ff. Im Zuge der 1917 in der UASSR einsetzenden Kannagne gegen den "wurzellosen Kosmonolitisnus" wurde der Komnaratist Veselkovskij zur wissenschaftlichen Unperson erkï̈rt. Wach 1955 wurde seine iberragende wissenschaftliche Leistung wieder gewirdigt; vgl. Struve, Geschichte der Sowjetliteratur, S.432ff., $517 \mathrm{ff}$.

1) In Märchen lebt der Mythos fort, im Westen von Herder, den Bridern Grimm, de Gubernatis, A. Kuhn, W'. Schwartz, Hax Miller U.a.; in Kußland von A.N. Afanas'ev und in gemäßigter Form von F.I. Buslajev vertreten. Afanas'evs drei Bände "PoétiCeskije vozzrenije slavjan na prirodu" waren noch fiir Jesenin eine wichtige quelle.

5) Verbreitung der M̈̈rchen von Indien aus in verschiedene Richtungen. Begrinder dieser Theorie ist Th. Benfey. In RuRland ibernahmen diese Theorie v.a. Vl. V. Stasov und Buslajev nach 1870. Vgl. Azadovskij, Istorija russkoj fol'kloristiki, Bd.II, $5.47 \mathrm{ff}$.

6) Vgl. S.84/15. 
einem Einfihrungsvortrag zu Maeterlincks Märchenspiel "L'oiseau bleu" ${ }^{1)}$ sagte er:

"Lieser Pendelschlag, dieser Rhythmus, dessen Name "Leben" ist.... ist in jedem Volksmärchen vorhanden; von ihm ist auch das Märchen Maeterlincks durchdrungen, dessen Wurzeln sich in der Tiefe der Volksseele verlieren..."2)

Blok sah im "Volk", besonders in russischen Volk, den Träger des "Rhythmus", des "Geistes der Musik". "Musikalisch" und "volkhaft" waren fiir ihn letzten Endes Synonyme. Was "musikalisch" ist, ist eo ipso "volkhaft", einerlei ob es sich um das Herk eines einzelnen Dichters oder um anonyme Folklore handelt. Der Unterschied zwischen Volksdichtung und Kunstdichtung schwindet danit vïllig. ${ }^{3)}$ Das zeigt die Eesprechung, von vaeterlincks Mirchenspiel, in dem man schwer eine cbjektivierung des "Volksgeistes" erblicken kann. Bloks Haltung erinnert an die vielen Romantiker, die sich gegen eine Unterscheidung von Naturpoesie und Kunstpoesie wandten ${ }^{4}$ und glaubten, im Kunstnërchen von hochgestochener Esoterik den poetischen Zustand der "Urzeit" wiederherstellen zu können. Novalis kleidete seinen Mythos von der Wiederfindung der All-Einheit, des Paradieszustandes der "goldenen Zeit an Ende" in die Form des Märchens. ${ }^{5)}$ Auch bei Blok spiegelt das Märchen den privaten Mythos, den Mythos von der Erlösungssehnsucht der gefangenen Seele RuBlands wider. ${ }^{6)}$ Im Gegensatz jednch zu Novalis "schielt" Blok iᄁ LS nach der Folklore. Er bewegt sich nicht frei im Rahmen seines privaten Mythos, sondern sucht ihn durch anleihen bei der Folklore "volkstijilich" zu nachen. Da er aber auch hier

1) Gehalten am 15. Nov. 1920; VI,410-420.

2) VI, 418

3) Das kufgehen der Kunstdichtung im Volk wie bei Nekrasovs "Korobejniki" (vgl. S.105/1) ist zwar ein husweis der "Volkhaftigkeit", doch sind fir Blok alle "musikalischen" Dichter Verkörperungen des Volksgeistes. Blok ist der Gefangene seiner philosophischen Tautologien.

4) Vgl. Kluckhohn, Ideengut, S.114f.

5) Im Märchen von Hyacinth und Rosenblistchen in den "Lehrlingen zu Sais" (im Teil "Die Natur") und im "Märchen" des 9.Kapitels des "Heinrich von of terdingen".

6) Vgl. dazu Einleitung zum 5.Bild. 
rein "musikalisch" verfährt, entsteht ein recht hybrides Gebilde Bloks Folklorismus, der auch in der Befragung des Spiegel-orakel, zum Ausdruck kommt, muB im Zusammenhang mit seinem Mythos vom dionysischen russischen Volksmädchen gesehen werden. 1)

Blok nannte als Thema des IS die Frage "Volk und Intelligenz".2) Diese Feststellung wird am deutlichsten im 4.Bild bestätigt. Nun ist aber German und nicht etwa der Mann mit Brille die männliche Hauptperson des Bildes und des gesamten Sticks. German hat aber an Kulturbetrieb keinen Anteil. Er gehört schon seiner aristokratischen Herkunft wegen nicht in den Kreis der ijbrigen Intelligenzler. Er ist der "Auserwählte", 3) der vielleicht das Wesen der Faina enträtseln und Rußland erlösen kann. Damit wäre German der Fortsetzer der besseren Traditionen der russischen Intelligenz, jener alten, vom russischen Adel geprägten Intelligenz, di, in der Gegenwart vïllig degenerierte. ${ }^{4}$ )

Das Problem "Volk und Intelligenz", dem Blok in seiner Publizistik mit einer irrationalen Kulturphilosophie gerecht werden wollte, wird im LS in Lichte eines Mythos vom "wwig-Heiblichen" gesehen. Die tberwindung des abgrunds zwischen Volk und Intelligenz, schien Blok offenbar in einer art kosmisch-nystischer Liebesvereinigung, zwischen dem männlichen susnahmeintelligenzler und dem weiblichen Urgrund des Volkes nïglich, wie sie im 5.Bild des I:S dargestellt wird. 5)

1) Yr.l. dazu Einleitung, zun 5.Bild.

2) $\mathrm{V}$ fl. seinen 3rief an Stanislavskij vom 9. Jez. 1908, zitiert in der 'Fntstehungsgeschichte". S.27ff.

z) $\mathrm{Vgl}$. S.85/12 und $\mathrm{V}, 324$ "bol'sije l judi".

4) $V_{g l} \cdot \mathrm{V}, 33,8 \mathrm{ff}$

5) Die Frage, ob Bloks irrationale Kulturphilosophie oder nicht vielmehr sein Bythos vom "Ewig-Weiblichen" (vgl. dazu Einleitung zum 5.Bild) die Grundlage filr seine Behandlung des Problems "Volk und Intelligenz" bildet, ist unwesentlich, denn beide Sphären gehen bei Blok ineinander llber. Beide Sphären sind allerdings gleich ungeeignet, einen solch komplexen soziologischen Phänonen gerecht zu werden. Es ist

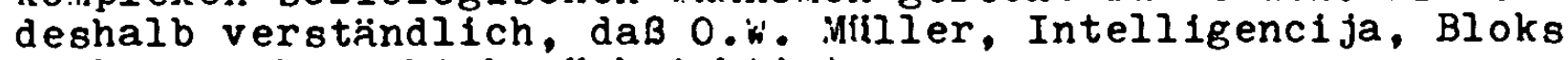
Publizistik nicht berflcksichtigt.

Wie sehr Bloks aussagen zum Problem "Volk und Intelligenz" Projektionen seiner Liebesmystik sind, zeigt der SchluB von "Narod i intelligencija", wo Blok eine selbstentsagende Liebes- und "homo-viator"-uystik predigt, die stark an den Schluß des IS erinnert. 
S.70/1 Dieses Bild fehlt in F1.

S.70/2 Die Ausstattung entspricht dem Geschmack einer Halbweltdame.

S.70/3 Die Gesellschaft der schöngeistigen Intelligenzler wird durch die Spiegelung ebenso uniform wie der marionettenhafte Großstadtpöbel. Die einzelnen Anwesenden verlieren inre Individualitä.

S.70/4 Im rus8. Text steht "prekrasnoj"; vgl. zu "prekrasnyj" S.48/1.

S.70/5 Im rus8. Text steht "Vot prekrasno!"; die tiederholung ist sicher beabsichtigt. Mit dem "mundlichen Wortstreit" uber die Qualitaten der Faina meinte Blok den widerlichen Klatsch der Intelligenzler uber Rußland.

S.70/6 Russ. "mira sego" ist archaisierend.

S.70/7 In "alten Sänger" verschmilzt der Rhapsode der Vorzeit (Homers Demodokos, die Barden und Skalden), der von Ruhm sang, mit dem Troubadour, der die Schönheit pries. Möglicherwelse splelte Blok auf Bojan an, der im Igorlied und in der Zadonžčina erwähnt wird. Der Schriftsteller setzt zu einer Preisrede an, die das kinstlerisch-literarische Gegenstuck zur technisch-naturwissenschaftlichen Rede des Professors werden soll. Schönhelt und Ruhm dieser Welt 1st Faina, der Star des Pöbels und die Muse der Intelligenzler.

S.70/8 Im Gegensatz zur schlechten Vergangenhe1t, wo der Sänger unfrei und dem willen seines Herrn unterworfen war, herrschen heute Freiheit und Gleichheit. Der Schriftsteller imitiert das Exordium der panegyrischen Preisrede in stilistischer und inhaltlicher Hinsicht. Die altertilmelnd-hochgestochene Sprache und der Topos der Entwertung der Vergangenheit (vgl. Curtius, Europäische Iit. u. lat. $M \dot{A}, S .174 f$ ) ) erinnern an das Igorlied und die Zadonztina ( $v g l$. neben der Gegenuberstellung von alter, vom mythischen Sänger symbolisierten zeit und Gegenwart im II 1, 1ff. und Zad. S.3f. den fusdruck "vozdadim pochvalu" in Zad., S.3). 
S.70/9 Der "mastityj Ivan Ivanovid" 1st eine Karikatur v ją. Ivanov8. Im 4.B1ld des is "verspottet Blok... die athetisierende Erotik und den Schonheits- und Griechenkult V. Ivanovs und seines Krelses als dekadentes Intelligenzlertum." (Kluge, Hesteuropa und RuBland, S.87). Ivanov hatte von seinen Bekannten und Schlllern den Be1namen "velikolepnyj" (der GroBartige) erhalten (vgl. Mocul'skij, Blok, S.139), worin die Hochachtung zum Ausdruck kommt, die er als fuhrende Erscheinung des russischen Symbolismus genob.

S.70/10 Die Katzbuckelei vor Ivan Ivanovid verträgt sich schlecht nit der Gleichheit und Preiheit des naufgeklarten zeitalters".

S.71/4 Russ. "mlads̆f $j$ " bedeutet neben "jünger" auch "untergeben, untergeordnet". Der Doppelsinn ist beabsichtigt.

5.71/2 In Auftritt Ivan Ivanovids gibt Blok elne sarkastische Darstellung der verlogenen Gleichheitsideologie der Intelligenz, deren Schönheitskult in "Tempel der Schönheit" mit seinem sakralen Anspruch als Gebrill eines intelligenzlerischen Pöbels in der "Garderobe" einer mondänen Halbwelt-"Schönheit" entlarvt wird.

$5.71 / 3$ "So svjatym1 upokof" ist der Beginn einer Passage der russisch-orthodoxen Sotenliturgie. Dieser makabre Querschläger nacht den Lobpreis auf Ivan Ivanovic und den Gottesdienst in Tempel der Schönheit noch grotesker. Die Passage wird im $\epsilon . B i l d$ vom Mönch fortgesetzt ( $\mathrm{g})$. S.95/9).

S.71/4 In Oktober 1907, also in der Zeit der Entstehung des LS, erschien die Zeitschrift "LuČ" (Der Strahl), die in einzigen erschienenen Heft Bloks Aufsatz uber Wedekinds "Frihlings Erwachen" enthielt (V,194-196; Blok lehnte das deutsche stifck als dekadent, faul und uberriechend $a b)$. Pber den kedakteur der Zeitschrift "Lư̌", einen gewissen S.S. Zusman, schrieb Blok:

"Es erschien in meinem Gesichtskreis ein neuer Typ von Speichelleckern: gerade verlieb mich der Redakteur des neuen Journälchen "Luẽ", der sich fast bis zur Gürtellinie verbeugt, auf jeden Satz "danke" sagt und gleich einen VorschuB daläBt." (VIII,207). 
Ptir den Jingling, in dem Blok den Journalismus verspottet, hat offenbar Zusman das Vorbild abgegeben.

S.71/5 lit dieser Replik erreicht Bloks Verspottung der Nachäffung des klassischen iltertums im "Turm" Ivanovs ihren Höhepunkt. Lie Katzbuckelei wird als Genius-Kult verbränt. Das Instrument des lyrischen Sängers wird durch einen Stuhl (russ. "sej stul" ist archaisierend) und die hohen Halbstiefel des Tragöden durch einen Schemel ersetzt.

S.71/6 Der andere Schriftsteller ist in Gegensatz zun .leporter ein gebildeter :lensch, der wei?, da? die Lyra und die Kothurne nichts niteinander $z u$ tun haben.

S.71/7 Las ist echte Briderlichkeit in iempel der Schönheit. S.71/8 : Ian beachte das anspruchsvolle geistige liveau dieser Symposien, in denen nur das simusement zählt.

S.72/1 Gronov bezeichnet den lann mit 3rille als eine "Gestalt, die keine direkte Beziehung zur Handlung hat und die in hohen Grade das Sprachrohr des hutors ist." (Gromov, "Fesnja sud'by", in: Geroj i vremja, S.519). Ler :iann nit 3 rille ist eine halb ernste, halb konische selbstdarstellung, 3loks. Ir fapt die Ideen 3loks zum Problen "Volk und Intelligenz" zusannen. Blok karikiert in dieser Gestalt seine eigene iolle als rublizist in ien Jahren nach 1905, besonders aber sein suftreten in cen verschiedenen literarischen $Z$ irkeln Petersburgs.

s.72/2 Der :iann nit Brille suricht zum thena, hat also eine sehr direkte Beziehung zur llandlung.

S.72/3 .uss. "Tol'ko už..." soll die individuelle .redeweise des Schriftstellers hervorheben. Vgl. S.73/1.

S.72/4 Der Mann nit Brille ist also Svmbolist.

$5.72 / 5$ Der Viann mit Brille schneidet das Thena "Gleichheit" in "̈hnlicher weise an wie Blok in den "literarnyje itogi 1907 goda", wo er der elitären Snobismus und dem endlosen Geschwätz der Intelligenz die Not des einfachen Volkes gegeniberstellte, das vor der ilur steht und auf Taten wartet.

S.72/6 Bloks Publizistik ist in der lat zu einem fronen 'ieil :nklage, die besonders der mussischer Intelligenz In- 
treue am "Geist der Musik" und Korruption durch die abendlandische Zivilisation vorwirft.

S.72/7 Die Begegnung mit dem echten Leben 1st der Wunsch Germans (vgl. S.61). Paina ist das verk8rperte Leben (vgl. S.99/15).

S.72/8 Blok litt selbst darunter, daB er Intelligenzler war und ohne die von inm angeprangerte Atmosphare der 11terarischen Salons, der Dichterlesungen und Diskussionen nicht leben konnte.

S.73/1 Zu russ. "Gde uz..." vgl. S.72/3.

S.73/2 Diese Haltung zeigt German im 7.Bild (vgl. S.99/7). Paina ist die Domina, die das ewige Wesen RuBlands verkörpert.

$5.73 / 3$ "koster" ist ein not-clé bei Blok. Der Scheiterhaufen ist ein Symbol fur die alles verzehrende Liebesekstase. Am bekanntesten ist das Bild aus hagners "Gotterdämmerung". Dort stirbt Brilnnhilde auf dem Scheiterhaufen den Liebestod.

In den Gedichten Bloks ist es immer der männliche lyrische leld, der den Liebestod stirbt. Die Geliebte ist "ein Scheiterhaufen, den der iirbelsturm zwischen irde und Aimmel hoch fegt" (II,105). "Sie war ein lebendiger scheiterhaufen aus schnee und Wein." (II,130f.) "Ich gehe selbst auf deinen Scheiterhaufen! Verbrenne mich!" (II, 251).

"Ind es stob der hohe Scheiterhaufen

ther den Gekreuzigten.

-...

winde dich, winde dich, leichte Plamme, "inde dich ums Kreuz!"

$$
\text { (II,252f.; "Na snežnom kostre") }
$$

(2u der katarchrestischen Verwendung des Scheiterhaufensymbols in Bloks Lyrik vgl. Zirmunskif, Poèzija A. Bloka, S.219ff.). Wahnrend in Bloks Lyrik das Bild des Scheiterhaufens weniger ideellen als vielmehr affektiven Gehalt hat und daher in die verschiedensten metaphorischen Bezlige eintreten kann, versucht Blok im LS, die ideelle Seite dieses Bildes stärker zu betonen. Inden er filir die Lieder der Faina das Bild des Scheiter- 
haufens wählt, erinnert Blok an das Bild der Selbstverbrenner (2.Bild, S.50) und gibt beiden Bildern eine gedankliche susrichtung, die den Gedichten "kryptisch" zugrunde liegt.

S.73/4 Nicht der banale Inhalt, sondern der hinreiRende Vortrag, die Stimme, das musikalische lioment machen das Strophen-Lied der Faina zun "Lied des Schicksals". Hinter den banalen iorten verbirgt sich die Eelieimnisvolle iacht der velodie.

lie worte des "iannes mit 3rille" erinnern an die Betrachtung Nietzsches "ber die intstehung des Volkslieds.

"Das Volkslied aber filt uns $2 u$ allernächst als nusikalischer ieltsniegel, als ursnringliche ielodie, die sich jetzt eine jarallele iraumerscheinung sucht und diese in der DichtunE aussnricht. Die ielodie ist also das Exste und allgemeine, das deshalb auch nehrere cbjektivationen, in mehreren Pexten, an sich erleiden kann. Sie ist auch das bei weiten ..ichtigere und jotwendigere in der naiven schätzunE des Volkes. Lie .ielodie gebiert die jichtung aus sich, und ziar immer hieder von neuem; nichts anderes :ill uns die stronhenform des Volkslieds sagen..." (jie Geburt der iragödie,70, 72f.).

Blok nachte sich in jezember 1006 ausfinrliche iotizen aus der schrift :ietzsches, insbesondere auch aus iem zitierten abschnitt (vEl. Zas.kn., 78ff.).

S.73/5 Die susfihrungen des "iannes mit 3rille" sind eine curzfassung der ̈̈ußerungen 3loks, die er zun Problem Volk und Intelligenz in seiner Publizistik machte. Eie stimnen insbesondere mit Bloks Vortrag "Lossija $i$ intelligencija" fberein.

( $V, 318-328$ mit den späteren 'ítel "Narod $i$ intelligencija"; s.o.) S. Jonneau fithrt hinzu aus:

"... Blok reprend dans son ihéatre tel thème déjà traité, telle thèse déjà soutenue dans un article antérieur... C'est ainsi oue le thène de l'opposition de l'Intelligentzia et le Peuple trouve son expression premiere dans l'article "Le Peuple et l'Intelligentzia". 
qui est de novembre 1908, son expression seconde dans les Quatrième et Cinquième Tableaux du Chant du Destin." (Bonneau, L'univers poétique d'Al. Blok, S.478). Diese Bemerkung stellt die Tatsachen auf den Kopf, denn Blok hielt seinen Vortrag fast ein Jahr nach der Arbeit in 4.Bild des LS.

Der weitgehenden inhaltilchen Pbereinstimung der Ausfihrungen des Mannes int Brille mit dem Vortrag entspricht die stilistische. In beiden Fällen gibt der Redner keine präzise soziologische Analyse, sondern er stellt in bilderreicher Sprache und ohne logische Systematik die Frage nach dem Schicksal der Intelligenz. Dabei flberwiegt in beiden Fällen der pessimistische, vor dem Nahen der Katastrophe warnende Unterton. Das Rußland, das in Iied der Faina ersteht, ist ein RuBland "in Sehnsuchtsträunen" (VIII,283), derselbe lockende Raum, in dessen Bann German gerlet (vgl. S.49/5). Diese räumliche Sphäre mit lebel, Sonnenaufgängen, Steppe, aus der vaina entstainmt (vgl. S.32/14 und 15), ist im 5.3ild der ilintergrund der Begegnung von Faina und Gernan.

2.73/6 Das russ. Verb "zagnat'" bedeutet "etwas Ungehöriges, ein vulgäres s.chimpfwort sagen".

$5.73 / 7$ Die Frage nach dem Interschied zwischen illegorie und Symbol spielte in der Iiskussion um das iesen des Symbolismus naturgemäß elne große Rolle (vgl. die Darstellung der leleinungen Ivanovs, Belyjs und Brjusovs zu dieser Frage in: Holthusen, Studien zur Asthetik und poetik des musischen Symbolismus, S.46ff.; speziell zu Ivanov siehe v.a. Hest, Russian Symbolism, S.5off.). Blok hat sich aus diesen Diskussionen völlig herausgehalten. Das theoretisieren flber Dichtung war inm, im jegensatz v.a. zu Belyj, zuwider. Der Vorwurf, sein "ierk sei allegorisch (vgl. Zap.kn., 106, fbersetzt in der "intstehungsegchichte", S.11), hat ihn nicht getroffen. 
S.73/8 Der Vorwurf des Nebelhaften wurde gegen Bloks Publizistik von Anfang an erhoben, so von 2. Gippius, deren Verurtellung von Bloks Ansichten in der Zeitschrift "Vesy", 1907, Nr. 5 und Nr. 7 unter dem Pseudonym Tovarisć German genau in die Entstehungszeit des IS fällt, und von P. Struve (vgl. die inleitung zum 4.Bild). Blok selbst bemängelte das Fehlen an Leben in LS ( $v g l$. "Entstehungsgeschichte", S.8f.).

S.74/1 Blok selbst war in seinem fuftreten weniger bescheiden.

$\mathrm{S.74/2}$ Im Kreis Ivanovs verkehrten auch vialer, so z.B. Bakst und Sonov.

S.74/3 Im Abgang des Ivan Ivanovit vor dem Erscheinen der Faina wollte Blok vermutlich die zeitwellige smigration kierezkovskijs beim susbruch der Revolution von 1905 versootten. Im berihmten Schriftsteller wäre dann neben Ivanov der zweite symbolistische Geistesheros Petersburgs karikiert.

Serezkovskij hatte die hevolution zwar begrifRt, aber er lehnte einige anarchistische Exzesee des revoltierenden Volkes ab.

S.74/4 Las ist eine Verspottung der traditionellen Vorstellung, vom Dichter als "vates", die bei den Symbolisten epidenisch war.

S.75/1 Offensichtlich soll die zerberstende Puderdose an eine Bombenexplosion erinnern. Diese stumme Szene ist eine Verspottung des Salonanarchismus der pseudorevolutionären Petersburger Intelligenz, insbesondere des "mystischen snarchismus" G. Culkovs, einem "liischmasch aus iarxismus, snarchismus, "systizinus und dischatologie" (Mocul'skij, illok, S.139). Die suseinandersetzung, un den "mystischen inarchismus" in den Jahren 1906-07 war der Beginn des Zerfalls des russischen Symbolismus. In den Streit zwischen den Petersburger Symbolisten mit Ivanov an der Spitze und den ijoskauer Symbolisten mit Belyj als ideologischen Wortfithrer wurde auch Blok hineingezogen, der sich nach anfänglichen Symnathien im Sonner 1907 vom "mystischen anarchismus" offiziell lossagte. (Zu Culkov vgl.: ilocul'skij, aal, s.137ff.; 
ders., Belyj, S.79ff.; Solov'ev, Poet 1 jego podvig, S.231f1.; West, Russian Symbolism, S.132ff.; eine genaue Darstellung der suseinandersetzung zwischen Blok und Belyj um den "mystischen snarchismus" gibt orlov, A. Blok $i$ A. Belyj v 1907 godu, in: Iiteraturnoje nasledstvo" 27-28, S.371-408, wo der Briefwechsel liber diese Frage publiziert und kommentiert ist; dazu: ders., Istorija odnof "druzby-vraždy" in: ders. Puti i sud'by, S.507-635, v.a. S.562ff.; Zulkovs Buch "O mistið̌eskom anarchizme", SPb. 1906, das einen Skandalerfolg hatte, ist 1971 als Nachdruck wieder erschienen, allerdings ohne das Vorwort Vjač. Ivanovs "O neprijatii mira"). Bloks Anarchismus, v.a. sein Aufsatz liber Bakunin ( $V, 31-35$ ) 1st von den Ideen Culkovs beeinflußt (vgl. Culkov, A. Blok i jego vremja, in: Pis'ma A. Bloka, S.109f.; Bakunin spielte in der Diskussion flber den "mystischen Anarchismus" in den Jahren 1906-07 eine große kolle. In seiner Rezension "Panteon sovremennoj posllosti" in "Vesy", 1907, Nr. 6, S.55-62, nahm Ellis Bakunin gegen seine mystischen Adedten Vjac. Ivanov und Culkov in Schutz). Bloks snarchismus ist eine Facette seiner irrationalen Lebensphilosophie (vgl. S.87/3).

Culkovs scharfe Kritik an Bloks Vorträgen "Narod $i$ intelligencija" und "Stichija 1 kul'tura", insbesondere sein Vorwurf, Blok ignoriere völlig die soziologischen Aspekte des Problems "Volk und Intelligenz", ist berechtigt (vgl. Čulkov, A. Blok i jego vremja, S.112ff. und die Anmerkungen $z u$ den beiden Vorträgen Bloks V,744 und 748). Bloks Definitionen von Volk und Intelligenz waren flir Culkov eine "subjektive Illusion" (Gronov, "Pesnja sud'by" in: ders., Geroj 1 vremja, S.489).

$5.75 / 2$. In dieser Nendung steckt ein Nebensinn. Blok wandelte den russischen susdruck "On vynosit sor iz izby" (wörtlich: er trägt den Kehricht aus der Hiltte, sinngemäß: er wäscht seine schmutzige Wäsche vor allen Leuten) $a b z u$ "on (d.h. poett) vymetajet sor iz chrana" (erg.krasoty). 
S.75/3 Faina 1st in dieser Szene die verkörperte "zornige Göttin" ("luCezarnaja" ist ein göttliches Epitheton der "Schonen Dame", vgl. z.B. I, 232, 353). Ihr Befehl "Hinaus!" wiederholt in dramatischer Weise die Unvereinbarkeit ihres Wesens mit dem der Intelligenzler, worauf der Mann mit Brille in seinem Monolog hingewiesen hatte. S.75/4 Hier endet der erste Teil des 4.Bildes, der in Thematik und stilistischer Gestalt eng mit dem 3.Bild verknilpft ist.

S.76/1 Vgl. Regieanweisung S.70/3.

S.76/2 Die Beleuchtung wechselt von grellem Licht im ersten Teil des Bildes (vgl. Regieanweisung S.70) zu einem märchenhaften jalbdunkel im zweiten Teil.

S.76/3 Die "starucha" ist das traditionelle russische GroBmutterchen, die Märchenerzählerin. Sie ist ein therbleibsel aus der Kindheit und Jugendzeit der Faina, als diese noch im magisch-abergläubischen Milieu des russischen Landvolkes lebte.

S.76/4 Die Wiederholung und der Gebrauch des umgangssprachlichen "chajat'" ("beschimpfen, in den Schmutz ziehen") geben den Worten der Alten den Charakter des Einfachen und Volkstumlichen.

S.76/5 Die Antwort der Faina ist ebenfalls recht umgangssprachlich.

S.76/6 Vgl. S.82/13 mit Bezug zur Erlösungsmystik.

S.76/7 Die russische Wendung "rasskazyvajet privy $\chi_{n o}$ drebezžažuju skazku" ist ungewöhnlich, denn das Verb"drebezzat' " wird nur konkret in der Bedeutung "klirren" u.ä. gebraucht. Es kann sich hier eigentlich nur auf die Stimme der Erzählerin beziehen, nicht aber auf das Märchen. Besser wäre wohl "rasskazyvajet skazku privyčno drebež̌ą̌im golosom" oder "rasskazyvajet privy̌no zvučçcu ju skazku".

S.76/8 Blok versucht, den Stil der russischen Märchen zu imitieren. Der Beginn und die mehrfache wiederholung "Kak ..." entspricht allerdings nicht dem normalen Wortlaut am Anfang der russischen Märchen (da heibt es 
"Ž1l-byl...", "Byval-žival...", "v nekotorom carstve, $v$ nekotorom gosudarstve zil-byl" u.ä.), sondern Im1tiert den Eingang einiger "lyrischer Lieder" (Russian Folk Literature, S.51,56), einiger "historischer Lieder" (aao, S.157; Chrestonatifa po russkof literature XVIII veka, S.41) und vieler Bylinen (Byliny, I, S.23, 28, 57, 64,86, 150, 187). In der Sammlung des Kirsa Danilov, die Blok gut kannte (s.u.), sind es besonders die Bylinen iber Il'ja thromec, die so beginnen (vgl. Sbornik K1rł1 Danilova, S.239: "Kak iz slavnoga goroda iz :luroma..."; 5.244 und 288). Mit "Kak s dalekogo sinego morja..." vgl.: "Iz-za morja, morja sinego..." (Byliny I, S.166, 174, besonders aber Sbornik Kirłi Dan1lova S.9, 2.5). Blok benutzt an dieser Stelle des LS das Wort "lebedka", Im folgenden "lebed", fem. (vgl. S.44/6). Das Bild von der schwimnenden Schwanenjungfrau kannte Blok v.a. aus Purkins "Skazka o care Saltane". Das Bild des Terem im Abendrot entlieh Blok aus der Byline iber Solovej Budinirovic (Sbornik K. Danilova, S.9ff., 2.130). Das Märchen der Alten wlederholt den Traun Germans (S.17). S.76/9 Faina kennt den Beginn des Märchens.

S.76/10 Die Zahl dreiunddreiRig kann aus Puškins "Skazka o care Saltane" entlehnt sein. Dort ist von dreiunddreibiE Recken die Rede. In der Byline iber Solovej Budimirovit erscheinen dreibig schiffe.

S.76/11 ks ist der "dobryj molodec" der russischen Folklore.

S.76/12 Der Ausdruck "pod vetrilom Gachmatnym" ist unilbersetzbar, denn Blok spielt hier offenbar auf sein Landgut "Sachmatovo" an.-Möglicherwelse wollte Blok sagen: "er segelt unter der Flagge von Šachnatovo". "vetrilo" ist ein ksl. wort und gegeniber "parus" poetisch und archaisch.

5.76/1? Von hier ab kennt Faina das Marchen offenbar nicht mehr. 
S.76/14 Der "wackere Jungling" ist ein umstilisierter Solovej Budimirovit (vgl. Sbornik K. Danilova, S.91.). Die Lippen bzw. der Mund sind in der russischen Folklore "glun". Der Vergleich "... Cto malina" 1st der Form nach archaisierend und dem Inhalt nach in der Folklore ungewrhnlich.

S.76/15 Das "Kak..." dieses Satzes ist normal, denn es leitet einen Nebensatz ein; "zavidel" lst umgangssprachlich.

S.76/16 In der Form "dobru molodcu" sollen der Gebrauch der Kurzform des Adjektivs und der Dativ den Stil der russischen Folklore nachahmen.

S.76/17 Diese Wendung findet man in Märchen öfters.

S.77/1 Das 1st die typische Metamorphose im Mărchen. Vgl. Puskins "Skazka o care Saltane": "I carevnoj obernulas'."

S.77/2 Blok imitiert die Baline uber Solovef Budimirovid. Dieser "podchvatyval devicu za bely mucki" (Sbornik $\mathrm{K}$. Danilova, S.9ff., 2.180). Dasselbe Bild finden wir in "Neznakomka", IV,74.

S.77/3 Diese Replik erinnert ebenfalls stark an die Byline uber Solovej Budimirovič. Vgl. Sbornik K. Danilova, S.9ff., Z.98ff.: Solovej lieB der Zapava drei Terems bauen "v višen'e" (2.118). Er legte auf ihr Bett "periny puchovyje" (2.182). "bela" ist wiederum Kurzform (Zum Bild des "Daunenlagers" vgl. die Byline "Lunaj Nastas' ja-Korolevila", Byliny I, S.286ff., 2.55f.). Das Märchen, das die Alte erzählt, ist eine freie Nachahmung der Byline Uber Solovef Budimirovic, der als Kaufmann fber das blaue Meer nach Klev kommt und dort die schöne Zapava Putjatilna freit. (Eine t"bersetzung dieser Byline steht bei irautmann, Volksdichtung der Großrussen I, S.210-213). Eine Besprechung von Bal'monts Gedichtzyklus "Žar-Ptican vom Sommer 1907 zeigt, da? Blok die Byline liber Solovej Budimirovit kannte und schätzte $(v, 140 f$.$) . Las Schwanenmotiv und andere Einzel-$ heiten stammen aus anderer Quelle. Obwohl die Stilisierung z.T. unecht wirkt, hat das Märchen seinen Reiz. 
S.77/4 Faina legt fifr kurze zeit die kaske der Halbweltdame ab. Ihr wahres wesen ist "einfach" und "kindlich". Sie gehört in die Reihe der "reinen Sfinderinnen". Die Spannung zwischen kindlichkeit und weiblicher Schönheit wurde un die Jairrhundertwende häufig in der Symbolgestalt der tva dargestellt. "Diese Snannung von Unschuld und Silnde, die ein einziges wesen verkörpert, ist wunsch- und sngsttraù v.a. des fin-de-siècle." (Hof stätter, Symbolismus, 5.191; diese Snannung durchzieht schon den sphroditeythos: vgl. (dussee, 8,362ff.).

¿.77/5 cuss. "rolodica" (vgl, bei Blok noch II,281f.(10)) ist eifentlich die "junge verheiratete Bäuerin". In dieser Zedeutung verwendet es Nekrasov in seinem Poem "hioroz, krasnyj nos", dessen Heldin stark an die saina v.a. der Gedichte erinnert. In Nekrasovs Poen "Korobejniki", auf das 3lok in LS direkt Bezug nimit, bedeutet "molodica" dagegen "das Bauernmädchen kurz vor der lochzeit". In dieser Bedeutung gebraucht auch Blok das wort.

¿.77/6 Taina wiederholt die ت̈rzählung des könchs (vgl. S.55f.). $\$ .77 / 7$ jies ist die "richtige" Version des ä̈rchens der ilten. Jer "wackere Jïngling" wird zu einer jürchenhaften Christusfigur, an die Fainas Erlösungssehnsucht geknüpft ist. ser sunkretistischen Verschnelzung Christi nit Gestalten der griechischen oder nordischen ivthologie (vgl. dazu Jost, Iiterarischer Jugendstil, S.21f.; iocke, ianierismus in der Literatur, S.236ff.) entsoricht in Bloks LS die Syntnese von mussischem "dobryj molodec" und Christus. Die "Jesusninne" der Faina erklärt sich aus ihrer Herkunft aus dem Milieu des Raskol. Die "altgläubige" Erlösungserwartung verbindet sich mit der Frihlingssymbolik (vgl. dazu Iriomphe, Sous le signe du nrintenps, in: Kes, Bd.38, S.197-206), die auch in der ت̈rzählung des Mönchs anklingt und auf die Frlihlingssyjolik bein sufbruch Gernans an Palmsamstag verweist (zur Verbindung von Frihlings- und Cstersymbolik vel. Zorstner, welt der symbole, S.119f.). Las iarten der Faina $a \cdot n$ luß nit der Christuserscheinung, spielt in der fleichen nuthischen zeit wie der sufbruch Germans. 
Zum Bild des im Boot nahenden Christus vgl. Bloks Gedicht "Kogda $v$ listve syroj 1 rzavoj...", II,263. Das hdventschiff ist ein Attribut des Saturn, des Gottes des "Goldenen Zeitalters". Im Schiff kam Apoll nach Griechenland. Das Bild des lichthellen Jinglings, der auf dem Fluß daherkommt, findet sich in der Autobiographie des ivvakum. "Und dann sehe ich ein drittes Schiff, nicht goldgeschmilickt, sondern ganz bunt, rot und weib und blau und schwarz und grau, - des Jenschen Verstand kann seine Schönheit und seinen Wert nicht fassen. Iin heller Jingling, (junosa svetel), am Heck sitzend, steuert. Es konmt auf der Volga auf mich zu, als wollte es mich verschlingen..." (Gudzij, Chrestomatija po drevnej russkoj literature, S.492). Bei avvakun ist das Schiff Symbol fllr sein Lebensschicksal. Er greift auf das uralte Bild von der "Schiffahrt des Lebens", auf die Idee vom "Lebensschiff" zurfick. Dieses Bild verschmilzt im Christentum mit dem Bild vom "Schiff der heiligen Kirche", das von Gott, Christus und dem Heiligen Geist gelenkt wird. (Vgl. Forstner, welt der Symbole, S.437f. und das kirchenlied "Es kommt ein Schiff, geladen..."). Die christliche Schiff-Sumbolik war v.a. im russischen Sektenwesen lebendig. (Filippov, kl jujev, S.16ff.). Das kiärchen der slten in der rendung, die ihm Faina gibt, ist also eine Legierung aus ganz verschiedenen ilementen.

S.77/8 Faina spielt auf inr Leben im Dorf an, von dem der liönch im 2.Bild (vgl. S.55f.) berichtete. Irotz ihrer ïrlösungssehnsucht ist sie die verkörperte îreiheit (wie die weitseele).

S.77/9 Vgl. die Erzählung des Mönchs (S.55/5). Der Fluß wird in der Bibel häufig als Symbol des Lebens gebraucht (Joh.7,38; Cff.22,1). ir gehört zu den zahlreichen Sinnbildern, die die Bibel aus dem Naturphänomen des fließenden Wassers entwickelt. (Vgl. Forstner, welt der Symbole, S.73ff.) In Bloks Gedicht "Vot reka..." (II,330) ist der eistreibende lius symbol aufbrechender Lebenskraft (ähnlich in "Vozmezdije, III,314, 2.389395. mit Bezug auf die Geschichte RuBlands; vgl. a. in 
Faust I, Csterspaziergang).

j.77/10 Das "Liebesorakel durch Spiegelschau" ist im ḱberglauben weit verbreitet. Das junge Hädchen erblickt dabei im Spiegel inren zukfinftigen liann. In Deutschland fand das Crakel häufig in der Silvesternacht statt, in kußland normalerweise am Vorabend von ípiphanias (krešcenije). Russ. "na Svjatkach" ist die Zeit vom 25. Dezember bis 6 . Januar, die in bäuerlichen Jahreszyklus besondere Bedeutung hatte. (Im deutsch-germanischen Brauchtum heißt diese Zeit "die zwölf lächte" oder "Zwölften"). Besonders typisch waren die verschiedenen Ratespiele, die von Liedern begleitet wurden (vgl. Poèzija krest'janskich prazdnikov, S.16ff., S.131ff.; gegentlber 5.65 ist ein Spiegelorakel abgebildet, das oroße Ähnlichkeit mit der Szene im IS hat). Blok kannte diesen Brauch seit seiner Jugend. Bei einem Besuch an ieujahr 1902 in Boblovo, in Haus seiner späteren Frau, fand offenbar ein solches Crakel statt (VEl. VII, 345 und I, 155 mit tinm. S.598). Das Gedicht "iot' na iovyj god", I,154 vom 31.

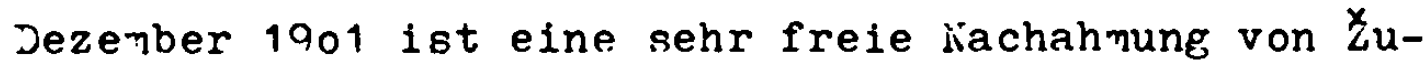
kovskijs Ballade "Svetlana", der jachiichtung von Birgers "Lenore". In Kukovskijs jallade wird das i.ahrsagen a Vorabend von Epiphanias geschildert. (Vgl. Ischižewskij, iussische Literaturgeschichte I, S.36).

$0.77 / 11$ Das ist ein ungeschickter Hinweis darauf, daR Faina als Bauernmädchen ärmer war als in sufenblick.

\$.78/1 Bis hierher ist Faina das abergläubische kädchen, das den im Spiegel erscheinenden Bräuticam mit einem christlichen Gegenzauber bannen will. Die inendung "S nami krestnaja sila" schrieb 31 ok in sein iagebuch als eine irt Gegenzauber gegen einen "schrecklichen" sberglauben, der in Landvolk von Jachmatovo lebendig war. (VII,49, تintrag vom 26. Juni 1902; vgl. VII, 38 und V,357). I. IS soll dieser susdruck die magische Religiosität des Bauernmädchens kennzeichnen, in "koza i krest" benutzt ihn der bretonische Fischer. Offenbar galt er filr Blok als besonders "volkstinlich" (vgl. IV,194). 
S.78/2 Die mag18che Atmosphare 18t durchbrochen. Faina hat German erkannt. Sie lot wieder "femme fatale".

$5.78 / 3$ In Zorn ze1gt sich inr leidenschaftlicher Charakter (vgl. S.75/3).

S.78/4 Vgl. S.68/2, Monolog Germans, letzte Zeile.

S.78/5 Die Antwort der Faina entspricht fast wortlich einer Stelle in Dostojevskijs "Idlot". Dort sagt Nastas'ja P1l1ppovna zu Myrkin: "Lebe wohl, Purst, zum ersten Mal seh $1 \mathrm{ch}$ einen Menschen!" (1.Band, 1.Te1l, XVI). Vgl. S.69/3.

S.79/1 Vgl. S.85/9.

S.79/2 Die Augen sind auch hier wieder Ausdruck des gelstigen Wesens der Heldin. Wichtig 1st die geheime Traurigke1t, Hinwels auf die ungestilite sehnsucht.

German erhebt sich in dieser szene schon auf das Niveau der Faina. Dennoch steht die eigentliche Begegnung noch aus, denn Faina blelbt in der Rolle der Halbweltdame verhaftet.

S.79/3 Dieses Motiv stammt aus Fainas "Lied des Schicksals" (S.67, str.1 und str.2).

S.79/4 German $18 t$ das elgentliche Wesen der Faina aufgegangen, das Im 3.B1ld von der áuBerlichen Hulle der Halbweltdame verdeckt war.

S.79/5 Diese Bemerkungen sind rätselhaft, wenn man sie auf die Halbweltdame Faina bezieht. Sie werden verstädlich, wenn man in Faina die Verkörperung Rublands sieht. Die Liebe zu Rubland naus der Fernen ist ein Vormurf, den Belinskij gegen Gogol's "Ausgewählte Stellen aus dem Briefwechsel mit Freunden" in seinem berilhmten Brief vom 15. Jul1 1847 aus Salzbrunn erhob. Belinsk1j bezog sich dabel auf die lyrische stelle in Gogol's "Toten Seelen", die Blok in gestraffer Form als zweites Motto des LS wählte. (Vgl. "Rus!! Rus!! vizu tebja, 1z mojego Cudnogo, prekrasnogo daleka tebja vizu:..."; Gogol'. Sobranije sočlnenij, Bd.5, S.258). Gogol'stellt in dieser Passage dem öden, wlisten, armen RuBland die uppigen Iandschaften und Relchtumer des Westens gegenuber. Doch gerade das öde Rubland verzaubert ihn. 
(Blok hat in seinem Motto diese Gegenuberstellung weggelassen; vgl. S.43/3). Belinskif warf Gogol' vor, in der Ferne die Verbindung mit RuBland verloren $z u$ haben und sich ein Bild von Rußland zu machen, das nur in seiner Phantasie existiere.

Bloks RuBlandmythos stutzt sich weitgehend auf Gogol'. Neben den "Toten Seelen" sind es gerade die "Ausgewăhlten Stellen", auf die er sich gerne beruft. Er hat Belinskif nicht zugestimmt (vgl. VI,27), erhob aber den Vormurf der "Liebe aus der Ferne" gegen die zeitgenössische Intelligenz. Demgegenüber wollte er RuBland kennenlernen und lieben, wie es "aus der Nähe" war, mit all seinen dunklen Seiten. "Man muB RuBland lieben, man muB "RuBland in alle Richtungen durchfahren", schrieb Gogol' vor seinem Tod..." (V,325. Vgl. Gogol', aaO, S.292, 294; (tberschriften). Diese Liebe muB RuBland als Ganzes umfassen $\left(v, 325 f_{.}\right)$.

Am prägnantesten kommt diese Liebe "aus der Nähe" in Bloks Gedicht "Grełit' besstydno, - neprobudno..." zum Ausdruck (III,274; der ursprüngliche Titel war "Rossija"). Blok nalt das Abscheu erregende Bild eines russischen Barbaren, dessen Leben eine Kette von Unzucht, Rausch und Heuchelei ist, doch er schliebt:

"Doch auch in dieser Gestalt, mein RuBland,

Bist du mir lieber als alle anderen Länder." (Vgl. Kluge, Westeuropa und RuBland, S.216. Tschizewskif hat in seiner ausgezeichneten Prosaubersetzung des Gedichts die für Blok entscheidenden SchluBverse weggelassen; vgl. Tschižewskij, Russische Geistesgeschichte II, S.155).

S.79/6 Im russischen Text steht: "Ja - sluCajnaja". Die Assoziationen, die hier geweckt werden, kreisen erstens um "Zufallsbekanntschaft", "Dirnenhaftigkeit" und zweitens um "Unmotiviertheit des Charakters", "Sprunghaftigkeit". Blok gebrauchte das Abstraktum "slučajnost'" bel der Charakterisierung der Natal'ja Nikolajevna Volochova (Zap.kn., 94; Eintrag vom 20. April 1907). 
S.79/7 Der russische Text 1st prägnanter als die Obersetzung ("Ja - sluðajnaja. - Ty - večnaja.").

S.79/8 Vgl. S.57/2. Obwohl hier das hotiv "Faina als gefallener Stern" (zvezda padutaja) deutlich ausgesprochen ist, wirkt die Stelle nicht peinlich. Faina ist hier die "Neznakomka" des Dramas (zweite Erscheinung, IV,84f.).

S.79/9 Sie ist die Domina, er der Sklave.

S.79/10 Faina 1st hier wieder die Ànrodite pandemos, die Wieltseele, die sich den Verlockungen der Welt hingegeben hat.

S.79/11 Die Anhrodite pandemos-Hypostase ist nur äußerliche Hille. In Wahrheit sucht Faina eine echte, erlösende Liebe. In der Replik der Faina verbindet sich, auf eine ffir Blok und seine Zeit typische leise, Erotik und Religion.

S.80/1 Das "Einfache" in Germans Augen erinnert wieder an den Fflrsten äyskin, den gerade seine entwaffnende Einfachheit zum echten lienschen macht und der wegen dieser Einfachheit von seiner Umgebung "Idiot" genannt wird.

S.80/2 Es sind die "engen Schlangenaugen" des "Lieds des Schicksals" (vgl. S.67, Vers 1 und 2).

S.80/3 Fainas KuR ist der Kuß des Vampirs, der Sphinx. (Vgl. Heines Gedicht "Das ist der alte Hörchenwald!" F. $v$. Stucks berihmtes Bild "Der Kuß der Sphinx" entspricht auffallend den Kuß der Faina mit der passiven Haltung Germans.).

S.80/4 In den letzten worten des 4 .Bildes ist Faina wieder ganz die stolze, verlockende und sich verweigernde "femme fatale". Die Begegnung mit German flbersteigt eine normale Hetären-Liebe. Faina erkennt in German den senschen, doch dieser ist in seiner Passivität noch nicht im Stande, sie zu erlösen.

Dieses Bild fehlt in $F 1$. Seine friheste Fassung hat in H1 die Datierungen "In schopferischem Vergessen - 29.XII.07" und "Und nochmals am 21. Januar." (Hedvedev, Dramy i poemy, S.71). Das Bild entstand demnach genau ein Jahr nach dem Gedichtzyklus "Snežnaja maska" gleichzeitig mit einigen Gedichten des zyklus 
"Paina". Der erste, satirische Tell des Bildes enthalt in M1 einige zusätzliche Repliken, die jedoch am Gesamtcharakter nichts andern (Medvedev, aao, S.721.). D1e Ansprache des Mannes mit Brille schlleBt in M1 mit den Worten "Paina, das ist RuBland selbst" (Faina - eto sama Rossija; Medvedev, aao, S.73). Dieser deutliche Hinwels auf den symbolischen, besser allegorischen Gehalt der Gestalt der Faina hat seine Entsprechungen im letzten Bild in $M 1$ und in mehreren passagen in $\mathrm{F} 1$. Blok hat in $\mathrm{F} 2$ darauf verzichtet, in dieser deutlichen Heise Faina mit RuBland gleichzusetzen. such der SchluB dieses Bildes weicht von F2 etwas ab (vgl. iledvedev, Dramy 1 poèmy, S.73). 


\section{FONPTES BIID}

Der Schauplatz des Geschehens im 5.Bild des IS 1st das russische Land, und zwar zunächst das toergangsgeblet von stadt und Land und am SchluB des Bildes ein mythisches RuBland, das stark an das Bild erinnert, das Kirejevskif vom "heiligen RuBland" gibt, dem unendlich velten, von unzähligen einsamen klöstern bedeckten Land. 1)

Bloks russisches Land ist ein mythischer Raum, der sich souverän einer orientierung an der Realitkit entzieht. Das zeigt der Vergleich von Bloks RuBland-Gedichten mit Belyjs Gedichtzyklus "Pepel" (Asche, 1909). Beide Dichter hatten die mystisch-hochGespannte Atmosphire inres ersten Gedichtbandes verlassen, $\left.{ }^{2}\right)$ waren in der GroBstadt dem Schrecken des Kapitalismus begegnet und hatten gehofft, im russischen Land eine den Ursprüngen noch nicht entfremdete Lebenssphäre zu finden. ${ }^{3)}$ Belyj hatte jedoch sehr bald die Unvereinbarkeit seiner Hoffnung auf ein dionysischurtümliches RuBland der "grünen Flur" mit dem wirklichen Zustand des russischen Landes gesehen, das wie die Stadt vom Kapitalismus verseucht war. ${ }^{4}$ ) Die Ähnlichkeit von Bloks RuBland-Gedichten und Belyjs Gedichtband "Pepel" ist augenfälifig.

"...ihre lyrischen Themen sind ähnlich: das dunkle, arme, schicksalvolle Land, die endlosen Weiten, die elenden Hutten, das vagabundierende und heimatlose Element."5)

Belyj jedoch ist erschiltert von der Armut und ode, der trostlosen Verkommenheit des russischen Landes und dem ausweglosen Elend seiner Bewohner. Seine Liebe zu RuBland lst die eines Empörten, und seine Gedichte erinnern in ihrem anklagenden Ton an Nekrasov. 6)

1) Kirejevskij, ther das Wesen der europäischen Kultur und ihr Verhältnis zur russischen, in: Tschižewskij-Groh, Europa und RuBland, S.278.

2) Belyj, Zoloto $v$ lazuri bzw. Blok, Stichi o Prekrasnof Dame,

3) Bely j, Lug zeleny $j$ (Die griine Flur, 1905); Blok, Bezvrenen'e (zeitiosigkeit, 1906), Einleitung zum 7.Bild, S.403ff.

4) Vgl. Einleitung zum 1.Bild, S.155f.

5) Mocul'skij, Belyj, S.126f.

6) Vgl. das Motto zum Gedichtband "Pepel" in: Belyj, Stichotrorenija, S.157. 
Bloks RuBland ist eine mythische Wesenheit, eine "lyrische Größe" 1) die nur "in Sehnsuchtsträumen" (v mectach) ${ }^{2}$ ) existiert, 3) die Transposition seines Mythos vom "Ewig-Weiblichen" in elne räumliche und geschichtliche sphäre.

Bloks Mythos vom "Ewig-Weiblichen" entwickelte sich in Abhängigkeit und Auseinandersetzung v.a. mit der Sophlenmystik VI. Solov'evs. ") Der philosophische Gehalt von Bloks Mythos wird besonders in seinem Jugendtagebuch von 1901-02 und in seinem Briefwechsel mit Belyj, der dichterische im Vergleich der "Gedichte von der Schönen Dame" mit den späteren Gedichtszyklen deutlich.

Bloks Jugendtagebuch enthält zahlreiche ÄuBerungen iber den Mythos vom "Ewig-Welblichen", in dessen Bann nach seiner Meinung nicht nur Tjuťev, Fet, Polonskij und Solov'ev, sondern auch er selbst und dariber hinaus jeder echte Kinstler steht. 5) Blok wollte diesen Mythos in der Philosophie, Theologie, schönen Literatur und in den Religionen aufspilien. 6) Das erklärt auch den synkretistisch-hvbriden Charakter der Darstellung, die Blok von den Grundlagen seines Weltbilds gab. 7)

Nach Bloks Auffassung durchläuft das mytholog1sche lieltverständnis zwei Stadien. Die "àsthetische Mythologie" umfaßt das (griechisch-römische) Heidentum, die "ethische Mythologie" das "alte", historisch gewachsene Christentum, das zwar in "Andeutungen auf das Antlitz des Logos" die offenbarung der Ankunft des Gelstes enthält, dies aber in 1rdischer, verdunkelter Weise. Die Mythen lassen die himmlische Wahrheit auf der Erde nur unvollständig durchscheinen. ${ }^{8)}$ sie sind ihrem wesen nach gedoppelt

1) VIII,289, Brief an seine Mutter vom 19. Jun1 1909.

2) VIII,283, Brief an seine Mutter vom 7. Ma1 1909.

3) MoXui'skij, Belyj, S.127 und Chmel'nickaja, Poez1ja A. Belogo heben glelcherwelse Ähnlichkeit und Unterschied in Bloks und Belyjs RuBlandgedichten hervor.

4) $\mathrm{Vgl}$. Kluge, Westeuropa und RuBland, S.37ff.

5) VgI. VII, 25, 29ff.. V.313.

6) Vgl. VII,48.

7) VII, 48-52

8) Blok sagt "nachahmen", VII,50. 
wie die Erde selbst, die in ihrer geschlechtlichen Bipolerität das entstellte spiegelbild des Himmels ist. Die tberwindung der Bipolarität der Erde, die Synthese von "Schön" und "Gut" zu der höheren, einheitlichen "Wahrheit" und damit der sprung aus der Sphäre des Mythos in die der Religion wird von Blok als endzeitliche Vermählung von "Geist" und "Braut", 1) als Erscheinen des aus dem Osten kommenden Messias vor der bangenden Weltseele dargestellt. Diesen "Prozeß" erwartete er fiir die nahe Zukunft. Die Unterscheidung von Mythologie und Religion und die christliche Einkleidung der endzeitlichen Hochzeit erwecken den Eindurck, als käme Blok der Solov'evschen Sophienmystik ziemlich nahe. Doch sind Bloks Aussagen iber den Logos, den Geist, den von Osten Kommenden so vage, daß sie sich bei genauem Hinsehen nur als schattenhafte Reflexe einer theologisch untermauerten Sophienlehre erweisen. 2)

Die Aufzeichnungen des Jugendtagebuchs sind Bloks einziger Versuch, seinen Mythos vom "Ewig-Weiblichen" im Zusammenhang darzustellen. Schon in seinem Briefwechsel mit Belyj verzichtete er darauf, seinen Mythos zu entwickeln.

Der Briefwechsel zwischen Blok und Belyj kreiste anfänglich um die Frage nach der Qualität des Weltprinzips, des Urgmunds des Seins, das nach Belyjs Ansicht einen personalen Aspekt in der als weibliches Wesen aufgefaßten "Weltseele" und einen noumenalen Aspekt als "Gelst der Musik" hat. "3) Belyj hot gegenüber

1) VII,50; Blok zitiert Matth. 19,5; Eph. 5,32; Off. 20,17.

2) Bloks ganze Darlegung ist antinomisch. Einmal ist die "Wahrheit" das Urspriinglich-Himmlische, das $81 \mathrm{ch}$ auf Erden nur verzerrt, gedoppelt, in "mythologischer" Brechung widerspiegelt. Zum andern soll die "Wahrheit" aus der Synthese von "Gut" und "Schön" erst entstehen (voznikat', VII,51), nicht etwa wiedergefunden werden.

3) Belyj bezeichnete die "Musik" als "Symbol der seele des weltelements" (VIII,563, Anm. 1 zu Brief 30), der Weltseele. Ich kann Kluge, aaO, S.91 nicht ganz zustimmen, wenn er als Thema der ersten Briefe zwischen Blok und Belyj die Frage nach dem mehr oder weniger noumenalen Charakter des "Geistes der Musik" nennt. Entscheidend fiur das Verständnis des Briefwechsels ist m.E. die enge Verklammerung von "Musik" als dem abstrakten und "Weltseele" bzw. "Ewig-Weiblichen" als dem personellen Aspekt des einen Urgrunds der Welt. Diese Verklammerung ist schon angedeutet, wenn Blok in seinem Jugendtagebuch von der "Philosophie, Musik und Liebe" Solov'evs und Fets spricht, wobel er sich auf Aussagen Plotins iber die Rilckkehr der seele zum Ur-Einen bezieht (VII,37). 
Blok die Zwienatur der Weltseele hervor:

"Die Weltseele ist ein gedoppeltes Wesen" (VI. Solov'ev). Wenn Sie Christus verkörpert, ist sie Sophia, Strahlende Jungfrau; wenn Sie Christus nicht verkörpert, - Mond jungfrau, Astarte, Feuerglthende Hure, Babylon."1)

Die Musik als Spiegel der Weltseele ist wie diese gut oder böse. Belyj hat den gedoppelten Charakter der Weltseele - und folglich auch des "Geistes der Musik" - in Anlehnung an VI. Solov'ev stark betont. ${ }^{2)}$ Seine heftigen Angriffe gegen das damals modische dekadente Gerede vom "Geist der Musik" und der allgemeinen Wagner-, Strauß- und Debussy-Begeisterung ${ }^{3)}$ wurden von der Erkenntnis bestimmt, daß Blok in zunehmendem Maße die Fähigkeit zur "Unterscheidung der Geister" verloren hatte. Während nämlich die ethische Ausrichtung in Belyjs Auffassung von der Weltseele nicht verloren ging, löste sich Blok von der dogmatischen Wertung der Weltseele als entweder sophianisch-gut oder luziferisch-böse schon in seinem Brief an Bely $j$ rom 18. Juni 1903. Dieser Brief Bloks war die Antwort auf die drängenden Fragen nach dem Wesen der "Schönen Dame", die Belyj an inn gerichtet hatte:

"Ist sie filr Sie die Weltseele oder eine bestimmte Person? ...Warten Sie auf Ihr Erscheinen vor der ganzen Welt, einer Gruppe von Personen, einer einzelnen Person? Wie verbinden Sie das Geffinl von ihr mit der religiös-dogmatischen Lehre der orthodoxen Kirche? Wie deuten Sie die heidnischen Mythen tber sie? :.elche Beziehung hat sie nach Ihrer Meinung zur Mutter Gottes, zu Christus, zur Frage nach dem Weltende?"1)

Die Fragen Belyjs zeigen, daß er den privaten, mehr gefiahlsnäßig erfaßbaren als durch den Verstand erschließbaren Charakter der "Schönen Dame" Bloks erkannte. Vor allem war es aber die Frage nach der erotischen Qualität der "Schönen Dame", die Belyj beunruhigte, und die er im Rifckgriff auf die mythologische

1) Blok-Belyj, Perepiska, S.9.

2) Wichtig ist Belyjs Brief vom 6. Januar 1903, Perepiska, S. 8ff.; dazu VI. Solov'ev, Stichotvorenija, S.XI-XIII.

3) $\mathrm{Vgl}$. Belyjs Aufsätze "Brjusov, poèt mramora 1 bronzy" in: Arabeski, S.448-453; "Na perevale Vl. Protiv muzyki" in: Vesy, $1907, \mathrm{Nr} .3 . \mathrm{S} .57-60$.

4) Perepiska, s.32f. 
Gestalt der Astarte ${ }^{1)}$ an Blok stellte:

"Wie schlingt sich um sie das Bild der Astarte? Kann es einen Unterschied zwischen einer geistigen Astarte und Artemis geben?"2)

Belyj befurchtete, daß in Bloks "Schöner Dame" die herbe Jungfräulichkeit der Artemis von der alles erfassenden Sinnlichke1t der Astarte besiegt wirde. Bloks Antwort ${ }^{3)}$ zeigt, wie berechtigt Belyjs Fragen waren, wie wenig aber ihre Eindeutigkeit dem rein gefihlsmäßigen Verhältnis Bloks zur "Schönen Dame" gerecht wurde:

"Fruher dachte ich ofter iber sie nach als jetzt. Jetzt immer weniger und ergebnisloser...4)

Ich fihle sie am haufigsten wie eine stimmung. Ich denke, man kann sie erschauen, doch nicht in einer Person verkörpert... Nur fluchtig kann man gleichsam Ihren Schatten in einem anderen Gesicht erbilicken. Das schließt nicht die Träumereien uber sie als keltseele aus, denn die Welt ist fiur den Mystiker (oder für den, der sich im Zustand des Mystikers befindet) näher, als das Volk; das Ganze ist verständlicher, als die Teile; der Makrokosmos (die Welt), wie auch der Mikrokosmos (die Person) sind năher, als alle dazwischenliegenden Glieder (Gesellschaft-VolkErdbail)."5)

Diese Passage enthält die wesentlichen Aspekte von Bloks mythischem Weltverständnis. Blok weicht allen Versuchen einer spekulativen Bestimmung des Fesens der "Schönen Dame" aus. Auch ein Begriff wie "Weltseele", der in der romantischen Philosophie und in der Sophiologie Vl. Solov'evs eine einigermaßen rational umgrenzbare Bedeutung hat, ist bei Blok nur ein Behelfswort. Wichtig fiur die Bewertung von Bloks soäteren Aussagen iber "Volk" und "Intelligenz" sowie über sonstige Fragen des volitischen Geschehens ist, daß die zwischen Mikrokosmos und Makrokosmos liegenden Kategorien unklar und im Grunde auch unwichtig bleiben und ihren Wert nur von den beiden End nunkten her erhalten.

1) Die Astarte od. I ztar wurde von den Griechen mit der Aphrodite gleichgesetzt, da sie ebenfalls alle Sphären des Weiblichen unfaßte, vgi. S.48/12. Wenn Belyj die semitische Astarte der griechischen Artemis gegeniberstellt, betont er den Gegensatz von triebhafter Sinnlichkeit und jungfräulicher Reinheit. Die Astarte-Aphrodite entspricht völlig Bloks dionysischem "Ewig-Weiblichen"; vgl. schon in nuce VII,50.

2) Perepiska, S.33.

3) Perepiska, S.34ff. Brief vom 18. Juni/1. Juli 1903 fehlt unverständlicherweise in VIII.

4) Perepiska, S.34.

5) Perepiska, S.35. 
Gegeniber der Beziehung Person - Kosmos, dem Verhältnis des "Ichs" des Mystikers zum All sind seine Beziehungen zu "Gesellschaft", "Volk". "Erdball" etc. von sekundärer Bedeutung, und sie ordnen sich immer in das Kräftefeld seines kosmischen Weltgefihls ein. Bloks "Personalismus", d.h. die Verdichtung pluralistischer Phänomene wie "Volk", "RuBland", "Revolution" etc. in einer Person"), sowie sein "Kosmismus", d.h. die Ausweitung aller Phënomene in kosmische Dimensionen, sind Konstanten, die nicht nur sein dichterisches Werk, sondern auch seine Publizistik bestimmen.

Im Gegensatz zu Belyj löste Blok seine Auffassung von "Ihr" aus jeder religiös-dogmatischen Bindung:

"Christus ist immer gut, bei Ihr jedoch ist das nicht wesentlich, denn das "Unvergängliche Iicht der Neuen Göttin"2) ist weder gut noch böse, sondern mehr."3)

Die Jungfräulichkeit verbindet die "Schöne Dame" zwar mit der vutter Gottes, doch bedeutet das keine volle Identität. Ihr wichtigstes Kennzeichen ist ihre enge Verbindung mit der Vorstellung vom Weltende. Hier steht Blok im Banne von Solov'evs apokalyptischen Ahnungen.

Die Frage nach den Verhältnis der "Schönen Dame" zu Astarte, in der Delyjs Sorgen sich an klarsten wiederspiegeln, versucht Blok mit folgenden Sätzen zu beantworten:

"Astarte driickt sich meistens an den beiden Extrempunkten des menschlichen Daseins aus: in der raffinierten sexuelien Sinnlichkeit und in der raffinierten Dialektik des Kopfes... Sie vertreibt die eine wie die andere Sinnlichkeit. Astarte ist "beweglich", da sich das eine des oben Gesagten in Blitzesschnelle ins andere verwandeln kann. Sie ist unbeweglich. Das ist eines ihrer wichtigsten Merkmale Twenn Sie so wollen, kann als Symbol die Vielfarbigkeit der Astarte und Ihre synthetisierende Einfarbigkeit gelten)."4)

In Bloks Absage an alle spekulativen Versuche, dem Geheimnis der "Schönen Dame" auf die Spur zu kommen, war ein filr den nur von Spekulationen lebenden Belyj völlig unhaltbares Prinzip der Welterfahrung enthalten, das des Mystikers, der ohne religirise Bindung ein nur "intuitives Wissen"5) von Ihr besaß.

1) Vgl. II,324 "Deve-Revoljucii". Bloks "Personalismus" ist romantisches Erbe.

2) Blok zitiert VI. Solov'evs Gedicht "Das Ewig-Weibliche".

3) Perepiska, S.35.

4) Perepiska, S.36.

5) Perepiska, S.36 
Als einziges, was in der Gestalt der "Schönen Dame" an Sicherem ibrig bleibt, kann ihre "Unbeweglichkeit" und ihre "Iichtnatur" gelten. Es differenzierten sich bel Blok zwel Prauen-Typen heraus, die im Gegensatz "weib" - "vielfarbig" und "statisch" "dynamisch" zueinander stehen. Zum Zeitpunkt,als Blok seinen Briefwechsel mit Belyj begann, verkörperte die "helle Schönheit" fur ihn noch das Wertvolle, an dessen erlösende Kraft er glaubte. Bald verschoben sich jedoch die Akzente, und die "Astarte" schob $81 \mathrm{ch}$ mehr und mehr in den Vordergrund. Das Fehlen eines unverriickbaren moralischen Kriteriums in der Unterscheidung der be1den weiblichen Archetypen, die Enttäuschung iber die "Pamsieverzögerung" ${ }^{1)}$ und die rein gefuhlsmäß1ge Einstellung Bloks zu seinen Erlebnissen machen seine Umorientierung seit etwa 1904 verständlich. Im IS hat der "bewegliche" Frauentyp in der Gestalt der Faina den "unbeweglichen" Typ in der Gestalt der Helena in den Hintergmund gedrängt.

Die Abkehr vom statischen Ideal, das in den "Gedichten von der Schönen Dame" vorherrscht, änderte nichts am myst1schen Charakter von Bloks Dichtung und fuhrte keineswegs zu mehr "Realismus". Die Frauengestalten "Neznakomka", "Sneznaja Deva", "Faina" usw. haben wie die "Prekrasnaja Dama" kosmische Attribute, v.a. den Stern, das Pneuma (Wind, Sturm) und die "Musik".

Die von Belyj an Blok gerichteten Fragen nach dem Verhältnis von Bloks "Ewig-Weiblichem" zur antiken Mythologie und zur orthodoxen Dogmatik und damit die Frage nach dem Gehalt von Bloks Mythos sind leichter zu beantworten, wenn Bloks Mythos vom "Ewig-Weiblichen" von der religionsgeschichtlich und dogmatisch gesicherten Position her beleuchtet wird, die vjat. Ivanov in der Nachfolge Vl. Solov'evs einnahm. 2) Eine Zusammenfassung der Ansichten Ivanovs enthält dessen Aufsatz "Terror Antiquus". 3) In einem religionsgeschichtlichen Exkurs deutet

1) Blok sah bekanntlich in seiner Frau die Verkörperung der "Ewigen Weiblichen" (vgl. VII,62f.). Die eschatologischen Erwartungen Bloks erfiliten sich nicht, seine Ehe marde vielmehr zu einem beiderseitigen Martyrium.

2) Vgl. dazu Stepun, Mystische Weltschau, S.236ff.; Blok waren die Ansichten Ivanovs bekannt und vertraut.

3) Der Aufsatz entstand 1909; Den Anstoß zu diesem Aufsatz gab ein Bild von I.S. Bakst mit dem Titel "Terror Antiguus". Fr ist in deutscher "bertragung wieder abgedruckt in: Iwanow, Das Alte Wahre. 
hier Ivanov den antiken Schicksalsglauben, den Glauben an die selbst Zeus und die olympischen Götter luberragende Macht des Schicksals, als Nachhall der urspriinglichen Verehrung einer allnächtigen weiblichen Gottheit, die in sich "vernichtendes Schicksal" und "gebärende Liebe" vereinte.

"Somit ist... noch ein Merkmal von altersher dem Schicksal zugeeignet: das Merkmal des Geschlechts. Ein Weib war Herrscherin uber Sterbliche und Götter. Das weibliche Prinzip murde nonotheistisch behauptet... Ein eigenartiger Dualismus war in den Grundlagen der Religion des Fatums angelegt: das schicksalhaft Weibliche wurde allem, was dem Schicksal unterworfen war, entgegengesetzt, sel es Gott oder Mensch, Mann oder Weib... Ist es nicht klar, daB die dargelegte religiöse Konzeption nicht urspriinglich sein konnte und daß die weibliche Gestalt des Schicksals nur eine Differenzierung der gehaltreicheren, vollblitigeren Idee des göttlichen Weibes als allein souveräner. als absoluter Herrscherin ist? DaB jener unvollstëndige Dualismus, von dem wir sprachen (der Dualismus zwischen Ananke-Schicksal und Aphrodite-Liebe; D.W.), nur ein abgeschwächter (lberrest eines älteren Dualismus zweier Prinzipien ist: des weiblich-absoluten und des männlich-relativen?... Herrscht nicht ilber den Götterberg, den Olymp, das Schicksal darum, well es zugleich Urania, die Himmelskönigin ist, - die höchste Lenkerin der Zeiten und Begriinderin der kosmischen Harmonie? Jede Untersuchung der Geschichte weiblicher Gottheiten fuhrt uns auf die Spuren eines urspriinglichen Thely-Monotheismus, eines weiblichen EinGott-Glaubens, unter welchem Namen immer sich die vielnamige Göttin verbergen möge, sei es unter dem Namen der Artemis, der Aphrodite, der Astarte, der Magna Mater, der Mylitta, der Anaitis oder der Isis. Alle weiblichen Götter-Personen... sind verschiedene Gestalten einer Götin, und diese Göttin ist das weibliche Weltprinzip - das Eine ins Absolute gesteigerte Geschlecht. Somit ist das Schicksal, der Gegenstand des antiken Schreckens, das Schicksal als vernichtende Macht eben jene Göttin der Liebe mit ihrem Lächeln und ihrer Taube, die wir im Vordergrunde des Bildes im Triumphe grenzenloser Lebensbejahung inmitten des Verderbens der in sie verliebten männlichen Kräfte sehen. Sie ist es, die das Männliche dem Untergang weint, und das Männliche stirbt, den Sold filr die weibliche Liebe entrichtend - stirbt, weil es der Unersättlichen nicht genilgt und vor der Unbesiegbaren sich als ohnmächtig erwiesen hat... Die gesamte männliche Energie ist unvermögend, das Maß der unsterblichen Winsche der vielgestaltigen Göttin zu erfilien, und darum richtet sie ihre Liebhaber... zugrunde. Sie richtet sie zugrunde und läbt sie von neue:: erstehen in der Hoffnung auf eine wahre Ehe... Die Grittin aber erwartet immerfort auf ihre wahre Befruchtung durch die Sonne.

Das ist die mystische Wahrheit von der Weltseele und ihrem warten auf den himmlischen Bräutigam, die sich schon jenen antiken Menschen, den Verehrern der Einen Götin erschlossen hat... Und noch eine andere mystische wahrheit erschlob sich im uralten weiblichen Monotheismus: die Wahrheit von der Jungfrau. Denn die Götin besaß gleich Helena viele Gatten, jedoch waren es keine rechtmäßigen Gatten, sondern Gewalttäter, die sich nur ihres 
Schattens und der sie umschließenden Hulle bemächtigten, die ihr Trugbild liebten und mit diesem ein gespensterhaftes Leben erzeugten. Maja liebten sie als Gattin und Mutter, aber jungeräulich und unerreichbar der ohnmächtigen männlichen Gewalttätigkeit verblieb die unberihrte Braut, die tiefste verborgene Wesenheit der Weltseele hinter jenem weiblichen Trugbild, welches Mutter der Liebe und des Fleisches, des Wunsches und der Vermehrung zu sein schien - hinter dem trugerischen Blendwerk, unter dem prächtig gewirkten Schleier der rätselhaft und 2 weideutig lächelnden Maja. Im Kultus sowohl der jungfräulichen Artemis als auch der eleusinischen Persephone erschlob sich diese Wahrheit, und sie ist in den Worten auf dem Sockel der verhullten Göttin zu Sais angedeutet - jener Göttin, die nach Herodot eine Hypostase der Jungfrau Athene war und auf ägyptisch Ne1th hieb: "Ich bin Das, was lst und war und sein wird, und kein Sterblicher und kein Gott hat je meinen Schleier geliftet".... Die Göttin von Sais war eine unvermählte Jungfrau, niemand hat sie erkannt.

Aber der weibliche Monotheismus forderte naturgemäb eine Ergänzung. Das eine Geschlecht konnte nicht ins Absolute erhoben werden, ohne daB auch dem anderen eine Apotheose zutell wurde. Glelchzeltig muBte aber das männliche Korrelat den Charakter der Relativität tragen, im Aspekt eines Prinzips erscheinen, das dem Verschwinden iberantwortet ist und den Untergang erleidet. Das männliche Korrelat der absoluten Göttin eignet sich die Zuge eines leidenden Gottes wie Dionysos und Osiris an. Martyrium und Tötung des männlichen Gottes ist das Grundmotiv der weiblichen Religionen (wie der des Dionysos)..."1)

Die liberwindung des welblichen Monothelsmus, die "Reaktion der Harmonie und Ordnung gegen das Orgiastische, der Religion der Sonne gegen die Religion des Mondes"2) in der männlich-patriarchaliechen Religion des Gehorsams und der Furcht vor den olympischen Göttern fihrte zur Unterdrickung des Weiblichen und damit zur Verschiltung der Seelenkräfte des Menschen. Im Namen des Schicksals und der "Wahrhelt der Mutter-Erde" empörten sich die Titanen und Prometheus "gegen eine gewaltsam-verninftige Ordnung und gegen elne allzu teuer erkaufte göttliche Harmonie, welche endgilitig den Göttern die Unsterblichkelt und den Menschen den Untergang bestimmte."3)

Der antike Konflikt beherrscht nach Ivanovs Heinung auch die Gegenwart. Auch heute scheint nur die wahl zwischen zwei den

1) Iwanow, Das Alte Wahre, S.57-63.

2) Iwanow, aa0, S.65.

3) Iwanow, aaO; S.68; Ivanov untermauert seine Thesen durch zahlreiche Hinweise auf die antike Mythologie und die Tragödien des Alschylos und Sophokles. Er ist sich seiner Abhängigkeit von Bacholen voll bewubt; vgl. S.63. 
antiken Verhältnissen entsprechenden Formen des Sch1cksalsglaubens zu bestehen, zwischen Determinismus und Schopenhauerscher Philosophie des blind waltenden Weltwillens. Angesichts dieses alten Dilemmas erinnert Ivanov daran, daB im Christentum eine Lösung schon längst angeboten ist, die aber allzu häufig vergessen wurde, "die christliche Auffassung der menschlichen Selbstbehauptung und die christliche Anschauung von der Weltseele."1)

In der Verbindung dieser beiden christlichen Antworten auf die "antiken Fragen des Heidentuns" spiegelt sich die gegenseitige Durchdringung von Anthropologie und Kosmologie wider, die fur die orthodoxe Dogmatik kennzeichnend ist und den Charakter der weiteren Äußerungen Ivanovs bestimmt.

Im Zentrum der christlichen Glaubenslehre steht das Geheimnis der Menschwerdung des Gottessohnes. Die christliche Anthropologie ist deshalb geprägt von der Gewißheit der Immanenz des göttlichen Vaters in seinem Geschöpf, das durch die göttliche Gnade der Menschwerdung Christi zur Gottessohnschaft berufen ist. In der Hingabe an Gott gewinnt der Mensch die Freiheit. Die Menschwerdung Gottes ist, als ein den gesamten Kosmos erfassendes Geschehen, die Ereignis gewordene Vorwegnahme der endzeitlichen Erlösung der Weltseele durch den göttlichen Logos.

"Das Äußere des Menschen, sein Leib - ist seine Erde; das ist das Weib, die Weltseele in ihm. Das, was der Mensch alltäglich sein Ich nennt, herrscht uber diese seine Erde. Aber jener, den sie als ihren Gatten und Herrn betrachtet, ist nicht ihr Gatte. Wie die Weltseele den Bräutigam im Makrokosmos sucht, so sucht die Erde des Menschen ihr anderes Ich im Mikrokosmos und erwartet das Kommen des Sohnes. Das menschliche Ich wird zum Sohne nur durch die Hingabe seines Willens an jenes ubersinnliche, jenes transzendente Licht, welches der Vater in inneren Himmel des Menschen ist. Wenn der Wille des menschlichen Ich Sein Wille geworden ist, dann wird im Menschen Christus geboren und dann ist er wüdig. Menschensohn zu heiBen. Dann hat die Erde ihren Bräutigam gefunden und der Menschensohn seine Braut, und dann ist das Gebet in Erfullung gegangen, der Wille des Vaters solle nicht nur im Himel sondern auch auf Erden geschehen."2)

In der Fleischwerdung des Logos ist die Sehnsucht der weiblichen Allgöttin nach Erlösung in Erfilllung gegangen, denn hier wurde sie nicht durch einen von ihr abhängigen und aus ihrer eigenen

1) Iwanow, aao, S.71.

2) Iwanow, aao, S.72. 
Machtfille lebenden Gott erlöst, sondern durch den eingeborenen Sohn Gottes.

"Die Notwendigkeit ist der Leib der Welt. Jene antiken Menschen, die in den ehemaligen Erdumwälzungen zugrunde gingen, verehrten das Fleisch, das kosmische Weib, und die Göttin spie solche Männer aus, die ihrem Wunsche nicht entsprachen. Denn sie waren gewalttätig aber ohnmächtig. Sie waren des Welbes Söhne und kannten nur dieses, den von der Mutter empfangenen Leib. Sie aber trachtet nach Samen des Logos. Ihr Sinn steht nicht nach denen, die von "Fleischeslust", sondern nach denen, die von Gott gezeugt murden. Von solchen Männern wird sie ihr neues Reich empfangen."1)

Nicht im GenuB des aus inr selbst geborenen Fleisches, nicht im ewigen Wechsel von Hoffnung auf die erlösende Kraft des Sinnenreizes und Enttäuschung an seiner Unzulänglichkeit konnte die weibliche Allgöttin wahre Befreiung finden, sondern in

"jener jungfräulichen Ehe des Logos und der Weltseele, deren absolute Verwirklichung der christliche Orient Sophia nennt und bald in der Gestalt des fleischgewordenen Wortes, bald in der Mutter Gottes anschaut und anbetet; die Erde als das Weib der Apokalypse, bei dem Empfang des Bräutigams auf dem Monde stehend, mit Sternen bekränzt, mit der Sonne bekleidet - das sind die Symbole des im Christentum geoffenbarten Ewig-Weiblichen und Geistig-Männlichen. Das Eindringen in dieses Mysterium, als Frucht innerer Schau und einer nur dem reinen Herzen vorbehal tenen Erfahrung, vermag allein uns von dem antiken Schrecken gänzlich zu hellen, welcher bis heute auch der unsrige ist."2)

Hinter der manchmal allzu synkretistischen Einschmelzung antiker Mythologien in die christliche Glaubenslehre bleiben bei Ivanov $z$ wei entscheidende Inhalte unangetastet, die seine insichten als wahrhaft christlich ausweisen: der Glaube an Gott-Vater und an das Mysterium der Inkarnation. Die in Christus Ereignis gewordene Einstrahlung des Logos in die Finsternis der Welt sprengt die Mauern der antiken Religion des Fatums und fiihrt die schon im antiken Schicksalsglauben geahnten Wahrheiten ins Licht einer geoffenbarten Gewißheit. Die Verwurzelung Ivanovs im christlichen Glauben zeigt sich besonders darin, daB er noch weniger als der Mystiker Vl. Solov'ev in Gefahr gerät, "Sophia" und "Ewig-Weib-

1) Iwanow, aao, S.73f.; Die im letzten Satz dieses Zitats latente Relativierung der Einmaligkeit Christi entspringt der Vermengung von Anthropologie und Kosmologie. Die Idee vom Menschen als dem Erlöser der Natur ist in ihrer kosmologischen Dimension Hybris.

2) Iwanow, aac, S.76. 
1 iches" zu vermischen. 1)

Ist bel Invanov die antike Mythologie vom Iicht der christlichen Heilsoffenbarung beleuchtet, so verbinden sich bei Blok antike und christliche Elemente zu einem hybriden Gemenge, das stark mit morbider fin-de-sidcle-Erotik angereichert ist. Bloks "EwigWeibliches"2) ist die Schicksal und Liebe, Tod und Leben in sich vereinigende Allgöttin, die rach Meinung Ivanovs am Ursprung des antiken Schicksalsglaubens steht. In thm verschmelzen Dirnenhaftigkeit und Jungfräulichkeit, Allmacht und Erlösungssehnsucht. Die Bipolarität, die nicht aufgelöste und nicht auflösbare Spannung von Gut und Böse unterscheidet das "Ewig-Welbliche" Bloks von der gedoppelten Weltseele Solov'evs und Ivanovs, die durch die Einwirkung der göttlichen Gnade zur Sophia verklärt wird. Das "Ewig-Weibliche" ist in seiner Verbindung von Allmacht und Erlösungssehnsucht Verkörperung des elementaren Urgrurds des Seins, das einerselts den harmonischen Kosmos aus sich gebiert und dem andrerseits der Kosmos entrungen werden muß. 3 ) Es unschließt "Ilcht" und "Finsternis". Bloks Interpretation von VI. Solov'evs Formel "Svet iz t'my" (Iicht aus Finsternis) 4 ) zelgt prägnangt den entscheidenden Gegensatz zu Ivanov: be1 diesem Einstrahlung des göttlichen Logos in die Finsternis der welt als götliches Gnadengeschenk ${ }^{5)}$, bel Blok Entstehung des Lichts aus der Finsternis, des Kosmos aus dem Chaos als Urgeheinnis des Lebens. 6 )

1) Vgl. dazu Stepun, Mystische Weltschau, S.237f .; Solov'ev sah sich veranlaBt, im Vorwort zur 3.Ausgabe seiner Gedichte den Unterschied von Sophia und Ewig-Weiblichem klarzustellen; vgl. Solov'ev, Stichotvorenija, S.XII-XIII.

2) Blok gebrauchte den dt. Ausdruck schon 1901-02; vgl. VII, $21 \mathrm{ff}$.

3) Vgl. S. 84/15, v.a. die Zitate aus VI,161ff., Zap.kn., 132, dazu V,161. Blok ist sich dieser Antinomie in seinem Weltbild offenbar nicht richtig bewubt geworden.

4) Vgl. Solov'ev, aaO, S.112, "My sozlis' s tobof ne darom", Str.3.

5) Vgl. Iwanow, Das Alte Wahre, S.77 mit Zitat aus Joh.1, 5.

6) Vgl. Peters, Symbole der sinnlichen Wahrnehmung, S.84f. mit $\mathrm{V}, 192$, wo die Verbindung zur Lebensphilosophie offenkundig ist. 
In den "Gedichten von der Schönen Dame" dominiert "Ihre" Lichtnatur ${ }^{1)}$, doch wird zunehmend deutlich, daB sich hinter der Reinheit und Helligkeit der "Schönen Dame" die Abgründigkeit des Dunklen und der Sinnlichkeit verbirgt. 2)

Bloks Frauenideal nach 1904 ist von der Vorherrschaft des Dunklen bestimmt. Doch verbirgt sich hinter der Nachtnatur die Sehnsucht nach dem Licht, hinter der Sinnlichkeit die Reinheit. Hinter dem "dunklen Schleier" der Dirne ahnt Blok ein "zauberhaftes Ufer". die "Sonne". 3) Von der dämonischen Heldin des Märchens "Skazka o toj, kotoraja ne pojmet jeje", die den Liebhaber nach nächtlicher Umarmung verläBt, heiBt es:

"Dieses ewig nächtliche und ewig unbekannte Gesicht war unbeweglich und, nach Schlangenart filr Augenblicke ehrlich, blickten inm in die sugen ihre schwarzen und strahlenden Augen. Und schon hatte sich ihr nächtliches, nur mit den Augen strahlendes Gesicht mit dem sanften Nebel der Unnahbarkeit wie mit einem Brautschleier bedeckt."4)

Blok hat zwar in der Riickschau das Einzigartige der "Schönen Dame" und inre absolute Andersartigkeit gegenilber der "Unbekannten", der "Schneejungfrau" und "RuBland" betont, 5 ) doch findet dies im Werk Bloks keine Bestätigung. ${ }^{6)}$

Ein wesentlicher Aspekt in Bloks Mythos vom "Ewig-Weiblichen" ist seine göttliche Allmacht, die die "Schöne Dame"7) mit den späteren Frauengestalten verbindet.

1) Sogar die Lichtnatur der "Schönen Dame" ist ambivalent; vgl. z.B. I, 186, 521f., dazu Peters, Symbole der sinnlichen Wahrnehmung, S.44ff.

2) VgI. I,94, 142,151,248, 284, 299, 381, 385, 512, 523 u.a.

3) II, 185f.. "Neznakomka", Str. 11.

4) Blok, Sobranije solinenif, 4.Bd., S.141f. Besonders deutlich ist die Mischung von Sinnlichkeit und Keuschheit in Bloks "Italienischen Gedichten"; vgl. z.B. III,101, 111, 113, 116f ., $118 \mathrm{f}$.

5) I,560, in der Skizze zu einem Vorwort fiir eine geplante Neuausgabe der "Gedichte von der Schönen Dame" von 1918.

6) Vgl. Stepun, Mystische Weltschau, S.391.

7) Vgl. I , 8,15,30,47,57,59,60,62,68,74,77,79,85,89,91,94,97, $101,102,107,109,110,116,117,120,126,128,129,141,156,160$, $164,166,170,171,173,174,184,185,190,193,196,197,213,230 \mathrm{f}$. $232,233,244,253,254,260,261,263,3661$. u.ö. 
Die rätselhafte Schönheit, die der "Dichter" in Bloks Drama "Neznakomka" in den Blicken der Prauen und hinter einem dichten Schleier zu sehen glaubte, 1) ist eine Verkörperung des "EwigWeiblichen", das die traditionellen Attribute der antiken Himmelsgöttinnen und der HI. Sophia trägt:

Der Mann im Mantel: ... eine hibsche Dame in einer Tunika ${ }^{2}$ ) sitzt auf dem Erdball und hält iber diesen Erdball das Szepter:3) unterwerft euch, sagt sie, gehorcht!...4) Der Dichter (berauscht): Ewiges Märchen. Das ist Sie, die Weltenherrscherin. Sie hält den stab5) und gebietet liber die Welt. Alle sind wir von Ihr bezaubert.

Der Dichter (betrachtet die Kamee): Ewige Wiederkehr. Wieder umfabt Sie den Erdball. Und wieder sind wir Ihrem Zauber untertan. Sie bewegt Ihren blithenden Stab...6)

Die "Unbekannte", deren Erscheinen der "Dichter" erfleht, 7) ist die "schöne Dame" 8 ), die "von der Ikone in zarten Rosen langsam herabstieg".9) Ihr Name ist "Mar1ja", "Meri".10) "Sie" im Gedichtzyklus "Schneemaske" trägt die "dreikränzige miara um die Stirn", die Herrscherkrone also, deren drei Ringe himmel, Erde und Hölle svmbolisieren. 11) An "Sie" ergeht die Aufforderung:

"Erhebe über der blauen Ferne

Das Szepter des verblichenen Königs!"12)

Auch die "Tochter des Baumeisters", die verkörperte "Ewige Weiblichkeit" in Bloks Drama "Korol' na plošadi", wurde vom gottähnlich "Baumeister" geschickt, um die Nachfolge des zum

1) IV,76f

2) Die Dalmatika der Sophia; vgl. I,91, Z.6.

3) Kuss. "skipetr".

4) Diese Passage wirkt im Zusammenhang der ganzen Szene naivironisch.

5) Russ. "zezl" (Szepter od. Herrscherstab; der caduceus bzw. kerykeion, Attribut der Iris, Nike, Eirene und der Sophia).

6) IV,78f.; der blihende Stab ist ein Symbol der Auferstehung.

7) IV,81.

8) IV,98.

a) IV.99.

10) IV,99ff : vgl, auch II,119f., III,165f.

11) II,227ff.., vgl. VI. Solov'ev, Stichotvorenija, S.165, "Izida trechveneðnaja"; die Tiara mit drei Kränzen ist seit dem hohen Mittelalter Insignie des Papstes und deutilchstes Svmbol seiner Weltherrschaft.

12) II, $217 \mathrm{f}$. 
Steinmonument erstarrten "Königs" anzutreten, den "lieben Sohn" des Baume1sters. 1)

"Sie" soll offenbar die Herrscherin des "dritten Bundes", die Nachfolgerin des toten Sohn-Königs sein. Damit nimmt Blok ein wesentliches Element des Kults der "schönen Dame" ${ }^{2)}$ in sein späteres Schaffen hinitber.

Neben der Allmacht" des "Ewig-Weiblichen" tritt in Bloks späteren Gedichten und v.a. Im LS die Erlösungssehnsucht stark in den Vordergrund. ${ }^{4)}$ Besonders kennzeichnend hierfilr ist das Gedicht "Snežnaja vjaz'" (Schneeband):

"Wir ziehen Schneespritzer hinter uns her

Und fliegen in M1lilonen Abgriinde...

Du blickst mit immer derselben gefangenen seele

In immer dieselbe sternenkuppel...

Und du blickst in Kummer.

Und der Schnee wird blauer...

Und wenn mir

Die unausweichlichen Augen begegnen,

Offnen sich schneeige Tiefen,

Nähert sich Mund zu Mund...

Höhe. Tiefe. Schneeruhe.

Auch du schweigst.

Und in deiner hoffnungslosen seele

Herrscht dieselbe leichte, gefangene Traurigkeit..."5)

Hier lst der Mythos von der gefangenen Weltseele angesprochen.

In Bloks Mythos vom "Ewig-Weiblichen" verschmelzen die bel VI. Solov'ev meist unterscheidbaren Sphären der "Sophia" und der "Weltseele", "Gut" und "Böse", "Lille" und "Schlange", "groBes Licht und böse Pinsternis"6). Allmacht und Erlösungssehn-

1) IV,60; mit deutlicher Anspielung auf Matth. 3, 17 u.a.

2) Vgl. MoCul'skij, Blok, S.95f.

3) Vgl. auch II, $232 f f ., 250$.

4) Dieser Aspekt ist bel der "Schönen Dame" nur angedeutet: I.77, 80 (vgl. Anm. S.587), 119, 147, 180, 256, 467; dazu VII, $343 \mathrm{ff}$.

5) II, $212 f$.

6) I, 190; vgl. I,94, 142, 151, 186, 190, 523 u.a. 
sucht. 1)

Die sexuelle Note, die Bloks Gedichte seit etwa 1905 durchzieht und die Erlösungssehnsucht des "Ewig-weiblichen" oft peinlich trivial erscheinen läBt ${ }^{2}$, klingt schon in Bloks Tagebuch von 1901-02 an, in dessen oft nur schwer deutbaren Notizen sich schon die Konturen des Mythos vom Integralen, aphrodisischen "EwigWeiblichen" abzeichnen. ${ }^{3}$ )

Das Korrelat von Bloks Herrschafts- und Erlösungsmystik im Bereich des "Ewig-weiblichen" ist die selbstentäuBerungs- und Leidensmystik Im Bereich des männlichen Antipoden. Sie ver-

1) Solov'ev hatte auch Visionen der gedoppelten Weltseele, und er kannte die Verbindung von Gut und Böse in "Ihr" (vgl. Stichotvorenija, S.74 u. 115), doch steht bei ihm immer die Hoffnung auf Klärung der ethischen Qualität im Hintergrund. Das "Entweder-oder" bel Solov'ev wurde bei Blok zu einem "Sowohl-als auch".

2) Vgl. II,257 u.v.a. 274(3) und das 5.B1ld des LS.

3) Die Eintragungen vom Oktober-November 1902, VII, $63 \mathrm{ff}$. mit dem mehrmaligen "Mater" Sveta!" ändert an der Grundtendenz nichts. "ile "unsauber" und hybrid Blok in religiös-dogmatischer Hinsicht verfäht, zeigt die vermengung von "Preðistaja Deva" (Allerreinste Jungfrau) und "Večnaja Ženstvennosti" (Ewige Weiblichkeit) im Konzept des Briefes an seine spätere Frau, VII,62. Vgl, auch Kluge, aao, S.49ff. Blok interpretierte schon in Sommer 1901 Solov'ev im Sinne seines integralen Mythos vom "Ewig-Weiblichen", vgl. VIII, $23 f$.. Brief an A.V. Gippius rom 23. August 1901 und vII,5if.. eine Tendenz, die sich verstärkte. Hatte Blok 1901 die "schwanengleiche" Natur Solov'evs gegenüber der sinnlichen Abgrundigkeit Tjutcevs ("Ljublju glaza troi, moj drug...") oder Brjusovs unterstrichen (vgl. VII, $33 f f$ ), stellte er in einem langen Brief an Zulkov vom 23. Juni 1905, VIII,126f1. dem Vorwort Solov'evs zur 3. Ausgabe seiner Gedichte mit der deutlichen Unterscheidung von Sophia und zweideutiger Veiblichkelt dessen ratselhaftes Lachen gegenuber und verwies auf die dionysische, erdhafte Natur Solov'evs. 
klamert die verschiedenen Hypostasen des männlichen lyrischen Helden in Bloks dichterischem Werk.

In den "Gedichten von der Schönen Deme" herrscht die RitterHypostase des männlichen Helden vor. Das Verhaltnis von "Ihr" zu "Ihm" gleicht dem der Herrin su ihrem Ritter. ${ }^{1)}$ Die RitterHypostase durchzieht auch die spateren Gedichte Bloks, v.a. die Zyklen "Schneemaske" und "Faina", wobei der erstarrten, "idealistischen" Pose des Ritters die dionysische sinnlichkeit der weiblichen Heldin gegenubergestellt wird. 2) Die stilisierung der Liebe zu einem pseudoreligiösen Minnedienst, nach Huizinga. eine einseitig männliche Auffassung der Liebe ${ }^{3}$ ) erklärt auch die uönchs-Hypostase in vielen Gedichten Bloks ${ }^{4}$ und die Verschmelzung der beiden Hypostasen im Ritter-Monch. 5)

Auch die weiteren Hypostasen des männlichen Antipoden des "Erig-

1) Vgl. I, 30,70,74,91,120,146,195,213,230f . 239,244,263,289, $316 \mathrm{ff} .33 \mathrm{f}, 349 \mathrm{f}, 374 \mathrm{f}, 463 \mathrm{f}, 514,530,534,535$ u.a. Dazu Bertran im Drama "Roza 1 krest".

In Dostojevskijs Roman "Id1ot" ist Fürst Mykrin der "arme Ritter", der Nastas'ja Filipporna in reiner liebe liebt und sie erlösen will; vgl. 1. Buch, 2. Teil, VI-VII, wo Aglaja bein Vortrag von Pukkins Gedicht "Zil na svete rycar' bedny J..." (Es lebte auf der Welt ein armer Ritter, 1829), von der Dostojevskif nur den "idealen" Tell kannte, A.M.D. (Ave, Mater Del bel Pułkin) durch N.F.B., die Initialen der Nastas'ja Filippovna ersetzt.

Blok ersetzte in seinem Tagebuch A.M.D. durch L.D.M.. die Initialen seiner spateren Frau; vgl. VII,64.

2) II,60,61f , 115,108f , 232ff., 237f , 242f , 244,249ff , $252 f ., 260,267 f$. $272 f$; dazu III, 29f ., 164,169,171,249ff.

3) Huizinga, Herbst des Mittelalters, S.101; vgl. das ganze Kapitel "Der Traum von Heldentum und Liebe", S.99ff.. Bloks Ehe scheiterte wohl v.a. daran, daß er die Stilisierung der Liebe zum Ritterdienst in sein Privatleben hineintragen sollte und damit dem natirlichen Wesen seiner Frau nicht gerecht wurde.

4) I, 67, 169,198,204,235; II, 11,283 u.a.

5) I,70; II,161,227ff., 267f. U.a. 
Weiblichen", Hamlet ${ }^{1)}$, Pierrot ${ }^{2)}$, der träumende oder betrunkene Dichter ${ }^{3)}$, der Bettler oder Vagabund ${ }^{4}$ etc. 5), werden durch ihren selbstentsagenden, leidenden und schwachen Charakter zusammengehalten.

Besonders ausgeprägt ist Bloks Leidens- und SelbstentäuBerungsnystik in den Rußland-Gedichten. ${ }^{6}$ )

Bloks Leidensmystik hat jedoch einen Aspekt, der zwar vom passiven, masochistischen Charakter des lyrischen Helden häufig verdeckt ist, der aber der Leidensmystik ihre eigentliche Bedeutung verleiht. Es ist die Hoffnung, daB in der Tiefe des Jeidens die Kraft zur Auferstehung und Erlösung wachse. Auch bei Blok gehören Leidens- und Auferstehungsmystik zusammen, auch wenn in seinem dichterischen Werk die zweite Komponente oft verdunkelt ist. Unter diesem Aspekt muB auch die Christusund Kreuzsymbolik in Bloks Gedichten und besonders im LS gesehen werden. 7)

Das Thema von Bloks bekanntem Gedicht "Vot on - Christos -

1) Vgl. Bloks Cphelia- und Hamlet-Gedichte: I, 11,14,17,46,243, 382,390 f. 449,525; III,91.

2) Vgl. Bloks lyrisches Drama "Balagantik", IV,7-21, und die "Balagan-Gedichte" I, 205,210,227,252,277,287; II, 37,67,123. Der unglückliche, leidende Pierrot ist ein kinstierisches "Le1tfossil" der Jahrhundertwende; vgl. dazu Hof stäter. Symbolismus, S.185f.

3) I $, 21,23,28,32,42,43,96,113,230(1), 281,318(5), 339,341,346,377$, $401,409,412,413,420 \mathrm{f} ., 421,429 \mathrm{f} .439 \mathrm{f} .440 \mathrm{f} \ldots 443,478 \mathrm{f}$. . 482; lyrische Dramen "Korol' na ploszadi", "Neznakomka", "Roza i krest" (Gaetan); die "Neznakomka"-Gedichte; II,130f . , $212 \mathrm{f}, 227 \mathrm{ff} ., 239,240 \mathrm{f}, 275 \mathrm{f} .(5), 280 \mathrm{f}$ (9), 286f.,288f. u.v.a. Vgl. dazu IV, 434 iber die Helden der lyrischen Dramen.

4) II,24f , 77,75f., 106f , 157; III,127f

5) Vgl. dazu Bonneau, L'univers poétique, S.179ff. Die dort vorgenommene Scheidung in "gute" und "böse" Hypostasen ist $z u$ oberflächlich und fiir die Mönchs-Hypostase falsch. Entsche1dend ist das transzendierende Moment der Selbstentäußerung; vgl. schon Bloks Jugend tagebuch, VII, 51.

6) Vgl. III,246,249ff, 254f, 256,257,259.

7) Z.B. II,136,139f., 230,232f .; dazu "Roza i krest"; V,475 u.a. $\mathrm{Vgl}$. besonders Bowra, The heritage of simbolism, S.176. 
$\checkmark$ cepjach 1 rozach..." $(1905)^{1)}$ ist die Verbindung von Selbstentäußerung und Erlösung.

"Da ist er, Christus, in Ketten und Rosen

Hinter dem Gitter meines Gefängnisses...

Im einfachen Beschlag des blauen Himmels

Schaut seine Ikone ins Fenster.

Ein ärmlicher Maler hat den Himmel gemalt.

Doch das Antlitz und der blaue Himmel sind eins.

-..

Und du wirst das blaue Auge nicht begreifen,

Ehe du nicht selbst wie ein Weg wirst...

Ehe du nicht derselbe Bettler wirst,

Nicht zertreten in einer öden Schlucht liegst,

Alles vergint und nichts mehr liebst

Und bleichst wie das tote Gras."

(Strophen $1,2,4,5$ )

Nach Bloks eigenen Worten ist dieses Gedicht von der Landschaftsmalerei M.V. Nesterovs inspiriert ${ }^{2)}$ und knflpft damit an die Tradition des "russischen Christus" an, die von den Slavophilen iiber Tjutcev und Dostojevskif bis zu den Symbolisten reicht. ${ }^{3)}$

Der kosmische Aspekt seiner Erlösungsmystik verbindet Blok mit der ostkirchlichen Tradition, denn in der Cstkirche ist die Hereinnahme der Natur und des ganzen Kosmos in die Erlösertat

1) II,84. Das Gedicht ist eine dichterische Korrektur der ÄuBerungen Bloks in Briefen an Je.P. Ivanov, wo er von seiner Ablehnung. Christi und der Religion geschrieben hatte; vgl. VIII, $104 \mathrm{ff} ., 130 f_{.}, 132 \mathrm{f}$., Briefe vom 15. Juni 1904, vom 25. Juni 1905 und vom 5. August 1905. Der direkte AnlaB zu dem Gedicht war eine Unterredung $z$ wischen Blok und Ivanov vom 8. Ckt.1905; vgl. Ivanov, Zapisi ob A. Bloke, in: Blokovskif sbornik, S.396.

2) Vgl. Anm. II,402. Nesterovs berilhmtes Bild "Svjataja Rus'" (Das Hellige Kupland; Christus, begleitet vom hl. Nikolaj, vom hl. Sergif und vom hl. Firsten Gleb erscheint dem Volk im winterlichen Kittelrußland) entstand 1905.

3) Vgl. Bonneau, L'univers poétique, S.187ff. Bei Blok fehlt jedoch jeder Versuch, die Vorstellung vom "russischen Christus" religionsphilosophisch zu "begrilnden"; vgl. auch den Exkurs "Blok und der "raskol"", S. $488 f f$. 
Christi ein wesentlicher Aspekt des Heilsgeschehens. 1)

Der "Kosmismus" durchzieht auch das Werk russischer Dichter, die nur bedingt oder gar nicht als Vertreter der orthodoxie angesehen werden können ${ }^{2)}$, insbesondere das Werk Dostojevskijs. ${ }^{3}$ ) Blok selbst hat auf die romantische Tradition verwiesen:

"Die Romantiker ${ }^{4)}$ stellten ibrigens die fur unser ohr eigenartig klingende Losung von der "Erlösung der Natur" auf, die einem unserer größten Romantiker nahe steht, nämlich vl. Solov'ev."5)

Die Idee von der "Erlösung der Natur" wurde in der romantischen Philosophie, insbesondere von Novalis, v. Baader, Schubert, Steffens und Schelling als Erbe neuplatonisch-mystischer spekulationen neu belebt. ${ }^{6}$ Die Spekulationen von der Erlösung der Natur durch den Menschen als dem "Messias der Natur"7), die eng mit der romantischen Anthropologie (der Mensch als Mikrokosmos, die Natur als Makroanthropos) ${ }^{8}$ ) und Liebesphilosophie (Wiederherstellung des verlorenen göttlichen Ebenbildes im Menschen) ${ }^{9}$ ) verbunden sind, geraten häufig in Gefahr, die Einmaligkeit der Gestalt Christi zu relativieren. Die in der christlichen Mystik

1) Vgl. Benz, Geist und Leben der 0stkirche, S.172. Ausgangspunkt hierftlr ist Röm. 8,19ff. Die kosmische Dimension des Heilsgeschehens findet ihren Niederschlag in der ostkirchlichen Osterliturgie; vgl. heiler, Ostkirchen, S.240ff.

2) Vgl. dazu ausfihrlich Sarkysianz, RuBland und der Messianismus des Ostens, S. $33 \mathrm{ff}$. Fur Blok besonders interessant ist der Hinweis auf A.M. Dobroljubov; vgl. dazu VIII,150f.

3) "Brat'ja Karamazovy", 6. und 7.Buch; vgl. dazu Doerne, Gott und Mensch in Dostojevskijs Werk, S.64, Anm. 13. "Podrostok", Teil 3, Kap.I u.ö.

4) Blok meint die Jenaer Romantiker, was aus dem Zusammenhang deutlich hervorgeht.

5) VI,366 in "O romantizme" (ttber die Romantik; VI,359-371).

6) Vgi. Kluckhohn, Ideengut, S.28f., 47f., $141 \mathrm{ff} ., 149 \mathrm{ff}$.

7) Die Idee vom Menschen als dem "Messias der Natur" ist dichterisch am stärksten gestaltet in Novalis' "Lehrlingen zu Sais" und "Heinrich von ofterdingen".

8) Vgl. Kluckhohn, aao, S.28.

9) Vgl. Kluckhohn, aaO, S.70. 
latente Tendenz der Selbsterlösung wuchert im deutschen Idealismus, v.a. bel Novalis, zu einer Selbstvergöttlichung im Genlekult aus, deren Konsequenz der Glaube an die Befähigung des Menschen ist, die Erlösertat Christi zu wiederholen. 1) Die geistige Verwandtschaft Bloks mit der Jenaer Romantik ist offenkundig. 2) Allerdings scheint Blok dies in seiner ganzen Bedeutung erst bel der Lektiire des 1914 erschienenen Buches von V.i. Zirmunskij "Nemeckij romantizm 1 sovremennaja mistika" (Die deutsche Romantik und die zeitgenössische Mystik) erkannt zu haben. ${ }^{3)}$ Die wichtigsten Außerungen Bloks iber die Jenaer Romantik stammen aus der Zeit nach 1914 und stitzen sich wohl vorwiegend auf $Z_{\text {irmunskij. }}{ }^{\text {) }}$

Bloks Erlösungsmystik steht stark im Banne Richard Wagners, 5) der die romantischen Ideen vom Genie-Menschen als dem Erlöser der Natur mit der Schopenhauerschen Verherrlichung des Leidens auflädt.

1) Nicht von ungefähr sagte Goethe von den Ronantikern: "sie selbst wollen ein Herr Christus sein..."; vgl. Heer, Europäische Geistesgeschichte, Bd.2, S.129. Auch die Orthodoxie steht in Gefahr, in zu große N̈̈he des "Genie-Affekts" des dt. Idealismus zu geraten; vgl. dazu Onasch, Einf'thrung, S.238, dazu $228 \mathrm{ff}$.

2) Vgl. zuletzt Kluge aao, S.3off. und schon Gofman, Romantizm, simvolizm i dekadentstvo in: "Poety simvolizna", S.1-32, v.a. S. 7 und 17 .

3) Vgl. Bloks Brief an Žirmunsk1j vom 3. März 1914, VIII,434.

4) Bìoks Verbindung zur deutschen Romantik geht iber Zukovskij und TjutCev; seine Jugendlvrik ist stark von den spätromantischen Epigonen Fet und Polonskij beeinflußt. Ther die Jenaer Romantik $\ddot{u}$ 3erte sich Blok v.a. in "O iudalzme u Gejne" (ftber das Judentum bei Heine; VI,144,-150), wo er auf die fiir die Jenaer Romantik und den fingeren mussischen Symbolismus gemeinsame platonisch-gnostische Grundlage hinweist, und in "O romantizme" ("ber die Romantik; VI,359-371), wo Blok in Sinne der irrationalen, antimaterialistischen und antipositivistischen neueren Lebensphilosophie den in der ienaer Romantik zwischen 1798 und 1802 verkörperten RomartikBegriff (vgl.VI,363ff.) auf den Urzustand der Menschheit, auf die ristlichen Mysterienkulte und das Urchristentum, auf die ionischen Naturphilosophen und Platon, auf das christliche Mittelalter und die Renaissance ausweitet (vgl.VI, 367f.; Bloks Aufzählung enthält die Ahnengalerie des Irrationalismus). Zu Bloks Meinung iber einzelne deutsche Romantiker vgl. VI.533f., Anm.2 zu "O romantizme"; zur Tradition der "blauen Blume" vgl. VI,412f.

5) Uber Bloks Verhältnis zu Wagner vgl. Kluge, aao., S.89ff. (mit Schwergewicht auf der Kunst- und Kulturphilosophie). 
Das Genie als das am hochsten entwickelte Geschopf, als eigentlicher "Mensch"1) leidet am meisten"), und die höchste stufe der Leidensfähigkeit erreichte die Menschheit in Christus, dem Genie des Leidens und dem Erlöser der Welt. 3) Die romantische Tendenz zur "Selbstverchristung" erreichte bei Wagner ihren Höhepunkt in der Idee von Jesus als dem genialen KunstlerMenschen, von der auch Blok stark beeindruckt war. ${ }^{4}$ ) Entscheidend firr kagner wie fiir Blok ist dabei nicht die Herabminderung Christi zum nur genialen Kiinstler, sondern die Erhöhung des Genies zu quasi religiöser virde. Jesus wurde bei vagner zu dem "nie zufriedenen Geist, der stets auf Neues sinnt", zu dem revolutionären, nur der Zukunft lebenden Genie, als das er sich selber begriff. 5) Bloks Erlösungsmystik tellt mit der Wagners den pseudoreligiösen'), sexuell uberspannten und in schrulstiges Pathos ausufernden ${ }^{7)}$ Charakter.

Während Schopenhauer den ästhetischen Weg der Erlösung, die Einswerdung mit dem weltwillen in der Musik, als trügerischen Schein der ethischen Erlösung, der echten Verneinung des Weltwillens in der christlichen Entsagung oder im buddhistischen Nirwana gegenilberstellt, hat bei Wagner der ästhetische Weg jede echte Religiosität uberwuchert. Dasselbe gilt fur Blok, der jedoch ein wirklicher Mystiker war und der erlosenden Kraft der Kunst immer wieder miBtraute. 8 )

1) Vgl. Hartmann, Die Philosophie des deutschen Idealismus, S.194ff. Uber Novalis; Genie-Begriff.

2) Vgl. Wagner, Tagebuch von 1858, in: Hauptschriften, S.198ff. mit fast wortlicher fbernahme schopenhauerscher und Nietzschescher Ideen.

3) Vgl. Wagner, Die Kunst und die Revolution, in: Hauptschriften S.115 und ders., Heldentum und Christentum, in: aao, S.418.

4) Vgl. Kluge, aao, S.258f.

5) Vgl. Wagner, Eine Mitteilung an meine Freunde, in: aao, S.19off. und ders., Das Publikum in zeit und Raum, in: aao, S.398f.

6) Bühnenweihfestspiel Parsifal (vgl. Wagners ÄuBerungen Uber den Gral in: Reich, Wagner, S.219f.).

7) Vgl. Wagners ÄuBerungen über den Fliegenden Holländer, der erlöst wird durch das "noch unvorhandene, ersehnte, geahnte, unendliche Weib.... das Weib der Zukunft."; In: Reich, aaO, S.132, uber Siegfried und Brinhilde in: Reich, aao, S.181 und besonders uber Kundry, die männermordende Nymphomanin, die sich danach sehnt, "durch einen Mann erlost zu werden", In: Reich, aao, S.223ff.

8) Vgl. "O sovremennom sostojanif russkogo simvolizma", V,425436 ; dazu "K Muze", III,7f. 
Bloks Auffassung von der Bestimmung des Menschen ist gepragt von der Uberreugung, daß der leidende Mensch das wahre Menschentum verkörpere. 1) Der Dichter ist "zuallererst Mensch", 2) "Mensch von Beruf", 3) denn nur als ganzer Mensch, als Mikrokosmos kann er aus den Tiefen der Volksseele schöpfen und Träger des "Rhythmus", 4) des blind waltenden, dionysischen Urgrunds des Seins werden. "Mensch", "Genie", "Künstler", "Christus" sind Teilaspekte eines synthetischen "Ubersymbols" für den männlichen Partner des "Ewig-Weiblichen" und setzen die Reihe der mannlichen Hypostasen fort. 5 )

Entscheidend für das Verständnis des LS und der RuBland-Gedichte Bloks ist, daß dieser seine Erlösungs-Mystik auf RuBland einengt. Die zu erlösende Natur bel Novalis entzieht sich völlig, die zu erlösende Weltseele bei Solov'ev fast völlig einer "nationalen" Beschränkung. Blok setrt sein "Ewig-Weibliches" mit RuBland gleich und schafft sich so ein mythisches RuBland ("Rus'"), das als eine Art 2 witter kosmische und nationale Züge trägt. ${ }^{6}$ ) In ahnlicher Weise verbinden sich auch in Bloks Christus kosmische und nationale Züge. 7 )

Die Symbolisierung des echten, "ewigen" RuBland in einer Frau hat eine lange literarische Tradition. ${ }^{8)}$ Fur Blok war in dieser Hinsicht Dostojevskij besonders vorbildich, denn die Verschmelzung von "Halbweltdame" und "russischer Schönheit", wie Blok sie in der Gestalt der Faina vornahm, ist auch für einige Frauengestalten Dostojevskijs charakteristisch.

1) Vgl.V,384; IV, 171 u.ö.: "Freude-Leid ist eins"; II,179.

2) $v, 247$

3 V,250.

4 Vgl. besonders "Dusa pisatelja", V,367-371.

5 In diese Reihe gehört v.a. auch der "gefallene Engel".

6) Auch in V1. Solov'evs bekanntem Gedicht "Ex oriente lux" wird die Identitat von Weltseele und RuBland angedeutet.

7) Vgl. insbesondere Bloks Revolutionspoem "Dvenadcat'", letzte Strophe, III, 359 und den Exkurs "Blok und der "raskoinn, S.488 und $f f$.

8) Tat'jana (Pußkins "Jevgenij Onegin"), Natała (Tolstojs "Vojna 1 mir"), Lara (Pasternaks "Doktor Zivago"); dazu: Nekrasov. 
Grüen'ka wird als "klihne, rassige mussische Schönhe1t, stolz und trotzig" geschildert. Sie trägt ein "schwarzes Seldenkleid", thr "bleiches Gesicht", thre "brennenden Augen und Iippen" sind beherrscht von "Trauer und Ungeduld". Die Silnderin, die Alesa "vernichten" wollte, fällt vor dem "Cherub" auf die knie und ruft verzilckt: "Mein ganzes Leben habe $1 \mathrm{ch}$ auf einen Menschen wie dich gewartet". 1)

Katerina N1kolajevna 1st eine "ganz gewöhnliche, ganz wertlose Frau", 2) eine "verdorbene Weltdame", 3 ) in der "alle Laster wohnen". 4) sie ist "streng, unnahbar und stolz", und ihr "Blick kann vernichten".5) Vor ihrer unbeschreiblichen Schönheit "erblindet" Arkadif, 6) und "alles in inm wird zu einem Chaos".7) Katerina ist "der Gipfel der Vollkommenheit", 8 ) sie "steht höher als alles andere auf der Welt", 9) und sie lst "wie die Sonne unerrelchbar". 10) Arkadij "sank ihr zu FijBen". 11) Von dleser Verkörperung des "Ewig-Welblichen" wird gesagt, ihr Gesichtsausdruck sel "kindliche Schelmerel und unendliche offenheit". Ihre Gestalt ist die eines "gesunden Dorfmädchens", Ihr Geslcht das einer "Jungen Dorfschonhelt,... rund, frisch, hell, kiihn, lachend und... schilchtern, keusch, kindlich... sie selbst sagt: "Ich bin Russin und liebe RuBland."12)

1) "Brat' Ja Karamazovy", Kap. "Lukovka" (7.Buch,3).D1e Chr1stus - Maria Magdalena-Thematik ist bei Dostojevskij kaum verhiiltt. Die "Brilder Karamazov" sind voller Mythologeme, die auch bel Blok immer wiederkehren, z.B. Bräutigam-BrautMystik, Christus als Sonne, Mutter-Erde-Mystik, In-die-Weltgehen, "Meine Stunde ist noch nicht gekommen". Trotz häufiger Hinweise auf Parallelen zwischen Dostojevskif und Blok in der Blok-I1teratur fehlt bislang eine erschöpfende Darstellung der Bezlehung zwischen diesen belden Dichtern. deren Ausgangspunkt eine mythische Deutung Dostojevskijs in der Art von v faX. Ivanovs "Dostojewsk1j, Tragöd1e - Mythos - Mystik" wird sein milssen.

2) "Podrostok", 3.T., 8.Kap.,II

4) $2 . \mathrm{T} ., 4$.Kap.,II

6) $2 . T ., 4 . K a p . . I$

8) $2 . T ., 8$. Kap.,IV

10) 3.T., 6.Xap.,III

12) 2.T., 4 .Kap.,II
3) 3.T., 10. Kap.,IV
5) $2 . \mathrm{T} ., 4 . \mathrm{Kap} ., \mathrm{I}$
7) 1.T., 2.Xap.,IV
9) $3 . \mathrm{T} ., 6 . \mathrm{Kap} ., \mathrm{I}$
11) 3.T., 6.Kap..II 
Paina gleicht in inrem äuBeren Erscheinungsbild der Heldin des Gedichtzyklus "Paina". 1) Besonders nahe steht das LS den Gedichten vom Herbst 1907. die zum großen Teil in einer Untergruppe mit dem Titel "Zakljat1je ognem 1 mrakom" (Beschwörung bei Feuer und Finsternis) zusamengefaßt sind. In diesen Gedichten erreicht die dionysische RuBland-Exotik Bloks ihren Höhepunkt.

Berihmt ist das Gedicht, das den Teil "Zakl jatije ognem 1 mrakom" einleitet.

"Oh, Pribling ohne Ende und ohne Grenze -

Ohne Ende und ohne Grenze das Sehnen!

Ich erkenne dich, Leben! Ich nehme dich an!

Und ich griibe dich mit dem Klang des Schilds!

Und ich begegne dir an der Schwelle -

Mit ungestilmem Wind in den Schlangenlocken,

Mit dem unenträtselten Namen des Gottes

Auf den kalten und zusammengepreßten Iippen..."

$$
\text { (II, 272f.(1), Str.1 und 5) }
$$

Die Idendität von "Leben" (objektive Sphäre, Str. 1-3) und dëmonisch-sphinxhafter "Frau" (personale Sphäre, Str.4-6) wird dadurch hergestellt, daß sich das Personalpronomen "tebja" (dich) am Schluß des Gedichts auf beides bezieht.

"Und ich schaue und ermesse die Feindschaft, Hassend, verfluchend und liebend:

Fiir die Qualen, fiir den Untergang - 1ch weiß es Einerlei: ich nehme dich an!"

\section{(str.7)}

Die Faina der Gedichte ist eine "verwegene Soldatenbraut"2)

"In Ihr ist die Kraft des spielenden Blutes,

benn auch ihre braunen Wangen bleich sind,

Fein ihre schwarzen Brauen

Und berauschend ihre strengen Worte."

$$
(I I, 281(10), \operatorname{str} .5)
$$

Sie ist schöner als alle andern jungen Frauen. 3 ) Ihre Elemente

1) II,254-293. Der Zyklus enthält Gedichte aus den Jahren 190608 und wurde wie der Zyklus "Schneemaske" von N.N. Volochova inspiriert.

2) II, 281f. (10), Str.2,6.

3) II,281f.(10); Str.4; dazu: II,254f.. Str.1 mit direktem Bezug auf Puskins Gedicht "Krasavice" (Einer Schönen, 1832) und auf das Hohe Iied $6,8 \mathrm{ff}$. 
sind "Feuer" und "Brand", 1) "Dunkelheitn"2) und "Schneesturm".3) sie ist untreu, ${ }^{4}$ ) streng, 5) von aggressiver sinnlichkeit. 6) sie lot frel wie ein Vogel, 7) unabhängig und auf niemand angewiesen. 8 ) Ihre dionysische Natur offenbart sich im Tanz zu den Klängen des Akkordeons. 9) Sie 18t das Leben, 10) die Sphinx, 11) und sie verkörpert das frele und ungebundene RuBland. 12) Ihr Tanz bereitet denen die Totenfeler, die an ihrer rauschhaften Urnatur nicht teilhaben können. 13) Faina ist das einfache Mädchen, das in der Nacht am FluB auf den Liebsten wartet ${ }^{14}$ ) und die dämonische Verfuhrerin, die mit der Troika davonrast. 15) Ihre Leidenschaft fegt die Scheinwelt des wortes, der Diskussionen und spekulationen hinweg. 16)

Der dionysischen Symbolik entsprechen Rhythmus ${ }^{17)}$ und Klangmalere1:

"Tam volja vsech vol'neje vol'

Ne prinevolit vol'nogo,

I bolej vech bol'neje bol'

Vernet 8 puti okol'nogo!"

$$
(I I .277 f .(7), \text { str. } 7)
$$

1) II,273(2); 274f.(4), Str.1,2,7; dazu Titel und "Lied des Schicksals" Z.17, vgl. II, 284f.

2) II ,274(3), str.1,3,4;274f.(4),str.2,7;280f.(9), str.5.

3) II,278ff.(8); dazu II,254f., Str.2; 267f.; das verbindet sie mit der Heldin der "Schneemaske"Gedichte.

4) II.274(3), str.1; 276f.(6), Str.6.

5) II, $274 \mathrm{f} .(4), \operatorname{str} .7 ; 281 \mathrm{f} .(10), \operatorname{str} .5$.

6) II,274(3), Str.1; 274f.(4), Str.3; 275f.(5), str.5; dazu II, 257, Str.2 und das "Iled des Schicksals".

7) II,276f.(6), str.6; dazu II,336f. und III,237f.

8) II,276f.(6), str.4,6.

9) II,276f.(6), str.1,3,6;278ff.(8), str.7,11-13; 280f.(9), Str.1,3,4; $281 \mathrm{f} .(10)$, str. $2,3,6$.

10) II,272f.(1), str.1-4;273(2), str.1.

11) II,272f.(1), Str.5-7; dazu II,258f .; $267 f$.

12) II,278ff.(8), Str.12.

13) II,276f.(6), str.1-3.

$14)$ II, 262

15) II,254f.; $264 \mathrm{f} .(3) ; 293 \mathrm{f}$.

16) II,275f.(5), Str.1; 276f.(6), str.1-3; dazu $288 f$.

17) Vgi.z.B. II,278ff.(8). 
Vor der elementaren Rauschhaftigkeit verliert der männliche Held den Verstand und vergeht in dionysischem Selbstvergessen.

"Ich schaue zu - sie hat die Arme hochgeworfen

Und ist in den weiten Tanz eingetreten,

Hat alle mit Blumen uberschuttet

Und hat sich im Iied verströmt...

$$
\text { ... }
$$

Den Verstand verliere ich, ich verliere den Verstand,

Im Wahnsinn liebe ich,

DaB du ganz Nacht bist, und ganz Finsternis,

Und ganz im Rausch...

Daß du meine seele geraubt hast,

Sie mit Gift gequält hast,

DaB ich von dir, von dir singe,

Und $d a B$ meine Iieder ohne $Z a h l$ sind...

$$
\text { (II,280f.(9), str.3,5,6) }
$$

In einer Tagebuchnotiz vom 6. März 1908 schrieb Blok:

"Faina - "In den Wäldern" Pexerskijs. Auch eine Altgläubige mit Dämoni schem."1)

Wahrscheinlich hatte Blok Flenư̌ka im Sinn, ein leidenschaftliches Mädchen, das Unglilck in der liebe hatte und Abtissin in einem Altgläubigenkloster wurde. 2) In einigen Gedichten und Skizzen Bloks aus dem Herbst 1907 ist die dämonische russische Schöne genau wie im IS eine Altgläubige.

Das Gedicht "Zadebrennyje lesom kruci..." (Vom haldesdickicht iberzogene Abhänछe...) im Zyklus "Rodina" 3) sollte urspriinglich eine Ballade iber die Altgläubigen und Selbstverbrenner werden. 4)

Die Skizzen zu diesem Gedicht stammen vom Oktober 1907 und enthalten Verse, die fast wörtlich mit Passagen des IS ubereinstimmen:

1) Zap.kn., 103

2) Vgl. Oriov, A. Blok, S.164; Triomphe, Le mysticisme d' Al. Blok, In: Cahiers du monde russe et soviétique, 1960, I, 3, S.406, Gromov, A. Blok, S.313.

3) III, 248

4) Vgl. III, 587, Anmerkung. 
"So braungesichtig und so stattlich

Unter dem Feuerschein des alten Glaubens...

Der Schwarzbrauigen, Braungesichtigen nach,

Mit erschreckter seele.

Du kamst in fener Hiitte dort zur Welt,

Wuchsest auf am Flußufer

Die Augen leuchteten unter dem Kopf tuch

Manchmal erschienst du mir

Im roten Sarafan von der Höhe,

Wenn im grauen FluBnebel

Die Flöße zusamengetrieben wurden."

(III, 586)

In der endgijtigen Fassung ist nur die Schilderung der unberihrten nordrussischen Landschaft geblieben, von der "dem erschreckten Rußland die Kunde vom brennenden Christus" gebracht wird. 1)

Das Gedicht "Raspußilas', raskadnulas'..." (Sie putzte sich heraus, bewegte sich hin und her... $)^{2}$ enthält ähnliche Bilder:

"Es drehte sich in schnellem Kreise iber dem FluB

Der rote Sarafan...

Und im wind wirbelten

Die Zipfel des Kopftuchs hin und her..."

$$
\text { (str. } 3 \text { und } 4 \text { ) }
$$

Die Skizzen vom Oktober stehen dem IS noch näher:

"Die 21 pfel des roten Kopftuchs schlagen im Wind,

Es wirbelt der rote Sarafan.

Und die Greise auf den Holzpritschen wissen,

Daß du, die Arme in die Hiiften gestemmt, zum Tanz geschritten bist."

(III, 633)

Im IS wurde aus dem roten ein schwarzer Sarafan, was die Ähnlichkeit der Faina mit einer altgläubigen "Christusbraut" 3) unterstreicht und zur "Dunkel"-Symbolik der Faina im IS paßt.

1) III, 248

2) III, 370.

3) Vgl: Pleyer, Das russische Altgläubigentum, S.137. 
Das Gedicht "Menja pytali v staroj vere..." (Man folterte mich um des alten Glaubens....) $)^{1)}$ gehort zeitlich und thematisch in die Reihe der oben erwähnten Gedichte. Bloks folkloristisch verbrámte RuBland-Exotik erreicht aber einen Hohepunkt im Gedicht "Pesel'nik" (Der Volksliedersanger). 2) Der Sanger, eine DichterHypostase, in der sich Anakreontik und Dionysiasmus verbinden, fijhrt die Mädchen zum Reigen und erlebt mit einer der Schönen eine Iiebesnacht im Schutze der Natur. Die Stilisierung erinnert an den hybriden Folklorismus S. Gorodeckijs. 3 ) Die Identität von Mädchen und Landschaft ist nur angedeutet: das Bindeglied ist der "blaue Nebel", den der Sänger in Besitz nimmt, eine Metapher, die sich im Rahmen der auch im IS stark ausgeprägten "Schleier"-Symbolik bewegt. iuch das "Feuer"-Symbol ist erotisch $\mathrm{zu}$ deuten.

Bloks Mythos vom russischen Volksmädchen ist nur eine besondere Form seines Mythos vom "Ewig-Weiblichen", wie er auch den "Neznakomka"-Gedichten, dem Zyklus "Schneemaske" und den Zigeunergedichten Bloks zugrunde liegt. Die Frauengestalten behalten ihre charakteristischen symbole in einer jeweils mit anderen Akzenten versehenen Umgebung. ${ }^{4)}$ Bloks Hochschätzung fir Gor'kij und dessen Kreis, die in den publizistischen jußerungen zum Thema "Volk und Intelligenz" immer wieder anklingt, ist von Bloks Mythos vom dionysischen "bwig-Weiblichen" her zu verstehen. Die Haltung Bloks ist sehr subjektiv, und in den romantischen, sehnsuchtsvollen oder dämonischen Frauengestalten Gor'kijs und in der Volga-Romantik Skitalec' sieht Blok

1) II.336 vom Oktober 1907

2) II, 335 vom Juni 1907

3) Vgl. Motto und Anm. II 445. "Volkstimlich" sind die häufigen Interjektionen (0j!Ej!), die Binnenreime, die kurzen Adjektive (sin' tuman, al sarafan, jar...zagar), die vergleichenden Partikel "lto" statt "kak", die Lexik (kosyn'ka, devka, sarafan) u.a.

4) Die "Ieitsymbole" sind das dunkle Gewand, der besondere Blick, Stern, Schneesturm, Feuer, Musik, Troika u.a. Bloks Identifikation von Zigeunerin und russischem Volksmädchen ist ethnologisch gesehen barer Unsinn und nur mit Bloks Mythos zu erklären. 
seinen eigenen Mythos bestätigt. ${ }^{1)}$

Während in den Gedichten des Zyklus "Faina" und im LS Bloks mythische "Rus'" noch durch eine besondere, individuelle Geetalt verkörpert wird, kommt Blok in seinen RuBland-Gedichten ohne deutlich abgrenzbare Realverkörperung aus. Die vom Dichter angesprochene weibliche Person ist die mythische "Rus'" selbst, Bloks tbersymbol des "Ewig-Weiblichen". In inm verbinden sich alle Tellaspekte der friheren Frauengestalten Bloks, Licht und Finsternis, Dirnenhaftigkeit und Reinheit, verzehrende Sinnlichkeit und untröstliche Trauer. RuBland ist die "schlafende Prinzessin", 2) die "Räuberschönheit", 3) die "Freundin", 4) die um den Sohn trauernde : Kutter, ${ }^{5)}$ die Unberihrbare und EwigReine, 6) die Sphinx. 7) In seinen RuBland-Gedichten hat Blok seinen Mythos vom "Ewig-Weiblichen" aus den Niederungen der fin-de-siècle-Erotik gelöst, was aber an der Bipolarität des illy thos nichts änderte.

Ru3land ist Bloks letzte und umfassende Verkörperung des "Ewigmeiblichen", Schwester, Geliebte, Gattin, Mutter in einem. ${ }^{8}$ ) Es sehnt sich nach Erlösung.

1) Vgl. V,173ff., 321; dazu Vengrov, 3lok i Gor'kij, in: Gor'kovskije ttenija, S.217ff. und V,111; Blok-Belyj, Perepiska, S.202, Bely js Brief vom 11. August 1907; VIII,

2) III,266f.

2) III, 254f.

4) 257,258 .

5) III,281.

6) II, $106 \mathrm{f}$; III, $254 \mathrm{f}$.

7) III, 360ff.

8) Vgl. III,246; V,321 und Kluge, aaO, S.189-196. Die Diskussion, die in jingster Zeit in der UdSSR iiber Bloks Formulierung "O Rus' moja! Zena moja! " gef"ihrt wurde, entziindete sich an dem Einwand I. Sel'vinskijs: "Mir ist es peinlich, daß mein Vaterland (rodina) die Frau von Aleksandr Aleksandrovit ist." Sel'vinskijs Formulierung ist zu vordergriindig und wird der Tatsache nicht gerecht, daB RuBland filr Blok eine "lyrische Einheit", eine metahistorische Wesenheit ist. Doch gehen auch die Entgegnungen $\mathbb{K}$. Cukorskijs und $P$. Gromovs an elgentlichen Problem vorbei, wenn sie auf den poetologisch besonderen Charakter des lyrischen "Ich" im Kontrast zur Person des Dichters abheben (vgl. Gromov, A. Blok, S.337. mit Anm.1, die völlig unbegriindet ist). Blok war Mystiker, seine Dichtung Bekenntnisdichtung und Abbild 
"Und da hebt sich der stille Vorhang unserer 2weifel, unserer Widersprilche, unseres Scheiterns und unseres Viahnsinns: hört ihr die a temberaubende Jagd der Troika?... Das ist RuBland, das, unbekannt wohin, in den blauen Abgrund der Zeiten rast, auf seiner geschmilckten und verzierten Troika. Seht ihr seine sternenaugen mit der flehenden Bitte an uns: "Ilebe mich, liebe meine Schönheit!n Doch uns trennen von 1hm diese endlosen Weiten der Zeiten, dieser blaue Frostnebel, dieses schneeige Sternennetz. Wer wird zu der dahinrasenden Trolka auf geheimen und weisen Pfaden durchdringen, mit einem sanften wort die schaumbedeckten Pferde anhalten, mit mutiger Hand den dämonischen Kutscher vom Bock stiirzen und..."1)

RuBland ist eine märchenhafte Schönheit, die von einem teuflischen Kutscher in atemberaubender Jagd durch die Sphären gefahren wird ${ }^{2}$, aber auf die Befreiung durch den starken Helden hoff. 3 )

Im Sommer 1909, als in RuBland die Reaktion gesiegt hatte, schrieb Blok in sein Tagebuch:

"Die russische Revolution 1st zu Ende. Alle Brände sind abgebrannt, oder die Kelche der Menschenherzen sind verschiittet, und der wein hat sich wieder in der ganzen Natur aufgelöst und wird die Menschen quälen, die inn vergossen haben. Die ganze Natur steht wieder unter einem Zauberbann, seit die Menschen nicht mehr verzaubert sind. Es harrt die Weltseele (toskujet Dusa Mira), wieder, wieder. Hinter den Tannenkreuzen schauen schreckliche Gesichter hervor in den bleifarbenen, dahinziehenden Wolken. Immer dieselben Gesichter, und dazu neue: die der

mystischer Erlebnisse. Das "lyrische Ich" gerade der RuBlandGedichte deckt sich mit dem "Ich" des Mystikers Blok, das dieser zweifellos als sein eigentliches, wenn auch nur mangelhaft verkörpertes und durch die Gebundenheit an Raum und Zeit verdunkeltes Ich ansah. Bloks personhafte Llebe zu RuBland ist keine literarische Attitiide, sondern Wesensmitte seiner Existenz. Gerade das verleint seinen Gedichten ihren besonderen Charakter und erklärt, daß sich Bloks Tagebicher ohne Bmuch ins dichterische lierk einfigen. Bloks Ausdruck "lyrische Einhelt" 1st nicht formalistisch zu verstehen, sondern bedeutet "mystische Einhelt" (vgl. Bloks Aufsatz "C lirike").

1) Zap.kn., 117f., Eintrag vom 2.6. Cktober 1908.

2) Die Bilder erinnern an indersens Märchen "Die Schneekönigin", das Blok sicherlich kannte (vgl. Zap.kn., 86,91). Der Elntrag bewegt sich ganz in der Topik der "Schneemaske"-Gedichte, ebenso wie das Gedicht "Ja prigvozden k traktirnoj stojke...", III, 168, das zu diesem Eintrag gehört; vgl. III,559f.

3) Es ist rätselhaft, weshalb Kluge, aac, S.195 den zweiten Teil des zitierten Eintrags unterschlägt. Gerade er enthält den entscheidenden Aspekt von Bloks RuBland-Mythos, die Erlösungssehnsucht und die Hoffnung auf den Helden; dieser Gesichtapunkt wird bel Kluge m.E. zu sehr vom elementaren Charakter von Bloks RuBland verdeckt. 
Beleidigten, Bestraften, Elenden, die Gesichter der großen Iiebhaberinnen, der Galla Placidia, der Isotta Malateste und meiner anderen..."

Der Eintrag schließt mit der Bitte an "Sie", wiederzukehren. Der Leidenskelch der Revolution wurde nicht bis zur Neige geleert; damit wurde die Erlösung Rußlands - der "klassischen" Geliebten, Weltseele, unerlösten Natur in einem - verspielt. In Bloks Eintrag verbindet sich Blut-Christi-Mystik und Weltseelenmystik in einer fïr Blok typischen, hybriden Weise. Nicht nur das Gedicht "Ty otoxla, 1 ja v pustyne...",2) das Bloks Gedichtzyklus "Rodina" einleitet, sondern auch der Zyklus "Na pole Kulikovom", der als ein Höhepunkt von Bloks dichterischem Schaffen gilt und im Zentrum des Zyklus "Rodina" steht, entstand aus Bloks Schmerz iber seine ungluckliche Liebe zu Ijuba. 3) Die Entstehung der Kulikovo-Gedichte fällt mit Bloks Bestreben zusammen, den ideellen Gehalt des IS deutlicher herauszuarbeiten, als dies v.a. in der Bahnhofsszene gelungen war. Die dortige Gegenỉberstellung von dämonischer Halbweltdame und schwachem Iiebhaber war wenig geeignet, die eigentliche Bedeutung von Bloks RuBland-Mythos durchsichtig zu machen. Bloks Briefe an seine Frau vom Sommer 1908 zeigen, daB er in Sachmatovo ein ihn tief ergreifendes mystisches Erlebnis hatte.

"Den ganzen Tag ritt ich iber die leuchtenden Felder zwischen Sachnatovo, Rogatevo und Boblovo. Erst neullch. Im Wald zwischen Pokrovskoje und Ivlevo waren immer noch dieselben diinnen Farne, leuchteten die stehenden Gewässer, blühten die Wiesen. Und die unendliche Ferne, und die Chausseen, und immer dieselben unerfillbaren, die seele traurig stimmenden windungen des liegs, wo ich immer allein und im Bunde mit dem Großen war (gde ja byl vsegda odin $1 \mathrm{v}$ sojuze s Velikim), auch damals, als du mich nicht kanntest, und als du mich kennengelernt hattest, und jetzt wieder, wenn du mich vergiBt. Aber es ist ganz wie friber, und ganz dasselbe tiefe Geheimnis, das mir allein bekannt ist, trage ich in mir - allein. Niemand von der welt weis von ihm. Auch du

1) Zap.kn., 153, Eintrag vom 8. Jul1 1909; zu Galla Placidia vgl. III, 98,100; zu Isotta Malateste vgl. IV, 548 .

2) III, 246

3) Vgl. VIII,186f., Brief an seine Frau vom 30. Mai 1907; VIII, $242 \mathrm{ff}$., Briefe an seine Frau vom 6., 14., 24. Juni, 18., 23. Jui1, 2. August 1908. 
willst es nicht wissen. Doch ohne dich hätte ich dieses Geheimnis nicht erfahren. Und folglich habe ich auf dich die Worte bezogen: "Pilr alles, filr alles danke ich dir...",1) wie vielleicht alles, was ich geschrieben, gedacht, wovon ich gelebt habe, wovon die seele so milde geworden ist, sich auf dich bezogen hat."2)

Mit dem "tiefen Geheimnis" meinte Blok die mystische Begegnung mit dem Wesen RuBlands, von dem er glaubte, es habe sich inm in diesen Sommerwochen offenbart. Eine Tagebuchnotiz Bloks vom Mai 1908, die in engem Zusammenhang mit dem IS steht, gibt AufschluB llber den Inhalt seines mystischen Erlebnisses.

"Das gelobte Land 1st der Weg (Zemlja obetovannaja - put'). Der verborgene Kern des "Lieds des Schicksals" liegt in dem, was bisher 1 ch allein weib - und selbst nicht errate."3)

Seine "homo-viator"-Mystik, die das IS durchzieht, bezog Blok in der Fortfihrung seiner Notiz auf Belyjs Gedicht "Kol'co".4) besonders aber auf VI. Solov'evs Gedicht "V zemlju obetovannuju".5) Dieses Gedicht ist elne Paraphrase der Verheißung des gelobten Landes in 1.Mos.12,1 und des Auszugs Abrahams aus Mesopotamien. Blok setzte die Orte bel Šachmatovo, die er durchstreifte, mit den biblischen Orten gleich, die Abraham auf Geheiß des Herrn verließ.

Doch wird bei Blok die "homo-viator"-Mvstik von einer "Relchs"Mystik iberlagert, ${ }^{6)}$ nicht als Ergänzune wie bel Solov'ev, der we1B, daß der Weg ins verhe1Bene Land fihren wird, sondern als ungelöste, antinomische spannung von Weg und ziel, ewiger Wanderschaft und ersehnter Ankunft. Diese Spannung, die im 5. Bild des LS scheinbar ihre Auflïsung findet, beherrscht auch

1) Blok zitiert den Beginn eines Gedichts von Lermontov.

2) VIII,246f., Brief an seine Frau vom 18. Juli 1908. Die Crtsnamen beziehen sich auf Dörfer in der Nähe von Sachmatovo. Es ist die Landschaft der RuBland-Gedichte Bloks (vgl. "Csennjaja vol.ja", II,75f. und "Rossija", III,254f.). Die Kulikovo-Gedichte enthalten mehrere Bilder und Motive, die sich in diesem Brief wiederfinden.

3) Zap.kn.., 107.

4) Blok zitiert Belyjs Gedicht im ersten Kulikovo-Gedicht und Im IS; vgl. S.115/13.

5) Zap.kn., 107. Das Gedicht steht In: Solov'ev, Stichotvorenija, S.85f.

6) Blok zitiert in Zap.kn. ungenau Solov'evs Gedicht: "Bis ich dir sage: halt!" ("stoj!" statt korrekt "zdes'"). 
Bloks Gedichtzyklus "Na pole Kulikovom". 1)

Dieser Zyklus ist von elner mystischen Erfahrung inspirlert, die inn in die Nähe der "Gedichte von der Schơnen Dame" ruckt. Das spiirte auch Belyf, der unter dem Eindruck dieser Gedichte den 1908 unterbrochenen Briefwechsel mit Blok wiederaufnahm. ${ }^{2}$ ) In den Kullkovo-Gedichten ersteht vor dem lyrischen Helden in einer Anamnesis die Nacht vor der Schlacht auf dem Schnepfenfeld. In Jener Nacht der Bangnis vor dem Kampf erschien inm das Wesen RuBlands in einer Lichtgestalt, die ihr Antlitz wie eine nicht von Händen genachte Ikone auf seinem Schild zuriickließ. In Erwartung der wieder bevorstehenden Schlacht erfleht der einsame, umherirrende und von Ängsten und Unsicherhe1t erfiillte Held, Sie möge ihn wleder erleuchten und fir den Kampf stärken, der - viellelcht - das ew1ge Getrlebensein beenden wird. 3)

Die Deutung der Schlacht auf dem Schnepfenfeld als die symbolische Vorwegnahme der drohenden Auseinandersetzung zwischen Volk und Intelligenz, die Blok in seinem Vortrag "Rossifa 1 intell1gencifa" gab, mutet bel den Kulikovo-Gedichten wie eine nachträgliche und von außen herangetragene Sinngebung an. Die Analogie damals-heute wird erst mit dem 4. und 5. Gedicht des 2yklus deutlich und wirkt in der Projektion auf das Problem "Volk und Intelligenz" kiinstlich. Blok selbst sagte zur gegenseitigen Abhängigkeit von KulikovoGedichten, LS und Vortrag:

"Ich schrieb zuerst die Verse, dann das Stifk, dann den Aufsatz - auf ein Thema."4)

Das 5.Bild des LS entstand im wesentlichen zusamen mit den dre1 ersten Gedichten des Kullkovo-Zyklus, der Vortrag mehrere Monate später, aber vor dem letzten Gedicht. Mit den drei ersten

1) Im ersten Gedicht des Zyklus findet sich als Ansplelung auf Solov'evs "V zeml ju obetovannuju" das Bild des Pfells und eine Varlante des "halt!" (Str.6, "ostanov1 !").

2) Vgl. Belyj, Vospominani ja o Bloke (Zap.mett.), S.191 und Blok-Bely j, Perepiska, S.252, Anm.9.

3) Das SchluBgedicht des Zyklus mit seinem Motto aus Solov'ev ist stark apokalyptisch gefärbt.

4) III,588; die Behauptung des Herausgebers VI. Orlov, die Reihenfolge sei in Wirklichke1t umgekehrt, ist falsch. 
Gedichten teilt das 5.Bild den mystischen Charakter und das Fehlen der von Blok in seinem Vortrag hervorgehobenen politischsoziologischen Dimension. Die Behandlung der Kulikovo-Schlacht in Bloks Werk zeigt, daB der Mythos vom "Ewig-Welblichen" das Primare 1st, und daß Blok die politische Wirklichkelt durch das "Prisma des Eros" ${ }^{1)}$ sah. Das komt nicht gerade der Relevanz seiner Aussagen zugute. In den Kulikovo-Gedichten ist Sie die helle, rätselhafte Himmelserscheinung ${ }^{2)}$ und Er der zerrissene, dunkle "fahrende Ritter", der auf Erleuchtung durch Ihre Lichtnatur hofft. 3) Die weibliche Erlösungssehnsucht ist nur angedeutet. ${ }^{4}$ Insgesamt sind die Gedichte von einer keuschen $\mathrm{Zu}-$ rilckhaltung, die wohl ein echter Abglanz der mystischen Erlebnisse Bloks ist. Im Gegensatz dazu durchzieht das gleichzeitig entstandene 5.B1ld des IS eln alle Fesseln sprengender, ins Kosmische geweiteter Orgiasmus.

Faina, die Verk irperung des "ewigen" RuBland, sehnt sich aus dem Zauberbann, in dem sie der alte Begleiter gefangen hält, nach Befreiung durch einen christusgleichen Messias. Sie 1st trotz inrer Aphrodite Pandemos-Hypostase "ewige Jungfrau", die zusammen mit der ganzen Kreatur auf die Ankunft des himmlischen Bräutigams wartet. Gernan, der seine elysische Heimat auf Geheiß des "Geistes der Musik" verlassen, seinen Leidensweg in die Hölle der Großstadt angetreten hat und dort zum Ebenbild des leidenden Christus wurde, entsagt nun dem Liebsten und Vertrautesten und nimmt die in langer, qualvoller Geschichte erduldeten Leiden seiner "rodina" auf sich. Die Menschwerdung im Leiden macht inn zum mïglichen Erlöser. Die Begegnung von German und Faina gleicht einer kosmischen Allvereinigung. Das Neue im 5.B1ld des IS gegeniber der Bahnhofsszene und den ibrigen Bildern 1st, daB Falna völlig ihre Dirnen- und VampHypostase aufgibt und als echtes Volksmädchen die jungfräuliche

1) Volkov, Dramy 1 poemy Bloka, S.94.

2) Vgl. III,250f.(3), Str. 6-8; vor einer allzu vorelligen Identifizierung von Ihr mit der Mutter Gottes muB man warnen.

3) III,251f.(4), Str. 3, 5-7.

4) z.B. Im Schrei der Schwäne, in Ihrem Rufen, Im Bild des Schleiers. 
Braut des Erlösers lst.

Blok glbt seinem Mythos einen "christlichen" Anstrich. Die kosmische Allvereinigung hat Ähnlichkeit mit der endzeitlichen Welterlösung. Doch ist die Aussöhnung von Himmel und Erde kein göttlicher Gnadenakt, sondern Pilgung des Schicksals. Hier findet der Titel des Stilcks seine eigentliche Bestätigung. German ist nicht der Gottessohn sondern Orgiast. Faina ist nicht die zur Sophia verklärte Weltseele, sondern die Schicksals- und Llebesgöttin, die sich in "heiliger Hochzeit" mit dem göttlichen Partner verbindet. Die Allvereinigung ist vergänglich wie die "heilige Hochzeit" der antiken Allgöttin mit ihrem nur fir kurze Zeit ebenbiirtigen Partner. Sie ist eine Gabe des Schicksals, des ewigen Kreislaufs der Jahreszeiten, des blinden Weltwillens, und sie wird wleder gelöst, um erneut erhofft zu werden.

Faina und Gernan können "die Mauern des alten Gefängnisses, aus dem das Heldentum auszubrechen strebte", nicht durchbrechen. Es bleibt die Hoffnung, daß eines Tages der ewige Wechsel von Enttäuschung und neuer Hoffnung, von Sehnsucht und Erfullung, von Chaos und Kosmos auf der Stufe einer alle Gegensätze aussöhnenden Harmonie angehalten werde. Die Hoffnung auf Endgiiltigkeit der Erlösung, der chillastische Unterton in Bloks Schicksalsglauben, ist ein letzter Nachhall christlicher Heilserwarting. 
S.81/1 Dieses Bild beginnt im Herbst vor Sonnenaufgang. Der Schauplatz ist das thergangsgeblet von Stadt und Land (vgl. Dostojevskijs "Chozjajka").

S.81/2 Das ist die weite russische Herbstlandschaft, ein fast irreales Bild des "ewigen" slavophilen RuBland, wie es Blok in ähnlicher Weise in "Stichija 1 kul'tura" beschwor (vgl. V,357, 21t. im Exkurs "Blok und der "Raskol"", S.478).

S.81/3 Die Elsenbahn ist das Symbol des industrialisierten Rußland, das sich hier mit dem bäuerlichen Rußland trifft. S.81/4 Zum Bild des ruhigen, entfernten Brandes vgl. $\mathrm{S.82/8}$. S.81/5 Ein ăhnliches Bild einer in der Ferne liegenden Stadt findet sich in Cechovs "Vibnevyj sad" (Regieanweisung zum 2.Akt).

S.81/6 Der Schwan ist ein Attribut der Faina (vgl. S.44/6 u. 7; S.49/5; S.82/1;S.84/9;S.88/16; als Attribut der sphrodite $S .48 / 12$ ).

Der Schauplatz des 5.Bildes wurde von Blok zwar nicht näher bezeichnet, es ist jedoch offenkundig, daß er in der Regleanweisung des 5.Bildes das kandgebiet Petersburgs im suge hatte. Die verschiedenen Elemente der Zivilisation (Fabrikschlote, Stadttirme, Eisenbahn), der Natur im Zwischenzustand (fiberwachsene halbfertige Gebkude, Park) und der unberfinrten ivatur (kbene, Flußabläufe, Herbstwälder) trafen v.a. in den nördlichen Vororten der Hauptstadt zusammen, die Blok häufig besuchte. Dieses Gebiet und seine Landschaft hatten fir Blok eine ähnlich mystische Bedeutung wie die Gegend von Sachmatovo. such hier glaubte er, dem echten, "magischen" RuBland zu begegnen, in dem der Seelenzustand einer mythischen Vorzeit noch bewahrt war. Uber Petersburg und seine Vororte schrieb Blok an Je. P. Ivanov:

"Ich schreibe dir jetzt so, weil in mir wieder eine $8 \mathrm{chreckliche}$ lut auf Petersburg kocht, denn ich weiR. daß das ein verfluchter fauler Kern ist, wo unsere Kithnheit sich abquält und welkt, umgeben von Abgrifinden und grundlosen Silmpfen, wie sie das menschliche uuge noch nicht gesehen und das ohr noch nicht gehört hat. Ich schmiegte mich an die Randgebiete unserer stadt 
und weiß, ja ich wei $\beta$, daß dort noch lange der Wind kreischen wird, die Teufel umgehen werden, die falschen $\mathrm{Za-}$ ren (samozvancy) in die Faust pfeifen werden! Noch lange wird bei Lachta die offenbarung umgehen, die Röte des Himmels wird die Brust erregen und sie mit dem Salz der Iränen liberschüten, und die Welt-Unsagbarkeit (Mirovaja Neskazannost') wird einen aus der Kloake ziehen. Doch wir leben täglich - in Schrecken, Gestank und Verzweiflung, im Qualm der Fabriken, im Geprassel geilen Grinsens, in der Schamröte widerilcher sutomobile... Ich spiire, Petersburg ist ein riesiges Freudenhaus." (VIII, 130f.: Brief vom 25. Juni 1905).

تinige der schönsten Gedichte Bloks sind in den Vororten Petersburgs entstanden und geben deren Atmosphäre wieder, so v.a. das Gedicht "Neznakomka". Es entstand in Ozerki, einer kleinen Bahnstation $10 \mathrm{~km}$ nördlich von Petersburg (vgl. Ivanov, Zanisi ob $A$. Bloke, in: Blokovskij sbornik, S.406, Eintrag vom 9. Viai 1906; P1s'ma A. Bloka, S.133, snm.29). Ther Bloks ausgedehnte Streifzlige in die Ungebung Petersburgs berichten viele Briefstellen, Tagebuchnotizen und sussagen von Zeitgenossen (vgl. Orlov, 3lok, in: Literaturnyje pamjatnyje nesta Leningrada, S.505ff.; zu Czerki vgl. noch VIII,349ff., Briefe an Pjast und an seine iutter vom 3. bzw. 5. Juli 1911; "Sedoje utro", II,207f.; Zan.kn., 183, iintrag vom 3. Juli 1911). Der schauplatz des 5.Bildes ist wahrscheinlich von der Gegend un Suvalovo, Czerki, Pargolovo und die Station Udel'naja insniriert. Lie Begegnung Germans mit Faina im 5.31ld konnte mit ihrer chiliastischen Jimension von Blok nur in eine Umgebung verlegt werden, in der die "ilirovaja Neskazannost'" noch erfahren werden konnte. (Um die Jahrhundertwende begann das nördliche Randgebiet Petersburgs schon mit den "Kulikovo pole", einer Gegend östlich der Kulikovskaja ulica. Eine Beziehung zu Germans Beschwörung der Schlacht auf dem "Kulikovo pole" (vgl. S.87/15) ist nicht auszuschlieren.).

5.81/7 Die iroika ist das Symbol des echten Rußland. Blok hat das Bild der dahinfliegenden Iroika aus Gogol's "iertvyje Duši" (1.Bd., Ende des 11.Kap.; Gogol', Sobr. sot., 3d.5, S.287f.) mehrmals aufgegriffen ( $V, 327 f .$, $343 f ., 347,353)$. Ihr Gegenbild ist die Eisenbahn, das Symbol des laschinenzeitalters. Sie hat die "uneinhol- 
bare Trolka Gogol's flberholt" (V,347). Vgl. S.90/8. Der Windstoß und der Schellenklang der Troika sind dynamische Begleitsymbole der Faina.

S.81/8 Der Sarafan ist ein langer, armelloser Leibchenrock und wichtigster Teil der russischen weiblichen vationaltracht.

Faina tritt in diesem Bild als russisches jlädchen auf. Sie erscheint auf der Buhne als das Person gewordene russische Land. (Ein äuBerlich sehr ähnliches Bild konnte Blok in Gogol's "laras Bul'ba" finden. Die schöne 'iatarin, die indrej in die belagerte stadt fllhrt, wird vom "iderschein einer fernen Feuersbrunst" beleuchtet. Gogol', Sobr.sod. Bd.2, S.87). Der Feuerschein fiber inrem Haupt gleicht dem Nimbus einer Heiligen oder der Gloriole der Gottesmutter. Im suftreten der Faina ist der Einflup der christlichen Symbolik an dieser stelle besonders deutlich.

S.81/9 In Fainas Erregung drfickt sich ihr iunsch nach Erlösung aus. (Vgl. S.84/11).

S.81/10 Nach dem Zeugnis von Bloks Frau verbirgt sich in der Gestalt des traurigen Begleiters der Faina Graf itte. (Vgl. Hedvedev, Drany 1 poemy A. 3loka, S.67). Graf S.Ju. iitte stammte väterlicherseits aus einer baltischen Familie holländischer Herkunft. Er wurde 1892 Pinanzminister und 1903 Vorsitzender des iinisterrats der zaristischen legierung. ir strebte die lodernisierung .ußlands durch Unwandlung des veithin agrarischen Staates in einen Industriestaat nach westeuropäischem Vorbild an. während seiner smtszeit machte die Industrialisierung .uBlands rasche Fortschritte. Witte wurde geradezu zur "Symbolfigur der Industrialisierunge- und sodernisierungsnolitik" ('Thalheim, in: .ußlands sufbruch, S.99) im iußland der Jahrhundertwende. Besonders tatkrăftig förderte initte den susbau des missischen lisenbahnnetzes, v.a. der iranssibirischen Eisenbahn. ifites hirtschaftsnolitik ffihrte zu einem starken kindringen ausländischen Kapitals und ausländischer inanziers nach kuRland (Hughes, Brfider 
Nobel). Bei den revolutionären Unruhen von 1905 trug Witte entscheidend zur Rettung der Monarchie bei, indew er den Zaren Nikolaus II. davon flberzeugte, daß nur die Gewährung einer Verfassung und eines Parlaments den Elan der Revolution $z u$ brechen vermochte. Als ifinisterpräsident der ersten Kabinettsregierung mußte Witte jedoch im Mai 1906 reaktionären Kräften weichen. Witte hatte in der Außenpolitik imner zur Zurlickhaltung gemahnt, da er klar erkannte, daß kriegerische Verwicklungen die inneren Reformen blockierten. Nachdem RuBland gegen seinen rat in den Krieg gegen Japan eingetreten war und schwere Verluste erlitten hatte, gelang es dem fiberlegenen Verhandlungsgeschick Wittes, in den Friedensverhandlungen mit Japan, die im September $19051 \mathrm{n}$ amerikanischen Portsnouth stattfanden, einen filr RuBland sehr vorteilhaften Friedensvertrag abzuschließen. Innen- wie außenpolitisch hat somit Witte entscheidend zur Rettung der Monarchie vor den Stilrmen der Revolution von 1905 beigetragen. (Vgl. Stökl, Russische Geschichte, S.532ff., 565ff., 6ooff.; Fischer-Lexikon Geschichte in Gestalten, IV, S. $287 \mathrm{f}$.).

In Witte, den Blok im September 1902 persönlich gesehen hatte, verkörperte sich die Verwestlichung der zaristischen sutokratie. Nicht nur die Vertreter der wirtschaft und der Verwaltung, sondern sogar die höchsten Repräsentanten des Staates waren "susländer". Das gilt im Grunde sogar fior die Zarenfamilie.

..81/11 Mit dem Bild des traurigen, auf einen Stein sitzenden Begleiters, schließt das 5.Bild (vgl. S.90/9). "Das Sitzen auf einem Stein symbolisiert im apos die Verzweiflung (vgl. A. Veselovskij, Band 3)" (v. Sklovskij, Sentimentale Reise, S.246f.). Blok kannte die Arbeiten A.N. Veselovskijs zur russischen Folklore recht gut. Bei seiner eigenen Beschöfigung mit der Folklore stiltzte er sich u.a. auf den damals berfihmtesten russischen Iiteraturwissenschaftler (vgl. V,568ff. und "Poezija zagovorov 1 zaklinanif", $V, 36-65)$. Es ist recht wahrscheinlich, daß Blok dieses Bild aus Veselov- 
skij kannte.

S.81/12 Der Begleiter der Faina hat Ähnlichkeit mit einem Märchen-Greis (langer Bart). Die Bedeutung des kostbaren Rings ist unklar, denn die Symbolik des Rings ist sehr vielfăltig (vgl. Forstner, lielt der Symbole, S.434ff.). Wahrscheinlich ist der Ring hier Symbol der ilacht. Der Edelstein soll vermutlich auf die Zauberkraft des Ringes hinweisen. In Wagners "Ring des Nibelungen" schenkt der Ring aus dem iheingold selnem iräger unbeschränkte Hacht, wenn er der Ilebe entsagt.

S.82/1 Das ist eine snspielung auf das ifächen der slten (vgl. S.77/3). Wieder erscheint der Schwan als Begleitsymbol der Faina.

$\mathrm{S.82/2} \mathrm{Vgl}$. S.81/7.

S.82/3 Diese Passage und eine Passage weiter unten (S.84/7) entwickelt den Gegensatz Schlaf - Sturn. Faina kann nur einen der beiden Zustände ertragen. Ias Erwachen oder das sufhören des windes ist fïr sie gleichermaßen unerträglich. Blok greift hier seine Idee vom erwachenden russischen Volk auf (vgl. die susfihrungen des izannes mit Brille S.73 und Einleitung zum 4.Bild, S.257f). Das erwachte kuRland gleicht der Iroika. Jinen Zwischenzustand $z$ wischen Schlaf und vorwärtsdrängender iynamik kennt surland-Faina nicht.

S.82/4 lier 1st die erotische Unerfilltheit der iaina besonders augenfällig.

S.82/5 Die physische Schwäche des Begleiters, die Verschiedenheit seines iesens von dem der Faina, die Hoffnungslosigkeit seiner Llebe, sein wissen darum, daß sie ihn verlassen will, - all das mu? auch als kussage Bloks llber den Charakter der musischen Staatsmacht gewertet werden. Bloks Verheiltnis zum russischen zaristischen Staatsapparat war eine lilschung von Haß und Ekel. (Vgl. Bloks Brief an seine intter vom 13. April 1909. VIII, 281; "Solnce nad Ross1jej", V,301-303, oder das Poem "Vozmezdije", 2.Kap.. III,328). 
S.82/6 Im russ. Text steht: "Za takuju ljubov' - b'fut!" Der Sinn ist unklar. Vielleicht soll an den Peitschenhieb, den Faina German gab, erinnert werden.

S.82/7 Wieder taucht das ilotiv des Fernwehs auf (vgl. 1.Bild: S.49/5; S.54/2; 2.Bild: S.55/8; S.56/4;6.B1ld: S.93/3).

S.82/8 Das Riechen nach Verbranntem ("pachnet gar'ju") ist bei Blok häufig zu finden. (Vgl. z.B. "Novaja Amerika", III, 268ff., Str.8; "Vozmezdije", III,301ff., Z.40; Pis'ma $k$ rodnym I, S.225, Brief an seine liutter vom 7. Aug. 1908). Es gehört zur Symbolik des Feuerbrandes, die besonders im Zyklus "lia pole Kulikovom" (III,249ff., 4.Ged., Str.4) deutlich ist:

"Ich sehe itber ikußland in der Ferne

Einen weiten und ruhigen Brand."

(Vgl. dazu "Rus"", II,106f., Str. ${ }^{x}$; "Rus' moja...", III,259, Str.5; "Dvenadcat'", III,347ff., v.a. Str.3 in (3)). Die Verbindung der Feuer-Symbolik zur kpokalypse ist besonders deutlich in Bloks Gedicht "Požar" (II,201f.). Die Vision der brennenden Stadt, durch die das anokalyptische Pferd liber einer erschreckten Menge dahinjagt, erlischt:

"liein, wieder erlöschen die Gebäude,

liein, wieder hat es getrogen, -

Des fernen atuf stands

iFahendes Getöoe." (Str. 7)

( (ur Feuer-Symbolik vgl. S.56/6).

S.82/9 Fainas Position gleicht der, in der sie tiber dem Flu? stehend auf den Erlöser wartete (rirzählung des itönchs, S.56, liärchenszene, S.77). Ihre irinnerung an diese Episode ( 5.83 ) zeigt, daß es sich in der ersten Szene des 5.Bildes um eine art wlederholung des wartens am Fluß handelt.

$5.82 / 10$ Die Replik des Begleiters zeigt, daß dieser nur die Sängerin Faina kennt. Die eigentliche Natur seiner Geliebten bleibt inm völlig verborgen.

S.82/11 Russ. "rusyj" (hellbraun, dunkelblond) stammt etymologisch von ${ }^{+}$rud- (vgl. lat. russus). Schon im 16. Jhdt. wurde es - im Zusammenhang mit der Lehre von Moskau als dem dritten Rom - volksetymologisch mit dem Namen "Rus'n 
(RuBland) in Verbindung gebracht. Hierher gehört auch das Sprichwort "Russkif narod - rusyj narod." Paina ersehnt sich einen "russischen" Brăutigam, der sie aus der Gewalt des "auslandischen" Begleiters befreien 8011 .

S.82/12 Die Augen in der russischen Folklore sind normalerweise "licht" ("jasnyje oti"). Vielleicht 1st an dieser stelle rus8. "seryj" (grau) mit "blau" zu ubersetzen. Im Altrussischen bezeichnete "seryj" die blaue Augenfarbe (heute wird dafur "goluboj" verwendet).

S.82/13 Blok verwendet den recht gebrauchlichen Ausdruck "progl jadet' (vse) glaza" (sich die Augen aussehen) mit dem gesuchteren "oti" anstelle von "glaza". Offenbar soll damit die Folklore imitiert werden. Beachtenswert ist die wiederholung der Augen-Symbolik.

S.82/14 Die Freundin des Hohen Lieds lst "strahlend wie die Morgenröte" (HL 6,10).

$\mathrm{S.82/15} \mathrm{Vgl}$. damit Germans Monolog, S.88/1. Das Bild des Schleiers 1st traditionell und besonders in der christlichen Braut-Mystik weit verbreitet (vgl. dazu Forstner, Welt der Symbole, S.462ff.). Der Schleier ist das Attribut der jungfraulichen Himmelsg bttinnen (Iris, Maja, Venus, Maria). Im Bild des Luftens des Schleiers, des "Erkennens" (Schiller: "Der Venuswagen", "Die Kunstler", "Das verschleierte Bild zu Sals"; Hölderlin: "ThaliaFragment"; Novalis: "Die Lehrlinge zu Sais") verschmilzt, ăhnlich wie im Bild des Gürtellobsens, erotische und naturmystische Symbolik. Bei Schopenhauer und Nietzsche ist der Schleier der Maja das Symbol der Scheinwelt der auBeren Realitat; das Einswerden mit dem Urgrund des Seins, die "Zerreissung des principil individuationis" ist die "Vernichtung des Schleiers der Maja" (Nietzsche, Die Geburt der Tragodie, 70, S.55f.). Blok kannte Vjac. Ivanovs Bild des Schleiers der Maja, der "die Welt, das Ganze" bedeckt und verbirgt (vgl. V,16). In der Replik der Faina verbindet sich das personhafte Moment des Schleier-Symbols mit dem raumhaften im Nebel-Symbol. 
Das Bild des Nebels ist im mystischen Vokabular so traditionell wie das des Schleiers. Es hat denselben Wert ("Unerkanntes". "Verborgenes") in Beziehung auf die răumliche, landschaftliche, kosmische Sphäre des mystischen Cbjekts. Die Gleichsetzung von Kosmos und Frau (Gottin Natur, Solov'evs ieltseele, Bloks Ewig-weibliches), die im 5.Bild des LS in der Gestalt der Faina sichtbar wird, erklärt die Verbindung von raumhafter und personaler Symbolik. Die Verbindung von Schleier- und Nebelsymbolik mit derselben Vermischung von Erotik und Naturnystik wie in IS findet sich in Bloks "Skazka o toj, kotoraja ne pojmet jeje". Die rätselhafte, nächtliche Schonheit bedeckt sich "mit einem weichen Nebel der Unnahbarkeit, wie mit einem Brautschleier" (Blok, Sobr.soc. 7 t., Bd.4, S.141). such in Bloks Gedicht "Neznakomka" verbindet sich Nebel- und Schleier-Symbolik (II,185f., Str. 710; zum Nebel-Symbol vgl. Solov'ev, Stichotvorenija, S.227; Blok, I, 31, 48, 78, 89, 100 u.v.a.; II, 105, 136, 137, 183f. U.a.; im Gegensatz zu Bloks frthen Gedichten hat das ijebel-Symbol im 2.Band neben der mystischen eine stark lokale, Petersburger Färbung.). Hinter dem dunklen Schleler der "Unbekannten" (vual' ist hier der Schleier der Dirne, was ebenfalls auf eine lange iradition zurijckpeht) liegt "ein verzaubertes Ufer und eine verzauberte Ferne" (II,185f., Str.10). Die Symbole "Schleier" (vgl. noch II,187f.) und "Ferne" kehren in ähnlicher ieise im Zyklus "Faina" wieder, diesmal in Verbindung nit Bloks "russicher" Schneesturmlandschaft (II,254I., str. 7).

Die Farbe Blau (eine Leitfarbe der Blokschen "Unbekannten"), hə̈ufig in Verbindung mit Weiß (im LS "blaue liebel") ist die traditionelle Farbe der Jungfrau Marla (vgl. Forstner, aao, S.125). Die Blau-Symbolik beherrscht die Darstellungen der Maria im abendlkindischen Mittelalter und in der Renaissance, die Blok bestens kannte (vgl. Al'fonsov, Slova 1 krask1, S.63-88. Leider hat Peters, Symbole der sinnlichen Wahrnehmung, S.122ff. 
in ihrer sonet aufschlußreichen Untersuchung auf diese naheliegende und fitr Solov'ev wie flir Blok maßgebende Tradition nicht hingewiesen.).

Ahnlich wie im Monolog des Mannes mit Brille (S.73) erscheint Faina hier als personifiziertes russisches Land.

S.83/1 $\mathrm{Zu}$ den "klaren" oder "lichten" fugen vgl. S.82/12.

$\mathrm{S.83/2} \mathrm{Vgl} . \mathrm{S.82/3}$.

$5.83 / 3$ such hier verwendet Blok einen Topos aus der russischen Folklore; vgl. S.77/2.

S.83/4 Die Erlösungssymbolik ist offenkundig.

S.83/5 Wer hier mit "sie" gemeint ist, bleibt etwas unklar. In Gedicht "Vse b tebe Zelat' vesel'ja..." (III,173) 1st das "schwarze Gefieder" (Str.2) und der "tote Kuf der Raben" (Str.4) Symbol filr das Einbrechen des Bösen, das die dionysisch-unbändige Heldin bedroht. Auf Faina als Person bezogen sind "sie" wohl die vielen dänner, die un ihre Gunst werben. Auf Faina als Verkörperung KuBlands bezogen sind "sie" wohl die vielen "Usurpatoren" und "Gewaltherrscher", die RuBland erdulden mußte. Das Bild der Raben, die liber Faina kreisen, erinnert an Bloks bekanntes Gedıcht "Koršun" (III,281; vgl. dazu "Vozmezdije", 1.Kap.. III,304ff.. Vers 596-615). Lie kaben sind in der Zadonščina $(S .13)$, im Igorlied $(17,7 ; 23,14)$ und in der russischen Folklore Unglifksvögel. (kaben als symbol filr die "Heiden, Juden, sbgefallenen, Irrlehrer und Ungläubigen": vgl. Forstner, "ielt der Symbole, S.254f.)

S.83/6 Der ersehnte Bräutigam ist der Beschittzer, der wie ein Gott iber ihr wacht. Einzelne Bilder erinnern an das Mrarchen der Alten (v.a. das "Schwanenlager"; vgl. S.76f.).

S.83/7 Der susdruck "krasnoje solnce" findet sich häufig in den Bylinen. Er ist mit "schöne Sonne" zu fibersetzen (vgl. Trautmann, Die Byline, S.73). Da im LS die Folklore nachgeahmt wird, ist diese Ubersetzung auch hier angebracht.

S.83/8 In diesem Bild gibt Faina ein weiteres ilal ihrer Sehnsucht nach Erlobung Ausdruck. Die wiederholung durch German (vgl. S.88/2) kfindigt an, daR Fainas bunsch kurz vor der Erffilung steht. 
S.83/9 Der Begleiter wird von der Elementarkraft des Sturms nicht erfaßt. Hier wird deutlich, das inn die Lebenskraft verlassen hat. ( $\mathrm{Vgl}$. dazu S.52/11).

S.83/10 Diese Replik wirkt komisch, denn sie past schlecht $2 u$ der ganzen Szene. (Vgl. S.82/10).

S.83/11 Hier wird die Erzählung des Monchs vom 2.Bild (S.56) wiederholt.

S.83/12 Diese Passage erinnert an die Klage der Jaroslavna im Igorlied (IL37, 18ff.; $\nabla g l . S .83 / 18$ ).

S.83/13 Fainas Warten hat schon fast zu lange gedauert. In F1 folgt auf den Satz: "Du hast mich getauscht." eine längere Passage: "I ch habe wunderbare Träume gesehen: wie es Frihling war und der Wind weinte, zu mir auf einer Eisscholle ein so schlanker und heller Jüngling... er brennt und strahlt... als sel er Christus selbst... Er schwimt daher und lachelt mir zu, und schwimmt davon, verschiindet in der Ferne, hinter Birken, im grauen Himmel... Ist dir das zu wenig?" (Abw. 239)) In F2 steht diese Passage fast wörtlich schon im Märchen der Faina (4.Bild, Garderobe der Faina, S.77). Blok hat eine wiederholung im 5.Bild vermieden. In F1 hat diese Passage dagegen ihre Berechtigung, denn da fehlt das Bild in der Garderobe der Faina. Zum Satz "Ich habe Träume gesehen" vgl. S.84/2, das Zitat aus Ostrovskijs "Groza".

$5.83 / 14$ Hier vird in anderer Form wiederholt, was der "Mann mit Brille" "iber die Lieder der Faina sagte (vgl. S.73/ 4). In dieser Replik ist Faina nicht die Estradensăngerin, sondern das Person gewordene "musikalische", kinstlerische Volk, das seine Lieder "in die Freiheit entläßt".

S.83/15 Faina 1st hier wieder die schicksalhafte Göttin, die Herrscherin der Welt (vgl, S.48/12, Abw. 44) und 46)). In dieser Passage scheint wieder das grausam-allmächtige Frauenideal des fin-de-siècle durch. (Vgl. Praz, Liebe, Tod und Teufel, Bd.1, 4.Kap., S.167-250). 
S.83/16 Dieser nusdruck stammt aus der Bibel (5.ivos.32,10; Psalm 17,8). Er wirkt hier etwas befremdich.

S.83/17 Diese Passage erinnert sehr stark an eine stelle in Gogol's "laras Bul'ba": Ler Kosak sndrij ist in die gegnerische Stadt eingeschlichen und der wunderschönen Polin begegnet. Sie ist von seiner Leidenschaft betroffen und auf seine Frage, weshalb sie so traurig sei, gibt sie zur Antwort:

"Bist du nicht nein grimmiger ilenker, on du nein grausames Schicksal? slle hast du (d.h. "Ch Schicksal"L...) Mir zu ïipen geleg,t: die besten jilen der ganzen Schlachta, die reichsten Pane, Grafen und fremdlindischen Barone und alle, die die Blite unserer Ritterschaft ausnachen. alle wollten meirie ilebe erringen, und jeder hätte sie als gropes Glilck betrachtet. Ich hatte nur mit der iand winken brauchen, und jeder von ihnen, der Schönste, der ierrlichate an Gestalt und Herkunft, Wäre nein Gatte geworden. Doch f"ir keinen von ihnen hast du mein Herz verzaubert, du mein prausames schicksal, sondern hast nein lerz verzaubert, vorbei an den besten selden unseres Landes, fir einen 'renden..." (Sohr.sot., Bd.2, S.97).

Grope AhnIichkeit mit dieser Passage hat auch eine Stelle in Gor'kijs "iakar Kudra". "berhaunt stehen die lepliken der jaina in proper iohe zu dem etwas hubriden Folklorisךus des "iaras jul'ba" und des "i:akar Cudra". jas lotiv der feinheit trotz aller s:nfechtungen kehrt in öhnlicher rorn in 3loks Gedichten wierer, z.i?. in "Rus'" (II,106f.):

"... sie hat ihre

lirsurfingliche Schönheit nicht befleckt." (str.10)

und "rossija" (III,254f.):

"Ich kann dich nicht bemitleiden

Und ich trafe behutsan mein śreuz...

Gib jeden Zauberer, dem du willst,

Deine däuberschönheit hin!

Soll er dich verlocken und betrifgen, iu wirst nicht untergehen, nicht verschwinden..."

(str. 3 und 4 )

(Vgl. die Äußerungen des iannes mit brille iber die Unvandelbarkeit des wesens kußlands; 's. $7^{2}$ ). Blok greift hier wieder das iotiv der "reinen jirne" auf. Paina, die Halbweltdame, erweist sich als jungfräuliche Schön- 
heit, die sich nach wahrer Liebeserfllluung sehnt. (Vgl. S.77/4).

S.83/18 Diese Bitte an den wind und an den Fluß, dem liebsten Kunde zu bringen, ist eine deutliche inspielung auf die Klage der Jaroslavna in "Igorlied" (38,6ff.). Jaroslavna wendet sich an den inind ("O vetre, vetrilo!"...) und an den Dnepr ("C Dnepre Slovuticju!..."), der ihren Liebsten zu ihr zuriicktragen soll.

iie entsprechende Stelle in der "Zadonšxina" (Satz 94ff.) enthält die snrede an den iind nicht.

j.94/1 Hier wird die Gestalt des Begleiters mit einer bisher fehlenden Iinension versehen. Er hat iber Faina eine geheinnisvolle vacht, der sie sich aus eigener kraft nicht entziehen kann. Las erinnert an Dostojevskijs "Chozjajka" und besonders an Gogol's "Strašnaja mest'". (Vgl. Grossman, Dostojevskij, S.95f., der auf die Ähnlichkeit dieses jotivs in beiden werken hinweist.). ias letztere werk und vor allem die Deutung, die Belyj der vani Katerina in seinem lyrischen sufsatz "Lug zelenyj" (Vesv, 1905, iir. 8, S.5-16) gegeben hat, haben auf Blok großen ilndruck genacht (vgl. Bloks Brief von 2. Ckt. 1905, VIII,135ff.; "Bezvrenen'e", V,66-82; iotizen zu diesen sufsatz, Zan.kn.. 70, lintrag von cuni unter "kraski i slova"). ier suisatz Belyjs ist eine Hymne auf die russische liatur und die Schönheit des russischen Landes. Belyj versucht, aus einer Gegeniberstellung von jechanistischer und organischer ielterklärung die Vision eines zukiinftigen kuBland zu entwickeln. kuBland ist fiir ihn ein in der Zukunft zu verwirklichendes "transzendentes Ideal" (S.5), das er symbolisch als eine auf Erlösung harrende Schönheit darstellt. Erst wenn diese Schönheit. diese Pani Katerina der Gogol'schen irzählung "Strašnaja nest"", aus den Schlaf erwacht ist, kann sie wählen: den ieg des Lebens in einer Entwicklung der Gesellschaft $z u$ einer Gemeinschaft (obłcina) von lebensvollen Individuen, oder den $\mathrm{Heg}$ des Iodes in einer sutomatisierung der gesellschaftlichen Kräfte. 
"Noch unlangst schlief RuBland. Der Weg des Lebens wie der Weg des Todes waren gleicherweise ferne von ihm. RuBland glich der symbolischen Gestalt der schlafenden Pani Katerina, deren Seele der schreckliche Zauberer gestohlen hatte... Pani Katerina muB... entscheiden, wem sie ihre Seele hingeben soll: entweder dem geliebten Mann, dem Kosaken Danil, der gegen die fremde Invasion kämpft, um fur seine schóne das vertraute Aroma der grínen Fiur zu erhalten, oder dem Zauberer aus dem fremden Land... In den kolossalen Gestalten der Katerina und des alten Zauberers hat Gogol' auf unsterbliche Weise die Qual der schlafenden Heimat (rodina) ausgedrflckt, - einer Schönen, die am Scheideweg zwischen mechanischer Abgestorbenheit (mertvennost') und urspringlicher Primitivität (pervobytnaja grubost') steht" (S.6f.).

Der Erlösungsmythos, der Belyjs Aufsatz zugrunde liegt, und die Vision eines archaisch-naturhaften, heidnischen RuBland von dionysisch-orglastischer Urnatur, haben Blok mehr angesprochen, als Belyjs pseudowissenschaftliche soziologische Ausfithrungen. Belyjs fremdländischer Zauberer, der sich die schone unterwirft, ist das Symbol des Kapitalismus, der im Bundnis mit der herrschenden Macht des Zarismus den freien russischen Raum mit einem Netz toter stadte, Fabriken und siedlungen bedeckt. Blok hat das Bild des alten Zauberers ofters gebraucht: z.B. in "Rus"" (II,106f., Str.2; das Gedicht zeigt deutliche spuren von Bloks Beschäfigung mit der russischen Folklore) und in "Vozmezdife" (2.Kap., III,328, Z.1-24; hier ist Pobedonoscev der alte Zauberer, unter dessen Blick die schlafende Schönheit RuBland dahindämmert. Vgl. dazu "Solnce nad Rossijej", V,301-303, wo Pobedonoscev als "alter Vampir" bezeichnet wird.). Im September 1908 hatte Blok Bram Stokers "Graf Dracula" gelesen. Er war von dem Roman sehr beeindruckt (vgl. VIII,251, Brief an Je.P. Ivanov vom 3. Sept. 1908; Zap.kn., 115, Eintrag vom 28. Sept. 1908). Der Vampir bzw. der alte Zauberer sind symbol fur die Macht des Bobsen. (Vgl. zur Symbolik des "alten Mannes" in Traum und Mrrchen auch C.G. Jung, Bewubtes und Unbewubtes, S.10off.. Auf S.112ff. wird der negative Aspekt des Archetypus besprochen.). 
S.84/2 Faina erscheint hier als Verkörperung der Weltseele, die sich nach Befreiung aus der Macht des Bösen sehnt. Die bisherigen Repliken der Paina im 5.Bild haben $\mathrm{Ahn}-$ lichkeit mit einigen Passagen aus A.N. Ostrovskifs Drama "Groza". Die Darstellung der Katerina in diesem Stilck durch die Schauspielerin Vera Kommissarževskaja war ein Höhepunkt der russischen Theatergeschichte. "Die Musik der Stinme, die irauer in den Worten waren 80 groß, daß man den Eindruck hatte, hier sehnt sich die Veltseele, die Heilige Sophia Solowjews, nach der kflckkehr in den Schoß Gottes." (Stepun, Nystische Weltschau, S.235). Stepun bezieht sich hier auf den 5.akt, Bilder 2 und 4. Fiir Blok war offenbar das 7.Bild des ersten aktes besonders eindrucksvoll ( $\nabla \mathrm{gl} . \mathrm{V}, 276)$, in dem Katerina von inrer in traumhafter Sorglosigkeit verbrachten iladchenzeit erzahhlt. Dabei kommt das Innerste ihres inesens zun :orschein.

".ie ausgelassen war $1 \mathrm{ch}$ doch! filer bin ich ganz verwelkt.... Ich lebte ohne mich zu sorgen, wie ein Vöglein in der Freiheit... was ich wollte, das tat ich. ...icn brauchte nichts, alles hatte ich zur Genfige. ind welche iräume ich träumte, ...welche Präume. Es war als ob ich fliege... In der wacht kann ich nicht schlafen, ich spirre ein flilstern: jemand redet mit mir so zärtlich, girrt und kost vie eine jaube ... es ist, als kisse mich jemand so heiB, und fihre nich fort, und $i \mathrm{ch}$ folge inm... Ind mich ergreift der Gedanke, da $1 \mathrm{ch}$, wenn ich die Freiheit hätte, jetzt auf der Volga im Boot fahren wirde, mit Iledern, oder auf der Iroika dahinjagen wifde, unter iffssen..."

whrend die Sehnsucht der Katerina nach Freiheit und

Liebeserfillung den realistischen Rahmen von Ostrovskijs stick nicht sprengt, ist bei Blok der Symbolbezug fast peinlich direkt.

S.84/3 huch diese kurze Regieanweisung zeigt, wie sehr das LS ein Iesedrama ist (silbernes Echo!).

S.84/4 Vgl. S.75/3.

S.84/5 Diese Passage knilpft an das in $S .84 / 1$ flber die Pani Katerina und Kußland als schlafender Schönheit Gesagte an. Faina will sich aus der Zaubergewalt des Begleiters befreien. (Vgl, auch $\mathrm{S} .77 / 8$ ). 
S.84/6 Blok nimmt an dieser Stelle Bezug auf die Wutter-ErdeMystik, in der sich die russische Volksfrömmigkeit und die romantisch geprägte Iiteratur und Philosophie des 19. Jhdts. begegnen. Die Erde galt dem russischen Volk als hellig und sie blieb, unter den Deckmantel des Christentums, in einer weise Gegenstand religiöser Verehrung, die ganz deutlich auf die vorchristlichen wurzeln des Erdmutterkultes verweist. (Vgl. Cnasch, Einfihrung, S.222; Kologrivov, Das andere Rußland, S. 158-166. Hier sind zahlreiche Beispiele fir die religiöse Verehrung der Mutter Erde in der russischen Volksfrömmigkeit aufgefiuhrt, so auch der "Schwur bei der Erde", die "Belchte an die ïrde", die "Bitte an die trde um Silindenvergebung" etc.).

In der mssischen Kunstliteratur findet sich ein ähnlich religiöses Verhältnis zur \},rde im .erk Dostojevskijs. (Vgl. v.a. "Brat'ja karamazovy", 6. 3uch, 2. und 7. Buch, 4 ; "Son sne snogo Celoveka". III; "Prestuplenıje i nakazanije", "Peil 5, IV und Teil 6, VIII; "Besy", Yeil 1, 4. Kap., V und 'ieil 2, 1. Kap., VII).

Die ekstatische Verehrung der Erde als Prinzip des Lebens bel Dostojevskij hat nit orthodoxem Christentum wenig gemein, sondern lst ronantisches Erbe. Die Verehrung der slutter-icus' in jiekrasovs poen "komu na susi zit' choroso" (Polnoje sobranije stichotvorenij $v$, tonach, 3.3d., S.243) steht der folklore nahe. Lagegen stehen die Symbolisten Brjusov ("U zenli", Stichotvorenija 1 poenv, S.182f.) und Vjat. Ivanov (vgl. Kologrivov, aac, S.166 und Iwanow, Die russische Idee, S.37, ann.5) in der Iinie Dostojevskijs.

Blok bringt Brjusovs Gedicht in Zusanmenhang mit VI. Solov'evs Gedicht "Zemlja - Vladycica! K tebe Celo sklonil ja ..." ( $V, 542$ in seiner zweiten dezension von Brjusovs "Urbi et orbi" von Mai 1904). Bei Blok verschmolz die ifutter-Erdennystik mit dem RuBland-.lythos. In russischen pext steht "Rodimaja! Rodimaja!" Jas erinnert an Ijutcevs Gedicht "C Cem ty vojes', vetr nocnoj?..." Dort wird das Chaos als "rodimyj", d.h. 
"lieb, teuer, heimatlich, urvertraut" bezeichnet (2.10). Im homerischen Demeter-Hymnus ist als Gespielin der Persephone eine Phaino genannt (418). Möglicherweise besteht eine Bezlehung zwischen dem Namen der Faina und der griechischen Erde-kythologie.

S.84/7 Vgl. S.82/3. Faina fleht um Erlosung von dem Dammerqustand $2 w 1$ schen echter Ruhe und Sturm.

S.84/8 Faina mit Tränen in den Augen 1st das "Ewig-Weibliche", das sich danach sehnt, dab Gott seine Tränen abwische (vgl. off.7, 17; das Bild erinnert an den Topos der "natura plangens" oder der "mater dolorosa").

S.84/9 Wie die Regleanweisung zeigt, schläft im Park ein Schwan (vgl. S.81/6). Er erwacht bei der Begegnung Germans mit Faina ( $\nabla g l . S .88 / 16)$.

$\mathrm{S} .84 / 10 \mathrm{Vgl}$. S.104/14.

S.84/11 Die erotische Symbolik 1st offenkundig. Blok bereitet hier das Bild des Lösens des Gurtels vor, das die Hingabe der Braut an den Bräutigam symbolisiert. Das Bild "alaja lenta" ( $v$ gl. Hohes Lied 4,3: "kak lenta alaja guby tvoi") findet sich auch in Bloks Gedichten. In "Dal1 slepy, dn1 bezgnevny..." (I,319ff., Str. 5) "blilhten Mädchen in roten Bändern". Im Gedicht "Belyj kon' Cut' stupajet ustaloj nogoj..." (II,18) 1st das rote Band der "Herrin der Tage" das Abendrot. Hier verschmilzt die erotische mit der Natursymbolik.

S.84/12 Dieses Bild erinnert an Bloks Aufsatz "Devulka rozovoj kalitki 1 murav'iny $j$ car" ", wo das kleine pfortchen die Welt der Legende von der Alltagswelt trennt $(v, 86,88)$. S.84/13 Hier endet die erste Szene des 5.Bildes. Die Abweichungen 195)-254) in $F 1$ sind bis auf Abweichung 239) unerheblich (vgl. dazu S.83/13). Blok hat in F2 nur einzelne Wörter oder Wiederholungen gestrichen.

S.84/14 Auch hier wirkt das LS wieder ein Lesedrama. Den anbrechenden Morgen begleitet der Wind, in dieser szene Symbol der alles erfassenden Dynamik.

S.84/15 Das Bild des Weltorchesters fithrt ins Zentrum von Bloks Weltanschauung. 
Die Grundbegriffe von Bloks Weltanschauung sind das "Ewig-Weibliche" (vgl. Einleitung zum 5.Bild), "stich1ja" (das "Elementaren) und "muzyka" ("Musik"), wobel rur "stichija" auch "chaos" und fur "muzyka" der Ausdruck Nietzsches "duch muzyki" ("der Geist der Musik") oder der ebenfalls bel Nietzsche, aber auch bel Novalis vorkommende Ausdruck "ritm" ("Rhythmus") stehen kann. (Zum Gebrauch der Ausdrucke vgl.: "Rhythmus": Zap.kn., 132; V,95,96,37 of .; VI,80,100f ., 349,395 u.a.; "Geist der Musik": VI,8,11,17,19f., 100,113,349,390, 392; VII, 360; "Weltorchester":

v,371f.: "Nur im Vorhandensein des Wegs wird der innere "Takt" des Schriftstellers, sein Rhythmus bestimmt. Am gefahrlichsten ist der verlust dieses Rhythmus. Die unaufhorliche Anspannung des inneren Ohrs, das Horen auf die ferne Musik, ist die unerlabliche Bedingung fur die Bxistenz des Schriftstellers. Nur wenn man die Musik des fernen "Orchesters" hort (das das "Weltorchester" der Volks8eele 1st), kann man sich das leichte "spiel" erlauben."

V.379: "Im Flug in die Vereinigung mit dem Ganzen, in der Musik des Weltorchesters, im Tönen der Saiten und Schellen, im Pfeifen des Windes, im Kreischen der Geigen - wurde das Kind Gogol's geboren. Dieses Kind nannte er RuBland. Es schaut uns an aus dem blauen Abgrund der Zukunft und ruft uns dorthin. Zu was es heranwachst, - wir wissen es nicht; wie wir es nennen werden, - wir wissen es nicht."

VI, 19: Aufgabe der Dichter ist es "Jene groBe Musik der Zukunft zu horen, deren Töne die Luft erfillen und nicht (vie die Politiker) die vereinzelten kreischenden und unechten Noten im grobartigen Brilien und Tönen des Weltorchesters herauszusuchen."

VI,10of.: "Es gibt gleichsam zweierlei Zeiten, zweierlei Räume; die einen sind historisch, kalendarisch, die andern sind unzählbar, musikalisch... in zweiten Raum, in der zweiten Zeit leben wir nur dann, wenn wir unsere Nahe zur Natur spuren, wenn wir uns der musikalischen Woge hingeben, die aus dem veltorchester kommt."

Zap.kn., 132: "Der Rhythmus (das Weltorchester), die Musik atmet, wo sie will: in der Leidenschaft und im Schaffen, in der Volkserhebung und in der wissenschaftlichen Arbeit, (in der Revolution).").

Das "Ewig-Welbliche" ist die Inkarnation des "Geistes der Musik". Dieser Bezug muB bei der folgenden Darlegung immer im Auge behalten werden. Fr wird sichtbar in der Identitat der stimme der Faina mit dem Klang 
des Wel torchesters ( $\mathrm{ggl}$. S.89/6).

Der Urgrund des Seins ist chaotisch. Nur das Chaos ist ewig. Es entbindet aus sich in ständigem Wandel neue Formen, die elne gewisse Zeit lang Bestand haben und dann wieder im chaotischen Urgrund des Seins versinken, um neuen Formen Raum zu geben.

"Das Chaos ist die urtilmliche, elementare ordnungslosigkeit; der Kosmos ist die geordnete Harmonie, die Kultur; aus dem Chaos wird der Kosmos geboren; das Elementare birgt in sich die samen der Kultur; aus der Ordnungslosigkeit entsteht die Harmonie. Das Leben der Welt besteht in der unaufhörlichen Erschaffung neuer Formen und Arten. Das ordnungslose Chaos wiegt sie in den Schlaf; es zieht sie auf, und die Kultur trifft unter ihnen eine Auswahl; die Harmonie gibt ihnen Gestalten und Formen, die aufs neue im ordnungslosen Nebel zergehen. Der Sinn hlervon ist uns unverständlich; das Wesen ist dunkel; wir trösten uns mit dem Gedanken, daB die neue Gattung besser ist als die alte; doch der wind löscht diese kleine Kerze aus, mit der wir uns muhen, die Weltnacht zu erhellen. Die ordnung der Welt ist beängstigend, sie ist das leibliche Kind der Unordnung, und sie fallt vielleicht mit unseren Vorstellungen von Gut und Böse nicht zusammen.

Wir wissen nur das eine: dab die Gattung, die an die Stelle einer anderen tritt, neu ist; jene, die sie ersetzt, ist alt. Wir beobachten in der welt ewige Verände rungen..." (VI,161).

Das Walten des Chaos, des Elementaren, den dauernden ProzeB des Entstehens und Vergehens immer neuer Formen, begreift Blok als das Grunaprinzip des Seins. Fur dieses Grundprinzip benutzt Blok die Bezeichnungen "Musik", "Geist der Musik", "Rhythmus", wobei v.a. die beiden letzteren Ausdricke deutlich machen, daß Blok ein abstraktes Prinzip meint, das in der Musik als Tonkunst nur unvollkommene konkrete Gestalt gewinnt.

"Am Anfang war Musik. Die Musik ist das Wesen der Welt. Die Welt wächst in federnden Rhythmen. Das wachstum wird gehemmt, um dann "hervorzubrechen". Das ist das Gesetz allen organischen Lebens auf der Erde, des Lebens des einzelnen Menschen und der Menschheit insgesamt. Willensimpulse. Das Wachstum der Velt ist Kultur. Die Kultur ist ein musikalischer Rhythmus." (VII,360, Eintrag vom 31. März 1919)

"Die Musik ist die vollendetste Kunst, weil sie die Absicht des Heltenbaumeisters am besten ausdruckt und widersniegelt... Die Musik erschafft die Welt. Sie ist der geistige Körper der Welt, der (fließende) Gedanke 
der Welt..." (Zap.kn., 150, Eintrag vom 29. Jun1 1909). "tber den grundlosen Tiefen des Gelstes, wo der Mensch aufhort Mensch zu sein, itber den Tiefen, die dem Stast und der Gesellschaft, die von der Z1vilisation geschaffen wurden, unzugänglich sind, fließen Tonwellen, gleich ätherwellen, die das Weltall umfassen. Dort gibt es rhythmische Schwankungen, ähnlich den Prozessen, die Berge, Winde, Meeresstromungen, Pflanzen- und Tierwelt schaffen." (VI, 163).

Auf den Unterschied zwischen Musik als Tonkunst und Grundprinzip des Seins wies Blok schon in seinem Brief an Belyj vom 3. Januar 1903 hin (VIII,51-54), und er wandte sich damit gegen die unzulässige Gleichsetzung von Musik als Kunstform und als noumenalem Weltprinzip in Belyjs Aufsatz "Pormy iskusstva" (in: "Mir 1skusstva", 1902, Nr. 12, S.343-361). Belyj hat die Richtigkeit von Bloks Einwand zugegeben (vgl. VIII,563, Anm. 1).

Der Abkehr von jeder ethischen Eindeutigkeit in der Bestimmung des "Ewig-welblichen" entspricht Bloks dua11st1sches Verhältnis zum "Geist der Musik". Die Musik als Symbol des "Ewig-Weiblichen" teilt dessen "transmoralischen" Charakter. Die Musik als stärkstes Medium zur Transzendenz steht als objektiv wirksames heltprinzip jenseits von Gut und Böse.

In Bloks Anschauungen ist die Verwandtschaft mit pythagoreischen (vgl. VIII,53, Hinweis auf den Mythos von der Sphärenmusik; Sarkisyanz, RuBland und der Messianismus des 0stens, S.49, Anm. 84) und besonders herakl1tischen Ideen (vgl. Blok - Belyj, Perepiska, S.13, Vergleich des "Rhythmus" mit Heraklits "Peuer-Logos") offenkundig. Sein Weltbild ist asthetisch und gleicht darin im Weltbild der deutschen Romantik. (Die hăufige Berufung Bloks auf den SchluB von Gogol's Aufsatz "Skul'ptura, živopis' 1 muzyka" zur Stütze selner Aussagen über den "Geist der Musik", V,379; VI,92,349,392, erklärt sich durch die gelstige Nähe. Auch Gogol' ist geprägt von der Ideenwelt der Romantik und ihrer Hochschátzung der Musik. Vgl. Zen'kovskij, Gogol', S.1141.; Kluckhohn, Ideegut, S.168-172). Bel Blok erscheinen die Ideen der Romantik in der Brechung durch Schopen- 
hauer, Vagner und Nietzoche. (Vgl. Kluge, Wostenrope und RuBland, S.91f1.; besonders Jedoch Gol'cer, 0 musykal'now rosprijatil mira u Bloka, in: 0 Bloke, S.261-282, dessen Darstellung nach wie vor grundlegend 1st.). Das Grundprinzip des Seins, das Entstehen immer neuer Pormen aus dem uranfänglichen und ewigen Chaos, welches Im "Geist der Musik", Im "Rhythmus" seine widerspiegelung findet, durchwaltet gleichermaBen alle Lebensbereiche. Daher ist "Musik", "Rhythmus", "Ge1st der Musik" "die einigende Substanz der verschiedensten Erscheinungen und Berelche des Lebens uberhaupt." (Kluge, aaO, S.104). Blok sagt vom "Rhythmus", daB er "die Planeten und die seelen irdischer Wesen miteinander verbindet" $(v, 95)$. Alle Phänomene des Lebens, so verschieden sie auch voneinander sein mögen, haben fur inn "einen einzigen musiralischen Sinn" (III,297; vgl. Zap.kn., 132; Orlov, Put1 1 sud'by, S.534f.).

Bei der Bewertung und Beurtellung der Phänomene des Lebens ist fur Blok die Prage entscheidend, ob und wie sehr das zu Beurteilende vom "Gelst der Musik" durchdrungen, vom "Rhythmus" erfaßt, kurz: "musikalisch" 1st. Bloks Äußerungen zu sehr verschiedenen Problemkreisen wie Kulturphilosophie und Kunstkritik, seine stellungnahmen zu Pragen der Tagespolitik oder zum Problem dichterischen Schaffens sind von hier her zu verstehen. "Seine "Lebensphilosophie" faBt Blok in der knappen Notiz des "Tagebuchs" vom 11. Februar (1913; VII,219 D.W.) zusammen: "Die Moral der Welt ist unergrundlich und gleicht nicht der, die so genannt wird. Die welt wird bewegt durch Musik, Leidenschaft, Begierde, Kraft." Das ist die genaue Pormel elnes "romantischen Lebensgefuhls", eines echt russischen Nietzscheanertums. Das Tagebuch des Jahres 1913 bricht ab mit unerwartet traglschen Ausrufen: "Wle qualt das Gewissen! Gott, gib Kraft, hilf mir! (VII,253 - D.W.)" (Mocul'skif, Blok, S.354). Hier 1st die Spannung 2 wischen Bloks amoralischer Lebensphilosophie und seiner Sehnsucht nach Geborgenheit im Glauben besonders deutlich. Das "qualende Ge- 
wseen" lot Ausdruck dieser nicht gelösten Spannung und zeigt den Abstand zu Nietzsche. (Vgl. das "GerissensMotiv" S.66/1 und öfters im IS).

S.84/16 Diese Passage ist in P1 ausfihrlicher: "Es 18t, als se1 hinter dem Dirigentenpult schon ein Mächtiger aufgestanden und habe ruhig den Geigenbogen erhoben..." ("Kto to Vlastnyf"; vgl. Abw. 257)). Ohne Zweifel will Blok in der Gestalt des Dirigenten des Weltorchesters eine Darstellung Gottes geben. Bedeutsam ist hierbel, daß diese Darstellung in der späteren Fassung noch unbestimmter 1st, als in der friheren. Bloks Gottesbegriff steht dem der neuplatonisch orientierten Mystik nahe, deren Gottesvorstellung auf Plotins unnennbares und unerklärbares Ur-Eines zurickgeht (vgl. dazu Kluge, Westeuropa und RuBland, S.43-46, der Bloks vergebliches Ringen um einen "persönlichen" Gott hervorhebt).

S.84/17 Geigen und Geigenmusik symbolisieren in Bloks Gedichten häufig das Wirken des "Geistes der Musik", das besonders in der Iiebesleidenschaft, bald als Verhängnis bald als Erlösung, erfahren wird. (Vgl. folgende stellen: II,67f., 1.Str.; III,11f.,2. und 6.Str.; 25, 2. und 4.Str.; 45.3.str.; 55(4). 2.str.; 141. 1.str.; 192. 3.Str. mit Bild des Weltorchesters; 195, 2.Str.; 210, 1.Str.; V.379, vgl. oben S.84/15, wo der ldeelle Kern des Bildes besonders deutlich ist; V,431f.; dazu: Peters, Symbole der sinnlichen Wahrnehmung, S.218ff.).

Die Symbolik des Weltorchesters und seines Dirigenten hat inre deutliche Entsprechung in der christlichen Symbolik der Musik, wie sie die altchristliche Patristik in Abhängigkeit von orphischen und pythagoreischen Gedanken entwickelt hat. Die patristische und mittelalterliche Allegorese kennt das Blld des "LogosMusicus", oder die Vorstellung von Gott als dem Tonkunstler und der Welt als seinem Instrument (vgl. Forstner, Welt der Symbole, S.424f1.; Curtius, Europaische Iiteratur und lateinisches Mittelalter, S.251 u.ö.).

In mehreren der oben angefihrten Gedichte steht das 
Bild der Geigen im Zusammenhang mit dem "Zigeunerthema", wo Blok das abstrakte Prinzip des "Geistes der Musik" in seiner Dichtung sinnlich greifbar gestaltet. (Vgl. Lotman 1 Minc, "Čelovek prirody", in: Blokovskij sbornik, S.98-156, v.a. S.149ff.). Bloks Musiker hat den Geigenbogen erhoben (nicht den Taktstock! vgl. Abw. 257) und erweist sich damit als göttlicher Zigeunerprimas. Das auf der Bihne schwer zu realisierende Bild des Weltorchesters und des Dirigenten ist auch von der Opernkunst Richard Wagners inspiriert, dessen orgiastische Musik in Bloks Ohren wie die Musik des "Weltorchesters" geklungen hat. Es bereitet im LS den Höhepunkt der Begegnung von German und Faina vor (S.89).

S.84/18 Vgl. S.82/9. Das beschwörende Herbeisehnen der Faina hatte Erfolg. German erscheint als der Ersehnte.

S.84/19 Zur "Schranme" vgl. S.68/3. Zum "erleuchteten Gesicht" vgl. $5.89 / 9$.

S.84/20 German gleicht in seiner ahnenden Verzllckung den hochpathetischen ielden Wagners. Die Fhnlichkeit mit der Haltung der Faina unterstreicht die geheime Verbindung Germans mit ihr. ("Große AuEen", "Blick in die Ferne", "Sturm" sind mehrfach wiederholte Attribute und Bilder.).

$\mathrm{S} .84 / 21 \mathrm{Vgl}$. oben $\mathrm{S.84/8}$.

$5.84 / 22$ German spilrt in seiner Verzilckung die Kälte nicht. Dies hebt den Unterschied $z$ wischen German und dem Freund hervor.

S.85/1 Mit diesem pathetischen Ausruf leitet German die mehrmals beschworene Morgen-Symbolik ein.

S.85/2 Die Worte des Freundes verraten, daB er nur die "reale" Seite des Geschehens sieht und fur die Verzllckung Germans kein Verständnis hat.

S.85/3 Diese Replik Germans ist eine inspielung auf die Symbolik des "Gifrtels der Aphrodite".

In F1 ist der Hinweis auf den mythologischen Gehalt noch stärker. Dort sagt German: "Mit solchen Băndern entscheiden die Frauen die Schicksale von Menschen und völkern". (Abw. 264)). 
Der Gurtel 18t kosmisches Herrschaftssymbol bel Aphrodite (oft als Regenbogen), bei der allegorischen Darstellung der Nacht (MilchstraBe) und bel Maria, die als "regina coeli" die Attribute der Aphrodite an sich zieht. In der Symbolik des Gurtels der Aphrodite verschmelzen das aus Homers Illas $(14,214 f f$.$) bekannte Bild mit Platons$ Aphrodite Urania (Symposion, $180 \mathrm{~d}$ ) und dem B1ld des Bandes, das das Weltall zusammenhảlt (Politela, 616 bc) und das bel Blok als "Morgenröte" (IS), "Abendröte" (II, 18), "Milchstrabe" (II,48,105,183f., 257 u.ö.; vgl. hierzu Hocul'skij, A. Blok, S.152) und "Girtel" (II, $125,132,183 f \ldots 217 f \ldots 254 f \ldots 257$ u.ö.) erscheint. Die Aufladung des Bildes des Girtels der Aphrodite zum Symbol fur die den Kosmos beherrschende "Zauberwirkung der Liebe und Schönheit" findet $81 \mathrm{ch}$ in Anlehnung an Heinses "Ardinghello" bel Schiller ("Die Götter Griechenlands". "Die Kilnstler") und Hölderlin ("Melodie an Lyda", "Hymne an die Göttin der Harmonie" mit Motto aus "Ardinghello"; vgl. Michel, Leben Hölderlins, S.162; Schadewaldt, Hölderlin und Homer $I$, in: Hellas und Hesperien, II, S. 1981.). Im IS 18t der allegorische Bezug ins Triviale gezogen, wenn das Band der Faina nach frischem Parfüm duftet. Der Duft ist ein Attribut der "Neznakomka", der "Faina" der Gedichte (II,48,105,117,185f., 254f., 2581., 290f. u.ö.; vgl. auch Peters, Symbole der sinnlichen Wahrnehmung, S.252) und der dömonischen Schönheit in "Skazka o toj, kotoraja ne pojmet jeje..." (Blok, Sobr. soð., Bd.4, S.141). Der Duft ist in Bloks Gedichten die Geruchsinn-Entsprechung zum Nebel- und Schleier-Symbol. Auf $5.90 / 1$ wird die Gurtel-Symbolik mit anderem Akzent wieder aufgenommen.

S.85/4 Vgl. S.46/2.

S.85/5 Die "prekrasnaja neznakomka" 1st die "Unbekannte" aus Bloks 2. Band mit dem Attribut der "Schönen" Dame" des 1. Bandes. Die Gestalt des "Neznakomka" verbindet mehrere Gedichte (II,81,105,183f., 185f., 187.; dazu gehören noch II,48,1301., 137,1701., 203,204 u.a.) mit dem lyrischen Drama (IV,72-102). (Vgl. zur wechselnden Anordnung der 
Gedichte in den verschiedenen Ausgaben: Gromov, A. Blok, S.167ff.; zur Gestalt der "Neznakomka" v.a. Bonneau, L'univers poétique, S.217ff. und Motul'skif, A. Blok, S.15off.; zum berthmten Gedicht "Neznakomka": Neumann, A. Bloks "Neznakomka").

Genetisch geht die "Neznakomka" auf die rätselhaftschöne Frau in Gogol's "Nevskif prospekt" zurlick, die "wie es schien, vom Himmel direkt auf den NevskijProspekt herabgeflogen kam und sicherlich wieder wer weiB wohin davonfliegen wiirde". (Vgl. Bloks lyrisches Drama).

Gogol's "Neznakomka" vereint in sich die wichtigsten Zuge der späteren Blokschen Gestalt:

"Sie blickte streng... doch auf diesem schönen (prekrasnom) Gesicht war selbst der Zorn zauberhaft" (vgl.s. 84/4). Sie ist eine "Gottheit", die im "trligerischen Licht" der Laternen erscheint. Mit einem geheimnisvollen Zeichen fordert sie den von Liebe luberwäligten jungen Maler Piskarev auf, ihr zu folgen, der nicht weiB,ob "all das nicht in Traum" geschieht. Er will fur sie sein Leben lassen, wie ein Ritter "sklavisch inre Befehle ausfihren". "Er zweifelte nicht, daB irgendein geheimnisvolles und gleichzeitig wichtiges Ereignis die Unbekannte dazu fihrte, sich ihm anzuvertrauen". Die Unbekannte ist eine Dirne. "Doch sie stand vor ihm in wunderbarer Schönheit;... inre Augen schienen trotzdem himmlisch;... sie war schön (prekrasna)... Sie wäre die unschätzbare Perle, die ganze Welt, das ganze Paradies, der ganze Reichtum filr den liebenden Gatten gewesen... Sie ware eine Gottheit gewesen in einem menschenerfullten Saal, ...In Lichterglanz der Kerzen, in der sprachlosen Ehrfurcht der Menge der ihr zu FuBen liegenden Verehrer." Doch war sie die Ausgeburt des "Höllengeistes, der die Harmonie des Lebens zu vernichten trachtete". Im Traum erschien sie Piskarev als "Königin, besser und schöner als alle andern", deren Weigerung, seine Gattin zu werden, den opiumsllchtigen Maler zum Selbstmord treibt (Gogol', Sobr.sod., Bd.3, S.7ff.). Die Zitate aus 
Gogol's Novelle haben alle ihre $z . T$. wörtliche Bntsprechung in Bloks Gedichten und im LS.

Eine weitere Vorlage fur Bloks "Neznakomka"-Gedichte waren die Gedichte "Prochožef", "Vstreła" und "V publicrom dome" von Brjusov. Die beiden ersten Gedichte sind Nachklänge von Baudelaires beruhmtem Gedicht "A une passante" (vgl. Brjusov, Stichotvorenija i poemy, Anm. zu "Prochozej" auf S.759). Das letztere Gedicht entwickelt den Aphrodite-Mythos in zeitgenössischer Umgebung. (Vgl. Mocul'skif, Blok, S.108f .; ders., Brjusov, S.92).

Bloks "Unbekannte" entsprach in ihrer rätselhaft-geheimnisvollen Sinnlichkeit dem Frauenideal des fin-de-siècle (vgl. die Darstellung Stepuns, Vergangenes und Unvergängliches, 1.Te1l, S.365).

S.85/6 Vgl. S.48/8 und S.60/4.

S.85/7 Anspielung auf das Ende des 3.B1ldes.

S.85/8 "dariber" ist betont. Ein weiteres Mal ist der Freund als "Lacher" gekennzeichnet.

S.85/9 Die Anspielung auf die Passion Christi ist deutlich. Das Blut Christi ist Symbol seines Leidens, durch das er die Menschheit erlöst. (Vgl. Peters, Symbole der sinnlichen Wahrnehmung, S.41f., die den ambivalenten Gehalt der Farbe Rot bei Blok und Belyj und den Zusammenhang zur christlichen Symbolik darstellt). Das Herz Christi ist Symbol der "messianischen Heilstat" und der "ErlöserLiebe". (Forstner, Welt der Symbole, S.373f.).

Die äußerliche wunde, die der schlag der Faina zuruckgelassen hat, ist unerheblich gegenuber der eigentlichen, an die Passion Christi gemahnenden Bedeutung des Schlages. (Vgl. S.69/3).

S.85/10 Die Herz-Symbolik ist hier anders zu verstehen. Das Erwachen des Herzens ist ein Bild fur die zunehmende ekotatische Lebenserfulltheit Germans, die in den folgenden Sätzen zum Ausdruck kommt.

S.85/11 Zur Bedeutung der Musik vgl. S.84/15. Seit dem Peitschenochlag wirkt in German der "Geist der Musik". 
S.85/12 Auch hier ist die Gleichsetzung Germans mit Christus beabsichtigt. (Vgl. Luk. 23, 35).

S.85/13 Vgl. S.56, wo Paina aus ihrem Dorf ebenfalls ins frele Feld lief.

S.85/14 Vgl. S.82/8 und $S .88 / 5$.

S.85/15 Das Bild des Wasserfalls ist in der russischen Romantik häufig (vgl. Čiževskij, On romanticism, S.11-28). Die "Psychologisierung der Natur" hat bei Blok ihr Endstadium erreicht, wenn er Wasserfall und Seele direkt vergleicht. Die dichterische Wirkung geht damit jedoch verloren.

S.85/16 Germans innere Unruhe und Spannung ist noch ohne Ziel. Das Bild des Nebels symbolisiert die Ungewibheit, die uber der Zukunft liegt (vgl. S.88/1). Die Unterscheidung von Gut und Böse 1st Schicksal des Menschen (vgl. Mos.2, 17; 3. 5ff.). Im Prolog zum Poem "Vozmezdife" stellt Blok dem Kunstler die Aufgabe der Wertung.

"Das Leben ist ohne Anfang und Ende. auf uns alle lauert der Zufall. tber uns herrscht das unvermeidliche Dunkel Oder die Klarheit des göttlichen Antlitzes. Doch du, Kiinstler, glaube fest An Anfang und Ende. Du sollst wissen, Wo Hölle und Paradies warten..." (III,301, 2.1-7). Das Problem der Unterscheidung von Gut und Böse stellte sich Blok mit besonderer Schärfe im Zusammenhang mit seiner Abkehr aus der relativ gesicherten Welt der "Gedichte von der Schönen Dame". Das "Elementare", der "Geist der Musik" und inre Inkarnation im "Ewig-Weiblichen" stehen Jenseits von Gut und Böse (vgl. S.84/15). Im Wunsch Germans, Gut und Böse zu unterscheiden, splegelt sich Bloks eigene Sehnsucht nach ethisch gesichertem Halt. Die Spannung zwischen dieser Sehnsucht und der tberzeugung, dab das Urprinzip des Lebens moralisch indifferent sei, 1st kennzeichnend fur Bloks tragische Weltanschauung. Es ist die Spannung 2 wischen ästhetischem und religiösem Weltverständnis, die bei Blok ein Erbe der Romantik ist.

S.85/17 In dieser Replik zeigt sich deutlich der Einflub von vjat. Ivanovs "Dionysiasmus". German irrt umher wie 
Dionyeos, der Gott des Rausches und der sinnlichen Iust. Das Motiv der Uberschussigen Kraft (vgl. auch S.60) 18t ein deutlicher Hinweis auf Dionysos. (VGl. NietzBches Ausepruch: "Das mundervolle Phänomen des Dionysos lst einzig erklärbar aus seinem Zuviel von Kraft"; Gotzendammerung, 77, S.179).

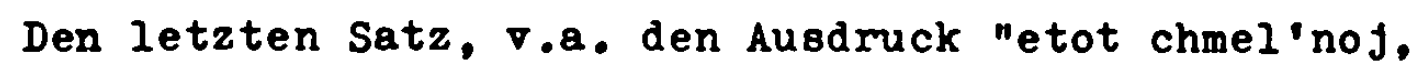
golodnyj, večno vljublennyj duch", hat Blok wohl als direkten Hinwels auf die dionysische Natur Germans formuliert und in F2 stehen lassen, obwohl die Anrede Germans an den inn beherrschenden Geist auf der Buhne unverständlich wirken muB. (Das etwas rätselhafte "ewig verliebter Geist" ist vielleicht eine Anspielung auf Ero8).

S.86/1 Der Freund warnt German vor den Gefahren seiner überspannten Leidenschaftlichkeit. Der Ausdruck "beregites'n wiederholt die Warnung der Paina vor ihrem Schlangenblick (S.67 "Lied des Schicksals", V.4). Im 7.B1ld warnt Faina mit derselben Wendung German vor dem Schneegestöber (S.100/6). Diese wiederholungen sind sicher beabsichtigt.

S.86/2 Die Vorhaltung des Freundes bezieht sich auf die eheliche Untreue und damit auf die "reale" Ebene des Verhältnisses von German zu Helena und Faina. Dabel nimmt der Freund das Motiv des reinen Gewissens aus dem 1. und dem 3.B1ld wieder auf ( $\nabla$ gl. S.50/4 und S.66/1). Seine Frage gibt German die Möglichkeit, sein Verhalten zu rechtfertigen (s.u.).

S.86/3 German hatte sich zuvor in Ekstase geredet. S.86/4 Die kurze Episode vom Verschwinden des Freundes im Steppengras wirkt recht ungeschickt. Vermutlich hat sich in inr der Konflikt Blok mit Belyj um dessen Märchenerzählung "Kust" niedergeschlagen. Blok hatte In Belyjs Aufsatz "Lug zelenyj" ( $\nabla g l .5 .84 / 1$ ) eine Bestätigung seiner eigenen dichterischen Neuorientierung gesehen, die vom Mystizismus der "stichio Prekrasnoj Dame" wegfuhrte zu einer Naturlyrik, die den Keim der klinftigen Rußlandgeschichte in sich enthielt. itber die Veränderung seiner stimmung schrieb 
Blok:

"Du weißt, daß mit mir im Sommer etwas uberaus Wichtiges geschah. Ich habe mich verändert, doch ich bin froh dariiber... Jemand sagt mir, daß ich sehr le1cht zum Dornbusch werden kann... Von Apoll verfolgt, werde ich zum goldenen Herbststrauch auf einer Waldwiese, den ein feines Netz von Regen iberzieht. Der Wind bläst, und meine stacheligen Hände tanzen fre1." (VIII,136; Brief an Belyj vom 2. Ckt. 1905).

Blok fiigte dem Brief einige Gedichte bel, die den Eindruck verstärken, daB er sich vom hohen Idealismus der "Stichi o Prekrasnoj Dame" gelöst hat (vgl. Anm. zu diesem Brief, VIII,575).

Der Brief Bloks löste bei Belyj eine heftige Reaktion aus. Die Gedichte gefallen inm zwar:

"Immer dieselbe unfabbare Anmut... Deine Muse flicht sich in die neuen Themen, deren Du Dich angenommen hast: die Verkörperung der elementaren Kräfte der russischen Natur wartet auf ihren Kiinder. Dieser Kiinder, so scheint mir, bist Du."

Doch dann kommt Belyjs schroffe ibsage:

"Wie man Deinen Appell an die "Schöne Dame" in Einklang bringen kann mit den fiir Dich neuen Themen, ... das wei $B$ ich nicht." (Blok - Belyj, Perepiska, S.155).

Besonderen Anstoß nimmt Belyj daran, daß sich Blok mit dem Lornbusch verglichen hatte. Blok hatte in seinem Brief das h'ort "Kupina" (mit Großschreibung!) benutzt. Belyj schreibt:

"Doch der Dornbusch ist das Symbol der Gottesmutter. So hoffst Du also zum Symbol der Gottesmutter zu werden, Du, der Student der kaiserlichen Petersburger Universität?" (aac).

Bloks Verhalten im Sommer 1905 ist ein Verrat an der gemeinsamen Verpflichtung zur mystischen Verehrung der "Schönen Dame":

"Komm zur Besinnung! Oder gib das Gehelmnis auf und vergesse es. Man kann nicht gleichzeitiemit Gott und dem Teufel sein." (aac, S.157).

Blok reagierte auf diesen Brief recht unwillig. Er verleugnete seine ganze mystische Vergangenhelt. Das Bild des Dornbusches verstand er "iberhaupt nicht als Symbol der Gottesmutter, sondern als ganz gewöhnlichen Dornenstrauch (ternovyj kust), der im Feld vor sich hinwächst und brennt..." (VIII,137; Brief an Belyj vom 15.0kt. 1905. 
Dem widerspricht die Verwendung des Bildes "Dornbusch" in II,20f.).

In seiner Erzählung "Kust" nimmt Belyj die Bilder von Bloks Gedichten und Briefen auf. Der zum Dummkopf Ivanuška gewordene Ivan Ivanovic will zum Dornbusch werden. Er kommt zu einem Busch, der wie ein Zauberer die schöne Gärtnertochter zu dämonischer Liebe verlockt. Die himlische Jungfrau, auf die Ivanukka gehofft hat, ist von der Astarte verdrängt worden. Diese erkennt Ivanuß̌ka als seine eigene seele.

"Ivanußka will seine Seele wieder haben, aber zu spät: das Anbëndeln mit dem Teufel fihrt zu nichts Gutem! Der sutor des "Kust" exinnert Ivanuska daran (und gleichzeitig den Dichter, der sich einbildete,ein Busch, ein ewig bluhender Dornbusch zu sein):

"Difrr und stachelig ist das vieljührige Steppengras, es kuBt dich nicht: es bohrt sich in deinen Körper mit Dutzenden von Nadeln, und du schreist vor Schmerz. Dilrr und stachelig ist das Steppengras!..." " (Solov'ev, Poet 1 jego podvig, S.156. Bely j benutzt "bur' jan" offensichtlich fast als Synonym von "kust". Beide Ausdricke verschmelzen im Bild des stacheligen Gestripps).

Ivanuß̌ka erliegt dem dämonischen Busch. (Eine ausfuhrliche Darstellung gibt Solov'ev, aav, S.151-160). In seinem Gedicht "Bur'jan" (Gedichtband "Pepel", Teil "Rossifa"; Stichotvorenija 1 poemy, S.175-177), das aufs Jahr 1905 zurtickgeht, verwendet Belyj z.T. dieselben Bilder wie in seiner Lrzählung "Kust". (Vgl. Str.5-7). Das stachelige, stmuppige Steppengras ist Symbol der lebensbedrohenden unheinlichen Kraft der russischen Weite, der die Wanderer erliegen. (Vgl. Mocul'skij, Belyj, S.121ff., der die Ähnlichkeit von Belyjs kuBlandgedichten mit denen Bloks hervorhebt. "Beide gehen von den "Morgenröten" Solov'evs zum "Stöhnen" Nekrasovs iber." aac, S.127). Im LS wollte Blok offenbar den oben dargelegten Konflikt init Belyj, in dem sich die Rivalität um Bloks Frau mit dem philosophischen und dichterischen Selbstverständnis der beiden "Freunde" in sehr eigenartiger Weise verknitpfte, in einer kurzen Episode darstellen. Der Freund, den für einen Augenblick das Steppengras verbirgt und der German ins Gewissen redet, 
1st ein Abbild Belyjs, welcher Bloks Naturlyrik als "Schamanismus" ablehnte (Perepiska, S.155). Das unterschiedliche Verhältnis zur russischen Natur, wie es im Konflikt zwischen Blok und Belyj 1905 deutlich wurde, spiegelt sich im LS darin wieder, das der Freund frierend und unwillig den enthustiastischen German begleitet.

S.86/5 German nimmt die "kosmische" Motivation aus dem 1.Bild mit den bekannten Motiven wieder auf (vgl. S.49/2).

S.86/6 Vgl. S.86/1.

S.86/7 Der Sinn von Germans erneutem jähen Angriff gegen den Freund (vgl. S.51/2) ist unklar.

S.86/8 Abweichung 284) (Peitschenschlag statt KuB) erklärt sich durch das Fehlen des 4.Bildes in $\mathrm{F} 1$.

S.86/9 Germans Replik schildert knapp das Geschehen seit dem Ende des 4.Bildes (Märchenszene). German hat die Erinnerung an Faina verdrängt.

S.86/10 Das frohe Lachen und die Replik des Freundes sollen offenbar den widerwärtigen Charakter des Freundes unterstreichen. Die ganze Passage, besonders aber die erneute Erwähnung der augen der Faina ist dramaturgischer Leerlauf.

3.86/11 Vgl. dazu 2.These. 3,3; 2.TIm. 2,13; 1.Joh. 1,9 v.a. cffb. 1,$5 ; 3,14$, wo Christus als "treu", "treuer Zeuge" u.a. bezeichnet wird.

S.86/12 German war den Kräften des Lebens treu, als er sein Haus verließ (Wind, Fruhling, "Geist der Husik").

S.87/1 Die Wiederholungen machen das Bild des "freien Weges" nicht sinnvoller. Blok hat gespurt, daB Germans Freiheitspathos an dieser Stelle recht hohl wirkt. Deshalb hat er die größten Ungereimtheiten in $F 2$ weggelassen (vgl. Abw. 286) mit dem Bild des "grunen Signallichts" für den Zug wie in II,91,99; III,180). German 1st erfullt von einem ekstatischen Lebensgefuhl, das nach Umsetzung in eine grobe Tat verlangt.

S.87/2 Russ. "zavetnyj" bedeutet im ubertragenen Sinne etwa "in Innern des Herzens gehegt" und zwar mit dem Aspekt des Zuklinftigen einerseits ("gelobt", "verheiBen", "ersehnt"; zavetnaja zemlja - das gelobte Land) und dem 
Aspekt des in der Brinnerung Zurickliegenden, Vergangenen, andrerseits ("vertraut", "Innig", "heimlich"). Blok meint Im IS das Letztere. Das "Trauteste" lst die Idylle des Hauses Germans, dessen Vorbild Sachmatovo war.

S.87/3 In diesen Worten Germans spiegelt sich Bloks Bejahung der Zerstörung, ein Wesenszug seiner irrationalen, von Nietzsche und Wagner bestimmten Weltanschauung. (Vgl. etwa: "Die Bejahung des Vergehens und Vernichtens ist das Entscheidende in einer dionysischen Philosophie." Nietzsche, Ecce homo, 77, S.351 und besonders: "Meine dionysische Weiheit: Lust an der Vernichtung des Edelsten als Lust am Kommenden". Der Wille zur Macht, 78, S.283. Wagners Zerstömungsmystik ist schon im "Fliegenden Holländer" stark ausgeprägt und durchzieht sein gesamtes Opernwerk, v.a. den "iing".). Besonders deutlich list Bloks Bejahung der Zerstörung in seinem aufsatz "Michail aleksandrovit Bakunin" ( $\mathrm{V}, 31-35)$ zum 30. Todestag des russischen inarchisten. Blok hebt Bakunins russischen Charakter hervor: "grandios und abscheulich, völlig russisch ( $c_{1}$ sto po-russki)" und vergleicht seine völlige innere Unabhänglgkeit von jeder Konvention mit dem Lebensstil VI. Solov'evs. Man kann Bakunin nicht zum Vorbild fïr das eigene Leben nehmen, denn er list elne Ausnahmeerscheinung. Doch: "Entleihen wir Bakunins Feuer! Nur im Feuer schmilzt der Schmerz, nur im Blitz löst sich der Sturm." $(v, 34)$. Blok zitiert dann den berihnten Satz Bakunins: "Laßt uns also dem ewigen Geiste vertrauen, der nur deshalb zerstört und vernichtet, weil er der unergrundliche und ewig schaffende Quell alles Lebens ist. Die Lust der Zerstörung ist zugleich eine schaffende Lust." ( $V, 34 f_{\text {.; }}$ Blok zitiert Bakunins irtikel "Reaktion in Deutschland" wahrscheinlich nach M. Dragomanov, M.A. Bakunin, Kazan', 1905).

Symbol fur den Geist Bakunins ist das Feuer. ( $V, 34$; vgl. S.56/6 und $\mathrm{S} .82 / 8$. 
In Bloks Aufsatz "Iskusstvo i revol fucija" (VI,21-25), der urspringlich als Einleitung zu Wagners Schrift "Die Kunst und die Revolution" (1849) gedacht war, wird wagner als Vorkämpfer der Revolution von 1848 in die Nähe von Marx und Engels, besonders aber in die Bakunins gebracht. Bakunin ist das Symbol der Revolution: "...den Wind fiir diesen Sturm säte, wie heute, unter anderem die russische aufruhrerische Seele in der Gestalt Bakunins; dieser, den "Realpolitikern" (darunter Marx) verhaete russische Anarchist mit seinem flammenden Glauben in den Weltenbrand" (VI,22) nahm wie Wagner im Mai 1849 am Aufstand in Dresden teil.

Bloks Befahung der Zerstörung als kusdruck des ewigen Werdens und Vergehens durchzieht seine sämtlichen kulturphilosophischen Schriften und findet ihren Höhepunkt in "Kruðeni je gumanizma" (VI,93-115). Hierher gehören auch die Poeme "Vozmezdife", wo Blok in dichterischer Form Kulturkritik ubt, und "Dvenadcat", wo das Toben der Revolution gepriesen wird. Eine besonders tragische Note enthalten viele Gedichte Bloks wie z.B. das Gedicht "Cbređennyf" (II,249), dessen erste Zeile "Heimlich erbittet das Herz den Untergang" prägnanter Ausdruck von Bloks "Lust am Untergang" ist. (Vgl. Cukovskif, A. Blok, S.278ff., der die Diskrepanz zwischen Bloks "idyllischer äuBerer Biographie" und seiner Lust am Untergang betont).

Bloks Haltung ist ausgesprochen "bipolar" (im Sinne Čizevskijs bezilglich Tjutðev in Russ. Literaturgeschichte I, S.131). Das äußerte sich in Bloks Reaktion auf die Zerstörung Šachmatovos, die er mit "glilcklichem Lächeln" hinnahm (Cukovskij, aa0, S.291), und uber die er im Traum Tränen vergoB (Zap.km., 428, Eintrag vom 22. Sept. 1918; 439, Eintrag vom 12. Dez. 1918). Majakovskijs Poem "Chorošo!" trifft Bloks bipolare Haltung genau. Blok begrübt die Revolution; sein "Očen' chorošo!" liefert den Titel filr Majakovskijs Poem. Gleichzeitig denkt er mit Trauer an sein Landgut. (Majakovskij, Choroš!, 7.Kap.; vgl. dazu Orlov, Poema A. Bloka "Dvenadcat'", 
S.1931.. Der Verouch Orlov8, die Darstellung Majakovskifs als falsch darzustellen und die Haltung Bloks zu "glatten", 1st unangebracht. Bloks Reaktion auf Majakovskijs Aufruf zur Zerstorrung des gesamten kulturellen Erbes zeigt deutlich seine zwiespältige Haltung: VII.350, Eintrag vom 30. Dez. 1918).

S.87/4 German wiederholt z.T. Bilder, die der "Mann mit Brille" zur Charakterisierung RuBlands gebrauchte (vgl. S.73).

S.87/5 Das Motiv des "ausweglosen Glllcks", das hier wiederholt wird (vgl. S.50/3), erinnert im Zusammenhang der Repliken Germans im 5.Bild an eine Passage von Nietzsche "Also sprach Zarathustra": "Was lst das Größte, das ihr erleben könnt? Das ist die Stunde der großen Verachtung. Die Stunde, in der euch auch euer Gluck zum Ekel wird..." (75, S.9; Zarathustras Vorrede. Die Passage ist Tell der Verklindigung des thermenschen S.8ff., die mit ihrer Erde- und Untergangsmystik wesentliche Themen der Lebensphilosophie anschneidet.).

S.87/6 Der Schluß dieser Replik labt die verschiedenen "Grtinde" fur Germans Aufbruch im 1.Bild zusammen (vgl. S.49/5; 50/1; 52/7 und 11). Die "pneumatische" Motivation (Wind) erinnert stark an Bloks Gedichtzyklus "O לem pojet veter" (Wovon der Wind singt; III,282-291, v.a. 286). Als Erklärung zu der Rechtfertigung Germans kann folgende Tagebuchnotiz Bloks dienen, in der er in einer fur inn endglltigen weise seine Meinung uber das wesen des menschlichen Gewissens zusammenfaßt:

"Noch elnmal: das (menschliche) Gewissen treibt den Menschen dazu an, das Bessere zu suchen und hilft ihm manchmal, sich vom Alten, Behaglichen, Lieben, aber Sterbenden und Verfaulenden loszusagen, - zum Nutzen des Neuen, anfangs UnbehagIichen und Unlieben, doch ein Prisches Leben Versprechenden." (VII, 388, Eintrag vom 24. Dez. 1920).

S.87/7 In den Augen eines "Realisten" muB Germans hysterische Rechtfertigung in der Tat als Prinzipienlosigkeit erscheinen.

S.87/8 Vgl. die Worte Christi: "...Ich bin nicht allein." Joh. 8,16 und 16,32 . 
S.87/9 Der Ausdruck "ne vo imja svoje" erinnert an die zahlreichen Bibelstellen, wo auf den Namen Gottes oder Christ1 Bezug genommen wird (z.B. Matth.21,9; Kol.3.17). S.87/10 Der Wind und das Iled sind die zeichen der göttlichen Macht, in deren Namen German handelt. Mit diesen Worten ist die "Rechtfertigung" Germans fur sein bisheriges Verhalten abgeschlossen. Die folgenden Repliken Germans verweisen auf das Kommende.

S.87/11 "Podvig" 1st hier wohl nicht mit "Heldentat" u.ä. zu ubersetzen, sondern mit "Kampf", was der ksl. Bedeutung entspricht (vgl. Phil.1,30; Kol.2,1; 1.Tim.6,12 u.ö., wo "podvig" fur griech. "agon" steht, was Luther mit "Kampf" (ibersetzte). Nur bel dieser tbersetzung wird die "schreckliche Unruhe" begreiflich.

S.87/12 Diese Worte bereiten den folgenden Monolog Germans vor. S.87/13 German wird eins mit dem auf Erlösung harrenden RuBland. Zur räumlichen Sphäre ("unermeBliche Weite") tritt in seinem folgenden Monolog noch die historische.

S.87/14 Mit diesen Worten, die völliges Unverständnis zeigen, ist die Aufgabe des Freudes im 5.Bild beendet. Zwar wendet sich German mit den ersten Sätzen seines kionologs noch an den Freund, doch ist dieser am Ende des Monologs verschwunden. Die Abweichungen der Szene zwischen Freund und German (Abw. 259)-294)) sind unbedeutend.

S.87/15 Hier wird auf Platos krklärung der dichterischen Inspiration als eines liahnsinns angespielt. (Ion, 533d535a, die Dichter gleichen in ihrer Begeisterung und Besessenheit den Bacchen; Phaidros, 244a-245a und 249d-250c). Diese Idee wurde von der romantischen Anthropologie neu begrilindet. Der Wahnsinn eroffnet, ähnlich wie der Traum, den Zugang zum Jenseitigen und macht den Dichter zum Seher. Wahnsinn und Erleuchtung gehören eng zusammen. In der russischen Literatur findet sich die romantische Idealisierung des Wahnsinns häufig, z.B. bei Pułkin (vgl. Tschizewskif, Russische Literaturgeschichte I, S.71). 
S.87/16 Rus8. "rodina" kann im Deutschen mit "Heimat" oder "Vaterland" wiedergegeben werden. Beide Ausdrlicke sind far die Bedeutung, die "rodina" besonders bei Blok hat, zu eng. "Heimat" 18t geographisch zu beschränt, "Vaterland" ist zu sehr mit politischem Inhalt erfullt. "Rodina" lat fur Blok das unermeBlich weite RuBland, das sich feder politischen oder geographischen Binigung entzieht (vgl. Kluge, Westeuropa und RuBland, S.189ff., v.a. Anm. 14). Es wurde die toersetzung "Vaterland" in diesem besonderen Fall vorgezogen, weil German ein konkretes historisches Ereignis anspricht, und der $\mathrm{Zu}-$ sammenhang jeden politischen Nebensinn aufhebt.

S.87/17 Diese Passage erinnert an den Monolog der "ganz in Weib" (vgl. S.44/3) auftretenden Nina Zarecnaja im 1.Akt von Cechovs "Cajka". (Vgl. v.a.: "Obそ̌aja mirovaja dußa eto ja ... ja ....... ja pomnju vse, vse, vse, 1 kazduju żin' $v$ sebe samoj ja pereživaju vnov'."). In diesem Monolog dríckt sich wie in den Worten Germans ein romantisches Naturgefuhl aus. German erlebt jedoch nicht wie Nina die Geschichte des Kosmos nach, sondern das Schicksal seiner "rodina". Dieser Unterschied beruht in Bloks RuBland-Mythos. In P1 (vgl. Abw. 297)) erinnert Germans dreimalige Einswerdung mit der "rodina" in der Anamnes18, der Ruckerinnerung an die Kulikovo-Schlacht an VI. Solov'evs dreimalige Begegnung mit dem "EwigWeiblichen" ("Tri svidanija"; vgl. V,451f.). In "Otvet Merezkovskomu" ( $V, 442-445)$ gibt Blok die ausfuhrliche Darstellung seines eigentümlichen Verhältnisses zu RuBland. Blok meint sein eigenes Verhältnis zu seiner Heimat, wenn er es verteidigt, daB "ein Schriftsteller ... sich mit seiner Heimat (rodina) vergleicht und meint, er sei an ihren Krankheiten krank, leide inre Leiden, werde zusammen mit ihr gekreuzigt und fuhle sich zusammen mit ihr erleichtert, wenn man inren geplagten Körper wenigstens eine Minute lang nicht quält. Je stärker man das Band mit der Heimat spurt, desto fester und lieber stellt man sie sich als einen lebendigen Organismus vor; wir sind dazu berechtigt, denn wir Schriftsteller mussen dem Leben möglichst aufmerksam ins Auge schauen; wir sind keine Gelehrten, wir fassen 
mit anderen Methoden wie sie die Erscheinungen zusammen ... Wir sind auch keine Staatsmänner und sind frei von der schweren Verpflichtung, ein starres Stahlnetz juristischer Schemata auf das aufgebrachte und aus den rechtlichen Fesseln ausbrechende Tier zu werfen. Wir sind Menschen, hauptsächlich Menschen, und das bedeutet, wir sind vor allem verpflichtet, den Atem des Lebens einzufangen, d.h. das Gesicht und den Körper zu sehen, zu fuhlen, wie jenes Wesen lebt und atmet, dessen Anwesenheit wir um uns vernehmen. Die Heimat ist ein riesiges, vertrautes, atmendes Wesen, ähnlich einem Menschen, aber unendlich traulicher, zärtlicher, hilfloser als ein einzelner Hensch; der Mensch ist eine kleine Monade, die aus fröhlichen körperlichen und seelischen Stahlmuskeln besteht, sein eigener Herr in dieser Welt ... Die Heimat ist ein altes, unendlich altes Wesen, groß und schwerfällig, und es kann selbst seine Kräfte, seine Muskeln, seine wioglichkeiten nie ermessen, so sehr sind sie uber die Mutter Erde zerstreut ... Die Heimat gleicht ihrem Sohn, dem Menschen. Wenn sie gesund ist und ausgeruht, wird ihr ganzer Körper so empfindlich wie ein gesunder menschlicher Körper ... ier aber spielt die Rolle der fühlenden Organe dieses uns ähnlichen und lieben Wesens?

Die Rolle dieser Organe spielen und missen alle Menschen spielen. wir aber, die Schriftsteller, frei von allen Verpflichtungen auBer den menschlichen, mussen die Rolle ihrer feinsten und wichtigsten fuhlenden Organe spielen. Wir sind nicht ihre blinden Instinkte, sondern ihre Schmerzen des Herzens, ihre Gedanken und Einfälle, ihre iillensimpulse ..."

$$
(\mathrm{V}, 443 \mathrm{f} .)
$$

Die Definition der Heimat als eines lebendigen Organisrus und die enge Verbindung von Heimat und einzelnem henschen in der Art eines Makrokosmos-MikrokosmosVerhältnisses zeigen Bloks Ábhängigkeit von der Philosophie der deutschen Romantik. Das gilt auch fur die Hervorhebung der Rolle der Dichter, die in besonderer Heise den Geist der Heimat verkörpern (vgl. dazu Kluckhohn, Ideengut, S.84ff. mit Novalis' Vergleich des Staates mit der Geliebten, S.87; S.176f. Blok sagt nicht "Staat", sondern "rodina".).

S.87/18 Die Schlacht auf dem Kulikovo pole (d.h. Schnepfenfeld) vom 8. Sept. $1380 \mathrm{zwischen}$ einem mussischen Heer unter der Fuhrung des Moskauer Grobfursten Dimitrif Ivanovič (1359-1389) und einem tatarischen Heer unter Mamaj endete mit einem teuer erkauften Sieg der Russen und 
leitete die Befreiung RuBlands vom Tatarenjoch ein. Der Moskauer Großfurst erhielt den Ehrennamen "Donskoj". Das Kulikovo pole liegt etwa $70 \mathrm{~km}$ suldöstlich von Tula am Einflub des FluBchens Neprjadva in den Don. Der Don pliebt an dieser stelle aus nördlicher Richtung und wird in seinem Lauf von der aus westen kommenden Neprjadva nach 0sten gedrängt. Genau im Suden des Zusammenflusses der beiden Gewäser eröffnet sich eine wenige kilometer breite Ebene, die in fruherer zeit beiderselts von waldern und schluchten eingefaßt war. Das russische Heer uberschritt am Morgen der Schlacht den Don und stellte sich slldich der Milindung so auf, dab es Im Rucken die beiden Flusse hatte (als Schutz gegen ein anrickendes litaulsches Heer) und das rechts und links das bewaldete und schluchtenreiche Gelände die Entfaltung der tatarischen Reiterei verhinderte. Die Schlacht wurde mit dem 2 weikampf zwischen dem russischen RitterMönch Peresvet und dem tatarischen Recken ¿elubej eroffnet, die beide fielen. Als in dem dann entbrennenden Kampf das russische Heer zu weichen begann, entschied die Reiterreserve unter dem Fursten Vladimir Andrejevit von Serpuchov, dem Vetter Dmitrijs, das Treffen. Die Reiterreserve hatte auf der östlichen russischen Flanke in einem Gehölz im Hinterhalt gelegen und wurde von ihrem militärischen Anfuhrer, dem Bojaren Dmitrij Michajlovid Bobrok-Volynskif lange zuruckgehalten und im entscheidenden Augenblick gegen die durchbrechende tatarische Reiterel eingesetzt. ( $\mathrm{Vgl}$. Rutid, Kulikovskaja bitva; Tichomirov, Kulikovskaja bitva). Der folgende Monolog Germans ist eine Paraphrase der Schilderung der Ereignisse vom Vorabend der Schlacht bis zum Eingreifen der russischen Reserve, wie sie die verschledenen Fassungen des "Skazanije o Mamajevom pobol če" enthalten. Blok selbst verwies auf diese Quelle ( $\left., 323,8 . u_{.}\right)$, doch weder das LS noch das ubrige Werk Bloks enthalten einen Hinweis darauf, welche der Fassungen des "Skazanije" er gekannt hat. Es werden daher im Folgenden die entsprechenden Passagen nach 
der sog. "Osnovnaja redakcija" angefuhrt (in: Povesti o Kulikovskof bitve).

S.87/19 Vgl. "Skazanije": "Der Grobfurst hatte seinen Bruder, den Pursten Vladimir, und die litauischen Fursten und alle russischen Fursten und Heerfuhrer versammelt und war auf eine erhöhte Stelle geritten..." (S.62; Fürst Vladimir wird als "Bruder" bezeichnet, da er den gleichen Rang wie Dmitrif von Moskau hatte. Im russischen Aufgebot befanden sich einige litauische Truppen.). Die Stelle im "Skazanife" eröffnet die Schilderung der Inspektion der Truppen, des Gebets und der Ermahnung zur Tapferkeit am Vorabend der Schlacht.

S.37/20 Dieser Satz greift eine Passage der "Zadonşina" auf: "Schon knarrten die Wagen der Tataren zwischen Don und Dnepr" (UŽe voskripeli telegy tatarskija...; "ZadonSCina", S.12, M4; Vgl. dazu die stelle Im IL, 9,11-13). s.87/21 Vgl. "Die Adler schreien" (orli klekčut, "Zadonšlina". S.13; dazu IL,9,17-19).

S.88/1 Vgl. "Schon aber kam die Nacht heran .... Es war aber in jener Nacht große Wärme .... (Uže bo noł̌' prispe ... Byst' ze $v$ tu noš' teplota velika .... "Skazanije", S.64). Die verschiedenen Fassungen des "Skazanije" berichten fbereinstimmend, daß die Nacht warm und nebelig war. Das Bild der geschmlickten Braut ist eine wiederholung (vgl. S.82/15) und findet sich in den Gedichten "Na pole Kulikovom" wieder (III,251,3, Str. 5: "A Neprjadva ubralas' tumanom,/ Čto knjažna fatoj.") Es ist Ausdruck der Brautmystik, die das LS und die Kulikovo-Gedichte durchzieht.

S.88/2 Diesen in der mussischen Folklore häufig wiederkehrenden Topos fur den Abschied der Mutter vom ausreitenden Recken entnahm Blok möglicherweise Gogol's "Taras Bul'ba" (Gogol', Sočinenija v 7 tomach, Bd.II, S.46). Bei Blok wird der Topos umgedeutet in ein Bild fur die Trauer der thutter liber den gefallenen Sohn. Solche Einzelheiten zeigen, daß Blok sehr willkurlich mit der Folklore umging. Das Bild findet sich wieder in den Kulikovo-Gedichten (III,251,3, Str. 3) und in 
"Narod 1 intelligencija" (vgl. folgende Anm.).

S.88/3 Vgl. "Skazanije": "Es sagte aber Ditrij Volynec zum Grobftirsten: "Ich will, Herr, in dieser Nacht mein Vorzeichen erproben." Und schon dunkelte das Abendrot, und es war tiefe Nacht. Da nahm Dmitrif Volynec nur den Grobfursten mit sich und ritt mit ihm auf das Schnepfenfeld und hielt zwischen den beiden Heerlagern und wandte sich auf die Seite des tatarischen Heeres und vernahm großen Lärm und Geschrei und Gebrilli, wie wenn ein Markt sich versammelt, oder eine Stadt gebaut wird, oder Donner erschallt. Hinter dem tatarischen Heerlager bellten drohend die Wölfe. Auf der rechten Seite des tatarischen Heerlagers krächzten die Krähen, und die Vögel schrien heftig. Auf der linken Seite aber war es, wie wenn Berge spielten - ein großes Gewitter. suf dem FluB Neprjadva aber schlugen Gänse und Schwäne mit den Flligeln und verkündeten großes Unwetter. Und der Großfurst sagte zu Dinitrij Volynec: "Wir hören, Bruder, dab ein großes Unwetter 1st." Und der Volynec sagte: "Rufe, First, Gott $2 u$ Hilfe!" Und er wandte sich zum russischen Heerlager, und es herrschte große stille. Da sagte der volynec: "Siehst du etwas, Fijrst?" Dieser aber antwortete: "Ich sehe, wie viele feurige Wetterleuchten aufflammen." Und der Volynec sagte: "Freue dich, Herr das sind gute Vorzeichen, rufe nur Gott an und lasse nicht nach im Glauben!" Und er sagte weiter: "Ich will noch ein anderes Vorzeichen erproben." Und er stieg vom Pferd und legte sich mit dem rechten Chr lange zeit auf die Erde. Als er sich erhob, ließ er den Kopf hängen und seufzte aus Herzenstiefe. Und der Großfirst sagte: "ïas ist, Bruder Dmitrij?" Dieser aber schwieg und wollte ihm lange nicht antworten. Der Grobfirst aber drang in inn. Da sagte er: "Das eine Zeichen ist ginstig fil dich, das andere unglucklich. Ich hörte, wie die Erde mit zwei Stimmen weinte: die eine Seite, wie eine Frau, weinte mit tatarischer Stimme um ihre Kinder; die andere Seite, wie eine Jungfrau, schluchate mit kummervoller stimme, wie eine Flöte, es war traurig anzuhören..." (s.64f.). 
Auf diese Episode aus dem "Skazanife" spielte Blok auch in seinem Vortrag "Narod 1 intelligencifa" an. Nach Bloks Auffassung stehen sich in RuBland im 19. und zu Beginn des 20. Jhdts. zwel Lager gegentuber: das Volk mit 150 millionen und die Intelligenz mit einigen hunderttausend. (Vgl. Einleitung zum 4.Bild).

"Unter den Hunderttausenden herrscht unruhige Erregung, ein unaufhaltsamer Wechsel von Richtungen, Stimmungen, Schlachtenbannern. toer den Städten herrscht ein Lärm, in dem selbst ein erfahrenes Gehör sich nicht zurechtfindet; ein solcher Lärm, wie er uber dem tatarischen Lager in der Nacht vor der Schnepfenfeld-Schlacht herrschte, wie die Erzahlung (skazanije) berichtet. Es kreischen zahllose Wagen Jenseits der Neprjadva, es herrscht Geschrei von Menschen, und auf dem nebilgen Fluß schlagen voll Unruhe Gänse und Schwäne die Flugel und schreien.

Uber dem Dutzend Millionen herrscht gleichsam Schlaf und stille. Doch auch uber dem Lager des Dmitrif Donskof herrschte Stille; doch der Vojvode Bobrok weinte auf, als er mit dem ohr zur Erde niederfiel: er hörte, wie die Witwe untröstlich weinte, wie die Mutter sich an den Steigbligel des Sohnes warf. ther dem russischen Lager flammte ein fernes und unheilverkindendes Wetterleuchten auf." $(v, 323)$.

Blok vergleicht hier die fur ihn zeitgenössische situation mit dem Vorabend der Schlacht von 1380. Die Folgerung ist klar: wie damals das tatarische Heer dem russischen Heer unterlag, so droht nun der Untergang der Intelligenz unter dem Ansturm des erwachenden $(V, 327)$ russischen Volkes. Die Grenzlinie, auf der sich Vertreter aus beiden Lagern begegnen, "der Arbeiter, der Sektierer, der Landstreicher, der Bauer dem Schriftsteller, dem Mann des öffentlichen Lebens, dem Beamten, dem Revolutionär" ( $V, 324)$, - lst sie nicht so schmal, "wie das neblige Flußchen Neprjadva? In der Nacht vor der Schlacht rann sie klar zwischen den belden Lagern dahin; aber in der Nacht nach der Schlacht und noch sleben Nächte lang $I I O B$ sie rot vom russischen und tatarischen Blut." $(v, 324)$. (Blok vermengt Skaz., S.75 und S.153). Im Zyklus "Na pole Kulikovom" sind die Gedichte "My, sam-drug, nad step'ju ..." (2) und "V not', kogda Mamaj ..." (3; III,250f.) die poetische sch11derung der Nacht mit der Verarbeitung der aus dem 
"Skazanife" bekannten Bilder (Schreien der Schwäne, Unruhe der vogel, Wetterleuchten, Nebel uber der Neprjadva) und der Episode mit dem Lauschen auf die Stimmen der Erde. (Zur letzten Episode vgl.: "Ja ucho priložll k zemle ...", III,86). Die Erscheinung, die in der Nacht zu dem Ritter herabsteigt und inr Antlitz als Ikone in seinem Schild hinterläBt, ist die weibliche Verkörperung des ewigen RuBland und hat inren Ursprung in Bloks RuBlandmythos (III,251,3, Str.6-9). In den verschiedenen Fassungen des "Skazanije" wird allerdings von mehreren wundererscheinungen berichtet, die mussischen Kriegern zutell wurden (Boris und Gleb, S.65; Hände aus dem Himmel reichen Kronen herab, S.70). Die Schlacht fand am 8. September, dem Tag der Geburt der Gottesmutter (Roždestvo Bogorodicy) statt, und der sieg wurde besonders auch von ihr erfleht (S.67) und als ihr Gnadengeschenk angesehen (S.73).

S.88/4 Vgl. "Skazanife" S.66: "... es ging die Sonne auf an einem nebligen Morgen."

Im IS bricht die Bloksche Symbolik des tindes wieder durch, die in der altrussischen Vorlage keine Entsprechung hat (vgl, aber Zad., S.11). Der Nebel, traditionelles Symbol fur das Ungewisse, Unentschiedene, wird vom Wind verjagt; die Entscheidung steht bevor. Bloks Natursymbolik ist eine Einschmelzung vorgefundener Bilder in das eigene mystische Bildreservolr. Auch hier ist v.a. die symbolische Bedeutung, der knbruch einer neuen zeit, wichtig (vgl. S.85/1).

S.88/5 Diese Passage und der SchluB des Monologs entsprechen der mehrmaligen Wiederholung des "opjat'" in den Kulikovo-Gedichten ( $v$ gl. III,250,2,Str.1; 251,4, Str.1; 252, Str.1), die den in "Narod 1 intelligencifa" klar entwickelten Vergleich von damals und heute auch in die Gedichte hineinträgt.

Zu dem "Brandgeruch" vgl. S.82/8.

S.88/6 Vgl. "Skazanije", S.66: "Es begannen sich die christlichen Banner zu entfalten ..." 
S.88/7 Vor dem Kampf stellte sich der "Starec" Peresvet einem riesigen Tataren zum $\mathrm{Zweikampf.} \mathrm{Beide} \mathrm{ritten} \mathrm{mit} \mathrm{den}$ Lanzen gegeneinander und fielen tot vom Pferd (vgl. "Skazanije", S.68f. und S.87/18). Blok folgte hier der Zadonłčina, wo Peresvet wie im LS als "Černec" bezeichnet wird (Zad., S.19).

S.88/8 Vgl. das "Skazanije" S.69 mit der Schilderung der Schlacht: "Und die beiden mëchtigen Heere trafen dräuend aufeinander ... Aus ihnen leuchtete blutige Röte, und in ihnen zuckten kräftige Blitze vom Schwerterschlagen. Und es war Splittern und lautes Krachen vom Brechen der Speere und den Hieben der Schwerter ... Und auf einmal, in einem sugenblick, o wieviele Tausend Menschenseelen, Geschöpfe Gottes, gingen da zugrunde! ..." (dazu: Zad., S.11f.)

Der Kampf dauerte allerdings nur bis zum späten Vormittag.

S.88/9 Vgl. das "Skazanije" S.7of.:

"Lie Heiden aber begannen die Cberhand zu gewinnen, und die keihen der Christen lichteten sich: wenig Christen waren da und iberall Heiden. Als Fürst Vladimir andrejevič den Untergang der Russensöhne sah, konnte er es nicht mehr aushalten und sagte zu Dmitrif Volynec: "Was taugt es, wenn wir stehen bleiben, welchen Erfolg haben wir, wem sollen wir noch helfen? Schon fallen unsere Fursten und Bojaren und alle Russensöhne vor den Heiden, wie Gras sich neigt! " Und Dmitrij sagte: "Das Unheil ist groB. Furst, doch noch ist unsere Zeit nicht gekommen: wer zu ungilnstiger Zeit beginnt, erleidet Schaden; ... warten wir noch etwas bis zur ginstigen Zeit, und dann werden wir dem Feind einen Schlag versetzen. Jetzt aber befehle jedem Krieger, eifrig $z u$ Gott $z u$ beten und die Heiligen um Hilfe anzurufen, und es wird Gottes Segen und Hilfe den Christen zuteil werden." Furst vladimir Andrejevic erhob die Hände zum Himmel und weinte bitterlich und sprach: "Gott, unser Vater, der du Himmel und Erde erschaffen hast, hilf dem christlichen Volk! LaB nicht zu, o 
Herr, daß unser Felnd uber uns frohlocke; strafe wenig und sei gnädig, denn ein sbgrund ist deine Gnade." Die Russensöhne in seinem Heer weinten bitterlich, als sie sahen, wie ihre Genossen von den Heiden erschlagen wurden, dilrsteten unaufhörlich (erg. nach Kampf), wie die Hochzeitsgëste nach suBem Wein. Der Volynec schalt sie und sprach: "Wartet noch etwas, stfirmische Russensöhne; eure Zeit wird kommen, da ihr euren Durst löschen könnt; ihr werdet genug Gäste finden, mit denen ihr euch ergötzen könnt!" Es brach die achte Stunde des Tages an, und ein leichter sildwind kam hinter uns auf. Da rief der Volynec mit mächtiger Stimme: "First vladimir, unsere Zeit ist angebrochen, und die günstige Stunde ist gekommen!" Und er sagte: "Keine Jruder und Genossen, seid mutig, denn die kraft des heiligen Geistes hilft uns!"

S.88/10 Rus8. "rabota" steht hier in der Bedeutung von "Kampf". Das ist ein miblungener frchaismus. Amuss. "robota" bedeutet "Sklaverei", "Unfreiheit" (nruss. "rabstvo) und aksl. "rabota" bedeutet daneben "Dienst", "Mthe" (wie mhd. "arebeit") u.ä. Sinnbild filr Kampf ist normalerweise die spezifische Arbeit des Mähens (vgl. Tschižewskij, AbriB der altruss. Literatur, S.40f.; dazu das IL,36, 1-2) oder das Hochzeitsmahl (s.0.).

S.88/11 Im "Skazanije" ist mehrfach vom Trompetenklang die Rede (S.66). Die irompete, die im russischen Mittelalter normalerweise aus Holz war (vgl. Istorija kul'tury drevnej kusi II, S.496), diente wie die römische tuba zur Befehlsibermittlung. Seit dem iltertum gehört der Trompetenklang zur Schilderung des Aufbruchs zur Schlacht, und der Topos fand Aufnahme in die altrussische Literatur (vgl. II,7,8; 34,14-14: "truby trub jat"; Zadonscina).

$\mathrm{S.88/12}$ "Ne nastal moj caš" ist ein ungenaues $\mathrm{Z}$ itat des Wortes Christi aus Joh.2,4, wo es heiBt: "meine Stunde ist noch nicht gekommen" ("jęre ne priłel tas Moj"). Die Christussymbolik ist an dieser Stelle verdeckt, da der Vergleich mit der Situation des Kriegers im Hin- 
terhalt Germans Worte hinrelchend erklärt (vgl. S.88/9). Der letzte Vers der Kulikovo-Gedichte (III,253) lautet: "Teper' tvoj Cas nastal. - Molis'!"

S.88/13 Die letzten Worte Germans erinnern an einige Stellen der Bibel, wo die chillastische Naherwartung besonders deutlich 1st ( $\mathrm{vgl}$. etwa Mark.1,15; Off.1,3; 22,10).

S.88/14 Germans Monolog ist im Gesamtwerk Bloks von besonderer Bedeutung, da er den Schllissel fiir die Beurtellung von Bloks Verhältnis zur altrussischen Literatur liefert. Diese Frage gehört nach $J u$. Lotman und 2 . Minc $z u$ den "wesentlichen Themen" ("uzlovyje temy") der Blokforschung (Blokovskif sbornik, S.99). Der Grund hierfür 1st der reiche Niederschlag der Lexik altrussischer Literaturdenkmäler in einigen Gedichten Bloks, besonders im Zyklus "Na pole Kulikovom" und im Gedicht "Novaja Amerika" (III,268ff.). Mehrmals wurde von russischen wissenschaftlern behauptet, da $B$ insbesondere das Igorlied auf den Kulikovo-zyklus groBen Einflub gehabt habe. So sollen die Bilder "Dröhnen der Erde vom Kreischen der Tatarenwagen", "Adlergeschrei", "Füstenbanner", "Schreien der Schwäne und Gänse", die bel Blok mehrmals wiederkehren (8.0.), die Abhängigkelt Bloks vom Igorlied beweisen (Il'ina, Nepostizimaja, in: O Bloke, S.315ff.). Man trifft auf die Behauptung, von den Symbolisten habe nur Blok den EinfluB des IL erfahren, die Wendung Bloks zum IL stehe im Zusammenhang mit seinem widerspruchsvollen "Weg zur rodina", seinem Interesse an der russischen Folklore und seinem neu erwachenden gesellschaftlichen BewuBtsein in den Jahren 1905-1907. In "Na pole Kulikovom", "Novaja Amerika" und "Skify" finde sich die Lexik des IL. (Aufsatz V.I. Stelleckijs "A.A. Blok und das "Lied von der Heerfahrt Igors"", in: ZSlw, XVI, 1971, Heft 4, S.557-580. Der Aufsatz gibt Stelleckijo Vortrag "A. Blok 1 Slovo o polku Igoreve" wieder, den er am 18.11.1955 in der Kommission uber das Igorlied beim Sovetischen Schriftstellerverband und am 22.11.1955 im Gor'kij-Institut fir Weltilteratur der Akademie der Wissenschaften der UdSSR gehalten hat; vgl. "Slovo o 
polku Igoreve", pod red. A.V. Pozdnejeva, S.55f. und Krestinskij, 75-letije so dnja rozdenija A.A. Bloka, in: Izvestija Adademii Nauk SSSR, tom XV, S.1961.). In der Tat zeigt ein Vergleich der Kulikovo-Gedichte mit dem IL auffallende lexikalische tbereinstimmungen. Eine genaue Untersuchung ergibt jedoch, daß die gesamte in Frage kommende Lexik ausnahmslos aus dem "Skazanije - Mamajevom poboisče" und zu einem geringeren Teil aus der "Zadonščina" stammt. Alle Parallelen der KulikovoGedichte zum IL gehen "ber diese beiden Denkmäler. (Stelleckijs Aufsatz enthält kein einziges Beispiel fur eine thereinstimmung $z$ wischen dem II und Blok, die nicht genauso gut und in den meisten Fällen besser und naturlicher als Parallele $z$ wischen Blok und dem "Skazanije" bzw. der "Zadonščina" erklärt werden kann. Unstatthaft ist v.a., daB Stelleckif die Bloksche mittelalterliche Lexik pauschal mit dem IL in Zusammenhang bringt, aber auch, dab er die "Zadonstina" immer nur am Rande erwähnt, obwohl sie Blok näher steht als das IL. DaB Blok in Inhalt und Lexik weitgehend aus dem "Skazanije" schöpft, ist stelleckij offenbar entgangen.). Ein direkter Einfluß des II auf die Kulikovo-Gedichte hat mit Sicherheit nicht bestanden. Blok hatte vielmehr nur das "Skazanije" und die "Zadonščina" als Vorlage, als er im Sommer 1908 das 5.Bild des IS und die Kulikovo-Gedichte schrieb.

Die vermeintlichen Spuren des II in Bloks Gedicht "Novaja Amerika" erklären sich einfach durch die Tatsache, daß er hier seine eigenen Kulikovo-Gedichte wieder zitierte (III,268ff., Str.8ff.). Aber auch ein Bild, das vorher fehlte, entnahm Blok in "Novaja Amerika" der "Zadonšcina" und nicht dem IL: Bloks "Ne šelomami Cerpajut Don" (Str.10) ist ein Reflex von "Don šelomy vyčerpati" (Zad., S.23; vgl. dagegen das IL: "iskusiti Donu...". "1spiti కelomom' Donu", 6,4-10; "Don కelomy vylijati", 28,9). Auch Str. 5 der "Skify" (III,36off.) mit dem etwas rätselhaften "Krylami b'et beda/ I každyj den' obidy mnozit" ist eher von der "Zadonžcina" als 
vom IL inspiriert (vgl. Zad., S.13; IL 9,141.; "obida" kommt in beiden Werken vor).

Die hier nur kurz skizzierten Tatsachen bedeuten nicht, daB Blok das II nicht gekannt hat. Der ursprlingliche Titel des Gedichts "Vot ona - v naletev sej volne..." $(I, 251)$ war "Deva-Obida", worin sicher ein Einflub des II,19,5-8 zu sehen 1st. (Vgl, auch S.83/18, obwohl das ind-Symbol, das dort fur einen Einflub des II spricht, bei Blok so häufig ist, daB es allein eigentlich nicht als Beweis fur Bloks Abhängigkeit vom IL vorgebracht werden kann). iuch bei Belyj finden sich Hinweise auf das IL. In seinem hufsatz "Nastojał̌eje $i$ budušceje russkoj literatury" von 1907, der zu einem großen Tell auch von Blok handelt und diesem sicher bekannt war, bezeichnete er das IL als "Apokalypse des russischen Volkes" (Belyj, Lug zelenyj, S.64). Dabei interpretiert er den Satz "C russkaja zemlja, (uže) za šelomenem' jesi" (II,10,3 und 12,14f.; Belyj läßt "uže" weg) als husdruck einer eschatologischen Zukunftssehnsucht nach dem wahren RuBland, von der die gesamte russische Literatur durchdrungen sei (Belyj, aao, S.65). is bleibt die Frage offen, welche Fassungen der altrussischen Denkmäler Blok gekannt hat und ob er sich iberhaupt auf den altrussischen Text oder nicht vielmehr auf eine tbertragung ins Neurussische stfitzte. $B l o k$ besaB ohne 2 weifel Kenntnisse der altrussischen Sprache und Iiteratur aus seinen Studienjahren an der Petersburger Universität. Im September 1901 wechselte er von der juristischen Fakultät in die slavisch-russische Abtellung der philologischen Fakultät um. Aus einer Notiz in seinen "Zapisnyje knizki" (vom Jahr 1901 oder 1902, Zap.kn., 25) geht hervor, daß er sich damals neben einigen Lehrbuchern zur slavischen Philologie auch einige Texte altrussischer Denkmäler und eine Chrestomathie, offensichtlich der altrussischen Literatur, gekauft hat. Im Jahre 1906 beendete Blok sein studium. Im gleichen Jahr veröffentlichte S.K. Sambinago in Petersburg die Untersuchung "Povesti o Mama- 
jevom pobolicen, in deren Anhang verschiedene Versionen des "Skazanije" und eine Version der "Zadonzxina" abgedruckt waren. 1907 erschien eine Ausgabe einiger Passungen des "Skazanije" mit einem Vorwort von Sambinago und der Reproduktion alter Illustrationen zu dem Werk (vgl. Povest1 o Kulikovskoj bitve, S.406, Anm. 1 und S.479f.; Gudzij, Istorija drevnej russkoj literatury, S.240, Anm. 1; Stelleckij, aao, S.566, Anm. 7). Wahrscheinlich kannte Blok die Arbeiten Sambinagos. Es 1st jedoch auch möglich, daß Blok die altrussischen Werke aus neurussischen toertragungen kannte. In einem Brief an A.V. Gipplus vom 23. Jul1 1902 (Blok war also schon in die philologische Pakultat ubergewechselt) erwhinte er den tatarischen Anfuhrer Mamaj: "..."beiseite gehend" ("otojdja $v$ storonu"), wie Mamaj vom Kulikovo pole" (VIII,37). Diese Passage bezieht sich auf das Verhalten Mamaj8, der sich, anders als Dmitrij Donskoj, zu Beginn der Schlacht auf einen sicheren Beobachtungeposten zurluckzog und die plucht ergriff, als er sah, daB die Schlacht fur inn unglinstig ausging. Palls es sich bei der Erwahnung der Feigheit des Mamaj in Bloks Brief um ein echtes zitat handelt, was die Anfunrungszeichen nahelegen, stamit es nicht aus einer altrussischen Vorlage, sondern aus einer neurussischen Bearbeitung des "Skazanije" oder der "Zadonšcina".

Ohne Bezugnahme auf die Arbeit von Il'ina und die vorträge Stelleckijs untersucht N.N. Jevreinova in ihrem Aufsatz "Cikl stichov A. Bloka "Na pole Kulikovom" 1 jego istoľniki $v$ drevnerusskoj literature" (im sammelband: Russkaja 1 sovetskaja literatura 1 stichovedenie, Moskva, 1969, S.151-172) Bloks Abhängigkeit von den altrussischen Vorlagen und verwelst auf das "Skazanie 0 Mamajevom poboļ̧̌" als Quelle des IS und der KulikovoGedichte (S.152 u.ö.). Die Porscherin betont die Eigenständigkeit Bloks stärker als Stellecklf. Sie verbaut sich jedoch m.E. das richtige Verständnis der Bloksehen Verarbeitung der Kulikovo-Episode selbst, wenn sie es unterläBt, die Gedichte und das IS von Bloks 
auf RuBland Ubertragenen Mythos des "Ewig-Weiblichen" her zu interpretieren ( $v$ gl. z.B. S.157 uber "O Rus' moja, Žena moja!" und S.165 "ber die Lichterscheinung). Auch sind die behaupteten stimmungsmäbigen und geistigen Parallelen der Gedichte Bloks zum Igorlied so vage und wenig lberzeugend dargestellt ( $S .158$ ), daß man hier Spuren des sovetischen Kultes um das Igorlied sehen muß. In derselben Linie stehen Ausfihrungen iber den angeblich "antifeudalistischen", "demokratischen" Charakter des "Skazanie" und der Gedichte Bloks (S.152ff.). Insgesamt jedoch werden die Ausfihrungen von Jevreinova der Vielschichtigkeit von Bloks anspielungsreicher Symbolik auf weiten Strecken gerecht.

Die Schlacht von 1380 war ein denkwfirdiges Ereignis der russischen Geschichte, und die russischen Schulbicher enthielten entsprechende Darstellungen dieser nationalen Großtat. Blok kannte die Berichte uber die SchnepfenfeldSchlacht sicher schon aus seiner Schulzeit. Die von Volkov, Blok i teatr, S.94, geäuBerte Auffassung, die "historischen Reminiszensen" im LS stammten aus Karamzin, ist völlig abwegig. Die Darstellung der Schnepfenfeld-Schlacht in Karamzins "Istorija Gosudarstva Rossijskogo" ( $B d .5, S .425 f f_{\text {. }}$ ) ist viel zu knapp und enthält die von Blok entlehnten Bilder nicht. Dasselbe gilt fijr die "Istorija Rossii s drevnejßich vremen" von S.H. Solov'ev (Buch I, Bd.3, Kap.7, S.979, Sp.1), die $3 l$ ok besaB (Solov'ev, Vospominanija ob A. Bloke, in: Pis'ma A. Bloka, S.34). Hier fehlt z.B. die Beschreibung des $\mathrm{Zweikampfes}$ vor der Schlacht. In Frage käme vielleicht die Darstellung des mussischen Historikers $\mathrm{Dm}$.I. Ilovajskij (1832-1920; vgl. Tichomirov, Kulikovskaja bitva in: Povesti o Kulikovskoj bitve, S.335f.). Eine endgultige Klärung dieser Frage ist erst nöglich, wenn der Bestand von Bloks Bibliothek genau bekannt wird.

Ein Indiz dafür, $\mathrm{da} B \mathrm{Blok}$ aus einer neurussischen Bearbeitung schöpfte, ist seine auffallende Zurfickhaltung bei der Verwendung altrussischer Formen. Die beiden 
Stellen im Monolog Germans, wo offenbar hietorisches Kolorit erzeugt werden 8011 ( $S .88 / 2$ und $S .88 / 1$ ), zeigen eher Bloks Unsicherheit im Umgang mit der russischen Folklore bzw. der altrussischen Literatur. Selbst an Stellen, wo es nahelage, etwaige altrussische Vorlagen nicht nur dem Inhalt nach $z u$ verwenden, sondern wörtlich zu zitieren, wählt Blok durchgehend neurussische Wendungen, die ihren stilistischen Wert nicht aus einer archaischen Stilisierung beziehen, sondern aus ihrem ekstatischen Lyrismus.

Blok beschrieb die Bedeutung der Schlacht von 1380 mit den Worten: "Die Kulikovo-Schlacht gehört nach der Uberzeugung des Autors zu den symbolischen Ereignissen der russischen Geschichte. Solchen Ereignissen ist eine Wiederkehr bestimmt. Ihre Lösung steht noch bevor." (III,587). Hier wird deutlich, daB es Blok nicht um eine historische Wertung geht. Entscheidend für Bloks Beurteilung historischer Phänomene ist allein ihre Analogie zur Gegenwart. Blok trägt das Schema "Musikalität" - "Unmusikalität" (vgl. S.84/15) an die Geschichte heran. Der Durchbruch des "Geistes der Musik" vollzog sich im Sieg des jungen Christentums uber den spatantiken Staat, im Sieg Dmitrijs iber Mamaj, und er wird sich im Sieg des Volkes uiber die Intelligenz wiederholen. Bloks Geschichtsverständnis entspringt seiner irrationalen, "musikalischen" Lebensphilosophie und ist völlig unhistorisch, da es keinerlei Dimension für das geschichtlich Eigenwertige kennt. Das gilt für die Kulikovo-Gedichte, für das Drama "Rose und Kreuz" (trotz Verarbeitung alter Quellen) und besonders für die kulturphilosophischen Spätschriften. Das Fehlen der eigentlich historischen Dimension in Bloks Geschichtsverständnis ist auch der Grund dafür, dab sich in seinen Gedichten und im LS nur wenige Archaismen finden, die dann z.T. noch unangebracht sind. Die mittelalterliche Stilisierung ist weitgehend romantisches Erbe, der Bezug zur Geschichte ist analogistisch und in Nietzschescher Weise unhistorisch. 
Die Schlacht von 1380 inspirierte seit dem Mittelalter russische Dichter (Zadonžlina, Skazanije, Bylinen vgl. dazu Gudzij, Istorifa drevnej russkof literatury, S.231-248; Ozerov, Tragödie "Dmitrif Donskoj"; Rylejev, Duma "Dmitrij Donskoj"; Jazykov, Ballade "Bajan k russkomu voinu pri Dimitril Donskom, prežde znamenitogo sraženifa pri Neprifadve"; Sajanov, Poem "Slovo o Mamajevom pobolłče"; Šmelev, Erzählung "Kulikovo pole"; Borodin, hist. Roman "Dmitrij Donskoj"; Solženicyn, Erzählung "Zachar-Kalita"; Rapov "Zori nad Rus'ju") und Maler (viele Miniaturen - vgl. Uklein, Kulikovo pole, S.12ff.; Sazonov; V. Vasnecov; Avilov; Bubnov; Korin). Der russische Komponist Ju.A. Saporin (1887-1966), ein Schiler von N.N. Xerepnin, war schon im Sommer 1918 an Blok herangetreten mit dem wunsch, zu den Gedichten "Na pole Kulikovom" eine Kantate zu schreiben (Zap.kn., 411, Eintrag vom 8. Juni 1918; vgl, aac, Eintrag vom 17. September 1918). Im November 1919 schrieb Blok als Ergänzung zu seinen Gedichten von 1908 die beiden Gedichte "Chor Tatar" und "Arija Nevesty" (III,373f.; Zap.kn., 479f., Eintrag vom 2. Nov. und 14. Nov. 1919). Das erste Gedicht sollte nach "Reka raskinulas' ..." (III,249f.) folgen. Es ist ein Aufruf zum Kampf und folgte einem, offenbar vom Komponisten vorgegebenen, metrischen Schema. Das zweite Gedicht sollte nach "My, sam-drug, nad step'ju v polnoč' stali ..." (III,250) stehen. Die erste Strophe stammt aus "Ja zivu v otdalennom skitu ..." (II,11). Die Braut wartet auf die Ruckkehr ihres Geliebten und schaut sehnsilchtig den vorbeifliegenden Gänsen, Schwänen und Kranichen nach. obwohl das Gedicht inhaltlich an die Klage der Jaroslavna bzw. der Klage der Moskauer Furstinnen in der "Zadonstina" erinnert, besteht kaum eine Ähnlichkeit nit der altrussischen vorlage.

1939 hatte Saporin sein Werk beendet. Der Text Bloks war mit einigen Ergänzungen von M.I. Lozinskif (18861955) versehen worden. Saporin erhielt fiur seine Kantate 1941 den Stalinpreis. Das Werk ist in RuBland 
sehr beliebt. Es wurde $1949 \mathrm{mit}$ großem Erfolg in der Berliner staatsoper aufgefuhrt.

Der wiederholte Ruckgriff auf den historischen stoff seit dem Ausgang der dreibiger Jahre lst eine Folge der Neuorientierung der sovetischen Geschichtsschreibung unter Stalin, die zu einer Umwertung der russischen Vergangenheit im Sinne eines "sovetischen Patriotismus" fuhrte. Der Kampf gegen das Tatarenjoch und die Schlacht von 1380 wurden in der Zeit des "Großen Vaterländischen Krieges" genau wie die Siege Aleksandr Nevskifs Uber Schweden und Deutsche oder der Sieg uber Napoleon zum Symbol des Freiheitskampfes gegen die fremde Invasion. Auch die Versuche, Bloks Abhängigkelt vom Igorlied nachzuweisen (8.0.), sind Ausdruck dieses russischen Nationalismus und ein Nebenprodukt des staatlich geforderten Igorlied-Kultes.

$\mathrm{S} .88 / 15 \mathrm{Vgl}$. $\mathrm{S} .81 / 8$.

S.88/16 Der schlafende Schwan ist Symbol der Keuschheit. (Vgl. I,8: "Sie" gleicht einer "reinen Madonna", einem "schlafenden Schwan"; Kluge, Westeuropa und RuBland, S. 31 ubersetzt "erwachender Schwan", was sinnentstellend 1st. Im 1. Band seiner Gedichte benutzt Blok das Bild des Schwans mehrmals als Symbol der Reinhe1t: I, 77,149, $268,296,537)$.

Im IS ist der Schwan ein attribut der Faina (vgl. S.81/6). Im Erwachen des Schwans 8011 das Erwachen der Heldin in einem halb erotischen, halb mystisch-religiösen sinn symbolisiert werden (vgl. $\mathrm{S} .82 / 3$ und $\mathrm{S} .83 / 2$ ).

S.88/17 Der Ausdruck "trubnym golosom" ist eine Anspielung auf die stimme in der Apokalypse (off.1, 10; 4, 1; vgl. Zap.kn., 35; Luther ubersetzt "Posaune"). Die Symbolik der apokalyptischen Tronpete ist ambivalent. Während in vielen Gedichten Bloks der Trompetenklang in Verbindung mit dem Thema des Todes steht, symbolisiert er im LS den Anbruch der neuen Zeit. (Vgl. dazu: Peters, Symbole der sinnlichen Wahrnehmung, S.229f., die auch eine kussage Belyjs iber den ambivalenten Symbolgehalt der apokalyptischen Trompete 
auffuhrt. Die von Peters behauptete AusschlieBlichkeit der Verbindung von Trompetenklang und Tod wird durch das IS eingeschränkt; damit verlieren die Feststellungen von Peters jedoch nicht an Wert.)

S.88/18 Zur Symbolik der aufgehenden Sonne vgl. S.89/9.

S.88/19 Das Erscheinen der Faina wird als Naturereignis dargestellt (vgl. auch S.98/7). Sie befindet sich im Zustand der Ekstase und wird vom "Weltwillen", vom "Geist der Musik" beherrscht.

Zum Morgenwind vgl. S.84/14. (Zum B1ld der Gewitterwolke vgl. S.53/5).

$\mathrm{S} .88 / 20 \mathrm{Vgl}$. $\mathrm{S} .88 / 3 \mathrm{mit}$ den verschledenen Stellen, wo Blok das Schreien und Flugelschlagen der Schwäne erwähnt.

S.88/21 Vgl. S.88/16. Diese Stelle zeigt besonders deutlich, wie subjektiv und unhistorisch Blok seine altrussischen Vorlagen verwertet. Das Bild der lärmenden Schwäne wird in Germans Monolog im Rahmen der Paraphrase des "Skazanije" und durchaus im Sinne der altrussischen Vorlage gebraucht: das Iärmen der Schwäne und Gänse verhe1Bt Ungluck (vgl. S.88/3; in ähnlichem Sinne wird im Igorlied $9,11-13$ und in der Zadonstina S.12 das Schreien der Schwäne verwendet; in den drei altrussischen Denkmälern wird außerdem der Topos der Falkenjagd auf Schwäne mit ganz verschiedenen Bedeutungen gebraucht; vgl. II $3,6-4,9 ; 41,5-9$; Zad. S. 12; Skaz. S.54).

Das Erwachen, Schrelen und Flugelschlagen des Schwanes im IS nimmt ganz offensichtlich Bezug auf das Iärmen der Schwäne im vorausgehenden Honolog Germans. Es ist Teil des komplexen "tertium comparationis", das die Situation von 1380 mit der aktuellen dramatischen Situation verbindet, und das noch die Bilder "Herbstmorgen", "Brandgeruch", "Nebel", "Brautschleier", "triumphale Musik der Sonne" umfaBt. Die Funktion des Schwanengeschreis als Bindeglied 2 wischen "damals" und "heute" 1st in den Gedichten "Na pole Kul1kovom" besonders deutlich: "Za Neprjadvoj lebedi kričali,/ I opjat', opjat' oni kricat..." (III,25o(2), Str.1); 
"Nad vraž'im stanom, kak byvalo,/ I plesk 1 truby lebedej." (III,252(5), Str.3). In den Gedichten wirkt die mehrfache Verwendung des Schwanengeschreis echt, was seinen Grund in der Vergleichbarkeit der historischen und der aktuellen Situation hat: belde Male steht der Kampf bevor. Dagegen besteht im LS keine Analogie zwischen dem von German beschworenen Ereignis von 1380 und der dramatischen Situation im 5.Bild. Von der Relevanz der Kulikovo-Schlacht bleibt allenfalls die gespannte Ungeduld des Kriegers im Hinterhalt. Ansonsten kann die ekstatische Liebesvereinigung Germans mit Faina schlecht mit dem mörderischen Geschehen von 1380 verglichen werden. Diese Unvereinbarkeit der beiden Situationen fithrt auch dazu, daß aus den Unglifck verheiBenden Schwänen des "Skazanije", der Kulikovo-Gedichte und des Monologs Germans jetzt ein erwachender Jugendstilschwan wird, der das "Erwachen" der Heldin als Anbruch der Endzeit symbolisieren soll. In F1 (vgl. Abw, 302)) geht der Bruch schon durch Germans Monolog.

Die Identität von Schwanenschrei und Frauenstimme hat in Bloks Gedichten eine ganz andere Sinnfille wie im LS. In den Versen "Slyłal ja Tvoj golos serdcem vešcim / V krikach lebedej." (III,251(3), Str. 2) ist "Sie" die metahistorische Wesenheit Rußlands, die ihrem Ritter einst erschien und inn jetzt wieder aus der Ferne ruft (vgl. III,251(4), Str. 1). "Sie" ist gleichzeitig umfassender historischer Raum voller tragischer Katastrophen und bangendes Individuum. Der Schwanenschrei ist in den Gedichten ein vieldeutiges Symbol, in dem sich mehrere Sinnbezuge verbinden: der Unglilck verheiBende Aufruhr der Tiere vor der Schlacht von 1380, wie es die altrussischen Denkmäler berichten, die Analogie damals-heute und die reiche Symbolik des Schwanengesangs. Auf die Vorstellung vom Schwan als einem Orakeltier, einem Musen- und Weissagevogel, dessen Gesang als Vorahnung des Todes oder der himmlischen Freuden gedeutet wurde, weist Bloks Ausdruck "serdcem vestim" hin. Der Schwan galt daneben als Seelenvogel, 
und im Schrei der Schwäne tat sich fur Blok die Seele RuBlands kund. Daneben spielt in die Kulikovo-Gedichte auch die Symbolik der Schwanenjungfrau, der Jungfrauverwandlung in einen Schwan und der Erlösung des Geistes einer Jungfrau in Schwanengestalt hinein, die ja im LS besonders ausgeprägt ist. In Bloks Gedichten verschmelzen im Symbol des Schwanenschreis der historische Bezug auf die Nacht vor der Schnepfenfeld-Schlacht und eine komplexe, halb traditionelle, halb private SchwanenSymbolik zu einer unlösbaren Einheit. Der private Bloksche RuBland-Mythos trat in den Kulikovo-Gedichten aus seiner esoterischen Vereinsamung heraus und ging eine Verbindung mit dem historisch gewachsenen nationalen RuBland-Mythos ein, was die Beliebtheit dieser Gedichte in RuBland erklärt.

Im Gegensatz zu den Kulikovo-Gedichten klaffen im LS die historische Dimension, die der Monolog Germans herstellt, und Bloks Mythos vom "ewig-weiblichen", auf Erlösung wartenden RuBland auseinander. Die Schwäne der Neprjadva und der Seelenvogel der Faina, der apokalyptische, nach dem Erlöser rufende Jugendstilschwan, haben keinerlei inneren Bezug zueinander. (Man kann verstehen, daB Gromov, A. Blok, jego predšestvenniki 1 sovremenniki, S.339 dem "einzigartigen Bild der Schwäne" in den Gedichten den Schwanenschrei des LS gegenflberstellt, der "an Geschmacklosigkeit grenzt".).

S.89/1 Vgl. die Stelle in Off. 22,17: "Und der Geist und die Braut sprechen: Komm!". (VgI. VII,50; hier zitiert Blok diese Bibelstelle bei der Darlegung seines Mythos vom "Ewig-Weiblichen").

S.89/2 Die hier anklingende Todessehnsucht ist zu verstehen als wunsch nach Erlösung aus dem schweren frdischen Dasein und gehört zur apokalyptischen Dimension des Auftritts der Faina. Im Rahmen der ganzen Replik ist jedoch der ekstatische Grundton entscheidender als die Todessehnsucht. (Der Tod 1st auch bel Blok ein Mittel zur Transzendenz).

S.89/3 Vgl. S.84/2. 
S.89/4 Vgl. S.82/3. Das Wachen 18t Ausdruck der Endze1terwartung (vgl. Matth.24,42; of $1,16,15$ ). Bel Blok durchdringen sich Murchensymbolik (Dornröschen), Wagnersche Erlosungsmystik (Brinnhilde usw.) und christliche Apokalyptik.

S.89/5 Paina gebraucht Ausdrucke, die alle auch in der Bibel vorkommen und in der christlichen ystik gebrauchlich sind. ( $\mathrm{Zu} \mathrm{"knjaz'"} \mathrm{rgl.} \mathrm{Jes.9,6;} \mathrm{Hes.34,24} \mathrm{u.} \mathrm{37,25;}$ zu "drug" vgl. HL 7,11f1.; zu "žen1ch" vgl. Jes.61,10 u. 62,5; Matth.25,1-13; dazu die Brautmystik in Psalm 45(44); 0ff,19,7 u. 21,2 u. 9). Die christliche "sponsus-8ponsa"-Mystik, die das Verhältnis von Christus und der inn suchenden Seele bzw. seiner Kirche als Liebesbeziehung zwischen Braut und Brautigam sieht (vgl. Heller, 0stkirchen, S.278), 1st hier auf das Verhiltnis von German und Paina ubertragen. Der Doppelaspekt des Brautsymbols (individuell: Braut = Seele; kollektiv: Braut $=$ Kirche) gilt auch fur das LS. Die "Christusbraut" Faina (vgl. S.81/8) ist als Einzelperson die Verkörperung RuBlands und des russischen "Volkes" (Vgl. $S .73 / 2$ und $S .73 / 5)$. Die Braut-Mystik ist in 5.Bild vorbereitet: vgl. S.82/15 und S.88/1.

Blok griff auf die Bräutigam-Braut-Mystik zurllck, als er Ibsens Verhältnis zu seinem Helmatland Norwegen beschrieb: "Ja, das 1st "der Bräutigam, der seiner Braut entgegengeht", wie der Biograph sagte; das ist der Träger "des königlichen Gedankens" Uber das Volk, das geistige Leben Norwegens ..." (, 311 ; ähnlich V,457. Blok bezog sich auf den Ibsen des "Brand".).

S.89/6 In Fainas Stimme drifckt sich der "Geist der Musik" aus. Vgl. dazu S.84/15 und Bloks ÄuBerungen Über V. Kommissarževskaja: Sie "griff mit ihrer Stimme das Weltorchester auf" $(\mathrm{V}, 418)$; "Ihre Seele war wie eine äuBerst zarte Geige; ... die Geige einer solchen Stimme verschmilzt mit dem Weltorchester ..." $(v, 419)$. Dieselben Bilder kehren wleder in den Gedichten "Na smert. Kommissarževskoj" (III,190f.) und "Golosa skripok" (III, 192). 
S.89/7 Diese Passage hat große Ähnlichkeit mit Bloks Aussagen uber das Wirken der Musik in seinem Vortrag "O sovremennom sostojanii russkogo simvolizma" (, $425-436)$. Dort stellt Blok der Sphäre der "These", des theurgischen, lichterfillten, die Verkörperung des "Lichten Antlitzes" fast erreichenden Sehertums die Sphäre der "Antithese", das autonome, als dämonisches Schicksal erfahrene Kúnstlertum gegenifber. Die Farbe der "These" ist "purpurlila". Mit dem Erlöschen der Farbnuance "purpur", dem sieg der Farbe "blau-lila", dem "zerreißenden Klang der Geigen und Stimmen", dem "betäubenden Brilllen des Orchesters" bricht die Sphäre der These zusammen (V,428). Blok ordnete in seinem Vortrag die Welt der "Neznakomka" der Antithese zu, der Sphäre der höllischen Verdammtheit des Kinstlers, den das "goldene Schwert", Werkzeug und Symbol der welt des Lichts, nicht mehr durchdringt. ( $\mathrm{Zu}$ diesem $\mathrm{Bild}$, das Kluge, westeuropa und Rußland, S.80 mit einem Hinweise auf Wagner erklärt, vgl. Luk.2,35). Der Umschlag der These in die Antithese wirkt als individuelles Schicksal, das Blok in seinem eigenen Abfall vom hohen Idealismus der "Stichi o Prekrasnoj Dame" erfuhr. Er wirkt als kollektives Schicksal im Scheitern der Revolution von 1905, die zu friih ersehnt wurde. Dieses Schicksal wird von Blok als selbstverschuldete Folge des Verrats am "Heiligtum der Musen", als "Siinde" empfunden. Bloks Vortrag ist filr die Beurteilung seiner Kunstphilosophie von groBer Bedeutung (vgl. dazu besonders Kluge, aaC, S.74ff., der Bloks Ideen in den Zusammenhang der romantischen Kunstphilosophie stellt, und Peters, Symbole der sinnlichen Wahrnehmung, S.189-192).

Der Vergleich des IS mit dem Vortrag zeigt, daß im Stick das hirken des "Geistes der iasik" mit den Farbsymbolen der Thesis (lila + rot) verbunden wird und die "heilige Hochzeit" Germans mit Faina auf dem Hintergrund einer kosmischen illvereinigung einleitet. Das ialten des "Geistes der Musik" ist ambivalent. (Vgl. zu der kommentierten Passage auch Peters, aac, 
die den ambivalenten Symbolgehalt der Geigenmusik, S.218ff., mit dem ebenfalls ambivalenten Gehalt der Parbe Iila, S.183ff., in Verbindung bringt.). Die SymDolik der Farbe Purpur-Violett ist traditionell; vgl. Porstner, Welt der Symbole S.125,129f. mit Hinweis auf die ostkirchliche Mariendarstellung. Im IS ist die Symbolik des "Weltorchesters", der "Geigen" und der Farben Rot und Lila eindeutig positiv. (Zur Verbindung lila + rot vgl. das von Peters, aaO, S.191 angefuhrte Gedicht II.91f.).

Den Unterschied zum LS hat Blok in seinem Vortrag ausdrucklich betont ( $V, 432$; Faina ist die Synthese der beiden im Vortrag scharf voneinander abgehobenen Sphären. Bloks wechselhafte Meinung llber den Wert seines Vortrags, vgl. V,758, zeigt, daB Stepun, Mystische Weltschau, S.385ff. das Richtige trifft, wenn er Bloks Charakteristik der "Neznakomka" als eines Dämon ablehnt, da sie der "Neznakomka" "nicht gerecht" wird.).

S.89/8 Diese Passage erinnert an den Lobpreis auf die Schönheit des russischen Landes im "Slovo o pogibeli Rusky fa zemli";

"O helleuchtendes und herrlich geschmilcktes russisches Land! Durch viele Schönheiten bist du wunderbar: durch viele Seen bist du schön, durch Flisse und gerthmte Quellen, durch zerklliftete Gebirge und hohe Berge, durch prächtige Walder und blthende Felder, ... durch große Städte und herrliche Dörfer, durch die Weingärten der Klbster und durch Gotteshäuser ..." (Gudzif, Chrestomat1ja, S.155; Ubersetzt nach: O Bojan, S.170).

Ähnliche Bilder finden sich im dichterischen Werk vl. Solov'evs bei der Darstellung der kosmischen Alleinheit:

"Was 1st, was war, was in Ewigkeit kommen wird Alles umfing hier ein unbeweglicher Blick... Es leuchten blau unter mir die Meere und Filusse, Und der ferne Wald, und die Höhen der Schneeberge."

("Tri svidanifa". III, Str. 19, Stichotvorenija, S.177; vgl. Stepun, Mystische Weltschau, S.45. Blok zitierte diese Strophe bei der Darstellung der thetischen Sphäre in seinem Vortrag "O sovremennom sostojanil misskogo simvolizma, V,427).

"Nicht nur ich, - der PluB, der Wald, die Berge, Die Bäume, die Tiere, die Sonne und die Blumen Rufen sie und erwarten sie." 
(Monolog des Mortemier in "Belaja l111ja", 2.Akt, 2. Aufzug, aao, S.49).

Die kosmische Alleinhelt ist bel Solor'er als "Bild reiblicher schonhe1t" Symbol der Sophia ("Tri Bvidanifa", Str. 19).

Blok Ubernahm die Bilder Solov'evs fast wortlich:

"Vor Dir leuchten blau ohne Grenze Die Meere, die Felder, die Berge, die Wălder..." $(I, 107)$

"Ich und die Welt, - Schneefelder, Bache,

Die Sonne, Lieder, Sterne, Vögel,

Scharen unklarer Gedanken -

Alle sind Dir untertan, alle sind Dein."

$(I, 193)$

Wie bel Solov'ev herrscht Sie ther das All:

"Du, die Du das Meer und das Festland Unbeweglich mit zarter Hand haltst!"

$$
\text { (II, 7, Str.4) }
$$

Die IS besitzt die kosmische Alleinheit ein stärker russisches Kolorit. Der Hintergrund der Allvereinigung lot Bloks "Rus'" (Vgl. S.81/2; II,8f.; V,357). In P1 18t das rus8ische Kolorit noch stärker, denn dort nehmen die Ebereschen an der Allvereinigung tell (vgl. Abw. 316); dazu Abw. 273), wo die Ebereschen im Monolog Germans erwahnt werden). Die Ebereschen mit ihren leuchtenden roten Drosselbeeren gehoren zu den wichtigsten Attributen der russischen Herbstlandschaft in Bloks Gedichten (vgl. II,75f., Str.2; 263,1, Str.1; Zap.kn., 941., Eintrag vom 9. Jun1 1907). Die Eberesche wird auch im russischen Volkslied besungen (vgl. 2.B. Pasternak, Doktor Živago, Kap. "Rjabina").

S.89/9 German erscheint hier als Sonnengottheit.

Im Christentum ist die Sonnensymbolik seit der Assimilierung heidnischer Sonnenkulte ("8ol invictus" etc.) stark ausgeprägt. Zur Passage des LS vgl.: "Und er ward verklärt vor lhnen, und sein Angesicht leuchtete wie die Sonne ..." (Matth.17,2; ähnlich off.1,16; vgl. Porstner, Welt der Symbole, S.102ff.; Heiler, 0stkirchen, S.228).

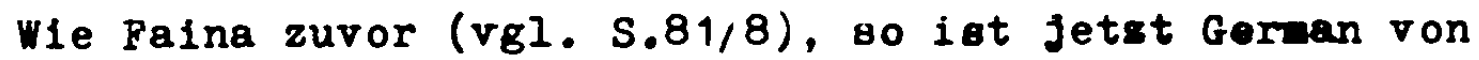
einem Nimbus umgeben. Er lst Person gewordene aufgehende Sonne. 
S.89/10 Faina ist im Zustand der Ekstase. Das Erheben der Hande ist in der Antike die normale Gebärde beim Anrufen der Gotter. Auch ist die Geste im Alten Testament bekannt (Ps.63(62), 5). Sie lebt fort in den oranten und besonders in der Figur der varia oranta. (Forstner, welt der Symbole, S. $343 f_{\text {.). }}$.

S.89/11 Das russische "zdravstruj!" ist die alltägliche Anredeform. Es entspricht nicht dem Pathos der Szene, aber dem Russischen fehlt ein stilistisch hoherer Ausdruck, der hier hätte verwendet werden können. Allenfalls hätte Blok das biblische "radujsja!" verwenden können. (Vgl. dazu die Anrede "Zdravstuj, knjaz'.", III,247, 1.Str.).

S.89/12 Die Sätze dieser Replik wiederholen die Stationen von Germans Verhältnis zu Faina (Peitsche: 3.Bild; KuB: 4.Bild; Traum: Zeit zwischen 4. und 5.Bild, allerdings anders als S.86; rotes Band: 5.Bild vor der jetzigen Begegnung). German erwähnt die Erscheinung (2.Bild) nicht, denn er wußte nicht, daß sie der kosmische Aspekt der Faina war.

S.89/13 Der Andere ist ihr Begleiter.

S.89/14 Zu "rusyj" vgl. S.82/11.

S.89/15 Die christliche lurzel der Sonnen- und Iichtsyinbolik ist hier deutlich (vgl. S.89/9). Zum Bild vergleiche etwa "... und seine augen wie eine Feuerflamme"(plamen'; Cffb.1,14).

Christus, das "Licht der W'elt" (Joh.8,12) wird "mit dem heiligen Geist und mit Feuer taufen" (vatth.3,11), und er ist gekommen, daß er "ein Feuer anzilinde auf Erden" (Luk.12,49). Das Feuer ist das stärkste Symbol des leltgerichts, und die christlich-chiliastische Feuersynbolik wirkt bei Blok stark nach (vgl. S.56/6).

S.89/16 Vgl. S.68/3 und $5.84 / 19$.

S.89/17 Vgl. S.55/9; S.56/4;S.57/5; S.77/6 und S.83/8.

S.89/18 In dieser Replik wiederholt Faina die wichtigsten Topoi aus Germans Monolog (s.87f.).

S.89/19 Vgl. S.89/1.

S.89/20 In der Bibel heint es: Die Frauen verlassen "in Furcht und Freude" das leere Grab Christi (Matth.28,6). German 
1st wie Faina in Ektase.

S.89/21 Vgl. den Titel des Stúcks. Paina lst das verkbrperte Schicksal. Vgl. S.67/2.

S.89/22 Der Ausdruck "den' bezzakatngj" ist der deutlichste Beweis fur die chiliastische Dimension dieser Szene. Faina ist fur German die Bringerin eines neuen Äon. ( $\mathrm{Vgl}$. die Bibelstellen Sach.14,7; Je8.60,20; Offb.22,5).

S.89/23 Vgl. S.88/12 und 13 .

S.90/1 Die vorher vorbereitete (S.84/11) Geste des Gurtellosens 18t Ausdruck der Hingabe der Braut an den Brăutigam. Der Gurtel der Frau ist Symbol der Jungfräulichkeit, und die Symbolik des Gürtellösens ist in der griechlsch-römischen Antike (Artemis, die Hüterin der Tugend, wurde u.a. als Gürtellöserin verehrt) und in der germanischen Mythologie (Brunnhilde im Nibelungenlied) als Bestandteil der Hochzeitsfeler bekannt. Die auf $5.85 / 3$ dargelegte Symbolik des Gurtels als eines kosmischen Herrschaftssymbols verleint der Geste der Faina die von Blok beabsichtigte Dimension: die Hingabe der Paina ist ein kosmisches Geschehen, eine "heilige Hochzeit" des Sonnengottes mit der Erde. Zum Bild des Gurtellosens vgl.:

"Nur Auserwählten löst sich der Gurtel,

Der die Lenden der Göttinnen umgibt." (I,531f., Z.7f.)

Im Ausdruck "Cresla bogin'" lst das christliche und heidnische Moment in der Symbolik verschmolzen. Auch in den Entwürfen zu dem Gedicht "Nox'" (II,48), das die "Neznakomka-Gedichte" eröffnet, ist die Gütel-Symbolik sehr deutlich (Holthusen, Studien, S.90f.). Die rätselhafte Frauenerscheinung in schwarzem Gewand mit rotem Nimbus, die personifizierte Nacht "wird den königlichen Gürtel lösen" (II,392). Die dunkle Schönheit in "Skazka o toj, kotoraja ne pojmet jeje" "erstand in seinem Herzen, streng gekleidet, mit gesenkten Lidern, den Gütel vor den Sterblichen nicht lösend - die undurchdringbare Pinsternis." (Blok, Sobr.so丈., Bd.4, S.142).

S.90/2 Die Proskynese ist seit der Antike die im Orient verbreitete Gebetshaltung, stärkster Ausdruck der Ehr- 
Purcht oder der Anbetung. (Forstner, Helt der Symbole, S.23). Aus der biblischen tberlieferung (Ps.95(94), 6; Matth.26,39) neben anderen Gebetsgesten bekannt ( $v . a$. Knien: Apg.9,40;21,5; Eph.3,14), ist sie in der orthodoxen Kirche verbreitet.

S.90/3 Mit dem Lösen des Gilrtels ist die "heilige Hochzeit" vollzogen. Der Schwan hat seine Schuldigkeit getan... In $F 1$ ist die Girtel-Symbolik noch aufdringlicher. Das Lösen des Gilrtels gleicht einem feierlichen Ritual. Dann gibt Faina ihrem Exlöser "den ersten jungfräulichen Kuß." (Abw. 323)).

S.90/4 Faina ergibt sich German wie die Frde der Sonne. Die kosmische Dimension ist offenkundig. Blok greift auf das zentrale Geschehen der Mythologie, den Sieg der solaren Kräfte iber die tellurischen, die kosmische Vereinigung des Männlichen nit dem ieiblichen zuriick. (Vgl. etwa Bachofen, inutterrecht, S.134ff.; James, Religionen der Vorzeit, S.217).

S.90/5 Vgl. S.88/17 und 21.

$\mathrm{S} .90 / 6 \mathrm{Vgl} . \mathrm{S} .84 / 2$ und $\mathrm{S} .89 / 3$.

$\mathrm{S} .90 / 7 \mathrm{Vgl}$. S.89/5.

$\mathrm{S.90/8} \mathrm{Vgl.S.81/7;S.82/2;S.98/3;} \mathrm{S.99/4;S.103/3} \mathrm{und} 6$. Die Troika ist eines der wichtigsten "dionysischen" Symbole in Bloks Gedichten. Es begleitet einerseits die dionysischen Frauengestalten (vgl. in Zyklus "Snežnaja maska": II,244,246,247; in Zyklus "Faina": II,254f., 257,264f.(3), 293f.; dazu III,20f., 195,196,254f., z.T. mit "homo viator"-Symbolik). is ist andererseits ein Symbol des dionysischen Rußland (vgl. Zap.kn., 117f., Eintrag von 26. Ckt. 1908, zitiert in der Einleitung zum 5.Bild S.315; vgl. das Gedicht III,168 vom gleichen Tag; dazu Kluge, lesteuropa und Kußland, S.194f.). Der Ausruf der Faina und der erste Teil der folgenden Regieanweisung erinnern an den Schlus von Gogol's "Zapiski sumasłedsego". Der wahnsinnige Poprišín ruft:

"Rettet mich! Holt mich fort! Gebt mir eine Troika windschneller Pferde! Setz dich, mein Kutscher, läute, mein Glöckchen, jagt los, Pferde, und tragt mich fort aus dieser ielt! lieiter, weiter, dap ich nichts mehr 
sehe, nichts..."

Gogol', Sobr.soc. v 7 tomach, Bd.3, S.204).

Blok zitierte diese Stelle in seinem Vortrag "Ditja Gogol ja" (V,376-379) zusammen mit einigen Passagen aus der "lyrischen Stelle", die den 1.Teil von Gogol's "Mertvyje dusi" beschließt, und anderen Werken Gogol's. Blok "stiftzte" seinen eigenen RuBlandmythos auf Gogol'. ( Vgl. besonders das Zitat V,379: S.84/15; zum TroikaSymbol vgl. v.a. Kruk, Blok i Gogol', S.98ff.). In der Troikafahrt des vereinten Paares in die unendliche Weite Rußlands erreicht das 5.Bild des IS seinen Hohne punkt. Es mu? hier an die uralte Symbolik der Wagenfahrt erinnert werden. Das B1ld der hagenfahrt des Sonnengottes ist in der orientaliscien, griechischrönischen und germanischen ifythologie bekannt. Die christliche Symbolik griff auf diese Vorbilder, auf die Himmelfahrt des Elia (2. Könige 2,11f.) und andere stellen des Alten Testaments (Ps.104(103), 3; Jes.66,15; Jer.4,13) zurifck und schuf das Bild des "Wagenlenkers Christus", dessen Himelfahrt VerheiBung und Vorbild der Erlösung ist.

Die Troikafahrt wird in zahllosen missischen Volksliedern besungen: "Vot nౌitsja trojka poðtovaja", "Vot mitsja trojka udalaja" (nach einem Gedicht von $F . N$. Glinka), "Cdnozvulno grenit kolokol'cik" (Text von I. Makarov), "Zaọrjagu ja trojku", "Kogda ja na poðte sluzil jamscikom" (Text von L. Trefolev) u.v.a. Auch in der russischen Kunstliteratur gehört die Troikafahrt nit den bald wehmiltigen, bald ausgelassenen Iiedern des Kutschers $z u$ den beliebten Themen:

"Auf dem winterlichen, oden heg Eilt die feurige Troika dahin, Das eintönige Glöckchen Tönt ermildend.

Etwas Vertrautes ist $\mathrm{zu}$ hören

In den langen Liedern des Kutschers: Bald draufgängerische kusgelassenhelt, Bald Wehmut des Herzens..."

(Pułkin, "Zimnjaja doroga", 1826, Str. 2 und 3). 
Nekrasovs Gedicht "Trojka" (1846), das ein ähnliches Sujet hat wie Bloks bekanntes Gedicht "Na Zeleznoj doroge" (III,26of.), wurde zum Volkslied. In Bloks Troika-Symbolik wirkt neben Gogol' eine reiche Tradition russischer Troika-Romantik nach (vgl. auch Belyjs Gedicht "Trojka", 1904).

S.90/9 Vgl. S.81/11 und 12. Zum Bild "brilliantene Träne" vgl. S.84/8.

Die Regieanweisung entspricht der vom Beginn des 5.Bildes.

S.90/10 Der Herbst ist die Zeit der Reife und der irnte und ninmt daher in Jahreskreis einen wichtigen Platz ein. Diese Symbolik begleitet die Begegnung Germans mit Faina und wird von der Symbolik der aufgehenden Sonne (Tageszeitsymbolik) \#berlagert (vgl. S.85: "trunkener herbstlicher Brandgeruch", S.88: "ein Aorgen, so herbstlich wie dieser"). Daneben ist der Herbst die Zeit des Vergehens, des Alterns, die Zeit, in der im alten Mythos die Vegetationsgötter starben, um im Frihjahr vieder aufzuerstehen. Dieser ispekt beherrscht den Schlu3 dieses Bildes. Nie Kraftlosigkeit des Begleiters findet ihre intsprechung in der Herbstetinmung, die in Fallen der Blätter und in klagen des Iindes das suslaufen der Zeit ankiindigt. (Vgl. auch S.101/3). lehrere Gedichte Bloks sind Herbstgedichte. Lie besondere, Reife und Vergehen, irfillung und Verzicht in sich vereinigende stimung des lierbstes libte auf ihn eine grose Faszination aus. (Vgl. etwa I,34,46,86,121, 212,396 (2), 446 ; II,22,23,24f., 45,75f, , 34).

Hedvedev fiihrt als bemerkenswert in $: 12$ gegen:iber $₹ 1$ an: Im Dialog $z$ wischen German und dem Freund, nach den worten Germans "Doch ich stehe fest auf irgendeinem weg... Wohin? wohin" (Abw. 291)). folgen in $M 2$ zusëtzlich zwei Kepliken: Der Freund antwortet mit dem Bibelzitat "Ein 2 weifler ist unbeständig in allen seinen wegen" (Jakobus-Brief 1,8). Hierauf entgegnet ihm German mit dem Bibelzitat "Die vollige liebe treibt die Furcht aus," das Blok als Motto den Stlick vorangestellt hat. 
Die letzte Replik Germans in diesem Bild ( $\nabla g 1$. Abw. 322)) 1st noch länger als in F1. Es heiBt in M2: "Auf deinem Gesicht das ganze Schicksal! Dein Gesicht ist wie der Tag, und die Haare sind wie die Nacht, und die Ilppen sind wie die FluBwindungen im Morgenrot, und die Augen sind wie die Fernen meines Vaterlandes!" (Medvedev, Dramy 1 poemy, S.77). Diese Passage 1st dem vierten lied aus dem Hohen Lied Salomos nachemplunden. Allerdings hat Blok dieses Liebeslied aus der personlichen sphäre in die seines Rußlandmythos transponiert. Diese beiden Passagen in 142 verstärken das "christliche" Element im IS nach dieser frithen Fassung.

Schließlich hat Blok in F1 gegeniber M2 das Vampirhafte der Faina, ihren tierhaften Charakter etwas gemildert. In M2 warf sie sich German entgegen "wie eine Löwin vor dem Lowen, wie die Erde vor der Sonne, wie das Schicksal vor dem Helden." (Medvedev, aac, S.77). 


\section{SECHSTES BIID}

Das 6.Bild knupft in Schauplatz und Geschehen ans 1.Bild an. Die dort angedeutete Liebesbeziehung zwischen Helena und dem Freund Germans kommt jetzt zu ihrem Ende.

Die Bedeutung des Bildes liegt vor allem darin, daB Helena nach einem Versuch, das von ihr verkörperte schönheitsideal metaphysisch zu rechtfertigen, die macht und die stärke des in Faina verkörperten Ideals anerkennt. Das ruhige, helle Ideal der "Gedichte von der Schönen Dame" weicht dem dynamischen, dunklen Ideal der späteren Gedichte Bloks. Der Vorrang des in Faina verkörperten Ideals ist ein "Mysterium", das nicht erklärt werden kann. Er ist Ausdruck des die Geschichte und die Gegenwart bestimmenden Weltwillens.

Im 6. Bild wird besonders deutlich, daB Blok sein Leben im Lichte seines mythischen Weltverständnisses begreift. In der Absage der Helena an den Freund Germans spiegelt sich der Bruch zwischen seiner Frau und Belyj wider. Die Verheißung des Mönchs, daß Helena am Ende eines langen Weges die Seele Germans finden werde, wiederholt die tberzeugung Bloks, daß die "Schöne Dame" ihm am Ausgang seines Lebens, nach vielen Versuchungen und Irrungen, wieder erscheinen werde. 1)

Helenas Aufbruch, mit dem die Idylle von Germans Haus endgultig zu Ende geht, ist das Werk des Mönchs, der ihr das Wesen threr Rivalin als Sinnbild der krisenhaften Zeit erklärt. Im Mönch, der die biblische, "orthodoxe" Begriindung der Helena fur ihren Vorrang mit dem Hinweis auf das Mysterium der Liebe zu FainaRußland zurilckweist, zelchnet Blok das Bild, das er sich nach seiner weltanschaulichen Neuorientierung von Vl. Solov'ev machte. Das orthodox-christliche Element in Solov'evs Weltbild ist zweitrangig; entscheidend ist, daß Solov'ev dem "Ewig-WeibIlchen" begegnete. 2)

1) Vgl. II,371f., Vorwort zu "Zemlja v snegu" vom März 1908 und I,56of., Skizze zum Vorwort einer geplanten Ausgabe der "Gedichte von der Schönen Dame" vom 15. Aug. 1918.

2) Vgl. VIII, 126ff., Brief an Culkov vom 23. Juni 1905; V,446454, "Rycar'-monach"; (später sah Blok in Solov'ev nur noch den Chiliasten: VI, 154-159, "VI. Solov'ev i nasi dni"); S.6, Anm.8, S.7, Anm.4 u.ö. S.43/8; S.48/5 und $11 \mathrm{u} .00$. 
Das 6.Bild steht in starkem stimmungsmäBigem Kontrast zum gleichzeltig spielenden 7.Bild. Es muß aber als dessen Ergänzung verstanden werden. Helena und German sind von nun ab vom Schicksal in ein schweres Leben "auf der Wanderschaft" geworfen. Dieses gemeinsame Schicksal bestimmt von nun an den Charakter ihrer Ehe. Auch hier schwingt ein stark biographisches Element mit: Blok sah nach 1904 selne the und ihre Tragik als vom Schicksal gewollte Entsprechung zur krisenhaften Zeit. Blok schrieb im Sommer 1917 in der Ruckschau:

"Kaum var meine Braut melne Frau geworden, als die lilafarbenen Welten der ersten Revolution uns ergriffen und uns in ihren strudel rissen. Ich, der ich langst insgeheim den Untergans wollte, lieB mich als erster in den grauen Purpur, die s1lbernen Sterne, das Perlmutt und die Amethyste des Schneesturms ziehen. Mir folgte meine Frau, fur die dieser foergang... qualvoll war, schwerer als fur mich. Nachdem der Schneesturm vorlibergegangen war, eröfnete sich die eiserne Leere des Tages, der jedoch weiterhin mit schneesturm drohte und in sich dessen Versprechungen barg. So waren die Jahre zw1schen den Revolutionen, die Seele und Körper ermudeten und verschlissen. Jetzt - wieder ein ansturmender WindstoB (seine Farbe und seinen Geruch kann ich noch nicht bestimmen)..."1)

Blok erwartete einen neuen "Wirbel von Atomen der kosmischen Revolution"2) und fragte voller Bangnis, wie er und seine prau aus thm hervorgehen wirden.

Die beiden Schlubbilder des IS zeigen den Aufbruch von Helena und German in die "elserne Leere des Tages" nach dem Verklingen der "kosmischen" Revolution von 1905. Helena ist stark genug, ihren Weg allein anzutreten, German bedarf zunächst der Hilfe des Hausierers.

1) VII,30of., Eintrag vom 15. August 1917. Zum kosmischen Charakter der Revolution von $1905 \mathrm{vgl}$. $\mathrm{V}, 431$ in "O sovremennom sostojan11 russkogo simvolizma.

2) VII, 301 
S.91/1 Der Schauplatz des 6.B1ldes lot der des 1.B1ldes (vgl. S.44/4).

S.91/2 Der Jahreskreis ist geschlossen. Im Gegensatz zum gleichzeitig spielenden 7.B1ld (vgl. S.98/1; Abw. 407)), dessen Schauplatz die vom Schneesturm durchtoste russische Weite lst, hat das Haus Germans die friedliche Ruhe einer "Insel der Seligen" auch im Winter bewahrt.

S.91/3 Die Regieanweisung und der folgende Dialog zeigen, daB dieser Szene ein Gespräch vorausging.

S.91/4 Die Liebesintrige zwischen Helena und dem Freund aus dem 1.Bild ( $5.46 / 5)$ findet in der Absage der Helena inre Lösung .

S.91/5 Der Freund hat demnach den "Ehebruch" Germans berichtet. Das in kosmische Dimensionen erwachsene Liebesverhältnis 2wischen German und Faina wird vom Freund mit den MaBstäben der bügerlichen Moral gemessen.

S.91/6 Das rus8. "choroła soboj" bezieht sich auf das äuBere, rein physische Erscheinungsbild. (Vgl. S.48/1 zu "prekrasny j"). Die Frage der Helena 18t Ausdruck threr Eifersucht ( $\nabla g l$. dazu auch Abw. 369)).

5.91/7 Das russ. "krasiva" 1st Synonym zu "choroša soboj"; es 1st der gebräuchliche, stilistisch neutrale Ausdruck fur "schön".

S.91/8 Mit dieser Meinung nimmt der Freund eine Position ein, die der Germans diametral entgegengesetzt 18t. Faina ist fur German der Inbegriff des "Ewig-Weiblichen", für den Preund eine ganz gewöhnliche Frau.

Im 1.Bild sagte der Freund von der gehelmnisvollen Faina ( $5.48 / 5$ und 6 ), sie sei "ganz einfach eine Kabarettsängerin..." (S.51/1). Vgl, auch $\mathrm{S.65/2}$.

S.92/1 "Kälte und Verachtung" der Helena erinnern an mehrere Gedichte Bloks, wo die "Schöne Dame" als "streng", "kalt", "unnahbar", "hochmutig" etc. bezeichnet wird $(I, 117,120,196,221,254,334 f$., 517 u.a.).

S.92/2 Vgl. S.87/15. Im Gegensatz zum Ekstatiker German 1st der Freund reiner Verstandesmensch. 
S.92/3 Der Ausdruck "goldene Mitte" geht auf Horaz, Oden, II, 10,2 zurlick, wo der römlsche Dichter das aristotelische Ideal der "aurea mediocritas", der weisen Selbstbescheidung und Mäbigung preist.

Im Munde der Helena klingt der Ausdruck abschätzig, was der Verachtung entspricht, die Blok dem Ideal der "aurea mediocritas", der Wohlanständigke1t und Burgerlichke1t, der "Mittellage des Gelstes" (Stepun, A. Bloks Veg, S.119) gegentiber empfand ( $v g l . V I I, 25)$.

S.92/4 Diese Bemerkung 1st anzllglich, wie die folgende Replik der Helena zeigt.

S.92/5 Hier endet die erste szene des 6.B1ldes, die in F1 nur unwesentlich ausfuhrlicher 1st (Abw. 335-343)). Die Dialogszene zwischen Helena und dem Freund 1st inhaltlich insofern von Bedeutung, als sie das Verhältn1s zwischen den belden Personen erklät, den AnschluB an das vorige Blld herstellt und die folgende wichtige szene einleitet und verständlich macht. Im elnzelnen sind Rede und Gegenrde jedoch recht kinstlich und phrasenhaft. Es 1st Blok nicht gelungen, einen naturlichen Ton zu finden.

5.92/6 In den Worten des Monchs 1st die christliche Leidensmystik deutlich. Helena hat einen Leidensweg vor sich. (Vgl. zum 2.Satz Hiob, 5,7: "...der Mensch wird zu Ungluck geboren."). Im weiteren Verlauf der szene wird das Leidensmotiv durch das Motiv des "homo viator" und des "Rreuztragens" ergänzt.

S.92/7 Dieser Satz deutet an, daB Helenas augenblicklicher Schmerz vergehen wird und inre elgentliche Aufgabe noch vor ihr steht. Dies wird in den folgenden Repliken weiter ausgefuhrt.

S.92/8 Gemeint 18t German.

S.93/1 Der Monch grelft das Motiv der Trauer der Mutter um den Sohn auf, das in Germans Monolog (S.88/2) anklingt. Daneben splelt diese stelle auf die besondere mutterSohn-Beziehung des 1.B1lds an (vgl. S.53/2). Der russische Wortlaut "mat', kotoroj n1 Kego $\checkmark$ mire, krome syna, ne ostalos'n 1st elgentlich widersinnig, denn der Satz 
bedeutet, daB der Sohn der Mutter erhalten blleb. Der beabsichtigte Sinn ist wohl aber: "die Mutter, die den einzigen Sohn verloren hat."

S.93/2 Die "homo viator"-Symbolik 1st deutlich. Zum Bild "weiBer Weg", "schneelger Weg" (S.96/7) vgl. Purkins Gedicht "Zimnjaja doroga" (1826) und Solov'evs Gedicht "V tumane utrennem..."

S.93/3 Der Mönch betrachtet es als seine letzte Aufgabe, Helena aus der Einsamkeit des friedlichen weiben Hauses auf einen schweren Lebensweg zu schlcken, damit sie den Zeichen der zeit gehorche. In der letzten Replik des Mönchs, deren zweimaliges "živoj Celovek" an Dostojevskijs Mystik des "lebendigen Lebens" erinnert, ist im Kern Bloks Antwort auf die Krise seiner zeit enthalten: die Flucht in einen romantischen RuBland-Mythos. S.93/4 Vgl. 1.Bild, S.49/5.

S.93/5 Helena gebraucht das kort "prekrasnyj" in der uber das rein ÄuBerliche hinausgehenden Bedeutung (vgl. S.48/1). Die drei Hauptpersonen des IS, German, Faina und Helena, sind im Verlauf des Stucks mit diesem Ausdruck bedacht worden.

S.93/6 In diesem Bild soll die besondere, metaphysische Dimension der Helena und ihr Unverständnis fur Germans Untreue verdeutlicht werden.

S.93/7 Hier stellt der Mönch in knapper Form die belden weiblichen Archetypen einander gegentiber, die Bloks Mythos vom "Ewig-Weiblichen" bestimmen (vgl. Einleitung zum 5.Bild).

S.93/8 Zur thersetzung des russ. "rodina" vgl. S.87/16. Das dt. "Heimat" wurde v.a. deshalb gewhlt, weil es wie "rodina" ein Femininum 1st, und damit der tbergang von Falna auf RuBland, der sich in den worten des Mönchs vollzieht, analog zum russischen Wortlaut möglich 1st. Der tbergang von Faina auf "rodina" erinnert an eine Stelle in Gogol's "Taras Bul'ba". Die schöne Polin 1st Andrijs "otð̇izna" (Gogol', Sobr.sod. 7 tomach, Bd.2, S.99). 
In ăhnlicher Weise wie Faina im IS verkörpert die schöne Annunciata in Gogol's "RIm" das echte Wesen Ihres Landes. S.94/1 Das Göttilche wirkt in der Ruhe, nicht in Sturm. Helena will den Vorrang ihres Wesens vor dem der Faina begrínden. Sie bezieht sich dabel auf die Erscheinung Gottes vor Elia am Horeb:

"... der Herr aber war nicht im Winde. Nach dem inde aber kam ein Erdbeben; aber der Herr war nicht in Erdbeben. Und nach dem Erdbeben kam ein Feuer; aber der Herr war nicht im Feuer. Und nach dem Feuer kam ein stilles, sanftes Sausen." (1.Kön.19,11f.). Auf diese Bibelstelle bezieht sich V. Solov'evs Gedicht "V strane moroznych v'jug..." (Stichotvorenija, S.75f.; Blok kannte das Gedicht, VGI. VII,134).

Helena verkörpert das "ruhige" Ideal Solov'evs.

Der Wortlaut "v glase chlada tonka" ist kirchenslavisch. Blok hat Feuer und Sturm als die stäksten Sinnbilder der Dynamik im IS mehrfach in Beziehung auf Faina gebraucht. Es ist nicht verwunderlich, dab er hier nur diese beiden Symbole verwendet.

S.94/2 Der Mönch gebraucht Worte des Paulus (Eph.5.32):

"Um deswillen wird ein Mensch verlassen Vater und Mutter und seinem weibe anhangen, und werden die zwe 1 ein Fleisch sein." Das Geheimnis ist grob; $1 \mathrm{ch}$ sage aber von Christo und der Gemeinde."

Diese Stelle des Epheserbriefes, in der die the als Abbild des Brăutigam-Brautverhältnisses Christi und seiner Kirche gesehen wird, wird im christlichen Trauungsritus mehrfach erwähnt. Diesen Sirnzusammenhang konnte Blok als bekannt voraussetzen.

S.94/3 Her sei auf eine Eigentumlichkeit verwiesen, die die Sprache des IS an manchen stellen so unerquicklich macht. Nach Ausdrucken wie "znat', uznat', ponimat'" u.ä. fehlt haufig die Erganzung. Die worter hägen in der luft und der Sinn bleibt dunkel.

S.94/4 Dieses Bild geht auf den uralten Topos vom "Lebenslicht" zuruck. Lampe und Fackel waren in der Antike Symbole des Lebens, ihr Erlöschen Sinnbild des Todes. Dieser Symbolgehalt wurde in christlicher zeit auf die Kerze ubertragen, die im christlichen Kult groBe Be- 
deutung erlangte.

I. Andrejev macht sich diese Symbolik zunutze, wenn er in seinem Drama "Žlzn' celoveka" den Lebenslauf des "Menschen" mit dem Abbrennen einer Kerze begleitet. (Vgl. Andrejev, P'esy, S.931. 1m "Prolog" und S.10off. bei jeder Station. Blok schätzte das Stfick sehr; vgl. $S .44 / 4$ und $S .53 / 5$. Er zitierte die Stelle aus dem "Prolog" des "Jemand in Grau", wo das Bild des Lebenslichts eingefihrt wird: "... mit zitternder Flamme brennt hell und klar die Kerze. Doch das Wachs nimmt $a b$, vom Feuer verzehrt. - Doch das Viachs nimmt ab..." $\mathrm{v}, 191)$.

Im IS hat das Bild ein starkes Lokalkolorit. Blok verwendet das Bild auch in dem Gedicht "Inok" (II,283), das in November 1907 entstand, und in dessen lyrischem Helden leicht der Mönch des LS wiederzuerkennen ist (vgl. S.56/10).

S.94/5 Der Mönch benutzt den gleichen Áusdruck wie Faina in 5.Bild ( $5.82 / 13)$, allerdings nit dem normalen iort "glaza".

S.94/6 Die Liebe zu Rußland, von der der ibonch hier redet, ist nit dem schon mehrnals im LS dargestellten Fernweh, der verzehrenden Sehnsucht nach der Ferne identisch (vgl. S.45/1 und S.54/2, die groRen traurigen Augen). Der Mönch ist den Fernweh genauso erlegen wie German. Sein ewiges Suchen nach Faina (S.56/10) wird von hierher verständlich.

S.94/7 Cb hiermit ein Vergleich nit dem Freund beabsichtigt ist, bleibt offen. (Vgl. S.46/2).

S.94/8 Helena glaubt noch an Gernans Riickkehr.

S.94/9 Helena wiederholt in etwas anderer Weise die Frage nach der Schönheit ihrer Rivalin; vgl. S.91/6. Russ. "luðł̌" bedeutet hier "hilbscher, schöner". Vgl. damit: Pußkin, Jevgenif Onegin, 8.Kap. XIIII: Cnegin ja togda moloze,/ Ja lu飞̌̆e ("hilbscher"), kað̌etsja, byla... Der ilönch gebraucht in seiner folgenden Antwort "luste" in der Bedeutung "besser" und transponiert in der Hiederholung desselben Worts den Vergleich der beiden Frauen von 
der ästhetischen in die ethische Sphäre. Das Wortspiel ist in der thersetzung nicht zu erkennen.

S.94/10 Im Gespräch zwischen Helena und dem Mönch geht es um den Vorrang eines der beiden in Helena bzw. in Faina verkörperten Schönheitsideale. Helena will den Vorrang der ruhigen, klaren, statischen Schönheit mit der $\mathrm{Be}-$ rufung auf das Erscheinen Gottes vor Elia begrinden. Der Mönch bezeichnet das lirken der unruhigen, dynamischen Schönheit, das sich in der Liebe Germans und in seiner eigenen, dem Fernweh gleichen Liebe zu FainaRußland offenbart, als "gropes Geheimnis". Die zweinalige Berufung auf die Bibel zeigt, daß es sich hier um einen metaphysischen Schönheitsbegriff handelt, in dem sich das lirken des Gottlichen kundtut. Dieser Schönheitsbegriff hat eine ethische Komponente, was von Bloks ästhetischen Veltbild her verständlich ist (vgl. S.84/15). Der Mönch läßt die Frage offen, welches Schönheitsideal das "ertvollere ist. Der ganze Zusammenhang zeigt jedoch, daß er in wirken der in Faina verkörperten russischen Schönheit das "Mysterium" sieht. Gogol' hatte schon gesagt: "Die Schönheit der Frau ist ein Geheimnis" (Sobr.sot., v 7 tomach, Bd.6, S.212). Blok steht, gewollt oder ungewollt, ganz in Schatten Dostojevskijs, der in der unbegreiflichen Faszination, die von der dynamischen weiblichen schönheit ausgeht, das Wirken des Göttlichen sah. Von der dämonisch-rätselhaften Schönheit der Nastas ${ }^{1 j a}$ Fllippovna heißt es: "Eine solche Schönheit ist eine hacht... mit einer solchen Schönheit kann man die Welt umstirzen" (Idiot, 1.Buch, 1.Teil, VII). Ähnliche Aussagen finden sich bei Dostojevskij noch ofters.

5.94/11 Helena wertet die Worte des Monchs mit Recht als Eingeständnis seiner geheimen Liebe zu Faina.

S.94/12 Mit dem Tod der Mutter ist auch die Idylle von Germans Haus erloschen.

S.94/13 Mit der Erwähnung dieser alltäglichen Dinge wird die intime Traulichkeit des verlorenen Glifcks beschworen. Helena greift ilotive aus dem 1.Bild wieder auf. 
S.95/1 Diese Replik erinnert an einige Stellen der Bibel, insbesondere an Apg.15,26. Germans Seele gehört FainaRußland (vgl. Abw. 376)).

S.95/2 Der Ausdruck "gor'ko plakat" " ist in Anlehnung an Matth.26,75 (auch Jes.33,7) zu einer geläufigen Wendung geworden.

S.95/3 Die seit dem fuftreten des Monchs immer wieder durchbrechende Trauer der Helena ist Durchgang zur Erkenntnis.

S.95/4 In 11 sagt Helena: "Schweig, :Hnch! Der Himmel ist klar. Ein Jahr ist vergangen. Er hat zu vir gesagt: ich verde zurickkonmen, wenn der Himmel klar ist. Jetzt ist er es*(Abw. 380)). Diese Stelle bezieht sich auf die Worte Germans in F1 beim ibschied (vgl. 3.53/5, Abw. 93)).

S.95/5 Die Annahme der Helena, German verde jetzt zurickkommen, ist vollig unmotiviert. Auch die "kosmische Motivation" in F1 (vgl. vorige $\mathrm{knm}$.) macht das Ganze nicht verständlicher.

S.95/6 In Cechovs "Višnevyj sad" steht zkeimal in der Regieanweisung: "Plötzlich ertönt ein ferner Laut, wie von Himmel, der Klang einer gerissenen Saite, ersterbend, traurig." (2.rikt und Schlu?).

$\mathrm{Zu}$ dieser Stelle fihrt Bicilli, Øechov, S.122, aus: "Offensichtlich fand Blok in dieser ingabe etwas inn Intsprechendes, als er sie in der "Pesnja sud"by" "Schicksalslied") Eusbeutete." ("is folgt das Zitat der kommentierten Passage des IS).

Bicilli stiltzt sich auf diese Parallele zwischen Cechov und Blok, um die Nähe Cechovs zu den Symbolisten $\mathrm{zu}$ beweisen (aao, S.120ff.). Er verzichtet dabei aber souverän darauf, die Bedeutung der Szenenangaben bei Cechov und Blok zu erklären. In 1 steht bei dieser fingabe zusätzlich: "...wie wenn ein Menschenherz zersprungen väre." (Ábw. 382)). Diese Passage hat Blok in F2 wohl deshalb gestrichen, weil sie akustisch schwer "realisierbar" ist. Immerhin ermöglicht sie den Versuch einer Sinnfindung. Bei Beachtung der Gleichzeitigkeit der beiden letzten Bilder des IS ist anzunehmen, da.3 Blok ein Ereignis des $7.3 i l d s$ in dieser verschlilsselten 
Form ins 6.Bild hereinwirken lassen wollte. Dabei handelt es sich in der Angabe im 6.Bild wohl um einen Hinweis auf die Trennung der Faina von German (S.105). Faina-RuBland ist un eine Enttäuschung reicher. Vgl. etwa: "Nun was? Eine Sorge mehr Eine Träne ist der Fluß lauter... ("Rossija", III,254f., str.5).

Eine Hoffnung mehr ist durch Germans Unfähigkeit zur Tat zunichte genacht. Kan könnte dann das "Zerspringen des Herzens" als Hinweis auf die Trennung der Faina von German, das "Krächzen des Kaben" als Hinweis auf die Rllckkehr der Faina in den Zustand der ingst und Bedrohung und der Sehnsucht nach den Beschitzer (vgl. S.83/5), und den "Saitenton" als Viderhall der Trennung in heltorchester interpretieren.

S.95/7 Dieser Befehl des Hönchs ist ein Hinveis darauf, daR Helena das Haus verlassen wird. Die mehrfache Erwähnung der "Einkleidung" erhält im Zusammenhang der ganzen Szene einen quasi religiösen Sinn (vgl. S.96/6).

S.95/8 Beim ostkirchlichen Trauungsritus erhalten Bräutigam und Braut am Beginn der Zeremonie Kerzen, die als Symbole der "Fort:flanzung des Lebenslichts" (Forstner, i.elt der Syıbole, S.418) gelten können.

S.95/9 Diese Worte und die unten $5.96 / 2$ folgenden sind die Fortsetzung der vom angetrunkenen Journalisten ( $5.71 / 3$ ) angestimmten Passage aus der Totenliturgie:

"So svjatymi upokoj, Christe Bože, dušu raba tvojego, ideze nest bolezn', ni pecal', ni vozdychanije, no zizn' beskonecnaja."

Bloks Zitat im IS ist ungenau. Er zitierte die Passage in seinen Jugendtagebuch (VII,31) und in Einleitungsgedicht zum 2. Gedichtband $(I I, 7)$ wie im IS zur symbolisierung der Erlösungssehnsucht und Reichserwartung, und in den "Zvolf" (III, 355) als Hinweis auf den Tod der Katja.

S.95/10 German sieht in seinem Traumgesicht (S.103) Helena mit der Kerze. kuch das ist eine sindeutung auf die Gleichzeitigkeit der beiden letzten Bilder.

$5.95 / 11$ Der Sinn dieses Befehls ist nicht ganz klar. Im ostkirchlichen kitus werden kerzen vor Ikonen und Relicuien ansezindet. Vgl. S.97/1. 
S.96/1 Zur Gebetsgeste vgl. S.50/4, S.68/4 und S.90/2. ile German betet auch Helena vor ihrem Abschied.

S.96/2 Vgl. oben, S.95/8.

S.96/3 Russ. "panichidnogo" zu "panichida" (Toten-, Seelenmesse). Die Substantiviemung dieses Adjektivs ist ungewohnl1ch.

S.96/4 German erwacht im 7.Bild aus einer Art todesähnlichem Zustand zu neuem Leben (vgl. S.105). Der Monch weiß das. Die Passage wäre "motiviert", wenn das 6. und 7.Bild gleichzeitig auf der Bilhne gespielt viliden. In der orthodoxen Totenliturgie wird die hoffnung auf îrlösung stark betont (vgl. Heiler, Cstkirchen, S.250f.), was ja auch in der vom Mönch angestimmten Passage zum Ausdruck kommt. Die Verbindung von Freude und Totengesang ist also verständlich.

S.96/5 Diese Aussage des Monchs bezieht sich wiederum auf den Schlu3 des 7.Bildes. German wird aus der schneewiste vom Hausierer gerettet und auf den rechten weg zurflckgebracht (Vgl. S.106).

S.96/6 Seit der ausgehenden hntike tragen Gläubige ein Kreuz auf der Brust, das in manchen Gegenden der Romania zur Volkstracht gehört. Diese sitte geht auf das seit ältester Zeit bekannte Tragen eines fimuletts zurflck. Das Brustkreuz entwickelte sich sogar zu einer Insignie, allerdings minderen Ranges. Im liesten wird das sog. "pectorale" von Papst, Kardinälen, Bischöfen und Äbten getragen. is ist aus dem Muttergottesmedailion, dem Enkoldion (russ. "panagija") der ostkirchlichen Prälaten hervorgegangen. Das Brustkreuz war Insignie des oströnischen Kaisers und der russischen Zaren bis Peter d.Gr.. Im alten Ru3land trugen auch :önche und fromme Laien, etwa Pilger, einfache Brustkreuze. In Unterschied zum Westen wird in der orthodoxen Kirche bei der Taufe (russ. "krełð̌enije") dem Täufling vom Geistlichen ein Kreuz umgehängt, das zeitlebens auf dem Körper getragen wird ("tel'nyj krest" oder "tel'nik"). Die Taufkreuze bestehen aus Metall oder Zypressenholz. Bei dem sog. "krestovan'e", einer feierlichen Form der 
Verbriferung, werden die Taufkreuze ausgetauscht. (Ein "krestovan'e" schildert Dostojevskif im Roman "Idiot", 2.Teil, IV).

Bei der Hönchsweihe, die sich an die Taufzeremonie anlehnt, reicht der Abt dem konch nach der Einkleidung das Zvangelienbuch, das Handkreuz und eine brennende Kerze (Heiler, Ostkirchen, S.271). In allen Fällen beruht die Kreuz-Symbolik auf den Worten Christi: "Und wer nicht sein Kreuz auf sich nimmt und folget mir nach, der ist mein nicht wert" (Satth.10,38) und "hill mir jemand nachfolgen, der verleugne sich selbst und nehme sein Kreuz auf sich und folge mir" (ifatth.16,24). Die ionche und Nonnen sind "Staurophoro1", "Kreuzträger". (Zur Symbolik des Kreuztrapens vgl.: die Szene in Dostojevskijs "Prestuplenije $i$ nakazanije" in der Sonja Raskol'nikov ihr Kreuz gibt (Teil 5, IV,6, VIII). Raskol'nikov weist snottend auf die Symbolik des kreuz-auf-sich-Wehmens hin. 3loks Gedicht "Rossija" (III,254f., 3.str.):

"Ich kann dich nicht bedauern, Und ich trage behutsan mein Kreuz..."; dazu Ijutčevs Gedicht "Eti bednyje selen'ja ..."). Die Szene im LS erinnert in ihrer christlichen Symbolik an die ironnenweihe, Helena wird zur "Kreuzträgerin". Dabei ist jedoch der nrivate Charakter der ganzen Szene entscheidend. Die "kinkleidung" ist realistisch motiviert und hat nit der sakralen Handlung nur sehr wenig gemein. Das "Reichen des Kreuzes" geschieht ebenfalls in anderer forn wie bei der echten Nonnenveihe. Die "Kerze" wird ausdrijcklich als Hochzeitskerze bezeichnet. Dadurch wird in diese Szene wieder die christliche Brautmystik hereingetragen, die in der orthodoxen Nonnenweihe im Gegensatz zur katholischen fehlt. Die Brautmystik ist dagegen im russischen Sektenwesen weit verbreitet.

Bloks "ruinöses Christentum" ist eine Mischung aus privaten ilenenten, Dostojevskij und Sektierertum. 
S.96/8 Der Mönch verheißt Helena die Wiederbegegnung mit German am Ende einer langen Wanderschaft. Der Schlup des 6.Bildes erinnert an das 1.Bild, wo German ebenfalls in die Welt geschickt wird. Die "homo viator"-Symbolik wird am Schlus des 7.Bildes wieder aufgenommen.

S.96/9 Die Redeweise des Mónchs ist biblisch gefärbt. Vgl. Matth. 7,7-8.

S.96/10 Blok ersetzt in traditionellen Abschiedsgruß "Bog $s$ toboj" das vort "Bog" durch "Gospod'", vas dem Gru? gröReres Gevicht gibt. (In seinen 'iagebuch, v.a. im Jahr 1913, kehrt die liendung "Gospod' s toboj" als Hunsch fir die "milaja", d.h. seine Frau Ljuba, höufie wieder. VII,207ff.).

S.96/11 Der letzte Satz erinnert an die Bibelstelle 4. ios.6, 24: "der Herr segne und behitte dich" und noch stirker an Psaln 121(120), 5.7.8: "der Herr behite dich..." Die letzten sepliken sind mit den zinreden "brat", "bratec", "rodnaja" und "milaja" besonders intim.

S.07/1 Der Mónch schaute auch German nach, als dieser sein Haus verlie $(S .54)$. Ier sbscnied der Helena ist verhalten und ruhiE, wie es ihren Charakter entsnricht. ile das erste Bild, so endet auch das sechste nit einen "leeren" Sumbol (veißes Kleid, Kerze), das an dieser Stelle reinen stimnunés"ert hat.

Die Szene zwischen den liönch und Yelena ist in $i 1$ un einiges länger. Blok hat bei der tberarbeitung des IS nehrere kepliken ganz gestrichen (vel. ibr. 366), 370), 385), 402)) und andere gekiirzt.

Bei seinen Erscheinen ist der abnch "bleich vie Iinnen" (Abw. 344); vgl. 1.Bild, fbw. 35)).

Bei der Beschreibune seines Fernwehs sagt der ininch: "Ich wirde losfliegen, wenn ich :llfgel hätte." (nhw. 366)), womit er die Symbolik des gefallenen Engels wieder aufninmt (vgl.S.45/2 und S.55/4). Danit geht auch die Anrede mit "snfel. Bozij" (sbw. 402)) zusammen. (Die Verbindung Engel-Änch ist in orthodoxen Christentum nicht ungewhinnlich. Las Nönchsleben filt als "encelgleiches Ieben".). 
In thereinstimmung mit den Kurzungen im 2.Bild hat Blok auch im 6.Bild dieses mythologische Beiwerk gestrichen. Ähnliches gilt fur die Gestalt der Helena, die in F1 nocheinmal als "Jelena prekrasnaja" bezeichnet wird (Abw. 402)).

German muß einen langen Weg gehen (Abw. 366)). Auf seinem Irrweg wurde er zun Bettler ("ni stij"), doch selig sind die Armen im Geiste ("blaženni nišije duchom", Abw. 397); vgl. Matth.5,3. Bloks "blaženni" ist eine Kontamination aus Ksl. "blaženi" und russ. "blaženny". Vgl. zum Motiv "Bettler" S.105/12). Helena bezeichnet German als Heiligen (Abw. 372)). Der dynamische Charakter der Faina wird in F1 noch stirker betont als in F2. In inrer seele herrschen Stiirme (Abw. 358)); noch im Grab ist sie voller Aufruhr (f́bw. 359)). Sie 1st "prostornaja, dikaja" (Abw. 370)). Deutlich wird gesagt, daB German "v Rossiju" ging, (Abw. 353); vgl, auch Abw. 354), dazu S.53/5, Abw. 97) und S.59/1, Abs. 141)), daß seine Seele an RuBland weggegeben ist (Abw. 376)), daß auch Helena nach RuBland geht $(A b w, 400))$.

Dieses Bild begann in der frihesten Version gleich nit dem Gesoräch Mönch - Helena. Die Aussprache zwischen Helena und dem Freund wurde von Blok zu einen relativ späten Zeitnunkt zugefilgt (Medvedev, Dramy i poèmy, S.74). Möglicherweise hängt das nit der Unsicherheit Bloks in der Behandlung des Freundes in der Bahnhofsszene von M1 zusammen (s. dort). Es ist auch denkbar, daß rein private Gründe mitspielten, die Im Verhältnis von Bloks Frau zu A. Belyj oder G. Čulkov $z u$ suchen sind. 


\section{SIEBTES BILD}

Das 7.B1Id spielt in der vom Schneesturm durchtosten russischen Weite.

Die Schneesturmlandschaft wird in vielen russischen Volksliedern besungen ${ }^{1)}$ und auch in der russischen Literatur oft dargestellt, wobei der Schneesturm meist einen besonderen, naturphilosophisch zu erklärenden Symbolwert erhält. In Pußkins Erzählung "Metel'" (Der Schneesturm; 1830) ist der Schneesturm "Symbol filr die Ábsurdität des Schicksalhaften. ${ }^{2}$ ) Ähnlichen Symbolgehalt hat der Schneesturm auch in Puskins Gedichten "Zimnij vexer" (Winterabend; 1825) und "Besy" (Teufel; 1830).

In Tolstojs frither Erzählung "Metel'" (1856) ist der Schneesturm noch bloße Naturerscheinung. In der Erzählung "Chozjajin 1 rabotnik" (Herr und Knecht; 1895) "wird der Schneesturm iber der russischen Steppe zu einer Art Symbol filr die Strafe, die die Natur an dem Menschen vollziehen will, der sich iber sie erhoben" hat. ${ }^{3)}$ Schon in polstojs Roman "sinna Karenina" (1877) ist "die Darstellung des Schneesturms... eine Symbolisierung der Identität jener iaturkraft, die sich sowohl im ziellosen, "blinden" Schneesturn wie auch in Annas Lebenswillen äußert."4) Von der Einschränkung auf die Sphäre individuellen Schicksals löst sich das Schneesturm-Symbol in der kurzen Erzählung Čechovs "Po delam služby" (In dienstlicher ingelegenheit; 1899). Das leitmotivisch wiederkehrende Heulen des Schneesturms versinnbildlicht die Trostlosigkeit des Lebens in der russischen Provinz, das von der Hauptperson der Erzählung als "ibergreifendes, iberindividuelles Schicksal erfahren wird. Das Schneesturmsymbol erhält in Bunins Erzählung "Derevnja" (Das Dorf; 1910) eine kulturphilosophische Dimension. Der

1) Vgl.z.B. "Kogda ja na potte služil jamßtikom..."

2) Scheffier, Das erotische Sujet in Pugkins Dichtung, S.205; die Selten $203 \mathrm{ff}$. enthalten eine kritische suseinandersetzung mit verschiedenen Interpretationen des lierks.

3) Hamburger, Tolstoj, S.110.

4) Busch, Tolstoj als symbolist, 3.23. 
"Schneesturm", der "Wind", die "wilde dunkle Trube", der "Schnee", zusammen mit dem Tanzen und dem Wolfsgebrlll der Prau, symbolisieren den Ruckfall des Dorfes in den Zustand der Barbarei, des Atavismus und der geschichtslosen Unkultur. Vjax. Ivanov gebraucht das Bild der Schneesturmlandschaft zur Darstellung des russischen Volkscharakters, als dessen Grundzug er "das Pathos der SelbstentäuBerung" ansieht:

"Die Seele, voll instinktiven Begehrens nach dem Unbedingten und instinktiver Abwendung von allem Konventionellen; die barbarisch-edle Seele, das heibt die verschwenderische, aller Beschränkung spottende und leidenschaftlich-maBlose, gleich den weiten leeren Steppen, wo das Schneegestöber namenlose Gräber verschütet und verweht; die Seele, die sich gegen alles Künstliche upd Küntlich-Erhobene, als Kulturschatz und Idol empört" , 1)

- das ist die russische Seele mit ihrem "Hang zum Hinabsteigen", inrem

"Willen zur organischen All-Einheit, der sich bald asketisch, bald zynisch und wild behauptet... in dem steten Sinnen danach, das mühsam Aufgebaute zu verlassen oder zu zerstören und... herabzusteigen zur undifferenzierten Gesamtheit, zu gen einfach und anspruchslos Lebenden, zu den Armen im Geiste."2)

Ivanovs Schrift "Die russische Idee" geht in ihrem Ideengehalt auf die Jahre 1907/08 zurick. ${ }^{3)}$ In dieser Zeit stand Blok stark im Bann von Ivanove "Dionysiasmus". 4) Bloks Vortrag "Stichija 1 kul'tura" vom 30. Dezember 1908 vor der religiös-philosophischen Gesellschaft wurde ergänzt durch Ivanovs Vortrag "O russkoj ideje" (Über die russische Idee), der eine Art Koreferat zu Blok war. ${ }^{5)}$ Die Ideen Ivanovs, v.a. die Betonung des "dualistischen Prinzips in Rublands geschichtlichem Dasein", das sich im Gegentuber von "Reich" und "Land", "Rossija" und "Rus'", "Staatsgefüge" und "russischem Volkstum" und der "völligen Entfremdung" dieser beiden Sphären "unter Peter dem Großen, dem radikalsten Vertreter der Idee des "Reiches"n

\footnotetext{
1) Iwanow, Die russische Idee, S.31

2) aa0,S.32

3 Vgl. aao, S.VIII

4 Vgl. Einleitung zum 4. Bild, S.248fl.

5) $v_{g 1} \cdot v, 748$
} 
manifestiert, stehen den kulturphilosophischen Ideen Bloks sehr nahe. 1)

Das Schneesturmsymbol findet sich schon in Bloks Jugendgedichten mit noch nicht fixiertem Symbolgehalt. ${ }^{2)}$

Im 2. und 3. Gedichtband Bloks ist der "Schneesturm" eines der zentralen "dionysischen" Symbole fur das valten des "Geistes der Musik" Im Bereich des persbnlichen, des nationalen und des kosmisch-ewigen Schicksals. 3)

Im Zyklus "Schneemaske" ist der Schneesturm die kosmische Aura des "Ewig-lieiblichen". In Poem "Dvenadcat'" ist der Schneesturm der gleichzeitig russisch-historische und kosmisch-ewige

1) In Unterschied zu Blok, der seine kulturphilosophischen Anschauungen mit Kategorien seines "musikalischen" Veltbildes untermauerte, bediente sich Ivanov konkreter, soziologischer und politologischer Kategorien, die aus der deutschen Romantik und dem russischen Slavophilentum stammen. Es sei noch angemerkt, daß der von Ivanov behauptete "Dualismus", ein Nachhall Herders und der Romantik, in kaum modifizierter Form der Darstellung zugrunde liegt, die $\dot{A}$. Weber von der russischen Geschichte gibt: Kulturpeschichte als Kultursoziologie, S.240ff., v.a. S.263-168.

2) In: I, 16 als Symbol der Unbili des Lebens; I, 143 als kosmische Aura der "Zauberin"; I, 144; I,258 in Verbindung mit dem Bild der apokalyptischen Posaune, die der im Crab ingeschlossene vernimmt; I.312 u.a. Blok hielt an der Unterscheidung in der Orthographie "mjatel" fifr den 1.Band und "metel" fur den 2. und 3.Band fest (vgl. I, 568,599). Hinweise auf die Abhängigkeit von Bloks Schneesturm-Symbol von vi. Solov'ev: Zirmunskij, Poezija s. Bloka, S.241; Mrcul'skij, Blok, S.34; Russkaja literatura konca ïIX-nácala XX v., Bd.2, S.238 u.a.

3) Die Schneesturmsymbolik in Th. Manns "Zauberberg" (6.Kap.., "Schnee") weist nicht nur in einzelnen Bildern "Chaos von weißer Finsternis, ein Unwesen"; "Urmonotonie"; "Totenstille"; "Urschweigen, das Hans Castorn belauschte"; "Drohung"; "Windsbraut"; der Traum des Hans Castorp), sondern auch in ihrer kulturkritischen Dimension groBe Âhnlichkeit mit Blok auf. (Die geistige Verwandtschaft zwischen Blok und $\mathrm{Th}$. ilann betont u.a. Maksimov, Kriticeskaja proza A. Bloka, in: Blokovskij sbornik, S.52f., Anm. 33. Sie beruht auf der gemeinsamen Abhängigkeit von der "neueren" Lebensphilosophien.). 
Hintergrund der "Revolution" und der Erscheinung Christ1. 1) Neben der kosmischen Dimension lst hier das "Lokalkolorit" der Petersburger Winterlandschaft stark betont. Eine zu starke Unterscheldung von personaler Beziehung des Schneesturmsymbols in Bloks 2.Band (als Symbol der Leldenschaft) und Uberpersonlicher Ausweitung in den "Zwolf"2) verkennt die bei Blok immer vorhandene Identität von persönlicher und kosmischer sphäre. 3) Die "Zwölf" entstanden aus der gleichen "dionysischen" Inspiration wie die "Schneemaske". 4)

Der Schauplatz des 7.B1ldes des LS hat zwar russisches Lokalkolorit und erinnert an die russischen Vorgänger Bloks. Die Schneesturmlandschaft des IS ist allerdings eher der in die szenische Realität projizierte mythische Raum der "Schneemaske"-

1) Vgl. dazu zuletzt Peters, Symbole der sinnlichen Wahrnehmung, S.53-66. Zum Schluß des Poems "Dvenadcat'" sei angemerkt, daß die Verbindung der Gestalt Christi mit dem "nur von Blok in dieser Weise benutzten "privaten" Symbol des "Schneesturms" (Peters, aao, S.66) eigentlich nicht so ungewohnlich 1st. Bloks Symbolik des "Schneesturms" und die des "Windes" gehören eng zusammen (vgl. Peters, aao, S.233ff.). gerade auch in den "Dvenadcat" ". Die "Wind"-Symbolik Bloks steht jedoch in der uralten, auf die antike philosophie (Anaximenes, Stoa, Neuplatonismus; vgl. Rohde, Psyche, S.249ff., 310ff.) zurückgehenden, v.a. durch das JohannesEvangelium $(3,8)$ ins Christentum integrierten Tradition der "Pneuma"-Symbolik. Die Verbindung von Theophanie und Sturmwind ist traditionell (1.Kön. 19,11; Hiob 38,1; Ps. 18,11ff.; Ps. 104(103),3-4; Hes. 1,4; 3,12-14; 37,9; Apg. 2,2-4). Der ambivalente Gehalt des "Wind"-Symbols in den "Dvenadcat" Strafgericht und Lebensodem - ist ebenfalls traditionell und entspricht der ambivalenten Symbolik des "Feuers" (vgl. zur biblischen Symbolik des "Windes": Forstner, Welt der Symbole, S.78ff.).

2) So z.B. Peters, aao, S.59 unter Berufung auf Bowra, The heritage of symbolism, S.175.

3) Schlagendes Beispiel fur die Verquickung von persönlichem Schicksal (Verhältnis zu seiner Frau), politischer Umwälzung (Revolutionen von 1905 und 1917) und kosmischer Katastrophe im Bild des Schneesturms ist Bloks Tagebucheintrag rom 15. Aug. 1917, VII,3oof. (zitiert in der Einleitung zum 6. Bild, S.286).

4) Vgl. Blok, Sobranije sotinenif v 12 tomach, Bd. 8, S.239. 
Gedichte, als wirkliche russische winterlandschaft. 1)

Das Verhältnis von Paina und German lat das getreue Spiegelbild des Verhältnisses der allbeherrschenden und Erlösung suchenden "ewig-weiblichen" Heldin der "Schneemaske"-Gedichte zu dem schwachen, der Heldin verfallenen, aber zu ihrer Erlösung unfähigen männlichen Antipoden. Die Begegnung des 5.Bildes war nur eine Episode, die allerdings die Hoffnung auf eine erneute, endgultige Begegnung begrundet. Faina-RuBland fällt wieder in den Bann des alten Zauberers zurick. German gerät weder in den Bann der Vergangenhe1t, doch ist er von nun an nicht mehr der ritterliche Held, sondern der Vagabund, die russische Verkörperung des "homo viator". 2)

Ihren stärksten Ausdruck findet Bloks "homo viator"-Mystik in seinem Aufsatz "Bezvremen'e" (Unzeit; 1906), 3) der Große Ähnlichkeit mit dem LS, v.a. mit dessen Schlußbild hat, und in dem sich wesentliche Elemente von Bloks RuBland-Gedichten wiederfinden. Der Aufsatz, in dem sich Kulturph1losophie und Literaturkritik durchdringen, mutet wie ein Prosagedicht an. Zunächst schildert Blok den Verfall des idyllischen patriarchalischen RuBland, des "goldenen Zeitalters" altväterlichen Familienlebens, in das der Ungeist der neuen zeit einbricht.

1) Zu der ibergreifenden, die Aura des "Ewig-Weiblichen" und die russische, mythisch-iiberhöhte Winterlandschaft umfassenden Symbolik $\nabla g 1$. Zap.kn., 117f., Eintrag vom 26. cirt. 1908 (zitiert in der Einleitung zum 5.Bild, S. 315). Dazu: Gorelov, Groza nad solov'invm sadom, S.210, Anm. 2.

2) Vgl. II,75,84,106 u.ö.; der Vagabund ist schon im Mittelalter der antíburgerliche Unbehauste, der sich in seiner Verachtung des städtischen Spleßblirgers mit dem Adligen einig war. Bei Blok verbindet sich die Gor'kijsche BosjakenRomantik mit einer säkularisierten Stranniki-Ideologie (vgl. dazu: Sarkisyanz, Rußland und der Messianismus des Orients, S.78ff., 149ff.).

3) V.66-82. Mit "bezvremen'e" bezelchnet man die zeit der grundlosen Wege und eine Epoche allgemeiner geistiger Stagnation, insbesondere die 80-er Jahre des 19.Jhdts.. die als "graue", "gesichtslose" Epoche galten (vgl. Tschižewsk1f, Russ. Literaturgeschichte, Bd.2, S.208f.). 
"Es gibt keinen häuslichen Herd mehr. Eine riesige klebrige Sninne hat sich an dem heiligen und ruhigen ort eingenistet, der das Symbol des Goldenen Zeitalters war. Die reinen Sitten, das ruhige Iächeln, die stillen Abende, - alles hat die Spinne zugewoben, und die zeit selbst ist stehengeblieben. Die Freude ist erkaltet, der Herd verlöscht. Es gibt keine Zeit mehr. Die Tiiren sind auf den schneeumtosten Platz geöffnet."1)

Das Symbol des Ungeistes der neuen Zeit, das große spinnengleiche Untier, ist das "Insekt" Dostojevskifs, die Verkörperung der Listernheit. Es "triumphiert auch auf dem Platz", es beherrscht auch die stadt mit ihren Dirnen und ihrer "wahnsinnigen Uysterie". 2) Im allgemeinen Niedergang taucht ein neuer Menschentyp auf, der Vagabund, der "brodjaga".

"In unserer Nitte erscheinen Vagabunden... Die stimme des Schneesturms hat sie aus ihren spinnenbehausungen gelockt, ihnen die kuhe und den Herd geraubt, ihnen ins Chr gesungen, - und sie haben das Iied vom ewigen Kreislauf verstanden... Ein kurzer Blick, der Blick einer Zigeunerin, deren "amburin erklingt, deren Stimme mit den Iiedern des Schneesturms verschmilzt, ruft auf den endlosen Weg. Kummer wird dem, der seinen Blick in ihren glisernen astralblick versenkt. Er ist zun Spiel der Zufälligkeiten verdamnt... sr wird im Jubel des Schneesturms erstarren... Docin der Schneesturm kennt suserwählte. Sein Kosen begreifen die Heruntreiber, die an den Zäunen gekreuzigt sind. Der Schneesturm trägt sie... Und da sind im Iunkel schon die Straßen und Plöze verschwunden. slles ist verschwunden: das Rasseln der Kessel in der Ferne, das Gelächter des larkts, die klaffenden Löcher der dunklen Fenster. Cde der Felder, und kaum sichtbar die Chaussee. Es gibt keine Städe mehr. Die Stimme des Schneesturns singt in den 'ielegraohenstangen... Die wesen, die aus der stadt gegangen sind, - das sind Vagabunden, irme im Geiste... Tag und Nacht, in der Cktoberkëlte und in der Sommerhitze ziehen hier mussische Henschen, ohne Freundschaft und Iiebe, ohne slter: die Nachfahren der Recken..."3)

Diese "seligen Geschöpfe", denen "das Gefihl filr den eigenen Herd, fiir die eigene Seele verlorenging", deren "Blick die Erinnerung an die geraden Iinien der stadt verloren hat", ") weihen sich der ewigen wanderschaft durch die endlosen Weiten kußlands. sie werden eins mit der armseligen, leeren Landschaft, in der

1) $V .70$, Kapitel "CXag".

2) V:71, Kapitel "S nloł̌cadi na "lug zelenyj""; vgl. Kluge, vesteuropa und RuBland, S.72.

3) $V .71-73$

4) $v: 73$. 
es "weder Zeit noch Raum"1) gibt, in der die Geschichte atillzustehen scheint.

"Wir sind weise, weil. wir arm im Geiste sind; wir werden freiwillig zu Waisen, nehmen freiwillig den Stock und das Bilndel und ziehen durch die russischen Ebenen. Aber hört der Wanderer etwas von der russischen Revolution, von den Schreien der Hungrigen und Geknechteten, von den beiden Hauptstädten, von der Dekadenz, von der Reglemung? Nein, denn weit ist das Land und hoch der Himmel und tief das lasser, und unmerklich vergeht das Treiben der Menschen und wird wieder fortgeflihrt... Wir sind Wanderer und hören nur die stille."2) Auf die Frage, ob diese Stelle jenseits allen menschlichen Treibens nicht auch die Todesruhe des Spinnennetzes sei, antwortet Blok: "So 8011 es nicht sein!". Er sieht in der völligen SelbstentäuBerung, der "ewigen Wanderschaft" die VerheiBung einer besseren Zukunft.

In jifngster Zeit nachte $M$. Nag den Versuch, Bloks "Zwölf" von der Schlußszene des Ibsenschen Schauspiels "Brand" her zu deuten. ${ }^{3)}$ viel naheliegender ist der Vergleich des "Brand" mit dem 7.Bild des IS. Schon P. :Hedvedev ${ }^{4}$ ) hatte darauf hingewiesen, daß German ursoriinglich als Heldennatur in der Art Brands gedacht war. N. Nilsson filhrt dazu aus:

"Von Ibsens männlichen Helden hat besonders einer Bloks Interesse geweckt: Brand. Das war ganz natiirlich, denn in der Gestalt Brands fand er die Tat- und Willenskraft, den fanatischen Trotz gegen das Schicksal, womit Blok, der einsame, schwache Dichter, sich selbst gern verhärtet hätte. Es war die erdichtete Gestalt, die zwangsläufig jenen Symbolisten als Wuster dienen mußte, die sich aus ihrem Pessimismus, ihrer Passivität und Weltabgewand theit herauszubrechen suchten...

1) V,74; Bloks mythisches Bild des endlosen armen RuBland erinnert stark an die "lyrische Stelle" im 11.Kapitel von Gogol's "Toten Seelen", aus der das 2.Motto des IS stammt.

2) V.82, Kapitel "Russkaja literatura".

3 Nag, Ibsen, Cechov und Blok, in: Scando-Slavica, Bd.X, S.47: "Wir sehen also, daß Blok bei Ibsen zwei Hauptelemente seiner eigenen Weltanschauung wiederfand: die Verehrung des "Rhythmischen" und die Verehrung des "ewig "Weiblichen". Und so vereinigten sich diese beiden Komponenten zum Begriff des "deus caritatis". Und das Wichtigste fifr uns: gerade aus diesen beiden Komponenten (vgl. neźnoj postup'ju und sileznoj rossyp'ju) setzt sich die Christusgestalt in der SchluBszene des Poems "Die "Zwölf" zusammen..." Nags Deutung llberzeugt nicht.

4) Medvedev, Dramy i poemy, S.64f. 
Die Brand-Gestalt findet man auch im Hintergrunde, als Blok das Drama Der Gesang des Schicksals (Pesnja sud'by) entwarf... Man kann sehen, dab der Held des Dramas, Hermann, urspringlich als heroische, individualistische Figur gedacht war... Aber im Verlaufe der Arbeit veränderte sich das Bild des Helden. Er wurde $z u$ einem jener weichen, lyrischen Helden, die fur alle Stiucke Bloks so bezeichnend sind, und denen er sich so verwandt fihlte. Im Grunde war es ja ein anderer von Ibsens Helden, dem sich Blok mehr verwandt fuhlen konnte: Brands Gegensatz, der weiche, lyrische Peer Gynt..."1)

Entscheidend in der Beurteilung der Gestalt Germans ist jedoch nicht der zweifellose vorhandene Unterschied von $\$ 1$ und $F 2^{2}$ ), sondern die Entwicklung vom helden zum Vagabunden, die German in beiden passungen durchmacht.

Jas 7.Bild, das in dreifacher ireise diesen Wandel zeigt - im Gegensatz zum 5. Bild, im Gegensatz des Eingangsmonologs zum veiteren Verlauf des 7.Bildes und im Kontrast des Traumbilis vom daherziehenden Helden zur szenischen Wirklichkeit - enthält eine Reihe von Motiven und Strukturelementen, die direkt an Ibsens "Brand" erinnern: der Schauplatz ist die "Eiskirche"; 3 ) German und Brand treten mit einem Honolog auf; beiden erscheint in Iraum die Vergangenheit (Brand träumt von ignes, German von Telena); in das Geschehen herein erklingt ferne Musik (im "3rand" der Chor der Unsichtbaren, in IS das Lied des Korobe jnik).

Diese Farallelen zwischen "Brand" und dem IS legen die Vernutune nahe, daß die Schlubszene des LS eine literarische Auseinandersetzung mit Ibsens "Brand" ist. Brand bleibt bis zum Schluß der harte, gegen sich selbst und andere unbeugsame Yönpfer, der seine liaxime "Alles oder nichts" nicht aufgibt. Mber seinem lod steht die VerheiBung, daß der alliebende und verzeihende Gott ihn $z u$ sich aufnehmen wird, obwohl Brand dem christlichen Ideal der Demut nicht genugte. 4 )

1) Vilelsson, Ibsen in Rußland, S.216f.

2) Vgl. S.53/5, Abw. 93)-99).

3) VEl. S.98/5.

4) Der Schlußvers lautet: "Gott ist deus caritatis." Der Schluß des Brand ist eine Variation der Erlösungsszene am Schluß von Faust II. 
Blok hielt die Lbsung des Dramas "Brand" offenbar fur zu einlach. Auch German ist im 7.B1ld am Ende. Doch versagt sich Blok das Ibsensche Ausweichen in die Unverbindlichkeit einer relig18sen Heiloverhe1Bung. Im Gegensatz zu Brand geht German nicht ins ewige leben eln, sondern muB seinen Weg in der Welt fortsetzen. Er wird zwar vom "Ewig-Weiblichen" geleitet und aus dem Schneesturm errettet, aber nicht von einer grttlichen Macht, sondern von einem Repräeentanten des russischen Volkes und nicht fur ein paradiesisch-erlostes, sondern fur ein irdisch-schweres Ieben. Dem hochgestochenen Individualismus Brands, dessen "quantum satis" der Vielfalt des Lebens nicht gerecht wird ${ }^{1)}$ und dessen Tod und Erlösung inn aus der echten Begegnung mit dem Leben enthebt, stellt Blok ein anderes Ideal entgegen: die Bereitschaft, das Leben in all seiner Tragik anzunehmen. 2)

In der Entwicklung Germans vom Helden zum Vagabunden schlägt sich Bloks eigene Abkehr vom hochgespannten Individualismus und "westlichen" Idealismus und die Hinwendung zu einer, der vielfalt des Lebens offenen, "tragischen" Geisteshaltung nieder. 3 )

Blok sah seinen eigenen Werdegang in Ibsen bestätigt. Dieser selbst hatte mit dem Individualismus Brands gebrochen:

"Welchen Schritt macht Ibsen, ...der einsamste Zeitgenosse, der höchste Individualist, der Familie, Gesellschaft und Vaterland verlassen hat, um sich in die Bergeshöhe Brands zu erheben... Der einsamste Nensch stieg vom Berg herab zl den Menschen. ... Ibsen kehrt zur "vertrauten" und "nahen" Wirklichkeit zurlick... Er verzichtete darauf, "Bräutigam im Hochzeitsgewand"4) zu sein und wurde zum groBen Tagelöhner..."5)

1) Vgl. III,344, SchluB des Poems "Vozmezdije":

Du wirst dann äiles billigen,

Denn du hast verstanden, daB das Leben unendlich mehr ist Als das "quantum satis" des Brandschen Willens,

Und die Welt ist schon wie immer.

2) $\mathrm{Vgl}$. II,272f.(1), zitiert in der Einleitung zum 5.Bild, s.309.

3) VGI. II, 191f., 203

4 Vgl S.89/5, das Zitat Uber Ibsen.

5) V,312f. in "Genrich Ibsen": V,309-317 vom Herbst 1908. 
Inmer jedoch steht Ibsen, wie jeder große Kunstler, unter dem Schutze des "Ewig-Weiblichen". 1)

In Auseinandersetzung mit der Gestalt des "Brand" wollte Blok in German demnach eine Entwicklung symbolisieren, die er in seinem eigenen und in Ibsens Werdegang verwirklicht sah. Die Schlußszene des IS fithrt das Thema weiter, das in der langen Skizze zu einem Theaterstück mit dem Titel "K "Dionisu Giperborejskomu"" (An den hyperboreischen Dionysos) vom 29. Dez. $1906^{2)}$ von Blok angeschlagen, aber nicht zu Ende gefuhrt vurde.

Dieses Stilck sollte das Scheitern eines "Helden" zeigen, der in der Árt Brands das Volk in die Höhen der Gletscherberge f'ihrt, aber an seiner lhaBlosigkeit zerbricht und ins Tal zurlickkommt. Die Hauptperson des Stifcks sollte ein Jungling sein, der dem "Helden" und den Kflhnsten nicht in die Höhe folgen kann, sondern allein in den Gletscherbergen zurilckbleibt, weit oberhalb der Stadt mit den einfachen Volk, aber hinter den Ersten zurfick. In einem konolog sollte er seiner Verzweiflung susdruck geben: er ist bereit zu sterben.

"Doch es singt in inm ein Maß des tieges, den er zurlickgelegt hat (jenes Maß, das den Menschen in inwesenheit einer Gottheit erfulit).

Er läuft auf die Felsen hinauf und ruft laut und beharrlich. Und auf seinen letzten, ersterbenden Ruf antwortet ihm Ihre tiefe Stimme."3)

Len Jilngling erlöst aus seiner quäienden finsamkeit das "EwigWieibliche", das filr Blok rätselhaft blieb:

"..er ist Sie? Ein Gott oder ein Dämon? Morgen werde ich das genau ansehen... Es geht un das fllerwichtigste..."4) Iie Fläne zur susffhrung des Sticks wurden von einer wielle

1) $v, 313$

2) Zạp.kn., 87-91.

3) Zan.kn..8 89f.

4) Zap.kn. 90. Das Stlick sollte offenbar ein Traumspiel sein, das gleichzeitig auf einer komisch-pantomimischen und einer pathetisch-aramatischen Ebene spielen sollte und damit in die Nähe der librigen lyrischen Dramen gerilckt wäre. Blok hatte anscheinend, ebenso wie beim IS, mit seinen "verdammten Abstraktheiten" zu kämpfen: "ile muB die Sprache dieses stilcks sein? Verse oder Prosa? Stilistische Einheitlichkeit wahren! Möglichst konkret. Ganz ruhig" (Zap.kn., 90). 
lyrischer Inspiration hinweggeschwemmt: in einem wahren Rausch schrieb Blok vom 29. Dezember 1906 - 13. Januar 1907 die Gedichte des Zyklus "Schneemaske" und die ersten Gedichte des Zyklus "Faina". Das reale Vorbild für die dämonisch-göttliche Prauengestalt dieser Gedichte, N.N. Volochova, war offenbar auch das Vorbild für die "Jungfrau der Schneeberge", das "Ewig-Weibliche" in dem geplanten Stück. 1 )

Die Gedichte des Teils "Snega" des Zyklus "Schneemaske" entwickeln die Szene der Begegnung des Jünglings mit "Ihr" in der Höhe der Gletscherberge. 2)

Der SchluB des IS sollte offenbar die Ausweglosigkeit des lyrischen Helden dieser Gedichte in der Verlorenheit der kosmischen Sternennacht uberwinden und in Fortführung der Pläne zum liegengelassenen "hyperboreischen Dionysos" einen Blick in die Zukunft eröffnen, die im Zeichen einer auf ein mythisches RuBland bezogenen "homo viator"-Mystik steht. 3 )

1) Mitten in den Skizzen zu "K "Dionisu Giperborejskomu" " steht als Gedächtnisstütze der Wortlaut eines kurzen Briefes, den Blok am 28.12.1906 an die Schauspielerin gerichtet hatte.

2) $v_{g l} \cdot z \cdot B \cdot I I, 232 f f$.

3) $\mathrm{V}_{\mathrm{g}}$. dazu die Kritik Je.P. Ivanovs in der Entstehungsgeschichte, S.35. Zum "Weg" als ein für Blok wichtiges Symbol für RuBland vgl. Motul'skij, Blok, S.168-171. Neuerdings untersuchte Maksimov, Ideja puti v poètiCeskom soznanii Al. Bloka, in: Blokovskij sbornik $(2), \mathrm{S} .25-121$, den poetischen und philosophischen Gehalt des Blokschen Symbols in seiner Vielschichtigkeit und in seinen Bezujgen auch zu Schopenhauer, Nietzsche, Dostojevskij, VI. Solov'ev u.a., sowie zum russischen Sektenwesen. 
S.98/1 Dieses Bild spielt gleichzeltig mit dem vorigen. F1 enthält ausdrucklich diesen Hinweis ( $\mathrm{Abw}$. 407)). In F2 ist die Gleichzeitigkeit an einigen Stellen aus dem Geschehen ersichtlich.

S.98/2 Der Schauplatz und die Atmosphäre des 7.Bildes stehen in starkem Kontrast zu Schauplatz und Atmosphäre des 6.Bildes.

5.98/3 Die Troika ist auch in diesem Bild ein Attribut der Faina (vgl. S.90/7).

S.98/4 Zu dem B1ld der "drel Leben" vgl. s.53/5, Abw. 93).

S.98/5 Dieser Monolog Germans besteht aus reimlosen funfhebigen Jamben (Blankversen; vgl. S.60/5).

Der Monolog ist elne freie Variation des Gedichts "Vtoroje krešcen'e" (II,216) aus dem Zyklus "Sneźnaja maska". Die ersten vier Verse geben den Seelenzustand Germans wieder. Die Vergangenheit ist für inn gestorben, seine Seele ohne Erinnerung. (Dieses Motiv wird weiter unten wieder aufgenommen: vgl. S.99/9). German verkörpert die von Ivanov (s.0.) geschilderte "barbarische Seele". (Der Vergleich "dusa, kak step' ..." ist mit seiner direkten Angleichung der äußeren Landschaft an die "Seelenlandschaft" etwas schwach; "ot kraju 1 do kraju" erinnert im IS an "ot morja do morja" im Motto aus Gogol's "Mertvyje dusi" (vgl. S.43/3). Ähnliche Ausdrilcke durchziehen Bloks Rußlandgedichte (z.B. II, 106f., II,272f.); sie bezeichnen das Umfassende, die Weite Rußlands.).

Die Verse 5-13 enthalten eine Gegenuberstellung von ruhigem häuslichem Gluck und rauschhafter Hingabe an die Elementargewalt des Windes. German stellt der Idylle des Familienherdes die Freiheit und das Glilck eines dionysischen Lebens entgegen und nimmt das Motiv des "ausweglosen Glilcks" aus dem 1. Bild wieder auf ( $v g l$. $\mathrm{S.50/3}$ und $\mathrm{S.87/5)}$.

(Zum Bild "Familienherd" vgl. I,70; zu den Bildern "Schneesturmnadeln", "Kälte, die verbrennt" vgl. Žirmunskij, Poezija A. Bloka, S.217ff., Peters, Symbole der sinnlichen Wahrnehmung, S.53ff.; das Bild "Taufe 
in einem schneeigen Becken", vgl. II,216, 1. Str., ist eine deutliche Anspielung auf das Symbol der "Eiskirche" in Ibsens Drama "Brand", 1. und 5.Akt.).

Die letzten beiden Verse enthalten den Wunsch einer völligen Aufgabe des Ich in der Verschmelzung mit dem Element des Schneesturms.

Der Monolog Germans steht mit seiner Absage an Geborgenheit und Häuslichkeit in grober thematischer Nähe zu Ibsens Poem "Auf den Höhen", wo ein Schneesturm den Rllckweg von der Höhe, von der Einsamkeit der Berge ins Tal, in den Frilhling, zu Mutter und Braut verhindert. Das selbstverschuldete Schicksal wird stolz angenommen:

"Mein Fuß verschwor den Tieflandstrott; Hier auf den Bergen ist Freiheit und Gott, Da drunten tappen die andern."

(Ibsen, Sämtliche Werke, Bd.1, S.104).

Die Symbolik der Höhe ist in Germans Position auf dem Hügel noch erkennbar.

German tritt im 7.Bild mit seinem Monolog als freie, starke, das dionysische Verschmelzen mit dem Element bejahende und lustvoll erfahrene Person auf. Die nochgestinmte Ekstatik erinnert an das 5.Bild (und an das 1.B1ld in F1; vgl. $5.53 / 5 \mathrm{mit} \mathrm{Abw.} \mathrm{93)} \mathrm{ff.).} \mathrm{Im} \mathrm{weiteren}$ Verlauf des 7.Bildes wird German ziemlich unvermittelt zu einem der Kraft des Elementaren hilflos ausgelieferten Schwächline.

S.98/6 In ähnlicher Weise wie Faina im 5.Bild als Personifikation der iussischen Landschaft auftritt, ist sie im 7.Bild die Inkarnation des "Schneesturms". Ihre stimme ertönt zusammen mit dem Singen des schneesturms ( $\mathrm{vgl}$. S.89/6). Sie taucht aus dem Dunkel des Schneesturms auf (vgl. folgende Anm.), ist Herrin uber den Sturm (vgl. S.100/7) und verschwindet im Schneesturm (vgl. S.105/9).

S.99/1 Das Auftauchen der Faina hat neben dem oben angedeuteten Sinn einen Symbolgehalt, der auf die Hell-Dunkel-symbolik bel Blok zurückgeht (vgl. $5.43 / 9$ ).

S.99/22 Diese Passage ist vermutlich als Hinweis auf den volkhaften Charakter der Faina, als "Folklorismus" zu verstehen (zum Bild "an der Hand nehmen" vgl. S.77/2 und 
die Byline von "Solov'ej Budimirovič", Sbornik Kirsi Danilova, S.9ff., 2.257; das Bild "ergötzen" ist Ausdruck von Bloks Mythos vom freien, leidenschaftichen russischen Volksmädchen, der in Faina Gestalt angenommen hat.).

S.99/3 Im 7.Bild wechselt die Beleuchtung mehrfach mit dem Anschwellen und Abklingen des Schneesturms.

S.99/4 Das Scheuen der Pferde im Schneesturm ist ein weit verbreitetes Motiv in der "Schneesturm-Literatur" (Volkslied "Kogda ja na počte služil janščikom"; Puškin "Besy" u.a.).

Die Passage "erklärt", wie German und Faina in die Schneewiste gelangt sind. Das Verschvinden der Pferde ermöglicht es, daß German am SchluB des Bildes vom Hausierer gerettet wird. Diese beiden "realistischen" Aspekte des Scheuens der Pferde sind allerdings vorgeschoben. Blok wollte das Troika-Symbol dramatisch "realisieren". Er konnte die îroika allerdings fifr den weiteren Verlauf des Stficks nicht mehr brauchen. So mußte er sie davonjagen lassen.

Das Lachen der Faina ist Ausdruck ihres ungezifgelten, unbekinmerten liesens.

S.99/5 Sie ist die Herrscherin.

S.99/6 Faina ist ein "therweib".

S.99/7 German nimmt in abgewandelter Form ein Bild des "kiannes mit Brille" auf $(S .73 / 2)$. German ist der Sklave, Faina die Donina. Zum Bild vgl. Solov'evs Gedicht "Poslednjaja ljubov'" (2.str.).

S. 39/8 Fainas Blick ist der rätselhafte, von Gernan nicht enträtselte Blick der Sphinx, der dämonischen Frau des fin-de-siècle (vgl. S.67/2).

Auch der Blick der Nastas'ja Filippovna ist rätselhaft (Dostojevskij, Idiot, 1.Bd., 1.Teil, IV, VI).

In $F 1$ vergleicht German den Blick der Faina mit dem Zlehen der wolken und dem Brennen der Steppe ( $A b w$. 419)).

5.99/9 Das Unvermögen Germans, sich zu erinnern, ist hier und später $(5.102 / 14)$ ein Zeichen der Schwäche und nicht 
wie im Monolog und in den Gedichten des Zyklus "Snežnaja maska" (vgl. etwa II,251) Ausdruck einer dionysischen Hingabe an die elementare, das Individuum auslöschende Iiebesleidenschaft.

S.99/10 Faina will Taten sehen. Germans "Worte" werden nicht "Fleisch" (Joh.1,14) oder "lat" (Goethe, Faust I, Studierzimmer).

S.99/11 Die Frage der Faina nach Germans Vergangenheit nimmt die vorige Replik der Faina wieder auf. Die Frage ist auf der realen Ebene durch das Interesse der Faina an Charakter und hiesen Germans motiviert. Im größeren $\mathrm{Zu}-$ sammenhang der Hechselrede dient die Frage dazu, um das unterschledliche Verhältnis von German und Faina zur "Vergangenheit" aufzuzeigen.

S.99/12 Der Peitschenschlag aus dem 3.Bild und die Schramme symbolisierten die Verbundenheit zwischen German und Faina. Im 7.Bild ist die Schramme verschwunden (vgl. S.102/4).

S.99/13 Vgl. S.87/2.

S.99/14 Bei German ist die seelische Leere und der Verlust der Vergangenheit susdruck der Schwöche und des Unvermögens (s.o.).

Blok nannte einen in Juli 1908 erschienenen Gedichtband, der einen Teil mit dem Titel "Pesnja sud'by" enthielt, und dessen Schluß der Zyklus "Snežnaja maska" bildete, "Zeml ja v snegu". In LS ist der direkte Vergleich von Landschaft und seele an dieser stelle recht unglifcklich. Die Natursymbolik verflacht $z u$ einer durchsichtigen Allegorik.

S.99/15 Faina ist das verkörperte Leben. Kan denkt an Dostojevskijs Ausdruck "lebendiges Leben", den u.a. Arkadij in "Podrostok" in Bezug auf Katerina Nikolajevna gebraucht (2.Teil, 5.Kan., II). Das "Leben" ist bei Blok begreiflicherweise ein zentraler Begriff, der in engem Zusammenhang mit seiner dionysischen, "musikalischen" ''eltanschauung steht.

Das "Leben" ist eine Urkraft jenseits von Gut und Böse. 
S.99/16 Faina ist die verkörperte Preiheit (vgl. S.77/8). D1e Passage erinnert an Dostojevskij und Gor'kij. Nastas'ja Filippovna sagt von sich:

"...ich bin immer noch Herrin in meinem Hause" und "...was ich will, das tu ich auch! Niemand soll mich stören!" (Dostojevskif, Idiot, 1.Bd., 1.Te1l,XVI) "...denn ich bin noch meine eigene Herrin"

$$
\text { (1.Bd., 2.Teil,III). }
$$

Radda, das "Teufelsmädchen" aus Gor'kijs Erzählung "Makar Cudra", "liebt ihre Freiheit mehr" als den kithnen Lojko. ( $\mathrm{Vgl}$, auch $5.84 / 2$ mit dem Zitat aus Ostrovskijs Drama "Groza").

S.100/1 Die "Blumen der Seele" sind ein Symbol filr die idyllische Vergangenheit Germans, die Paina mit Filßen tritt. (Vgl. zum Bild den Monolog Germans, S.68, V,18). Filr "blau" verwendet Blok das Adf. "goluboj". Damit stellt er das Bild "blaue Blumen" in die Tradition der "blauen Blume" des "Heinrich von Ofterdingen". (Vgl. Peters, Symbole der sinnlichen Wahrnehmung, S.122, Anm. 3. Bloks Rechtfertigung der tbersetzung des Titels "L'oiseau bleu" von Maeterlinck nit "Golubaja ptica" stlltzt sich auf den Hinweis auf Novalis; VI,412f.).

S.100/2 German gebraucht ein etwas abgegriffenes Bild aus der volkstilmlichen Iiebeslyrik.

In F1 trug er Faina "unter dem Herzen", was an die Symbolik des Gebärens in kufsatz "Ditja Gogolja" (V.376379) erinnerte (Abw. 427)).

$5.100 / 3$ In seinem Monolog hatte German einer dionysisch-rauschhaften Unbekimmertheit gegeniber dem Tod Ausdruck gegeben. Das entsoricht dem dionysischen Charakter des Zyklus "Snežnaja maska" (vgl. Peters, Symbole der sinnlichen Hahrnehmung, S.57ff. zum Thema "Liebestod"). Die Wiederaufnahme des Motivs des Todes und der Gleichgiltigkeit Germans wirkt an dieser Stelle jedoch lächerlich.

S.100/4 Vgl. S.99/10. 
S.100/5 Das "Märchen", auf das hier angespielt wird, ist vermutlich "Tristan und Isolde", dessen Iiebestod-Mystik v.a. seit der Oper Richard Wagners die Literatur des fin-de-siecle heimsuchte. Der Schluß des Dramas "Roza i krest" hat große Ähnlichkeit mit Iristans Liebestod (vgl. Kluge, Westeuropa und Rußland, S.90).

Die Gegenfiberstellung von iärchen und Realität an dieser Stelle erinnert an eine spisode aus Dostojevskijs "Idiot" (1.Bd., 1.Teil,XV: "Nun, das stammt aus Romanen! Das sind alte Faseleien...!"). In beiden Fällen, bei Blok und Dostojevskij, wendet sich die Heldin gegen die Verstiegenheit des Helden.

Der Einwand der Faina erinnert außerdem an die ernitchternde Bemerkung von Germans Mutter in F1: "Mein Junge, hast du zu viele dumme Märchen gelesen?" (vgl. S.53/6, abw. 99)).

S.100/6 Vgl. S.67, "Lied des Schicksals", V.4; S.86/1.

S.100/7 Vgl. S.98/6.

Fainas Warnung vor dem Schneesturm zeigt, daß sie selbst "in ihren Element ist".

S.100/8 Vgl. S.98/6 und S.99/1.

S.100/9 Das ist die 1. Strophe eines bekannten Volkslieds, dessen Text aus Nekrasovs Verserzöhlung "Korobejniki" (Die Hausierer) stammt (Verse 1-24 des 1. Kanitels; Nekrasov, Poln.sobr.stichotv. v 3 t., Bd.2, S.71f., 2.13-36). In weiteren Verlauf des IS folgen die Strophen 2 und 6 (vgl. S.101/4 und S.105/1). Der lext des Volklieds weicht in Einzelheiten vom 'lext Nekrasovs ab. (Im Volkslied wird 2.B. meist "Ach polnym-polna korobuska..." gesungen.). Blok folgt in 2.3 der 1.Str. dem Text des Volkslieds. Bei Nekrasov steht nicht "duła zaznobuška", sondern "moja zaznobuskka".

$3.100 / 10$ Das Bild stammt wohl aus den "Korobejniki". Ein später weggelassenes Motto des 5. Kapitels der Verserzählung hieß "Bez dorogi v put' otpravilsja" (Nekrasov, Poln. sobr.stichotv. v 3 tomach, Bd.2, S.492. Das Motto stammt aus A.V. Kol'covs Gedicht "Izmena suženoj", 1838). Möglicherweise spielt Blok auf den Roman "Bez 
dorogi" (1895) von V.V. Veresajev an, der das Scheitern der Ideale des "narodnilestro" und die Suche der fungen Generation nach neuen Wegen schildert.

Im Gegensatz zu German, der in seiner Schwäche dem Toben der Elemente ausgeliefert ist ( $\nabla g 1$. Abw. 422)), findet sich der Hausierer im Schneesturm zurecht (vgl. S.105/22).

S.100/11 Russ. "golubdik" ist ein umgangssprachliches Kosewort fifr den gellebten Mann und entspricht dem Ausdruck "golubka", "mein Täubchen". Faina soll offenbar reden wie ein Mädchen aus dem Volk.

S.100/12 German 18t dem Liebeswerben der Faina nicht gewachsen. In $\mathrm{F} 1$ 18t die Sinnlichkeit der Faina in recht trivialer Weise noch stärker betont ( $\mathrm{gl}$. Abv. 417)).

Das hier angeschnittene Problem der sexuellen Unzulänglichkeit des Helden erinnert an Bloks lyrisches Drama "Neznakomka". Dort kann der "Blaue" das irdische Liebesverlangen der "Unbekannten", die sich "Maria" nennen läßt, nicht erfllilen:

"In Ihrer Stimme erwacht irdische Leidenschaft. Die Unbekannte: Du will st mich umarmen?

Der Blaue: Ich wage nicht, dich zu berihren. Die Unbekannte: Du kennst die Leidenschaft? Der Blaue (leise): iein Blut schweigt.

Die Unbekannte: Du liebst mich?

Der Blaue schweigt.

Die Unbekannte: Das Biut singt in mir." (IV,87)

Die Unbekannte, die "schlanker ist als die Mädchen, schöner als die Damen, leidenschaftlicher als die Bräute", folgt dem Herrn, der ihre Sehnsucht nach irdischer Liebe erfilitt.

Blok greift ein zentrales Thema Dostojevskijs auf, das v.a. Im "Idiot" die Beziehung des Ffirsten Myłkin zu Nastas' ja Filippovna bestimmt: die Unfuhigkeit des Mannes zur integralen Liebesbeziehung, die die geschlechtliche Liebe einbezieht.

In Bloks RuBlandgeschichten ist dieses Thema unterschwellig immer wirksam: 
"Du bist selbst im Traum ungewöhnlich. Ich werde dein Kleid nicht berthren.

Sie ist auch in Träumen ungewöhnlich. Ich werde ihr Kleid nicht berthren." ("Rus'", II,106f., Str. 1 und 11)

Dasselbe Bild findet sich auch in der Bahnhofsszene (vgl. S.113/3) und in "Skazka o toj, kotoraja ne pojmet jeje" (vgl. Blok, Sobr.soc. $\nabla 7$ tomack, Bd.4, S.141). Das Thema der Schwäche des Mannes vor der sinnlichen Frau tellt Bloks Mythos des "Ewiglieiblichen" mit der neuromantischen Iiteratur und Malerei des ausgehenden 19. Jhdts. (Praz, Liebe, Tod und Teufel, S.167-250. Han könnte das Kapitel "La Belle Dame sans Merci" bei Praz leicht um einen Abschnitt llber Blok ergënzen. Vyl, auch Hofstätter, Symbolismus, S.187-200).

$\mathrm{S} .100 / 13 \mathrm{Vgl}$. S.77/7 und $\mathrm{S.83/11}$.

S.101/1 Erneut greift Blok die Symbolik des Blicks, der iugen auf, die im IS eine bedeutsame kolle spielt:

Mönch: große traurige Augen ( $5.45 / 1 ; S .55$, Kegieanweisung zum 2.Bild; S.58). kranke, welke jugen, filr die es keine Zuflucht gibt $(\mathrm{S} .54 / 2)$.

Faina: inre sugen leuchteten unter dem Tuch hervor (S.55/7;S.56/4)

das Flammen inrer großen Augen ( 5.67 )

schmale Augen einer Schlange; schwarzer, schmaler Blick (Lied des Schicksais, S.67)

lachende, zusammengekniffene augen (S.80/2)

sie schaute in das ferne kuBland $(5.55 / 8)$

inr Blick geht in die Ferne und ist grenzenlos traurig ( $S .69)$

sie schaut in die Ferne; inre sugen brennen (S.81)

sie schaut in die ferne mit beschwörenden sugen $(\mathrm{S} .82 / 9)$

die Augen blitzen vor Zorn ( $5.78 / 3$ )

riesipe, wahnsinnige und im geheimen traurige Augen (S.79/2)

klare Augen (S.84/16)

schreckliche augen (S.86)

schöne Augen (S.86)

dunkle Augen (S.102/15; S.104/6)

tragische Augen ( $S .114 / 9$ )

aufmerksame Augen (S.182/4)

sie läßt ihren Blick llber die Menge gleiten

(S.67)

sie schaut an allen vorbei ( $5.83 / 17$ )

Tränen wie blitzende Diamanten in den Augen $(\mathrm{s} .84 / 8)$ 
sie hatte mit Blicken beschworen ( $5.84 / 18$ )

sie hat sich die Augen ausgesehen ( $5.82 / 13$ ) verbrennend, wie der dunkle Blick der Faina (S.98)

inr unbekannter, brennender Blick (S.99/8; S.113/5)

Erscheinung: große, traurige Augen blicken nach vorne $(5.57 / 2)$

German: in seinen Augen ist so etwas - Einfaches

(S.80/1)

in den weitgeöffneten Augen - die Vorahnung des Sturms; er schaut in die Ferne ( $5.84 / 20)$ weitgeöffnete Augen (S.104/10)

wunderbare graue Augen ( $S .82 / 12$, als Erlöser) laß mich dich (Faina) nur ansehen ( $5.114 / 11$ )

Mädchen im Gefängnis: ruhige, helle, traurige Augen (S.601.)

Nasenlose: bleierner Blick aus roten Lidern ( 5.61 ) Der Augenfetischismus ist auch in Bloks Gedichten stark ausgeprägt, worin die Nähe Bloks zur Kunst und Iiteratur des fin-de siècle ein weiteres Mal deutlich wird (vgl. Hof stätter, Symbolismus, S.201ff.). Im 2. und 3.Band, v.a. in den Gedichtzyklen "Snežnaja maska" und "Faina" findet sich der genze Vorrat "dekadenter" Augensymbolik wieder: die Augen sind "dunkel", "durchdringend", "giftig", "goldbraun" (wie bei einer Katze), "trübe", "schrecklich", "wahnsinnig", "grün und böse" etc.etc. (vgl. II,126,132,166,181,185f , 203,204,207f ., $215,217 f \ldots 219,220,221 \mathrm{f}$, 223,227ff ., 232ff ., 237f ., $245,246,247,248,250,251,252,254,257,258 f$. 269ff., 273(2); III,55( 3 und 4), 57f.(8), 101,207f.u.v.a.; dazu Bonneau, I'univers poétique, S.242f., 326; Peters, Symbole der sinnlichen wahrnehmung, S.93, S.117ff.). Der Einwand der Faina, sie habe rotbraune ("ryzije") Augen, ist schwer zu deuten, denn die "schwarzen Augen" sind nicht nur im LS, sondern auch in den Gedichten Atribut der Faina.

"Ryzij" bedeutet "rot" und bezeichnet im Russischen die Haarfarbe (frz. "roux"; "ryževolosyj", "ryžeborodyj"). In Bezug auf die Haarfarbe benutzt Blok den Ausdruck z.B. II,86 und III,235. Als Bezeichnung der Augenfarbe ist "ryžif" ungewöhnlich (die tibersetzung mit "rötlich" bei Peters, aao, S.22 und 92 gibt nichts her). Im Gedicht II,258 wird "ryžij" auch auf die 
sugen bezogen:

"Ich weiB, du wirsit wieder kommen, Um mich mit dem Duft der Iilien des Nils $\mathrm{Zu}$ fesseln und zu berauschen.

Und der rotbraune ("ryžij") Dämmer deiner Áugen Verbirgt die Untreue der Schlange ...

Und mit dem dunkièn Blick des stechenden Schmerzes Durchsteche das lebendige Herz. (Str.2,4,6)

Der Zusammenhang legt die Vermutung nahe, daß Blok mit "ryzij" die spezifische hugenfarbe der Schlange, und zwar der Kreuzotter, bezeichnet ("Iichtes kötlichbraun", Brehms Tierleben). Der "Iuft der Lilien des Nils" (s.o.), der Hinweis, daß die Heldin von ihrer "Heimat Ägypten träunt" und die "Sphinx an der Neva mit leichtem Aufschrei" begrißBt (II,267), - all das zeigt, daB Faina eine Schwester der Kleopatra, der "liisternen Zigeunerin", der "Schlange am alten Nil" (Shakespeare) ist (vgl. auch II,207f.; Kleopatra war eine der beliebtesten dömonischen Frauengestalten des fin-desiécle; vgl. Praz, Liebe, Tod und Teufel, Bd.1, S. $181 \mathrm{ff}$.$) .$

"kyžij" kann auch, wie frz. "fauve", die Augenfarbe der Raubkatzen bezeichnen. A. Samain sagt von Kleopatra "ses yeux fauves dardent l'éclair". "Eine frîhe Fassung (erg.: des Sphinx-ilotivs bei Franz von Stuck) zeigt das Rätselwesen als ieib und Riesenkatze zugleich... Rote :aubtierpupillen starren auf die Beute..." (fofstätter, aac, S.189).

In jedem Fall ist der ungewöhnliche Gebrauch von "ryzij" nur im Zusamnenhang der Schlangen-, Sphinxund Kleopatra-Symbolik zu sehen, die bei Blok "dekadentes" Erbe ist. Im Gegensatz zu II,258 soll im IS der "dunkle" Blick wohl "entmystifiziert" werden. German, der paina gegenüber dieselbe, in mythischer Distanz verharrende Haltung einnimmt wie der männliche "lyrische Held" der Gedichte gegeniber den Frauengestalten (Neznakonka, Snežnaja Deva, Faina u.a.), 
kann den Blick der Partnerin nicht enträtseln (Sphinx!). S.101/2 Vgl. S.82/11.

S.101/3 Die Wiederaufnahme des Motivs "German ist ein Kind" (vgl. S.48/8, S.51/4,S.53/6, Abw. 99), S.60/4, S.85/6) an dieser Stelle muß im Zusammenhang mit der $\mathrm{S} .100 / 12$ angeschnittenen sexuellen Problematik, der Sphinx-Symbolik und dem mythischen Verhältnis von Mann und Frau in Bloks Dichtung gesehen werden.

Auch First ilyskin, der impotente Partner der Nastas'ja Filipporna, ist ein kind, das eigentlich noch eine Amme braucht (Dostojevskij, Idiot, 1.Bd., 1.Teil, XV).

S.101/4 Das ist die 2. Strophe des Volkslieds "Korobołka" (vgl. S.100/9).

S.101/5 Diese Replik mit dem Cxymoron will die Stille des 1.Bildes mit der jetzigen vergleichen. Die Stille des 1.Bildes entspricht der "Stille" des Gedichtzyklus "Stichi o Prekrasnoj Dame".

Peters (Symbole der sinnlichen Wahrnehmung, S.195-199) legt Hberzeugend den unterschiedlichen Symbolgehalt des akustischen Phänomens "Stille" in Bloks Gedichten dar. In 1. Buch ist die stille häufig ittribut der "Schönen Dame" und ist in Verbindung mit Farben wie izur und Gold Symbol der "hohen Iranszendenz". In 2. und 3. Buch findet sich die stille häufig "in Beziehung zu einer Synthese der themen "hohe" und "niedrige" Transzendenz. Jeistens ist sie auch in diesen Gedichten Entsprechung zur Dunkelheit, die als chaotisch-schöpferischer Urgrund des Seins sowohl das "geheimnisvoll Vertraute" wie auch das "unheimlich Zerstörende" umfassen kann." (Peters, aaO, S.197). Diese Symbolik liegt dem Oxymoron zugrunde. Fifr einen Zuschauer bleibt die Replik sinnleer.

s.101/6 Faina ninnt recht unvermittelt die Unterhaltung uber Germans "Vergangenheit" wieder auf.

S.101/7 Die Passage bezieht sich auf das Weinen der Helena im 6.Bild. Die Gleichzeitigkeit der Bilder "erklört" die Identifikation von dem ieinen des findes und dem Veinen der Helena. 
Die Wiederaufnahme des Traummotivs an dieser Stelle bezieht sich wohl auf $Z .1$ von Germans Monolog (S.98). Das Vergangene ist nicht ein "Traum", sondern "Realität". Es gewinnt in 7.Bild wieder Macht iber German. Fainas scharfe antwort: "Im Traum!" ist als "Nein!" zu verstehen. Wiederum versucht sie, German aus seiner Traumwelt in die 'iliklichkeit zu holen (vgl. oben: "nur in den Märchen stirbt man"; die "schwarzen Augen" sind an Tage "rotbraun").

S.101/8 Man ist geneigt, in "Stöhnen des bindes" etc. das Klagen der Helena un German zu sehen.

In 1 steht "ein und derselbe alte, herbstliche Ton" (Abw. 441)). Offenbar bezieht sich die Regieanweisung in 1 auf den Schluß des 5.Bildes (S.90/10). Das Stöhnen des inds ist eine Art Leitmotiv des Begleiters der Faina. In lind, dem Symbol des weltwillens, verbindet sich die Klage der Helena um Gernan mit der Frauer des Begleiters um Faina. Die Vergangenheit gewinnt nicht nur iber German liacht, sondern auch iber Faina. Deshalb horcht sie unruhig auf den "alten Ton".

S.102/1 Faina ist wieder die verkörperte Freiheit (vgl. S. $99 / 16)$.

Zun Bild "erwiirgen" vgl.:

"Hit dem Ärmel meiner Schneestline verde ich erwiligen." (II,220, Z.15f.)

"Mit dem schwarzen Zopf werde ich erwiligen." (II, 258f., Z.28)

snders als in den Gedichten wirkt das Bild im IS absurd. Es gehört in beiden Föllen in den Zusammenhang der "dekadenten" Vampir- und Schlangensymbolik, die in Bloks berk eine große Rolle spielt. In F1 ist jaina frei "zu töten" (Abw. 442)). Das erinnert an Bloks Gedicht "Syroje leto..." (II,334 vom Juni 1907):

"...Ich kenne eine Frau. In ihrer seele

i'ar eine Feuergarbe. In ihrem Gang war Wind.

... in ihr waren die vier kilemente

Vereint. Sie konnte töten -

Sie konnte auch wieder zum Leben erwecken..." $(2.26 f ., 30 f f$. 
Das Gedicht bezieht sich auf N.N. Volochova, dem realen Vorbild der Faina.

S.102/2 German versucht sich gegen den Einbruch der Vergangenheit zu wehren. Faina dagegen hört auf den wind. Das widerspricht der Freiheitssymbolik der vorausgehenden Sätze. Die logische Hidersprifchlichkeit, die in der Verbindung von Freiheit und Erlösungssehnsucht in einer Person liegt, kommt im Satz "Ich bin frei, zurilckzudenken!", in dem die Rilckkehr der Faina unter die Macht des Alten (vgl. S.105/6) angekindigt wird, klar zum Ausdruck.

S.102/3 VgI. S.75/3; S.78/3; S.111/1.

S.102/4 Das sexuelle Versagen Germans, dessen Darstellung im LS das Triviale streift, wird hier in eine pseudoreligiöse Dimension iberhöht.

In der Replik der Faina verbindet sich Weltseelen-, Leidens- und Menschwerdungsmystik.

Im 1. Satz wird das im IS mehrfach verwendete hotiv des Wartens, der Erlösungssehnsucht wieder aufgenommen. Das warten der Faina wurde enttäuscht.

Im 2. Satz wird auf die "ecce-hono"-Symbolik des 3.Bildes zurfickgegriffen. German war Mensch, solange er das Stigma vom Schlag der Faina trug, solange er Leidender war.

Der Schluß der Replik spielt auf das Geheimnis der Menschwerdung Christi an, das bei Joh.1,14 als Fleischwerdung des Logos symbolisch verstanden wird. German hat mit den Verlust des Stigma auch seine Eigenschaft, "Mensch" zu sein, verloren. Er fiel zurfick in die nur geistige belt des Logos: der "schönen Worte" und der "Unkörperlichkeit".

S.102/5 Vgl. S.101/8.

S.102/6 Die Zusammenziehung der beiden "Attribute" der Estradensängerin (3.Bild) und der Elementarkraft Faina (7.Bild) ist unglificklich. Im Gegensatz zum 4.Bild (vgl. S.79/2) ist German im 7.Bild den Blicken der Faina nicht gewachsen. 
In F1 ist die Replik Germans länger: "... wie der Schneesturm, - gerade ins Gesicht. Dieser tönende Schneesturm tost - vor einem neuen Frlthling. Und dieser Frihling gleicht nicht dem vergangenen: man kann sich nirgendshin vor seinen Schlägen retten." (Abw. 446). Vgl. II, 374, Zit.S.105/1).

Die Aussicht auf einen neuen Frfhling erinnert an die Verheißung der Wiederkehr der Faina (vgl. S.104/14 und S. 105/7).

S.102/7 Vgl. S.99/10 und S.100/4.

In Verbindung mit der vorhergehenden keplik der Faina erhält die Wiederholung des Topos "viele schöne horte" eine pseudoreligiöse, an die Inkarnations-Mystik anknifpende Bedeutung. Gernans "fiorte" sind nicht "Fleisch" geworden, sondern leeres Gerede geblieben.

Der Hauptvorwurf, den Blok gegen die Intelligenz erhebt, ist ihr Verharren in der sphäre des bloßen Geredes ( $V, 210$; vgl. Einleitung $z .4 .3 i l d, S .244 f)$. Bloks Vorstellungen davon, wie das Verharren in der unverbindlichen wortwelt zu fiberwinden sei, enthält sein Aufsatz "Tri voprosa" (vom Febr. 1908): Nachdem die "neue Kunst", d.h. der Symbolismus, in kuBland populär geworden sei, und die Probleme der Form ("kak?") und des Inhalts ("Cto?") gelöst seien, stelle sich nun

"die dritte, verlockendste, gefährlichste, doch russischste Frage: "wozu?". Die Frage nach der Notwendigkeit und dem Nutzen der Kunstwerke." (V, 236$)$

Ursprifnglich waren Schönheit und Nitzlichkeit eine Einheit.

"Die neuesten Forscher sagen uns, daB Nutzen und Schönheit in der Volkskunst zusammenfielen, daß eine der frithen Formen dieser kunst, das lied zur srbeit, untrennbar, rhythmisch mit der ausgefihrten irbeit verbunden war. Das Bindeglied zwischen Kunst und Arbeit, Schönheit und Nutzen war der khythmus." (V,237f.) Blok greift hier eine Idee auf, die er in seiner hrbeit "Poèz1ja zagovorov i zaklinanif" ( $V, 36-65)$ in Berufung auf Je.V. Ani Xkov ausfthrlich dargestellt hatte. Ani $X_{k}$ ov hatte sich bei seinen von Blok benutzten Arbeiten ausdrficklich auf die Darlegung 
Nietzsches "Vom Ursprunge der Poesie" (in: "Die Pröhliche Wissenschaft", 74, S.98-102) gestutzt (vgl. V,53, Anm. 16). Bloks Arbeit geht in Titel ("Zauberlied und Besprechung scheinen die Urgestalt der Poesie zu sein", Nietzsche, aao, S.100) und "theoretischem Teil" (V,5153) auf Nietzsche zuruck.

"In der uranfänglichen Seele nehmen Nutzen und Schönheit gleicherweise Ehrenplatze ein. Sie befinden sich in Einheit und tbereinstimmung; ihre Verbindung drucken wir mit den Worten aus: das Schöne ist nútzlich, das Nutzliche ist schön." - $(v, 51)$.

Diese Einheit zerfiel im Bewubtsein der Intelligenz. "Der Spaltung dieser religiösen Einheit entging das "dunkle" Volk." $(\mathrm{V}, 51)$. Im Unterschied zur Intelligenz lebt demnach das Volk noch im Zustand der seelischen Ganzheit, in der "das Rhythmische eine magische Kraft" ubt (Nietzsche, aao, S.100).

"Wenn Schönheit und Nutzen im urspringlichen Bewubtsein zusammenfallen, ist es klar, das dies nicht unsere Schönheit und nicht unser Nutzen 1st. Unsere Schönheit lst zaghaft und einsam, unser Nutzen lst hart und grob. Unsere individuelle Poesie ist nur ein Wort, und wir unternehmen die vielberufenen nutzlichen Taten, ohne nach ihrem Rat zu fragen, neben und nicht mir ihr. Die urspringliche Harmonie bringt diese worte und Taten in thereinstimmung: die Worte werden zur Tat. Die Kraft, die ihre tbereinstimung zustande bringt, ist die schöpferische Kraft des Rhythmus. Sie hebt das Wort auf dem Kamm einer musikalischen Welle, und das rhythmische Wort wird spitzig wie ein Pfeil, der wohlklingend gerade ins $Z$ iel fliegt..." $(\mathrm{V}, 52)$.

Die magische Einheit der Urzeit ist heute verloren.

"Bislang bleiben Worte Worte, das Leben bleibt Leben, das Schöne unnutz, das Nutzliche häblich. Der Kunstler, um Kunstler zu sein, erschlägt in sich den Menschen, der Mensch, um zu leben, verzichtet auf die Kunst." (v,239).

Un diese Einheit wiederherzustellen, muB der kunstler vom Gefuhl der pflicht geleitet sein.

"Das Schaffen Ibsens sagt uns, ...dak der Rhythmus unseres Lebens die Pflicht 1st. In Bematsein der pelicht, der groben Verantwortung und der Verbindung mit Volk und Gesellschaft, die inn hervorgebracht hat, findet der Kunstler die Kraft, rhythmisch den elnzig unumgänglichen Weg zu gehen." $(\nabla, 238)$. 
Die Wiedererlangung der verlorenen Einheit ist fflr Blok eine Art "Wunder", das "eine Art Demiurg" wirkt, eine neue Inkarnation, in der "das hort Fleisch wird, der Kfinstler - Mensch." (V,239). Die Einheit soll verwirklicht werden in einem kinftigen Theater. ("0 teatre", $\mathrm{V}, 241-276)$.

Bloks Ideen gehen zurfick auf die romantischen Vorstellungen von der "Urzeit", der "goldenen Zeit", in der der Mensch in Einheit mit den Kräften der Natur die Ganzheit seiner Seelenkräfte bewahrt habe. (Vgl. Kluckhohn, Ideengut, S.117ff.). Im russischen Volk lebt dieser magische Seelenzustand noch. Die Intelligenz hat dagegen die seelische Ganzheit verloren. Blok erhoffte sich offenbar die wiederherstellung der Einheit von Wort und Tat im Finden des "khythmus", in einer art neuer Kenschwerdung aus dem "Geiste der Musik" (vgl. S.84/15). German erweist sich als schwacher Intelligenzler eben dadurch, daß er unfëhig ist, das "Vort" zur "Tat" werden zu lassen. Die "geheime Hoffnung, daß die Kluft zwischen horten und Taten nicht ewig ist, daß es ein Wort gibt, das zur Tat wird" von der Blok in "Narod $i$ intelligencija" $(v, 319)$ spricht, ging nicht in Erffillung. German schafft es nicht, Kfinstler-ilensch zu werden. Damit kann er seine "Messias"-Aufgabe, die Erlösung der im Chaos gefangenen Faina-Rußland-Weltseele, nicht erfililen.

S.102/8 Vgl. S.94/3. Die dort bemängelte Unklarheit, das Unvermöger des Dichters, Sachverhalte beim Namen zu nennen, wirkt auch an dieser stelle peinlich.

S.102/9 Peitsche und KuB "weckten" German im 3. und 4.Bild. S.102/10 Vgl. S. $100 / 6$ und 7 .

S.102/11 German resigniert. Er gibt seine Erlöserrolle weiter. S.102/12 Das Motiv des "iachens", das in den letzten Repliken anklingt, erinnert an den "Schlaf" der Faina und ihre Sehnsucht nach Erweckung, (vgl. S.82/3). Die Aufforderune der Faina, aufzuwachen, ist wahrscheinlich eine Anspielung auf das liachen Christi und den Schlaf der Jfinger im Garten Gethsemane (:iatth.26,36-46; :lark.14,32-42; 
Luk. 22, 40-46).

Germans "Fleisch ist schwach". Er hält der "Anfechtung", dem Einbruch der Vergangenheit nicht stand.

S.102/13 Vgl. S.101/8 und 102/5.

S.102/14. Vgl. S.99/9.

S.102/15 Vgl. S.101/1.

S.102/16 Die zarten, sanften Hände passen nicht zum Bild der Domina. Sie gehören zur Volksmädchen-Hypostase (vgl. $S .77 / 2$ und $5.83 / 3)$.

Die "schmale Hand" ist eines der Kennzeichen der Faina in Bloks Gedichten (II,254f.).

S.102/17 Faina ist filir inn wieder die verschleierte Braut (vgl. S.82/15), deren Rätsel er nicht lösen kann. Die Erlösung, die "heilige Hochzeit" des 5.Bildes war nur eine Episode. (Vgl. Abw. 452)).

S.103/1 Vgl. S.55/11.

S.103/2 Faina sielt hier nicht auf ihr "schamloses" "Lied des Schicksals" an, sondern auf die Lieder, die sie als :nädchen des Volkes sang (vgl. S.73/4 und $\mathrm{S.83/14}$ ).

$5.103 / 3 \mathrm{Vgl}$. $\mathrm{S.90/8}$ u.ö.

S.103/4 "Er" ist ihr trauriger Begleiter.

Faina will German mit der Erinnerung an ihre Volksmidchen-Hypostase aus seiner Schwäche aufritteln. Ihre ieplik beschwört die gemeinsam verbrachte zeit zwischen dem Schluß des 5.Bildes und dem Beginn des 7.Bildes herauf.

S.103/5 Zu russ. "v bredu" (im Fieberwahn, in der Fieberphantasie) vgl. Bloks Gedicht "Bred" (II,67f.). In diesem Gedicht ziehen vor dem "lyrischen Helden" im TodesFieberwahn die Bilder der Vergangenheit vorbei: der "vertraute Wald und Berg", die "Erscheinungen der ganzen Vergangenheit, des gewohnten, bekannten Landes", in dem er die "HeiRe Jungfrau" suchte.

Im LS erlebt German im Fieberwahn nocheinmal seine Vergangenheit (vgl, u. S.103/13).

Der Ausdruck "v bredu" bezeichnet im zyklus "Faina" die Schwäche, das Versagen des "lyrischen Helden" vor der dionysischen ivatur der dëmonischen Frau (II,274f. 
(4): er ist der "dunkle Sklave", das "arme Kind", der "wahnsinnige und gehorsame Sklave" in "brennenden Fieberwahn" unter ihrem "allzu schwarzen Blick".).

Arkadij Dolgorukij ist in Dostojevskijs homan "Podrostok" der "verkörperte Fiebertraum" (1.Teil, 8.Kap., I), der von Fieberphantasien inmer wieder heingesuchte Träumer.

S.103/6 Die Replik Germans kennzeichnet den völligen Gegensatz der Situation, in der er sich in 7.Bild befindet, zu seinen Auftreten im 5.Bild, wo "alle wege frei" waren (vgl. S.87/1).

S.103/7 Die Replik soll offenbar zeigen, daß die "heiBbl"itige" Faina die verkörperte Lebenskraft ist.

S.103/8 Vgl. S.99/4.

S.103/9 Vgl. S.99/9 und S.102/14 und 17 .

Lie Passage erinnert an den Schluß des Jramas "lieznakonka": Der Dichter "blickt hoffnungslos. suf seinem Gesicht ist Sehnsucht, in seinen rugen - Leere und Dunkel. Ir schwankt vor schrecklicher Anstrengung. Doch er hat alles vergessen". (IV,10?) Jr kann sich an die "Unbekannte", die Verkörperung des "Ewig-ieiblichen" nicht erinnern.

S.103/10 Faina will German zu neuem Leben erwecken. Sie ist Herrin ijber Leben und Iod (vgl. S.83/15). In F1 nennt German sie "mein lod" (vgl. «bw. 456)). Sie teilt diese :hacht nit den Himmelsgöttinnen der verschiedenen fythologien und dem dönonischen Frauenideal des fin-de-siècle. In 3loks "Ewig-"eiblichem" findet sich die in lythologie und riefenpsychologie weit verbreitete Vorstellung vom bipolaren wesen des ieiblichen als zugleich Leben spendender und Leben in sich zuricknehnender kraft (iutter irde; sstarte, Isis, Aphrodite etc. als Liebes- und lodesgöttinnen). Das Bild des "Lebensatens" ist traditionell (1..jos.2,7; Pneuna).

S.103/11 Faina umsorgt German wie eine Mutter ihr fieberndes Kind. Die Verbindung von "Mystik" und "mlltp̈glichem" in dieser Passage entspricht einem wesenszug in Bloks gesamten lierk. 
S.103/12 Faina gerät immer stärker in den Bann des Begleiters, gegen den der Kuß Germans sie "feien" soll.

S.103/13 Im Fieberwahn wird German von Traumgesichten heimgesucht, in denen seine Vergangenheit wieder lebendig wird. Zunächst sieht er die Stadt. ( $z u$ den einzelnen Bildern vgl.: Maschinen, sterbende Menschen - S.64/1; Plätze, Turm, Blick - S.61/1).

S.103/14 In F1 lautet die keplik der Faina: "Hit der Stimme der Hutter rufe ich!" ( $\mathrm{Abw} .464)$ ). Lamit wird die in F2 etwas unklare Bedeutung der Replik verständlicher. Faina thernint im 7.Bild fiir eine gewisse Zeit die ifutterrolle. Dazu paBt S.101/3. Bloks "kuBland" ist eine mythische Frauengestalt, die genau wie die luttergottheiten der verschiedenen Mythologien, Jungfrau, Schwester, Geliebte und lifutter in einer Person ist (vgl. Kluge, hesteuropa und Rußland, S.189ff.; besonders treffend ist das 2 itat aus V,314 iber Ibsens Heinat Norwegen: "die Heimat (rodina), die Mutter, die Schwester und Gattin." Von Gor'kijs Liebe zu Rußland sagt Blok: "Gor'kijs Herz sorgt sich und liebt... wie nan die sutter, die schwester und die Gattin im einen Gesicht der Heimat, in Kußland, lieben kann." $(\mathrm{V}, 321)$. wegen dieser ilebe ist Gor'kij fir Blok ein echter Kinstler und ein vann des Volkes. Ähnlich beschreibt Dostojevskijs Heimatliebe Stepun, Dostojevskij und Tolstoj, s.30).

S. $103 / 15 \mathrm{Vgl}$. S.45/9.

$\mathrm{S} .103 / 16 \mathrm{Vgl}$. S.52/8.

S.103/17 Vgl. S.95/8.

S.103/18 VEl. 0.S.103/13.

Im Traum sieht German Helena. In seiner Reblik faßt German die entscheidenden fttribute der Helena aus dem 1. und 6.Bild zusammen.

S.104/1 Cffenbar verwechselt German im Fieber Faina mit Helena. Das zeigt der Fortgang der Replik.

S.101/2 German benutzt dieselben Horte wie der Mönch in Abw. 385), wo die Farbe "weiß" den rod symbolisiert. Helena zeigt German offenbar den "langen, weißen, schneeigen 
Weg" (vgl. S.93/2 und S.96/7 und 8).

S.104/3 In F1 wird Helenas Erscheinen "realistisch" motiviert. Helena hat ebenfalls "den iind gehört! sie kommt vorbei!..." (Abw. 470)).

S.104/4 In Germans iraum lebt die Heldensymbolik wieder auf, die in F1 im 1.Bild den Vieggang Germans begleitet hatte.

In F1 ist die kede vom "fernen Horn des verirrten Helden" (Abw. 475)). Blok gebraucht dieses Bild auch am Schluß des sufsatzes "Tri voprosy" (V,240).

Der Hörnerklang steht bei Blok meistens im Zusammenhang mit dem Bild des Helden und dessen Schicksal (vgl. II, 40f., 82f., 108f., 232ff., 275). Iie von Peters, Symbole der sinnlichen Wahrnehmung, s.23of. festgestellte "Verbindung nit dem Thema des Todes" ist in dem von ihr angefihrten Gedicht II,219 zutreffend, ebenso in II,214 und 230f., in den andern Beispielen aber sekundär als Ingredienz der Heldensymbolik.

Die Symbolik des Horns als liusikinstrument ist uralt (vgl. Forstner, Helt der symbole, S.426f.). lian darf bei Blok jedoch den direkten Einfluß $R$. iagners unterstellen, und zwar den berihnten Hornruf Siegfrieds aus der gleichnamigen Oper (zuerst 1.Aufzug, 1.Szene). Der "geflügelte Helm", einst Helm der Germanen (Flügelhelm), und das "Schwert auf der Schulter" sind ebenfalls typisch iagnerianische Renuisiten. 'lan denke dabei an die realistischen Inszenierungen der damaligen $2 e i t$, an die "nuincaillerie" wagnérienne" (Michaud).

Lie martialische Symbolik des irommelklangs ist traditionell, in Zusannenhang nit den "ibrigen Heldenrecuisiten allerdings ein snachronismus.

S.104/5 Gernan sieht Faina, ohne sie zu erkennen; sie ist das verkörnerte Schicksal. (Vgl. S.89/21).

Der tbergang von der Person ("Ty - neizbeznaja") auf das ibstraktun ("sud'ba") wird in kussischen dadurch erleichtert, daß das ibstraktum ebenfalls ein Feminium ist (vgl. $\mathrm{S} .93 / 8$ ). 
In F1 steht noch: "Immer bist du da, wenn im Feld ein Held stirbt." (Abw. 477)). Damit ist die Parallele zu der Erzählung des wönchs in $F 1$ von seinem eigenen Heldentod (vgl. S.55/4, Abw. 109)) besonders deutlich.

S.104/6 Vgl. S.101/1.

S.104/7 Die kalten Lippen können sich auf den Tod oder die Sphinx beziehen, die beide das "unausweichliche Schicksal" verkörpern. (Zum Mund-setischismus im fin-desiècle vgl. Hofstätter, Symbolismus, S.201).

S.104/8 Diese Passage 1st eine Anspielung auf die Rätsel der Snhinx. German kann die Fragen des "Schicksals" nicht beantworten. (Blok teilt mit dem fin-de-siècle die hybride Vermengung der ägyptischen und der griechischen Sphinx-ily thologie: vgl. dazu noch II,258; 267; III, 36off., Str.7).

Das "Schicksal", dem der Held begegnet, ist das sphinxhafte "Ewig-weibliche". Das Gegenuber von Heldenund Rittersymbolik einerseits (in der Sphäre des männlichen "lyrischen lelden") und Schlangen-, Sphinxund Vanpirsymbolik andererseits (in der sphäre der weiblichen Partnerin) kennzeichnet auch Bloks Zyklen "Snežnaja naska" und "Faina".

Besonders repräsentativ ist hierfilr das Gedicht "Za cholmom otzveneli unrugije laty..."(II.260). Die schlangenhafte Göttin der ivacht, in deren Liebesumarmung der Held dem Schicksal begegnet, ist in einer friheren Fassung "kalk!ire, Jungfrau, Schlange", die mit ihrer "Leidenschaft" seine "brennenden liunden heilen wird". (II,429f.).

S.104/9 Die Helden-Hypostase Germans, die in seinem Fiebertraum nocheinmal auflebt, stirbt den Heldentod. Zurick bleibt der Bettler (vgl. S.105/12).

S.104/10 German erwacht gleichsam aus dem Tod.

S.104/11 Im 1.3ild eröffnete der prophetische Traum Germans die eigentliche irirklichkeit (vgl. S.44/8). Im 7.Bild eröffnet der rilckwärtsgewandte Traum die eigentliche Wirklichkeit: Germans Verhaftetsein mit Helena und der Vergangenheit und den Zusammenbruch seiner Helden- 
Hypostase.

S.104/12 Das Ausbleiben einer Antwort auf Germans Fragen bedeutet "nein". Faina, die wegen Germans Schwäche wieder im Bann des alten Begleiters steht, weiB den keg nicht.

S.104/13 Die Trauer (vgl. die Regieanweisung zu Faina zuvor) und Zärtlichkeit ( $v g l$. die "zärtlichen Hände"; das "Anschmiegen") ktinden den Abschied an.

In F1 lautet die Regieanweisung: "mit ungewöhnlicher Traurigkeit und Zärtlichkeit. Is ist,als spreche schon nicht mehr sie selbst, sondern Jemand, Der iber alle Schicksale gebietet und am steuerruder der Tragödie steht." (Ábw. 480); nan beachte die Großschreibung. Diese stelle entspricht Abw. 257), S.84/16). In F1 ist der Abschied ein von Gottes billen gelenktes Geschehen. S.104/14 Diese Repliken enthalten die drei wesentlichen Aspekte der Beziehung zwischen Faina und German: die Gewißheit der Liebe, das Rätselhafte der Faina (SphinxSymbolik; "Neznakomka") und die Gewißheit einer kinftigen Begegnung. Diese drei Aspekte kennzeichnen Bloks mystische Liebe $z u$ Kußland. Diese Passage ist gegeniber F1 von großer Prägnanz (Abw. 481)-483)). Germans in F1 gegebenes Versorechen, nie zurilckzukehren ( $A b w$. 484)) soll in F2 aus dem Zusammenhang direkt hervorgehen. German bleibt fiir immer auf der suche nach FainaRußland. Die Idylle des "weißen Hauses" ist vorbei. Die verheißene Begegnung von Helena und German (S.96/8) steht unter den Zeichen des "Heges".

S.105/1 Vgl. S.100/9 und S.101/4. Es erklingt die 6. Strophe des Volkslieds. Bemerkenswert ist der inhaltliche und stimmungsmäßige Gegensatz zwischen dem Volkslied (Liebeserfillung) und der Handlung des IS (Trennung). Las Volkslied wurde deshalb von den meisten Zuhïrern der Lesung des IS bei G. Culkov vom 4. Mai 1908 als Fremdkörper in dem esoterischen Stifck empfunden (vgl. Entstehungsgeschichte, S. 14).

In Unterschied etwa zu Bulgakovs St'ick "Beg" (Die Flucht, 1926/28), wo das Volkslied von kudejar und den 
zwölf Räubern, das Nekrasov in seinem Poem "Komu na Rusi zit' chorošo" verarbeitete, in engstem Zusammenhang nit dem Schicksal des Helden und dem Sinn des Stucks steht, ist die Funktion des Volkslieds im IS nur zu verstehen, wenn man die Bedeutung dieses Lieds filr Bloks RuBland-Mythos kennt.

K. Cukovskif berichtet uber Bloks besondere Vorliebe fifr die "Korobejniki":

"... er sprach von den "Korobejniki" als von einer der magischsten Dichtungen, in der er immer den wilden Schneesturm fihle, der in den russischen Weiten losbreche.- "Cj, polna, polna, korobułka" sagte er verliebt." (Cukovskij, Sobr.sot. v 6 t., Bd.2, S.298)

Bloks RuBlandgedichte verraten in inrer Thematik und in inrem Bildreservoir den Einfluß jekrasovs (vgl. v.a. Močul'skij, Belyj, S.126f., der die thematische Abhängigkeit von Bloks und Belyjs RuBlandgedichten aufzeigt).

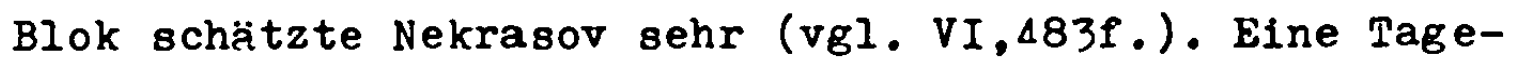
buchnotiz vom Juli 1908 zeigt jedoch, daB es sich bei Bloks Verhältnis zu den "Korobejniki" nicht nur um eine Frage literarischen "Einflusses" handelt.

"Man beklagt sich daruber, dab die Leser in der Provinz keine Namen kennen. Aber Gott sei Dank! Namen gibt es allzuviele. In "Volks"theater kennt man die Namen Ostrovskij und Voliere nicht, - und trotzden wird man ergriffen. Und den :haler, der meine Verse sang, ging ich nichts an. Den Autor der "Korobejniki" kennen sie nicht, den von "Solnce vschodit i zachodit..." kaum." (Zap. kn., 111, Eintrag vom 22. Juli 1908).

Die Größe des Dichters und der Wert des dichterischen Herks zeigt sich darin, daß das einfache Volk den Namen des Dichters vergißt, das lerk sich vom Autor löst und zun Besitz des Volkes wird. Echte Dichtung ist nach Bloks Meinung Ausdruck des Volksgeistes, und der Dichter ist Organ und Medium der Volksseele. Ein geplanter Aufsatz "Pesnja neizvestnogo proischoždenija", dessen Titel sich direkt auf das Volkslied "Korobejniki" bezog, wurde zwar nicht ausgefihrt (vgl. Zap.kn., 122; Eintrag Nov. 1908-Febr. 1909), doch enthält schon Bloks Aufsatz "O lirike" ( $\mathrm{V}, 130-159)$ vom Sommer 1907 eine Passage, in der der Sinn der Tagebuchnotiz vom 22. Juli 1908 vor- 
weggenommen $18 \mathrm{t}$.

"Der Lyriker gibt den Menschen nichts. Aber die Menschen kommen und nehmen. (Blok splelt vermutlich auf Off.22,17 an: "... Und wen dirstet, der komme; und wer da wili, der nehme das Wasser des Iebens umsonst."). Der Lyriker ist "arm und hell"; aus seiner "hellen Freiglebigkeit" (Blok zitiert ein Gedicht von V. Ivanov) schaffen die Menschen unzählige Reichtllmer. So ist es, und 80 war es immer. Auf den weiten Feldern singen diè musischen Bauern belm Pflugen eln groBes Lied, - die "Korobefniki" Nekrasovs. ther den Hindungen des russischen Flusses singen die frbeiter, die die alte Kirche mit dem moosbedeckten Vorplatz erneuern, "Solnce voschodit 1 zachodit" Gor'kijs."

Das bäuerliche, arbeitende Volk "nimmt" die Poesie, die der "gefallene Engel-Dämon, der erste Lyriker" aus den Tiefenschichten des Mythos entbindet. (Vgl. V,130-133). Das 1. Kapitel von Bloks Aufsatz iat ein unglucklicher Versuch, die Idee vom Lyriker als einem gefallenen Engel und der Poesie als Ausdruck des Volksgeistes zu einer Einheit zu verschmelzen. (Bloks Bild der "langbärtigen und friedlichen Christen-Arier", V,131, ist schlecht verdauter Richard Hagner; vgl. dessen "Heldentum und Christentum", 1881). Diese Passage traf auf berechtigte Kritik; vgl. V,724).

Die Verbindung von Kiinstler und Volkseele stellt in Bloks Aufsatz "Dußa pisatel fa" die Musik, der Rhythmus als vereinigende Substanz her (V,367-371; vgl. S.84/15). Die geistig-seelische Identität zwischen Dichter und Volk ist dann erreicht und erwiesen, wenn das Gedicht zum Volkslled wird (vgl. zum Volkslied S.73/4). Der romantische Ursprung dieser Ideen ist offenkundig (vgl. Kluckhohn, Ideengut, S.1141., 177). Blok wurde offenbar von einer realen Begebenheit inspiriert. Das läßt die Tagebuchnotiz zum 9. Juni 1907 vermuten, die Blok im Zug von Petersburg nach Sachmatovo niederschrieb:

"Die "Hausierer" werden mit einer geheimen Traurigkeit gesungen. Besonders "Ich habe selbst nicht wenig bezahlt, handle nicht, sel nicht geizig..." (das ist die 4. Strophe des Volkslieds - D.t..; Zap.kn.. 94).

In dem Volkslied, das wohl im Zug gesungen wurde, liegt 
die ganze Wehmut der russischen Landschaft beschlossen, die Blok in seinen Gedichten und in LS spfirbar machen wollte (vgl. Entstehungsgeschichte, S.5). In der Einleitung $z u$ seinem Gedichtband "Zemlja $v$ snegu" spannt Blok den Bogen von seinen Jugendgedichten bis zu den Gedichten des zyklus "Snežnaja maska". Nach der Abkehr vom hohen Mystizismus der "Stichi o Prekrasnoj Dame", dem Aufgehen in der Vielfalt und Widersprlichlichkeit des Lebens im Zyklus "Neðajannaja Radost'" und der Begegnung mit dem Schicksal in der Gestalt der zigeunerhaften Zirkusreiterin (vgl. S.67/2), scheint es keinen Ausweg aus den Verstrickungen des Lebens zu geben. Doch das Schicksal siegt nicht.

"Denn am Ende des liegs, der voll ist von Scheitern, Widersprifchen, kummervollen fuf achwitngen und nutzloser Wehmut, breitet sich die ewige und grenzenlose Ebene aus, - die uranfängliche Heimat (rodina), vielleicht Rußland selbst. (Vgl. danit Zap.kn., 117f.). Und der Schneefall, der das Strahlen des Einen Sterns verdunkelte, legt sich. Und die Schneemassen, die die Erde bedecken, liegen da vor dem Frihling (vgl. dazu Abw. 446)). Wahrend aber der Schnee die Augen blendet, und die Kälte die Seele gefangen hält und die Wege versnerrt, ertönt aus der Ferne das einsame Lied des Hausierers, die sieghaft-traurige, rufende Melodie, vom Schneesturm hergetragen:

Ach, so voll, so voll mein Kästelchen ..." (II,373f.)

Blok zitiert dann dieselben drei Strophen des Volkslieds wie im IS.

Der "Hausierer", der in den frtheren Fassungen mit "Mužik" (Bauer) bezeichnet wurde (vgl. IV,453), 1st der selbstsichere, "musikalische" Mann aus dem Volk, wie inn sich Blok aufgrund seiner irrationalen "musikalischen" Weltanschauung vorstellte. In der Gestalt des Hausierers konkretisiert sich Bloks Glaube an die Kraft des russischen Volkes, das jenseits aller Zweifel in den Stfirmen der Zelt seinen Weg geht.

S.105/2 Die Zahl Dre1 1st die heilige Zahl (Anfang, Mitte, Ende bei den Pythagoräern; dreifache Göttergruppen in vielen Religionen; christliche Trinität; vgl. Forstner, Welt der Symbole, S.51f.). Sie spielt insbesondere in der christlichen Kunst und Mystik, aber auch in der Folklore eine bedeutende Rolle (vgl. dazu die interessante 
Studie von V.Je. Vetlovskaja: Simvolika čisel v "Brat'jach Karamazovych", wo insbesondere die Symbolik der Zahl Drei mit ihrer christlichen und folkloristischen Wurzel bel Dostojevskif untersucht wird).

Der dreimalige Kuß der Faina ist eine Art religiöser Geste. In F1 ist die religiose Symbolik ganz deutlich: "Dreimal bekreuzige ich dich." (Abw. 486)). Diese Stelle ist eine Parallele zur Kreuz-Symbolik beim Abschied der Helena (S.96/6).

S.105/3 Dieser Satz hebt die "Ankunft der Zeit" im 5.Bild auf und enthalt den eigentlichen Grund fir die irennung der Faina von German. Die "Schwäche Germans" und das "Erklingen der alten Töne im lind" sind eigentlich nur Folgeerscheinungen dieses "Grundes". Diese Stelle des IS kann als Entsprechung zu den Aussagen Bloks uber die Revolution von 1905 gesehen werden:

"Ja, wir sind am Vorabend "eines großen Aufruhrs". Wir sind an Vorabend von Ereignissen, und das, was beim ersten, zweiten und dritten Mal nicht gelang, wird beim vierten Mal gelingen." ( $\mathrm{V}, 258$; diese Aussage ist von Februar-März 1908 und demnach aus der Endphase der ersten Periode von Bloks Arbeit am LS.).

"Es ist Rußland, das s ich einer Revolution entriß und gierig in die Augen der anderen schaut, die vielleicht noch schrecklicher ist." ( $V, 486$; nit diesem Satz schließt Blok seine "Rezension" des Buches "Plamen'" von P. Karpov, die sein Verhältnis zu den missischen Sekten beleuchtet).

Blok war liberzeugt, daß die Revolution von 1905 nur das Vorspiel einer weit größeren Umwälzung war.

S.105/4 Vgl. S.96/4, S.100/5, vor allem aber $5.103 / 10$.

S.105/5 iile Aufforderungen, von denen die belden letzten inhaltlich die Repliken von S.104/14 wiederholen, sind eine Art religiöses Vermächtnis der scheidenden, aber die Wiederkehr verheiBenden Gottin.

S.105/6 Faina, die einerseits die verkörperte Freiheit und Unböndigkeit ist ( $\mathrm{vgl}$. S.99/16, S.102/1), ist andrerseits dem alten Begleiter verfallen. Rußland gerät wieder in den Bann der sutokratie (vgl. S.81/10). Die Weltseele fällt zurick in die Bande des Bösen. 
Die Spannung zwischen Freiheit und Hörigkeit ist ein Grundzug der "femme fatale" des fin-de-siècle und der dämonischen Frauengestalten Dostojevskijs, v.a. der Nastas'ja Filippovna. Sie, die verkörperte Freiheit, ist der unheimlichen Sinnlichkeit Rogozins verfallen, vor der sie der nur mitleidende, zu integraler liebe unfähige Ffirst ihy̌kin, nicht zu erretten vermag. Während jedoch die Frauengestalt Dostojevskijs in inrer inneren Zerrissenheit psychologisch glaubhaft dargestellt ist, und das mythische Element nur durchscheint, entbehrt die R!ickkehr der Faina zu dem alten Begleiter jeder psychologischen Glaubwirdigkeit. Der Weltseelenmythos ist zu offen dargelegt.

S.105/7 Hier ist Allgegenwart und baldige diederkehr gemeint (vgl. Phil.4,5).

S.105/8 Die Handlung des IS ist an dieser Stelle "unglaubhaft". Man kann sich schwer vorstellen, dab Faina den schwachen Geliebten im Schneesturm zurilckläBt. Der Abschied der Faina ist die allegorische Darstellung des Scheiterns der $z u$ frith erwarteten $(V, 435)$, aber in Bälde mit größerer Macht wiederkehrenden Revolution von 1905. (Vg. S.105/3).

S.105/9 Faina geht in ihre Elenente, den Schneesturm und die Dunkelheit zurfick (vgl. S.98/6 und S.100/7). Die Verwendung des Wortes "mrak" in Zusammenhang mit Faina erinnert an den Titel "Zakljatije ognem 1 mrakom" (Beschworrung mit Feuer und Dunkel), unter dem im Rahmen des Gedichtzyklus "Faina" elf Gedichte von Oktober und November 1907 zusammengefaßt wurden. Der litel lautete ursprfinglich "... i pl jaskoj metelej" (... und dem Tanz der Schneestifme).

S.105/10 Vgl. S.99/14. Hier symbolisiert die Farbe V'eiß die Leere nach dem Verschwinden der Faina.

F1 ist konkreter. Hier folgt: "Unberihrter Schnee. Wann wirst du die Heimaterde freigeben." (Abw. 489)).

S.105/11 Vgl. S.50/4; S.66/1; S.86/2.

German hat dem Ruf des Schicksals gehorcht. Die Passage hat stark autobiographischen Charakter, denn Blok em- 
pfand seine Liebe zu N.N. Volochova als schicksalhafte El ementargewalt.

S.105/12 Vgl. S.97/1, Abw. 397).

German, der als Held auszog, ist zum Bettler geworden.

S.105/13 Die Lage Germans scheint aussichtslos. Er ist unfähig, sich aus eigener Kraft vor dem Untergang im Schneesturm zu retten.

S.105/14 Das Walten der Elemente hat seinen Höhepunkt erreicht.

S.105/15 Das Auftauchen des Hausierers ist durch das Erklingen des Volkslieds vorbereitet, soll aber dennoch "fberraschend wirken. In $F 1$ soll der Hausierer "wie ein GesDenst, wie ein unerwarteter Helfer aus einer andern Welt" erscheinen (Abw. 491)). Er ist der "deus ex machina". Der Hausierer erscheint als Retter und Fihrer wie Vergil im 1. Gesang von Dantes "Divina Commedia" (v,61ff.).

S.105/16 Die Sprache des Hausierers 8011 "volkstilnlich" wirken. Es zeigt sich aber, daß Bloks Fähigkeit, die Sprache des bäuerlichen Volkes zu imitieren, sehr begrenzt war. In Erkenntnis dieser Tatsache und in Erinnerung an die von Remizov vorgebrachten Einwände (Zan.kn., 106; vgl. Entstehung sgeschichte, S.11) schwächte Blok in $i 2$ die volkstimliche Stilisierung ab. Die Ausdrücke "Cego..." (statt "¿to...") und "Zamerznut' zachotel? (Wortstellung und Verwendung des Verbs "zachotet'", "Lust bekommen" o.ä.) sind jedoch offensichtlich als volkstifmliche kedeweise anzusehen, ebenso die Anrede mit "du".

Die erste Replik des Hausierers ist in $F 1$ um die Frage: "Bist du ein :hensch, oder nicht?" länger (Abw. 492)). Hier soll wieder auf das Motiv "Mensch" (vgl. S.68/2; $\mathrm{S.69/3} ; \mathrm{S} .78 / 4$ und $5 ; \mathrm{S} .102 / 4)$ angespielt werden. Russ. "al'" flir "ili" (oder) in dieser fbweichung ist volkstilmlich und auch bei liekrasov häufig (vgl.a. Bloks "Dvenadcat'", III,347ff.(5) u. ̈̈.).

S.105/17 Im russ. "Sam dojdu." fehlt die Erg̈̈nzung.

S.105/18 Russ. "nas brat" (unsereiner) ist ein volkstimlicher Áusdruck. 
S.105/19 Die Gegenilberstellung "Heiliger" - "normaler Mensch" bzw. "Bettler" nimmt das Motiv "German als Heiliger" aus dem 6.Bild von F1 wieder auf (vgl. S.97/1, Abw. 372)).

F1 ist hier ausfihrlicher und volkstimlich (vgl. Abw. 493)).

S.105/20 Der lausierer gebraucht das liort "v'juga" (Schneesturm), das in Bloks Gedichten meist als Synonym von "metel'" gebraucht wird. Im Poem "Dvenadcat" hat es im 10. Gedicht (III,356) neben der normalen Betonung auf der vorletzten auch die Betonung auf der letzten silbe (vgl. Kiparskij, Viortakzent, S.190f.).

S.105/21 Vgl. damit:

"Ich habe Könige und Helden

In den Schlaf gewiegt..."

(II,232ff., Str.6)

"Und in den Schneebetten

Schlafen Könige und Helden Vergangener zeit

In silbrigschneeiger Ruhe -

Oh, Deine, Unbekannte, schneeigen Opfer!"

$$
\text { (II,250, Str.4) }
$$

In $F 1$ folgen auf die Worte des Hausierers zwei Repliken: Auf die Frage Germans, von wem er spreche, antwortet der Hausierer: "...vom Mflterchen RuBland: nicht nur eine lebendige Seele hat es in seinem Schnee und in seinen Steppen zur Ruhe gebracht..." (Abw. 497)). Das Hinilbergleiten von "v'juga" iber "ona" zu dem volkstimlichen "Rasseja-matuß̌ka" erinnert an S.93/8. (Das vom Kontext evozierte "smert'" ist ebenfalls ein Femininum!). Die Verbindung von Mutter- und Todessymbolik sowie die metaphorische Verwendung von Ausdrficken wie "wiegen", "in den Schlaf singen" filr "töten" ist traditionell. Neben "pro Rasseju-matusku", "ne odnu...", "da" (alles Abw. 497)) ist "...prostojat' nipotem" und "malo li narodu..." als "volkstumlich" oder besser als "volktimelnd" zu werten. Die Vertrautheit, mit der der Hausierer fiber den Tod und das Mutterchen RuBland redet (vgl. "Izvestno, pro kogo", Abw. 497)), soll inn als "elementaren Menschen" (vgl. zum Ausdruck "elementarer Mensch" v,94) kennzeichnen, der mit der Natur auf du und du steht. 
S.105/22 "...kak ne znat'" ist volkstumlich. Die Replik zeigt die Selbstsicherheit des Hausierers. (Vg1. auch S.100/ 10).

S.105/23 Die Wortstellung und der Ausdruck "Cto li?" sind volkstumelnd. $\mathrm{Vgl}$. damit die Redeweise des "Rybak" in "Roza 1 krest'" (III,194ff.).

S.105/24 Frage und Antwort sind der Versuch einer "realistischen" Motivierung fur Germans Verirming (vgl. auch Abw. 499)).

S.106/1 Russ. "ogonek..." bedeutet "Lichtschein im Fenster". (Vgl. den susdruck "na ogonek zajti k komu-n." und (II,373).

S.106/2 Russ. "prigljadet'sja" bedeutet wörtl. "sich an einen Anblick gewöhnen". In der Ubersetzung ist sinngemä $B$ "an die Dunkelheit" ergänzt.

S.106/3 Die Symbolik des "Lichts in der Finsternis" ist in der "realistischen" Verbrämung noch deutlich.

S.106/4 Im russ. Text steht "brodjalij". Blok verwendet nicht "brodjaga" oder "strannik", weil diese beiden v'orter mit der Vagabundenromantik des jungen Gor'kij bzw. der Pilgerronantik zu eng verknupft sind.

Mit "brodjacij" ist das ziellose Umherirren Germans am besten unschrieben. Fifr den Hausierer, der ebenfalls ein ianderleben fuhrt, ist Germans vorherige Replik unverständlich.

S.106/5 Die Replik des Hausierers klingt wieder volkstflmlich. Der Ausdruck "kuda znajeß'", den German in der nä.chsten Replik wiederholt ("kuda znaju"), ist ungewöhnlich. Er zeigt wiederum die Nebelhaftigkeit von Germans (und Bloks) Vorstellungen.

S.106/6 Russ. "prochozif" bedeutet "der Vortibergehende", "der Handerer".

S.106/7 Der Schluß des 7.Bildes ist wie der des 6.Bildes ganz von der "homo-viator"-Symbolik beherrscht.

Die Fassung dieses Bildes nach $M 1$ ist jetzt abgedruckt in IV, 445-454. Es fehlt allerdings ein im Manuskript durchgestrichener Einschub von 7 Zeilen im Monolog Germans (nach der Zeile "Sžigajustij kak temnyj vzor Fainy."; Medevedev, Drany i poèmy, 
S.75). Dort entwickelt German die Antithese zu der 2. Taufe im Schneesturm: es 1st die erste Taufe in der Kindheit zu einem sich dahinschleppenden kläglichen Leben. Blok hat diese Passage weggelassen und eine größere Intensităt der Aussage erreicht. In M1 1st der wilde, freiheitsdurstige Charakter der Faina stärker unterstrichen als später. So sagt sie zu German: "Du brilstest dich, daB du das Gesetz gebrochen hast. Aber ich bin mir selbst Gesetz." (Ty gordis'sja tem, Cto zakon narušll. A ja - sama sebe zakon.; IV,447). German identifiziert sie in seiner Antwort hierauf mit RuBland: "Dich, Faina, dich, RuBland trage ich unter dem Herzen." (Tebja, Faina, tebja, Rossija, nosu ja nod serdcem.; IV,447).

Der am Schluß der Szene auftauchende Jausierer war in $M 1$ anfangs nur mit "Bauer" (muzik) bezeichnet (IV,453f.); vgl. S.105/1. In tibrigen steht diese Szene nach M1 der Fassung F1 ziemlich nahe. So ist die "Heldensymbolik" und das "Lokalkolorit" in der Redeweise des Hausierers in F1 beibehalten. 


\section{BAHNHOPSSZENE}

Die Handlung der Bahnhofsszene besteht aus einer wechselweisen Konfrontation von Faina, German, dem Freund Germans und zwei weiteren Freunden Germans. Es wird die tragische Situation Germans dargestellt, der sich aus Liebe zu Faina von seiner Frau und seinen Freunden, satirischen Karikaturen von Intelligenzlern, abwendet, aber das Rätsel seiner dämonischen Partnerin nicht lösen kann. Die Freunde sehen in Faina nur die Dirne. German spurt, daß sie mehr ist, aber er ist zu schwach, un ihrer dianysisch-aphrodisischen Natur gerecht zu werden. Die Schwäche Germans vor der selbstsicheren Urnatur der Faina ist Symbol des Versagens der Intelligenz vor der elementaren Kraft des Volkes. Selbst fur diejenigen Intelligenzler, filr die das Volk mehr ist als ein Objekt der Verachtung und des iblen Geredes, bleibt es eine dämonische Sphinx. Der Konflikt zwischen Volk und Intelligenz wird in diesem Bild im Konflikt zwischen der dämonischen Frau des fin-de-siècle und ihrem schwächlichen opfer versinnbildlicht. Faina gleicht in diesem Bild der Heldin von Bloks "Skazka o toj, kotoraja ne pojmet jeje" (Märchen uber die, die es nicht verstehen wird), das im Cktober 1907 entstand, also gleichzeitig mit dem zyklus "Faina" und mit dem Beginn der Arbeit an LS. Der Inhalt des Märchens ist die Begegnung des männlichen schwachen Helden mit dem dämonischen, sphinxhaften Schlangenweib. Die Frauengestalt des Märchens ist ein Konzentrat aus den dämonischen Hypostasen der "Unbekannten", der Heldin der "Schneemaske" und der "Faina" der Gedichte. Die dämonische Frau ist für den männlichen Partner Sinnbild "der Freiheit, der Luft und des Feuers". Nach der nöchtlichen BegegnunE verlößt sie ihn und entschvindet als unenträtselte verkörperung der Finsternis in die kosmische sternennacht.

Germans Rechtfertigung seiner Liebe zu Faina und die Verteidigung seiner Freiheit entspricht weitgehend den Passagen des 5.Bildes. Doch ist Faina in der Bahnhofsszene nur die rätselhafte, dämonische Dirne, der städtische kspekt des "Ewig-lieiblichen". Ihre eigentliche, "russische" Hypostase, die Hypostase der jungfräulichen Braut, die den Erlöser ersehnt, ist in der Bahnhofsszene völlig von der Hypostase der unersättlichen 
Aphrodite Pandemos iberlagert. Blok empfand dieses Bild deshalb als ungenilgend.

Die bedeutsame Neuerung des 5.Bildes gegentlber der Bahnhofsszene ist die Ausweitung des Mythos vom "Ewig-Weiblichen" von einem "dekadenten", an die GroBstadt gebundenen fin-de-siècle-Erotizismus in eine pseudoreligiöse, an die Sophienmystik Vl. Solov'evs erinnernde Sphëre, in der auch Bloks RuBland-Gedichte stehen. So bezeichnet die Bahnhofsszene den einen Pol in Bloks Mythos, dessen Ergänzung und Korrektur die Erlösungsmystik des 5.Bildes ist. 1)

1) Vgl. zur Bipolarität von Bloks Mythos des "Ewig-Weiblichen" die Einleitung zum 5. Bild. In seiner überaus umfangrelchen Blok-Monographie gibt B. Solov'ev dem Blokschen "Märchen über die, die es nicht verstehen wird" eine zu einfache Deutung. Die dämonische Frau ist für inn die Verkörperung des Raubtierhaften, Bösen der Reaktion. Die helle Seele des männlichen Antipoden hält jedoch der Versuchung durch das

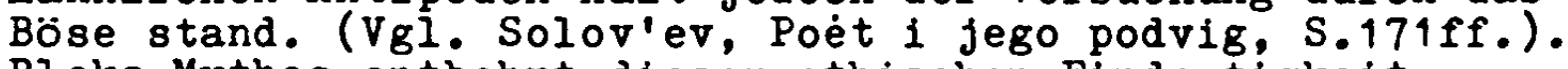
Bloks Mythos entbehrt dieser ethischen Eindeutigkeit. 
S.107/1 Diese Szene fehlt in F1 und in F2. Sie folgte in M1 auf die Szene in der Garderobe der Faina (vgl. Entstehungsgeschichte). Blok bezeichnete die Szene schon am 8. Januar 1908 als zwar "gut geschrieben, aber ideell unbefriedigend" (VIII,224; vgl. Entstehungsgeschichte, S.6). In F1 und F2 wurde diese szene durch die szene auf dem öden Platz ersetzt, in die eine ganze Reihe von Bildern und Motiven aus der Bahnhofsszene aufgenommen wurde.

S.107/2 Wenige Tage nach der Entstehung des Gedichts "Neznakomka" fuhrte Blok seinen Freund Je. Ivanov nach Ozerki, wo das Gedicht entstanden war.

"Schließlich fuhrte er mich in den Bahnhof von Czer$k i$ (an der Sestrorecker Bahnlinie). Aus einem großen venezianischen Fenster sieht man die "Schlagbäume"; auf all das wies er in seinen Versen hin. Im Fenster sieht man die Bahnlinie, die Finnische Eisenbahn. Ziige fahren häufig vorbei... Mit diesen vorbeijagenden Maschinen ist die Erscheinung der Unbekannten im Fenster verbunden..." (Ivanov, Zapisi ob A. Bloke, in Blokovskij sbornik, S.404, Eintrag von 9. Mai 1906. Vgl. II,423, Anm. zu "Neznakomka". Das Fenster, in dem die "Unbekannte" erscheint, wird II, 185f., str. 7 erwähnt.). Im Gedicht "Ja minoval zakat bagrjanyj..." (II,137), das in die Reihe der "Neznakomka"-Gedichte gehört, erscheint "sie" im Bahnhofscafé. Dieses Gedicht entstand zwar erst im Februar 1908, die weibliche Erscheinung trägt jedoch die Zilge der "Neznakomka". Das "reale Vorbild" fitr den Raum der Bahnhofsszene und der Szene auf dem öden Platz liegen in unmittelbarer Nähe beieinander (vgl. S.81/6). Die Eisenbahnsymbolik findet sich in beiden Bildern (vgl. S.81/3). In der szene auf dem öden Platz gewinnt die "Troika" und das musische "Land" das tbergewicht gegen die "Lisenbahn" und die "Stadt". In der Bahnhofsszene ijberwiegt die städtische Atmosphäre.

S.107/3 Zu Faina als Zigeunerin vgl. Germans Monolog S.68.

S.107/4 Diese Passage erinnert stark an den infang von Bloks "Skazka o toj, kotoraja ne pojmet jeje" vom 12. Okt. 1907: "Schon verbreiteten sich in der stadt die Gerilchte und das Gerede..." (Blok, Scbr.soc. v 7 t., Bd.4. S.139). 
S.107/5 Die vorige Replik, besonders aber die Antwort Germans haben stark biographischen Charakter (vgl. S.111/8).

S.107/6 Zum Motiv "German als Kind" vgl. S.101/3 u.ö.

S. $107 / 7 \mathrm{Vgl}$. S.86/5.

S.107/8 Der Freund ist "Realist".

S.107/9 Das bezieht sich auf das 1.Bild. Vgl. S.46/5.

S.107/10 Der Freund kneift.

S. $107 / 11 \mathrm{Vgl}$. S.86/5.

$\mathrm{S} .108 / 1 \mathrm{Vgl}$. S.86/5.

S.108/2 German ist Gefilhlsmensch.

S.108/3 Zum Sëngerin-Aspekt vgl. S.51/1,S.65/2 und das 3.Bild, wo die Zigeunerin- und Sängerin-Hypostase verschmelzen.

S.108/4 Rus8. "njanXit'sja"/ (s vami) zu "njanja" Kinderfrau; also eigentlich: "Ihre Amme zu sein".

S.108/5 Vgl. S.87/15.

S.108/6 Vgl. S.87/1. Die Berufung auf die "grifine Signallampe" ist hier so absurd wie in F1, Abw. 286).

S. $109 / 1 \mathrm{Vgl} . \mathrm{S} .87 / 7$.

S. $109 / 2 \mathrm{Vgl} . \mathrm{S} .87 / 2$.

$\mathrm{S} .109 / 3 \mathrm{Vgl}$. S.108/6.

S.109/4 Vgl. dazu kegieanweisung zum 1.B1ld und S.52/6 und 8 (Blumenbeet, Iilie. Pomeranzenbliften) und S.100/1 (Blumen der seele).

S.109/5 .zus8. "zarja" bedeutet "ilorgenröte" und "Abendröte". je nach Kontext. Da sich Gernans worte auf das 1.Bild beziehen, läge es nahe, hier mit "Abendrot" zu fibersetzen. Die ieplik hat jedoch stark autoblographischen Charakter, denn sie spricht das Verhältnis Bloks zu seiner Frau und damit die ielt der "Stichi o Prekrasnoj Dame" an, die ganz im Zeichen der "aurora" steht (vgl.z.B. I,185,494; dazu Kluge, Hesteuropa und Rußland. S.49). Im IS ist die "aurora" ein Attribut der Faina (vgl. S.82/14), und sie begleitet die Begegnung Germans mit Faina im 5.Bild (vgl. S.89/8).

S.109/6 Dieser Satz ist der einzige Hinweis in LS auf die "Vorgeschichte" der Beziehung zwischen Helena und German. Der biographische Charakter des LS ist an dieser Stelle besonders deutlich, denn dieser Satz bezieht sich 
offensichtlich auf die mystische Liebe Bloks zu seiner Frau (vgl. S.43/5).

S.109/7 Vgl. S.46/8. Auch hier ist das biographische Element offenkundig.

S.109/8 Vgl. S.49/2, S.86/5, S.107/7 und S.108/1.

S.109/9 Vgl. S.87/4.

S. $109 / 10 \mathrm{Vgl}$. S.87/5.

$\mathrm{S} .109 / 11 \mathrm{Vgl} . \mathrm{S} .87 / 3$.

S. $109 / 12 \mathrm{Vgl}$. S.87/2, S. $108 / 6$ und $\mathrm{S} .109 / 3$.

S.110/1 Vgl. S.87/7.

$\mathrm{S} .110 / 2 \mathrm{Vgl} . \mathrm{S} .87 / 2$.

S.110/3 Liese Frage erinnert an die kusf'ihmungen des "hannes mit Brille, S.72/2.

S.110/4 Vgl. S.108/3.

S.110/5 German wirde etwa die Meinung des "Mannes mit Brille" wiedergeben.

S.110/6 Lie schwarze Kleidung und die StrauBenfedern sind httribute der "Neznakomka" (vgl, II,183f., 185f.. 187f.).

S.110/7 Vgl. II,183f.: "Troje lico blednej, とem bylo..." und S.81/9, wo die erregte und bleiche Faina nicht als Halbweltdame, sondern als mussisches Hädchen auftritt.

S.110/8 Die Szene zwischen German und dem Freund entspricht inhaltlich der Szene zwischen den beiden im 5.Bild. Sie ist gelungener als die spätere Version, weil sie "realistischer" ist. Der Freund tritt als Verteidiger der Ehre Helenas auf. Germans "Rechtfertigung" ist ebenso "mystisch" wie im 5.Bild, allerdings nicht so exaltiert und wirkt deshalb echt.

S.110/9 Vgl. zum Motiv "warten" S.89/17.

Im Gegensatz zum 5.Bild, indem raina als die "wartende" erscheint, ist es hier German, der wartet.

S.110/10 Diese Passage soll die Freiheit und ingebundenheit der Faina unterstreichen.

S.111/1 Vgl. S.102/3. Faina ist hier die dämonische "Belle Dame sans merci".

S.111/2 Vgl. S.79/7.

S.111/3 "Lichter", "Schnee", "tind", "Finsternis" sind immer wiederkehrende attribute der "Neznakonka" und der 
"Paina" in Bloks Gedichten.

S.111/4 Die Replik unterstreicht den städtischen Charakter der Faina. (Vgl. damit II,267f., Str.4-6, wo Paina als Herrscherin der stadt erscheint).

S.111/5 Damit endet die kurze Szene zwischen German und Faina. Ihr Abgang wird durch den SchluB von Fainas Replik "motiviert".

S.111/6 Die Anzahl der "Freunde" erinnert an die Anzahl der "Mystiker" in Bloks Stfick "Balagancik" (vgl. IV,gff.). Genau wie diese haben die Freunde mit sicherheit reale Vorbilder.

Der "zweite Freund" ist möglicherweise eine Karikatur S. Solov'evs. Dieser hatte am Kult um Bloks Frau antell und wurde nach der Entfremdung von Blok im Sommer 1905 einer seiner publizistischen Gegner. Der "zweite Preund" hat die Eigentimlichke1t, französische Ausdricke zu gebrauchen (vgl. S.111/8, menage \& trois; S.119/1, teteà-tete). Der "dritte Freund" nimmt eine Haltung ein, die stark an Brjusovs l'art pour l'art-standpunkt erinnert. ilan vergleiche mit den Repliken des "dritten Freundes":

"Sei von allem kalter Zeuge, Deinen Blick auf alles richtend.

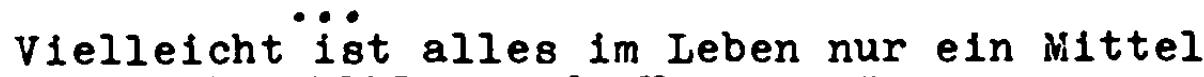
Filr hell-wohlklingende Verse..."

(Brjusov, "Poètu", 1907, Str.2 und 3; vgl. damit "Junomu poétu, 1896, Str.2).

Bloks Dichtung ist Bekenntnisdichtung. Filr den Standpunkt Brjusovs, der in dieser szene verzerrt, aber treffend dargestellt wird, hatte Blok kein Verständnis.

S.111/7 Vgl. den SchluB des 1.B1ldes (S.53).

S.111/8 So heiBt es wörtlich im russ. Text.

Die Beziehung zwischen Blok, seiner Frau und N.N. Volochova glich in der Tat während einer gewissen Zeit einem "ménage à trois". Das Privatleben Bloks bot nicht nur AnlaB zu allgemeinem Klatgch (vgl. Beketova, $A$. Blok, S.111f.. Die Passage betrifft die Zeit von 190708). Sogar in der literarischen Polemik der Jahre 1906ff. wurde mit Anspielungen auf Bloks Privatleben 
nicht gespart (vgl, z.B. V,732, wo die Reaktion Rozanovs auf Bloks Aufsatz "Literaturnyje itogi 1907 goda" dargestellt wird.).

S.112/1 Das Nebeneinander von "Weltanschauung opfern" und "heilige Pflicht" entspricht der Geisteshaltung, die Blok in seinem Aufsatz "Ironija" (V,345-349) verdammt. S.112/2 Jeder der drei Freunde beruft sich auf seine "Pflicht", un die Einnischung in Germans Privatleben zu rechtfertigen. Der "Freund" ist Helena "verpflichtet"; der "zweite Freund" beruft sich auf seine "Blirgerpflichten"; der "dritte Freund" ist der "Wissenschaft" "verpflichtet". Die Karikatur wirkt allerdings iberzogen.

S.113/1 Damit endet die 3.Szene des Bildes, deren SchluB an den kleinlichen Zank der Intellektuellen zu Beginn des 4.Bildes erinnert.

S.113/2 Der Wein spielt in Bloks Leben und in einer Reihe seiner Gedichte eine große Rolle. Blok trank in den Jahren 1906ff. häufig, besonders bei seinen ausgedehnten Wanderungen in die Vororte von Petersburg (vgl. Zap.kn., 110, Eintrag von 18. Juli 1908; 111, Eintrag vom 27. Juli 1908; 130, Eintrag vom 27.-28. Jan. 1909 u.ö.; VIII,239, Brief an seine Mutter vom 28. April 1908 u.ö.). Er hatte diese Gewohnheit in Frihjahr 1906 angenonmen, in der Zeit der Vorbereitung aufs Examen und der Krise mit Belyj. In einer Brief vom 7. Mai 1906 an V.d. Pjast schrieb Blok:

"An diesem Tag, wie an vielen anderen, war ich wohl fort und "trank Rotwein" (ich schreibe das in fnfithrungszeichen, weil dieser Prozeb filr mich schon zur strengen Formel geworden ist, aus der man viele theoretische Folgerungen ziehen muB)." (VIII,155).

Der tein war filr Blok ähnlich wie filr Baudelaire ("Les paradis artificiels"; Kapitel "Le vin" in "Les Fleurs du Mal") ein Mittel zur "Transzendenz" und zwar in dreierlei Weise.

In einer Reihe von Gedichten erlöst der Rausch aus dem Elend und der Verzweiflung des Alltagslebens (II,191f., 193f.; III,45.64f.. Diese Gedichte enthalten z.T. stark autobiographische Elemente). 
Der Rausch schafft andrerseits den Dämmerzustand, In dem der Dichter die Vision der "Neznakomka" und anderer Frauengestalten hat (Drama "Neznakomka". 1. und 2. Erscheinung, IV,72ff.; II,159f., 170f., 185f ., 187f., 195,204; III,11f., 25). Belyj berichtet, wie Blok betrunken nach Hause kam und das Gedicht "Neznakomka" aus der Tasche zog. (Belyj, Vospominanija o Bloke, Epopeja III, S.170. Vgl. damit Je. Ivanov, Zapisi ob A. Bloke, in: Blokovskij sbornik, S.405ff., Eintrag vom 6., 9. und 10. Ma1 1906).

Schlieblich sind "Wein" und "Rausch" Symbole der dionysischen Sprengung der Grenzen von Raum und Zeit und gehören in die Reihe der Symbole "Tanz", "Wind", "Schneesturm", "Feuer", "Tro1ka" etc. (II,75f., Str.5 und 6; 211 "Sneznoje vino"; 239 "Skvoz" vinnyj chrustal'"; 257, str.4; 261, str.2 und 4; 264 (3), str.5; 278ff.; 280f.(9), Str.281: "I vsja ty - vo chmelju...", vgl. dazu Kluge, Westeuropa und RuBland, S.122f.). Blok selbst hat die Dämonie des Weins, der er selber häufig genug erlegen war, erkannt und gegeibelt ( $V$, 346f.; diese stelle zeigt besonders deutlich, daB der "Wein" bel Blok ein ambivalentes Symbol 18t.).

S. $113 / 3 \mathrm{Vgl}$. S.100/12.

Faina ist die sich verwelgernde dämonische Frau.

In "Skazka o toj..." heibt es:

"Sie ließ sich auf die schweren Teppiche nieder und sagte: "Berlinre mich nicht!", und... Ihr Herz bebte und flusterte: "Nimm mich!nn' (BIok, Sobr. sox. $\nabla$ t., Bd. 4, S.141).

S.113/4 Vgl. S.99/8. Zur Symbolik des Blicks Vgl. S.101/1. S.113/5 Vgl. S.99/10.

S.113/6 Diese Replik erinnert an die fur das fin-de-siècle typische Konstellation: der schwache Mann, der an der Seite des tberweibs leben will (vgl. Praz, Liebe, Tod und Teufel, Bd.1, S.183).

Vgl. auch $\mathrm{S} .99 / 7$. Faina 1st das verkorperte Leben.

S.113/7 Vgl. damit:

"Der Dichter (trinkt): Viele weibliche Gesichter sehen... Sie lieben. Sie begehren..."

(IV,76, Drama "Neznakomka") 
"Es waren viele - schöne Mădchen." (1I,3371., 1.Str.)

"Es waren viele...

Es waren viele. Doch mit einem

Wesenszug vereinte ich sie,

Mit der einen wahnsinnigen Schönheit,

Deren Namen ist: Leidenschaft und mein Leben." (III,160, str.2 u. 3)

Die beiden Gedichte sind vom Fruhjahr 1908.

Die Passage hat direkten Bezug zu Bloks Privatleben (vgl. Zap.kn., 303, Eintrag vom 29. Ma1 1916).

Blok suchte im tiechsel das "Ewig-lieibliche".

S.113/8 Vgl. zum Motiv "Spiel mit der Liebe" Bloks Gedicht "Na ostrovach" (III,2of.): Die Liebe wird banal, zur Routine.

S.113/9 Faina ist die strenge Domina (vgl. S.75/3 und $\mathrm{S.102/3}$ ). S.113/10 Vgl. das "Lied des Schicksals", S.67, Str.2.

S.114/1 Vgl. S.99/9, 12 und 14.

S.114/2 Vgl. S.87/3. Die letzten Sätze der Faina erinnern an die Darstellung Majakovskijs von Bloks Reaktion auf die Zerstörung Sachmatovos, die filr den "Menschen" Blok tragisch war.

S.114/3 Vgl. S.99/16.

S.114/4 Faina lehnt die belt der "Zivilisation", des "homo faber" ab. Hier scheint Bloks Kulturkritik durch. In "Stichija 1 kul'tura" (V,350-359) ist das "endlose und eifrige Bauen" $(V, 344)$ Symbol der zivilisatorischen Tätigkeit.

"Die Menschen der Kultur, die Anhänger des Fortschritts, die auserwählten Intelligenzler - mit Schaum vor dem Mund bauen sie Maschinen, bringen die Wissenschaft voran..." $(\mathrm{V}, 356)$

S.114/5 Die Passage hat Ähnlichkeit mit Passagen des 7.Bildes (vgl. S.104/14 und S.105/5).

S.114/6 "volja", "dal'", "veter" sind Kernsymbole von Bloks Rußland-Mythos. (Vgl. II,75f. "Osennjaja volja" mit sämtlichen Bildern des 2. Teils von Germans Replik.). Das Bild "du gehorchst keinem Gesetz" erinnert an S.102/1. In M1 ist Faina "sich selbst Gesetz" (IV,447). S.114/7 Faina ist eine Dirne. Vgl. dazu Ihr "Lied des Schicksals", S.67, Str.4. 
Dieser Aspekt in der Gestalt der Faina ist zwar im IS auch an anderer stelle deutlich, tritt aber in der Bahnhof sszene besonders krab hervor.

Faina teilt die Dirnen-Hypostase mit der "Neznakomka" und den anderen dämonischen Frauengestalten Bloks (vgl. u.a. II,136,137,17of, dazu: Peters, Symbole der sinnlichen Wahrnehmung, S.22-28, wobei die Deutung des "kiein"-Symbols anfechtbar ist., 181f., 185f., 187f., 293f.; III.31; V,71 und "Skazka o toj...").

S.114/8 Vgl. S.83.

S.114/9 Worauf Blok hier anspielt, ist unklar.

S.114/10 Vgl. S.113/10 und das "Lied des Schicksals", S.67, Str.2.

S.114/11 Germans Haltung ist wieder die des Sklaven vor der Domina.

S.115/1 Der Sinn der Stelle (vgl, auch die Wiederholung von "spielen" auf S.113) ist unklar. Vgl. S.113/8.

S.115/2 Vgl. S.99/15.

S.115/3 Vgl. damit: "Net, nikogda mojej, i ty nit'ej ne budeš." (III,239, 1.2eile. Dieses Gedicht beschließt den $2 y-$ klus "Karmen", der den Höhepunkt von Bloks dionysischer Zigeunerdichtung darstellt.).

Diese Stelle erinnert an eine Episode in Dostojevskijs Roman "Podrostok", 3.Te1l, 10.Kap.. IV.

Die Spannung von Lasterhaftigkeit und Unberfhrbarkeit (vgl. S.100/12 und $\$ .113 / 3$ ), die hier besonders kraß dargestellt wird, beherrscht die Frauengestalten auch in Bloks Gedichten.

So ist Faina im gleichnamigen Gedichtzyklus gleichzeitig "Schneefungfrau" und "Unberfihrbare" (II,267f.) und "Tochter der Erniedrigung" (II,293f.) und "Schlangenweib" (II,258f., 260,269ff., 284f.). Im Zyklus "Snežnaja maska" ist "Sie": "Jungfrau der Sternenabgrilnde (II,232ff.) mit "unschuldigem Iächeln in schweren schlangenhaaren" (II,211).

S.115/4 Die Frau als wildes Tier, besonders als wildkatze (Sphinx!) ist eine geläufige Vorstellung im fin-desiécle (vgl. Hofstätter, Symbolismus, S.206). In : 2 
gleicht die Begegnung zwischen Faina und German der zweier Raubkatzen (vgl. Kommentar zum 5.Bild, S.384). Dasselbe Motiv hat Blok im Gedicht "V djunach" vom Sommer 1907 (II,306f.) breitgetreten.

S.115/5 Diese Passage erinnert an die Repliken der Faina S.82f.

S.115/6 Vgl. S.99/12.

$\mathrm{S} .115 / 7$ Vgl. S.100/1.

S.115/8 Das Motiv der Erlösung der Dirne scheint hier durch. Germans Liebe zu Faina ist von besonderer, "metaphysischer" Art.

S.115/9 Das erinnert an Germans Schwäche und den Abschied der Faina Im 7.Bild (S.104f.).

S.115/10 Diese Passage 1st absurd, denn "Gedanken" hat German keine, allenfalls vage Vorstellungen.

$\mathrm{S} .115 / 11 \mathrm{Vgl}$. S.111/3 und 4 und $\mathrm{S.115/5}$.

S.115/12 Vgl. S.115/10. Dieser Vergleich soll das Getriebensein, die Unruhe symbolisieren (vgl, zu diesem Symbolgehalt Forstner, helt der Symbole, S.237).

S.115/13 German bezieht sich hier auf eine Antwort des Freundes im 3.Bild (Abw. 157); vgl. S.60/3).

Die Worte Germans sind eine Variante der Formel "Pokoja net" (Es gibt keine Ruhe) in Belyjs Gedicht "Kol'co" (Mai 1907), die Blok auch wörtlich zitierte (z.B. III, 249f., Str.5-7; III,95, Str.3). Sie entsprach seinem "elementaren" Lebensgefiihl.

S.115/14 Faina ist allmächtig. Vgl. S.78/12, Abw. 44) und 46) und $\mathrm{S.83/15.}$

S.115/15 Die Passage 1st im Zusammenhang mit der Erzählung des Mönchs im 2.Bild zu sehen.

S.116/1 Vgl. S.50/1. Faina gebraucht das hort "inok", was an das glelchnamige Gedicht im Zyklus "Faina" erinnert (II ,283).

S.116/2 German ist eine Art Doppelgänger oder geistiger Erbe des Mönchs (vgl. S.55/4, Abw, 109)).

S.116/3 Die Passage ist in inrer gewollten Hintergrilndigke1t sinnlos. Der Hinweis auf den liein ist völlig rätselhaft. 
S.116/4 Vgl. S.82/13. In Gegensatz zum 5.B1ld 18t auch hier German der Wartende (vgl. S.110/9).

S.116/5 Damit 1st die 4. Szene dieses Bildes zu Ende.

S.116/6 Der Gebrauch von "dama" an dieser Stelle ist ironisch.

S.116/7 Faina 1st Sängerin und Dirne. Die Prage klingt zwe1deutig.

$\mathrm{S} .116 / 8 \mathrm{VgI} . \mathrm{S} .111 / 3$.

S.116/9 Der dritte Freund 1st der kalte Beobachter ( $\mathrm{g} g$. S.111/6).

S.117/1 Damit ist die Liste der Pflichten um einen Punkt erweitert ( $v$ gl. S.112/2).

S.117/2 Dieser Ausdruck ( $v$ gl. a.S.71), In Anwesenheit der Betroffenen gebraucht, zelgt die geringe Meinung, die der Freund von Faina hat.

S.117/3 Vgl. S.112/1 und 2 .

S.117/4 Vgl. Beketova, A. Blok, S.111: "Das Leben der Bloks spielte sich vor aller Augen ab..."

S.118/1 Die Strophen, die German vorträgt, stammen aus den "Stanzas to Augusta" von Lord Byron (24. Jul1 1816; in: The Viorks of Lord Byron, Poetry, vgl. IV, S.5456). Bloks Obertragung folgt dem Byronschen Metrum (dreihebige Anapäste mit abwechselnd weiblichem und männlichem Reim).

Die 1. Strophe des IS entspricht der 1. Halbstrophe von Byrons Gedicht:

"Though the day of my destiny's over, And the star of my fate hath declined, Thy soft heart refused to discover The faults which so many could find."

Die 1. Strophe folgt inhaltlich sehr genau dem englischen Original. Blok stellte sie als Motto vor den 5.Teil "Poslanija" seines Gedichtbandes "Zemlja $v$ snegu", 1908 ( $v$ gl. Literaturnoje nasledstvo, Bd.27/28, S.520).

Die 2. Strophe im IS entspricht der 2. Halbstrophe der

3. Strophe der "Stanzas":

"There 18 many a pang to pursue me:

They may crush, but they shall not contemn; They may torture, but shall not subdue me; "T is of thee that I think - not of them." 
Auch hier folgt Blok inhaltlich dem Original; dabei verengt er Byrons Bilder in seiner gewohnten Heldensymbolik-Manier ("sud'ba"; "ne probit' im zakovannoj grudi").

Die 3. Strophe im LS entspricht den Versen $1,2,6,8$ von Byrons 4. Strophe:

"Ihough human, thou didst not deceive me, Though woman, thou didst not forsake.... Though parted, it was not to fly,... Nor, mute, that the world might belie."

Die beiden letzten Strophen im LS sind den Versen Byrons frei nachempfunden. Nur einzelne Bilder sind aus der englischen Vorlage entnommen ("oblomki", "pustynja" und "razvaliny" in Str.4, Z.1; Str.5, 2.1-3 stammen aus Str.3, 2.1f.: "rock", "fragments" und Str.6, 2.5f.: "desert", "wide waste" der "Stanzas"). Insgesamt folgen Bloks Schlußstrophen jedoch dem vorgegebenen ihuster: Lobpreis auf die Stärke und Unverbrichlichkeit "ihrer" Liebe im Angesicht allgemeiner Verfenung. (Die letzte Zeile des Gedichts im LS mit dem Bild des vom Feuer unverletzbaren Diamanten erinnert an den Schluß des "Prologs" zum Poem "Vozmezdije" (III,301ff., 2.72ff.). Im LS ist der Diamant Symbol der ireue, in "Vozmezdije" der besseren Zukunft). Blok "ibersetzte $z w 1$ schen dem 3. November 1905 und dem 10. Januar 1906 mehrere Gedichte Byrons fflr die russische Gesamtausgabe der Werke Byrons im Verlag "Brokgauz $i$ ifron" unter der Redaktion S.A. Vengerovs (vgl. dazu II,449f.; VIII,141 Brief an Je.P. Ivanov vom 3. Dez. 1905; VIII,144, Brief an seinen Vater vom 30. Dez. 1905; VIII, 147, Brief an Belyj vom 3. Jan. 1906). Die Gedichte Byrons, die Blok (lbertrug, kreisten größtenteils um themen, die filr Bloks Dichtung seit 1905 von großer Bedeutung sind:

Liebesleidenschaft, enttäuschte Freundschaft, Impörertum (vgl. v.a. II,347f., 350ff., 354 (1 u. 2), $354 \mathrm{f} .$, 355f.).

S.118/2 Diese Geste sowle die ganze Deklamation Germans wirken recht gekiinstelt. 
S.118/3 Die Reaktion der Faina auf die Rezitation widerspricht eigentlich ihrem Abscheu gegentlber "schönen horten".

S.118/4 Der russische Wortlaut unterstreicht den herablassenden und dffmmlichen Charakter der Frage.

S.118/5 Die "Bildung" des 3. Freundes ist vermutlich wieder ein Seitenhieb gegen Brjusov, dessen phänomenale Kenntnisse der Weltliteratur bekannt waren (vgl. etwa Mocul'skij, Brjusov, S.152). Brjusov thertrug ebenfalls einige Byron-Gedichte fllr die russische Gesamtausgabe.

S.118/6 iährend die Byron-Verse filr den 3. Freund ein "literarisches Phänonen" sind, identifiziert sich German mit inren etwas schwfllstigen Pathos.

S.119/1 So wörtlich im russischen rext. Vgl. S.111/6.

S.119/2 Der Freund faBt die Byron-Verse offenbar als "Satire" auf. Damit soll wohl sein völliges Unverständnis flir die in der Rezitation deutlichen Liebe Germans zu Faina uberspitzt dargestellt werden.

S.119/3 Faina wilrdigt die Freunde keiner anrede.

S.119/4 Faina ist wieder die Domina. Vgl.a. S.114/6.

S.119/5 Die Freunde sind dem Tod geweint. Die Passage soll ein Hinweis darauf sein, daB sie Intelligenzler sind, uber die das "elementare" Rußland hinwegschreiten wird (vgl. die susfithrungen des "Mannes mit Brille", S.73/3). $\mathrm{Vgl}$.a. S.115/2.

S.119/6 Was damit gemeint ist, bleibt unklar. Ein inerk der Dekadenzliteratur kommt nicht in Frage.

Möglicherweise spielt Blok auf die Ilias an. Im 2. Gesang versucht der häBliche, schielende, lahme und bucklige Thersites mit lästerlichen Reden die Achäer zur Heimkehr zu bewegen. Der edle Cdysseus schlägt ihn deswegen mit seinem Szepter (Ilias 2, 211-270).

S.119/7 Diese Passage erinnert an den SchluB des "Prologs" zu Bloks Versepos "Vozmezdije" (III,301ff., Z.60-80). Vgl. auch:"... Solche Liebe Und $H a B$ können die Menschen nicht ertragen Wie ich sie in mir trage." (II,295ff., vorletzte Strophe; dazu III,95. Str.2; II,96, Str.4).

Der "schöpferische Groll" ist gegen die "Unmusikalität" der Freunde gerichtet, die im IS Vertreter der Bour- 
geoisie und ihrer Scheinmoral sind.

S.120/1 Germans Absage an seine Frau ist fast eine Profanation. "Svjataja", "Xistaja", "prekrasnaja" sind die wichtigsten Attribute der "Schönen Dame" ( $\mathrm{ggl}$. I,91,101,171, $232,261,352 f ., 491$ u.a.).

$\mathrm{S} .120 / 2 \mathrm{Vgl} . \mathrm{S} .85 / 16$.

S.120/3 Die Regleanwelsung zeigt deutlich, daß die Leidenschaftlichkeit Germans nur seine Unsicherheit verbergen soll.

S.182/4 Faina ist wieder die Sphinx, die kalte, beobachtende Göttin, die sich an den Qualen ihrer opfer weidet.

S.182/5 Diese Replik der Faina ist eine deutliche Anspielung auf Nietzsche, dessen "Jenseits von Gut und Böse" im Jahre 1900 ins Russische ubersetzt wurde ("Po tu storonu dobra I zla"; vgl. Russkaja I1teratura konca XIX natala XX V., Bd.1,S.476). Dieser Titel wurde auch in RuBland zu einem Schlagwort (vgl. Mocul'skij, Brjusov, S.40).

Am nächsten steht die Replik der Faina einigen Stellen aus "Also sprach Zarathustra" ("Tak govoril Zaratustra"); dieses Werk Nietzsches wurde schon 1898 ins Russische flbersetzt (vgl. Russkaja literatura konca XIX - nacala XX V., Bd.1,S.410 und S.476):

"Gleichnisse sind alle Namen von Gut und Böse: sie sprechen nicht aus, sie vinken nur. Ein Tor, welcher von ihnen Vissen will." (75, S.81)

"Es gibt einen alten wahn, der heiBt Gut und Böse." (75, S.223) u. ̈.

Faina ist im LS die Verkörnerung des "Geistes der Musik", der "jenseits von Gut und Böse" die Urkraft des Lebens darstellt.

Diese Szene fehlt in beiden Iruckfassungen. Wie aus dem Manuskrjpt $M 1$ hervorgeht, sollte sich urspriinglich der Freund in Faina verlieben. Ihm war auch das Gedicht von Byron in den Mund gelegt, das ursprilnglich nach der ersten strophe eine zusätzIiche Strophe aufwies (Medvedev, Dramy i poèmy, S.74).

Der ursprungliche Plan, demzufolge sich der Freund in Faina verlieben sollte, ist etwas befremdlich. Hätte Blok daran festge- 
halten, wären die Bezlehungen der Personen zueinander ziemlich unklar geworden. Möglicherwelse sollte zu diesem frlihen Stadium der Freund noch deutlicher als später den Doppelgänger Germans repräsentıeren. Das könnte das ursprïngliche Vorhaben erklären. 


\section{EXKURS}

Blok und der "raskol"

Viele russische Symbolisten, v.a. die "jilngeren", hatten großes Interesse an der russischen Folklore. Der "Neopopulismus" ist verständlich, wenn man die theoretische Begriindung des Symbolismus als einer mythenschaffenden, Dichter und Volk verbindenden Kunstrichtung beriicksichtigt, wie sie die "deutschen" Symbolisten in RuBland vortrugen. 1) Das Interesse an der Folklore ist ein Kennzeichen des "Neuromantismus", der in der Volkskunst den Zugang zum "kollektiven Unbewußten" suchte. 2) Hierbel stand der Symbolismus nicht nur in RuBland ganz im Banne Richard Wagners. 3)

Der Höhepunkt des russischen symbolistischen Folklorismus ist das Frihwerk S.M. Gorodeckijs. 4) Mit seinen frihen Gedichten, die voll von Motiven aus der slavischen Mythologie sind, hatte der Junge Gorodeckif im "Turm" Ivanovs einen sensationellen Erfolg. 5) In den Versen des jungen Dichters schien das dionysisch-barbarische, in orgiastischem sinnenrausch schwelgende echte Rußland wiederzuerstehen, von dem viele Symbolisten träumten. ${ }^{6}$ Der folkloristisch verbrämte Panerotizismus ist

1) Vgl. Pomeranceva, A. Blok i fol'klor, in: Russkij fol'klor, Bd.III, S.203f .; West, Russian Symbolism, S.143f ;; dazu Bloks Aufsätze "Tvor Čestvo vją. Ivanova", V.7-18 und "Duß̌ pisatel ja", V, 367-371.

2) Vgl. Michaud, Ie message poétique du symbolisme, S.405f.

3) Vgl. Michaud, aac, S.205ff. u.ö. Zum rein ästhetischen Mythos-Begriff Wagners vgl. das Kapitel "Mythos und Drama", S. $506 \mathrm{ff}$. Im Schlubteil der vorliegenden Arbeit.

4) Die Gedichtbände "Jar" (Sommerkorn; 1907), "Perun" (1907), "Rus" " (1908).

5) Vgl. die Erinnerungen Pjasts, zit. In: Russkajs literatura konca XIX - nacala XX v.. S.464. Im Kreise Ivanovs hatte man den Eindruck, ein neues Genie sei erschienen. Zu Gorodeckif vgl. Holthusen, Russische Gegenwartsliteratur, Bd.I, S.81f.

6) Ivanov, Blok, Bely $f$. Auch in den Gedichten Ivanovs und Belyjs finden sich zahlreiche Folklorismen. Zur Abhängigkeit Gorodeckijs von Ivanov vgl. Gofman, S. Gorodeckif, in: Poèty simvolizma, S.328-342. 
besonders ausgeprägt in Gorodeckijs Gedicht "Rosjanka" (Sonnentau), der Imitation eines Chlystenlieds. ${ }^{1)}$

Auch die Malerei des ausgehenden 19. Jahrhunderts ist in Rußland von einer Hinwendung zur Volkskunst als Reaktion gegen den sterilen Klassizismus der Petersburger Akademie geprägt. Die Orientierung an der Volkskunst verbindet die russischen "Realisten" und die "Idealisten", die sich um die Kunstzeitschrift "Mir iskusstva" (Welt der Kunst) gruppierten. Die Vorliebe der Maler fiir nationale, volkstumliche Themen zeigte sich in der Historienmalerei, ${ }^{2}$ die sich gern dem vorpetrinischen, ja vormonologischen RuBland zuwandte, manchmal im Banne des slavophilen ilythos vom "russischen Christus", 3) aber auch in der Landschafts-4) und Genremalerei ${ }^{5)}$ mit vorwiegend "echt russischen" Sujets. Ein weiterer Themenkreis war die russische Folklore; ${ }^{6)}$ von ihr wurde häufig auch die Historienmalerei beein-

1) Vgl. Poèty simvolizma, S.347ff., hrsg. v. M. Gofman.

2) Vgl. I.Je. Repin, "Ivan Groznyj i syn jego Ivan 16 nojabrja 1581 goda", "Zaporožcy pišt pis'mo tureckomu sultanu"; V.M. Vasnecov, "Vitjaz' na rasout'e", "Bitva slavjan so skifami"; V.I. Surikov, "Utro streleckoj kazni", Bojarynja Morozova", "Pokorenije Sibiri Jermakom"; A.M. Vasnecov, "Staraja Moskva"; S.V. Ivanov, "Sem'ja"; A.P. Rjabužkin, "Moskovskaja ulica XVII veka"; "Svadebnyj pojezd v Moskve (XVII stoletije)"; N.K. Rerich, Zyklus "NaCalo Rusi. Slavjane" ("Gonec. Vosstal rod na rod", "Zamorskije gosti", "Idoly", "Slavjane na Dnepre") u.a.;

3) M.V. Nesterov, "Svjataja Rus'".

4) I.I. Levitan, "Zolotaja osen'", "Chmuryj den'", "Ozero"; V.A. Serov, "Baba v telege", "Zimoj"; K.A. Korovin, "Severny $j$ pejzaz"; I.E. Grabar', "Zima", "Fevral'skaja lazuri"; u.a. K.F. Juon, "Troickaja lavra zimoj"; u.a.

5) I.Je. Repin, "Burlaki na Volge"; A.Je. Archipov, "Na Volge", "Radonica"; A.P. Rjabułkin, "Ozidanije novobrąnych ot venca v Novgorodskoj gubernil"; F.A. Mal javin, "Baby", "Vichr"" K.A. Korovin, "Severnaja ldililja"; B.M. Kustodijev, "Guljan'e na Volge", "Maslenica".

6) I.Je. Repin, "Sádko"; V.M. Vasnecov, "Bajan", "Gamajun, ptica vescaja", "Sirin i Aikonost"; M.A. Vrubel', "Bogatyr'", "Tridcati tri bogatyrja", "Carevna-Lebed""; I.Ja. Bilibin, Graphiken und Märchenillustrationen (vgl. Lichačeva-LichaČev, Chudožestvennoje nasledije drevnej Rusi 1 sovremennost'. S.42); V.V. Kandinskij, "Russische Schöne in Landschaft". 
flubt. 1) Die Vertiefung in das nationale Erbe war von einer Wiederentdeckung der Kunstschatze der russischen vorpetrinischen Vergangenheit, $\mathbf{v} . a$. dem Kirchenbau und der Ikonenmalerei, begleitet. 2) Die "modernistische" Kunstzeitschrift "Mir iskusstva" widmete mehrere Nummern der russischen Volkskunst und der Kunst des alten RuBland. 3 )

Russisch-nationale Sujets und Motive beherrschen seit M.I. Glinkas Oper "Ivan Susanin" (1836) auch die russische Musik. Die Hinwendung zur Volksmusik war der wesentliche Programmpunkt der "moguxaja kuðka". 4) Besonders die russische Oper schöpfte aus der nationalen Folklore ${ }^{5)}$ und Geschichte. ${ }^{6)}$ Ihren Höhepunkt

1) Vgl dazu Mil jukov, Outlines of Russian culture, Teil III, S.59ff.; Istori ja russkogo iskusstva, pod red. I.E. Grabarja, Bd. IXff.; einen guten therblick bietet: Gosudarstvenny $j$ Russkif muzej, putevoditel', pod red. V.A. Pukkareva; vgl.a. Lichaceva-Iichačev, aa0, S.32; Behrens, Kunst in RuBland, S.51ff.; Hofstätter, Geschichte der europäischen Jugendst11malere1, S.235ff.

2) Vgl. Lichačeva-Lichačev, aa0, S.30. Der aus dem Kreis von "Mir 1skusstva" stammende Maler Grabar' wurde auch als Kunsthistoriker und Erforscher der altrussischen Kunst berihmt. Die Sophiologie in inrer russischen Ausprägung wird von ihren Vertretern mit dem Hinweis auf die Ikonenmalerei Novgorods (v.a. auf die Ikone "Sofija sozda sebe dom", vgl. Gosudarstvennaja Tret'jakovska ja Galereja, Katalog drevnerusskoj Zivopisi, Bd. II, S.25f. und Reproduktionen 3-5) als orthodox und dabei genuin russisch-volkstumlich gerechtfertigt; vgl. Zernov, The Russian religious renalssance of the 20 th century, S.283ff.

3) Vgl. z.B. Mir iskusstva 1904, Nr. 11, "Narodnoje tvorčestvo severa" von I.Ja. Bilibin mit reichem Bildmaterial. Zur Entdeckung des "russischen Altertums" vgl. Arsen'ev, Die geistigen Schicksale des russischen Volkes, S.234ff.

4) Zum "mächtigen Häuflein" gehörten Balakirev, Borodin, Cui, Musorgskif und Rimskij-Korsakov.

5) A.S. Dargomyzskij, "Rusalka".

6) A.P. Borodin, "Knjaz' Igor'" (1908 von Rerich ausgestattet). 
und Weltgeltung erreichte die russisch-nationale Musik im Werk M.P. Musorgskifs. 1) Besonders wichtig fur die in diesem Exkurs behandelte Frage 1st sein musikalisches Volksdrama "Chovanžina" (1886). Das Werk verbindet eine Liebesintrige mit dem Kampf der Altgläubigen und Strelicen gegen die Herrschaft des Reformers Peter d.Gr., wobel der Aufstand I.A. Chovanskijs von 1682 ${ }^{2}$ mit dem Aufstieg Peters zusammengebracht und damit die Geschichte frei behandelt wird. Im 5. Aufzug der oper verbrennen sich die Altgläubigen unter dem Gesang von Kirchenliedern. Das Volksdrama "Chovanstina" ist neben dem "Bor1s Godunov" ein Höhepunkt der russischen historisierenden Oper. Auch N.A. Rimskif-Korsakov, der den "Boris" und die "Chovanscina" instrumentierte, hatte eine Vorliebe fur Stoffe aus der russischen Geschichte ${ }^{3}$ und Folklore. ${ }^{4)}$ Der Höhepunkt seines Schaffens ist die Oper "Skazanije o nevidimom grade Kitež 1 deve Fevronif" (1907), 5) in der Rimskij-Korsakov die Legende von der unsichtbaren Stadt Kitez mit der Legende von Petr und Fevroni ja verbindet. ${ }^{6)}$ Die Musik Musorgskijs und Rimskijs ist stark von der Folklore und der russischen Kirchenmusik geprägt. Ihre Werke sind Marksteine des spätromantischen musikalischen Narodni Xestvo, als dessen letzte Höhepunkte I.F. Stravinskijs Ballette "Žar-ptica" (1908) und "Vesna svjašcennaja" (Le sacre du printenps, 1912-13) angesehen werden können. Diese Werke des jungen Stravinskif schlagen die Brijcke zur Moderne. Sie wurden von Djagilev 1910 und 1913 in der Alssstattung von Golovin. Bakst und Rerich in Paris uraufgefuhrt. ${ }^{7)}$

1) "Boris Godunov" (diese Oper wurde von Šl japin zum Weltruhm gefihrt), Liederzyklen.

2) Vgl. Stökl, Russische Geschichte, S. 335.

3) "Pskovit janka" nach L.A.MeJ.

4) "Majskaja nod'" nach Gogol'; "Snegorucka" nach Ostrovsk1j (1912 von Rerich ausgestattet); "Mlada"; "Sadko"; "Skazka o care Saltane" nach Puškin; "Kašlej Bessmertnyj"; "Zolotoj petułok" nach Pułkin u.a.

5) Vgl. Mil jukov, aao, III, S.118; Arsen'ev, aao, S.234ff. Die oper wurde 1907 von $V$. Vasnecov, 1908 von Korovin ausgestattef

6) Vgl. Gudzif, Istorija drevnej musskoj literatury, S.287.

7) Vgl. Art. "Ballett, Russisches" in: Knaurs Lexikon Moderner Kunst, S.19-22. Zur Entwicklung der russischen Musik vgl. Mil jukov, aac, S.107ff. 
Auf dem Hintergrund des weit verbreiteten Interesses an russischer Geschichte, Volkskunst und Volkskultur ist auch die Hinwendung vieler Forscher und Künstler zum Phánomen des "raskol" und der russischen Sekten zu sehen. "Raskol" ist die russische Bezeichnung fur das seit $1666 / 67$ bestehende Schisma in der russischorthodoxen kirche und das in Gegnerschaft zu den Nikonschen Reformen stehende russische Altgläubigentum. Die Anhänger des "raskol" bezelchnen sich selbst als "staroobrjadcy" (Altritualisten) bzw. "starovery" (Altgläubige). Die orthodoxe Staatskirche bezelchnete die Altgläubigen mit "raskol'niki" (Spalter, Schismatiker), elnem Ausdruck, der urspringlich einen stark negativen Beigeschmack hatte. In genetischem Zusammenhang mit dem Altgläubigentum stehen die russischen Sekten. Während jedoch das Altgläubigentum weitgehend auf dem Boden christlicher Rechtgläubigkeit steht, handelt es sich bei den russischen Sekten um häretische Bewegungen. "Ihre Prömmigke1t hat mit der Orthodoxie nur sehr wenig zu tun... Manche Ziige verweisen auf uralte heidnische und finnische Urspriinge." 1 )

Fiir die orthodoxe Staatskirche war bis in die neueste zeit "raskol" und Sektenwesen in gleicher Weise häretisch und unvereinbar mit dem Ideal des "heiligen Rubland". 2) Doch auch Krelse, die aus verschiedenen Griinden sich fiir "raskol" und Sekten interessierten, machten häufig keinen Unterschied zwischen den beiden außerhalb der Staatskirche stehenden Gruppen. 3)

Der Raskol war schon Ende des 17. Jhdts. In die beiden Hauptgruppen der "Popovcy" und "Bezpopovcy" zerfallen. Die Popovcy hielten sich an die Bestimmungen der orthodoxen Kirchenkonzilien und blieben der Staatskirche nahe. Ihre Zentren hatten die Popovcy am Kerženec, einem nördlichen Nebenfluß der Volga mit unzugänglichen Wäldern, in Starodub sildwestlich von Brjansk, am Irgiz. einem östlichen Nebenfluß der Volga bei Saratov, an den Flissen Don und Kuban (dort und jenseits der unteren Volga in Verbindung mit dem niederen Kosakentum und mit aufrihrerischen Volksbewegungen) und im Rogožskoje kladbizte in Moskau (seit 1771; die

1) Onasch, Einfilhrung in die Konfessionskunde der orthodoxen Kirchen, S.222. Dort wird mit Recht der Unterschied zwischen Altgläubigentum und Sekten hervorgehoben. Vgl. a. Pleyer, Altgläubigentum, S.177, Anm. 1 .

2) Vgl. Klibanov, Istorija religioznogo sektantstva v Rossii, S.15f

3) Es geht nicht an, das russische Altgläubigentum in einem artikel "Russische Sekten" abzuhandeln (so in RGG V, Sp. 12291235), auch wenn oft fließende t'bergönge vorhanden waren. 
1791 entstandene Pokrovski j-Kathedrale enthält wundervolle Ikonen). Zentren der Bezpopovcy befanden $81 \mathrm{ch} \mathrm{v.a.} \mathrm{am} \mathrm{Vyg-FluB,} \mathrm{am}$ Cnega-See und an den Ufern des WeiBen Meers (die sog. Pomorcy) und im Preobraženskoje kladbizce in Moskau (seit 1771; mit großen Privilegien ausgestattet).

Die wichtigsten Sekten sind die "Chlysty" ("GeiBler", urspgl. Bezeichnung war "christovstina"). Die Filhrer der Sekte galten seit dem 17. Jhdt. auf Grund ihrer "geistigen Gaben" als "Christusse", "Propheten" und, wenn sie Frauen waren, als "Gottesmiitter". Bei den nächtlichen Zusammenkifnften, den sog. "radenija", mit derwischartigen Tänzen und Trancezuständen murde die GeiBelung praktiziert. Sexuelle Orgien wurden den Chlysten in oft ubertriebener Weise zugeschrieben. Die "christov šlina" hat in den Liedern, die bel den "radenifa" gesungen wurden, eine wertvolle Folklore hinterlassen. Aus Reaktion gegen die sexuelle Preiheit Im Zustand der Ekstase entstand die Sekte der "Skopcy" (Kastraten). Das Duchoborcentum, ebenfalls aus dem Chlystentum entstanden, wurde später mit den Quëkern in Verbindung gebracht. In den Jahren 1845ff. in den Kaukasus verbannt, emigrierten sie zu einem großen Tell 1898-99 nach Kanada. Eine Splittergruppe der Bezpopovcy sind die "stranniki" (Wanderer) oder "beguny" (Läufer), die sich durch dauernde wanderschaft den Fesseln der welt entziehen wollten (Matth. 19, 27-29). Das Ideal eines christlichen Urkommunismus mit stark apokalytischen Zugen predigten die "obకčfe". Um 1900 entstanden aus dem Chlystentum mehrere Sekten, die z.T. ältere Formen des Sektenwesens wieder neu belebten. Eine besondere Gruppe sind Sekten westeuropäischer oder amerikanischer Herkunft.1)

Das Entstehen des Altgläubigentums "trug von Anfang an unverkennbar Ziige eines nationalen Widerstandes gegen eine vermeintliche Uberfremdung. "2) Altgläubige und noch stärker Sekt1erer wurden als Staatsfeinde 3 ) behandelt und grausamen Verfolgungen ausgesetzt. Seit der Thronbesteigung Nikolaus' I. (1825) nahmen die staatlichen 2 wangsmaßnahmen, die unter Peter d.Gr. und Katharina d.Gr. mehr sporadisch waren, den Charakter einer systematischen Vernichtungskampagne an. Auch unter Alexander II. und Alexander III. ließen die Verfolgungen nicht nach. Doch gelang es der staatilichen Polizei nicht, den ftberlebenswillen der Altgläubigen und Sektierer zu brechen. Erst mit der Revolution von 1905 brach die Zeit einer gewissen Freiheit an. Die Revolution von 1917 und der Sieg des militant atheistischen Bolschewismus brachte fijr Altgläubige und Sektierer in gewisser Hinsicht die Rfickkehr längst gewohnter Zustände.4)

1) Vgl. Miljukov, Outlines of Russian culture, I, S.40-121; Klibanov, aao, S.35ff.

2) Stökl, Russ. Geschichte, S.310. Das nationale, fremdenfeindliche Elenent im Raskol betont auch Tschizewskij, Russ. Gelstesgeschichte I, S.136. Derselben Auffassung war schon Kl jucevskij.

3) Ukaz vom 17. April 1685.

4) Vgl. Kolarz, Die Religionen in der Sowjetunion, S.129-149 und $343-368$. 
Die Beschaftigung mit dem Altgläubigentum und den Sekten murde den gebildeten Kreisen RuBlands erst mit der 2. Hälfte des 19. Jhdts. möglich, als nach dem Tod Nikolaus' I. (1855) eine gewisse Grobzligigkeit in der Handhabung der staatlichen Zensur Platz ergriff. Die Tatsache, daB große Teile des russischen Volkes ${ }^{1)}$ in mehr oder weniger starker Gegnerschaft zum zaristischen Gewaltstaat und der orthodoxen Staatskirche standen, rief das lebhafte Interesse der Intelligenz hervor. Je nach der eigenen weltanschaulichen oder religiösen Haltung und der Beurtellung von Geschichte, politischer Lage und kinftigem Schicksal RuBlands flel das Urteil uber die Bedeutung des Raskol und der Sekten sehr verschieden aus.

BeI den Kirchenhistorikern standen Verfechter der offiziellen rücksichtslosen $\mathrm{Zwangsmis8ionierung}{ }^{2)}$ einer Gruppe von Forschern gegenüber, die dem Raskol und den Sekten mit größerem Verständnis und mehr Toleranz begegneten. Diese Forscher rechtfertigten z.T. das Festhalten der Altgläubigen am alten Ritus, ${ }^{3)}$ oder sie lenkten die Aufmerksamkeit auf den sozlologischen und sozialen Aspekt der religiösen Massenbewegungen. ${ }^{4)}$ Die anfänglich ablehnende Haltung des Religionsphilosophen Vl. Solov'ev gegenüber dem Raskol scheint einem zunehmenden Verständnis gewichen zu sein, während V.V. Rozanov den umgekehrten Weg ging. 5) Auch die Ethnographen, die seit der Mitte des 19. Jhdts. die russische Folklore sammelten, kamen mit dem Raskol und den russischen Sekten in Berihrung, denn in diesem Milieu war die Volkskunst häufig noch lebendiger als im orthodoxen Volk. ${ }^{6}$ )

1) Vgl. die Angaben bei Sarkisyanz, RuBland und der Messianismus des Orients, S.83; Spuler, Gegenwartslage der 0stkirchen, S.72; sie stiltzen sich wohl auf Mil jukov, aao, I, S.115ff.; dazu auch Kolarz, Die Religionen in der SU, S,129f.

2) v.a.N.I. Subbotin (1827-1905); er war die rechte Hand Pobedonoscevs in diesen Fragen; vgl. Pleyer, aao, S.17ff.

3) z.B. N.F. Kapterev (1847-1917), der in der Frage des Zweifingerkreuzes die Unterstiitzung Je.Je. Golubinskifs (18341912) fand. Vgl. Pleyer, aao, S.20.

4) So erstmals A.P. SCapov (1830-1876); vgl. Pleyer, aao, S.15f. und Klibanov, aao, S.20f.

5) Vgl. Pleyer, aaO, S.24.

6) Vgl. Trautmann, Die Byline, S.4. 
Der beriuhmte Bylinen-Sammler P.N. Rybnikov (1832-1885) war Sohn eines Altgläubigen und wurde wegen seines Interesses für den Raskol an den Onega-See verbannt. Er erforschte die Folklore am Onega-See, einem Gebiet mit starkem altgläubigem Bevölkerungsanteil, das später der Narodnik A.F. Gil'ferding (1831-1872) nochmals besuchte. 1) Besonderes Interesse fur den Raskol hatten u.a. S.V. Maksimov (1831-1901), der auch die sekten gut kannte, ${ }^{2)}$ und Je.v. Barsov (1836-1917).3)

Viele der bedeutenden Bylinen-Sänger waren Altgläubige, so Agrafena Krjukova, Trofim Rjabinin, dessen Sohn Ivan u.a.

Die wissenschaftliche Beschäftigung mit dem Raskol wurde häufig von einer ganz bestimmten 1deologischen Position her motiviert. Die sozialrevolutionären Kreise sahen in der altgläubigen und sektiererischen Bevölkerung den natülichen Verbundeten im Kampf gegen die Monarchie. So ist das Interesse des PetraßevskijKreises fur den Raskol zu verstehen. ${ }^{4)}$ A.I. Gercen und N.P. Ogarev gaben als Ergänzung zu ihrer Zeitschrift "Kolokol" (Die Glocke) ein Extrablatt heraus, ${ }^{5)}$ um ihre Ideen in das altgläubige Volk zu tragen. Politisch motiviert ist auch das Interesse, das der Cernysevskij-Kreis dem Raskol entgegenbrachte. ${ }^{6}$ ) Von marxistischer Seite sind Plechanov und Lenin zu nennen, die dem Raskol in ihren Schriften einigen Raum widmeten. Spezialist filr Fragen des Raskol und der sektierer und Bevollmächtigter fiir Kontakte und Agitation wurde Lenins Kampfgefährte v.v. BončBrujevid (1873-1955). Seine Tätigkeit war ganz darauf abgestellt, mit Agitationsliteratur in Form von Broschuren und Flugblättern Altgläubige und sektierer für die revolutionären Ideen zu gewinnen und die nötigen Verbindungen von den Zentren in den

1) Byliny, Bd. I, S.VI-IX.

2) Vgl. KI ibanov, aaO, S.14, 134, $141 \mathrm{ff}$.

3 Pleyer, aao, S.22.

4 Klibanov, aao, S.20.

5) "Obłreje veðe" $(1863 / 64)$; $\nabla g l$. Kl1banov, aao, S.21. Sie veranlaßten mehrere Arbeiten des Raskolforschers V.I. Kel'sijev.

6) KIibanov, aao, S.21. 
Städten zu den Zirkeln auf dem Lande herzustellen. Die Hauptaktivität Bonc-Brujevičs fältt in die Jahre 1901-1905.1) Irgendeinen Erfolg hatte die radikale Agitation weder zu Zeiten Gercens noch nach 1900 .

Die Elnstellung der sovetischen Geschichtsschreibung zum Raskol und zum Sektenwesen wurde bis in die 3o-er Jahre von den Ansichten M.N. Pokrovskijs bestimmt. Dieser sah in Raskol eine Bewegung, deren im wesentlichen demokratischer Charakter sich im Kampf gegen den zaristischen Zwangsstaat und in der Teilnahme an den Bauernaufständen geăuBert habe. Die im ganzen positive Beurtellung des Raskol schlug sich auch darin nieder, daß Avvakum geradezu als Nationalheld gefelert wurde. Die stalinistische Umwertung der russischen Geschichte stempelte dagegen den Raskol als reaktionäre, von Großkaufleuten und Strelicen getragene Verschwörung gegen die GroBtat des zaristischen RuBland: die Einigung des Volkes und Zentralisierung des Staates. Nach dem Tod Stalins wurden die Auswilchse des "levacestvo"2) wieder vermieden und v.a. der Raskol wieder mit objektivitat erforscht.3)

Eine weitere Gruppe von Ideologen, die fur den Raskol ein naturliches Interesse hatten, waren die Narodniki aller schattierungen. Schon der Slavophile I.S. Aksakov hatte Kontakt mit Altgläubigen-Kreisen. ${ }^{4)}$ Dostojevskij berief sich bel seinem Lobpreis der echt russischen, von der Kirche getragenen christlichen Bildung ausdrucklich auf die Altgläubigen. 5

Der Tendenz einer Idealisierung erlagen einige liberale Narodniki, die im Raskol den Sieg einer rationalistischen Ethik uber die abergläubische kirchliche Religiosität der orthodoxie,6)

1) Klibanov, aao, S.6ff.

2) Klibanov, aao, S.32.

3) Vgl. Kolarz, aao, S.130ff .; Klibanov, aao, S.31f.

4) Pleyer, aao, S.17; Miljukov, aaO, I, S.115; Sarkisyanz, aao, S.83.

5) In seiner Antwort auf Gradovskijs Kritik an der Puskin-Rede, "Dnevnik pisatel ja" (Aug. 1880). Dostojevskij fuhrt hier Gedanken Kirejevskijs von der klösterlichen, christlichen, "ganzheitlichen" Bildung Rußlands veiter.

6) So interpretierte den Raskol I. Juzov, dessen Buch "Russkije dissidenty" (1881) viel staub aufwirbelte. 
die Verwirklichung einer liberalen Gesellschaftsordnung ${ }^{1}$ ) bzw. eines brilderlichen Gemeinwesens auf der Grundlage eines "obščnnyj socializm" (Gemeindesozialismus), 2) oder eine Schule der Demokratie ${ }^{3)}$ erblickten. Gegen die Idealisierung des Raskol durch die Narodniki, aber auch durch Historiker wie N.I. Kostomarov $(1817-1885)^{4}$ wandten sich der Kirchenhistoriker P.S. Smirnov (1861- ? ), dessen Arbeiten trotz des orthodoxen Grundtons sich durch Objektivität und Sachkenntnis auszeichnen, 5) und einige realistischer denkende Narodniki.6) Der literarisch bedeutendste Narodnik, Gleb Uspenskif, hatte in seinen Reiseberichten iber einige Sekten ein Bild des "ganzheitlichen" Hundertmillionen-Volkes entworfen, das stark an Bloks Ausfunrungen in "Narod 1 intelligencija" erinnert. 7) Sein Bericht hatte das Interesse Plechanovs erregt. 8 )

Die Tolstojaner P.I. Birjukov (1860-1931) und V.G. Certkov (1854-1936) traten von der Schweiz und von England aus fir die unterdrickten Duchoborcen ein, nachdem sie aus RuBland verbannt worden waren. 9) Tolstoj sah in den kaukasischen Duchoborcen echte Nachfahren der Urchristen. Er schrieb ein Nachwort filr den Aufruf "Pomogite!", 10) mit dem die uffentlichkeit iber die Terrormaßnahmen gegen die als staatsfeindlich gemabregelte sekte unterrichtet und zur Hilfe fiir die Ausreise nach Kanada aufge-

1) So verstand den Raskol der Ethnograph A.S. Prugavin, der seine programmatische Studie "Značnije sektantstva v moskoj narodnoj zizni" (1881) durch einige Arbeiten ergänzte, die 2.T. von der Zensur verboten wurden. Nach Jahren des Schweigens ver ̈ifentlichte er $1906 \mathrm{ff}$. mehrere stark ideologisch ausgerichtete Werke. Vgl. Pleyer, aao, S.21 und ergänzend KIIbanov, aaO, S.17f.. v.a. auch Anm. 15 mit Prugavins wichtigsten Árbeiten.

2) So P. Ujmovit-Ponomarev; Vgl. Klibanov, aaO, S.18.

3) So S.P. Mel'gunov; vgl. Klibanov, aaC, S.18f.

4) Pleyer, aao, S.21f.

5) Pleyer, aao, S.22-24.

$6)$ v.a. I.N. Charlamov; vgl. Klibanov, aao, S.22ff.

7) Zitat in Klibanov, aao, S.25; vgl. dazu v, 323, zitiert in der Einleitung zum 4.Bild, S.255.

8) Plechanov, I1teratura i éstetika, Bd.2, S.242ff. lehnt Uspenskijs Vorstellung von der Einheitilchkeit der Volkskultur als hegelianische Illusion ab.

9) Klibanov, aao, S.19f.

10) Tolstof. Polnoje sobr. soc.. Bd.39, S.192-196. Vgl. auch S.209ff. den nicht veröffentlichten Brief an ausländische Zeitungen. 
fordert wurde. Tolstoj wollte das gesamte Honorar fur seinen Roman "Voskresenije" (Auferstehung; 1899) den Duchoborcen zugute kommen lassen. Die Qukker, die die Transaktion vermitteln sollten, fanden das Buch jedoch zu anstöbig und lehnten ab. 1)

Eine besondere Stellung in der Historiographie des Raskol und der Sekten nimmt der Historiker P.N. Mil jukov (1859-1943) ein. Mil jukov war 1905 aus den USA nach RuBland zuruckgekehrt und murde Fithrer der Konstitutionellen Demokraten und Redakteur ihrer Zeitung "Rec'". Er gehörte zum radikalen Flilgel der Liberalen, war 1917 kurze Zeit AuBenminister und enigrierte nach der Oktoberrevolution in die USA. Miljukovs wichtigster Beitrag zum Raskol und den russischen Sekten ist in seinen berilhmten "OCerki po istoril russkoj kul'tura" (AbriB der Geschichte der russischen Kultur; 3.Bde., 1896-1903) enthalten. ${ }^{2)}$ Neben der Geschichte der orthodoxen Kirche wird in gleicher Ausfuhrlichkeit das Schisma von 1666/67, die Geschichte der Popovcy, der Bezpopovcy und der sekten behandelt. In der damaligen zeit mußte das als Angriff gegen Kirche und Staat aufgefaßt werden. Miljukov lehnte die Aufteilung der sekten in "rationalistische" und "nustische" ab und unterschied "evangelische" und "geistige", Je nachdem ob die "Schrift" oder die Erleuchtung durch den "Heiligen Geist" Richtschnur der Religiosität war. ${ }^{3)}$

Von narxistischer Seite werden die Verdienste Miljukovs anerkannt, ${ }^{4}$ gleichzeitig wird aber kritisiert, daß er theologische und nicht soziale Kriterien seiner Darstellung zugrunde legte. ${ }^{5}$ )

In der schonen Literatur des 19. und beginnenden 20. Thdts. spielte der Raskol und das Sektenwesen eine nicht geringe Rolle,

1) Sklovskif, Tolstoj, s.523ff.

2) Das Werk wurde 1930-37 in Paris erneut aufgelegt. Die englische thersetzung mit dem Titel "Outlines of Russian culture" von 1948 ist unvollständig. Sie enthält aber die einschlägigen Kapitel.

3) Miljukov, aao, I, S.78.

4) Vgl. Klibanov, aao, S.16f

5) Vgl. Klibanov, aaO, S.332f.; dazu auch Sarkisyanz, aao, S.75, Anm. 24 . 
die jedoch der Bedeutung dieses Phänomens fur die russische Kulturgeschichte nicht gerecht wurde. P.I. Mel'nikov-Peðerskij (1819-1883), der sich im Kampf der Staatsmacht gegen den Raskol recht unruhmlich hervorgetan hatte, schrieb nach längeren Vorarbeiten von 1871-1874 seinen großen Roman uber die Altgläubigen an der Volga. 1875 kam das Verk in zwei Büchern "V lesach" (In den läldern) und "Na gorach" (Auf den Bergen) heraus. Im 2. Buch schildert Mel'nikov auch das Milieu der Chlysten. ${ }^{1)}$ Die zahlreichen Folklorismen des Romans stamnen häufig aus unechten Quellen. ${ }^{2)}$

Auch im Werk N.S. Leskovs (1831-1895) wird häufig der Raskol geschildert, erstmals im bekannten Roman "Soborjane" (Die Klerisei; 1872), dann in der Erzählung "Zapecatlennyj angel" (Der versiegelte Engel; 1873) und in weiteren Erzählungen. Leskovs Sympathie fur die Altgläubigen ist offenkundig. Er hält sie für die "Personifizierung des alten, gottesfurchtigen RuBland, ...beharrte aber bei seiner Meinung, daß die Altgläubigen allein religiöse ziele verfolgten und keinerlei politische Tendenzen hegten." 3 ) Leskov stand mit dieser Haltung im Gegensatz sowohl zu den linksradikalen Kreisen als auch zur offiziellen staatsideologie. 4 )

Dn.H. Hamin-Sibirjak (1852-1912), der den Narodniki nahestand, schildert v.a. das Leben der Altgläubigen im Uralgebiet. Er kannte das dortige sltgläubigentum aus eigener Erfahrung und sah im Raskol hinter allem äußerlichen kultischen Formalismus eine tiefe religiöse Kraft. ${ }^{5)}$

1) Pleyer, aao, S.77-83, 177ff.; dazu Arsen'ev, aao, S.112f.

2) Pleyer, aao, S.177ff; Tschizewskij, Russ. Literaturgeschichte, Bd.2, S.159ff.. Die Erforschung der folkloristischen Quellen Mel'nikovs ist noch nicht abgeschlossen; vgl jünstens V.F. Sokolova, Ješe raz o fol'klornych istolnikach romana P.I. Mel'nikova-Pecerskogo "V lesach", in: Poetika 1 stilistika russkoj literatury, S.180-187 mit tbersicht uber die bisherige Forschung. Der Folklorismus Gorodeckijs scheint stark von Mel'nikov-Pecerskij beeinflußt zu sein.

3) Pleyer, aao, S.104f.; sie bezieht sich auf das 18. Kapitel von Leskovs "Pečerskije antiki" (Originale von Pečrsk), in: Polnoje sobr.sot. N.S. Leskova, izd.3 , Bd.31, SPb. 1903 , S. 35 .

4) Vgl. Pleyer, aao, S.97-106; Tschizewskij, aaO, Bd.2, S.93ff. 5) Vgl. Pleyer, aaO, S.84-99, 182ff. 
Der Narodnik VI.G. Korolenko (1853-1921) schildert in mehreren seiner Werke die langen Fahrten, die er in die Wălder von Kerzenec und der Vetluga auf den Spuren Mel'nikov-Pečerskijs gemacht hatte. 1) Seine Reiseerzählung "Reka igrajet" (Der Flub schäumt; 1891), die im Gebiet des Svetlojar-Sees spielt, zerstört die gewohnte Vorstellung eines idealen Volkes und wurde deshalb von den orthodoxen Narodniki kuihl aufgenommen. Doch hielt Korolenko an seinem Glauben an die Stärke und den Wert des russischen Volkes fest, dessen schlummernde Kräfte im Held der Erzählung, dem trunkenen Vetluga-Fährmann Tjulin, symbolisiert werden. Korolenkos besonderes Interesse galt den tberlieferungen der Altgläubigen, besonders der Legende von der unsichtbaren Stadt Kitež, die er mehrmals erwähnt. 2)

Die Legende erzählt, daB die Stadt Kitez vor den anriickenden Tatarenhorden für das menschliche Auge unsichtbar geworden sei. Sie stehe noch heute, und wer nur fest daran glaube, der könne im Svetlojar-See die Mauern der Stadt, die Prozessionen der Mönche sehen und Glockengeläut hören.j) Friiher hat, so erzählt Mel'nikov-Pecerskij, das Volk heidnische Feste zu Ehren des Lichtgottes Jarilo hier gefeiert; daher rüht auch der Name des Sees. Im 19. und 20. Jhdt. versammelten sich zweimal im Jahr am Svetlojar-See Tausende von Altgläubigen und Sektierern der verschiedenen Richtungen, um hier zu beten und ïber Glaubensdinge zu diskutieren.

Die Pilgerziige der Altgläubigen zur stadt Kitez haben auch in neuester Zeit nicht aufgehört. Die Besucher des Sees ließen sich auch durch die kleinlichen Schikanen der sovetischen Behörden vom Pilgerzug nicht abhalten.4)

Im Sommer 1930 und 1968 wurden Expeditionen zum Svetlojar-See unternommen, die die Herkunft der Legende und die Geschichte des Sees klären sollten.

K1tez ist das Symbol des von der Erde bis zur Wiederkunft Christi verschwundenen Reiches. "welches am Ende der Zeiten sozusagen als Himmlisches Jerusalem empirische Verwirklichung finden und wiedererscheinen solite."5)

1) Vgl. Pleyer, aao, S.91-96, $186 \mathrm{ff}$.

2) Vgl. Pleyer, aao, S.91-96, 186ff.

3) $\mathrm{Zu}$ den verschiedenen Versionen vgl. Sokolova, aao, S.185f.

4) Vgl, dazu Kolarz, aao, S.139.

5) Sarkisyanz, aao, S.59ff. 
Auch im Werk der Symbolisten und dew Symbolismus nahestehender Schriftsteller spielt der "raskol" im Rahmen des allgemeinen Neopopulismus eine wichtige Rolle.

Din.M. Merezkovskif (1865-1941) versuchte, seine Geschichtskonzeption in der Romantrilogie "Christos 1 Antichrist" (Christ und Antichrist) darzustellen. Er deutete die europäische Geschichte als Auseinandersetzung zwischen Heidentum und Christentum, zwischen Körper und Geist, ${ }^{1)}$ die den Kampf Julian Apostatas um die wiederherstellung des heidnischen Glaubens ${ }^{2}$ und die Wiedergeburt der heidnischen Antike im Zeitalter Leonardo da vincis ${ }^{3)}$ bestimme. Den Kampf zwischen Heidentum und Christentum

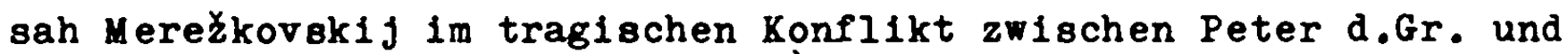
seinem Sohn Aleksef verkörpert. ${ }^{4}$ ) Aleksej war die Hoffnung der konservativen Kreise, die sich den Neuerungen Peters entgegenstellten. Eine besondere Rolle in der Opposition gegen die absolutistische staatsmacht kommt in dem Roman den altgläubigen und sektiererischen Volksmassen zu, die in Peter d.Gr. den Antichrist erblickten, und dessen Witen sie nur durch massenweise Selbstverbrennung zu entkommen glaubten. ${ }^{5)}$ In der kollektiven Massenverbrennung, die von skrupellosen Agitatoren des alten Glaubens inszeniert wurde, verbanden sich heldnische MutterErde-Mythologie mit eschatologischen christlichen Motiven des endzeitlichen Weltenbrands und der himmlischen Hochzeit in den Flammen. 6) Im Epilog des Romans schilderte Merežkovskif unter dem Titel "Christos grjadušlı" (Der kinftige Christus) die ekstatischen Tänze der Chlysten, in denen uraltes dionysisches Bacchantentum und geiblerische Orgien sich in einer perversen Mischung von Erotik und Religion verbinden.

1) Vgl. Eliasberg, Russ. Literaturgeschichte, S.132ff.

2) "Smert" bogov. Julian Otstupnik" (1894).

3) "Voskresłije bogi. Leonardo da Vinci" (1896).

4) "Antichrist. Petr i Aleksej" (1902).

5) Diese Selbstverbrennungen schildert Merezkovskif nach einer Vorbereitung im 2. Buch mit dem Titel "Antichrist" v.a. Im 9. Buch, dem er die tberschrift "Krasnaja smert" (Der rote Tod) gegeben hat.

6) VerheiBung des Weltenbrandes be1 2. Petrus 3,10. 
Während seiner Arbelt am Roman "Petr 1 Aleksej" unternahm Merezkovskif zusammen mit seiner Frau 2. Gippius im Sommer 1902 die beschwerliche Reise zum Svetlojar-See, um dort den sommerlichen Pilgerzug zum unsichtbaren Kitez zu erleben. Z. Gippius erinnerte sich noch 40 Jahre später mit Preude an diese Reise. 1) In einem Reisebericht, der kurz nach dem Besuch des Svetlojar-Sees erschien, äuBerte sie die tberzeugung, daß in den frommen Pilgerscharen der Keim einer sittlichen Wiedergeburt aus den Tiefen der russischen Volksseele liege. 2 )

Den kulturphilosophischen Kommentar zu Merežkovskijs Romanwerk enthält der Sammelband "Le Tsar et la Révolution" (1907), mit Beiträgen von Merezkovskij, Z. Gippius und D.V. Filosofov. Die Gottsucher verurteilten darin die orthodoxe staatskirche, die im Staat aufgegangen und damit ihrer religiösen Bestimmung untreu geworden sei und zusammen mit der Autokratie verschwinden misse. Die russische Revolution sei eine religiöse Tat, die ihre Antriebe aus einer brennenden Sehnsucht nach dem kommenden Reich des Geistes beziehe. Die Raskol'niki wurden von Merežkovskif als die ersten russischen Revolutionäre bezeichnet.

"BewuBt sind sie Verfechter jeder Finsternis, der Sklaverei, des Rilckschritts und des statischen Prinzips; unbewuBt leuchten sie aber im hellen Iicht einer wahrhaft religiösen Kraft und einer Dynamik, die nicht aus Westeuropa stammt, sondern aus den Tiefen der russischen Volksseele kommt."3)

Die altgläubige Volksrevolution drang auch in die Sekten. Der Raskol wird sich, nach Meinung Merezkovskijs, friher oder später nit der sozialpolitischen Revolution verbiinden. Merezkovskif berichtete iber seine Gespräche mit Sektierern und Raskol'niken am Svetlojar-See und stellte eine innere Einheit seiner Ideen von einer allumfassenden revolutionören Erneuerung aus dem Geiste

1) Z. Gippius, Merežkovskif, S.110; dort erzählt sie auch kurz die Legende.

2) 2. Gippius, Svetloje ozero, in: Novyj put', 1904, 1-2 und im Sammelband "Aly j meX", SPb., 1906.

3) Merezkovskij, Der Zar und die Revolution, S.99. 
eines dritten Evangeliums mit den Sehnsilchten des Volkes fest.

"Das Dekadententum... ist in Wahrheit der Anfang eines neuen Lebens, ein enger unterirdischer Gang, der zum dunklen sternbesäten Himmel der Volksseele fiihrt."1)

In Jugendwerk M.H. Prišvins (1873-1954) nimmt die Darstellung des Altgläubigentums breiten Raum ein. Pri \&̌in hatte 1906 und 1907 auf Veranlassung des Ethnographen OnCukov ${ }^{2)}$ den Vyg-See, das WelBe Heer und Karelien besucht und von seinen Erlebnissen in den Bänden "V kraju nepugannych ptic" (Im Iand der unaufgescheuchten Vögel; 1907) ${ }^{3)}$ und "La vol Sebnym kolobkom" (Auf den Spuren des Zauberbrotes; 1908) berichtet. Prił̌in glaubte, in der. unzugänglichen Wald- und Seengebieten des mussischen Nordens, be1 den anspruchslosen Jägern und Fischern, dem echten Leben $z u$ begegnen. Seine Reiseskizzen hatten großen Erfolg im Kreise um Renizov und Merezkovskij. In Sommer 1908 unternahm Prizvin wohl auf ihre Anregung hin eine Reise zum Svetlojar-See, deren Eindrijcke er im Buch "U sten grada nevidimogo" (An den Mauern der unsichtbaren Stadt; 1909) berichtete. Trotz einer gewissen Enttäuschung uber die scholastischen Dispute der Altgläubigen, trotz der Erkenntnis, daß der alte Glaube viel von seiner urspriinglichen Frische und Kraft verloren hatte, trotz der Skepsis gegeniuber der romantischen Verklärung des Raskol durch die Gottsucher um Merezkovskij, ${ }^{4}$ hielt Priłvin an seinem Glauben an die Erlöserkraft des natiirlichen Lebens fest. Prí̌vin riickte später von den Ideen des "Gottsuchertums" ab. Doch sind Spuren seiner einstigen Sehnsiichte noch in der meisterhaften schilderung des Altgläubigenmilieus in der Romanerzählurg "Csudareva doroga" (Der Zarenweg; 1948) vorhanden. Dort werden in der Gegenilberstellung der patriarchalischen Lebensform der Altgläubigen und

1) Merežkovskif, aao, S. 161.

2) N.E. OnCukov' (1872-1942) sammelte Märchen, Bylinen und Volksdramen v.a. im Norden RuBlands. Seine Bücher "PeCorskije byliny" (1904). "Severnyje skazki" (1909) u.a. gehören zum Kernbestand der russischen Folkloristik.

3) Die Reiseskizzen enthalten Berichte iber Bylinensänger ("Pevec bylin"), Märchenerzähler, allerlei heldnisches Brauchtum ("Kolduny"), v.a. aber einen historischen AbriB iber das Altgläubigentum am Vyg-See ("Vygovskaja pustyn" ") und iber die Stranniki ("Skrytniki").

4) Im Herbst und Winter 1908/09 besuchte Priłvin die Diskussion der "Religiös-philosophischen Gesellschaft" in Petersburg. 
des jugendilchen Ploniergeistes einer sovetischen Bautruppe die gesellschaftischen Umwalzungen der neuen Zeit sichtbar. ${ }^{1)}$

Eine kihnlich historiosophische Thematik wie das Romanwerk Merezkovsk1 j8 hat der Roman "Serebrjanyj golub'" (Die silberne Taube; 1909) von A. Belyj, der eine packende, wenn auch dichterisch recht freie Darstellung einer Chlystensekte glbt. Belyj stellte sein Thema, die Frage nach dem gelstigen Standort RuBlands zwischen Westen und 0sten, im Schicksal Dar'jal'skijs dar, der in der elementaren Sinnlichkeit der Matrena die Seele RuBlands zu finden glaubt. ${ }^{2)}$ Die geheimnisvolle sekte der Tauben erblickt in Matrena eine "Gottesmutter", aus deren Verbindung mit Dar'jal'skij ein neuer "Christus" hervorgehen soll.

Belyj bezog sein Wissen uber die Chlysten aus Darstellungen Prugavins, Bon $\not-B r u j e v i \chi_{8}$ und anderer Ethnologen. Er hatte 1904, unmittelbar vor seinem ersten Besuch bel Blok in Sachmatovo, den Sohn Mel'nikov-Peterskijs besucht, der ihn mit dem Werk seines Vaters bekennt machte und wohl auch für direkten Kontakt mit Sektenmitgliedern sorgte. ${ }^{3)}$ Titel und wichtige Motive von Belyjs Roman erinnern an Mel'nikov-Pečerskijs Erzählung "Belyje golubi" (Die weiBen Tauben).4) Dort werden die Orgien einer skopcengemeinde geschildert, bel denen eine junge "Gottesmutter" den ersehnten "Christus" empfangen soll. Die Erzählung diente der "Entlarvung" der skopcen und beruht auf tatsächlichen Vorkommnissen. Doch fehlt ihr naturgemäß völlig die kulturphilosophische Thematik Belyj8. 5)

1) Vgl. Chajlov, Prıłvin, S.8ff.. 119ff.; Jerǧov, Priłuin, S.36-57; Motjałov, Prízvin, S.44-66.

2) Vgl. die Elnleitung zum 1.Bild, S.155f.

3) Vgl. Belyj, NaXalo veka, S.306ff;; ders., Vospominanija o Bloke (Zapiski mextatelej), S.117.

4) Mel'nikov-Peterskij, Poln.sobr.soz., Bd.6, S.300-422.

5) Zu Belyjs Roman siehe: Ivanov-Razumnik, A. Blok - A. Belyj, S.92ff.; Holthusen, Studien, S.109ff.; Honig, A. Bely Js Romane; v.a. aber Motul'skij, Belyj, S.157-168. Wie das IS enthält Belyjs "Serebrjanyj golubi" stark autobiographische Elemente; vgl. dazu Belyj, Mezdu dvuch revol juc1j, S.354 mit einer selbstinterpretation und der Angabe einiger Quellen und Mocul'skij, Bely j, S.159 und 162 .

Ich kann der von Holthusen, aaO, S.109 vorgetragenen Auffassung, In Belyjs Roman "Serebrjanyj golub" " würden mit "Osten oder Westen" "keine faßbaren geographischen und erst recht keine politischen Begriffe gedeckt", In dieser Ausschließlichkeit nicht zustimmen. Der Reiz des Romans (und 
Im dichterischen Nierk K.Dm. Bal'monts (1867-1942) setzten sich folkloristische Motive erst durch, als der Dichter sich aus der Emigration ${ }^{1)}$ nach der Heimat zurücksehnte. Von den Gedichtbänden "Žar-ptica" (Feuervogel; 1907), "Pticy $v$ vozduche" (vögel in der Luft; 1908) und "Zelenyj vertograd" (Der grüne Garten; 1909), die alle von der Beschäftigung Bal'monts mit der russischen Folklore geprägt sind, ist der letzte bemerkensv:ert, weil er Nachahmungen von Liedern der Chlysten enthält. 2)

Auch M.A. Kuzmin (1875-1936) kannte das Altgläubigenmilieu von Jugend auf und hatte mehrere Reisen mit Altgläubigen gemacht, um in Nordrußland nach Ikonen $z u$ suchen. Die Bekanntschaft mit dem Altgläubigentum hat in einigen Gedichten Kuzmins Niederschlag gefunden, v.a. jedoch in seinem Roman "Kryl'ja" (Flügel; 1906) und in der Erzählung "Nežnyj Iosif" (Der zärtliche Josenh; 1909). In beiden Prosawerken, die wegen ihrer homosexuellen Thematik Skandalerfolge hatten, wird der dekadenten "elt der zeitgenössischen Zivilisation die natúrliche Welt der Altgläubigen gegenibergestellt. Doch dient das $\dot{A} l t g l a ̈ u b i g e n t u m$ Kuzmin nur dazu, um den Gegensatz Zivilisation - Natur an einem "russischen" Sujet darzustellen. Dabel ist für ihn zwischen russischen Altgläubigenmädchen und den heiteren Gespielinnen der Bilitis kein Unterschied. Nan hat dem Autor der "Kryl'ja" zurecht Geschnacklosigkeit vorgeworfen. ${ }^{3)}$ Mit einer ernst zu nehmenden Darstellung des Kaskol haben die werke Kuzmins nichts gemein.

das gilt auch filir die Gedichte Belyjs aus dieser Zeit, v.a. filr den Gedichtband "Pepel") liegt gerade in der gegenseitigen Durchdringung von traditionell gefärbtem slavophilentum und Anthroposophie. Der russische Schauplatz ist auch in "Petersburg" nicht bloßes Beiwerk. Der Petersburg-Mythos ist als wesentiliches Element immer vorhanden und gehort zur Substanz dieses Romans. (Dagegen ist Brjusovs Prosa immer "international").

1) Bal'mont war durch die Ereignisse von 1905 aus seiner individualistischen Vereinsamung gerissen worden und hatte sich an revolutionären Umtrieben in Moskau betelligt. fus begrifindeter Furcht vor der Reaktion war er nach Paris geflohen, wo er von 1905 bis 1913 lebte. Dorthin emigrierte er zum zweiten Mal endgülig 1918, enttäuscht vom wahren Gesicht der Revolution, die er 1917 begriat hatte.

2) Vgl. Orlov, Bal'mont, S.32.

3) Diks, Kuzmin, in: Gofman, Poèty, s.39of. 
Während die Folklore bei Bal'mont, Gorodeck1J, Kuzmin, Belyj und den anderen Symbolisten mehr äuBerliche Verpackung als echt nachempfundene Substanz ist, wird das Werk N.A. Kl jujevs (18871937) ganz von ihr durchdrungen. Kl jujev stammte wie Jesenin aus dem patriarchalisch-bäuerlichen Milieu des russischen Sektierertums, und er war mit dem Leben der Altgläubigen, sowie der Chlysten und Skopcen tief vertraut. Als Jugendlicher verfaßte er fur Chlysten geistliche Lieder, die z.T. verloren gingen, von denen jedoch einige erhalten geblieben sind und mit dem Titel "Bratskije pesni" (Brilderliche Lieder; 1912) als Kljujevs zweiter Gedichtband erschienen. 1) Wohl wegen seiner Sympathien filr die Sekte der Beguny saß er 1906-o7 einige Zeit im Gefängnis und war anschließend in verschiedenen Missionen fur die sekten unterwegs. Im Herbst 1907 trat er in Kontakt mit Blok. Seit 1911 verkehrte Kljujev in den Kreisen der Petersburger und Moskauer Literaten, die in ihm den echten Bauerndichter entdeckten. Zusammen mit Jesenin und Klyckov gehörte er zu der Gruppe "Skify" (Skythen) um Ivanov-Razumnik. Diese Gruppe, zu der auch Belyj und Blok enge Bezlehungen hatten, war 1917 entstanden und gehörte ideologisch zu den Iinken Sozialrevolutionären.

"Wie Jesenin begrilite Kl jujev die Revolution als eine Art mystische Offenbarung des "Bauernparadieses". Es war die nationale, oder "skythische". Seite der Revolution, die ihn faszinierte. Er verfaßte sehr viele revolutionäre Gedichte, und in seinem Lenin zeichnete er die legendäre Gestalt des Fihrers der Bolschewiken aus der Sicht des religiösen Revolutionismus, Indem er Lenin mit dem Erzpriester Avvakum, dem Fiihrer der Altgläubigen im 17. Jhdt. verglich."2)

Ähnlich wie Jesenin wandte sich Kljujev dann von der Revolution $a b$, deren Erstarrung in einem antidemokratischen, vom Apparat beherrschten Zwangsstaat ihn enttäuschte. Er wurde 1933 verhaftet und nach einem Aufenthalt in der Lubjanka nach Sibirien verbannt. Dort fand er unter nicht genau bekannten Umständen 1937

1) Vgl. Kljujev, Polnoje sobr.sot., Bd. I, S.246ff. (vgl. dazu Anm. Bd. I, S.518ff.) mit Aufzählung der 1912 in diesen Band aufgenommenen Gedichte.

2) Struve, Geschichte der Sowjetliteratur, S.43. "Lenin" in Kl jujev, aao, Bd. I, S.279ff.. Die erste Zeile "Jest' v Lenine Kerzenskij duch,...." (In Lenin ist der Geist der Kerzenec-Wälder...) enthält das gesamte Thema. 
den Tod. 1)

KI jujev erlag dem Zwiespalt

$$
\begin{aligned}
& \text { "Umu - respublika, a serdcu - Mater'-Rus'... } \\
& \text { Umu - respublika, a serdcu - Kitež-grad..." } \\
& \text { (Dem Verstand - die Republik, aber dem Herzen - Mutter- } \\
& \text { Dem Verstand - die Republik, aber dem Herzen - RuBland... } \\
& \text { Kitezt...).2) }
\end{aligned}
$$

Dem allgemeinen Interesse an der russischen Folklore und dem kiinstlerischen Vermächtnis des vorpetrinischen RuBland konnte sich Blok nicht entziehen. Besonders nach seiner weltanschaulichen Neuorientierung nach 1904, die in eine auf RuBland bezogene "musikalische" Volkstumsideologie mundete, wand te sich Blok dem Studium der russischen Folklore zu. Doch schon Bloks Jugendtagebilcher enthalten Notizen, die zeigen, daß inn die altrussische Kunst und die russische Folklore interessierten. Tief betroffen war Blok von einem Volksglauben in der Gegend von 3oblovo, der an die Vorstellung von der dämonischen Roggenmuhme erinnert. ${ }^{3)}$ Blok verstand diesen Volksglauben als BestätigunE seines Mythos vom "Ewig-Weiblichen", den er in den verschiedenen Religionen, Philosophiei, Literaturen und Mythologien aufspüren wollte. 4 )

Eine beklemmende Faszination ging f'ir Blok auch vom Gesang der Bauern in Sachnatovo aus. Hier schien inm die Elementarkraft des Volkes entgegenzutreten, die ihn gleichzeltig schreckte

1) Filippov, Nikolaj Kljujev, in: Kljujev, aao, Bd. I, S.5-156, gibt eine ausfihrliche Darstellung von Kljujevs Leben und seinem geistigen Standort.

2) KI jujev, aaC, Bd. I, S.477f. Schon Trockij hatte in "Literatura i revol jucija" Kl jujev den Untergang prophezeit.

3) VII,38, Eintrag vom Januar 1902; VII,48, Eintrag vom 26. Juni 1902 ; vgl. III,34, Brief an Z. Gippius vom Juli 1902; V, 357, in: Stichija i kul'tura; vgl. Pomeranceva, Blok i fol'klor, in: Russkij fol'klor, S.205. Zur Roggenmuhme vgl. Nekrasovs "Moroz, krasnyj nos" (21). Man denkt auch an den griechischen Demeter-My thos.

4) Vgl. VII,48. Diese Aufgabe stellte sich Blok in seinem Jugendtagebuch VII, 19-68. 
und anzog. 1)

Im Sommer 1902 besuchte Blok Moskau. Hier interessierten ihn besonders einige folkloristische und historisierende Bilder von V.M. Vasnecov, Nesterov, Repin u.a. In der Tret jakov-Galerie,2) die alten Baudenkmăler des Kreml, die Vasil1 j-Blaženny j-Kathedrale, das Novodevidij-Kloster u.a. kirchliche und historisierende Denkmäler. 3 )

Das Interesse fur die altmussische Kultur, die sich in den fruhen Notizen zeigt, erklärt auch den längeren Eintrag Bloks vom 20. November 1908. Dort faßte er Ausfihmungen eines Kunsthistorikers uber Jaroslavl' an der Volga zusammen. 4)

In seinem lyrischen Aufsatz "Das Mädchen vom Rosenpförtchen und der Ameisenzar" stellte Blok dem erstarrten Abendland die unberiihrten, hyperboreischen lieiten Nordrußlands gegenuber. In der magisch-urtilmlichen Welt der sibirischen Taiga, in Zentrum des Schamanentums und dionysischer Rauschhaftigkeit leben nach Bloks Meinung "echte Menschen". 5) Die Lebenskraft des russischen Nordens zeigt sich im Vorrang des Märchens vom imeisenzar vor den zun Iod erstarrten westeuropäischen Märchen und Legenden.6)

1) Vgl. Zap.kn., 32, 34, Eintrag vom Juli 1902; dazu VI,169-173 "Ni sny, ni jav'". Die Skizzen dazu von 1908-09, VI,487-490 sind noch "folkloristischer"; die Bauern gleichen russischen "Recken" aus mythischer Vorzeit.

Die vor Belyj, Na talo veka, S.342 und Vospominanija o Bloke, Epopeja $\mathrm{Nr} .1$, S.268 behauptete Abneigung Bloks gegen die russische Folklore trifft offenbar nur eine Seite. Kluge, Westeuropa und RuBland, S.223 miBt hier Belyj unnötigerweise zuviel Gewicht bei.

2) Vgl. Zap.kn., 36f. Blok kannte die "nationale" Malerei der Jahrhundertwende sehr gut; mit vielen russischen Malern seiner Zeit war er persönlich bekannt.

3) Vgl. Zap.kn., 37ff. Der Kunstband, den Blok Im Herbst 1902 fiir eine Prifungsarbeit iber Mutter-Gottes-Ikonen durcharbeitete, enthielt auch russisches Material; vgl. Zap.kn., 43f. Zur "Polklore" vgl. noch Zap.kn., 7o, Elntrag vom Sept. 1905 mit einem Volksliedvers; 95, Eintrag vom 9. Juli 1907, hier werden die zahlreichen Bezugnahmen Bloks auf die "Zigeunerfolklore" in seinen späteren Tagebiichern vorweggenommen.

4) Zap.kn. 121

5) V.93f. Blok hatte offenbar Culkov im Sinn, obwohl er das Belyj gegeniber abstritt.

6) V,92f. Von hier aus mu $B$ auch die Behauptung zurijckgewiesen werden, in dem Aufsatz werde "die russische Volksdichtung von Blok verworfen, weil ihr jeglicher Zug zur Idealisierung und Vergeistigung fehlt" (Kluge, aaO, S.223). Bloks Ausfall 
Das Bild, das Blok in "Stichija i kul'tura" vom magisch-elementaren russischen Volk glbt, ist eine Fortfihrung der Deutung des Märchens vom Ameisenzar.

"Sie sehen Träume und erschaffen Legenden, die sich nicht von der Erde lösen: iiber Kirchen, die iber ihr Gesicht verstreut sind, 1) iber Klöster, wo die Statue Nikolajs des Wundertäters hinter elnem Vorhang steht, unsichtbar filr alle, darijber, das wenn der Wind in der Nacht den Roggen neigt, "Sie uber den Roggen fegt"... Die Erde ist mit ihnen, und sie sind mit der Erde, man kann sie nicht auf ihrem SchoBe unterscheiden, und manchmal sieht es aus, als lebe der Higel, als lebe der Baum, und als lebe die Kirche, und als lebe der Bauer. Auf dieser Ebene schläft noch alles, aber wenn es sich rithrt, wird alles, wie es ist, daherkommen: die Bauern, die Haine an den Hängen; und die Kirchen, Fleisch gewordene Gottesmiitter werden kommen, und die Seen werden aus den Ufern treten, und die Flitsse werden ihren Lauf umkehren; und es wird die ganze Erde kommen."2)

Der Aufbruch des Volkes gleicht einer apokalyptischen Zeitenwende.

Das "Märchen vom Ameisenzar" gehört zu dem reichen mythologischen Material, das Blok in seiner Arbeit "Poézija zagovorov 1 zaklinanif" (Die Poesie der Zaubersprifche und Beschwörungen) darlegte, ${ }^{3)}$ die theoretisch von Nietzsches Ausfihrung "Vom Urscrunge der Poesie"4) abhängen. 5)

Die Kenntnis der russischen Folklore und des russischen Mittelalters erlaubte es Blok, die folkloristisch eingefärbten Gedicht-

gegen die russische Volksdichtung, den die Herausgeber zu kommentieren sich veranlaßt sehen ( $V, 719$, Anm. 5 ), erweist sich $b \in i$ Esnauem Hinsehen als vordergrindig. In der Tiefe dieser oberflächlich ästoßenden Dichtung "singt das Gold", das fietzsche als "ierz der Erde" bezeichnet ("klso sprach Zarathustra", $75,3.145)$.

1) Vgl. LS, 5.Bild und III,268ff.

2) $v, 357$

3) $v, 36-65$.

4) in "Die Fröhliche Wissenschaft", 74, S.98ff.

5) Pomeranceva, aaO, S.207ff. gibt Bloks zahlreiche Quellen an. Sie behauptet, Bioks Arbeit stehe wissenschaftlich auf der Hohe ihrer Zeit (aaC, S.207). Dem widerspricht allerdings die schlechte Aufnahne, die die arbeit bei den Fachleuten fand; vgl. Anm. V,715. Bloks Darstellung der magischen Kraft des Zauberers ( $v, 43 f .47$ ) ist als Projektion Nietzschescher Ideen (vgl. Kluge, aao, S.103) auf die Folklore eine verkappte Selbstdarstelluifg seines Dichtertums, das er als magische Beschwörung verstand (vgl. 2.B. VII,53; V,133: "Tak ja chołu"; V,429f. u.ö.; dazu: Pomeranceva, aao, S.21of. mit Hinweis auf Bal'mont und $v$ jac. Ivanov). 
bände Bal'monts "Žar-ptica"1) und Gorodeckijs "Jar'", "Perun"2) und "Rus'"3), sowie ein Lehrbuch uber Volksdichtung und altrussische Literatur 4 ) als "Fachmann" zu beurteilen. Bloks Beschäftigung mit der musischen Folklore ${ }^{5)}$ und der altmassischen Iiteratur schlug sich auch in seiner Dichtung nieder. ${ }^{6)}$ Blok vermied es allerdings in den meisten Fallen, die Folklore imitatorisch nachzudichten. ${ }^{7)}$ Er schmolz vielmehr die Folklore in seine eigene dichterische Manier ein, was der Behandlung folkloristischer Motive durch die "Neuidealisten" nicht widerspricht. 8) Zwar enthalten die Zyklen "Kreuzwege",9) "Erdblasen"10) und "Nachtviole"11) eine vorwiegend private "Mythologie" oder "Dämonologie", ${ }^{12)}$ doch gewinnen schon Bloks Gedichte "Gamajun. Ptica vełtaja"13) und "Dali slepy, dni bezgnevny..."14) ihren Reiz aus dem Durchscheinen des Blokschen privaten Mythos durch folkloristisch-russische Motive und Bilder. Die in diesen

1) $\mathrm{V}, 136-141 ; \mathrm{vgl}, \mathrm{V}, 551$.

2) V,145-151. Blok hielt Gorodeckijs Gedichtband "Jar'" eine Zeit lang fir genial; vgl. Zap.kn., 85, Eintrag vom 21. Dez. 1906.

3) $v, 649 f$

4) V,622-624, Besprechung des Lehrbuchs von V.V. Sipovskij.

5) Hier und im folgenden ist damit die bäuerliche Folklore gemeint, die aus der vorpetrinischen Zeit bis ins 20 . Jhdt. hinein in RuBland lebendig war.

6) Kluge, aac, S.224 behauptet vililg zu Unrecht, die russische Folklore (außer den Castuski) finde in Bloks Dichtung keinen Eingang.

7) Eine Ausnahme ist z.B. das in der Manier Gorodeckijs geschriebene Gedicht "Pesel'nik"; vgl. Einleitung zum 5.Bild, S.313.

8) Man denke hier etwa an die Sinfonien Gustav Mahlers. Vgl. zur Verarbeitung der Folklore bel Blok den Kommentar zu den entsprechenden Stellen des LS, z.B. S.76/4 u. ̈̈.

9) $I, 239-323$

10) II, 8-25.

11) II, 26-34

12) Vgi. KIuge, aao, S.223. Das gilt auch filr einige Gedichte des Zyklus "Raznyje stichotvorenija": II, 35,38,42,48,80, u. ̈.

13) I, 19, nach dem Bild V. Vasnecovs; vgl. auch I,403f. "Sirin i Alkonost".

14) I,319ff.. inspiriert von Vrubel's Bild "Carvena-Lebed". 
Gedichten angedeutete Spannung von Lokalkolorit und privatem Mythos bestimmt auch den Charakter von Bloks RuBland-Gedichten ${ }^{1)}$ und den folkloristisch eingefärbten Passagen des LS. In seinem berthmten Gedicht "Rus'"2) gibt Blok ein Bild des heidnisch-barbarischen nördlıchen Rußland der Zauberer, Wahrsager und Hexen, das in magischer Urspriinglichkeit ruht. ${ }^{3)}$ Wie in diesem Gedicht ist die "private" Mythologie auch im Zyklus "Rodina" durch eine "russisch-national" gefärbte Mythologie ersetzt. Blok beschwört die heidnisch-urzeitliche Vergangenheit, ${ }^{4}$ ) die vergeblichen, in mystische Zeiten zurickgehenden Kriegszige nach Car'grad-Konstantinopel, 5$)$ die zahllosen Heerzilge in die Steppe gegen die Kumanen, Tataren und Tiirken, ${ }^{6}$ ) die wehmiltige Landschaft Mittelrußlands ${ }^{7)}$ und das nördliche, von Wäldern und simpfen bedeckte Rußland der Altgläubigen ${ }^{8}$ ) herauf. In dieses urzeitliche RuBland der nördlichen Urwälder wird sich das russische Volk zurilckziehen, wenn das Abendland nicht seinem Ruf zur Verbrilderung folgt.9) "Russisch" eingefärbt ist das Märchen von der schlafenden Prinzessin ${ }^{10)}$ und das Bild der um ihren Sohn klagenden Mutter, ${ }^{11}$ ) beides Symbole des unerlösten, leidenden RuBland. Die nationale Note, das Lokalkolorit, der "folkloristisch-altrussische" Charakter von Bloks Gedichten ist sicherlich der wesentliche Grund dafiur, daß der offizielle Kult um das Revolutionspoem "Dvenadcat'" in der UdSSR der Beliebtheit Bloks nichts

1) Das gilt in entsprechender Abwandlung auch fiir die GroBstadtgedichte $\mathrm{Bloks.} \mathrm{In} \mathrm{vïllig} \mathrm{gleicher} \mathrm{Heise}$ hat $\mathrm{Blok}$ auch das griechische (vgl. z.B. I, 56,65,71,91,101,164,238,327, $341,36 ?, 516$ u. o. und das LS) oder das christiliche mythologische Material verarbeitet.

?) II,106f. Das Gedicht entstand während Bloks Arbeit an "Poezija zagovorov i zaklinanij". Blok selbst wies auf den Zu sammenhang von Gedicht und Auf satz hin; vgl. Anm. II,406.

3) Vgl. Mocul'skij, Blok, S.170.

4) III, 259, Blok erwähnt die al ten Stämme der Cud' und Merja; vgl: auch V,41; III,268ff. "finskaja Rus'".

5) III, 259 .

6) III,249,259,268ff.

7) II,75f., 77; III,254,257,272f .

8) III, 248 .

9) III, $360 \mathrm{ff}$.

10) III, 266f .

11) III, 281. 
anhaben kann. Offenbar Ubt das "altrussische" Kolorit der RuBland-Gedichte Bloks heute in der Sovetunion eine größere Faszination aus als die Verarbeltung zeitgenössisch-großstädtischer Polklore in den "Zwölf". 1)

In Bloks frther Zeit fehlte es nicht an Beruhrungspunkten zum Raskol. Blok verkehrte im Kreise Merežkovskijs und kannte dessen Roman "Petr 1 Aleksej". 2) Belyj besuchte Blok 1904 in Sachmatovo, unmittelbar nachdem er den Sohn Mel'nikov-Pecerskijs kennengelernt hatte, und es 1st wahrscheinlich, daß er damals uber seine Erlebnisse berichtete. Bloks einziger wirklicher Freund, Je.P. Ivanov, stammte mutterlicherseits aus dem Altgläubigentum, und die religios-patriarchalische Atmosphäre seiner Familie war Blok vertraut. 3)

Bloks Interesse fur den Raskol ist jedoch erstmals in seiner Arbeit "Poézija zagovorov i zaklinanif" greifbar. Im Altgläubigentum schien die heidnisch-magische seelenlage der ursprunglichen Menschheit noch besonders lebendig, was sich $1 \mathrm{~m}$ "dvojeverije", dem Fortleben heidnischen Mythengutes in christlichem Gewande, zeigte. 4 )

Im Herbst 1907, in einer Zeit, als Blok nach den schweren 11terarischen und persönlichen Auseinandersetzungen mit Belyj vom Petersburger Kulturbetrieb besonders angeekelt war, schien er im Raskol die Lebenssphäre zu erhoffen, die ihn aus seinen Zweifeln hätte erlösen können. Er schrieb am 20. September 1907 seiner Mutter, er wolle sich mit dem Raskol beschätigen, offenbar um aus der intelligenzlerischen schwile Petersburgs in die frische luft des echten RuBland entfliehen zu können. Als Vorbild diente inm Kuzmin. 5 )

1) Aus der umfangreichen Literatur hierzu vgl. Pomeranceva, aao, S.219ff. (mit Iiteratur); Timofejev "Poéma Bloka "Dvenadcat'" i jeje istolkovatel1, in: Voprosy literatury, 1960, Nr. 7 , S.121; Kluge, aao, S.224ff.; Orlov, Poéma Bloka "Dvenadcat'", S.130f.

2) Vgl. VIII,47, Brief an seinen Vater vom 29. Nov. 1902; VIII, 92, Brief an A.V. Gippius vom 23. Febr. 1904. Blok fand in jener Zeit den Roman schlecht.

3) Vgl. Maksimov, A. Blok 1 Je. Ivanov, in: Blokovskif sbornik, S. $344 \mathrm{ff}$.

4) $v, 45$.

5) Vgl. VIII,207f. Blok war viellelcht auch vom "Ins-Volk-Gehen" A.M. Dobroljubovs und I.D. Semenovs angeregt. 
Wenige Tage später erreichte inn ein Brief Kljujevs, eines echten Raskol'niken, 1) der Blok schrieb, wie sehr er und seine Genossen vom Gedichtband "Neðajannaja Radost" "begeistert seien.2) Zw1schen Blok und $\mathrm{K} I$ Jujev begann ein Briefwechsel, der b1s 1915/16 andauerte ${ }^{3)}$ und in Bloks Werk tiefe spuren hinterließ.

Wohl unter dem direkten Eindruck der ersten Briefe Kljujevs, die Blok als Beweis für die Verwurzelung seiner Gedichte im russischen Volksgeist auffassen konnte, ${ }^{4)}$ entstanden die meisten Gedichte des Zyklus "Faina", die Raskol-Gedichte ${ }^{5)}$ und die entsprechenden Passagen des LS.

Blok machte sich die "berzeugung KIjujevs vom fast uniiberbrilckbaren Gegensatz zwischen Volk und Intelligenz zu eigen. Große Teile seiner publizistischen ÄuBerungen ỉber den elementaren Charakter des Volkes sind Zitate aus Brlefen Kljujevs,6) die fiur Blok eine Art gelstiger offenbarung waren.

"Es lst belustigend, auf das winzige Häuflein der russischen Intelligenz, die in zehn Jahren einen Haufen von Weltanschauungen getauscht hat und in 50 feindliche Lager zerfallen ist, zu schauen und auf das vielmillionenstarke Volk, das seit dem 15. Jhdt. ein und denselben beharrlichen Gedanken iber Gott festhäl (im Sektierertum). Der Brief Kljujevs hat mir endgiltig die Augen genffnet."7)

1) $V_{g l}$. VIII,215, Brief an seine Mutter vom 9. Okt. 1907.

2) Vgl. VIII,587, Anm. 4 zum oben erwähnten Brief; dazu VII,7of., Eintrag vom 17. Okt. 1911. Kl jujevs erster Gedichtband ist stark von Bloks Band "Necajannaja Radost" beeinfluBt.

3) Bloks Frau besan angeblich 46 Briefe Kl jujevs, die leider bis heute nicht veröfentlicht wurden. Die vermutich etwa gleiche Zahl von Bloks Briefen an KIJujev, die mit Sicherheit fiir die Beurteilung von Bloks gelstigem Werdegang von allergrößter Bedeutung wären, sind bel der Untersuchung Kl jujevs durch die GPU bzw. INKWD verschollen. Vgl. Filippov, aao, S.25 mit Ann. 51 und 52 auf 5.160 .

4) Vgl. einen Tagebucheintrag Bloks vom 11. März 1914 in Zap.kn.. 216 über seine Resonanz beim Volk; dazu S.105/1.

5) Vgl. Einleitung zum 5.Bild, S.311ff.

6) Vgl. V,213f. In "Iiteraturnyje itogi 1907 goda"; $V, 281$ in "Pis'ma o poezi1"; V,358f. in "Stichija 1 kul'tura".

7) VIII,219, Brief an seine Mutter vom 27. Nov. 1907. Blok wiederhoit seine Ansichten in "Literaturnyje itogi 1907 goda", vgl. V,215. Die Rilckfihrung der Religinsitèt des russischen Volkes auf das 15. Jhdt. stammt offenbar von Kljujev. Erst am Ende des 15. Jhdts. bildete sich nit dem Einschwenken des Staates auf die Ideologie Josif Volockijs und der Unterdrickung der Schule Nil Sorskijs die zaristische Staatsideologie heraus, gegen die sich dann der Raskol empörte. 
Im Sektierertum sieht Blok den Kern des "elementaren" Volkes, das die Intelligenz der beiden Hauptstädte hinwegfegen ${ }^{1)}$ und die Rache des Elements und der Erde an der todgeweinten zivilisation vollziehen wird. 2)

Der große Einfluß, den die Ansichten Kl jujevs auf Bloks Beantwortung der Prage "Volk und Intelligenz" ausubten, 3 ) ubersteigt die rein ideelle sphäre. Blok betrachtete $\mathrm{Kljujev}$ eine zeitlang geradezu als sein besseres Ich. ${ }^{4}$ )

Angeregt durch den Briefwechsel mit Kljujev befaBte sich Blok mit dem Raskol. In diesem rätselhaften Phänomen hoffte Blok dem Wesen des echten RuBland zu begegnen, denn im Raskol trat inm ein RuBland entgegen, das weit vor die "kaiserliche Periode" zurückreichte, die sein wahres Nesen verfülschte und auf die unverständlicherweise die Petersburger Intelligenz bislang so versessen war. ${ }^{5)}$ Blok studierte offensichtlich Berichte tber den Raskol, die aus der Feder der "Tolstojaner" Naživin, Birjukov und Prugavin stamten. ${ }^{6}$ ) Besonders erfreuen mußte es Blok,

1) $\mathrm{v}, 215 \mathrm{f}$

2) $v, 359$

3) Vgl. Kluge, aaO, S.228.

4) Vgl. VIII,258, Brief an seine Mutter vom 2. Nov. 1908; VII, 70, Eintrag vom 17. Okt. 1911; VII,97, Eintrag vom 27. Nov. 1911; dazu die ausfuhrliche Darstellung von Filippov, aao, S.8f., S.24ff.; etwa ein Fünftel der Darstellung gilt dem Verhältnis Bloks zu Kljujev. Filippov führt die wesentlichen Passagen aus Bloks Publizistik, Tagebichern und Briefen an. Die Tatsache, daB Blok llber Jahre hindurch mit Kl jujev in engem Kontakt stand, mulssen auch sovetische Forscher zugeben; vgl. Z.B. Desnickij, Social'no-psichologiðeskije predposylki tvor zestva A. Bloka, in: Pis'ma Bloka k rodnym, Bd. 2, S.27; Pomeranceva, aao, S.216; Timofejev, Tvorčestro A. Bloka, S.129f. mit Anm. 4.

Es ist kein Zufall, daß gerade der Blok-Spezialist Vl. Orlov am 21. Nov. 1966 in der Zeitschrift "Literaturnaja Rossija" auf Wunsch zahlreicher Leser einen längeren Aufsatz llber Kl jujev schrieb; vgl. Filippov, aao, S.153f. Die Leser, die einen solchen Aufsatz erbaten, ahnten wohl in Kljujev den Geist von Bloks RuBland-Gedichten und wuBten, an wen sie sich mit ihrer Bitte wenden muBten.

5) Vgl. V,215.

6) v,215f.; insbesondere erwähnt Blok das Schicksal des Kondratif Malevanny j (1844-1913), der die Sekte der "malevancy" gründete, in der alteres "geistiges" Christentum und chlystischer Orglasmus wieder auflebte; vgl. Klibanov, aao, S.218ff. Daneben ergriff inn der Dulderheroismus eines Sektierers namens Jegor Rozkov, der in Sibirien alle Folterqualen uberstand. 
daB sein Vortrag "Rossija 1 intelligencijan" vom 13. November 1908 von einigen Sektierern mit Zustimmung aufgenommen wurde. Er schrieb dartiber seiner Mutter:

"Auf der Versammlung hörte man mị gut zu, nach der Versammlung umringten mich Sektierer, etwa funf, und laden mich zu sich ein. Ich werde gehen."1)

Seinen Plan, zu den Sektierern zu gehen, griff Blok bald danach wieder auf. Im Februar 1909 schrieb er in sein Tagebuch:

"Ich kann nach Caricyn an der Volga fahren - zu Ion Brichnicev. Ins Olonecker Gouvernement zu Kl jujev. Mit Prisvin umherziehen? Zu den Sektierern - nach RuBland."2)

I.P. Brichnicev war ein Geistlicher, der wegen seiner Sympathien für den Raskol und die sekten und wegen seiner revolutionären Gesinnung seines Antes enthoben worden war. Er gab religiöse Zeitschriften heraus, in denen u.a. Kl Jujevs Gedichte erschienen. 3) Blok hatte inn wohl in der Religiös-philosophischen Gesellschaft kennengelernt, ebenso wie Prił̌in, uber dessen Jugendwerke er eine Rezension verfaßte. ${ }^{4)}$

Tatsächlich besuchte Blok, sehr wahrscheinlich im Frühjahr 1909. mit Prib̌vin eine Gruppe von Chlysten. Der Bericht Priłvins daruber ist ziemlich knapp, zeigt aber, daB Blok sich nicht in den dionysischen Orgiasmus der Chlysten integrieren konnte. 5) Die Begegnung mit dem "echten" RuBland war fur Blok eine Enttäuschung, die umso herber sein mußte, als er gleichzeitig erkannte, daß sein publizistisches Wirken ohne Erfolg geblieben war. Trotzdem hielt Blok an seinem RuBland-Mythos fest f $^{\text {und }}$

1) VIII,261, Brief an seine Mutter vom 16. Nov. 1908. Bei der zweiten Lesung fand Blok v.a. bel Korolenko Unterstutzung; vgl. VIII,269, Brief an seine Mutter vom 14. Dez. 1908.

2) Zap.kn., 131, Eintrag vom 16.-17. Febr. 1909.

3) Vgl. Filippov, aaO, S.43f.; Blok 8chrieb inm am 26. Aug. 1912 einen längeren Brief, In dem er seine Weigerung begründete, mit Brichnicev zusammenzuarbeiten; Blok sollte eine Rezension uber Kljujev schreiben, fuhlte sich aber dazu nicht in der Lage; vgl. VIII,400-402.

4) Vgl. V,651, "M. Pri zvin. O sten grada nevidimogo." Blok kannte offenbar Prisvins Reiseerzahlung "V kraju nepugannych ptic" zu diesem Zeitpunkt nicht. Besonders interessierte inn Prisvins Besuch am Svetlojar-see, wie friber schon der Besuch der Merezkovskijs (vgl. VIII,35, Briel an Z.N. Gippius vom Jul1 1902).

5) Vgl. Zap.kn., 547, Anm. 41 zur oben zitierten Passage.

$6)$ Vgl. z.B. VIII,288f., Brief an seine Mutter vom 19. Juni 1909; Zap.kn., 149, Eintrag vom 25. Juni 1909; Zap.kn., $153 f$.. Einträge vom 8. und 15. Juli 1909. 
blieb in Kontakt mit Altgläubigen und Sektierern. 1) Sein Interesse am Raskol blieb nach wie vor bestehen. 2)

Bloks weltbild war zwar genetisch weitgehend von westeuropäischen Vorbildern abhängig (v.a. von Wagner und Nietzsche). Die zahlreichen Bezlehungen Bloks zum Raskol und Sektenwesen, v.a. die jahrelange enge Bekanntschaft mit Kljujev, lassen sich jedoch nicht nur mit einer zufälligen und oberflächlichen seelischgeistigen Verwandtschaft $z$ wischen Blok und den religiösen Randgruppen erklären. Vielmehr stand Blok direkt unter dem EinfluB von Vertretern und Kennern des Raskol und der Sekten, der allerdings an der synkretistisch-hybriden verarbeitung durch Blok seine Grenzen hatte. Die Verwandtschaft $z$ wischer. Blok und den religiösen Randgruppen erstreckt sich besonders auf die orgiastische Verehrung eines weiblichen religiösen Urprinzips (in den religiösen Randgruppen als heldnisches Erbe; bei Blok als romant1sch-lebensphilosophisches Erbe mit starker individueller Prödisposition), eine selbstentsagende "homo-viator"-Mystik (bei den Randgruppen wörtlich ausgelegtes, "gelebtes" Christentum; bei Blok mit dem Hinweis auf die "Arme-Ritter-Thematik" bei Dostojevskij und Solov'ev oder gar mit lebensphilosophischen Einfliissen allein nicht zu erklären), einen maximalistischen Anarchismus (in den Randgruppen als religiöses und sozialrevolutionäres Empörertum; bei Blok zum großen Tell Nietzschesches Erbe) und ein geistig-apokalyptisches Christus-Verständnis (das zentrale Thema des Raskol und vieler Sekten; bei Blok lebensphilosophisch gar nicht und mit dem Hinweis auf Solov'ev nur bedingt erklärbar). Diese Punkte bilden einen Gesamtkomplex, von dem jeweils der eine oder andere Aspekt stärker in den Vordergrund tritt.

1) z.B. mit P.I. Karpov; vgI. VIII,303f.; VII,70, 105 Einträge vom 17. Okt. und 23. Dez. 1911.

2) Vgl. Triomphe, Le mysticisme d'A, Blok, in: Cahlers du monde russe et soviétique, vol. I, 3, S.403ff. und Filippov, aao, S.41ff., mit Angabe zahlreicher Kontakte Bloks zum Raskol und den Sekten. 
Schon Bloks "Gedichte von der Schönen Dame" wurden in Sektiererkreisen geschätzt, ${ }^{1)}$ wohl wegen ihres ekstatischen, in der Anbetung des "Ewig-Weiblichen" Religion und Sinnlichkeit vermengenden Grundtons. ${ }^{2)}$ Der orgiastische Charakter der späteren Gedichte Bloks war es wohl auch, der die Brilcke zu Kljujev schlug. 3) Der von Nietzsche herkommende Orgiasmus vjaX. Ivanovs und Bloks hatte eine unmittelbare Affinität zum Erotizismus der Chlysten und anderer sekten. ${ }^{4}$ ) Blok konnte Nietzsches Ausfihrungen iber das dionysische Griechenvolk und iber die dionysischen Umzige des deutschen Mittelalters ${ }^{5}$ ) auf das russische Volk beziehen. 6) Den orgiastisch-erotischen Charakter des IS verurteilte Je.P. Ivanov, wenn er es mit den Tänzen der Chlysten in Verbindung brachte. ${ }^{7)}$ Man muB N.S. Arsen'ev zustimmen, wenn er von den Symbolisten besonders Blok mit der sexuellen Ekstatik der Chlysten in Zusammenhang bringt. 8 )

Die Selbstentsagungs- und "homo-viator"-Mystik Bloks, die in

1) Vgl. Belyj, Vosṇominanija o Bloke (Zapiski mečtatelej), S.85.

2) Vgl. Belyjs Aussage, E.K. Metner habe in einigen Jugendgedichten Bloks "chlystovskije privkusy". (einen geiBlerischen Beigeschnack) gefunden; Belyj, Vosnominanija o Bloke, Epopeja I. S.233; ders.. Vosnominanija o Bloke (Zaniski mextatelej), S.117; dazu: Moxul'skij, 3lok, s.71. Belyj, "Nastojašxeje $i$ budusčje russkoj literatury" in: Lug zelenvj, S.86; dazu: "ocul'skij, Belyj, S.109f.: "Das Zusammenbringen der lyrischen Welt Bloks mit der Helt des Sektierertums und der Schönen Dane mit einer "Chlysten-Gottesmutter" Behört zu den tiefsten Intuitionen des Kritikers Bely.j."

2) Vzl. Filippov, aac, S.3of.. 49 u. ̈.

4) Vgl. Filippov, aac, S.51f.

5) Vgl. Nietzsche, Die Geburt der Tragödie, 7o, S.51.

6) Las tut z.B. Erwin Rohde in seiner theoretisch ganz von Nietzsche abhöngigen Darstellung der Dionvsos-Religion: Rohde, Psyche, 2. Band, S.4ff.. v.a. S.25f.. Anm. 1. Ivanov hat das Buch Rohdes mit Sicherheit gekannt.

7) Vgl. "Entstehungsgeschichte", S.35.

8) Arsen'ev, Die russische Literatur der Neuzeit und Gegenwart, S.241ff.: zu Blok vgl. S.243f.; ders., Die geistigen Schicksale. S.113ff.; hier behandelt Arsen'ev völilig zurecht den literarischen Ekstatiker Blok unmittelbar nach den Chlysten und betont die Affinität von Chlystentum und Dekadenz. 
"Bezvremen'e" und im IS einen Höhepunkt erreicht, 1) erinnert stark an das Stranniki-Ideal der ewigen Wanderschaft um Christi willen. Blok sah dieses Ideal in der Figur Dar'jal'skijs bestätigt. 2) Die Verlockung, alles aufzugeben und auf ewige Wanderschaft durch das weite RuBland zu ziehen, trat mehrmals an inn heran. 3)

Blok sah sein anarchisches Verhältnis zur Wirklichkelt, Ausdruck seines "musikalischen" Weltbildes, durch Kljujev bestätigt, dessen Bild vom Lavastrom des russischen Volkes er ibernahm. ${ }^{4)}$ In Karpovs Roman "Plamen'" (Die Plamme) sah Blok das echte, anarchisch-revolutionäre RuBland dargestellt, das von "Blut, Axt und rotem Hahn" heimgesuchte RuBland, das Pułkin in seiner "Hauptmannstochter" beschrieb, und das bald wieder Wirklichkeit zu werden drohte. 5) Den revolutionären Gelst Sten'ka Razins und Pugaxevs galt es gegen die alte Welt zu richten.6)

In längeren Notizen fïr einen Vortrag iber das in RuBland sehr beliebte Volksstijck "Car' Maksim1l'jan" vom September 1919 iibernahm Blok das Schema, das auch Merezkovskij seinem Roman "Petr 1 Aleksej"7) zugrunde gelegt hatte.

"Maksimilian - das ist Peter, Alexander I. Adolf - das ist das Volk (der Carevid Aleksej, die Flucht in die Wiiste, der Raskol, die "pugalev ślina" und der revolutionäre Geist)...

Der russische Zar wird gekrönt, besteigt den Thron und vermählt sich mit der Göttin Venus. Sein ungehorsamer Sohn Adolf erhebt sich gegen ihn. Anfangs will er den orthodoxen Glauben nicht gegen den heidnischer eintauschen (ein Nachhall des Raskol); dann geht er zu den Räubern (Volga, "pugačev šxina")...

1) Vgl. Einleitung zum 7.B1ld. Der Gegensatz von asketischer "homo-viator"-Mystik und orgiastischem Erotizismus ist nur vordergriindig und bei Blok Ausdruck eines pathologischen Verhältnisses zur Sexualität; vgl. Zap.kn., 149, Eintrag vom 20. Juni 1909. Askese und Orgiasmus sind als Wege zur Transzendenz in vielen Kulten eng verschwistert.

2) Vgl. VIII, 304f., Brief an seine Mutter vom 1. April 1910.

j) Vgl. Mocul'skij, Blok, S.96; VII, Einträge vom 6. und 9. Dez. 1911.

4) In "Stichija 1 kul'tura", vgl. V.358f.; Zap.kn., 127, Eintrag vom 26. Dez. 1908.

5) $V, 486$

6) Vgl. VII,297, Eintrag vom 7. Aug. 1917.

7) Eine dramatisierte Fassung wurde am 25. März 1920 in Petrograd aufgefihrt; vgl. dazu Bloks Einfihrung "O Merezkovakom", VI, 393-395. 
Den belden von uns gestellten Grundbedingungen (Romantik und Persönl1chke1t) genilgt das Stiick: 1.) Das romant1sche Element ist groB. 2.) Adolf ist einerseits der Träger des Massenbewußtseins; andererseits sind in thm persönliche Zilge (Carevit Aleksej, Peters Sohn; die Empörung der Persönlichkeit ist schismatisch (raskol'nidij), räuberisch, revolutionär."1)

Die Deutung des Volkssticks als einer allegorischen Darstellung der Auseinandersetzung zwischen Peter d.Gr. und seinem Sohn ist auch in der wissenschaft verbreitet. ${ }^{2)}$ Hier interessiert nur die Bloksche Gleichsetzung von Volk, Raskol, Flucht in die Einöden RuBlands hinter der Volga, Räuberromantik und revolutionärem Geist.

Bloks Verhältn1s zum Christentum und besonders zur Gestalt Christi ist vielschichtig und widerspruchsvoll. 3) Der vergleich zweier Tagebuchnotizen vom 14. November und vom 3. Dezember 1911 fihrt jedoch an das zentrale Problem heran, das für Blok Im Christentum $1 \mathrm{ag}$.

3lok schrieb am 14. November 1911 Tjutð̌ers Gedicht "Dva golosa" (Zwei Stimmen) ab. Das Gedicht Tjuttevs predigt in einem Anruf an die kämpfenden Waffengenossen ein innerweltliches Schicksalsethos.

"Ermannt euch, oh Freunde, und kämpft voller Elfer, Ist die Schlacht auch ungleich, der Kampf ohne Hoffnung!

Sollen die olympier mit neidischem Auge Auf den Kampf der unbeugsamen Herzen blicken, Wer kämpfend fiel, nur vom Schicksal besiegt, Der entriß ihren Händen den Siegerkranz."4)

1) VI,480ff. Interessanterweise fand Blok nur bel Je.I. Zamjatin Verständnis, der ebenfalls den "élan" der Revolution betonte.

2) Vgl. Krupjanskaja, Narodnyj teatr, in: Russkoje narodnoje poeticeskoje tvorcestro, pod red. P.G. Bogatyreva, S.399ff.; Bogatyrev Narodny teatr, in: Russkoje narodnoje tvordestvo, S.99ff.; Cicerov, Russkoje narodnoje tvorcestvo, S.409ff.

3) Bloks Haltung schwankte zwischen völliger Ablehnung und immer neuer Faszination; vgl u.a. I $166,183,187,222,225,259$; II, 2 of. $84,139,177,246,248,263(1)$; III,70,82,83f., 206,359 u. ö.; LS; VIII, $104-107,110,130 \mathrm{ff}, 235 \mathrm{ff}$. (vgl. VIII, 89); VII,97. $99,195,316 f ., 329 \mathrm{u} .0 ̈ . ;$ dazu Bonneau, L'univers poétique d' Al: Blok, S.187-194. Kluges, aaO, S.255f. vertretene Meinung, die Gestalt des Heilands habe in Bloks Leben keine besondere Rolle gespielt, vereinfacht die Sachlage zu sehr.

1) Vgl. VII,88; Blok unterstrich die 2. Zelle. 
Indem der Mensch Im Wissen um seinen Untergang und die Endlichkeit und Vergeblichkeit seines Strebens stolz sein Schicksal annimmt, erhebt er sich uber die Götter. Blok schrieb zu dem Gedicht:

"Der Sinn der Tragodie ist die Hoffnungslosigkeit des Kampfes; doch gibt es hier keine verzwelfiung, Schlaffheit, Sinkeniassen der Hande. Es ist eine hohe Weihe erforderlich." $\left.{ }^{1}\right)$ Er ubernahm die Verherrlichung des "antiken" Schicksalsglaubens. 2) Doch schon am 3. Dezember 1911 hatte sich Bloks Einstellung geăndert:

"In dem Gedicht TjutČevs ist Hellenisches, vorchristliches Schicksalsgefuhl, Tragisches (V stichotvorenil Tjutとeva - ellinskoje, do-christovo Cuvstvo Roka, tragi(eskoje). Es gibt auch eine andere Tragödie - die christliche. Doch so sehr man uber alles, was vorchristlich lot. sprechen kann, well dies das Unsere, das Hier-seiende, jetzt ist, so sehr mub man iber das christliche, selbst wenn man etwas weib, besser schweigen (nicht wie Merezkovskif), damit keine "Teufelei" (Musorgskij) herauskommt. Wir wissen weder Tag noch Stunde, in der des Menschen Sohn kommen wird, zu richten die Lebendigen und die Toten (Ne znajem ni dnja, ni Casa, v on' ze grjadet Syn Celovečskij sudit' zivych i mertvych)."3)

Dem "griechischen" diesseitigen Schicksalsbegriff stellte Blok einen "christlichen" transzendenten gegenuber, der "griechischen" Ausweglosigkeit die "christliche" VerheiBung des nahen Weltgerichts. Entscheidend für die "christliche Tragödie" ist das apokalyptische Moment, in dem Blok die Wesensmitte des Christentums im Unterschied zum Griechentum sah.

Die hier spübare Antinomie von Schicksals- und Erlösungsglauben ${ }^{4)}$ durchzieht auch Bloks Notizen uber den "Zukunfts-Ritter" und Bertran, die ein Tell von Bloks Notizen zu "Roza 1 krest" sind. Sie orientieren sich ebenfalls an TjutCevs Gedicht. Bertran lot der trag18che Mensch, der im Untergang sein Menschentum bestatigt. Der "Zukunfts-Ritter" 1st Träger eines "drohenden".

1) VII,89. Bloks Notiz entzilndet sich am Schicksal der "arischen", d.h. weiben welt angesichts der Bedrohung aus dem "gelben" Osten.

2) Man könnte ihn auch "germanisch" nennen.

3) VII,99. Im letzten Satz des 21 tats sind verschiedene Passagen aus der B1bel zusammengefabt, z.B. Matth. 25,13 und 2. Tim.4, 1 bzw. 1. Petr.4,5. Blok notierte in sein Tagebuch die kirchenslavische Lautung der Bibelstellen.

4) Vgl. VII, 164, Eintrag vom 11. Okt. 1912. 
apokalyptischen Geistchristentums, uber dessen Charakter sich Blok jedoch selbst nicht schlüssig wurde. ${ }^{1)}$

Blok war davon iberzeugt, daB gerade im russischen Raskol die typisch christliche Erwartung des Weltgerichts und des Anbruchs des Reichs des Gelstes noch lebendig sei. Das zeigt der Brief, den er unmittelbar nach dem Besuch von Musorgskifs musikalischem Volksarama "Chovanščina" am 29. November 1911 an seine Mutter schrieb:

"Die "Chovanscina" hat, wie sich herausstellt, eine groBe Rolle filr mich gespielt... Die "Chovansitina" ist noch nicht genial (d.h. nicht das Wehen des Heiligen Geistes2)), wie auch ganz RuBland noch nicht genial ist, in dem sich das zukiinftige erst bereit macht. Doch sie steht mitten im Zentrum, gerade auf der schmalen Zone, wo das Wehen des Geistes vorbeirast. DaB sie in einem Hof theater gespielt wird, ist richtig; sie ist eine offenbarung nur für uns, die man ständig erinnern muB, deren Gedächtnis noch kindlich, kurz ist. Wir haben das noch nicht auswendig gelernt. Filr die Raskol'niki ist das ein unnötiges, vielleicht sogar langwelliges Abc, wie fur das Volk unsere "volkstilmlerischen" Bewegungen und MaBnahmen. "3)

Das apokalyptische Element im Raskol betonte Blok schon in den Notizen, die in einer Mischung von Elgenem und aus $\mathrm{Kljujevs}$ Briefen Entlehntem das Gerilst für den Aufsatz "Stichija 1 kul'tura" bilden.

"Die Raskol'niki - tausendjähriges Reich auf Erden. Die Orhthodoxen - unsere Erde.

Wir hassen die orthodoxe schwarze Hundertschaft, wir haben fïr die Raskol'niki einen "Rationalismus" ausgedacht (die Tolstojaner, Miljukov), nur ja "nicht hinhören". Aber das Element kommt." 4)

Im russischen Volk verbiindet sich die soziale Revolution der orthodoxen mit der religiös-geistigen, chiliastischen Revolution der Raskol'niki. 5) Blok verteidigte den elementar-chiliastischen Charakter des Raskol gegen die, wie er meinte, falsche

1) Vgl. IV,458-461. Blok schlieBt eine Notiz Hber den "ZukunftsRitter", in der dieser mit dem Vagabunden, der Ferne, dem armen Ritter in Verbindung gebracht wird, mit dem Satz: "All diese Uberschriften passen nicht, weil der Zukunfts-Ritter unklar ist."

2) Blok schreibt hier und später "Duch" groB.

3) VIII,379f. Gerade in Jener Zeit stand Blok stark im Banne KI jujevs; vgl. vII,70,97,101,103, EInträge vom 17. Okt., 27. Nov., 7. Dez., 17. Dez. 1911.

4) Zap.kn., 127, Eintrag vom 26, Dez. 1908.

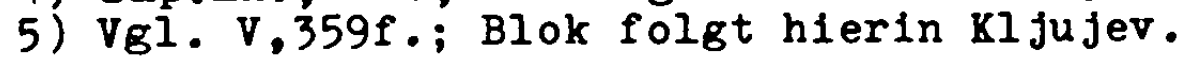


"Intelligenzlerische" Deutung der Tolstojaner und Miljukov8. In der Tagebuchnotiz verbindet $\mathrm{sich}$, ähnlich wie in den Notizen iber den "Zukunfts-Ritter", das "elementare" und das "apokalyptische" Element von Bloks Weltbild zu einer Einheit. Die altgläuoige apokalyptische Erlösungserwartung, die christliche Sehnsucht nach der Ankunft des Messias wollte Blok in der Gestalt der Faina darstellen. Auch wenn Blok im IS in einer Art "antikem" Schicksalsglauben stecken blieb, steht die Christus-Mystik des LS, die Hoffnung auf Durchbrechen des ewlgen Krelslaufs von vordergründiger Erlösung und Rifckfall in die Unerlöstheit, in unmittelbarem Zusammenhang mit der Herkunft der Faina aus dem Milieu des Raskol.

Die im IS enttäuschte, aber dennoch weiter genährte Reichserwartung, die Blok im Raskol lebendig sah, verbindet das LS mit den "Zwölf".

Die Gestalt Jesu Christi am SchluB von Bloks Revolutionspoem wurde in der umfangreichen Blok-Literatur sehr unterschiedlich interpretiert. Die Vielfalt der Deutungen beruht auf dem vielschichtigen Verhältnis zu Christus. So wird der Christus der "Zwölf" unter Hinweis auf andere Stellen in Bloks Werk als Mann aus dem Volke, als Sozialrevolutionär, als Kiinstlermensch, als Symbol der kosmischen Zeitenwende, als russisch-sektiererischer, revolutionärer Christus, als Antichrist u.a. gedeutet. ${ }^{1)}$

Eigenartigerweise wurde bisher noch nicht bemerkt, daß die Orthographie des Namens "Jesus" am SchluB der "Zwölf" einen deutlichen Hinweis darauf gibt, wie Blok die Gestalt Christi in seinem Poem verstanden wissen wollte. Blok schrieb "Isus Christos", obwohl die normale Schrelbweise "Jisus Christos" metrisch völlig gleichwertig ist. Er folgte damit der Schreibung

1) Vgl. Orlov, Poèma A. Bloka "Dvenadcat" ", S.89-114; Kluge, aao. S.244-260 mit Anmerkungen 22-80 auf S.361ff:; Peters, Symbole der sinnlichen Wahrnehmung, S.38-43 und S.62-66. 
des Raskol. 1)

Die Schrelbung "Isus" wahlte Blok in zwel der drel Varianten der Schlubzelle der "Zwölf", 2) v.a. aber im original.3) Dagegen schrieb er "Jisus" an den Stellen, die zeitlich mit den "Zwölf" zusammenfallen, so im Plan zu einem Drama "Jisus", 4) in "Katilina"5) und in "Vladimir Solov'ev 1 nasi dni".6) Bloks Schreibweise "Isus" ist mit Sicherheit bewuBt und beabsichtigt. Sie entspricht z.B. der Jesenins 7) und knüpfte damit gewollt und fur den russischen Leser sofort erkennbar an die von Jesenin, Kljujev und anderen vertretene Deutung der Revolution als einer Erfull ung der altgläubigen Endzeiterwartungen an.

Im Zusammenhang mit der Interpretation der "Zwölf" wurde verschiedentlich auf den anarchistisch-zerstörerischen Geist des russischen Raskol und der sekten hingewlesen, der in Bloks Poem durchbreche. ${ }^{8)}$ Nun war Blok das Bild des rächenden Christus der Selbstverbrenner zwar vertraut ${ }^{9)}$ - es ist eine besondere Form von Bloks "russischem Christus". Blok identifizierte die rote Garde der "Zwölf", der Christus vorausschreitet, mit dem russischen Sektierertum; beide waren nach seiner Meinung vom Geist des echten, aber aus der orthodoxen Staatskirche geschwundenen Christentums erfuilt. ${ }^{10)}$ Allerdings ist Jesus Christus in den "Zwölf" nicht als Empörer und nicht als ein Christus der selbst-

1) Vgl. Pleyer, aao, S.41. Die unterschiedliche Schreibung und Aussprache des Jesus-Namens war ein zentraler Streitpunkt zwischen Raskol und Or thodoxie.

Blok war in Fragen der Orthographie auBerordentlich pedantisch; vgl. I,567f. (die hier getroffene Unterscheldung von "metel'" und "mjatel" könnte auch das Schneesturm-Symbol der "Zwölfn betreffen; VgI. III, $628 \mathrm{mit}$ "mjatel'n gegentiber VII, 320 mit "metel'") und VII,319f., Eintrag vom 18.Jan.1918.

2) VgI. III, 347 .

3) III, 359

4) VII,316f.; Kluge, aao, S.256 schreibt falsch. Vgl. auch Zap.kn., 386, Eintrag vom 25. Jan. 1918.

5) VI, 61 u.ö.

6) $\mathrm{VI}, 156$

7) Vgi. etwa "Tovariłx" (1917), "Inonija" (1918) und "Sel'skij Casoslov" (1918).

8) Z.B. von MoCul'skij, Blok, S.399,407, der betont, daB dieses "mussische" Erbe nur eine Facette von Bloks Anarchismus ist; von Bonneau, aao, S.191f.

9) VgI. III, 248

10) VgI. VII,329f., Eintrag vom 10. März 1918. Blok zitierte hier sein Poem und schrieb "Isus Christos". 
verbrenner gezeichnet. 1) Träger und Symbol der alles erfassenden Zerstörung sind die zwölf Rotarmisten, die, ohne es zu wissen, Christus nachfolgen. ${ }^{2}$ ) Ihr Strafgericht uber die groBe Hure Petersburg geschieht - ihnen selbst unbewuBt - im Namen des altgläubigen Geist-Christus, des Christus des russischen Landes. ${ }^{3)}$ Der endzeitliche Christus geht seinen mordenden und sengenden Aposteln als eine atherische, halb visionare kosmische Erscheinung voran. 4)

Diese Konstellation ist in einer Tagebuchnotiz Bloks rom 4. Januar 1918 schon deutlich greifbar. Wenige Tage vor dem Entstehen der "Zwölf" hatte der Dichter elne längere Unterredung mit Jesenin über Kljujev, den Raskol, das Sektenwesen und die Revolution. Ein wesentlicher Punkt der Unterredung war die blinde Zerstörungswut des Volkes. Blok resijmiert in seiner Tagebuchnotiz Jesenins und seine eigene Einstellung hierzu:

"Man zerstört (Kirchen, den Kreml', um den es Jesenin nicht leid ist) nur aus Ubermut. Ich fragte, ob es nicht auch welche gäbe, die im Namen höherer Werte zerstören. Er verneint das (d.h. ist meine Idee hier voraus?)."5)

Der atherische Christus der "Zwölf" erinnert an den ätherischen Christus in der ersten Fassung von Belyjs Roman "Peterburg", der RuBland vor "westlicher" Revolution und "östlicher" Reaktion - beide für RuBland todbringend - errettet. ${ }^{6)}$

Auch die Farbensymbolik "Rot"-"WeiB" am Ende der "Zwölf" mit

1) Das betonen u.a. Orlov, aao, S.108; Cekarlieva, Blok i revol jucijata, in: Ezik i literatura, 1961, Nr. 3, S.55f.

2) $\mathrm{Vgl}$. besonders Kluge aao, S.245ff.

3) Blok sagte nach der Revolution zu Zamjatin: "Bolschewismus und Revolution - die gibt es weder in Moskau noch in Petersburg. Bolschewismus, der echte, russisch fromme, der ist irgendwo im öden Innern RuBlands, vielleicht auf dem Lande. $\mathrm{Ja}$, wahrscheinlich dort..."; Zamjatin, Lica, S.25.

4) Der kosmische Aspekt wird v.a. im Schneesturm-Symbol deutlich. Vgl. zuletzt Peters, Symbole der sinnl. Wahrnehmung, S.59ff.

5) VII, 314

6) Vgl. Mocul'skij, Belyj, S.172. Revolution und Reaktion waren damals für Belyj urverwandte, "mongolische" Phänomene. Der Christus Belyjs behielt anthroposophische Züge bei, obwohl Belyj sich von Steiner bald lossagte; vgl. Mocul'skij, aao, S.212ff. 
Ihrem apokalyptischen Gehalt verbindet Blok mit Belyj. 1) Während jedoch bei Belyj ein anthroposophischer Christus als Erlöser RuBlands erscheint, 2 ) ist es bel Blok der altgläubige. Der altglăubige, sektiererische Aspekt Christi unterstreicht einerseits den nationalen, musischen Charakter Christ1 und setzt damit die Tradition von Bloks RuBland-Gedichten fort. 3 ) Andererseits weist er auf den pneumatischen Charakter des Christus-Symbols hin, was völlig der oben zitierten Briefstelle Uber Musorgskijs "Chovanstina" entspricht. Der Christus der "Zwölf" entzieht sich zwar - wie Bloks RuBland-Mythos uberhaupt - einer einseitig politisch-nationalistischen Festlegung, was Blok wohltuend von Dostojevskij unterscheidet. 4 ) Doch geht es nicht an, den national-messianistischen Aspekt in Bloks Christusbild und Revolutionsverständnis mit dem Hinweis auf die kosmische Dimension von Bloks Weltbild einfach abzuleugnen. 5) Das Christus-Symbol am Ende der "Zwölf" 1st Ausdruck einer chiliastischen Reichserwartung, die von Anfang an Bloks Heltbild bestimmte, ${ }^{6)}$ und die mit der Reichserwartung $\mathrm{k}$ ljujevs fast iden-

1) Vgl. VII,42f., Eintrag vom 26. März 1902. Blok resümiert hier Ideen Belyjs zur Apokalypse, v.a. dessen Ausf uhrungen uber die Farbe "WeiB", die denen in Belyjs Aufsatz "Svjažcennyje creta" (1903) in: Arabesk1, S.115-129 entsprechen. Hier deutet Belyj das Hohe Lied als allegorische Darstellung der Apokalypse, der endzeitlichen Hochzeit Christi mit seiner Kirche. Von hierher ist wohl auch Bloks " $v$ belom ventike iz roz" in den "Zwölf" als Hochzeitskranz des endzeitlichen Bräutigams zu verstehen.

2) Vgl. Belyjs Poem "Christos voskres" (1918).

3) Der russische Charakter von Bloks "Zwölf" ist evident, nicht nur wegen der Verarbeitung russischer Folklore, sondern auch wegen der Einschmelzung lokaler Petersburger und tagesaktueller politischer Elemente.

4) Vgl. zuletzt Doerne, Tolstoj und Dostojewskij, S. $124 \mathrm{f}$

5) Das versuchte Kluge, aao, S.246,255,259 u.ö. Es ist ein Kennzelchen jeder Art von Messianismus, daß dieser mit ubernationalem, kosmisch-apokalyptischem Anspruch auftritt und sich als historisch objektiv begrlindet ansieht. Das gilt fur den deutschen Messianismus so gut wie fur den russischen; vgl. Kohn, Die Slaven und der Westen, S.121; Sarkisyanz, aao, S.10, Anm. 19, S.33ff.

6) Vgl. I, 170,214,215f.. 258,262,269,286,297,503f \&; II, 57,139f ., 170 u.ö.; III,278; Zap.kn., 35, EIntrag vom 8. Aug. 1902; V.357,451,453f.,524f.,583f.; VI,8,12f.,59,90f.. u.ö.; VII, $325 \mathrm{f}, 328$. 
tisch war. ${ }^{1)}$ Von der Revolution erhoffe sich Blok den Anbruch eines vollig neuen Äon, den Sprung aus der bisherigen Geschichte. ${ }^{2)}$ Während im LS nur ein Trugbild Christi erschien, und die Er1 ösung nur elne scheinbare war, sollte nun das Ende der Ze1ten tatsächlich anbrechen. ${ }^{3)}$ Das Christus-Symbol war am besten geeignet, den spezifisch apokalyptischen Aspekt in Bloks Einstellung zur Revolution zu verdeutlichen. Des Erscheinen des pneumatisch-endzeitlichen Christus sollte den Anbruch eines "dritten Bundes" symbolisieren, der von Dauer sein sollte.4) Die Tatsache, daB Blok zur Symbolisierung des Umbruchs der Zeiten nicht das "Weltorchester" oder ein ähnliches Bild gebrauchte - was seiner Publizistik eher entsprechen wurde - sondern den Altgläubigen-Christus, zeigt, daB er seinen eigenen Chiliasmus als Entsprechung der Sehnsüchte des russischen Volkes verstand.

1) Kljujev ibernahm in seinem ersten Gedichtband Bloks damaliges Symbol dieser Reichserwartung, die "Unverhoffte Freude"; vgl. Kl jujer, Sotinenija, S.215 (Widmung), S.231f.(20), S.243f. $(37-38)$.

2) Vgl. VI,12, v.a. aber 59: "Die Welt trat in elne neue Ära ein. Die Zivilisation, die Staatlichkeit, die Religion - sind tot." BIok war nach Ernst Bloch der "unbestreltbare Bolschewik und ebenso unbestreitbare Chiliast". (Freiheit und Ordnung, S.55). So richtig das letztere ist, so völlig absurd ist das erstere.

3) Die bisher einzige Darstellung, die der sektiererisch gefärbten, chiliastischen Erlösungs- und Reichsmystik Bloks gerecht wird, ist Triomphe, aao, in: Cahiers du monde russe et Boviétique, vol. I, Nr. 3, S.387-417. Der Verfasser erkennt, daB Blok seine Mystik der drei Zeitalter, die Bloks Urtelien uber den Untergang der Antike zugrunde liegt, in engen Zusammenhang mit dem russischen Sektenwesen steilt. Er betont die tbereinstimmung $z w i s c h e n$ Blok und $K I$ jujev und die chiliastische Reichserwartung, die das IS mit den "Zwölf" verbindet (vgl. S.403ff.). Triomphes Ausdruck "la secte du raskol" ( 5.405 ) zeigt jedoch, daB er sich uber den Unterschied zwischen dem Altgläubigentum und dem Sektenwesen in RuBland noch weniger klar ist, als Blok es war.

4) Die bei Blok immer anzutreffende Antinomie von Schicksalsglauben (ewiger FluB der Erscheinungen, ewiger techsel von Kultur und Zivilisation, musikalischer und unmusikalischer Zeit) und Endzeiterwartung ist in den "Zwölf" chiliastisch "gelobst". Das entspricht dem Schema von Mythologie und Religion in Bloks Jugend tagebuch; vgl. Einleitung zum 5.Bild, S.286f. 


\section{SCHLUSS}

Bloks 2weifel an der Tragfählgkeit seiner "Lyrik" und seine Hinwendung zum "Melodrama" als Vorform des "Volkstheaters".

In enger Anlehnung an Nietzsche sah Blok in der Lyrik das Medium, in dem der Urgrund der Welt in bildhafter spiegelung wiedergegeben wird. Der echte Iyriker schöpft seine Visionen aus der rauschhaften Verschmelzung mit dem musikalisch-elementaren Weltengrund. Die in dem Kontakt mit dem Urgrund entstandene Iyrik ist nicht individuell-subjektives Phantasieprodukt, sondern als Abbild des elementaren Urgrunds des Seins uberindividuell-objektiv. Echte Iyrik aus dem "Geiste der Musik" ist eo ipso "volkstumlich", was im Eingehen der echten Kunstdichtung in die Volksdichtung auch äuBerlich sichtbar wird. 1)

Eigenartigerweise hat nun Blok in der Zeit der Entstehung des IS, einer zeit, in der seine dionysisch-musikalische lyrische Inspiration nach der rauschhaften Explosion der "Schneemaske"Gedichte im Zyklus "Faina" und besonders in den Gedichten "Zakljatije ognem 1 mrakom" ${ }^{2}$ ) einen Hohepunkt erreichte, ganz offensichtlich am "objektiven" Gehalt seiner Lyrik gezweifelt und im Drama die Kunstform gesehen, in der im Gegensatz zur Lyrik die Gefangenheit im Subjektivismus uberwunden werden kann. Es besteht hier ein offenkundiger Bruch in Bloks Auffassung vom Wesen des lyrischen Dichters.

"Die gegenwärtigen Zweifel, die Widerspruche, das Schwanken der betrunkenen Sinne und das Gären unnutzer Kräfte darzustellen, das kann nur die blegsame, hinterlistige und heimtukische Lyrik. Das geräumige Element des epischen Poems, des ungestumen Ileds, das die Helden beseelt, des langen und klagenden Lieds, in dem die Volksseele weint, dieses Element zerteilte sich in seichte schöne Bächlein. Das elntönige Brausen des Wasserfalls wurde zum zauberischen Gesang vieler selchter Rinnsale, und die Spritzer dieser lyrischen Rinnsale flogen uberall hin: in den

1) Vgl. dazu die grundlegende Darstellung von Kluge, Westeuropa und RuBland. S.98aff. Blok exzerplerte die Darlegungen Nietzsches über den iyrischen Dichter in der "Geburt der Tragödie": Zap.kn., 80. Zum Verhältnis von Kunst- und Volksdichtung vgl. S.73/4 and $S .105 / 1$.

2) Vgl. Einleitung zum 5.B1ld, S.309ff. 
Roman, in die Erzählung, in die theoretische Abhandlung und schließlich ins Drama.1) Und der Einfluß der heutigen Lyrik der Kunst des Vermittelns feinster Empfindungen - war fur das Drama vielleicht besonders verhängnisvoll. Anscheinend ist die ganze Luft voller Lyrik, denn die freien Bewegungen sind ebenso verschwunden wie starke Leidenschaften, und an die Stelle der lauten Stimme ist das Flustern getreten. Die feinen lyrischen Gifte haben die einfachen Säulen und starken Ketten zerfressen, die das Drama stutzen und zusammenhalten."2)

Hier ist Lyrik nicht die freie, nur dem elementaren Urgrund des Seins verhaftete und inn in realen Bildern spiegelnde dionysische Volkskunst, sondern eine in den $\mathrm{Zweifeln}$ und der Gespaltenheit der Gegenwart gefangene kunst, die in Analogie zur Zivilisation die Ganzheit verloren hat. Lyrik ist die Kunstform des Individualismus. Von inr ist außer Ibsen das gesamte westeuropäische Theater vergiftet, aber auch das russische Theater und besonders Cechov. ${ }^{3)}$

In dieser kritischen Einstellung zur Lyrik, die weit von der an Nietzsche gewonnenen therzeugung entfernt ist, daB die Lyrik das objektive Abbild des Urgrunds der Welt sei, verfaßte Blok im August 1907 das Vorwort zu seinen "lyrischen Dramen". Es ist im Hinblick auf die Bedeutung, die Blok dem LS beimaß, von großem Interesse.

"Die Lyrik gehört nicht zu jenen Bereichen des künstlerischen Schaffens, die das Leben lehren. In der Lyrik fixieren sich die Erlebnisse einer in unserer Zeit notwendigerweise vereinzelten Seele. Diese Erlebnisse sind gewöhnlich kompliziert und chaotisch, und um sich in innen zurechtzufinden, muB man selbst "ein wenig von dieser Sorte" sein. Doch auch wer sich in dem komplizierten Erlebnissen der zeitgenössischen Seele zurechtgefunden hat, kann sich nicht damit brüsten, daß er auf einem festen Weg stehe. Nun erwartet aber jeder Leser und besonders der russische schon immer von der Literatur, dab sie inm einen Lebensweg zeige. In der zeitgenössischen Literatur ist anscheinend das lyrische Element das stärkste; es lberwiegt nicht nur in der reinen Poesie, wo es auch laberwiegen muß, sondern es beherrscht auch die Erzählung, die theoretische Abhandlung und schließlich das Drama...

1) Bloks Darstellung der Degeneration der Lyrik gleicht auffallend seinen ëußerungen uber die Degeneration der Kultur zur Zivilisation in "Krułeni je gumanizma", VI,101ff.

2) Beginn von "O drame", V,164.

3) $\mathrm{VgI}, \mathrm{V}, 171 \mathrm{f}$ 
Die Lyrik schenkt uns in erlesenen und vielfältigen Formen den ganzen Reichtum verfeinerter und vereinzelter Erlebnisse... Der ideale lyrische Dichter ist ein kompliziertes Instrument, das gleichermaßen die widerspruchlichsten Erlebnisse hervorbringt. Und die ganze Kompliziertheit der zeitgenossischen Seele, die reich $18 t$ an Eindrücken der Geschichte und der Wirklichkeit, geschwächt durch Zweifel und widerspruche, die lange und qualvoil leidet, wenn sie leidet, die tanzt, Possen reibt und lästert, wenn sie sich freut, - der seele, die die freien Todesqualen und die freien Lebensfreuden vergessen hat, - kann man diese ganze Kompliziertheit uberhaupt beschreiben?

In Anbetracht all dessen halte 1 ch es fur unumgänglich, gleich von vorherein darauf hinzuweisen, daß die drei kleinen Dramen, die hier der Aufmerksamkeit des Lesers empfohlen werden, lyrische Dramen sind, $d . h$. solche, in denen sich die Erlebnisse einer einzelnen Seele, thre zweifel, ihre Leidenschaften, ihre MiBerfolge und ihr Scheitern niederschlagen, - nur dargestellt in dramatischer Form. In ihnen ziehe ich keinerlei ideelle. moralische oder sonstige Folgerungen.

Alle drei Dramen sind untereinander verbunden durch die Einheit des Typs der Hauptgestalt und seines Trachtens. Der karikierte Pechvogel Pierrot im "Balagantik", der moralisch schwache Dichter im "KoroI' na Dloscadi" und der andere Dichter, der vollig in Träumerei und Rausch versunken ist und seinen Traum in der "Neznakomka" versäumt, - all das sind gleichsam verschiedene Seiten der Seele eines einzigen Menschen; ebenso gleichartig ist das Trachten dieser drel Figuren: alle suchen sie das schöne, freie und helle Leben, das allein von thren Schultern die allzu schwere Last der iyrischen Zweifel und Widersprüche nehmen und die aufdringlichen und gespenstischen Doppelgänger verjagen könnte. Für alle drei ist das schóne Leben die Verkörperung des Bildes der Ewigen Welblichkeit: für den einen die Kolombine...; fiir den andern die Tochter des Architekten....; flur den dritten die Unbekannte...1)

Dieses Vorwort wirft ein helles Licht nicht nur auf Bloks Selbstverständnis als Lyriker in jener zeit, sondern auch auf die Bewertung seines bisherigen dramatischen Schaffens. Die lyrischen Dramen sind, wie die Lyrik selbst,Ausdruck der Zerrissenheit, der Persönlichkeitsspaltung, der verlorenhelt der Einzelseele in den Widersprichlichkeiten einer krisenhaften Zeit. Die äußere Form der Dramen ist nur Akzidens, die Begegnung mit dem "Ewig-Weiblichen" wie in der Iyrik nur traumhafte Wahnvorstellung. 2)

1) IV, $433 f$

2) Blok hat mit der chronologischen Anordnung seiner Gedichte den dissonantischen Gesamteindruck seiner Iyrik verstärkt. 
Bloks Vorwort ist das Ergebnis einer schmerzhaften tberprifung seines dichterischen Schaffens, die von elner dramatischen $2 u-$ spitzung seiner Beziehung zu Belyj ausgelost murde. Noch im Jun1/Jul1 1907 hatte Blok stolz die absolute Preiheit des Lyrikers von allen gesellschaftlichen, moralischen und religibsen Zwängen proklamiert und sein "musikalisches" Weltverständnis vor allem gegen die Angriffe Belyjs verteldigt. 1) In seinem langen Brief vom 15. - 17. August 1907 an Belyj ${ }^{2)}$ bekennt Blok, daB ihn die Niederungen der zeltgenossischen Erotik abstoBen:

"Ich will nicht die schwlle Atmosphäre, die die Erotik erzeugt; $1 \mathrm{ch}$ will freie luft und Raum... Ich fuhle in mir eine gesunde Ganzhe1t und die Pahigke1t, ein freler, unabhängiger und ehrenhafter Iensch zu sein."3)

Er gibt zu, daB Belyjs Vorbehalte gegen viele seiner Werke begrundet sind und nennt in diesem Zusammenhang $u . a$. den zyklus "Schneemaske", ${ }^{4)}$ das Gedicht "Poét" (Der Dichter), 5) den Zyklus "Nenužna ja vesna" (Unnötiger Fruhling), 6) besonders aber sein lyrisches Drama "Balagancik":

"Wo ist "Gotteslästerung" in meinen Dramen (ausgenommen der "Balagan(1k")? Wenn ich mein Helliges verspotte, schmerzt mich das. Doch dem "Balagancik" geben sie eine ungeheure Bedeutung. weshalb, wozu? Wenn man die Prage dreht wie Sle, ist er wider-

1) V,134f. in "O lirike"; vgl. Kluge, Westeuropa und RuBland, S.101. Belyj8 "antimusikalische" Schriften sind: Brjusov, poét mramory 1 bronzy, 1907, in: Arabesk1, S.448-453 und Protiv muzyki, in: Vesy, 1907, $\mathrm{Nr}, 3, \mathrm{~S} .57-60$. Sie richten sich v.a. gegen Ivanovs Wagnerkult: vgl. Ivanov, Vagner 1 Dionisovo de jstro, in: Vesy, 1905, Nr. 2, s.13-16 und andere Aufsätze; siehe dazu Mocul'skij, Belyj, S. 103 .

2) VI. Orlov bezelchnet diesen Brief als "bemerkenswerten, "bekenntnishaften" Brief, der elne auBerordentliche, wichtige Bedeutung fur Bloks literarische Blographie hat"; Iiteraturnoje nasledstvo, 27-28, S.394.

3) VIII,197; vg1. auch Zap.kn., 961f., Einträge vom 1. und 20. Aug. 1907.

4) VIII, 200; doch sieht Blok in diesem 2yklus die VerheiBung von etwas Hoherem.

5) VIII,201. Dieses Gedicht hatte Belyj besonders verletzt. Blok hatte es inm 1905 geschlckt (vgl. Pereplska, S.150f.):

"Er will ubèrs Meer,

Wo die Schöne Dame lebt. -

Ist diese Dame gut? -

Ja. -

Warum kommt sie dann nicht? -

Sie wird nie kommen:

Sie fährt nicht mit dem Schiff."

6) VIII,199; der 2yklus steht II, 33119. 
$11 \mathrm{ch}$, schädl1ch, sogar "mystisch-anarchistisch".1) Weniger ernst genommen ist er ein nichtiges dekadentes Stickchen nicht ohne Eleganz und mit ein pagr Typchen, - miBlungenen Kartonfigurchen lebend1ger Menschen." 2 )

Blok besteht jedoch darauf, das er sich trotzdem im Innersten seines Wesens treu geblieben sel.

"Ich bekräfte, daB bei all meiner Treulosigkeit, im Verrat, im Scheitern, in den 2weifeln, in den Fehlern ich treu bin...3) Im Grunde meiner seele liegt nicht der Balgancik, das schwöre 1ch."4)

Der Brief enthät zwar eine erneute Darlegung von Bloks "lyrischer" Welthaltung, 5) doch ruckte nun Blok von der Position ab, die er noch im Juli eingenommen hatte:

"... 1ch lade nicht ins chaos ein, Ich hasse das Iastern im Leben und die Blutschande in der Ilteratur. Ich verachte die verfeinerte ironische Erotik. Und sofern all das in mir selbst steckt, hasse ich mich und verfolge mich selbst im leben und in der Presse (z.B. Im Aufsatz "tber die Lyrikn), streife die Petzen der Nacht von mir ab, der $1 \mathrm{ch}$ im Kern hell bin." 6 )

Die Auseinandersetzung mit Belyj brachte Blok nicht von seinem "musikalischen" Weltbild ab, doch erweckte sie in inm zweifel daran, ob seine den Abgrtinden morbider Erotik wie den Hohen echt empfundener RuBland-Mystik offene Lyrik das wahre Instrument des "Geistes der Uusik" sel, und ob er nicht den schwankenden Grund der Iyrik verlassen sollte.

Als das Medium, das besser als die Lyrik dazu geeignet war, Splegelbild des "Geistes der Musik" zu sein, bot sich Blok das Theater an, denn

"... das Theater 18t das Fle1sch der Kunst, jene hohe Sphäre, in der "das Wort Fleisch wird." ... Im Theater mus die Kunst auf das Leben treffen." 7)

1) Anspielung auf Culkovs "mystischen Anarchismus".

2) VIII,199f.; vgl. VIII,2081., Brief an Belyj vom 23. Sept. 1907 .

3) Vgl. S.86/12.

4) VIII, 199

5) VIII, 199; vgl. Kluge, Westeuropa und RuBland, S.102; dazu: VIII, 203 .

6) VIII,209, Brief an Belyj vom 23. Sept. 1907. Vgl. dazu "Na pole Kulikovom", III,251f.(4), Str. 6 und 7; German als der Dunkle: S.46/9; German als der Llchtgott: SchluB des 5.B1ldes.

7) V,27o; vgl. a. VI,273. 
Die Begegnung mit dem Leben konnte allerdings nicht im raffiniert-esoterischen "lyrischen Drama" der feinen Nuancen und 8 chwachen Helden erreicht werden.

Schon in seiner ersten Theaterkritik, die dem reorganisierten Theater der Kommissarževskaja galt, 1) läßt Blok erkennen, wie er sich eine Erneuerung des Theaters vorstellt. Blok meint, der Individualismus befinde sich in einer Krise, uberall sel das Verlangen nach einem neuen, einfachen Verhältnis zum Leben erwacht, jeder warte sehnsuchtig auf einen Widerhall in einer fremden seele. 2 )

"In einer solchen Epoche muB das Theater auferstehen. Der Boden dafur 1st schon getränkt von den elementaren Regengussen der Wagnerschen Musik, des Ibsenschen Dramas. Die Wissenschaft und die Phantasie geben sich die Hand, rechtfertigen und lassen auferstehen das uranfängliche Element der Erde, den Rhythmus, der die Planeten und die seelen der irdischen Wesen verbindet. Und da erwachen wir, ängstlich und halb blind, wir eilen auf die Marktplätze, wo der Wind weht und Menschenblicke zusammenträgt; und die Menschen schmucken sich fureinander, schauen sich an, verlieben sich in das vielfarbene Leuchten der zahllosen und abgrundtiefen Augen.3)

Ein solcher Marktplatz muB in unserer zeit das Theater sein, eine Wiege irdischer Leidenschaft... Saal und Buhne sollen sein wie Bräutigam und Braut... Jeder soll das Theater verliebt und der Erde treu verlassen."4)

Bloks Vorstellungen von einem dionys18ch-orgiastischen, Schauspieler und Zuschauer in einer erotisch-musikalischen Woge vereinigenden Theater sind eine tbernahme der Vorstellungen vjac. Ivanov8, die Belyj scharf kritislert hatte. Das Theater der Kommissarževskja, auf das Blok so große Hoffnungen gesetzt hatte, blieb dem "Rhythmus" nicht lange treu. 5)

1) "Dramaticeskij teatr V.F. Kommi s8arževskoj", V,95-98; vgl. dazu Volkov, Blok 1 teatr, S.65ff.

2) V,95. Hier spiegelt sich Bloks elgenes Suchen nach einem neuen Verhältnis zur Realität wider, das durch die Revolution von 1905 gefördert wurde.

3) Vgl. IV.76, Keplik des Dichters im Drama "Neznakomka".

4) $V, 95 f$.

5) Als beste Inszenierung des Theaters der Kommissarzevskaja hielt Blok I. Andrejevs "Žnn' celoveka", das am 22. Febr. 1907 uraufgefuhrt wurde; vgl. v, 186ff. In der Saison 1907/08 wurden Wedekinds "Fruhlings Erwachen" und Maeterlincks "Pelleas et Mélisande" aufgefuhrt. Zur Ablehnung dieser Inszenierung vgl. V,194-202; zur Enttäuschung Bloks an der Entwicklung des Koma1ssarževskaja-Theaters vgl. V,242. Auch später war für Blok der "Rhythmus" das entscheidende Kriterium fur den Wert einer Theaterauffuhrung; vgl. VI,273, 348f., 353 u. ö. 
Am 18. März 1908 hielt Blok im Theaterklub in Petersburg ein langes Referat mit dem Titel "O teatre" (Uber das Theater)" ${ }^{1}$, das als umfassende Stellungnahme zum Zustand des gegenwätigen Theaters gedacht war und einen Weg aus der Misere aufzeigen wollte. Der Vortrag kann als programmatische Entsprechung zum IS gelten. Er entstand in den Wochen, in denen Blok angestrengt am LS arbeitete, und enthält eine ganze Reihe von Bildern, die im LS wiederkehren. 2) Blok nimmt in ihm das Thema auf, das er unter dem Eindruck seines Briefwechsels mit Belyj im Sommer 1907 in seinem Aufsatz "Tri voprosa" (Drei Pragen) ${ }^{3)}$ angeschnitten hatte, die Frage nach dem Sinn und Nutzen der Kunst und nach der wiederherstellung der Einheit von Leben und Kunst, Schonheit und Nutzen, die er von einem zukinftigen Theater erhoffte. ${ }^{4}$ ) Nach der Feststellung, daB es um das russische Theater gegenwärtig sehr schlecht bestellt se1,5) nach Ausfuhrungen uber das Verhältnis von Schriftsteller zu Schauspieler und Regisseur kommt Blok zu einer Diagnose der zeitgenössischen gesellschaftlichen Krise, die an entsprechende ÄuBerungen in selner Ubrigen Publizistik erinnert. 6) Die Gespaltenheit des gesellschaftlichen Organismus und der einzelnen seele, die der Grund fur den allgemeinen sittlichen und künstlerischen Verfall 1st, und deren asthetischem Genuß Blok sich in seiner Lyrik ergab, soll durch den Kampf "fur die Ganzheit des Lebens, gegen die Gespaltenhelt der Ästhetik" Uberwunden werden. 7)

1) $v, 241-276$

2) VGl.z.B. "die Hand der Geschichte hat selbst schon das Steuerrad gedreht", V,243 mit S.104/13, Abw. 480); "Und da ist der elnzige Weg fúr einen Menschen, der allein blieb, die Seele verlor, zum Bettler wurde; der Weg zur Tat", V,259 mit dem Schlus des 7.Bildes.

"Peltsche des Sch1cksals", V,261 mit S.67/2; "der Schnee, der unsere Wege verhullt, weht uns den Friniling ins Gesicht", $\mathrm{V}, 261$ mit $\mathrm{S} .102 / 6$, Abw. 446); "das Horn des verirrten Helden", V,27o, 273 mit S.104/4.

3) v, 233-240; Hinweis auf Belyj: v,235.

4) $v, 2391$.

5) V,242. Blok bezieht das Moskauer Kunstlertheater in die Kritik ein: es ist zwar "das beste theater unserer Tage", doch kann "der trligerische Reiz der "Cechovitinan" nicht uber die schwäche hinwegtauschen.

6) Vgl. Einleitungen zum 3. und 4.Bild.

7) $v, 261$. 
Das zeitgenos81sche Theater ist nach Bloks Auffassung dem unmusikalischen Zeitgeist verhaftet und spiegelt die Unkultur einer nur auf billige Zerstreuung bedachten Epoche wider. Dabei beruft er sich auf die Kritik LunaCarskijs am Theaterwesen der Gegenwart, ${ }^{1)}$ die mit der Kritik Lessings ubereinstimmt, die dieser am unwurdigen und dem Wesen echten Volkstums entfremdeten Unterhaltungscharakter des Theaterbetriebs seiner Zeit ubte. 2) Besonderes Gewicht hat jedoch das Zeugnis Wagners, der in der Kunst seiner zeit und besonders im Theater den Ungeist der burgerlichen unnaturlichen, seelenlosen und faulen Zivilisation verkörpert sah, die ihrem einzigen Ziel, dem Streben nach Profit, das Mäntelchen christlicher Nächstenliebe umhängte. 3 ) Die Rettung erwartet Blok von einem neuen Publikum, das an die Stelle des alten, intelligenzlerischen, dem Tod geweihten Publikums treten wird. Diesem neuen, jungen, völkischen Publikum kann das blutleere und esoterische Theater der Gegenwart nicht genügen. Es fordert ein kraftvolles und leidenschaftliches Theater.

"Rußland schwankt $\mathrm{zwischen} z$ wel Extremen. Sein Theater ist schon dabei, auf den Geschmack des intelligenzlerischen Pobels herabzusinken, 4) doch das unmittelbare Gefuhl fur Geschichte sagt uns, daß wir eine andere Wendung des musischen Theaters vorziehen werden: zum reichen Aufbluhen des hohen Dramas mit großen Leidenschaften, mit außergewöhnlicher Handlung, mit tiefem Ideenfluß. Das wird nur dann eintreten, wenn an die stelle der Theaterintelligenz eine neue, junge Intelligenz mit frischer Aufnahmefähigkeit, munterem Geist, neuen Fragen und einer kategorischen "Ja" und "Nein" treten wird."5)

Das Theater der großen Leidenschaften soll die dünnblutigen Stuckchen der Maeterlíncks, Hofmannsthals und Wedekinds hinwegfegen. 6)

1) V,262 mit 2itat aus Iuna Carskijs Artikel "Socializm 1 i skusstvo" (1908).

2) V.263 mit Zitat aus Lessings "Hamburgischer Dramaturgie".

3) V,263f. mit Zitat aus Wagners Schrift "Die Kunst und die Revolution".

4) Vgl. die Realisierung dieser Gefahr im 3.B1Id des IS.

5) $v, 269$

6) $V, 272$. 
Die Vorstufe fur das Theater der Zukunft, das ein echtes Volkstheater sein wird, sieht Blok im Melodrama:

"Ich will nicht viel uber das "Volkstheater" sagen, einfach weil mit diesem Namen schon allerlel Enttäuschungen, Sentimentalitäten und viel alter Trödel verbunden sind. Deshaib verwende ich auch mit grober Furcht den Begriff "Melodrama". Und doch sehe $1 \mathrm{ch}$ auf dem Weg, den das russische Volkstheater in weniger als vierzig Jahren seit seinem Entstehen gegangen 1st, die reale Vorahnung des Theaters der nächsten Zukunft und in der Entwicklung des Melodramas... den ersten Schritt in Richtung eines neuen Theaters der Handlung und Leidenschaften... Ich vermute, da $B$ der Weg $z u$ neuen und geräumigeren dramatischen Formen uber das romantische Theater fuhrt, das auch ein melodramatisches Element enthält."1)

Dieses neue Theater, das einen neuen, leidenschaftilchen Schauspieler und einen neuen, verantrortungsvollen Autor erfordert, wird die verschiedenen zeitgenössischen Experimente in die "Studios" und "intimen Theater" verdrängen. 2) Es wird die kluft zwischen volk und Intelligenz uberwinden helfen. 3 )

Bloks Ausfuhrungen sind die Projektion seines "musikalischen" Weltbilds auf den Fragenkomplex der Erneuerung des Theaters. Die Empfindung, daB die zeitgenössische Bünne an innerer Auszehrung leide, ist angesichts der esoterischen Experimente Mejerchol'ds, der ätherischen Stimmungsmache der Stanislavskijschen techorInszenierungen und der Weltfremdheit der antikisierenden symbolistischen Dramen zu verstehen. Die Lösung, die Blok vorschwebt, 1st jedoch nur eine Potenzlerung seines dionysischen Orglasmus, der die Einheit von Dichter und Volk, die in der Lyrik nicht zu erreichen war, nun auf der Buhne erzwingen sollte. Bloks Hinweise auf die Vorliebe des Volkes fur Schiller, Gogol' oder 0strovskif, 5 ) auf den Unterschied zwischen dem Publikum im Parkett und dem auf den Rängen, ${ }^{6)}$ auf die Tradition des "russischen Volkstheaters" oder auf das Melodrama können nicht daruber hinwegtäuschen, das die empirische Seite seines Referats nicht

1) $v, 273$

2) $V: 274$; das ist ein Angriff v.a. gegen Mejerchol'd.

3) $v, 275$.

4) Sogar Mejerchol'ds Inszenierung von Andrejevs "Žizn' Xeloveka", die Blok begeisterte, interpretierte souverän am willen des Autors vorbe1; $\nabla$ gl. Andrejev, P'esy, S.565f.

5) $v, 256,273$

6) $v, 265$. 
solid begrundet ist. Das "russische Volkstheater", das nun bald vierzig Jahre alt wird, ${ }^{1)}$ hat mit dem Blokschen Volkstheater der Zukunft nur den Namen gemein. Und unter Melodrama verstand Blok kaum eine bestimmte typisch russische Theaterform, ${ }^{2)}$ sondern die Verschmelzung Wagnerianischer Klangekstase mit Ibsenscher Dramatik. Blok blieb der Gefangene seines "musikalischen" Weltbilds, wenn er an die Stelle des esoterischen "dekadenten" Theaters der Halbtöne und feinen kuancen nicht ein "realistisches", psychologisch motiviertes, sondern ein "rhythmisches", melodramatisches Theater der großen Leidenschaften forderte, das allein seiner Fiktion eines "ganzheitlichen", "musikalischen" Volkes genügte. 3 ) Doch nicht nur ir der melodramatischen Form, sondern auch in der geforderten "ideellen Tiefe" sollte das zuküntige Theater dem elementaren Volk gerecht werden. ${ }^{4}$ ) Die Ausführungen Bloks enthalten zwar keinen direkten Hinweis auf den ideellen Gehalt des "Theaters der großen Leidenschaften", doch gibt der SchluB von Bloks Referat "O teatre" hierüber eine recht klare, wenn auch verschluisselte Auskunft:

"Die Geschichte des russischer. Theaters... hat uns einen wunderschönen Mythos erhalten, der wie dje platonische Aramnesis von nun an vor unseren Augen steht." 5 )

Es ist der Niythos von der gefangenen, sich nach Erlösurg sehnenden russischen Volksseele, den Ostrovskij in seinem Drama "Groza" in der Figur der Katerina gestaltet hat, ${ }^{6}$ ) und den Blok mit fast wörtlicher Anlehnung an Ostrovskij im Ls darstellt. 7) In diesem Stuick hoffte Blok, der von inm an das neue melodramatische Theater gestellten Forderung nach "grober Leidenschaft" und "tiefem Ideerfluß" zu genügen und den "schwankenden Boden der Lyrik" zu verlassen. 8)

1) Blok meint wahrscheinlich das 1872 eröffnete "Narodnyj teatr" in Moskau oder ein Unternehmen Ostrovskijs.

2) Das scheint Kluge, Westeuropa und RuBland, S.113 anzunehmen.

3) Die Theateraufführungen der damaligen Zeit, besonders des symbolistischen Theaters, waren ein "synthetisches" Zusammenspiel von Theater, Malerei und Musik; zu Bloks"Balagantik" vgl. IV,568. Blok wollte die schwebend feine Musik durch Siegfriedfanfaren und die "lyrische" Handlung durch Brandsche Heldenhaftigkeit ersetzen. Wagners EinfluB auf Bloks Kunstverständnis wird auch in der UdSSR zunehmend anerkannt.

4) Wagner spricht von "Gedankenkunstwerk".

6) $\mathrm{Vgl} \cdot \mathrm{V}, 276$ 7) $\mathrm{Vgl}$. S.84/2

5) $v, 275$

8) Vgl. dazu die Entstehungsgeschichte, S. 6, 1of. 13 u.ö. 
Bloks Drama "Das Lied des Schlcksals" als besondere Version seines Mythos rom "Ewig-We1blichen".

\section{1.) Mythos und Drama}

In Blok lebt die von Wagner gehegte, von Nietzsche philosophisch vertiefte und in RuBland besonders von vjac. Ivanov theoretisch begrindete Hoffnung weiter, in einem Gesamtkunstwerk, dessen dramatischer Inhalt der Volksmythos 1st, die in der griechischen Tragödie vorgelebte Ganzheitlichkeit des Volkes wieder zu erreichen.

Nietzsche schreibt uber den Gehalt der griech1schen Tragödie:

"Es ist eine unanfechtbare Uberlieferung, daß die griechische Tragödie in ihrer ältesten Gestalt nur die Leiden des Dionysus zum Gegenstand hatte.... daB alle die beruhmten Figuren der griechischen Bihne. Prometheus, Odipus usw. nur Masken jenes ursprilnglichen Helden Dionysus sind...1) In Wahrhelt ist aber jener Held der leidende Dionysus der Mysterien, Jener die Leiden der Individuation an sich erfahrende Gott... Die Hoffnung der Epopten ging aber auf eine Wiedergeburt des Dionysus, die wir als Ende der Individuation annungsvoll zu begreifen haben..."2)

In seiner Deutung des Dionysos-Mythos hat Nietzsche

"alle Bestandteile einer tiefsinnigen und pessimistischen weltbetrachtung und zugleich die Mysterienlehre der Tragödie zusammen: die Grunderkenntn1s von der Einheit alles Vorhandenen, die Betrachtung der Individuation als des Urgrunds des tbels, die Kunst als die freudige Hoffnung, daB der Bann der Individuation zu zerbrechen sei, als die Ahnung einer wiederhergestellten Einheit."3)

Die Musik, die

"unmittelbar hbbild des Willens selbst ist und also zu allem Physischen der Welt das Metaphysische, zu aller Erscheinung das Ding an sich darstellt,4)

ist befähigt,

"den Mythos... zu gebären und gerade den tragischen Mythus: den Mythus, der von der dionysischen Erkenntnis in Gleichnissen redet."5)

1) Derselben Ansicht war Ivanov, Novy je Maski, in: Vesy, 1904. $\mathrm{Nr} .7, \mathrm{~S} \cdot 1-8$. Blok exzerpierte den zitierten Passus in Zap. $\mathrm{kn}$., S.83; vgl. auch V,14.

2) Nietzsche, Die Geburt der Tragödie, 70, S.97ff.

3) Nietzsche, aau, S.99. Blok exzerpierte diese rassage in Zap. kn., 83.

4) Nietzsche, aav, S.135.

5) Nietzsche, aao, S.137. 
In der griechiochen Tragödie offenbart sich der "innerste Abgrund der Dinge" ${ }^{1)}$ in der Musik als dem unmittelbaren Abbild des Weltwillens und Im tragischen Mythos, der, aus dem Geist der Musik geboren, das "Gleichnis der allemuniversalsten Tatsachen", 2) die "Verbildlichung dionysischer Weisheit durch apollinische Kunstmittel"3) 1st. Das musikalische und das dramatische Element bilden eine Einheit. Das dramatische Geschehen, ursprüglich nur eine vision des Chors, ${ }^{4}$ ) ist die symbolische Darstellung des Dionysos-Mythos ${ }^{5)}$ und seines philosophischen Gehalts: im Schicksal des tragischen Helden wiederholt sich das Mysterium des Dionysos, das im Leiden erfahrene Sich-Lösen vom Urgrund des Seins und die Aussicht auf die lustvolle wiederverschmelzung mit dem Ursein.

Die Tragódie ist die "Spitze der unserm Auge erreichbaren Kunstpyramide",6) weil in inr einerseits "der Mythus zu seinem tiefsten Gehalt kommt"7), und andererseits durch ihre Wirkung "die Kluft zwischen den Menschen einem Einheitsgefuhl weicht." 8 ) In inr wird also die Einheit von Individuum und Urgrund und die Einheit von Kinstler und Publikum Ereignis.

Nietzsches Jugendschrift ist

"eine "bertragung der romantischen (polaren) Grundkonzeption Schopenhauers auf den Boden des Altertums...9)

Seine Gabe war, ein Erlebnis kompliziertester Art auszusprechen und auf einen bestimmten Punkt des Altertums anzuwenden. Alles iibrige bleibt begriffliche Konstruktion."10)

1) Nietzsche, aao, S.167.

2) Nietzsche, aao, S.169.

3) Nietzsche, aao, S.174.

4) Nietzsche, aaO, S.88; vgl. Blok, Zap.kn., 83.

5) $\mathrm{Vgl}_{\text {. }}$ auch Nietzsche, aaO, S.88f.

6) Nietzsche, aao, S.207.

7) Nietzsche, aac, S.101.

8) Nietzsche, aao, S.80.

9) Baeumler, Das mythische Weltalter, S.271.

10) Baeumler, aao, S.266. Baeumler trägt eine umfassende Kritik an Nietzsches "Geburt der Tragödie" vor, die nicht nur einzelne Annahmen erschuttert, wie z.B. die, das die tragischen Helden nur Masken des Dionysos seien ( 5.57 , Anm. 6; S.63, 66, 260), sondern auch Nietzsches Mythus-Begriff mit Recht als völlig verfehlt ablehnt (S.266f.). 
Ausgangspunkt Pür Nietz8che war die Musik-Philosophie Schopenhauers und Wagners Opernwerk, in dessen licht er die griechische Tragödie deutete. ${ }^{1)}$ Wagner hatte, ausgehend von einer angeblichen inneren Einheit aller Mythen ${ }^{2)}$ und unter Berufung auf die griechlsche Tragödie, die als Gesamtkunstwerk "Ausdruck des Tiefsten und Edelsten des Volksbemubtseins" sei, 3) in uberaus willkurlicher Weise "urdeutsche" Mythen aus zum Teil recht zweifelhaften Quellen destilliert ${ }^{4}$ und mit einer spätromantisch-orgiastischen Musik verbrämt. Damit wollte er die Einheit von Leben und Kunst, Volk und Kunstler wiederherstellen, die seit dem Niedergang der griechischen Tragödie verloren war. Die Gewähr fur die Volkhaftigkeit war vor allem, das im Musikdrama im Mythos der objektivierte Volksgeist zu Wort kam.

In seiner Deutung des Mythos knupfte Wagner an romantische Vorstellungen an, verkannte aber, wie später Nietzsche, völlig den religiösen Charakter des Mythos und den Kultcharakter der Tragödie. Der Mythos war fur ihn ein Kunstwerk, das jederzeit zu neuem Leben erweckt werden konnte. Wagners ÄuBerungen verdienen kurz angefuhrt zu werden, weil sie fur Blok richtunggebend sind.

"Im Mythos erfaßt die gemeinsame Dichtungskraft des Volkes die Erschelnungen gerade nur noch so, wie sie das leibliche Auge zu sehen vermag, nicht wie sie an sich wirklich sind... Aller Gestaltungstrieb des Volkes geht im Mythos somit dahin, den weitesten Zusammenhang der mannigfachsten Erscheinungen in gedrängtester Gestalt sich zu versinnlichen: diese zunächst nur von der Phantasie gebildete Gestalt gebart sich, je deutlicher sie werden soll, ganz nach menschlicher Eigenschaft, trotzdem inr Inhalt in Wahrheit ein Ubermenschlicher und ubernaturlicher 1st... Das Unvergleichliche des Mythos ist, das er jederzeit wahr, und sein Inhalt, bei dichtester Gedräng theit, fur alle Zeiten unerschöpflich ist. Die Aufgabe des Dichters war es nur, inn zu deuten..."5)

1) Vgl. Nietzsche, aao, S.45, 159, 168ff., 178, 188f., $193 \mathrm{ff}$. u.ö.

2) VgI. Wagner, Hauptschriften, 5.63 uber die Identität des uythos vom "Fliegenden Holländer" mit Odysseus, uber den Grundzug des Lohengrinmythos im griechischen My thos usw.

3) Wagner, aao, S.108 (Die Kunst und die Revolution); S.116ff. (Das Kunstwerk der Zukunft) u.ö.

4) Vgl. Reich, Wagner, S.131f. uber den "Fliegenden Holländer"; S.144 uber den "Tannhäuber", hier erhebt sich Wagner zum "Volksauge", das das wahre Wesen des Mythos aus dem Trumerhaufen der vielfältigen tberlieferungen "ersieht"; S.169ff. uber den Siegfried- und den Nibelungen-Stoff; S.219 liber den "Parsifal".

5) Wagner, Hauptschriften, S.134ff. 
Im Mythos glaubte Wagner, der feindseligen Kälte der Gegenwart entfliehen zu können und dem ganzheitlichen , "wahren Menschen" zu begegnen, der sein Ideal für die zukunft war.

Das Mythosverständnis Wagners und Nietzsches ist völlig unhistorisch und läßt der subjektiven Willkür freien Raum. Esoterische Kunstwerke, bei denen psychologische Komplexe des fin-de-siècle in griechische oder germanische Sagengestalten projiziert wurden, erhoben den Anspruch, als Deutung oder Neubelebung alter Mythen die Ganzheit der griechischen Tragödie wiederherstellen zu können. Diesen von einer hochst willkfirlichen kunstphilosophischen Fiktion getragenen Glauben hegte auch vjat. Ivanov und mit inm eine ganze Reihe russischer Symbolisten, die hofften, in der "Mythenschopfung" (mifotvorcestvo) die Einheit von Dichter und Volk wiederzuerlangen. ${ }^{1)}$

Von seinen geistigen Anregern ubernahm Blok die Vermengung zweier qualitativ grundlegend verschiedener Mythos-Begriffe. Er unterschied nicht zwischen dem "primären" Mythos, dem Produkt eines historisch frïhen Bemutseins, der als Gemeinbesitz des Volkes von kollektiver Reichweite ist, und späteren, literarischen, "sekundären" Mythen, die archetypisch nur im Sinne der Psychologie Jungs, keinesfalls aber urzeitlich im sinne der Frïhgeschichte sind. ${ }^{2)}$

Bloks Mythos vom "Ewig-Weiblichen" ist rein literarischer Natur, auch wenn der Dichter seine uberindividuelle Geltung durch zahlreiche Anleihen bei "primären" Mythen und deutliche Bezugnahmen auf literarische Vorbilder sichern wollte. Bloks Mythos lebt völlig in und aus der literatur. In seiner spezifischen Ausformung ist er - im Gegensutz zu jedem echten Mythos - völlig privat. Als literarisches Gebilde ist er, im Unterschied zum

1) Vgl. West, Russian Symbolism, v.a. S.76ff., 137ff. mit Hinweis auf Blok, S.142. Zum symbolistischen Theater in RuBland vgl. Dukor, Problemy dramaturgii simvolizma, in: Literaturno je nasi edstvo, 27-28, S.106-166.

2) An diesem Punkt setzt Baeumlers Nietzsche-Kritik an. 
"primaren" Mythos, nicht nachrollzogen. Er ist keine "Aufdeckung" eines vorhistorischen Mythos, sondern er 1st hervorgebracht, ersonnen, erdichtet. 1) Als "sekundärem" Mythos fehlt inm die kollektive Relevanz, die das gesamte Volk umspannende Reichweite, die sich Blok in seiner Vermengung der Begriffe erhoffte. ${ }^{2}$ ) Blok hatte schon 1905 die Ideen Ivanovs von der Aussöhnung des Dichters mit dem Volk "im Iichte des verbindenden Mythos" volifg kritikl08, gleichsam als wissenschaftich gesicherte Erkenntnis, Ubernommen. ${ }^{3)}$ Anfang März 1908 hörte Blok in Petersburg Ivanovs Vortrag "Dve stichi1 $v$ sovremennom simvolizme" (Zwei Elemente Im zeitgenössischen Symbolismus), in dem Ivanov seine Kunstphilosophie vortrug. ${ }^{4}$ Als Hauptgedanke dieses Vortrags notierte sich Blok:

"Der Mythos ist die objektive Wahrheit uber das Seiende."5) Aus dieser tberzeugung heraus entstand sein Vortrag "O teatre", aber auch das LS, mit dem Blok ein Gesamtkunstwerk schaffen wollte, dessen Inhalt trotz einiger griechischer und germanischer Relikte die russische "Deutung" des Mythos vom "EwigWeiblichen" hätte sein sollen, und um das sich das "dunkle" Volk im Wiedererkennen eigener Traumbilder in der magischen Verzauberung hätte scharen sollen, wie es Blok am Schluß von "O teatre" uber das Publikum von Ostrovskijs "Groza" ausfuhrte. 6) Bloks Tragik lag darin, daB er unter dem EinfluB wagners und Nietzsches an die Verankerung seines trotz zahlreicher literarischer und mythologischer "Rückversicherungen" völlig privaten Mythos Im "Volk" glaubte - wie hätte ein Mythos denn nicht volk-

1) Schon im Terminus "mifotvor Cestvo" ist die Bloksche Verquickung enthalten.

2) Vgl. zur gegenwärtigen Diskussion Wellek-Warren, Theorie der Iiteratur, S.168ff. mit Anmerkungen.

3) Vgl. S.70/9.

4) Der Vortrag erschien in "Zolotoje runo", 1908, $\mathrm{Nr} .3 / 5$; er ist wiederabgedruckt in Ivanov, Po zvezdam. ther Inhalt und Bedeutung vgl. Stepun, Myst. Weltschau, S.221ff. und West, Russian Symbolism, S.5off.

5) Zap.kn., 104, Eintrag vom 8. März 1908 (21tat aus Ivanov; vgl. das Z1tat aus Wagner).

6) $v g 1 . v, 276$ 
haft sein können? -, in einem Volk, das er sich "musikalisch", "rhythmisch", "ganzheitlich" dachte und das sich, als er es kennenlernen wollte, als Fiktion herausstellte, an die zu glauben er trotzdem nie aufhörte. 


\section{2.) Bloks Mythos rom "Ewig-Weiblichen" im "Lied des Schicksalg"}

Das LS 1st die Projektion des Mythos von der Begegnung des Erlösers mit der gefangenen "Ewigen-Weiblichkeit", dem Scheitern dieser Begegnung nach der "helligen Hochzelt" und der VerheiBung einer Wiederbegegnung in den Raum des persönlichen und kollektiven Schicksals. Blok hat offensichtlich sein eigenes Leben und das Verhältnis von Volk und Intelligenz im Lichte dieses Mythos verstanden. Dies erklärt die Vermengung von biographischen und kulturphilosophischen Elementen im LS.

Ohne $Z$ weifel versuchte $B l o k$, in seinem Stuck die in nO teatren vorgetragenen Ideen $z u$ verwirklichen. Die Unterschiede $z$ wischen den früheren Stucken Bloks und dem LS fügen sich zwangslos in den Gegensatz von "lyrischem Drama" und "Melodrama" - in Bloks subjektivem Verständnis - ein. Das betrifft die Idee so gut wie einzelne Strukturelemente.

Sowohl den "lyrischen Dramen" als auch dem LS liegt der Bloksche Mythos rom "Ewig-Weiblichen" zugrunde. Das LS soll offenbar eine umfassende, alle Aspekte des "Ewig-Weiblichen" einbeziehende Darstellung dieses Mythos geben, der in Bloks Lyrik und in den lyrischen Dramen nur in Splittern, Ausschnitten und Bruchstucken sichtbar wird und nur in der synopse erahnt werden kann. Nicht in einem vagen "Wechsel der Masken", 1) sondern in einer zusammenhängenden, fortschreitenden Abfolge der verschiedenen Hypostasen sollte sich das "Ewig-Weibliche" offenbaren. Bloks Versuch, seinen Mythos aus der subjektiven Perspektive des "lyrischen Helden" selner Gedichte und der männlichen Helden seiner lyrischen Dramen ${ }^{2}$ herauszulösen und inn

1) So sieht es Gromov, A. Blok, jego predsestvenniki 1 sovremennik1, S.313, der keinen Úterschied zwischen Bloks Lyrik und dem IS macht.

2) Die subjektive Perspektive ist besonders augenfällig im "Balagantik", dessen Geschehen sich am SchluB als Phantasiegebilde des Plerrot herausstellt, und in der "Neznakomka", deren drei "Erscheinungen" Tagträume und Alkoholphantasien des "Dichters" sind. 
objektiv erscheinen zu lassen, gelang insofern, als German und Faina in gleicher Weise unter dem $Z$ wang des Mythos stehen, beide eine Entwicklung durchmachen und der Mythos nicht nur die Vision des männlichen Helden ist. ${ }^{1)}$

Eine weitere Folge von Bloks Bestreben, seinen Mythos in der Realität zu verankern, ist die Ausweltung der raum-zeitlichen Sphäre des LS aus der Abgeschlossenheit der Schaubude (Im "BalaganCik"), der Enge der Kneipe, Straße und Bürgerstube (in der "Neznakomka") und der Begrenztheit einer geschlossenen Stadt (im "Korol' na ploščdi") in die Weite RuBlands, seiner verschiedenen Räume und Zeiten. Diese Ausweitung hat, wie das IS zeigt, jedoch nicht zu mehr "Realismus" oder "Lebensnähe" bei Blok gefuhrt.

Blok wollte im IS offenbar sein lyrisches Werk, das seinen Mythos nur in disparaten Bruchstücken widerspiegelte, und seine Publizistik, die sein "musikalisches" Weltverständnis in undichterischer, unkünstlerischer Form wiedergab, in die Gestalt eines objektiven Mythos zusammenfassen und seinem Gesamtwerk damit die elnheltliche, klunstlerisch uberhöhte und damit besonders wirkungsvolle Ausrichtung geben. ${ }^{2)}$ Wie Bloks langer Brief an Stanislavskij vom 9. Dezember 19083) zeigt, hatte er an der objektiven Realität seines "Themas Rußland" keinen Zweifel, eines Themas, das inn "seit dem Beginn seines bewnBten Lebens" beschäftigte, und das er als von außen inm aufgetragen ansah, als "Edelstein", den er nur nicht habe "schleifen" können, dessen Wert aber dadurch nicht gemindert sei. Das LS zeigt, daB

1) Hier muB Volkov, Blok i teatr, S.88ff. widersprochen werden, der in German die einzig "reale" Person des LS sieht und meint, das LS handle "nur von German". Ihm folgen Medvedev, Dramy i poèmy, S.57f.., Rubcov, Lramaturgija Bloka, S.65f.; anders urteilt Gromov, "Yesnja sud'by", in: Geroj i vremja, S.506.

2) Bonneau, L'univers poétique d'Al. Blok, S.435, 447, 450 u.ö. betrachtet Bloks Theater nur als Nebenprodukt seines lyrischen Werks: "le Théatre de Blok... n'est qu'un reflet de sa Poésie". Sie sieht weder den Unterschied des IS zu den "lyrischen vramen", noch bemerkt sie, daß Blok im LS gerade auch seine Lyrik ideell ausrichten wollte, sondern sie glaubt, mit einer Aufzählung der Selbstzitate sei der Gehalt der Dramen und besonders des LS erschöpt.

3) VIII,265-267; vgl. Entstehungsgeschichte, S.27ff. 
Bloks "Thema RuBland" sein privater Mythos vom "Ewig-Weiblichen" ist, der sich weder in der Projektion auf die Prage nVolk und Intelligenz", noch in der melodramatischen, aus dem "Geiste der Musik" geborenen Darstellung in einem Gesamtkunstwerk als objektiv gultig erwies und damit die "Ganzheitlichkeit des Lebens" hatte erwirken können.

Die Frage 1st, ob Bloks Scheitern mit dem LS von seiner Unfähigkeit herruhrt, sein "Thema" zu "schleifen", wie er selbst offensichtlich glaubte, oder ob nicht das Thema selbst der Grund fur den MiBerfolg war. Der esoterische Charakter des Stucks steht außer Zweifel, ebenso das Fehlen einer psychologisch vertieften Motivation der Gesamthandlung und einzelner Episoden. ${ }^{1)}$ Nur mit viel Phantasie und einiger Anstrengung kann man im Konflikt zwischen German und Faina das Problem "Volk und Intelligenz" erkennen. Blok selbst hat, wie die Entstehungsgeschichte zeigt, unter den "verdammen Abstraktheiten" gelitten. Die sovetischen Forscher lösen das Dilemma, Indem sle einerseits die Mängel des Stucks hervorheben, andererseits die Bedeutsamke1t des Themas unterstreichen und das IS als einen entscheidenden Wendepunkt in Bloks Schaffen ansehen. Das IS sei zwar kunstlerisch nicht gelungen, es habe aber fur Blok den Weg zu einem realistischeren Verhältnis zu den Schicksalsfragen der Nation eröffnet: die Größe des Themas wiege die küstlerischen Unzulänglichkeiten auf. ${ }^{2)}$

1) Vgl. Volkov, Blok 1 teatr, S.9off.; Medvedev, Dramy 1 poèmy Bloka, S.58; Orlov, Blok, S.170; Rubcov, Dramaturgija A. Bloka, S.65f.

2) Vgl. Volkov, Blok 1 teatr, S.931.; Medvedev, Dramy 1 poèmy Bloka, S.60; Dukor, Problemy dramaturgil simvolizma, in: Ilt.nasl. 27-28, S.160; Orlov, Blok, S.170; Rubcov, Dramaturg1 ja Bloka, S.70; Gromov, "Pesnja sud'by", In: Geroj 1 vremja, S.494f., $497 \mathrm{ff}$; ders., Blok, S.312ff.; Dolgopolov, Anmerkungen zu IV, S.560f.

Gromov, der das is am ausfuhrlichsten behandelt, unterstreicht seine große Bedeutsamkeit für Bloks Entwicklung. Er sieht im IS eine entscheidende Vertiefung von Bloks Weltverständnis, was sich einerseits darin zeige, daB Blok die Möglichkeit einer Aussöhnung der Intelligenz in ihren besten Vertretern mit dem Volk erkannt habe, und $d a b$ er andererseits im 5.B1ld das Problem "Volk und Intelligenz" in seiner historischen Perspektive besser begriffen habe. Das dichterisch ungleich wertvollere Ergebnis dieser Neuorientierung sel der Zyklus "Na pole Kulikovom". Anstatt Blok von seinem zugestan- 
Diese Deutung halte ich firr abourd. Bloks Weltverständnis war weder friuher noch später "realistischer" als im IS, wenn man darunter versteht, daB er sich von seiner mythischen, die Welt und die Geschichte nur in der Brechung seiner mystisch-irrationalen Denk- und Gefilhlskategorien erfahrenden Welthaltung gelöst und sich aus dem Bann seiner Visionen befreit habe. Ebenso wie seine mystischen Erlebnisse immer nur autistischen Charakter tragen, ist auch sein Mythos vom "Ewig-Weiblichen" und dem "Geist der Musik" ein nur privater. ") Die stark biographische Färbung des $\mathrm{LS}^{2}$ ) und seine Esoterik, die sich nicht zuletzt in zahlreichen Selbstzitaten äuBert, sind die direkte Folge von Bloks Autismus. Blok hielt einfach seine eigenen Bilder und Symbole und seine Anspielungen auf Mythen, auf die Bibel, auf andere Werke der Weltliteratur usw. fur real und verständlich. Große Teile seines dichterischen Werks sind mehr oder weniger Montage. Das dialektische Ich-Welt-Verhältnis war bei Blok ein Ich-Literatur-Verhältnis, was wenig dazu geeignet war, die ständige Selbstbesplegelung zu durchbrechen, zumal Blok auch in der Literatur immer nur die Bestätigung seines eigenen Mythos suchte. Das Fehlen von psychologischer Motivation im IS ist Ausdruck der mythischen Grundstruktur. Der

denermaßen "musikalischen", Idealistischen und mystischen Weltverständnis her zu interpretieren, versucht Gromov krampfhaft, Blok einen Sinn auf die soziale Problematik seines Themas zu unterschieben und wundert sich, das im Verhalten der Faina "kein klares sozial-geschichtliches Motiv" zu entdecken ist. Die Aussohnung zwischen Intelligenz und Volk hat bei Blok nicht das geringste mit einer "berwindung sozialer Schranken zu tun, sondern wird als "unio mystica" empfunden und $z$ war sowohl im LS wie in den KulikovoGedichten, die allerding 8 als kunstlerisch wertvoller gelten kónnen als das 5. Bild des LS.

1) Der Ausdruck "privater Mythos" ist eigentlich eire contradictio in adjecto, die allerdings das Problem des LS und der Weltanschauung Bloks am besten umschreibt.

2) Vgl. Volkov, Blok 1 teatr, S.93; Medvedev, Dramy 1 poèmy Bloka, S.59f.; Bonneau, L'univers poétique d' A. Blok. S. 428 , die Medvedev zitiert; Gromov, "Pesnja sud'by", in: Geroj i vremja, S.520; Rubcov, Dramaturgija Bloka, S.80. Alle berufen sich auf Zorgenfrej. A.A. Blok, in: Zapiski mextatelej, 1922, Nr. 6, S.135 (vgl. Entstehungsgeschichte, S.12) und Beketova. Blok, S.101 (vgl S.43/9). Der Vorwurf, das LS sei "allzu persönlich" (Zorgenfrej), ist absurd; er müßte gegen Bloks gesamtes Schaffen erhoben werden. 
Mythos, wie inn Wagner und N1etzeche begriffen, konnte als "Abbreviatur der Erscheinung", als "zusammengezogenes Weltbild" das "Wunder nicht entbehren". 1) "Psychologien, "Wahrscheinlichkeit" usw. sind Kategorien, die auf den Mythos nicht anwendbar sind. 2) Er spiegelt den allgemeinen Weltwillen; ${ }^{3)}$ der menschliche Wille fehlt in ihm, denn die Menschen sind

"tanzende Schiffe, die widerstandslos das Leid, den Kampf, die Ilebe, die Erlösungssehnsucht ihres untermenschlichen Meeres mitmachen, und uber die in jedem entscheidenden Augenblick, statt der Begegnung aneinander und der eigenen Schicksalstiefe nur die Weltroge des Schopenhauerschen willens hinweggeht." 4)

Diese auf Wagner bezogene ÄuBerung gilt auch fïr Blok.

1) Nietzoche, Die Geburt der Tragödie, $70,5.179$.

2) Vgl. Nietzsche, aaO, S.143, 178f. Das gilt auch filr Dostojevsk1 j8 "Idiot".

3) Vgl.S.84/15 und $16 ; S .104 / 13$.

$4)$ Bloch, Wegzeichen der Hoffnung, S.131. 


\section{3.) Der mythische Charakter der Handlung}

Der mythische Charakter des LS zeigt sich deutlich im Schicksal der beiden Hauptgestalten. German durchläuft die folgenden Hypostasen:

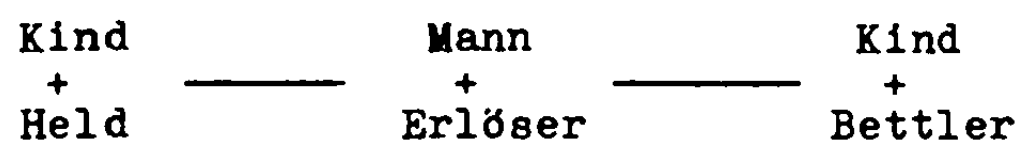

Sein Schicksal ist das der Reifwerdung und des Zuruckfallens in die Kindlichkeit und die gleichzeitige Wandlung vom Helden zum Bettler. Es vollzieht sich in der Begegnung mit den verschiedenen Hypostasen des "Iwig-Weiblichen", das in Faina verkörpert wird.

German begegnet

im 1.Bild dem disparaten Komplex aus "Musik", "Weite", "Wind" etc., der Andeutung ihrer geheimnisvolien Größe und der Andeutung ihrer Dirnen-Hypostase;

im 2.Bild ihrem kosmischen Aspekt;

im 3.Bild ihrer Dirnen-Hypostase;

im 4.B1ld ihrer Volksmädchen-Hypostase, die jedoch von der Dirnen-Hypostase noch verdunkelt ist;

im 5.B1ld der unverfälschten, kosmische Züge tragenden Volksmädchen-Rus ${ }^{\circ}-$ Hy postase ;

im 7.Bild der in den Bann des Bösen zurückfallenden Volksmädchen-Hypostase.

Dieses Schema wird dadurch angereichert, daß der Faina als dem jetzt und heute regierenden dionysischen "Ewig-Weiblichen" das statische, apollinisch-klassische Ideal der Helena gegenübergestellt wird. Damit erscheint Germans Weg, die Abkehr von einem uberholten und die zuwendung zu dem heutigen Ideal, als eine Art Konversion. Wie einst die Ekklesia über die Synagoge, die Sophia iber Aphrodite siegte, so siegt jetzt die russische Faina liber die westliche Helena. ${ }^{1)}$

1) Die "Dreiockgeochichte", German zwischen zwe1 polaren Frauentypen, erinnert an Wagner (z.B. "Tannhäuser"), Bizet ("Carmen"), v.a. aber an Ibsens "Catilina" (vgl. VI,9of.). 
In Gegensatz zu Bloks lyrischen Dramen, v.a. zur "Neznakomka", findet im LS zwischen dem männlichen Helden und dem "Ewig-Weiblichen" elne wirkliche, die Fesseln der Individuation sprengende Begegnung statt. Diese 1st nach des Weltwillens unerforschlichem RatschluB nur vorläufig, aber belde Gestalten leben in der Hoffnung auf eine wiederbegegnung. Diese Zukunftsperspektive fehlt in den lyrischen Dramen völlig. Auch die ubrigen Hauptgestalten des LS erfahren an sich das Walten des Weltwillens. Das Scheitern des Mönchs wird durch die Gewibhelt aufgehoben, daB sein Suchen von einem Andern fortgesetzt wird. Helena erkennt die Macht des dionysischen "Ewig-Weiblichen" an. Der Freund wird in seiner MittelmäBigkeit weder dem einen noch dem andern Frauenideal gerecht. 


\section{4.) Der mythische Charakter der Raum- und Zeitstruktur}

Die Räume des LS und das in ihnen ablaufende Geschehen kann man schematisch folgendermaben darstellen:

\begin{tabular}{|c|c|c|c|}
\hline ort: & Herrenhof & Stadt & Russ.Land \\
\hline Charakter: & $\begin{array}{l}\text { naturlich } \\
\text { halboffen }\end{array}$ & $\begin{array}{l}\text { kunstlich } \\
\text { geschlossen }\end{array}$ & $\begin{array}{l}\text { naturlich } \\
\text { offen }\end{array}$ \\
\hline Handlung : & runig & bewegt & bewegt \\
\hline Personen: & Individuen & Menge & Individuen \\
\hline Darstellung: & $\begin{array}{l}\text { uberhöht } \\
\text { verhalten }\end{array}$ & satirisch & $\begin{array}{l}\text { uberhöht } \\
\text { pathetisch }\end{array}$ \\
\hline
\end{tabular}

Die Räume des LS sind mythische Größen, mythisch-visionäre tberhöhungen bzw. Verzerrungen der Wirklichkeit. 1) Der mythische Charakter der Räume des IS äußert sich besonders auch darin, daB der Bilhnenraum immer wieder vor "evozierten" Räumen zuriicktritt, so z.B. in der Erzählung des Mönchs im 2.Bild, im Märchen der Faina im 4.3ild und im tionolog Germans im 5.Bild. Die dort beschworenen Schauplätze (Landschaft am Fluß; Märchenlandschaft; Kulikovo pole) miiBten bei einer dem IS gerecht werdenden Inszenierung optisch sichtbar gemacht werden.

Blok fügt das Geschehen des LS in den Gang der Jahreszeiten ein und knüpft deutlich erkennbar an den Jahreszyklus der verschiedenen Mythologien mit ihrem Wechsel von Geburt, Hochzeit, Tod und Wiedergeburt an. Dem Jahreszyklus ist der Wechsel von Tag und Nacht ${ }^{2)}$ eingeordnet.

1) Vgl. die Einleitungen zu den jeweiligen Bildern. Unzureichend lst Volkov, Blok i teatr, S.87f., dessen Gegenuberstellung von Stadt und Land iberdies zu einfach ist. Das obige Schema ist, bel allen Aufweichungen in Detail, fiir weite Teile von Bloks Werk maBgebend.

2) Der Wechsel von Tag und Nacht erinnert an das Drama "Korol. na plołxadi", das am Morgen, am Mittag und in der Nacht eines einzigen Tages spielt. 
D1e Zeiten des IS kann man schematisch folgendermaBne darstellen:

\begin{tabular}{lcccc} 
& Prilhjahr & (Sommer) & Herbst & winter \\
\cline { 2 - 5 } Abend & 1.Bild & & & \\
Nacht & 2. Bild & $\begin{array}{c}3 . \text { Bild } \\
4 . \text { Bild }\end{array}$ & & \\
Morgen & & & 5. Bild & \\
Tag & & & & 6. Bild \\
& & & & 7. Bild
\end{tabular}

German verläbt sein Haus im Frühjahr bei Sonnenuntergang. Hier ist die Jahreszeit Symbol des Aufbruchs, die Tageszeit Symbol für die "abendländische", "untergehende" Welt von Germans Haus. Die beiden Grobstadtbilder spielen in der Hollennacht; die stadt hat am Vegetationszyklus keinen Anteil. Das 5.Bild spielt im Herbst, Bloks "russischer Jahreszeit"; es beginnt am frîhen Morgen und erreicht seinen Höhepunkt mit der Begegnung von German und Faina vor dem Hintergrund der aufgehenden Sonne. Hier 1st, wie im 1.Bild, die astralmythische symbolik ("ex oriente lux") offenkundig. " Die beiden letzten Bilder spielen gleichzeitig bei Tag im winter, das 6. Bild in einer ruhigen, das 7.Bild in der mythischen Blokschen Schneesturmlandschaft. Der Zeitstruktur des LS liegt kein physikalischer, sondern ein mythischer Zeitbegriff zugrunde. ${ }^{2}$ ) Das Geschehen ist durch das Zusammenwirken von zwei my thologischen Zeitkreisen gekennzeichnet. Dabel strukturiert der Jahreszyklus den Handlungsablauf als Ganzes, während die Symbolik des Tag-Nacht-Kreises mehr punktuell auf die Bedeutsamkeit des einzelnen Bildes einwirkt. Doch gibt letztlich nur das Zusammenspiel beider Zeitkreise dem Jewelligen Handlungsabschnltt das inm elgentumliche Gepräge.

1) Vgl, dazu Goldammer, Der Mythus von Ost und West, v.a. S. $35 f f$.

2) Das gilt fur Bloks Werk uberhaupt. Zur Bedeutung der Jahreszeiten fur Blok vgl. Triomphe, Sous le signe du printemps, RES, Mélanges Plerre Pascal, 1961, S.197. 
Die Jahreszeitensymbolik spielt eine entscheidende Rolle in der Mythologie der Vegetationsgötter. ${ }^{1)}$ besonders im Dionysos-Mythos, der fur Blok im Gefolge Vjac. Ivanovs einerseits die Brucke zum Mythos des "Ewig-Weiblichen" schlug, 2) andrerseits der Ausgangspunirt fur die Verbindung von Mythos und dramatischer Form war.

Der mythische Charakter von Handlung, Raum und Zeit erklärt auch, daß der Versuch einer Zuordnung des LS zum "geschlossenen" oder "offenen Drama" 3) Unbehagen bereitet. Die Kriterien, die eine solche Zuordnung erlauben, erweisen sich in Bezug auf das LS als unbefriedigend und als nur teilweise relevant. So sind die Räume des LS, was ihren "empirischen" Aspekt angeht, vielfältig und "speziell".4) "toer der Vielfältigkeit der Empirie steht aber die Einheitlichkeit des Mythos; die Räume beziehen ihre Bedeutsamkeit aus ihm, nicht aus der Empirie. Das LS spielt insgesamt in einem Raum: in Bloks mythischer "Rus"".

Die Zeiten des LS sind ebenfalls "uneinheitlich". In "physikalischem" Sinne ist jedes Bild ein "Ausschnitt". 5)

Volkov bemerkt zur Zeitstruktur des IS:

"Vom Gesichtspunkt der Entwicklung der Handlung benötigt das LS keine "Jahresfrist": es könnte in den Zeitraum von einigen Monaten oder in den Zeitraum von einigen Wochen zusammengedrängt werden."6)

Diese vom Standpunkt des "Realisten" vollig einleuchtende Bemerkung verkennt das Wesentliche, den mythischen Charakter von Bloks Zeitbegriff. Die verschiedenen, in der Empirie "speziellen" Zeiten sind im mythischen Zeitbegriff "einheitlich"; die Zeiten des IS sind sowohl "Ausschnitt des Ganzen" als auch "Kontinuun"?) Dasselbe gilt fiir die Handlung. Diese Zwitterhaftigkeit ist Ausdruck von Bloks dualistischem Weltbild.

1) Tammuz, Attis, Osiris (vgl. James, Religionen der Vorzeit, S.177ff.); diese Vegetationsgötter sind die abhängigen Partner der souveränen weiblichen Gottheiten Astarte, Kybele und Isis (vgl. Einleitung zum 5.Bild).

2) Vgl. die Einleitung zum 5.Bild, S.291ff.

3) Klotz, Geschlossene und offene Form im Drama.

4) Klotz, aao, S.125.

5) Klotz, aaO, S.113.

6) Volkov, Dramy 1 poèmy, S.88.

7) Klotz, Geschlossene und offene Form im Drama, S.115 u.ö. 
In engem Zusammenhang mit der mythischen Zeltetruktur des IS steht die Anzahl der Bilder. In deutlicher Anknupfung an die Symbolik der Zahl Sieben wollte Blok die Fulle eines ganzen Lebensabschnittes und einer ganzen Epoche in oleben Bildern einfangen. 


\section{5.) Sprache und Musik. Das LS als "Gesamtkunstwerk".}

Der mythische Charakter des IS prägt auch die Sprache des Stlicks. Es war offenbar Bloks Absicht, die Personen des LS "realistisch" sprechen zu lassen. Man kann deshalb im LS mehrere stile unterscheiden. Hierbei ist jedoch zu beachten, daB die Personen als "Yedien metahistorischer Wesenheiten" keine im eigentlichen Sinne normgerechte Sprache sprechen, sondern hybride, zwischen "Echtheit" und "Unechtheit" schwankende Sprachen, die sich zwar "realistisch" gebärden, aber eben nur nach der Realität schielen. ${ }^{1)}$ Die Redewelse des Mönchs ist bestimmt von der Häufung biblischer Ausdricke und Wendungen. Doch hat wohl kaum ein russischer Mönch je so geredet. Auch die "volkstiumliche" Sprache der Alten und des Hausierers ist keine Volkssprache, sondern ein stilisiertes Kunstprodukt. Die Sprache der Städter im 3. und 4.Bild und in der Bahnhofsszene, des greisen Professors, des Redrers, der Schriftsteller, der Freunde usw., ist eine satirische therspitzung des populär-wissenschaftlich-dozierenden, politisch-deklamatorischen, literarisch-phrasenhaften "städtischen" Jargons, der nur deswegen noch heute "echt" wirkt, weil Satire heute mehr ijerzeugt als Pathos.

Die Hauptpersonen des LS sprechen ihre Individualsprache, die starken stimmungswert hat. So ist die Sprache der Helena, v.a. in der Unterhaltung mit German und dem Mönch, verhalten, auf unechte Weise einfach und alltäglich. Der intime Gesprächston soll ein Spiegel ihres ruhigen, "adligen" Wesens sein. Aber wie Helena hat wohl nie eine junge russische Landadlige geredet. Germans Redeweise ist einerseits verhalten und einfach; sein Gebet im 1.Bild entspricht der weichen Stimmung des gesamten Bildes. Andererseits ist er Ekstatiker, und seine lyrischen Erglisse im 3. und 5.Bild leben fast ebensosehr vom ekstatischen Ton, vom Pathos wie vom Inhalt. Auch hier darf man bezweifeln, dab ein noch so "auserwählter" Intelligenzler in RuBland je

1) Vgl. 2um Folgenden zahlreiche Anmerkungen im Kommentarteil, die hier im einzelnen nicht nochmals aufgefuhrt werden. 
80 geredet hat. In der Sprache der Faina, die Blok "volkstümlich" stilisierte, 1st ebenfalls das Atmosphärische entscheidend. Ihre Märchenerzählung im 4.B1ld, ihr Lied im 3.Bild, ihre ekstatischen Ausbriche im 5.Bild und ihr selbstbemater Ton im 7.Bild, - all das bezieht seinen "Informationswert" ebensosehr vom Stimmungs- wie rom Sinngehalt. Dasselbe gilt von den Regieanwelsungen, die zum groBen Tell lyrische Prosa sind.

Besonders eigentülich für das LS ist der "leitmotivische" Gebrauch einzelner Ausdrücke, Wendungen, Bilder, Handlungselemente usw. Einzelne Motive werden in Nah-oder Fernwirkung analogisch oder kontrastierend wiederholt, varifert, ergänzt oder weitergefuhrt. Häufig sind es Bloksche Kernsymbole wie Wind, Traum, Ferne, Schwan, Feuer, Troika, Blick, Weg, Spiegel usw., aber auch "Philosopheme" wie Menschwerdung, Gewissen, Leiden, Erlobungssehnsucht usw., die immer wieder verwendet und angesprochen werden.

Dieses leitmotivische Prinzip im is entspricht der strukturelien Besonderheit von Bloks Lyrik, die eine relativ begrenzte Anzahl von Leitsymbolen in immer neuer Welse verkmupft und varilert. Als Rechtfertigung der Anwendung dieses Prinzips im Drama konnte Blok die Theorie Wagners vom Leitmotiv als kleinster strukturbestimmender Einheit seiner Operndramen betrachten, 1) die er schon aus Wagners Fruhschrift "Oper und Drama" kannte. ${ }^{2}$ ) Das Leitmotiv Wagners hat keinen ornamentalen, sondern einen sinntragenden Wert und bringt die Grundmotive der Handlung in ihrem vollen ideellen und gefuhlsmäßigen Gehalt zur Geltung. 3)

Das leitmotivische Prinzip, das Blok im IS anwandte, ist nur ein, allerdings wesentlicher Hinweis auf den musikalischen Charakter des LS. Die Musik ist in Bloks Drama allgegenwärtig; das IS verlangt geradezu nach musikalischer Ergänzung. Schon die Eroffnung des Stücks 1st ohne Klangmalerei nicht zu realisieren. Im 1.B1ld "singt der Wind wie das lied des Schicksals": gleichsam im Vorgriff ist das Lied der Faina zu hören.

1) Wagner spricht von "Grundmotiv". "Grundthema".

2) Blok war diese Schrift bekannt; vgl. VI,107, VII, 362.

3) Vgl. Wagner, Hauptschriften, S.166f. 
Das 3.Bild lebt von Musik, "überall ist Wind und Musikn, die Zeitungsverkäufer singen, eine Frauenstimme singt von Freiheit, Faina singt das "Lied des Schicksals". Im 4.Bild sind Musikanten da, die offensichtlich die Diskussionen mit Musik begleiten. Auch die Märchenszene lst ohne akustische Untermalung schlecht vorstellbar. Voll von musikal1sch-akust1scher spannung ist das zentrale 5.B1ld. Man hört in der Ferne verschiedene Geräusche, so das Pfeifen des Zuges und Trolkaglöckchen. Die Auftritte der Faina und Germans sind ohne Musik undenkbar: das "Weltorchester" greift sichtbar ins Geschehen ein. Im 6.B11d wird die Wende in Helenas Verhalten von einem musikalischen Phänomen verursacht. Der Mönch setzt den vom betrunkenen Journalisten angestimmten Totengesang fort. Das 7.Bild ist ebenfalls erfullt von Musik: der wind pfeift, tost und schluchzt, Troikaglöckchen erklingen, der Hausierer singt sein Lied.

Diese kurzen Hinweise machen deutlich, daß Bloks Stuck als "Melo-Drama" konzipiert war. Musik und Schauspiel sollten sich als gleichberechtigte Kunstsphären in elnem synästhetischen Gesamtkunstwerk verbinden, um Bloks RuBland-Mythos allumfassende wirkung zu verlethen. 


\section{Literaturverzeichnis:}

Blok, A.

Blok, A.

Blok, A.

Blok, A.

(Blok, $\left.A_{0}\right)$

(Blok, $\left.A_{0}\right)$
Blok, A.

Sobranife socinenif ( $\nabla 7$ tomach). Berlin 1923. ("Alkonost").

Sobranije sodinenij ( $v 10$ tomach). Leningrad 193219 .

Sobranije sotinenif v vos'mi tomach. MoskvaLeningrad 1960-1963.

Pesnja Sud'by. Dramatiðeskij prolog. In: Al'manach "Sipornik", 9, SPb. 1909, S. 193252.

Zapisnyje knizki 1901-1920. Moskva 1965. Pis'ma Aleksandra Bloka. Leningrad 1925.

Pis'ma Aleksandra Bloka k rodnym.

I. Leningrad 1927.

II. Moskva-Leningrad 1932.

/Blok/ Block, A. Ausgewăhl te Aufsätze. Ausgewählt und aus dem Russischen übertragen von A. Kaempfe. Prankfurt a.M. (edition suhrkamp 71).

/Blok/ Block, A. Die Zwölf. Ausgewählte Dichtungen. Ubertragung und Nachwort von J. v. Guenther. Stuttgart 1966 (Reclam Universal-Bibliothek Nr. 8725).

/Blok/ Block, A. Gesammelte Dichtungen. Deutsch von J. V. Guenther. Múnchen 1947.

Abalkin, N.

Aksenova, Je.

Das Stanislawski-System und das SowjetTheater. Berlin 1953.

A. Blok. "Dvenadcat'". In: "Voprosy literatury", 7,1957 , S. 33-52.

Aksenova, Je. Chudozestrennoje vyrazenije pozicil pisatelja. Sbornik statej. Vladimir 1959.

Darin: Poema A.A. Bloka "Dvenadcat'n; S. 75-98.

Al'fonsov, $V$.

Slova 1 kraski. Ocerki iz istorii trordeskich svjazej poétov 1 chudožnikov. MoskvaLeningrad 1966. Darin: A. Blok, S. 11-88.

Andrejev, L. P'esy. Biblioteka dramaturga. Moskva 1959.

/Arsen'ev/ Arseniew, N. von Die geistigen Schicksale des russischen Volkes. Graz-Wien-Köln 1966.

/Arsen'ev/ Arseniew, N. von Die russische Frömmigkeit. Zürich 1964. Bibliothek für orthodoxe Theologie und Kirche, Band 3.

/Arsen'ev/ Arseniew, N. von Die russische Literatur der Neuzeit und Gegenwart. Mainz 1929. 
Arsen'ev, N.S. Iz russkoj kul'turnoj i tvorceskoj tradicil. Frankfurt a.M. 1959.

/Arsen'ev/ Arseniev, N. La sainte Moscou. Paris 1948. Asmus, V.

Pilosofija 1 éstetika russkogo simvolizma. In: Iiteraturnoje nasledstvo 27-28. Moskva 1937. S. 1-53.

Azadovskij, M.K. Istorija russkoj fol'kloristiki. Band 2. Moskva 1963.

Baade, M.

Aleksandr Blok. 60 Jahre deutsche Rezeptionsgeschichte. Ein Überblick (1905-1966). In: "Zeitschrift für Slawistik", Band XII, Heft 3,1967 , S. 328-363.

Baade, M.

Die Aufnahme von Aleksandr Bloks Poem "Die Zwölf" in Deutschland. Te1l I: 1920-1933. In: "Zeitschrift für Slawistik", Band IX, Heft 2, 1964, S. 175-195. Teil II: 19451963. In: aaO, Heft 4, 1964, S. 551-573.

Bachofen, J.

Mutterrecht und Urreligion. Eine Auswahl. Stuttgart 1954. (Kröners Taschenausgabe Bd. 52).

Baeumler, A. Das mythische Weltalter. München 1965. Bal'mont, K.D. Stichotvorenija. Biblioteka poeta. Bol'saja serija. Leningrad 1969.

Beketova, M.A. Aleksandr Blok. Biograficeskij očerk. $\mathrm{Pb} .1922$.

Beketova, M.A.

Aleksandr Blok i jego mat'. LeningradMoskva 1925.

Beketova, M.A. siehe auch: Lesnevskij, St.

Belyj, A.

Belyj, A. Arabeski. Voskva 1911. Vachdruck: Slavische Propyläen Bd. 63. München 1969.

Iug zelenyj. Kniga statej. Moskva 1910. Nachdruck: liew York, London 1967.

Belyj, A.

Belyj, A. Meždu dvuch revoljucij. Leningrad 1934. liachdruck: Chicago 1966.

Načlo veka. Noskva-Leningrad 1933.

Nachdruck: Chicago 1966.

Belyj, A. Peterburg. Noskva 1928. Nachdruck: Slavische Propyläen Bd. 29. München 1967.

Belyj, A. Belyj, A. Serebrjanyj golub'. Moskva 1922. kachdruck: Slavische Propyläen Bd 38. München 1967. Simvolizm. Moskva 1910. Nachdruck: Slavische Propyläen Bd. 62. Viüchen 1969.

Belyj, A.

Stichotvorenija i poèmy. Biblioteka poèta. Bol'saja serija. Moskva-Leningrad 1966. 
Belyj, A.

Vospominanija o A.A. Bloke. In: "Ëpopeja" 1 - 4, Berlin 1922-23. Nachdruck: Slavische Propyläen Bd. 47. München 1969.

Belyj, A.

Vospominanija ob A.A. Bloke. In: "Zapisk1 mextatelejn, 6, 1922. Nachdruck: Letchworth 1964 .

Benz, E.

Geist und Leben der Ostkirche. Hamburg 1957. (rde 40).

Berberova, N. Alexandre Blok et son temps. Paris 1947.

Berg-Papendick, $W$. Der Mystiker Alexander Block im Spiegel seiner Lyrik. Ausgewählte Dichtungen.

Frankfurt a.M. 1967.

Berkenkopf, G. Welterlösung - ein geschichtlicher Traum RuBlands. München 1962.

Bezzubov, V.I. Aleksandr Blok $i$ Leonld Andrejev. In: Blokovskij sbornik (1). Tartu 1964. S. 226320.

Bicilli, P.M. Anton Cechov. Werk und Stil. Forum Slavicum Bd. 7. München 1966.

Blagoj, D.

Aleksandr Blok i Apollon Grigor'ev. Zuerst in: 0 Bloke. Moskau 1929. Erweitert in: Blagoj, D.: Tri veka. Moskva 1933. S. 269300 .

Bloch, E.

Freiheit und Ordnung. Abrib der Sozialutopien. Reinbek bei Hamburg 1969. (rde 318/9).

Bloch, E.

Wegzeichen der Hoffnung. Eine Auswahl aus seinen Schriften: Mythos, Dichtung, Musik. Freiburg 1.Br. 1967. (Herder-Taschenbuch 300).

Blokovskij sbornik. Trudy naučnoj konferencil, posvjał̌cennoj izuCeniju žizni i tror̋̌estva A.A. Bloka, maj 1962 goda. Tartu 1964.

Blokovskij sbornik (2). Trudy Vtoroj nauxnoj konferencil,

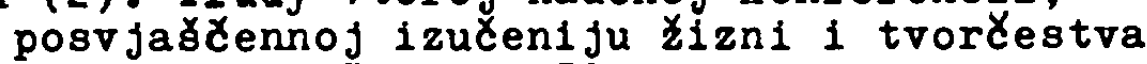
A.A. Bloka. Tartu 1972.

Bogatyrev, P.G. Narodnyj teatr. In: Russkoje narodnoje trorCestro. Moskva 1966.

(Bonneau) Laffitte, $S$. Le symbolisme occidental et Alexandre Blok. In: "Revue des Etudes Slaves", Bd. 34, 1957, S. 88-94.

Bonneau, S. L'univers poetique d'Alexandre Blok. Paris 1946.

Bowra, C.M. The heritage of symbolism. London-New York 81967. Darin: Alexander Blok, S. 144-179.

Brjusov, V.Ja. Izbrannyje sotinenija $v$ druch tomach. Moskva 1955. 
Brjusov, V.Ja.

Rasskazy 1 povesti. Nachdruck der Ausgaben "Zemnaja osin u.a. Slavische Propyläen Bd. 49. Munchen 1970.

Brjusov, V.Ja. Stichotvorenija 1 poémy. Biblioteka poéta. Bol'baja serija. Leningrad 1961.

Brokgaus, F.A. - Jefron, I.A. (Hrsg.) EnciklopediCeskij slovar'. SPb. $1890 \mathrm{ff}$.

Bunin, I.A.

Izbrannoje. Moskva 1970.

Busch, U.

L.N. Tolstoj als Symbolist. Zur Deutung von

"Anna Karenina". In: Busch - Gerigk - Hock Tschižewskij: Gogol'-Turgenev-DostojerskijTolstoj. Zur russischen Literatur des 19. Jahrhunderts. Forum Slavicum Bd. 12. München 1966. S. 7-36.

Byliny $v$ dvuch tomach. Podgotovka teksta, vstupitel'naja stat'ja 1 kommentaril V.Ja. Proppa i B.N. Putilova. Moskva 1958.

Byron, G.G.N. Lord The works of Lord Byron. London-New York 1898-1904.

Černysevskij, N.G. Cto delat'? In: Polnoje sobranije soðinenij v 15 tomach. Moskva 1939ff. Tom 11.

Čechov, A.P. Izbrannyje proizvedenija $v 3$ tomach. Moskva 1967.

Chajlov, A.N. Michail Prišvin. TvorČeskij put'. Leningrad 1960.

Chmel'nickaja, T. Poèzija Andreja Belogo. In: Belyj, A. Stichotvorenija i poèmy. Moskva-Leningrad 1966, S. 5-66.

Cholsevnikov, v. Fedor Michajlovic Dostojevskij. In: Literaturnyje pamjatnyje mesta Leningrada. Leningrad 21968. S. 460-499.

Cičerov, V. Cizevsiji, D. Russkoje narodnoje trorcestvo. Moskva 1959. Cukovskij, K. siehe: Tschižewskij, $D$.

Sobranije soð̌inenij v 6 tomach. Moskva $1965 \mathrm{ff.}$ Darin: Aleksandr Blok. Tom 2, S. 265-318.

Čulkov, G.I.

Aleksandr Blok i jego vremja. In: Pis'ma

Čulkov, G.I. Aleksandra Bloka. Leningrad 1925. S. 91-120. 0 misticeskom anarchizme. SPb. 1906. Nachdruck: Letchworth 1971.

vahm, $\mathrm{H}$.

Die Chance der Philosophie und das Verhängnis der slawophilen Utopie. In: RuBlands Aufbruch ins 20. Jahrhundert. Freibug $1 . B r$. 1970. S. 234-262.

Dantes Werke. Das neue Leben. Die göttliche Komödie. Neu übertragen und erläutert von R. Zoozmann. Leipzig 31909. 
Desnickij, V.A.

Dikman, M.I.

Diks, B.

Doerne, M.

Doerne, M.

Dolgopolov, L.

Dolgopolov, I.

Dolgopolov, I.

Donchin, G.

Dostojevskij, F.

Dostojerskij, F.

Dukor, I.

Eliasberg, A.

Elkin, B.

Erlich, V. Erlich, V. Etkind, Je.

Fedorov, A.

Filippov, B.

Fischer-Lexikon. Bde. 37-40. Geschichte in Gestalten. Hrsg. H. Herzfeld. Frankfurt a.M. 1963.

Social'no-psichologi Ceskije predposylki tvor Cestra A. Bloka. In: Pis'ma Aleksandra Bloka k rodnym. II. Moskva-Leningrad 1932.

Blok - kritik. In: Istorija russkoj kritiki $\checkmark 2$ tomach. Moskra-Leningrad 1958. Bd. 2, S. 646-664.

M.A. Kuzmin. In: Gofman, M. (Hrsg.) Poèty simvolizma. Pb. 1908. S. 385-391.

Gott und Mensch in Dostojewskijs Werk. Göttingen 21962.

Tolstoj und Dostojewskij. Zwei christliche Utopien. Göttingen 1969.

"Dvenadcat'" Al. Bloka. (Idejnaja osnova poémy). In: "Voprosy sovetskoj literatury", VIII, 1959, S. 134-180.

Poèmy Bloka i russkaja poèma konca XIX nałala XX vekov. Moskva-Leningrad 1964.

TjutCer i Blok. In: "Russkaja literatura", 2 , 1967, S. 59-80.

The influence of French symbolism on Russian poetry. 's-Gravenhage 1958.

Sobranije soð̌inenij $\vee 10$ tomach. Moskva 1956-1958.

Winterliche Aufzeichnungen über sommerliche Eindrucke u.a. Ubersetzt von S. Geier und A. Eliasberg. Hamburg 1962. (Rowohlts Klassiker Bd. 111/2).

Problemy dramaturgii simvolizma. In: Literaturnoje nasledstvo 27-28. Moskva 1937. S. $106-166$.

Russische Literaturgeschichte in Einzelporträts. München 1964. (Goldmanns Gelbe Taschenbidcher Bd, 1450).

Die russische Intelligentsia am Vorabend der Revolution. In: Pipes (Hrsg.): Die russische Intelligentsia. Stuttgart 1962.

Russischer Formalismus. München 1964.

The double image. Baltimore 1964.

Ten' Danta... (Tri stichotvorenija iz ital'janskogo cikla Bloka). In: "Voprosy literatury", 11, 1970, S. 88-106.

Dramaturgija Bloka. In: "Voprosy literatury", 11,1970 , S. 67-87.

Nikolaj Kljujev. Materialy dlja biografil. In: Kljujev, N.: Sodinenija. Tom 1. S. 5-182. 
Fischer-Lexikon. Bde. 34-35/1,2. Iiteratur. Hrsg. W.-H. Friedrich und W. Killy. Frankfurt a.M. $1964 \mathrm{f}$.

Forstner, D.

pie Welt der Symbole. Innsbruck-Wien-München 21967.

Frenzel, E.

Stoffe der Weltliteratur. Ein Lexikon dichtungsgeschichtlicher Längsschnitte. Stuttgart 31970. (Kröner TB 300).

Frenzel, E. Stoff $\bar{F}$, Motiv- und Symbolforschung. Stuttgart 21966. (Sammlung Metzler 28).

Priedrich, H.

Die Struktur der modernen Lyrik. 4. Auflage der erweiterten Neuausgabe. Hamburg 1971. (rde 25).

Gerasimov, Ju.K. Ob okruzenii Aleksandra Bloka vo vremja pervoj russkoj revoljucii. In: Blokovskij sbornik (1). Tartu 1964. S. 539-544.

Gerasimov, Ju.K. Stanislavskij i Blok. In: "Neva", 1963, 2, S. 166-169.

Gippius, Z.

Dmitrij Merezkovskij. Paris 1951.

Gippius, Z.

Svetloje ozero. In: "Novyj put'", 1904, 1-2. Gippius, Z. (Tovariß̌ German) "Trichina". In: "Vesy", 1907, 5, S. 68 .

Gippius, Z.

Zेivyje lica. Vypusk pervyj. Fraga 1925.

Gofmar, V.

Jazyk simvolistov. In: Iiteraturnoje nasledstvo 27-28. Moskva 1937. S. 54-105.

Gofman, M. (Hrsg.) Poèty simvolizma. Pb. 1908. Nachdruck: Slavische Propyläen Bd. 106. München 1970. Darin: Gofman, M. Romantizm, simvolizm i dekadentstvo. S. 1-32; ders. Aleksandr Blok. S. 299-311; ders. Sergej Gorodeckij. S. 333342 .

Gogol', N.V. Sobranije solinenij v 7 tomach. Moskva 1966. Gol'cev, V. 0 muzykal'nom vosprijatii mira u Bloka. In: O Bloke. Moskva 1929. S. 259-282.

Goldammer, $\mathrm{K}$.

Der Mythus von Ost und West. Eine kulturund religionsgeschichtliche Betrachtung. München-Basel 1962. (Glauben und Wissen 23).

Golovałenko, Ju. Aleksandr Blok v Bol'som dramatiðeskom teatre. In: "lveva", 1970, 11, S. 202-208.

Gorelov, A. Groza nad solov'inym sadom. Aleksandr Blok. Leningrad 1970.

Gorelov, A. Vysokoje naznaðenije poèta. In: "Zvezda", 1970,11 , S. 177-189.

Gor'kij, M. Rannije rasskazy. lrarodnaja biblioteka. Moskva 1965.

Gourfinkel, N. M. Gorki in Selbstzeugnissen und Bilddokumenten. Hamburg 1958. (Rowohlts Monographien 9). 
Gosudarstrennaja Tret'jakovskaja galereja. Katalog drevnerusskoj Zivopisi ₹ 2 tomach. Moskva 1963.

Gosudarstrennyj Russkij muzej. Putevoditel'. Pod obscej redakcijej V.A. Pułkareva. Leningrad 1969.

Gromov, P.

Gromov, P.

Gromov, P.

Grossman. L. Guenther, J.von

Guenther, J.von Hamburger, $K$.

Hartmann, N.

Hauser, A.

Heer, F.

Heller, F. A. Blok, jego preḑestvenniki 1 sovremenniki. Leningrad 1966.

Apollon Grigor'ev. In: A. Grigor'ev. Izbrannyje proizvedenija. Biblioteka poéta. Bol'zaja serija. Leningrad 1959. S. 5-79.

Geroj 1 vremja. Stat'i o literature 1 teatre. Darin: Teatr Bloka. Besonders: "Pesnja sud'by" v tror ̌eskoj évoljucil Bloka. S. 482-521. Leningrad 1961.

Dostojevskij. Moskra 21965.

Alexander Block. Versuch einer Darstellung.

In: Block, A. Gesammelte Dichtungen. München 1947. S. 409-499.

Ein Leben im Ostwind. München 1969.

Tolstoi. Gestalt und Problem. Göttingen

21963. (Kleine Vandenhoeck-Reihe 159-161).

Die Phifosophie des deutschen Idealismus. Berlin 21960.

Sozialgeschichte der Kunst und Literatur.

2 Bde. München 21953.

Europäische Geistegeschichte. II. Von Erasmus bis Goethe. Stuttgart 1970. (Urban-TB 132).

Die Ostkirchen. München 1971.

Hermand, Jo. (Hrsg.) Lyrik des Jugendstils. Eine Anthologie. Stuttgart 1969. (Reclam Universal-Bibliothek Nr. 8928).

Hocke, G.R.

Manierismus in der Literatur. Sprach-Alchimie und esoterische Kombinationskunst. Hamburg 1959. (rde 82/83).

Holthusen, J.

Nachwirkungen der Tradition in A. Bloks Bildsymbolik. In: Slawistische Studien zum V. Internationalen Slawistenkongre $B$ in Sofia 1963. Göttingen 1963. S. 437-444.

Hol thusen, J. Russische Gegenwartsliteratur. I. 1890-1940. Bern 1963. (Dalp TB 368D).

Hol thusen, J.

Ibsen, $\mathrm{H}$.

Studien zur Ästhetik und Poetik des russischen Symbolismus. Göttingen 1957.

Sämtliche Werke in deutscher Sprache. Berlin $1903 f f$.

Igorlied

siehe: Slovo o polku Igoreve.

Il'ina (Seferjanc), A. Nepostižmaja. (K éjdologii Bloka). In: 0 Bloke. Moskva 1929. S. 303-331. 
Istorija russkogo iskusstva. Pod obłcej redakcijej I.E. Grabar ja. Moskra 1953-1964.

Istorifa russkof literatury. Tom X. Irdatel'stvo Akademil nauk SSSR. Moskva-Leningrad 1954. Darin $\nabla_{. a .:}$ Aleksandr Blok. S.659-702.

Ivanov, Je.P. Vospominanija ob Aleksandre Bloke. In: Blokovskif sbornik (1). Tartu 1964. S. 362-388.

Iranov, Je.P. Zapisi ob Aleksandre Bloke. In: Blokorskij sbornik (1). Tartu 1964. S. 389-424.

Ivanov-Razumnik Aleksandr Blok. Andrej Belyj. Pb. 1919. Nachdruck: Chicago o.J. (Russian Study Series No. 64).

Ivanov, V.

Aleksandr Blok. Stichi o Prekrasnoj Dame.

In: "Vesy", 1904, 11, S.49f.

/Ivanov/ Iwanow, W. Das alte Wahrs. Berlin-Frankfurt a.M. o.J. (1955). Darin besonders: Anima. S. 7-30. Terror antiquas. S. 31-76.

/Ivanov/ Iwanow, W. Die russische Idee. Tübingen 1930.

/Ivanov/ Iwanow, W. Dostojewskij. Tragödie - Mythos -Mystik. Tübingen 1932.

Ivanov, $\mathrm{V}$.

Niçe 1 Dionis. In: "Vesy", 1904, 5, S. 17-28.

Ivanov, $\mathrm{V}$.

Ivanov, $V$.

Ivanov, $\mathrm{V}$.

Novyje maski. In: "Vesy", 1904, 7, S. 1-8.

"Poẻt 1 Cern'". In: "Vesy", 1904, 3, S. 1-8.

Vagner i Dionisovo dejstro. In: "Vesy", 1905, 2, S. 13-16.

James, E.0.

Religionen der Vorzeit. Köln 1957.

Jesenin, S.

Sobranife sodinenif v 5 tomach. Moskva 19661968.

Jevreinova, N. Cikl stichov A. Bloka "Na pole Kulikorom" i jego istodniki $v$ drevnerusskoj literature. In: Russkaja sovetskaja poezija i stichovedenije. Sb. statej. Moskva 1969. S. 151-172.

Jost, D. Literarischer Jugendstil. Stuttgart 1969. (Sammlung Metzler 81).

Jerß̌ov, G.

Michail Prił̌vin. Oðerk žizni i trorčestva. Moskra 1963.

/Katajev/ Katajew, V. Kraut des Vergessens. Aus dem Russischen von H.D. Becker. München 1968.

Karamzin, N.M. Istorija Gosudarstra Rossijskogo. SPb. 18161829.

Kemball, R.

Alexander Blok. A study in rhythm and metre. London - The Hague - Paris 1965.

Kirpotin, V.

Polemiðeskij podtekst "Solov'inogo sada". In: "Voprosy literatury" 1959, 6, S. 178-181. 
Kisch, Sir C.

Klibanov, A.I.

KIjujev, N.

Klotz, V.

Kluckhohn, P.

Kluge, R.-D.

Alexander Blok. Prophet of revolution. London 1960.

Istorifa religioznogo sektantstra $\nabla$ Rossii (60-je gody XIX v. - 1917 g.). Moskra 1965.

Sodinenija. Pod obłðej redakcijej G.P. Struve 1 B.A. Filippova. 2 Bde. München 1969.

Geschlossene und offene Porm im Drama. München 1969.

Das Ideengut der deutschen Romantik. Tubingen 51966 .

Westeuropa und RuBland im Weltbild Aleksandr Bloks. Philosophisahe Dissertation der Universität Mainz. München 1967. (Slavistische Beiträge Bd. 27).

Knaurs Lexikon moderner Kunst. Stuttgart 1955.

Kohn, H.

Kolarz, W.

Kologriwow, I.

Krasnova, I.V.

Krasnova, L.V.

Kruk, I.

Kruk, I.

Krupjanskaja, V.

Labry, R.

Lafitte, S.

Laksin, $V$.

Leskov, N.S.

Lesnevskij, St.

Lesnerskij, St.
Die Slawen und der Westen. Die Geschichte

des Panslawismus. Wien-München 1956.

Die Religionen in der Sowjetunion. Uberleben in Anpassung und Widerstand. Freiburg-BaselWien 1963.

Das andere RuBland. Versuch einer Darstellung des Wesens und der Eigenart russischer He1ligke1t. München 1958.

PoetiCeskij stroj "Skifor" A. Bloka. In: "Voprosy russkoj literatury", vyp. 2 (8), I'vov, 1968, S. 104-110.

Poétika Aleksandra Bloka. L'vor 1973.

Blok 1 Gogol'. In: "Russkaja literatura", 1961,1 , S. 85-103.

Poèzija Aleksandra Bloka. Moskva 1970.

Narodnyj teatr. In: Russkoje narodnoje poètiCeskoje tror ̌estro. Pod red. P.G. Bogatyreva. Moskva 1954. S. 382-414.

Alexandre Blok i Nietzsche. In: "Revue des Etudes Slaves", 1951, 27, S.201-208.

siehe: Bonneau, S.

Blok i Stanislarskij. In: "Russkaja literatura", 1958, 4, S. 189-190.

Polnoje sobranije solinenij. SPb. 31902-03.

Sachmatoro. Semejnaja chronika. (Neopublikovannyje vospominanija $M$. Beketovoj). In:

"Voprosy literatury", 1970, 11, S. 107-121.

$\nabla$ Sachmatovo, k Bloku. In: "Junost'", 1970 8, S. 103-104. 
Levin, V.I.

Levf, $\mathbf{J}$

Lewitter, I.R.
Poéma Aleksandra Bloka "Dvenadcat'n glazaml sovetskogo 1 amerikanskogo 188ledovatelja. In: "Irvestija Akadem11 nauk SSSR", serija I1teratury 1 jazyka, 1963, XXII, vyp. 5, S. 386-396.

Die literarische Ubersetzung. Theorie einer Kunstgattung. Prankfurt a.M. - Bonn 1969.

The Inspiration and Meaning of Alezander Blok's "The Rose and the Cross". In: "Slavonic and East European Review", 1957, 85, S. 428-442.

Lexikon der Alten Welt. Zurich-Stuttgart 1965.

Lexikon fü Theologie und Kirche. Freiburg 1.Br. 2 1957-65.

Lichąeva, V.D. - Lichacev, D.S. Chudožestrennoje nasledije drevnej Rusi 1 sovremennost'. Leningrad 1971.

Lieb, F.

Sophia und Historie. Aufsătze zur östlichen und westlichen Geistes- und Theologiegeschichte. Zurich 1962. Darin besonders: Das westeuropäische Geistesleben im Urteil russischer Religionsphilosophie; S. 55-82. Ursprung und Entfaltung des slawophilen Messianismus in RuBland; S. 83-113. Die Anthropologie Dostojewskij8; S. 145-180. "Der Geist der Zeit" als Antichrist. Spekulation und offenbarung bei Wladimir Solovjev; S. 181-201.

Iiteraturnoje nasledstvo 27-28. Moskva 1937.

Literaturnoje nasledstvo Aleksandra Bloka. In: Literaturnoje nasledstro 27-28, S. 505-574.

Lotman, Ju. I Minc, Z. "Celovek prirody" $v$ russkoj literature XIX veka 1 "cyganskaja tema" u Bloka. In: Blokovskij sbornik (1). Tartu 1964. S. 98156.

Lunąarskij, A. Aleksandr Blok. In: Ders.: Sobranije sotinenij v 8 tomach. Moskva 1963ff. Tom 1, S. 464496.

Majakorskij, V. Vladimir II'ił Lenin. Chorošo! Narodnaja biblioteka. Moskva 1966.

Makovskij, S.

Na parnase serebrjanogo veka. München 1962.

Maksimov, D.Je. Aleksandr Blok 1 Jevgenif Ivanov. In: Blokovskif sbornik (1). Tartu 1964. S. 344-361.

Maksimov, D.Je. Brjusov. Poèzija 1 pozicija. Leningrad 1969. Maksimov, D.Je. Ideja puti $v$ poètičeskom soznanil Al. Bloka. In: Blokovskij sbornik (2). Tartu 1972. S. 25-121.

Maksimov, D.Je. KritiČeskaja proza Aleksandra Bloka. In: Blokovskif sbornik (1). Tartu 1964. S.28-97. 
Maksimov, D.Je. 0 proze Aleksandra Bloka. In: Blok, A. Sobranije solinenij $\nabla 8$ tomach. Moskva-Leningrad 1960-1963. Tom V, S. 695-708.

Maksimov, D.Je. Poètið̌eskoje trorð̌estvo Valerija Brjusova. In: Brjusov, V.: Stichotvorenija i poemy. Leningrad 1961. S. 5-66.

Maksimov, D.Je. Lermontov i Blok. In: Ders.: Poezija Lermontova. Moskva-Leningrad 21964. S. 247-265.

Malia, M. Was ist die Intelligentsia? In: Pipes, R. (Hrsg.) Die russische Intelilgentsia. Stuttgart 1962. S. 11-32.

Maslenikov, 0.A. Russian symbolists. The mirror theme and allied motifs. In: "Russian Review", vol. 16, Jan. 1957, Nr. 1, S. 42-52.

Maslenikov, 0.A. The frenzied poets. Andrey Biely and the Russian symbolists. Berkely - Los Angeles 1952.

Masur, G. Propheten von Gestern. Frankfurt a.M. 1965.

Mayr, E. Die lyrischen Dramen Alexander Bloks. Philosophische Dissertation der Universitat Wien. 1950.

Medvedev, P. Dramy 1 poèmy Al. Bloka. Leningrad 1928.

Melchinger, S. Anton Tschechow. Velber bei Hannover 1968. (Friedrichs Dramatiker des Welttheaters 57 ).

Mel'nikov-Peðerskij Polnoje sobranije sođinenij. SPb. 1909.

Merežkovskij, D. Christos i Antichrist. III. Antichrist (Petr i Aleksej). SPb. 1906 .

/Merežkovskij/ Mereschkowski, D. u.a. Der Zar und die Revolution. München 21908 .

Michajlovskij, B. Simvolizm. In: Russkaja literatura konca XIX - natala XX v. (1901-1907). Moskva 1971. S. 229-318.

Michaud, G. Message pottique du symbolisme. Paris 1947. Michel, W. Das Leben Friedrich Hölderlins. Frankfurt a. M. 1967 .

/Miljukov/ Miliukov, P. Outlines of Russian culture. Philadelphia 31948 .

Minc, Z.G. Blok i Gogol'. In: Blokovskif sbornik (2). Tartu 1972. S. 122-205.

Minc, Z.G. Foèma "Dvenadcat'" i mirovozzrenije A. Bloka épochi revoljucii. In: "UCennyje zapiski Tartuskogo gos. universiteta", vyp. 98. Trudy po russkoj i slavjanskoj filologi, tom III. Tartu 1960. S. 247-278.

Minc, Z.G. Poètičeskij ideal molodogo Bloka. In: Blokorskij sbornik (1). Tartu 1964. S. 172-225. 
Mocul'skij, K. Močul'skij, $\mathrm{K}$. Močul'skij, K. Mocul'skij, $\mathbf{K}$. Motjašov, I.

Muchnik, H.

Miiller, $0 . w$.

Nag, M.

Mebol'sin, S.

liekrasov, N.A.

Neumann, F.-W.

Nietzsche, F.

Nietzsche, F.

Nietzsche, F.

Nietzsche, $\mathrm{F}$.

N1etzsche, $F$.

(Nietzsche, F.)

Nigs, W.

Nilsson, N.A.

Nilzson, N.A.

Novalis
Aleksandr Blok. Paris 1948.

Andrej Belyj. Paris 1955.

Valerij Brjusov. Paris 1962.

vladimir Solov'ev. Paris 1951.

Michall Prišin. Kritiko-biografiteskij

oðerk. Moskva 1965.

From Gorky to Pasternak. London 1963. Darin: Alexander Blok. S. 104-184.

Intelligencija. Untersuchungen zur Geschichte eines politischen Schlagworts. Frarkfurt a.M. 1971 .

Ibsen, Łechov und Blok. In: "Scando-Slavica", $\mathrm{X}, 1964, \mathrm{~S} .30-48$.

Aleksandr Blok $\nabla$ sovremennom zapadnom literaturovedenii. In: "Voprosy literatury", 1968, 9, S. 189-196.

Polnoje sobranije stichotvorenija v 3 tomach. Biblioteka poéta. Bol'̧aja serija. Leningrad 1967.

Aleksandr Bloks "Neznakomka". Versuch einer Interpretation. In: "Die Welt der Slaven", VIII, 1963, S. 5-17.

Also sprach Zarathustra. Stuttgart 1956. (Kröners Taschenausgabe Bd. 75).

Die Fröhliche Wissenschaft. Stuttgart 1965. (Kröners Taschenausgabe Bd. 74).

Die Geburt der Tragödie. Der griechische Staat. Stuttgart 1964. (Kröners Taschenausgabe Bd. 70).

Götzendämmerung, Antichrist, Ecce homo, Gedichte. Stuttgart 1965. (Kröners Taschenausgabe $\mathrm{Bd}$. 77).

Unzeitgemäße Betrachtungen. Stuttgart 1964. (Kröners Taschenausgabe Bd. 71).

Nietzsche-Register. Stuttgart 1965. (Kröners Taschenausgabe Bd. 170).

Das ewige Reich. Geschichte einer Hoffnung. Miunchen und Hamburg 1967. (SiebensternTaschenbuch 105/106).

Ibsen in RuBland. Stockholm 1958. (Etudes de philologie slave Bd. 7). Darin: Blok und Ibsen. S. 207-221.

Strinberg, Gorky and Blok. In: "ScandoSlavica", IV, 1958, S. 23-42.

Werke und Briefe. Minchen 1968. 


\section{O Bloke. Sbornik literaturno-1ssledovatel'skoj associac11 C.D.R.P. pod redakcijej Je.P. Nikitinoj. Moskra 1929.}

Onasch, $\mathbf{K}$.

Onasch, $\mathbf{K}$.

Orlov, V.N.

Orlov, V.

Orlov, v.

Orlov, V.

Orlov, v.

Orlov, V.

Orlov, v.

Orlov, v.

Einfuhrung in die Konfessionskunde der orthodoxen Kirchen. Berlin 1962. (Sammlung Gorschen Bd. 1197/1197a).

Grundzüge der russischen Kirchengeschichte. Götingen 1967. (Die Rirche in ihrer Geschichte, Bd. 3, Lieferung $M, 1 . T e 11$ ).

Aleksandr Aleksandrovit Blok. In: Literaturnyje pamjatnyje mesta Leningrada. Leningrad 21968 . S. 500-525.

Aleksandr Blok 1 Andrej Belyj $\nabla 1907$ godu. In: Iiteraturnoje nasledstvo 27-28. Moskva 1937. S. 371-408.

Aleksandr Blok. Ođerk tvořestva. Moskva 1956.

Aleksandr Blok. Vstupitel'nyj očerk. In: Blok, A. Sobranije sočinenij $\nabla 8$ tomach. Moskva-Leningrad 1960-1963. Tom I, S. VIILXIV.

Bal'mont. Žizn' 1 poezija. In: Bal'mont, K.D. Stichotvorenija. Leningrad 1969. S. 5-74.

Nekotoryje 1togi 1 zadači sovetskogo blokovedenija. In: Blokovakij sbornik (1). Tartu 1964. S. 507-521.

poèma Aleksandra Bloka "Dvenadcat" . Moskra 21967.

Puti i sud'by. Literaturnyje ocerki. Leningrad 21971. Darin: Istorija odnof "druzbyvrazdy"; S. 507-635. Istori ja odnoj l jubvi; S. 636-743.

Ostrovskif, A.N. Groza. Les. Bespridannica. Narodnaja biblioteka. Moskva 1964.

Paperny j, Z.

Samoje trudnoje. Stat'1, recenzil, fel'etony. Moskva 1963. Darin: Blok i revoljucija; S. 66-99.

Pasternak, B. Stichotvorenija i poemy. Biblioteka poèta. Bol'̧̧aja serija. Moskra-Leningrad 1965.

Paulys Realencyclopădie der classischen Altertumswissenschaft. Neu bearbeitet von $G$. Wissowa u.a. Stuttgart 189411.

Peters, J.

Symbole der sinnlichen Wahrnehmung im lyrischen Werk A.A. Bloks unter besonderer Berúcksichtigung der Parb- und Lichtsymbole. Philosophische Dissertation der Universitat Kiel. Kiel 1968. 
Pipes, R.

Die historische Entwicklung der russischen Intelligentsia. In: Pipes, R. (Hrsg.) Die russische Intelligentsia. S. 65-82.

Pipes, R. (Hrsg.) Die russische Intelligentsia. Stuttgart 1962. Flaton Sämtliche Werke. Hamburg 1957-59. (Rowohlts Klassiker).

Plechanov, G.V. Ilteratura i éstetika. Band 2. Moskva 1958. Pleyer, $\mathrm{V}$.

Das russische Altgläubigentum. Geschichte. Darstellung in der Literatur. Munchen 1961. (Slavistische Beitrăge Bd. 4).

Pozija krest'janskich prazdnikov. Biblioteka poéta. Bol'saja serija. Leningrad 1970.

Poggiol1, R. The poets of Russia 1890-1930. CambridgeLondon-0xford 1960.

Pomeranceva, E.V. Aleksandr Blok 1 fol'lor. In: "Russkif

fol'klor. Materialy i issledovanija", III, 1958, S. 203-224.

Pomirtij, R.

Vokrug Bloka. In: "Voprosy l1teratury", 1971, 5, S. 184-188.

Povesti o kulikovskoj bitve. Otvetstvennyj redaktor M.N. Tichomirov. Moskva 1959.

Praz, M.

Liebe, Tod und Teufel. Die schwarze Romantik. 2 Bände. Muinchen 1970. (dtv Wissenschaftliche Reine 4051/4052).

Prižin, M.M.

V kraju nepugannych ptic. Osudareva doroga. Petrozavodsk 1970.

Pư̌kin, A.S.

Polnoje sobranije solinenij v 10 tomach. Moskva 21956-1958.

Randa, A. (Hrsg.) Handbuch der Weltgeschichte. 4 Bände. OltenFreiburg i.Br. 31962 .

Reeve, F.D. Aleksandr Blok. Between Image and Idea. New York-London 1962.

Reeve, F.D. Structure and Symbol in Blok's "The Twelve". In: "The American Slavic and East European Review", vol 19, 1960, S. 259-276.

Reich, W. Richard Wagner. Leben. Fühlen. Schaffen. Olten 1948.

Die Religion in Geschichte und Gegenwart. Tubingen 31957-1965. Remenik, G. Poèmy Aleksandra Bloka. Moskva 1959.

Rodina, T.M. Aleksandr Blok i russkij teatr načla $X X$ veka. Moskva 1972.

Rohde, E. Psyche. Seelencult und Unsterblichkeitsglaube der Griechen. Darmstadt 1961.

Roscher, W.H. (Hrsg.) Ausfühliches Lexikon der griechischen und römischen Mythologie. Leipzig $1884 f f$. 
Rozanor, M.

Rubcov, A.B.

Rudnickij, $\mathrm{K}$.

Rühle, J.
Motivy "mirovoj skorbi" v lirike Bloka. In: 0 Bloke. Moskva 1929. S. 219-258.

Dramaturgija Aleksandra Bloka. Minsk 1968. Režisser Mejerchol'd.Moskra 1969.

Literatur und Revolution. Die Schriftsteller und der Kommunismus. Köln-Berlin 21962.

Russian folk literature. Edited by D.P. Costello and I.P. Foote. Oxford 1967.

Russkaja literatura konca XIX - nacala XX veka. Redakcionnaja kollegija B.A. Bjalik, Je.B. Tager, V.R. SCerbina. Tom I: Devjanostyje gody. Moskva 1968. Tom II: 1901-1907. Moskra 1979. Tom III: 19081917. Moskva 1972.

RuBlands Aufbruch ins 20. Jahrhundert. Politik - Gesellschaft Kultur 1894-1917. Herausgegeben von G. Katkov, E. Oberländer, N. Poppe, G. von Rauch. Freiburg 1. Br. 1970.

Sapovalov, I.A. Ob odnom lermontovskom obraze u A. Bloka. In: M.Ju. Lermontov. Issledovanija 1 materialy. Voronež 1964. S. 221-235.

Sarkisyanz, E. RuBland und der Messianismus des Orients. SendungsbewuBtsein und politischer Chiliasmus des Ostens. Tübingen 1955.

Sbornik Kirł̌i Danilova. Drevnije rossijskije stichotrorenija sobranny je Kiršeju Danilovym. Moskva-Leningrad 1958.

Schadewaldt, W. Hellas und Hesperien II. Zürich-Stuttgart 21970 .

Schapiro, I.

Die vorrevolutionäre Intelligentsia. In: Pipes, R. (Hrsg.) Die russische Intelligentsia.Stuttgart 1962. S. 33-48.

Schapiro, I.

The Vekh1 group and the mystique of revolution. In: "The Slavonic and East European Review", 34,1955 , S. 56-76.

Scheffler, I.

Das erotische Sujet in Fuskins Dichtung. Philosophische Dissertation der Universitat Tübingen. München 1968.

Scheibert, $P$.

Die Petersburger religiös-philosophischen Zusammenkiunfte von 1902 und 1903. In: "Jahrbücher für die Gèschichte 0steuropas", 12, 1964 , S. 513-550.

Šelud'ko, D. Ob istoð̌nikach dramy Bloka "Roza 1 krest". In: "Slavia", IX, 1930, S. 103-139.

Simon, G. Kirche Staat und Gesellschaft. In: RuBlands Aufbruch ins 20. Jahrhundert. Olten-Freiburg i.Br. 1970. S. 199-233.

Skaldin, A.

o pis'mach A.A. Bloka ko mne. In: Pis'ma Aleksandra Bloka. Leningrad 1925. S. 175-182. 
Skatov, N.N.

Rossija u Aleksandra Bloka 1 poètiCeskaja tradicija Nekrasova. In: "Russkaja literatura", 1970, 3, S. 37-56.

Šklovskij, v. Lev Tolstoj. Moskra 21967.

sklorskij, v.

Sentimentale Reise. Aus dem Russischen übersetzt von R.-E. Riedt unter Mitwirkung von

G. Drohla. Frankfurt a.M. 1964 .

Slovo o polku Igoreve. Bibliografičeskij oð̌erk. Perevod. Pojasnenija k tekstu $i$ perevodu. Pod red. A.V. Pozdnejeva. Moskra 1963.

Slovo o polku Igoreve (zit.: IL): Staroruski ep Slovo o polku Igofeve. Slovensko izdajo priredil R. Nahtigal. Ljubljana 1954.

Smelev, I. Kulikovo pole. Staryj Valaam. Paris 1958.

Sokolova, V.F. Jeşe raz o fol'klornych istodnikach romana P.I. Mel'nikova-Peđerskogo "V lesach". In: Poétika i stilistika russkoj literatury. Pamjati akademika V.V. Vinogradova. Sb. statej. Leningrad 1971. S. 180-187.

Solor'er, B.

Solov'ev, B. Solor'ev, B. Blok i Dostojerskij. In: Dostojerskij i russkije pisateli. Sbornik statej. Moskva 1971. Poèt i jego podvig. Moskva ${ }^{2} 1968$.

"Volja k podvigu". K semidesjatipjatiletiju so dnja roždenija Aleksandra Bloka. In: "Zvezda", 1959, 11, S. 157-172.

Solor'er, S.M. Istorija Rossii s drevnejofich vremen.SPb. $0 . J$. (1851-1879).

Solov'er, S.M. Vospominanija ob A. Bloke. In: Pis'ma Aleksandra Bloka. Leningrad 1925. S. 9-45. .

Solov'ev, V. Stichotrorenija. Sutoðnyje p'esy. Nachdruck der Ausgaben Moskau 1922. Slavische Propyläen Bd. 18. München 1968.

Spengler, 0 .

Der Untergang des Abendlandes. Umrisse einer Morphologie der Weltgeschichte. 2 Bde. München 1972. (dtv 838/839).

Spoerri, Th. Dante und die europäische Literatur. Stuttgart 1963.

Standop, E. - Mertner, E. Englische Literaturgeschichte. Heidelberg 1967.

Stanislavskif, K.S. Sobran1je sotinenif $\vee 8$ tomach. Moskva 1954-1961.

Stelleckif, V.I. A.A. Blok und das "Lied von der Heerfahrt Igors". In: "Zeitschrift für Slawistik", Bd. XVI, Heft 4, 1971, S. 557-580.

Stenbock-Fermor, E. Das silberne Zeitalter der russischen Literatur. In: RuBlands Aufbruch ins 20. Jhdt. Olten-Freiburg 1.Br. 1970. S. 263-289. 
Stepun, F.

Stepun, F.

Stepun, F.

Stepun, F.

Stepun, F.

Stepun, F.

Stökl. G.

Struve, G.

Śuvalov, S.V.

Terapiano, Ju.

Thalheim, K.C.

Tichomirov, MiN.

van Tieghem, P.

Timofejev, -...

Timofejev, L.I.

Timofejev, L.I.

Timofejev, I.I. Tokarev, S.A.

Tolstoj, L.

Trautmann, R.

Triomphe, R.

Triomphe, R.
Alexander Blocks Weg von Solowy ow zu Lenin. In: "Eckart", Dez.-Jan. 1951/52, Jg. 20/21, S. 111-122.

Das Antlitz RuBlands und das Gesicht der Revolution. Miinchen 1961.

Der Bolschewismys und die christliche Existenz. Mínchen 21962 .

Dostojewskij und Tolstoj. Christentum und soziale Revolution. München 1961.

Mystische Weltschau. Fünf Gestalten des russischen Symbolismus. München 1964.

Vergangenes und Unvergängliches. Aus meinem Leben. 1. Teil München 1947.

Russische Geschichte. Stuttgart 21965. (Kröners Taschenausgabe $\mathrm{Bd} .244$ ).

Geschichte der Sowjetliteratur. München 0.J. (Goldmanns Gelbe Taschenbücher Bd. 1395/6/7).

Blok i Lermontov. In: 0 Bloke. Moskva 1929. S. 95-126.

Vstredi. New York 1953. Darin uber Blok: Tajna poeta. S. 159-171.

Die wirtschaftliche Entwicklung RuBlands. In: RuBlands Aufbruch ins 20. Jhdt. Olten-Freiburg i.Br. 1970. S. 86-110.

Kulikovskaja bitva 1380 goda. In: Povesti o Kulikovskoj bitve. Moskva 1959. S. 335-376.

Le romantisme dans la litterature europénne. Paris 1969. (L'evolution de l'humarite vol.19). Aleksandr Blok. Moskva 1957.

Foèma Bloka "Dvenadcat" i jeje tolkovateli. In: "Voprosy literatury" 1960, 7, s. 116-127. Poétika kontrasta $\checkmark$ poézil Aleksandra Bloka. In: "Russkaja literatura", 1961, 2, S. 98-107. Tvorłestvo Aleksandra Bloka. Moskva 1963. Religioznyje verovanija vostodnoslavjanskich narodov XIX - načala XX veka. Moskva-Leningrad 1957.

Polnoje sobranije soð̌inenij. Moskva 1935ff.

Die Volksdichtung der GroBrussen. 1. Band:

Das Heldenlied (Die Byline). Heldelberg 1935.

Le mysticisme d'Alexandre Blok. Etude de structure. In: "Cahiers du monde russe et soviétique", vol I, fasc. 3,1960, S. 387-417.

Sous le signe du printemps. In: "Revue des Etudes Slaves", vol. 38, 1961, S. 197-206. 
Trockij, L.

Pschizewskij, D.

Cižerskij, D.

TschiZewskij, D.

Tschizewskij, D

Tschizewskij, D.

Tschöpl, C.

Turkov, A.

Tynjanov, Ju.

Uklein, V.N. Utechin, S.V.
Tschizewskif, D.

Literatur und Revolution. München 1972. (dtv 851).

Das hellige RuBland. Russische Geistesgeschichte I. Hamburg 1959. (rde 84).

Zwischen Ost und West. Russische Geistesgeschichte II. Hamburg 1961. (rde 122).

On romanticism in Slavic literature. 's-Gravenhage 1957.

Russische Literaturgeschichte des 19. Jahrhunderts. Band 1: Die Romantik. Munchen 1964. Band 2: Der Realismus. München 1967.

Tjutðer und die deutsche Romantik. In: "Zeitschrift für Slavische Philologien, IV, 1927, S. 299-323.

Valerij Brjusovs Prosa. In: Brjusov, V. Rasskazy $i$ povesti. München 1970. S. $/ 9 /-/ 10 /$.

- Groh, D. (Hrsg.) Europa und RuBland. Texte zum Problem des westeuropäischen und russischen Selbstrerständnisses. Darmstadt 1959.

Vjaceslav Ivanov. Dichtung und Dichtungstheorie. Göttingen 1966. (Slavistische Beiträge Bd. 30).

Aleksandr Blok. Moskva 1969.

Archaisty i novatory. Leningrad 1929. Nachdruck: Slavische Propyläen Bd. 31. München 1967.

Kulikovo pole. 0.0. 1971. (Ein Reisefuhrer).

Geschichte der politischen Ideen in RuBland. Stuttgart-Berlin-Köln-kainz 1966.

Vechi. Sbornik statej o russkoj intelligencil. Moskva ${ }^{2} 1909$. Nachdruck: Frankfurt a.M. 1967.

Vengerov, S.A. Russkaja literatura XX veka. Moskva 1914-16. Nachdruck: Slavische Propyläen Bd. 115. München 1972.

Vengrov, N.

Vengrov, $N$. A. Blok i M. Gor'kij. In: Gor'kovskije ttenija 1953-57. Moskva 1959. S. 200-261.

Vetlovikaja, v.

Put' Aleksandra Bloka. Moskva 1963.

Simvolika Łisel $\vee$ "Brat'jach Karamazovych". In: Drevnerusskaja literatura i russkaja kul'tura XVIII-XX vv. "Trudy otdela drevnerusskof literatury", XXVI, 1971, S.139-150.

Volkov, N. Aleksandr Blok 1 teatr. Moskva 1926.

Volkov, S. I Red'ko, R. A. Blok 1 nekotoryje muzykal'noestetiðeskije problemy jego vremen1. In: Blok 1 muzyka. Sbornik statej. LeningradMoskva 1972. S. 85-114. 
Wagner, R.

Wagner, $R$.

wagner, $R$.

keber, A.
Die Hauptochriften. Stuttgart 21956. (Kronero Taschenausgabe Bd. 145).

Götterdämmerung. Wortlaut der Partitur.

Stuttgart 1969. (Reclam Universal-Bibliothek Ni. 5644).

Siegfried. Wortlaut der Partitur. Stuttgart 1966. (Reclam Universal-Bibliothek Nr. 5643). Kulturgeschichte als Kultursozlologie. München 1963.

Wellek, R. - Warren, A. Theorie der literatur. Frankfurt a.M. -Berlin 1963. (Ullstein Buch Nr. 420/21).

west, $J$.

Russian Symbolism. A study of Vyacheslav Ivanov and the Russian symbolist aesthetic. London 1970.

willets, H.T.

Die Agrarfrage. In: RuBlands Aufbruch ins 20. Jhdt. 01ten-Freiburg 1.Br. 1970. S. 111136.

Woloschin, M.

Die grine Schlange. Lebenserinnerungen. Stuttgart 41968.

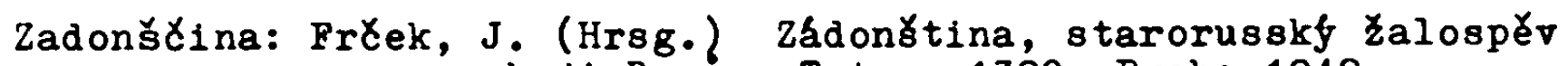
- boji Rusu s Tatary 1380. Praha 1948.

Zajcev, B. Dalekoje. Washington 1965. Darin uber Blok: Pobezdonny j. S. 7-19.

Lamjatin, Je.

Lica. New York 1967. Darin: Aleksandr Blok. S. 13-28.

Zavalişin, V.

Aleksandr Blok i russkaja revoljucija. In: "Grani", 36, 1957, S. 163-184.

Zelinskij, K. lia rubeže dvuch époch. Moskva 1960.

Zen'kovskij, V. Aus der Geschichte der ästhetischen Ideen in RuBland im 19. und 20. Jahrhundert.

' 8-Gravenhage 1958.

Zen'kovskij, V. N.V. Gogol'. Paris 0.J. (1961).

Zen'kovskij, V. Istorija russkoj filosofil. Tom II. Paris 1950. (S. 11-72 uber VI. Solov'evi S. $293 \mathrm{ff}$. ïber den Symbolismus und Merezkovskij).

Zernov, $\mathrm{N}$. The Russian religious renaissance of the 20 th century. London 1963.

Zirmunskij, V. Drama Aleksandra Bloka "Roza i Krest" . Literaturnyje istolniki. Leningrad 1964.

Zirmunskij, V.

Voprosy teorii literatury. Stat'i 1916-1926. Leningrad 1928. Nachdruck: 's-Gravenhage 1962. Darin besonders: Poézi ja Aleksandra Bloka. S. 190-268.

Zorgenfrej, V.A. Aleksandr Aleksandrovit Blok. In: "Zapiski mextatelej", 1922,6 , S. 123-154. 


\section{Nachtrag:}

Aleksandr Blok $v$ portretach, 11 ljustracijach 1 dokumentach. Sostavitel' A.M. Gordin. Obrcaja redakcija V.N. Orlova. Leningrad 1972.

Cekarlieva, $\mathbf{N}$ A.A. Blok i revoljucijata. In: Ezik 1 I1teratura, 3, 1961, S. 43-58.

Curtius, E.R. Europälsche Iiteratur und lateinisches Mittelalter. Bern-Múnchen 81973 .

Hamburger, $M$. Die Dialektik der modernen Lyrik. Von Baudela1re bis zur Konkreten Poesie. München 1972. (List Taschenbïcher der W1ssenschaft Nir. 1443).

Rutic, N. Kulikovikaja bitva. In: Grani, 5, 1949, S.113116.

Sartre, J.-F. Baudelaire. Paris 1964. (Collection "Idés" 



\section{SLAVISTISCHE BEITR ̈̈GE \\ Verzeichnis der bisher erschienenen Bände}

1. Maurer,J.: Das Plusquamperfektum im Polnischen. 1960, 64 S. -2 . Kadach,D.: Die Anfänge der Literaturtheorie bei den Serben. 1960, V, 182 S. - 3. Moskalik,M.: Janka Kupała, der Sänger des weiBruthenischen Volkstums. 1961, $241 \mathrm{~S}$. - 4. Pleyer,V.: Das russische Altgläubigentum. 1961, 194 S. - 5. Mihailović,M.: Tempus und Aspekt im serbokroatischen Präsens. 1962, VIII, 64 S. - 6. Rösel,H.: Aus Vatroslav Jagićs Briefwechsel. 1962, $75 \mathrm{~S}$. - 7. Schmidt,A.: Valerij Brjusovs Beitrag zur Literaturtheorie. 1963, $159 \mathrm{~S}$. - 8. Minde, R.: Ivo Andrić. 1962, $198 \mathrm{~S}$. - 9. Panzer,B.: Die Funktion des Verbalaspekts im Praesens historicum des Russischen. 1963, $106 \mathrm{~S}$. - 10. Mrosik,J.: Das polnische Bauerntum im Werk Eliza Orzeszkowas. 1963, $211 \mathrm{~S}$. - 11. Felber,R.: Vojislav Ilić. 1965, 271 S. - 12. Augustaitis,D.: Das litauische Phonationssystem. 1964, 155 S. - 12a. Auras,C.: Sergej Esenin. 1965, 211 s. - 13. Koschmieder-Schmid,K.: Vergleichende griechisch-slavische Aspektstudien. 1967, 196 S. - 14. Klum,E.: Natur, Kunst und Liebe in der Philosophie Vladimir Solov'evs. 1965, $333 \mathrm{~S}$. - 15. Albrecht,E.: Das Türkenbild in der ragusanisch-dalmatinischen Literatur des XVI. Jahrhunderts. 1965, 250́ S. - 16. Gesemann,w.: Die Romankunst Ivan Vazovs. 1966, 131 S. 17. Perišić,D.: Goethe bei den Serben. 1968, 304 S. - 18. Mares,F.V.: Die Entstehung des slavischen phonologischen Systems und seine Entwicklung bis zum Ende der Periode der slavischen Spracheinheit. 1965, 87 S. - 19. Holzheid,S.: Die Nominalkomposita in der Iliasübersetzung von $\mathbf{N}$. I. Gnedic. 1969, 92 S. - 20. Chmielewski,H.: Aleksandr Bestužev-Marlinskij. 1966, 134 S. - 21. Schaller,H.W.: Die Wortstellung im Russischen. 1966,389 S. - 22. Hielscher,K.: A. S. Puškins Versepik. 1966, 169 S. - 23. Küppers,B.: Die Theorie vom Typischen in der Literatur. 1966,354 S. - 24. Hahl-Koch,J.: Marianne Werefkin und der russische Symbolismus. 1967, 126 S. - 25. Gardner,J.: Das Problem des altrussischen demestischen Kirchengesanges und seiner linienlosen Notation. 1967, IX,270 S. - 26. Baldauf, L.: Der Gebrauch der Pronominalform des Adjektivs im Litauischen. 1967, $104 \mathrm{~S}$. - 27. Kluge,R.-D.: Westeuropa und RuBland im Weltbild Aleksandr Bloks. 1967, $393 \mathrm{~S} .-28$. Kunert, I.: J. U. Niemcewicz: Spiewy historyczne. 1968, II, $132 \mathrm{~S}$. - 29. Steinke, K.: Studien über den Verfall der bulgarischen Deklination. 1968, X, $133 \mathrm{~s} .-30$. Tschöpl,C.: Vjaceslav Ivanov. 1968, $235 \mathrm{~S}$. - 31. Rehder,P.: Beiträge zur Erforschung der serbokroatischen Prosodie. 1968, 247 S. - 32. Kulman,D.: Das Bild des bulgarischen Mittelalters in der neubulgarischen Erzählliteratur. 1968, 276 S. - 33. Burkhart,D.: Untersuchungen zur Stratigraphie und Chronologie der südslavischen Volksepik. 1968, III, 549 S. - 34. Günther, H.: Das Groteske bei N. V. Gogol'. 1968, 289 S. - 35. Kazoknieks,M.: Studien zur Rezeption der Antike bei russischen Dichtern zu Beginn des 19. Jahrhunderts. 1968, $269 \mathrm{~S} .-36$. Schmidt, H.: Hus und Hussitismus in der tschechischen Literatur des 19. und 20. Jahrhunderts. 1969, 296. S. - 37. Schneider,S.: Studien zur Romantechnik Miroslav Krlezas. 1969, $285 \mathrm{~S}$. - 38. Stephan, B.: Studien zur russischen Castuska und ihrer Entwicklung. 1969, 358 S. - 39. Girke,w.: Studien zur Sprache N. S. Leskovs. 1969, VIII, 220 S. - 40. Mareš, F. V.: Diachronische Phonologie des Ur- und Frühslavischen. 1969, $126 \mathrm{~S}$. - 41. Wosien,M.-G.: The Russian Folk-Tale. 1969, 237 S. - 42. Schulz, R.K.: The Portrayal of the German in Russian Novels. 1969, V, $213 \mathrm{~S}$. - 43. Baudisch,G.: Das patriarchalische Dorf im Erzählwerk von Janko 
M. Veselinović. 1969, 225 S. - 44. Stölting,w.: Beiträge zur Geschichte des Artikels im Bulgarischen. 1970, VII, 296 S. - 45. Hucke,G.:Jurij FedoroviC Samarin. 1970, 183 S. - 46. Höcherl,A.: Zur Ubersetzungs technik des altrussischen "Jüdischen Krieges" des Josephus Flavius. 1970, 183 S. - 47. Sappok,C.: Die Bedeutung des Raumes für die Struktur des Erzählwerks. 1970, 154 S. - 48. Guski,A.: M. Ju. Lermontovs Konzeption des literarischen Helden. 1970, $225 \mathrm{~S}$. - 49. Lettmann, R.: Die abstracta 'um' und 'razum' bei Belinskij. 1971, 167 S. - 50.Lettmann-Sadony,B.: Karolina Karlovna Pavlova. 1971, 181 S - 51. Brümmer, C.: Beiträge zur Entwicklungsgeschichte der frühen Romane L. M. Leonovs, 1971, $231 \mathrm{~s}$. - 52. Schmidt,C.: Bedeutung und Funktion der Gestalten der europäisch östlichen Welt im Werk Thomas Manns. 1971, $366 \mathrm{~S}$. - 53. Eschker,W.: Untersuchungen zur Improvisation und Tradierung der Sevdalinka an Hand der sprachlichen Figuren. 1971, 275 S. - 54. Schmidt О.: Неизвестный поэт П.Д.Бутурлин. Анализ творчества. 1971, 229 S. 55. Mönke,H.: Das Futurum der polnischen Verba. 1971, 184 S. - 56.Raekke,J.: Untersuchungen zur Entwicklung der Nominalkomposition im Russischen seit 1917. - 57. Müller-Landau,C.: Studien zum Stil der Sava-Vita Teodosijes. 1972, 183 S. - 58. Dippe,G.: August Senoas historische Romane. 1972, 177 S. - 59. Hetzer,A.: Vjaceslav Ivanovs Tragödie "Tantal"! 1972, 202 S. - 60. Andreesen,W.: Untersuchungen zur Translation von Sub stantiven zu Adjektiven im Altrussischen. 1972, 151 S. - 61. Neureiter, F.: Kaschubische Anthologie. 1973, VIII, 281 S. - 62. Gavrin,M.: Kroatische Ubersetzungen und Nachdichtungen deutscher Gedichte zur Zeit des Illyrismus. 1973, $226 \mathrm{~S}$. - 63. Grahor,0.: France in the Work and Ideas of Antun Gustav Matos. 1973, 247 S. - 64. Döring,J.R.: Die Lyrik Paster: naks in den Jahren 1928-1934. 1973, XXVI, 390 S. - 65. Högemann-Ledwohn E.: Studien zur Geschichte der russischen Verserzählung in der zweiten Hälfte des 19. Jahrhunderts. 1973, 428 S. - 66. Gonschior,H.: Die geneigten Vokale als Reflexe altpolnischer Längen im Wörterbuch von Jan Maczýnski. 1973, 391 S. - 67. Talev,I.: Some Problems of the Second South Slavic Influence in Russia. 1973, XIV, $430 \mathrm{~S}$. - 68. Auerbach, I.: Nomina abstracta im Russischen des 16. Jahrhunderts. 1973, VI, 368 S. - 69. Holthusen,J.: RuBland in Vers und Prosa. 1973, 212 S. - 70. Guski,H.: Die satirischen Komödien V.I.Lukins (1737-1794) . 1973, 250 S. 71. Sternkopf,J.: Sergej und Vladimir Solov'ev. 1973, XXXI, 667 S. 72. Wenzel,F.: SPLIT. Ein Verfahrer zur maschinellen morphologischen Segmentierung russischer wörter. 1973, IX, 203 S. - 73. Bachmann, E.: Ivo Kozarcanin - Leben und Werk. 1974, 250 S. - 74. Schmidt, B.: Stilelemente der mündichen Literatur in der vorrealistischen Novellistik der Serben und Kroaten. 1974, 309 S. - 75. Jakoby,W.: Untersuchungen zur Phonologie und Prosodie einer kajkavischen Mundart (Gornja Stubica) 1974, X, 256 S. - 76. Schultze,B.: Der Dialog in F. M. Dostoevskijs Idid 1974,314 S. - 77. Hilf,E.A.: Homonyme und ihre formale Auflösbarkeit il System Sprache, dargestellt an altrussischen Berufsbezeichnungen. 1974, 129 S. - 78. Wiehl,I.: Untersuchungen zum Wortschatz der Freisinger Denl mäler. Christliche Terminologie. 1974, 169 S. - 79. Pribic, R.: Bonaventy ra's Nachtwachen and Dostoevsky's Notes from the Underground. A Comparison in Nihilism. 1974, $155 \mathrm{~S}$.

\section{IN VORBEREITUNG FüR ENDE 1974:}

80. Ziegler,G.: Moskau und Petersburg in der russischen Literatur (ca 1700-1850). Zur Gestaltung eines literarischen Stoffes. VI,198 S. - 81. Wörn,D.: Aleksandr Bloks Drama Fesnja sud'by, übersetzt, kommentiert und interpretiert. $\mathrm{X}, 545 \mathrm{~S} .-82$. Timberlake, A.: The Nominative object in Slavic, Baltic, and West Finnic. $265 \mathrm{~s}$. 